\title{
Dwelling on the Future
}

Architecture for the Seaside, Middle England and the Metropolis 
Dwelling on the Future 


\section{Series Editors:}

Murray Frase

The Bartlett School of Architecture, UCL

Jonathan Hill,

The Bartlett School of Architecture, UCL

\section{Lesley Lokko,}

\section{Bernard and Anne Spitzer School of Architecture}

at City College of New York, CUNY

Since the Renaissance a number of architect-scholars have created methods of intelectual scrutiny of architectural design that rely upon the interplay of drawings, models, textual analysis, intellectual ideas and cultural insights. Yet there is still no cohesive framework or outlet for design research in architecture. This innovative book series - still the only one of its kind - showcases the very best proponents of architectural design research from around the globe, drawing on a range of exemplar positions between

Featuring work from Early Career Researchers and leading architect-scholars in practice and academia, books in the series vary in tone and structure, covering aspects such as design method, visual representation, reasoned critique, social processes and strategies for action. The series is deliberately inclusive to encourage a vibrant, novel approach, and is openly international. Each book combines serious historical or theoretical research with creative propositions expressed through drawings, models or texts: indeed, it is the symbiotic interplay between these components that forms the basis for design research in architecture. Now is a fertile time for design research and this book series acts as the heart of these investigations. 
Dwelling on the Future

Architecture for the Seaside, Middle England and

the Metropolis

Pierre d'Avoine

UCLPRESS 
Available to download free: www.uclpress.co.uk

Text $\odot$ Pierre d'Avoine, 2020

Images () Author and copyright holders named in captions, 2020

Foreword

Pierre d'Avoine has asserted his right under the Copyright, Designs and Patents Act 1988 to be identified as author of this work.

A CIP catalogue record for this book is available from The British Library.

This book is published under a Creative Commons Atribution Non-commercial Non-derivative 4.0 International licence (CC BY-NC-ND 4.0). This licence allows you to share, copy, distribute and transmit the work for personal and non-commercial use providing author and publisher attribution is clearly stated. Attribution should include the following information:

d'Avoine, P. 2020. Dwelling on the Future: Architecture for the Seaside, Middle England and the Metropolis. London, UCL Press. https://doi.org/10.14324/111.9781787350533

Further details about Creative Commons licences are available at http://creativecommons .org/licenses/

Any third-party material in this book is published under the book's Creative Commons licence unless indicated otherwise in the credit line to the material. If you would like to re-use any third-party material not covered by the book's Creative commons licence, you will need to obtain permission directly from the copyright holder.

Front image: The cover is an abstraction of Hieronymus Bosch's Haywain Triptych. In the Haywain, Bosch focuses on the sin of avarice - the desire for worldly gain. The left panel depicts the creation and fall of man with the sea (blue) in the background. The right panel depicts the hellscape (red) of the city. The centre panel focuses on a haycart (gold), the symbol of greed, pride, and complacency which leads to discord and violence. The haycart is followed by men of all kinds plucking the hay, an allegorical reference that 'In the end it is al hoy'.

ISBN: 978-1-78735-054-0 (Pbk.)

ISBN: 978-1-78735-053-3 (PDF)

DOI: https://doi.org/10.14324/111.9781787350533
Ning Clare Melhuish

xvii Acknowledgements

Introduction

Twelve projects for more than

just housing

The Seaside, Middle England and

the Metropolis

Proposals

Opportunist practice

Plot and multiply

The Boke Named the Governou

Overproduction of the

built environment: Richard

Douthwaite, the limits of growth

14 Jacques Tati and Paul Lafargue.

The Right to Be Lazy

15 Anglo-Exotic: Multicultura

necessities and choice

18 Monad: Nomad

Many-sidedness

\section{The Seaside}

Aberystwyth Arts Centre Introduction Interview: Jonathan Vining Drawings

4 Pleasure Holm at Birnbeck Island Introduction

Man-made island data centres

Interview: Jonathan Vining

Interview: Aran Chadwick

Interview: Bill Watts

Drawings

Crowcombe Court

Introduction

Interview: Kim Austo

Drawings

Bengough's House

Introduction

Interview: Jonathan Vining

Interview: David Jones

Drawings 


\section{Middle England}

$\begin{array}{ll}125 & \text { Glastonbury Houses } \\ 125 & \text { Introduction } \\ 126 & \text { Interview: Nick Oliver } \\ 134 & \text { Drawings } \\ & \\ 145 & \text { A Counterproposal for Belper } \\ 145 & \text { Introduction } \\ 146 & \text { Collaborative practice } \\ 148 & \text { Interview: Barry Joyce } \\ 156 & \text { Belper Vision } \\ 158 & \text { Drawings } \\ & \\ 163 & \text { Swaythling Housing } \\ 163 & \text { Introduction } \\ 165 & \text { Interview: Alex Ely } \\ 173 & \text { Drawings } \\ & \\ 185 & \text { Sixty Houses for Crouches Field } \\ 185 & \text { Introduction } \\ 186 & \text { Interview: John Wickham } \\ 196 & \text { Interview: Iim Green } \\ 208 & \text { Drawings } \\ & \\ 221 & \text { Patterns for Letchworth: From } \\ & \text { Garden City to Patchwork City } \\ 221 & \text { Introduction } \\ 223 & \text { Aspley Guise Patchwork City } \\ & \text { Association } \\ 225 & \text { Interview: Ian Abley and Alec } \\ & \text { Scragg } \\ 238 & \text { Drawings }\end{array}$

\section{The Metropolis}

245 House + Garden + House

A New Suburban Code for

London

Interview: Jess Rayat

Photo essay: Rayat family by

Sebastian Tiew

260 Drawings

269 Rocket Room: Pencil Tower

269 Introduction

270 Interview: Crispin Kelly

1 Drawings

93 Pembury Octagon

293 Introduction

294 Interview: Liam Dewar

317 Postscript

323 Credits

325 References

335 Index

\section{'A Sort of a Song'}

Let the snake wait under

his weed

be of words, slow and quick, sharp

to strike, quiet to wait,

sleepless

-through metaphor to reconcile

the people and the stones

Compose (no ideas but in things) invent!

Saxifrage is my flower that splits

the rocks

-William Carlos Williams 1944 
Foreword | Clare Melhuish
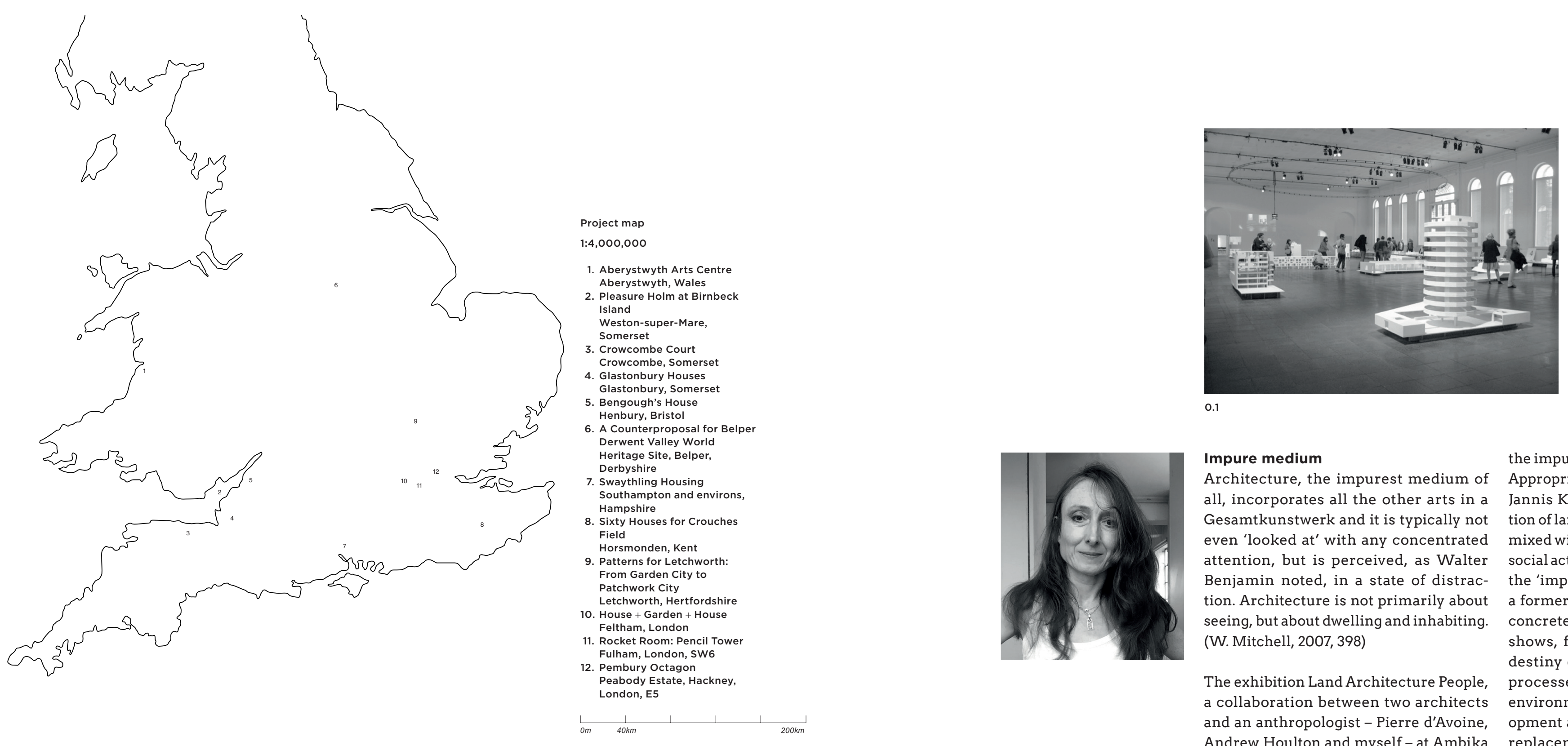

Impure medium

the impurity of architecture as a medium. Architecture, the impurest medium of Appropriately, it followed on the heels of all, incorporates all the other arts in a Jannis Kounellis's magnificent installaGesamtkunstwerk and it is typically not tion of large-scale industrial found objects even 'looked at' with any concentrated mixed with remnants of everyday life and attention, but is perceived, as Walter social activity-overcoats, wine bottles-in Benjamin noted, in a state of distrac- the 'impure' setting of Ambika P3 itself: tion. Architecture is not primarily about a former engineering workshop used for seeing, but about dwelling and inhabiting. concrete construction, now used for art (W. Mitchell, 2007, 398)

shows, fashion and media events. The destiny of P3 reflects the reality of the

The exhibition Land Architecture People, processes of reproduction of the built a collaboration between two architects environment: a repetitive cycle of develand an anthropologist - Pierre d'Avoine, opment and redevelopment, demolition, Andrew Houlton and myself - at Ambika replacement and reuse, of the physical 


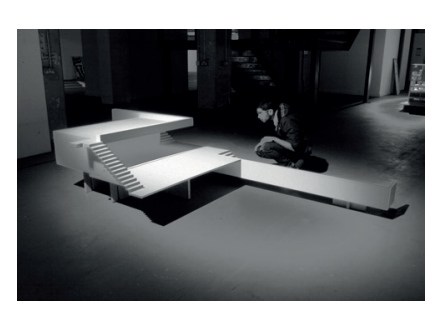

needs, which embodies a thick layering of social history.

Architectural history is often cha acterised as a narrative of ideologica movements expressed in built form, as a visual statement of strongly held aesthetic beliefs. It conforms to the ocularcentric outlook which has dominated Western

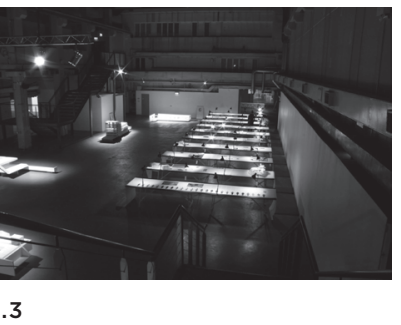
temporary culture is described as one 'hyper-visuality' (Boyer, 1996). The centraty of the visual image, enhanced by th proliferation of new vise, enhanced by the digital technoly is only claimed hegemony over the written word, but subverts any notion of objective physical reality in the environment. But the

0.2 Claude viewing model, Land
Architecture People, P3, London, a difficult negotiation between the powe and 'purity' of the visual image, and the confused and impure realities of archecture's functionality, occupation and transformation over time in response to ocial impulses and aspirations.

In the contemporary context, the very notion of a 'pure' architecture, or architetural ideology, has become more and mor ephemeral, even while the compulsion to establish a clear and strong visual identity for architectural production in the contex of a competitive, global market driven by brand recognition becomes increasingly difficult to resist. Historically, patter books were used as a vehicle for circulating clear visual representations of stylistic models in architecture (Melhuish an d'Avoine, 2005) which could be copied by Avoine, 200 ) which could be copied by work of individual architects, closely associated with particular patrons whose socia and economic status would be thereby enhanced. Today, most architectural practices invest money in promotional visual material which sets out a clear and distinctive visual style for their work within a spectrum of broadly recognisable idioms - even in a social context understood as being very conservative, where, as the developer Crispin Kelly notes, 'the least you can do is to make [a new building] look as if it was there before' (Kelly, 2009). It is broadly understood that architects work within a planning system which imposes tight constraints on the possibilities for development of on the posibiront the the lo a 'neo-vernacular' approach at the level en to pror end the pressures to promote and market cities as destination environments, as a basis for economic growth, have generated the phenomenon of 'brandscapes' (Klingmann, 2007), landmark buildings and special planning dispensations (as in the case of The Shard). This is the architecture of the so-called experience economy (Lonsway, 2009), which is heavily dependent on the power of the visual image, however superficial and dislocated from underlying social realities it may be, to identify specific physical contexts with the required 'lifestyle experience' to attract the appropriate consumer to the site.

The aim of Land Architecture People was to open up a debate about the realities of architectural practice and production in a projected middle ground between these two ends of the spectrum between in which architecturectrum-a contex in which architecture is understood not
simply as a visual phenomenon but as a

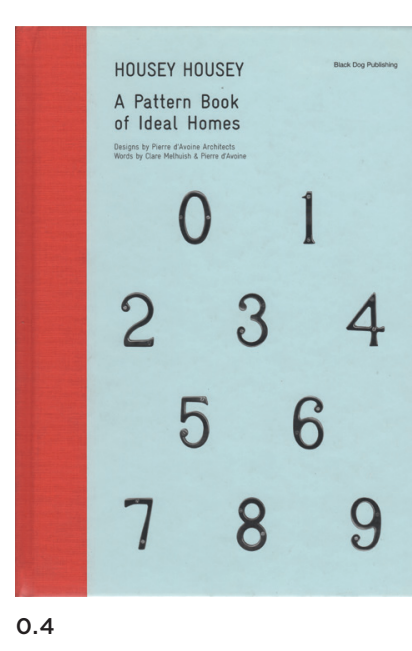

O.4 Housey Housey: A Pattern
Book of Ideal Homes, Clare

Melh 2005 complex, impure negotiation between land architecture and people; a medium ' unde stood in Raymond Williams's definition as 'a material, social practice', and one that evolves, moreover, during its lifespan to assume new identities. The use of large white models, built in varying thicknesses of MDF, devoid of surface or interior detail may then seem a contradiction in terms: neutral, unoccupied, abstract - typical, perhaps, of a certain kind of architectural minimalism. But the intention and effect is quite the opposite. It is the very lack of quite the opposite. It is the very lack of any obvious surface visualisation or materialsating ack of an projected, predetermined occupation of the buildings, that opens up the field of interpretation and inaginary occupation by the

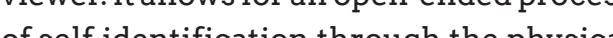
of self-identification through the physical activity of walking around the models in the expansive space of $P 3$, leaning over them from above, bending down to experience them from eye level, peering in to experience the different perspectives through th internal volumes from different angles, an visiting the accompanying tables on which were strewn a collage of detailed materials generated by the design process, including transcripts of interviews with clients.

The material contained in long tables represented the detailed counterpart to the apparent abstraction of the models, revealing an array of minutiae associated with the development of architectural concepts embedded in a specific social and cultural context. The interview transcripts provided unique access to the multivocal narratives which lay behind the production of the architectural artefact, and belied its identification solely with the voice of the architect as 'auteur. They pointed to an architecture which is intended not to be prescriptive, 'branded' or 'signature' in ts qualities, while also fiercely denying the pressure to be innocuous and neovernacular. Rather, it is understood and appreciated as the acknowledged outcome of a process of dialogue and negotiation with clients, a response to their aspirations and desire for choice, and to the realities of the inhabitation which will ensue. We have defined this process as 'ethnographic' (n) in bectice and production undestood as an ed rescod misul docume aspiration to product a bel whe In this context, and belying the apparthe f ims a the qualites werive werlo to conwhich reflects the diversity of contemporary society, particularly in the metropolitan tectural practice tends to be concentrated. it is no longer possible of of specific architectural idioms, where the cultural references 'brought to the table' yy clients and architects are so diverse and richly nuanced. In contrast both to the pattern books of old and to the modernday pattern books produced by the volume house builders to aid their customers in making a choice based on limited options, the repertoire of design possibilities produced by an ethnographic, anthropologically informed approach disregapo- 
traditional typologies and stylistic categories. Instead, it represents a contextualise notion of design and aesthetic expression
that allows for a playful, inventive and interactive approach to programme and site at both the detailed and larger scale.

Central to this approach is an understanding of architecture as an expression ied in material form and context. But this premise foregrounds the central problem for architects working in the all-important middle ground between the innocuous and middle groundbetween the innocuous and on which to buld for wilaby can be no architecture. According to the majority of respondents interviewed as part of the exhibition, the search for a suitpart of the exhibition, the search for a suitthe an project was the most difficul part their project was the most difficult part highlights the lack of, or right to, accessibilhighlights the lack of, or right to, accessibitity to land as a fundamental dimension of social relations as they are mapped onto the physical environment; but it is one which
architects rarely engage with, even while the inability of first-time buyers to get onto the 'property ladder' has become a malais of contemporary life.

For anthropologists working in the context of traditional societies, land or property tenure represents one of the key areas of social inquiry, fundamental to an understanding of social organisation and relationships. In the modern context of complex urban societies, national planning systems may be understood as one of the most explicit forms of social representation and yet he planningand development framework, and the land ownership system on which it is based, is mostly accepted as a given. In fact, as Healy notes, surprisingly little is known about its detailed workings:

All cities require the production of space in the form of both buildings and sites for various activities. Yet we still understand little about the production processes involved. The role of land ownership, the organisation of the construction industry the nature of the finance invested in urba development, and the significance of intermediaries, from developers to of interconsultants, lie hiddelopers to property more tha hore than a passing reference in many (Healey and Nabarro, 1990, 3)

Healy suggests that part of this lack of interest derives from a general assumption that 'the conversion of economic and social processes into land use change and built form [is] unproblematic' - that it will naturally flow from demand into supply. However, as we have seen in recent years, this is clearly not the case. The planning system in the UK depends upon land being put forward for development. Hence, th role played by landowners is central to the problems experienced by architects and the public in engaging with the reproduction of the built environment more fully, especially since the passing of the Local Government, Land and Planning Act of 1980. This reform effectively re-created a free market in development land by repealing the Community Land Scheme and acted as a catalyst for the steady rise in price for rady steady rise in prices for residenta the land ownership system in determining and proscribing the opportunities for a wider variety of development approaches has been largely overlooked due to a widespread public understanding that 'it is th developer and planner that dominate the development process' (Goodchild and Munton, 1985, vii).

The ownership and exploitation of land as an investment like any other, and a scarce resource, has generated a balance of power and influence which militates against individual clients and architects wishing to work at a smaller and more inventive scale. The normalisation more invering gaining beceen ape nocant and planners as into the hands of those with the greats inco ing pow It has been pointed out by Kevin ing pow It has been pointed out by Kevin Cahill that 59 million people in Britain live in 24 millon dwellings sited on a mere 7.5 per cent of the total acreage of the country; 77 per cent of the popula only 5.8 per cent of the total land area, an the average size of a residential plot is 0.07 acres per person (Cahill, 2002, 12). The scale and quality of new construction is a direct corollary of the scarcity and consequent high price of land, while the major private and institutional landowners sit on vast tion by huge public subsidies.

Such figures make architecture look like a very 'impure' medium indeed. The aims of Land Architecture People were therefore to divert attention from the purely visual dimensions of architectural practice, and to draw attention to the need Prounder text It is a powerful medium (nent and representation of cocial entions at flocal environments, just as much, if more so, than the large scale of the 'land mark' building on the global stage, and it is only rigt cove ress to the have greater access to the architectural its possibilities. 


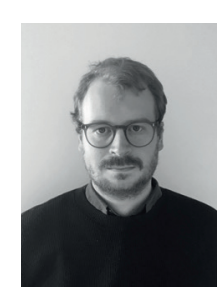

Ryan McStay
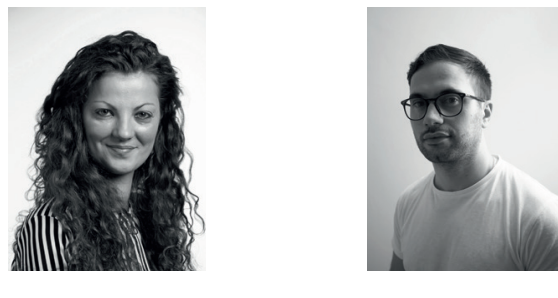

Erika Pietrovito

Urim Islami
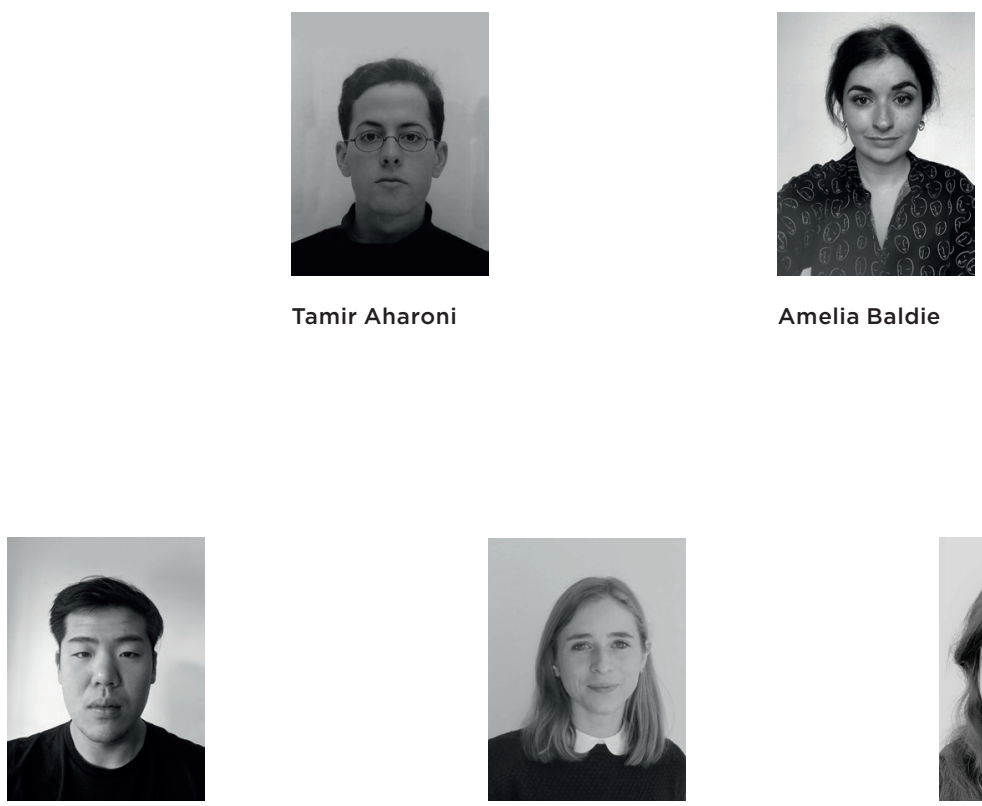

Bryony Henson Sebastian Tiew
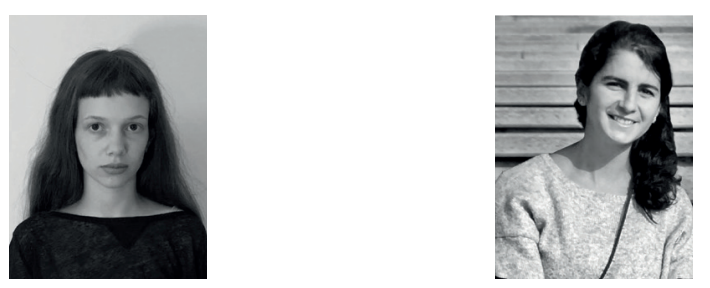

Amy Glover
Elena Pardo

Georgia Hablutzal

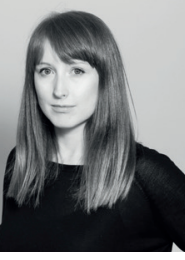

Eleanor Lygo

This book could not have come about family, as it has evolved from my childhood in Bombay to the London of my teen years and after, from the Birminghm my student days and the wider world we all now inhabit as the electronic increasingly interacts with the organic. There is a broad as well as intimate sweep of history each of us has to acknowledge if we live as long as I have.

I would like to thank Murray Fraser and his fellow editors at UCL Press for inviting Clare Melhuish and me to make Land Architecture People, inaugurated Land Architecture People, inaugurated at RDAFA, Copenhagen 2009, was held at Ambika P3 in 2010 at the invitation of Kate Heron, curator of Ambika P3 and head of Westminster School of Architecture, and Murray, professor and director of the MArch course at Westminster School of Architecture. Clare sadly had to withdraw from the project owing to other commitments. I have persevered with the book which includes a series of interviews which I undertook. The idea was initiated by Clare following a similar exercise for Land Architecture People in Copenhagen in which we presented interviews of several of my clients by clients. The interviews form a vital part of this book.
Some years ago, Clare and I published Housey Housey: A Pattern Book of Ideal Homes in which we presented projects for houses we had designed. We used 'found' material as it existed digitally and as hand drawings and photographs in the office. ousey, there was an ambition the he office. The morerialin this book has con drawn cowondefulgroup ofcollabora(D) Tiew, Georgia Hazbuld A Tiew, Georgia Hazblutzel, Any Glover and . gre tha tocus for this book.

I would like to thank the interviewes Jonathan Vining, Aran Chadwick, Bill Watts, Kim Auston, Nick Oliver, Barry Joyce, Alex Ely, John Wickham, Iim Green, Ian Abley, Alec Scragg, Jess Rayat, Crispin Kelly and Liam Dewar, who submitted themselves to my amateur interviewing technique with such good grace, for their helpful and revealing comments, as well as for their diligence in reviewing my edited transcriptions. My thanks also to Bryony Henson for transcribing the interview recordings with such care and clarity.

I am deeply indebted to all my collaborators, architects and assistants in my office and the consultants who worked on 
the projects at the time of their inception to work together at various times since, and afterwards. The projects would not including teaching MArch at Kingston and have turned out the way they have without the Cass. My thanks to Andrew, with whom their vital contributions. And although I I shared an office for five years, for the take full responsibility for the work in playful but serious conversations we had the book, I feel that each project has been and continue to have and to whom I am infused with a spirit of creation unique hugely grateful for his support during a to the particular combination of people time of great emotional turmoil. My thanks involved.

The projects in the book span a period of 15 years and would have been impossible to imagine without the involvement of four people: Pereen d'Avoine, Andrew Houlton, Jonathan Vininge, Andrew Melhuish Icannot believe my good forture heren and I have bencollaboras ince she was a child of 10 years old when we worked togther on the site model the Invisible House. We have continued to Jonathan Vining for his always generous collaborative spirit and for his invitation to work together in Cardiff and London during the period when I was visiting professor at the Welsh School of Architecture and consultant to WYG.

And lastly to Clare Melhuish for her Aniling support and for her imm for contribution to the work presented in this book. I would like to dedicate this book Clare and our sons Ivan and Reynard.

\section{Introduction}

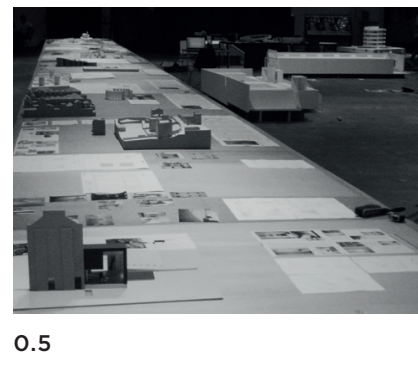

0.5 Long table, Land Architecture
People, RDAFA Copenhagen, People,
2009
Twelve projects for more than just understood as process as well as outcome. housing-The invitation to write this book The interviews existed as part of the wider was a direct result of the exhibition titled Land Architecture People, held at the Royal Danish Academy of Fine Arts School of Architecture, Copenhagen, in 2009 to inauArche my guest professorship there, held subsequently at Ambika $P 3$ Gan University of Westminster, in 2010 at the Unive the head of school. The exhibition was a collaboration between anthropologist Clare Melhuish, Andrew Houlton and myself. An important element of the exhibition was the inclusion of 10 interviews by Clare with my clients. These were presented as unexpurgated texts alongside photographic portraits of each client. The aim of the interviews was to communicate directly that the architectural project is an inclusive process that is necessarily contingent upon external conditions and that the outcome is dependent on the interaction between a range of protagonists. The Danish audience commented that the presentation of the interviews as an integral part of Land Architecture People was a brave and valuexhibition itself and to the wider discourse about the nature of the way that archirs ture can be communicated, explained and , tions, other sketches, maquettes,

This book has evolved from a longtanding interest in the design of houses explored in an earlier book, Houser Housey: A Pattern Book of Ideal Homes, wich $A$ Pattern Book of Ied 2005. In that boo, we and conter that book we explos inclu 33 hous locition We proposed a botrm ap approach to We proposed a bottom-up approach to housing that does not preclude larger-scale development but challenges the hegemony of the volume house builders and advocates for new government legislation to be formulated and implemented to enable individuals and small groups to obtain land at affordable costs on which to build homes for themselves, without being priced out of the 'market'. We attempted to discuss the and the designs were offered as opportunities for new approaches to contemporary ingly diverse population.

In an era when architecture and land fied, Dwelling on the Future attempts to conditions which govern house building, lifestyles and the aspirations of an increasitself has become increasingly commodi- 
explore ideas about identity, land use, in the Soviet Union during the Cold War, housing and the conditions for contempo- but always implicit, and ever more so, in rary architectural production in a process the West today.

that is simultaneously questioning of the This book is not about the housing status quo and intimately engaged with crisis. There will always be a housing crisi interpreting the specific requirements of within a market economy. One doesn't have a particular project. This is always a messy to scratch the surface too hard to discover and complex process that demands a nec- a long and corrupt history here in the essarily collaborative approach - one that UK which goes at least as far back as the balances the needs and desires of the client enclosures. Architecture too is always in also with the need to consider the benefit crisis, always at a crossroads. Architects to the wider community in order to achieve should always beware of complacency to the wider community in order to achieve

The book focuses on the design of dwellings and their varied environments, and asks how an architect responds to the challenge of providing humane places in which to live for a growing, multifatworld. Of course, it is never just housing. world. Of course, it is never just housing
People -individuals, groups, societies-can People-individuals, groups, societies-can
and do have widely different goals and aspirations. Is it possible to imagine an implement a world in which a level of comfort and stability is available for eve the poorest members of societies? The book covers a wide range, including proposals for luxury housing and designs for low-cost dwellings, which addresses the needs and desires of potential inhabitants. I am interested in an inclusive approach to the design of settlements, not just in cities, that recognises difference - an approach resolve humanity's increasing inequality for the benefit of all. Can we respond with optimism to the Kabakovs's mordantly titled installation Not Every nordantly Taken into the Future (2001)? Irenically, statement of fact in Russia and elsewhere should always beware of complacency,
anticipatory even, but not it seems in control of their destiny or able to influcon the influwhich we all dwell. The situanment in to move too quickly. How do we interp to mo Can we be mis anticipar? Can we be more anticipatory? How do we communicate with each other and create harmonious environments where we are the broader environment? Is this a possibility? Has it ever been possible, even desirable, to aim for equilibrium, or is there always tension and imbalance between individuals, groups and societies that is necessity in order to evolve without desiccation and stasis?

The Seaside, Middle England and the Metropolis-The projects in this book form a non-linear sequence from the seaside towns of Weston-super-Mare on the Bristol Channel and Aberystwyth in West Wales facing the Irish Sea, crisscrossing the varied landsape of crosing the varied landscape or Middle Engtup to the molis London where what is to cone before in order to anticipate mutually responsive to each other and to projects may appear arbitrary but has been carefully considered. The projects are not in chronological order, but the decision to start at the seaside implies a reversion in the way we privilege the metropolitan centre, in this case London, over provincia Middle England and its peripheral edges. London has never been more cosmopoli$\tan$. The city is undergoing huge changes, including new infrastructure and building to accommodate a diverse and fast-growing population. The impact is mainly on the South-East of England but affects the country as a whole. However, in starting with the seaside, one is also invoking a sense of the primordial-an understanding that the ocean is where human life had its that the ocean is where human life had its begnnings, and it may be where we need to concern ourseles more asthe nature of the land is threatened with drastic change owing to the effects of climate change an environmental degradation.

0.6 Postcard, 'Parade from
Pier, Herre Bay', sent by Marcel
Duchamp to Max Bergmann, 1913. Suchrec: Image courtesy
Klaus-Peter Bergmann.
The book's subtitle 'The Seaside, Middle England and the Metropolis' is intended to suggest as much a state of mind as actual locations and places. The British seaside conjures up associations that may now appear somewhat nostalgic but continue to haunt the imagination of the generations that grew up just before and after the Second World War. The reality has been a long slow decline in the popularity of seaside towns as holiday destinations as holidaymakers have taken advantage of cheap travel abroad. There has subsequently been rinvigoration and reinvention of seaside towns a local ath ts fight Wekwith mixed results. Aberystwy and Weston-super-Mare in their different ways petition has been used to assist in such petition has been used to assist in such regeneration. Aberystwyth, in its more isolated location in West Wales, is a university town and less dependent on the holiday trade. Weston, on the other hand, has suffered neglect and lack of investment since before the Second World War. An architectural competition to revitalise Birnbeck Island and its derelict pier was initiated by developer Urban Splash and the local council with great fanfare and pizzazz, but was scuppered by the 2008 recession and has been dormant since. Crowcombe Court on the coastal edge of the Quantock Hills adjacent to the Bristol Channel, South of Weston, and Bengough's House near the Severn estuary at Henbury on the outskirts of Bristol to the north offer completely different understandings of completely different understandings of seaside. They are other geographical and cultural settings. 
At Crowcombe, the scenario is an English The last is a village exception site consisting stately home intimately connected to of a redundant fruit orchard that had bee its church and village set within a land- almost surrounded by houses as the villag scape of outstanding natural beauty, and has expanded. Experiments in researching at Bengough's House, an existing award- and designing new ways of rural habitation winning old people's home is sited on a reflecting the varied demographic of the small suburban roundabout surrounded village and its rural hinterland have been by postwar residential development. The undertaken with the encouragement of land slopes down to the Severn, with distant the landowner and his developer advisers. views across to Wales. The river edge has London earns the appellation 'metropbeen industrialised and is constantly olis' owing to its overwhelming almos changing owing to its tidal nature

Middle England may be a shorthand way of identifying a large part of the population - predominantly middle-class and middle-income living mainly in the ural and suburban parts of Southern England. It is also used pejoratively describe a misdle-brow conservemindset, resistant to change and philistine in its attitudes to the arts and contemporary culture. I have also taken it as a term from the coastal edges of the country an the metropolitan centres. Four projec are located in this geographically varied heartland, including Belper in the Derwent Valley, Derbyshire, where Pereen d'Avoine, Aslihan Carapapoulle and I were invited to make a counterproposal for the development of the town centre and its meadow edge following the refusal of a plannin mall; two competition proposals initated by the Swaythling Housing Societ in Hampshire and Tomorrow's Garde City at Letchworth for new house types augment existing settlements; opment of 60 houses at Croula Horsmonden, near Tunbridge Wells, Kent. otherworldly scale in relation to the rest sprawlgiveslieto any singur muningrous word'metropolis' House bia Lon In Invisio House located in West permis to coject obtain planning permission to convert a large domestic garage in the back garden of a suburban West Loched house in Feltham, SouthWest London. Rocket Room: Pencil Tower a faceted cylindrical tower of 10 flats on a triangular B1 office plinth, is located in Fulham in inner suburban London. It is proposed as an extension of the Pipe rooftop houses on an existing 12-storey British Gas research laboratory buildin which had been converted into residential and $\mathrm{B} 1$ office units by the developer Crispin Kelly. Rocket Room: Pencil Tower may also be understood as a polemical project designed to accommodate the desire to densify, by building high in already dense neighbourhoods unshackled by successive London mayors and Len by succeswith the need to cons and London councils when making a new mainly residential

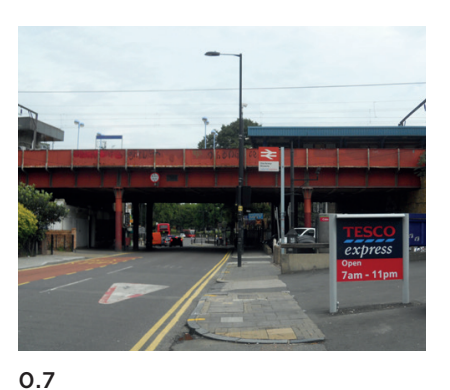

development for the wealthy to reflect the consolidation of a changed demographic from the old working class Fulham of the 1970 s to a more cosmopolitan, monied clentele. One hesitates to identify them as new residents, as the properties are often left empty and bought as investments. The final project in the book is Pembur Octagon proposed in response to an open competition held by the Peabody Trust for 0.7 Hackney Downs overground
station the Ginger Line, revitalsed infrastructure - a trigger for of urban Britain. However, its multifarous is a polmical project for densifying suburfor The Invisib Hom an earler project Building where we built two prefabricated during the nineteenth century and exemplified by New York. In truth, even at its apogee, the skyscraper environment of the Manhattan urban grid, the foundation myth of the twentieth century city, was only a part of a wider metropolitan environment. Even then, it was only the most dominant primarily because of its visual impact and the concentration of power conferred by wealth. However, the wider city consisted of a variety of urban scenarios and inhabitants that did not comply with such a reading. The mythic dimensions of the seaside, Middle Engl dimensions of angland and he rialin the dectico myth and rationality compromise the two held in a rociprocal tensin 38). Th r is aloch 38). There is always an oscillation between the impulse to make sense and order of the environment which is anticipatory and the realisation that change happens beyond our reach, and all of us struggle in our response to achieve some level of control at the scale of the city and the land outside the city. All of the projects in this book are polemical to some degree, in that although they are responsive to a lived history under bourgeois capitalism, they are also an attempt to 'construct' other histories in response to different political visions which embrace the notion of collective responsibility to the well-being of all peoples and a planet increasingly under threat from environmental degradation on an unprecedented scale. The very real threat to the survival of humanity forces us to engage with the moralculturl question of what we in 
Proposals-The 12 proposals are un-built and cover a range of scales and locations:

The Seaside:

Aberystwyth Arts Centre, Ceredigion Wales

Pleasure Holm at Birnbeck Island, Weston-super-Mare, Somerset Crowcombe Court, Somerset

Bengough's House, Henbury, Bristol

Middle England:

Six houses in Glastonbury, Somerset A Counterproposal for Belper, Lower Derwent Valley, Derbysire Swaylhing Hoy, Derbyshire Swaythling Housing, Hampshire Tunbridge Wells, Kent Patterns for Letchworth: From

Garden City to Patchwork City, Hertfordshire

The Metropolis, Suburbia: House + Garden + House, Feltham Middlesex

The Metropolis, Inner City Rocket Room: Pencil Tower, Fulham, South-West London

Pembury Octagon, Hackney, East London

Interviews-The 12 proposals are complemented by interviews with protagonists involved in the projects, including a private client, a commercial client, a landowner, historians, a property auctioneer, a develhistorians, a property auctioneer, a deveopment manager, environmental and

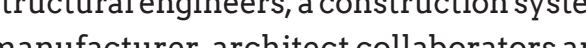
manufacturer, architect collaborators and the chair of a competition jury. The aims of the interviews are to provide a differen context to each project and to encourage an understanding of the proposals as documents embedded in a broader social as well as professional architectural milieu. The interviewees were encouraged to discuss their personal histories, as well as their relation to the specific architectural project and their own professional position and expertise. In this way, it is hoped that something of the spirit of the times during which the proposals were designed is conveyed the proposals were designed is conveye and helps the reader to understand a little more about the background and contex to the projects presented in the book than a conventional presentation of the work alone would do. To quote Alec Scragg, an interviewee, 'It's about relating family history to a lived understanding of these abstract social phenomena and how we came about'. In different ways, each interviewee may be understood as a collaborator whose involvement in and action on the design processes, however tangential, is a factor in the way the projects have evolved and have emerged in their current form. The interviewees include:

Jonathan Vining, architect and historian - Aberystwyth Arts Centre, Pleasure Holm at Birnbeck Island and Bengough's House

Aran Chadwick, structural consultan and Bill Watts, environmental consultant-Pleasure Holm at Birnbeck Islan

Kim Auston, historian and ex-officer, Historic England - Crowcombe Court

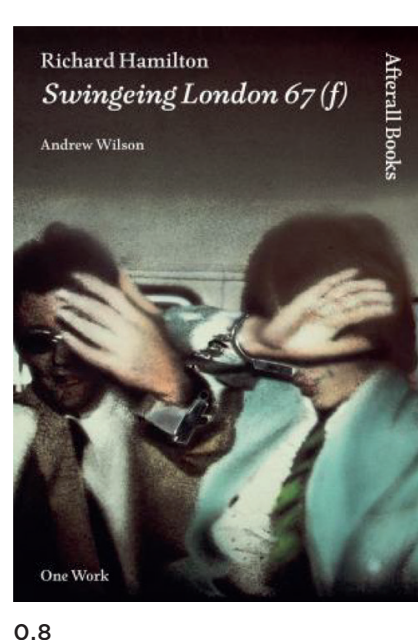

0.8 Richard Hamilton Swingeing
London $67(f)$, Andrew Wilson, London $67(f)$, Andrew Wilson,
book cover, 2011. I I ource: Image
courtesy of Afterall Books.
David Jones, chief executive of Bristol Charities - Bengough's House

Nick Oliver, Cooper and Tanner, land agent and auctioneer - Six houses in Glastonbury.

Barry Joyce, ICOMOS UK World Heritage Committee Member and former conservation and design manager at Derbyshire County Council - A Counterproposal for Belper

Alex Ely, principal of Mae Architects and he Swaythling Housing competition jury -Swaythling Housing Joh Field

Iim Green, development manager Baylight Properties plc-Crouches Field Ian Abley, architect and Alec Scragg, urban designer - Patterns for Letchworth: From Garden City to Patchwork City

Jess Rayat, private client - House + Garden + House

Crispin Kelly, chief executive, Baylight Properties plc - Rocket Room: Pencil Tower

Liam Dewar, director, Eurban-Pembury Octagon

The majority of the interviews were conducted in August 2016, with some in
2017 and 2018, by Pierre d'Avoine. Clare Melhuish interviewed David Jones in 2009 for the exhibition Land Architecture People held at the Royal Danish Academy of Arts School of Architecture, Copenhagen, in 2009 and at Ambika P3 Gallery, London, 2010.

Opportunist practice-Bernard Tschumi in Architecture and Disjunction set out three modes in which the architect can operate: the conservative, providing form to the political and economic priorities of existing society; the intelloctual, who revily ffers posible courses of action; and

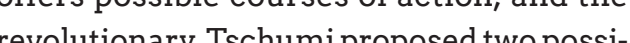
revolu possiactions' and 'counterdesign' (Tschumi 1996). For the artist Richad (Tschum, 1996). For the artist Richard Hamilton, the dilemma of engagement and subversion an 'ironism of affirction an 'ironism of affirmation' that allowed for critique and celebration, distance and engagement to be present at one and the same time (Wilson and Hamilton, 2011). Robert Venturi, who has been an inspiration to me ever since reading Complexity and Contradiction in Architecture in 1972, in which he discussed the idea of inclusivity in the context of architectural form, preferring both/and to either/or, stated hat architects can no longer afford to be intimidated by the puritanically moral language of orthodox modern architecture' nturi, 1977).

Tschumi, Hamilton and Venturi evolved their careers and developed their positions in the postwar period, which up to the late 1970 s seemed to be 
and celebration manifested in consumerand youth culture and in Bitain with the invention of the welfare state. Howeve the seeds of neo-liberalism had already been sown in the Cold War by Americanled militaristic corporatism. It achieved overwhelming ideological dominance in the era of Reagan and Thatcher in the 1980s for which the intellectual underpinning and basis was provided by Hayek and Friedman, among others, and its consolidation ensured by the gradual erosion of the traditional working class in thrall to mass traditional wor

It prevails today as the model for global corporations and their nation-state acolytes, so much so that the writer and cultural commentator Mark Fisher in his book, Capitalist Realism: Is There No Alternative?, despairs as to how the hegemony of neo-liberalism can be challenged:
'It's easier to imagine the end of the world than the end of capitalism' (Fisher, 2010). than the end of capitalism' (Fisher, 2010). Fisher illustrates the deleterious effects 'of 'business ontology' on education and 'market Stalinism' in public life (Amsler, 2010) but identifies the situation since the financial crash of 2008 as a tipping point, an opportunity to create an alternative to an increasingly oppressive and unsustainable global order. Fisher argues that this does not mean a re-tread of political scenarios of the left that were obliterated during the 1980 s, but that an alternative should be model of neo-liberalism we find ourselves living with now: the argument that a marthe ideology of individualism and incapacitates at almost every level the ability of societies to think and act collectively for the common good which has now to be understood in worldwide terms. In his book, Fisher calls for new forms of collective action

What forms can collective action take in architectural practice in London since the start of the new millennium? I wrote nearly 30 years ago that I have been given opportunities to explore the notion of public architecture in my work, wher the social ideals of modernism still offer a broad base from which to sill offer designing and making building and dettings, and thaking buildings and their the Lissitzky had writte Russia in the ton to social revolution (El century are tied tolieve this still to be true, and a the condions in wich we and athough the conditions in which we live may have changed, the need for forms of collective action in finding fresh ways of dwelling is ever more urgent. The situation is now irrevocably tied to the need for an environmental revolution that demands a transnational response.

The period during which I have set up my architectural practice and led my professional and personal life has been one which has seen the partial dismantling of the welfare state, resulting in the demise of local authority architects' departments in Britain and the rise of the corporate developer operating on a global scale. Successive UK governments have been complicit in initiatives such as Right to Buy, private finance initiatives and private-public partnerships which further limit and reduce the which further limit and reduce the contribution the state at the national level makes to provide decent housing and toplic spaces for all members of society, diminishing the potential of the architect to make a contribution beyond that of stylist - servant to a system unable to re-imagine and implement a world beyond the corrupting impact of an unfettered market.

This book is a document, a modern 'ethnography' of architectural practice lived through these conditions. To quote James Clifford:

Ultimately my topic is a pervasive condition of off-centeredness in a world of distinct meaning systems a state of being distinct mente in culture while looking at culture, a form This predicament ... responds to the twenThis predicament.... responds to the twentieth century's unprecedented overlay of traditions. A modern 'ethnography' of conjectures, constantly moving betwee cultures, does not, like its Western alte ego 'anthropology' aspire to survey the ful range of human diversity or development. It is perpetually displaced, both regionally focused and broadly comparative, a form both of dwelling and of travel in a world where the two experiences are less and less distinct. (Clifford, 2002, 9)

At the heart, it seems there is a loss of authenticity in our lived experience. It is almost a century since 'a truly global space of cultural connections and dissolution has become imaginable: local authenticities meet and merge in transient urban and suburban settings' (Clifford, 2002,4).

William Carlos Williams haswritten

In Spring and all the human future is something to be creatively imagined, not simply endur. reality itself... To enter a new world, and have there freedom of movement and newness' (W. Williams, 1966). But geopolitical questions must now be asked of every inventive poetics of reality. Whose reality? Whose new world? In Women: The Longest Revolution, Juliet Mitchell states:

I do not think that we can live as human subjects without in some sense taking on a history, for us, it is mainly the history of being men and women under bourgeois capitaism andeconstructing thathistory we can only construct other histories. What are we in the process of becoming? (J. Mitchell, 1984, 294)

The situation still persists, endures - in fact, it has been exacerbated and intensified during the past seven years that I have been assembling material for this book.

Plot and multiply-This book may have been titled 'Plot', intentionally implying more than one meaning, and principally in reference to land that has been subdivided, but also in terms of narrative, to the sequence of events inside a story which affects other events through the principle of cause and effect. In this case, these are narratives about identity, land use, housing and the conditions for contemporary architectural production, but also plot as something active and anticipatory. something subversive, planned secretively that intends and threatens change. It could be incremental change or change as revolution Le Corbusier posited architecture 
or revolution', and declared that revolution ing his the beginning - our expulsion from Eden paternalistic diktats about Radiant Cities presaged an inevitable conflict of interest cloaked in poetic mysticism. It seems, inherent in the way we as human beings however, in the zeitgeist of the early twenty- relate to each other, in families and larger first century that architecture has been social gatherings.

avoided (A. Williams, 1993). 'Multiply' as it reuld also have been titled because of its inherent qualities and potenland on which a builes to the idea that the tial for dwelling, occupation and use. The balance between defensible space and land ffect multiplied and its value is increased for cultivation and other forms of producsometimes several times over through tion is a constant in our lives as individuals the use of a plot ratio or site ratio. This is and in the globally interconnected sociean overtly political idea that now widely ties in the early twenty-first century. Eve y ties in the early twenty-first century. Even is moresonow ithat the ror to ma majo At anver envents, and hat the world's populaAt an elementallevel, we build in order tion is ever increasing. Yet, in Britain and to provide ourselves with shelter, to dwell elsewhere, with finite, probably depleting more comfortably by constructing a layer resources, we are transfixed, struck dumb, of material between ourselves and the raw immobile and seem unable to create the environment. We need to create a medi- governance with which to act in a responsiated world in which we may exist and carry ble and honourable manner for the commo out our daily lives and a range of actions good, denying many people the opportunity and activities that would be impossible of adequate livelihoods and accommodaotherwise. The only natural environment tion. The potential for dwelling in the futur that would have provided adequate shelter, seems more limited in an era of continuprivacy and protection to our primitive ous warfare, huge economic problems and ancestors is the cave, but even then, it would environmental degradation. To offer evehave been necessary to construct some- ryone the opportunity to live well, there thing additional in order to make the space needs to be a new economic paradigm, one secure from intruders: a gateway which that brings stringent, enforceable marke provided a threshold between the private control, sets limits to growth, profligate domain and the world at large. Man as an waste of natural resources and human essentially social animal rarely operated capital-a world which aims to eradicate in isolation but most often in family and inequality, but sharing what we have, and interrelated tribal groups. These groups by intelligent husbandry of the land and were inevitably territorial, whether hunter- by were inevity territorial, wh for conflict between individuals a d groups

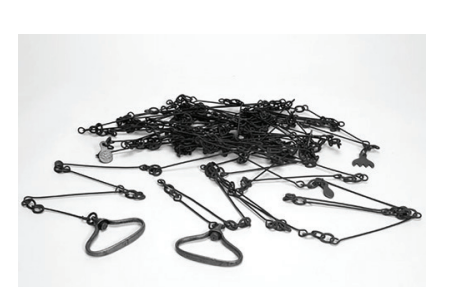

The Boke Named the Governour-In The The Named the Gover published in 31, Sir Thomas Elyot advised that 'The first step to be taken by the governours whether of kingdoms or estates is to draw up a map of the estate'. Elyot understood that the map was a political document that described territory and asserted ownership of it. Accurate measurement of the land became increasingly important in the sixteenth century when English landowners began to commission surveyors to measure out their estates and make maps of them the Domesday Book, which wasinstituted by William the Conqueror in 1086, dimenby Willam the Conc, which was instiunenand hides that varied in size according to and hides that varied in size according to how productive the land was. A hide was

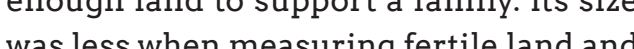
was less when measuring fertlle land and greater in upland pastures where the soil was of low quality. Measures were flexible, as land was held in exchange for services. The number of people it could feed and so make available to render those services was more important than its exact area (Linklater, 2002, 6). The dissolution of the monasteries was instigated by Henry VIII between 1536 and 1541, when the Crown needed cash to pay for England's defences. The sale of land for cash effectively created a new land-owning class. Prior to this, land was valued in terms of the number of people it supported. In its aftermath, it became an investment opportunity and the basis for transaction involving exchange of mone rather than for services. In other words, it may be understood as the beginning of modern capitalism where power increasingly laid with income depended on the size of their prophow much rent could be raised from

Accuracy of measurement became of undamental importance in the preparation of cadastral maps defining ownership and property boundaries. Gunter's chain invented by Edmund Gunter in the early seventeenth century became the predominant instrument for measuring land. Its genius lay in its synthesis of traditional English land measurement, based on the number four and the decimal system, first published in 1585 by the Dutch engineer Simon Stevin based on the number 10. Gunter'schin, which measures $22 \mathrm{y}$ ards till the len out out cluding the USA where the imperial inctur system is chain was a device for mang chain was a device for making private property and establishing a true market propery cum supply and demand would determine the price, and it could be treated as a commod'y' (Linklater, 2002). This was not Gunter's intention but rather a consequence of the accuracy of his chain. It was applied to great effect in the USA where 'new' land could simply be divided into a grid of square parcels to be sold for settlement. In the old world, including England, recording the extent of land ownership has been considrably more complicated and problematic nd a continual source of contention.

In successive attempts to record land ownership in Britain including The land 
Registration Acts passed in 1862, 1875 and $\begin{array}{ll}\text { Registration Acts passed in 1862, } 1875 \text { and } & \text { selfishly as we liked because the 'invis- } \\ 1897 \text { and 1925, landowners have been reluc- } & \text { ible hand' would turn everything to good. }\end{array}$ (their then in the compounded ou 作 only 65 per cent of the land in the UK is primary social goal. Historically, a troika included in the registry (Cahill, 2002). The of competing influences has generally govimplication is a form of protectionism and erned Western societies. The economic possibly the original form of land banking, system was, of course, one influence, bu a term pejoratively used to describe the it was constantly regulated and modified process of restricting the supply of land by the other two, the political system and to increase its market value no matter the moral-cultural system which is made how pressing the need to release the land up if diverse elements such as the press, for housing the poor and needy. This has the universities, writers and artists and become once a pin of the major issues of course, the churches. Unfortun and of this century both on a national scale however, this latter group largely abdicated of this cen bourgely abdicated and globally owing to increasing numbers its moderat ing rol of the dispossessed and disenfranchised ble hand almost two centuries ago and cenied the basic human right of adequate then, when the politicians made increasing space in which to dwell. The implications nationalic are serious, given the increase in popu- the rule of economics became absolute lation, but also the sheer unfairness and In short we are all victims of an economic selfishness of the political and economic totalitarianism and have little freedom to system, even in crowded Britain, where 59 determine what we think and do in the million people 'live in 24 million dwellings economic sphere. (Douthwaite, 1992, 314-5) sited on a mere $7.5 \%$ of the total acreage of the country' (Cahill, 2002). We have to ask Douthwaite, an economist turned writerourselves why we seem intent on crush- activist, articulated with many others ing more and more people into smaller concern that economic growth was not and smaller spaces in which to live. The sustainable and the problem had to be situation calls for a complete recalibration addressed on a global scale if it was to to create an inclusive and humane body provide a serious response to rising inepolitic that works for us all. quality and environmental degradation The consequences of rapacious profi-

Overproduction of the built environ- teering by the rich at the expense of the ment: Richard Douthwaite, the limits of growth

Capitalism... is morally netural our mistake has been to ascribe morality to

it by accepting that we could behave as poor used to be something that happene elsewhere, and it was easy to turn a blind eye and ignore it. The situation since the economic crash of 2008 has been one of increasing instability, including in the 'developed' West, leading to extreme conditions of poverty and wealth. We are assuaged by statistics pointing out that the general standards of living have never been so high. Yet, we are now faced with evidence everywhere in our towns and cities, and in the rural countryside, of decadent affluence and of homelessness and people living in dire circumstances. It appears the situation is so intractable that governments give up the struggle and acquiesce to maintaining the dominan status quo Other statistics suggest tha there is enough to go round and that it is question of distribution and sharing question $\mathrm{dith}$ bi does not seem to bep option where the production, production, aided and abetted by the politcal classes everywhere, are too myopic and self-interested to see the potentially disastrous outcome to the planet, including themselves. We are bombarded with such news on a daily basis, but our leader seem powerless to respond.

In her book Doughnut Economic (2018), the economist Kate Raworth encourages us to be agnostic about growth and to change from our fixation on GDP, or national output, as the primary measur of progress - a fixation that has been used to justify extremes of inequality and the destruction of natural habitat through her concept of the doughnut as a means of achieving economic balance. The implications for architecture and housing in particular are problematic in that faced with an increasing population, the first response is to build more everything - offices, shops, art galleries, prisons, houses, surprisingly in the UK ven factories and of course more infrastructure. Architects are mainly educated to build buildings, and no matter what the quality of the buildings that are built, this is a fundamental problem. It may be easy perhaps to argue for a moratorium on building if the population had stabilised, as it did in Britain for 50 years at the end of the war in 1945, except perhaps for wear and tear of the built fabric, and evolve a practice of maintenance and restoration. Something like this has happened for difincluding the value we place on some of the architecture of the . Maybe we are all conservative in valuing continuty and the humane qualities of historic cities and towns and the bucolic mage of the countryside. The ravas of war a d changingsocialas postwar population resulted in wions for the changes, a guably not for cher the ambitions of well-intentioned politicians. However, limiting growth could be initiated by a range of initiatives inspired by Raworth's participatory economics. A Commons Transition Plan which was commissioned by the city of Ghent in Belgium in 2017 aimed at exploring the potential of enabling the control of local resources, including land. by the local community in perpetuity for the shared benefit of its inhabitants. Projects in this book including Crouches Field and Patchwork City have proposed similar initiatives and explore scenarios including forms of participatory politics predicated on 'radical devolution and a fine-grained democratic control over 
the decisions affecting our lives' (Monbiot, 2017).

Jacques Tati and Paul Lafargue: The Right to Be Lazy-In the 1949 film Jour de Fête set in Sainte-Severe in smaltown France, Jacques Tati, who stars as the postman Francois, creates an ambivalent scenario of rural life as nostalgic and
backward looking, with a xenophobic attitude held by a broad section of the public, simultaneously celebrating the conviviality of rural France and making fun of its smelly awfulness. In the making of the film, Tati involved many of the villagers as extras, and the resulting popularity of the film has meant that ever since, SainteSevere has been seriously afflicted by 'Tati-mania'. In his biography of Tati, David Bellos states:

Tati as performer and mime artist creates through gesture and bodily movement an intensification of everyday human interaction. In his persona as Francois the postman and later as Monsieur Hulot, he promotes an attitude of concerned ineffectiveness and inutility if not indolence at odds with modern bourgeois society's demand that man is defined by his work and has to be productive above all else. Paul Lafargue, Marx's son-in-law, in his essay 'The Right to Be Lazy' published in 1883 critiqued this attitude in political term as a position of resistance, satirising both the promotion of the work ethic and its the promoth of the work ethic and it assing Lafargue pointsout, the extreme demands placed on the human body in pursuit of increase in increase in leisure time promised by mechanisation has become a chimera, despit Jour de Fete is the local (Sainte-Severe's) the IT revolution and the potential of robotfoundation myth, the proof that such a ics and artificial intelligence to liberate us small and unremarkable town really exist. from the tyranny of work.

Yet there is no powerful marketing organisation behind the Sainte-Severe spin-of business: the theme-park mentality seems to be generated by the townsfolk themsmall-holder farming, there is not much else of note in Sainte-Severe. But the irony of Jour de Fête as a satire of American cultural influence on French life is what can Severois themselves. In the film, Francois is a loveable gullible fool; in the longerterm history of the film, however, in is not entirely clear who has been taken in. (Bellos, 1999, 145-6)
Disneyfication had overtaken the English countryside by the late twentieth century. In an earlier mode, it wa encountered in architecture as 'the castle air' in the work of Vanburgh and exemplified later by Nash's cottage orné houses at Blaise Hamlet near Bristol in the eighteenth century. The aristocratic penchan for dressing up and playing at being farmhands and milkmaids went hand in hand with the architecture. Blaise Hamlet was an enclosed garden setting of gimcrack gothick cottages for aged retainers retired from service at Blaised retainers attitude carries over from manners and architecture to how the English countryside is mythologised, and was codified as the picturesque in the landscape proposals
by Repton and others. Raymond Williams by Repton and others. Raymond Williams suggests it was the moment the countryside as one of production and that the 'naturalising' of the English landscape throughout the eighteenth century took place at the cost of depriving rural workers of their livelihood. Williams made the point not only in terms of the economic arguments of enclosure, but also in terms of a new way of seeing the land ( $R$. Williams, 1993). This of seenge, bund (R. Will Middle England, and its stultifying impoct on the architecure and environment of on the architecture and environment of towns and villages of rural England is inesholistic paradigms for the land outside our cities, including a world where people may choose not to work and where a political
system is implemented to encourage this system is implemented to encour

The global embrace of Middle Englishness is not just about the triumph of branding culture but may also be understood as the collective fear of headlong technological change and a retreat into scenarios where the individual can exercise some level of control, even if it means abandoning responsibility for the wider environment, which increasingly is the example of government as well as of individual attitudes. It suggests and demands that we require a recalibration of our attitude to work production and leisure and a different way of seeing Tati's example, though ambivalent, has a universality that transcends language through bodily in new ways and makes a claim for a world in which leisure could help us define how we make architecture and places in which to dwell.

Anglo-Exotic: Multicultural necessities and choice-In this book, I discuss the context of my architectural practice since the 1970s and the lived histories of the projects. I also discuss my personal experience and the experience of working s an architect during this extended period. The conversation on housing reflects (t) capable thatl of an architect's work as a conscious being is an engats work a he act of dwelling ind that is has been play child on delight of aranging ones personat space ang and things of course mostly within a larger o in a home of one's own. Ithink my decision to study architecPure was taken at an early age. My father Plerre Avicenna d'Avoine was an architect in India. He was born in Bombay. His father Charles Lionel was a doctor - a French colonial born in Mauritius, who settled in Bombay in the late nineteenth century and married my grandmother Rose D'Cruz an Indian-Christian whose family name had been given by the Portuguese in the seventeenth century before Bombay had as part of Catherine of Braganza's dowry

(Bellos, 1999, $145-6)$




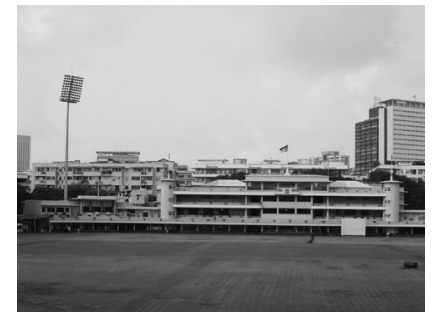

when she married Charles II. My father's family history is not unusual - a fairl and aspiration of post-independence India led by the social democratic government is unpick in any detail, and so it retains a world full of optimism and enterprise tha mystery and ambiguity that I enjoy for its ended for me when my father died suddenly unresolved open-endedness. It may have led to my embracing of the idea of hybridity and open-endedness in my own work an aspirations as an architect, but this is also

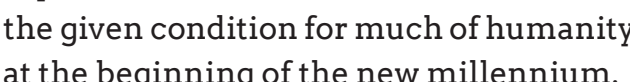

0.11 Brabourne Stadium, Mumba

My father began his architectural education at the JJ School of Art in Bombay where Claude Batley was professor. $M$ father later studied at the Bartlett in Gathet Gregson Ba rey and King (GBK), a po jo Gregson Balley and King (GBK), a prompartner. My father was a notable athlete and well connected in sporting circles in India. This led to his appointment as architect, in his 30 s, for the design of the Brabourne Stadium home of the Cricket Club of India in Bombay and to later commissions for in Bombay and to later commissions for sports stadia throughout India

GBK was the quintessential coloni

chitectural practice with a typical work load comprising government buildings, banks and large commercial buildings as well as work for the Indian aristocracy. M father became the first Indian principal of any architectural office in India after independence when his British partners retire office into new areas of work in India and abroad in the 1950s. These included large pharmaceutical developments and lar industrial projects reflecting the ambitio at the age of 53 in 1960 .

Edward Said in Orientalism (1978) discusses identity, considered ethnograph cally, as always being mixed, relational an inventive and the ethnographic idea as relativist and plural involving the serious fiction of culture James Clifford discusses 'straining for a coscest thasses 'straindifferentiating functions wheserve culture's collective conceiving of tinuous inventive proces' (Cliffor discon10) For ind is impossibs' (Clifford, 2002 inauthentic, oscillating between separate worlds temporal, not just the duality of the orien and the occident but in relation to much else. Todal hered old fashioned, given the globalised natur of our culture and the way we live our daily lives where the 'familiar turns up at the end of the earth' (Clifford, 2002, 14).

One responds to the idea that identity is inventive and susceptible to change, depending on circumstance and location Global exchange provides surprising juxtapositions. My mother was Indian born but Irish, and she, my sister and I emigrated to London in 1962. We were part of a reverse diaspora of British colonial subjects still seeking to be connected with a homeland most had never seen before. In our case we had spent holidays in Englond in the 1950s, but short visits in England in the couldn't prepare one for the expe i). For me, it is impossible not to be hybrid of settling permanently in London in the early 1960s. We lived first with $\mathrm{m} Y$ aunt in Bedford Park, West London, in small terraced house before moving to a first-floor flat in neighbouring Acton. My mother bought the newest house she could afford-a 1920s three-bedroom semidetached house in Acton. This was a very Indian desire and preference for all things new in contrast to the nostalgia for the past we experienced in Britain an attitude that still persists and if anything has intensified In India, the departing British left a void filled by the new consumer culture abich exploded from a domina Bombay, everyone owned cars, our family had an Ord cars, our family had an Oldsmobile, and Anserican pop culture was readily accepted hybrids a process that we now realise hybrids - a process that we now realise was taking place across the world in other tropical cities such as Havana and Rio, even Dakar and Addis Ababa, where $\mathrm{m}$ father, just before he died, was negotiating to build the national stadium for Heile Selassie - but then they seemed to exist in self-contained little pockets unaware of th transcontinental spread of cultural ideas, influences and fashions. Architecturally, Bombay had responded to the influence of high and low modernism before the war while the British still ruled India, and the city extended from its High Victorian core, using Art Deco stylings constructed in reinforced concrete. Some of these buildings still stand, including the Brabourn Staduim, the Ritz Hotel, the Glaxo headquarters and Cadbury building designed by my father.
The response to modernism in London after the war was grittier and focused on the urgent need to rehouse a significant part of the population displaced by extensive bomb damage and a desire by politicians and their advisers to use the opportunity to experiment with new construction methods - prefabrication, steel frames and reinforced concrete - and typologies including residential high-and medium-rise developments. As a child in new city, it was necessary to adapt, to assimilate and be assimilated into the, for me, very strange culture of British suburban life. The semi-detached house was a bastardised tradition both form and in they that it was construct, und in the way that it was constructed, using facing brickw in as the thin outer skin of a cavity wall The ubiquity of the semi is in part a triumph of mediocrity - an interesting idea watered down and reduced by ing to orer cho and ing to offer choice, but cynically limited in its aspiration as towns and cities were extended to privilege the motor car and road networks. It also triumphed because of its essential flexibility in terms of land use and the way it accommodated the car in a driveway, thus freeing up the road. The denser urban fabric, the streets and terraces of the inner city, did not anticipate the dramatic expansion of motor transport and was mostly abandoned by the middle classes in the 1950s and 1960s to the working class and the poorest post-colonial newcomers who re-created communities where rents and property were affordable. What were salubrious middle-class enclaves transformed from 
large owner-occupied terrace houses to much more densely populated multi-tenanted buildings in areas such as Notting Hill where my mother worked as a primary school teacher. At the same time, experimental social housing in the form of towers and low-rise blocks were being built for council tenants and gave rise to a new hybrid environment of estates intermingled with the existing fabric of Italianate Victorian streets and squares, some with large communal gardens for use by local residents - a model derived from earlie inner London residential development such as the Bloomsbury Estate.

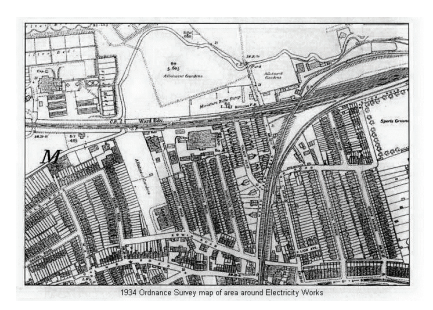

0.12

\section{Monad: Nomad}

But all invocations of an archaic, centred dwelling demand questioning. If the shape f modernity militates against all centres, should we not welcome this? Suppose were to discover a place that deserved to be called not just a centre but the centre of my world, were to discover, say, the place
where I truly belong, my true home: how where I truly belong, my true home: how could I bear to leave it? Were I to dwe in such a home, I would no longer know would no longer be a place to go, since that place I would already be occupyin The voyage of my life would have ended. So understood, the plenitude suggested by dwelling at the centre means death and it only seems appropriate that the devil was thought to dwell in the earth's centre and God somewhere beyond the periphery; beyond the firmament, everywhere and nowhere... To be genuinely

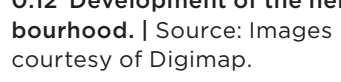

1. 1863
2.1915
3.1934 essential homelessness, a homelessness illuminated by shifting ideals of genuin dwelling. (Harries, 1998)

Land has always been contested. Given human nature, it is hard to believe in an early Eden, when land was freely available in which to live, traverse and dwell, withou fear of being challenged and displaced. Land ownership has become a complicated and ambiguous issue, such that the layman must resort to the legal profession in propI bought a house in London with I bought a house in London wit Jacqueline Pitfield when I was 22, at a tim when a year-out architect could contemat the time of the first oil crisis OAPEC Oesulted in the price of petrol quin overnight It meant a sudd quadrupling cars on the streets of Londen dearth of cars on the streets of London, and for time, it was easy to drive into the Wes estate agency windows offering 100 per cent mortgages on houses. This was the spark that led to us buying an end-of-terrace house in Twickenham

The house at 66 Hamilton Road was untypical of West London suburbia. The first impression of Twickenham in the late nineteenth/early twentieth century was one of wealth and prosperity, but this was not the case in all parts of the borough. In the area north of Twickenham Green, large number of Victorian and Edwardia large number of Victorian and Edwardian the numbers of working-class people who erty negotiations and land trasion in property negotiations and land transactions, $\mathrm{n}$ End and park freely. There were signs in
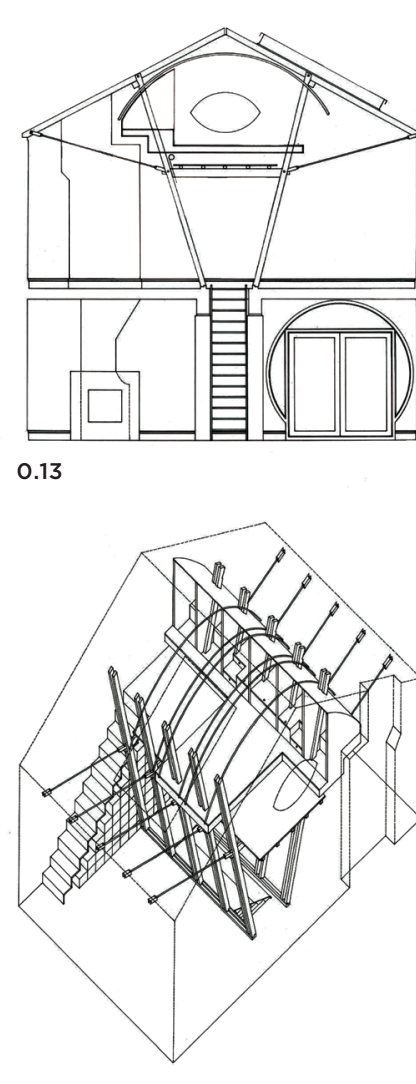

home in this world, we have to affirm our
0.13 Section, 66 Hamilton Road,
1977

0.14 Axonom
Road, 1977

were moving into the area to support the many small industrial works that wer opening up. Hamilton Road and Warwick Road were culs-de-sac abutting an electricity station, laid out on part of a plot of arable land of 4 acres 3 roods 19 perches adjacen to the railway line. The houses were buil in rows of six, with a narrow passage in between. When built, they consisted of a front room, a back room and a kitchen There was also an outside toilet and coal shed. There were three bedrooms on the first floor, and each house had a small fenced-in garden at the rear. The front fenced middle bedrooms, all had small fireplaces. It was not unusual for two families to share a house, with the family upstairs using the fireplace for cooking.

66 Hamilton Road was at the end of the terrace. Like other houses in the row, it had a small backyard. However, the reason for buying it was that it also had a triangular side garden enclosed by broken-down fencing. Although the end-gable wall face south and the side garden was a suntrap there were no doors or windows openin onto it. It was always our ambition to ope up the house to the garden and the sun. was only when we started repairing the fence and a neighbour asked if the side garden was ours, mentioning that others like it in the neighbourhood belonged to the council and were rented, that we had to appoint a local solicitor to clarify the situation and find out if the side garden

actually belonged to us. It turned out that

our side garden was not ours legally, but had been enclosed for a sufficient period of time for us to be able to file an ownership claim. However, our claim had to go uncontested for seven years before the land legally belonged to us.

In the period we owned the house, we made extensive changes, including opening up the interior to the side garden, and were part of the gentrification of the area. This was a term first used by Ruth Glass, urban sociologist and founder of UCL's former Centre of Urban Studies (1958-80). She predicted in 1964 that 'London may quite soon be a city which illustrates the principle of the survival of the fittest - the financially fittest, who can still afford to work and live there. Not long ago the then housing minister advi ice to move out' (Glass, 1964, in 2015). We were stll living there Buy f The Housing Act 1980 during argart Thatchers first trm as prim Several houses in the street were bough The bought the housing association the diately sold on to developer landlords at a pront. We had bought our house for 25000 in 1973 and sold it for $\$ 33,000$ in 1983. It has subsequently changed hands on several occasions and, now extended and improved, sold for $£ 725,000$ in 2015. In the meantime, the electricity station also been converted to residential use. It has been pointed out by Simon ns that:

whatever the media's 'crisis' hysteria says, buying a house has seldom been so affordble. I bought my first studio flat in the 
Seventies and it cost four times my starter time - a constant reminder that place is salary. The 85 per cent mortgage cost 17 experienced through all the senses includer cent, It consumed 40 per cent of my ing the haptic-and an understanding that income and was crippling, The same job touch may also invoke the uncanny and today also buys a studio flat at the same mul- a remembrance of things felt intuitively tiple. But the mortgage is 4 per cent, which and not necessarily understood rationconsumes a mere 15 per cent of income. The ally. Place and materiality experienced Council of Mortgage Lenders' index has through touch and bodily engagement with London's average mortgage interest in 1990 the world become important aspects of the consuming 30 per cent of average income. way we think about the human condition That is 10 per cent today. Yes the deposit in order to anticipate how we may live in is bigger and payment may take longer, but no-one can say London property is less affordable to buy. The difference between means the design of places for other people y experience and the same studio today to live in. It is an act of imaginative thinkis its location, no longer in Camden but in ing and something done collectively. To points east and south-though still in Zone 1. accommodate the needs and desires of The great London house price conversa- others requires empathy, and the architon has never been about money but about tect can never be neutral and completely lass. (Jenkins, 2016)

objective. The use of all one's faculties is necessary in the design process, given

lenkins also makes the point that 'London's that our built environments affect us in truly residential rich want to live in town almost every possible way and we mus houses, not somewhere like a Moscow experience them at all levels. The brillian suburb' (Jenkins, 2016) - a pejorative discoveries across the fields of science, comment, as not all Moscow suburbs are the humanities and the arts made at the the same.

beginning of the twentieth century may have changed the way we understand th

Many-sidedness-In designing one's world. As architects, how we think and act home, one engages intimately with the way are inevitably driven by these discoveries. that places affect the senses with a view to They have opened up our eyes and imagicreating spaces of comfort and well-being. nations to latent possibilities for humane It seems however that one must acknowl- interaction and for design to be accomedge the impossibility of designing such modating and open ended in its aims and a building or environment and that a goals. The Jain theory of 'many-sidedness' dwelling will always contain some sense or 'multi-perspectivism' (Ane-kanta-vada) of the unhomely and this is desirable. The suggests that since the world is multifacun the ung is also a condition of certain suggests thaltifacnhom is a a ced, any single view point is limited. Jain bourhoods. This condition changes over knowledge. In my work I aim for open endedness as a design approach (it's never Blundell Jones writing about Haring and just about the design) and also in recog- Scharoun states that 'Surely (they and not nition that the interpretation of context Mies) were right, for if we cannot be totally has limits beyond one's comprehension rational and objective then we have to be and scope. Not everything is measurable subjective, but we can at least be relevantly and can be provided for rationally. Peter 

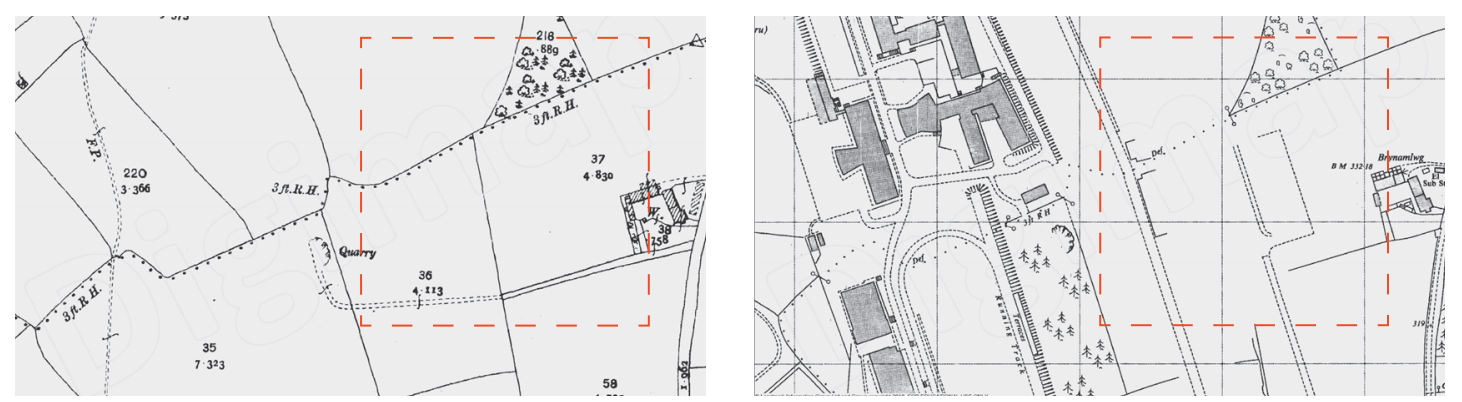

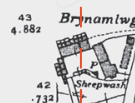

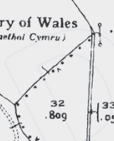

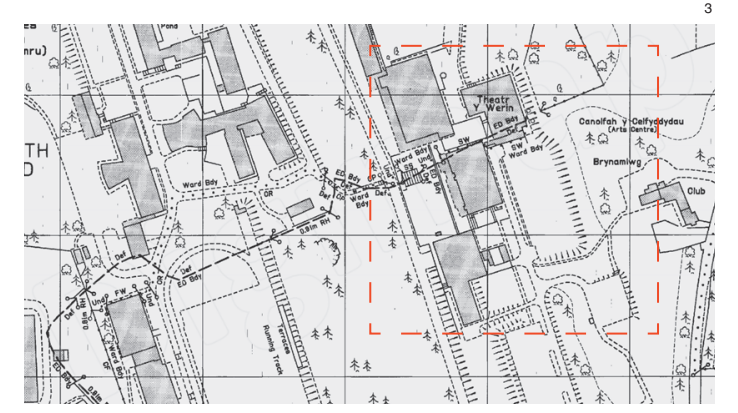

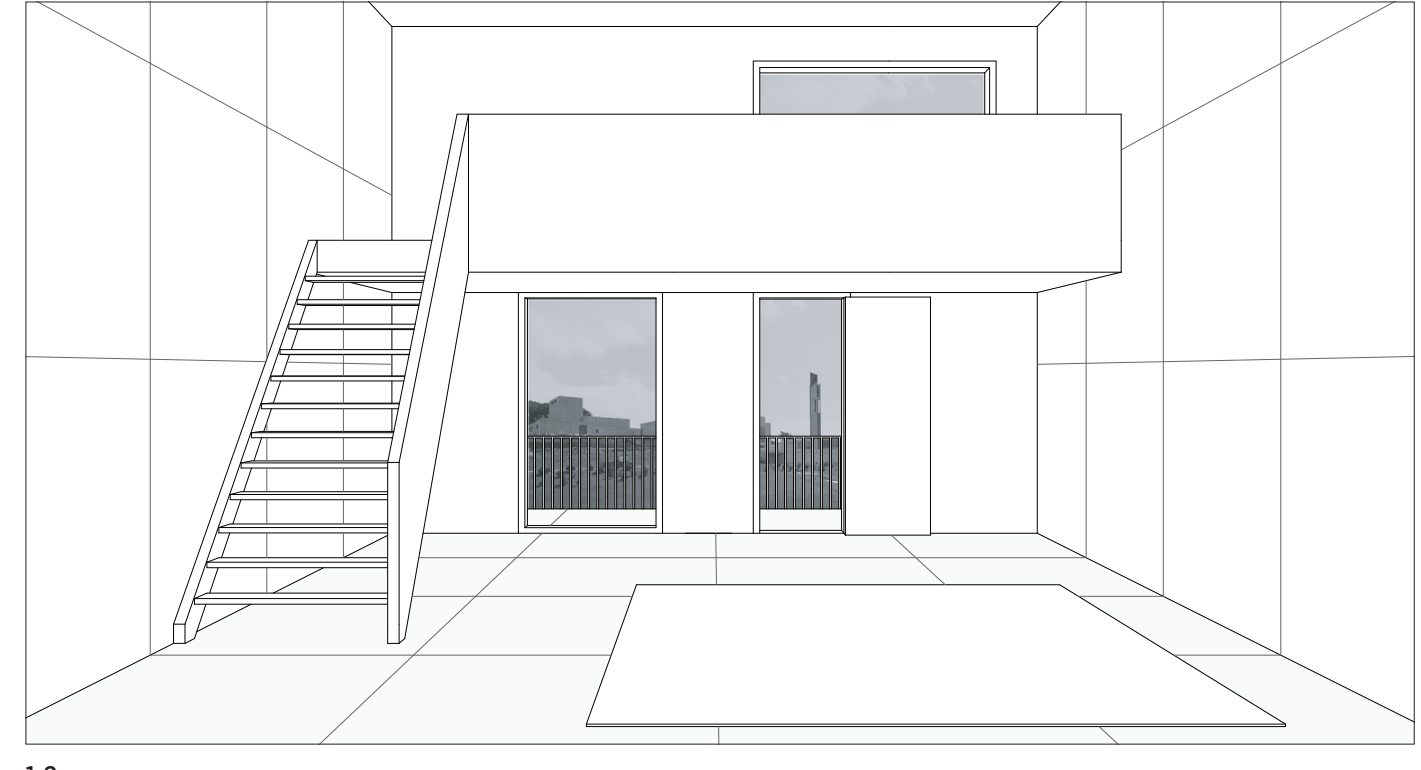

A limited competition was held to design space. The proposal aims to respond Creative Industries Business Units at to the spirit of the original master plan Aberystwyth Arts Centre. Aberystwyth and also to accommodate the more University, Penglais campus, designed recent additions to create a new public by Dale Owen of the Percy Thomas ground that extends the scope for large Partnership in 1970 is one of the most outdoor events as well as maintaining significant postwar buildings in Wales, and reinforcing informal routes through planned like a Greek acropolis and com- the site. Clare Melhuish carried out intermanding the high ground overlooking views with several potential occupants. the sea to the west. The site is located The transcriptions informed the design in woodland upslope at the rear of the process and led to the design of loose-fit

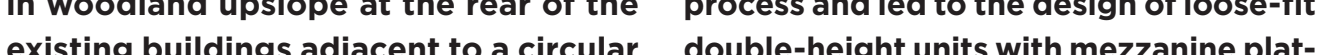
extension completed in 2000 housing a forms. The units with mezzanine platcinema, bookshop and further exhibition occupation, including accommotion

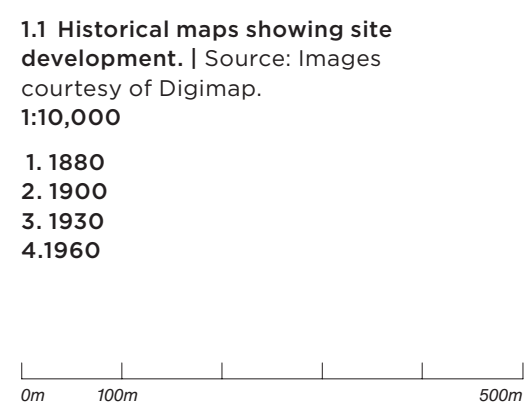




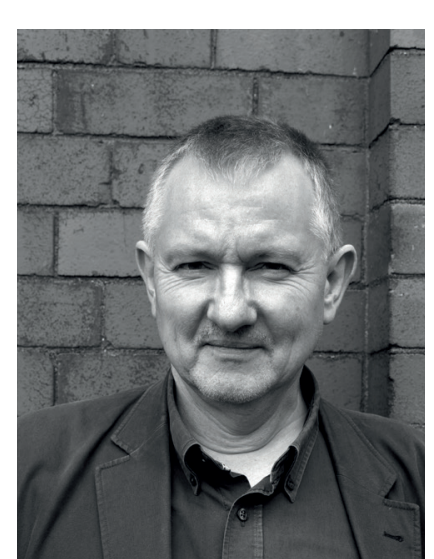

by doctoral student couples as well as we did go to beaches, but we also visited proposal included a double-height event people like pace and southon two levels used for access and for Alongside his work as a ceramics teacher spectating events held on the new public my father had a pottery when I was young ground. The undercroft was intended and was making modernist vessels and for use by children that used the site as exhibiting quite widely at that time, includa short-cut between school and home.

Jonathan Vining

Interview at Aberystwyth Arts Centre, 20 August 2016-I was born in Cardiff in 1957 where llive and work now Both 1957 fothers worked in colleries my mand grandfather looked after the horses, having stand staredworkin his teens athecoal ace, and born, was a sawyer. The forebears of both of bom, was a to work in the mines in the late nineteent century - from Devon and Somerset. M century - from Devon and Somerset. MY
father was born into that background actually on 29 February 1924 in a house late destroyed in the Aberfan disaster in 1966 He went to grammar school in Aberdare and won a scholarship to art college. He was obviously extremely gifted and went to the School of Art in Cardiff before and after war service in the Royal Navy, where he was taught by Ceri Richards.

He became a lecturer at Cardiff College of Art in 1950 and founded the ceramics department there, which he ran for nearly 30 years. It had an international reputation by the 1970 s. He retired due to ill health in the early 1980s. My background, therefore, was working class and rooted in a fore, was wos went on family holidays when I was young ing here in Aberystwyth (although not in this building, which was constructed later). We were asked, when we were in junio school, what we wanted to be when we grew up, and I said, even then, that I wanted to be an architect-although that early ambition faded when I was in compro school Ididn' dovery well in A

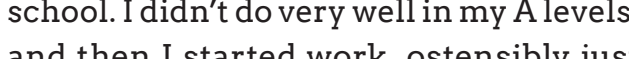
for the summert, as it turned for four years. That was 1975, when I was 18 and I worked bacally as a print was and I worked basically as a print and tea drawing drawing board. The firm was called $W y$ Thomas + Associates and had been se up by Wyn Thomas, a well-established very well-respected practitioner in Sout Wales, joined by my brother, Paul. It was town-planning practice originally, then expanded into architecture and landscape architecture after a period of time and became Wyn Thomas + Partners a couple of years later. I went to college in the evenings, and then I did day release, doing an ONC and the first year of a HNC. Around 1978 , we had a couple of young graduates who came to work for us straight from the Welsh School of Architecture, and they go to university and that I couldn't had to being a techniciand in couldn't carry on up not finishing my HNC; I just did the first were the ones really who said that I had to

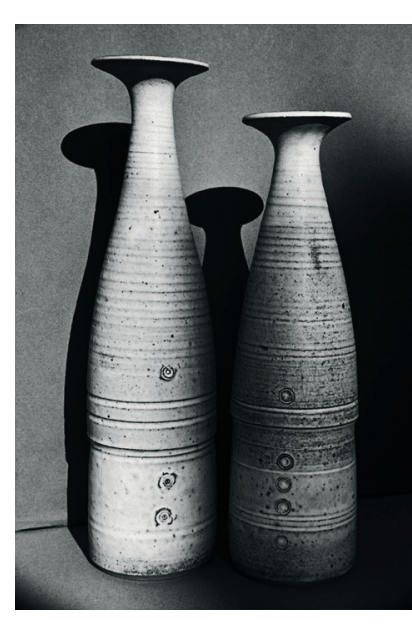

year of it and instead went to the Welsh School of Architecture in Cardiff. Wyn Thomas wrote me a marvellous reference, and this helped get me into the School of Architecture alongside $\mathrm{my} O \mathrm{ONC}$ and HNC first-year results really, rather than my $\mathrm{A}$ levels. I also had a good portfolio of drawings, which included freehand sketche that I had done with my father's tuition, but obviously I had drawings from my working life up to that point as well. I doubt that I'd even get into the School these days with even get into the School these days with The work I was doing in the office

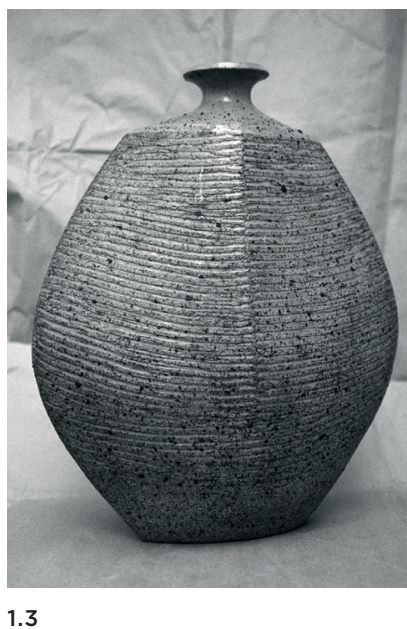

1.3 those four years was extremely wide ranging. I remember the first drawing that ever did was of aclose-borded timber fence. But I worked as a technician on architectural, town-planningand landscape projects. I came into work on (probably in 1979), find a note from $W$ an saing 'Drop everything you've done so far, I Dant you to rything you've done so far, I want you to work on this'. And it was actually to work with an architect and landscape architect called David Singleton to do the landscape drawings for the Ford engine plant that was being built near Bridgend. It was the largest landscape contract in Wales at the time, and I did all the drawings for that contract package. Terrific. And I made a large model of a proposed new mine at Margam when was working there. Looking back, I did such an amazing range of things in those four years-far more than I see with year-out students and young graduates nowadays. The office was about 20 strong I guess, and had a broad base, including town-phanning lond- scape and architectural projec exclusively in Wales.
My mother, Gwyneth Vining, was born in Aberdare, and she has been a homemaker all of her life. She never worked full-time, outside of the home that is, except when she was young during the war when she worked in an ammunitions factory in Trefforest, which she hated. When times were tough in the early 1970s, after we had moved to a much larger Victorian house with outbuildings in North Cardiff, she did work part-time in the fruit and vegetable shop nearby which she enjoyed. But she cared for her parents and my father's mother a lot Her father died. Ican't remember exactly when - perhaps in 1969 - when he wasin his arly 80 s I don'think hever ived with us, but her mother came from Aberdare tolvewith us for a few my grand orive come to vistus rather than round There come to the house to visit her. We used to cons to count he cups of tea at times, but it was a

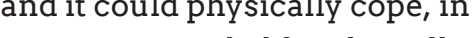
. had one sister who died from bout 18. Her eldest brother aso had TB and was hospitalised for a long time, and he never really worked again after that. When I was young, we used to visit my grandparents in Aberdare every Saturday. t seemed a lot further away in those days than now: it's about 25 miles, but it used to take (with the roads as they were back in the 1960s) the best part of an hour. Now you can get there in less than 30 minutes According to my mother Aberdare was a very nice town iny of the valleys' and had a fantastic municipal 
park with a lake, half a dozen Italian cafes and even opera performances in the 1930 and 1940s. People used to gather and walk around the park on a Sunday evening like was a Spanish paseo; it was a very civilised and social place, I think.

There were regeneration projects in Aberdare in the 1970s before I started working. Interestingly, I found some slides the other day that I took in 1974 of a very nice piece of graphics on a wall in Aberdare designed by Vernon Barber, who was a lecturer at the Welsh School of Architecture the time: tall, compact lettering in colours tyical of the period-black, white, antelope , hen an arrow, and 'Aberdare', all going then an arrow, and 'Aberdare, all going you know? The wall's still there, butit's you been painted over now, but that was my first encounter with the idea of regeneraion', I suppose.

When I went to the Welsh School Architecture in 1979, the head of schoo was Dewi-Prys Thomas, and he was a gre figurehead. ${ }^{2}$ I went there with quite a lot of skills really, which other people didn't have initially. It was at a time when postmodernism was becoming the fashion an the School was starting to embrace that which was disappointing to me at the time. I sort of embraced that ideology, I suppose, in the work that I was doing but with some really was in modernism. I remember a early project that we did in first year was housing project, and I was very much the into the work of Aldington and Craig as their Bledlow housing scheme had be published in the AR in 1978. My housing project very much derived from that sort of the time. I suppose my later work in college was a bit collagist and eclectic, if truth be known. But the first year was particularly interesting, I think, because there was a lecturer called Bob Fowles who was very much into the 1970s 'design methods' approach, J. Christopher Jones and all that. And so, found that helpful and interesting as well not just in terms of learning about the design process butalso in trying to develo a design to meet the needs of the users. I did my year out in London, and it was id difficult to the economy wan't great I worked for the first few mo tic for the Porto tised at Powoll Moya and Paro was advertised at Powell Moya and Parthers, which appled for. I started here in January 1983 and that was where I wanted to be: it was my dream job really. They were an ageing practice at that time, and very sadly they don't exist anymore. I was working mainly on the conversion of part of a hospital in High Wycombe that the practice had built in the 1960s. I also worked on a large housing scheme at Endell Street in Covent Garden, which was just being finished at the time, and I did all the ex-contract works drawing for that. During the seven months that I was there, I also worked on Maidstone Hospital the appearance of which Philip Powell would characterise as 'Nippo-Kentish', which is quite amusing. I did all of the internal drainage drawings for this second phase, and that made me sor sis second phase, and that the whole office. Just before I left they won the project for Hastings Distict Ge wo
Hospital (which is now Conquest Hospital) and I was involved with that at its very early stage, preparing a drainage strategy for the whole thing, which is quite bizarre for a youngster. But when I arrived in January I was sat next to Paul Newman, our great mutual friend through whom we met, and who tragically died in 1997-and he went on to work on the Hastings hospital. He had a project programme that was 10 years long and he could predict five years in advance that he'd be in a particular meeting on particular day and I thought'now is the tim to leave and go back to college' or become embroiled in 10 vears working on one hos pital project Ivisited several Powell and Moya buildings including the Powell and Moya buildings, including the great Cripps Building at St John's College, Camber to me, and I $m$ pretty sure that by that time, rabeen to Oxford as well to the underground Christ Church Picture Gallery, which is an amazing building. I also went to see the School for Advanced Urban Studies building in Bristol, sadly now demolished, which was a terrific building.

I returned to do my final year (it's only one year at Cardiff) - a very intense year. My final design project was for an ar gallery and office development in Cardif on a site diagonally opposite the great civic centre. It was subsequently exhibited at the Royal Academy in the Summer Exhibition in 1985. Wayne Forster and I were in the same year at university. ${ }^{3}$ There was an almost inseparable group of six of us who met within weeks of entering the Schoo in 1979, and Wayne was one of those. We collaborated on some projects in college and have remained friends and practised together in one way or other ever since. We've done competitions together; we had practice together; like you, we were in the Under Forty exhibition in 1988; and we till do the odd thing together, even now. After Part 2, I went to Bristol to work for Bruges Tozer and later was invited to come back to Cardiff, back to the Wyn Thomas practice, by Wyn himself. This was because the architect Bill Davies, who is now recognised as one of the most significant postwar Welsh architects, had left his practice in North Wales (the Bowen Dann Davies Partnersh Thomas + Partners at Dewi-Prys Thomas's ecommendation. Wyn asked me to come and work with him, and knowing his work well it was an opportunity that Icouldn'tturn

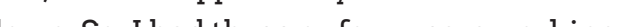
long chero We worked together new faculty of enginger ma Universty and the Rho Univer well it was like aner interesting things as well. It was like an apprenticeship really. But it was towards the end of that period, in Buld o practice together. Through a friend of ours from college, we were given a Job on a plate to do a $50,000 \mathrm{ft}^{2}$ office buildin for a developer in Swansea, and that set us up. Wayne, though, never actually left his teaching life, so he wasn't engaged as fully as I was timewise. We did another two office buildings for that same developer, as well as a car showroom, a mosque and some well-crafted house extensions. So, that practice ran full-time, I suppose, for about five years until the r r suppose, for the early 1990s when we ran out of work. 

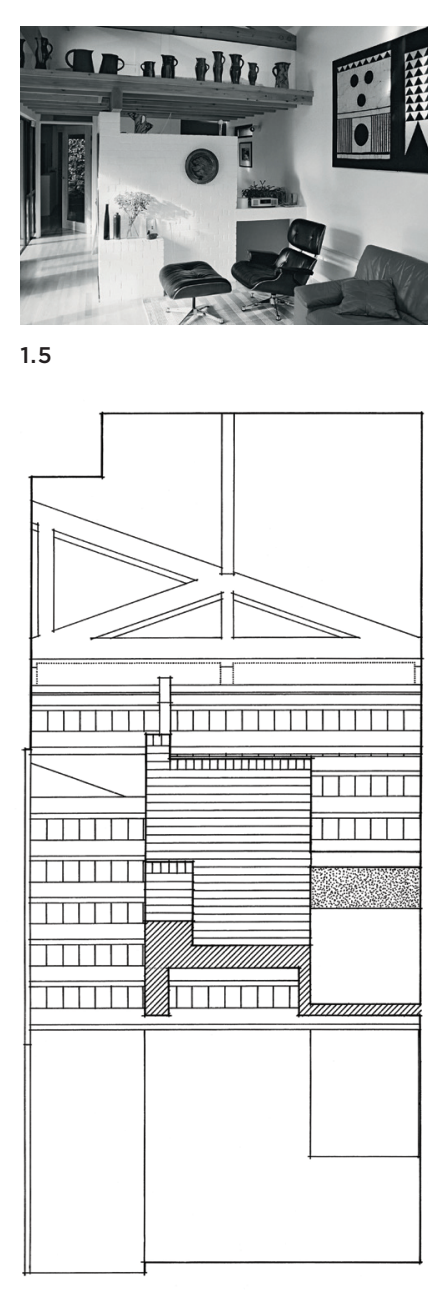

1.6

\subsection{Courtyard ho
Jonathan Vining}

1.6 Courtyard house planometric
by Jonathan Vining 1.7 Gateway mega-graphics
signalling social, economic and environmental regeneration
intent, Aberdare (1974). I Source Image courtesy of Jonathan
Vining.

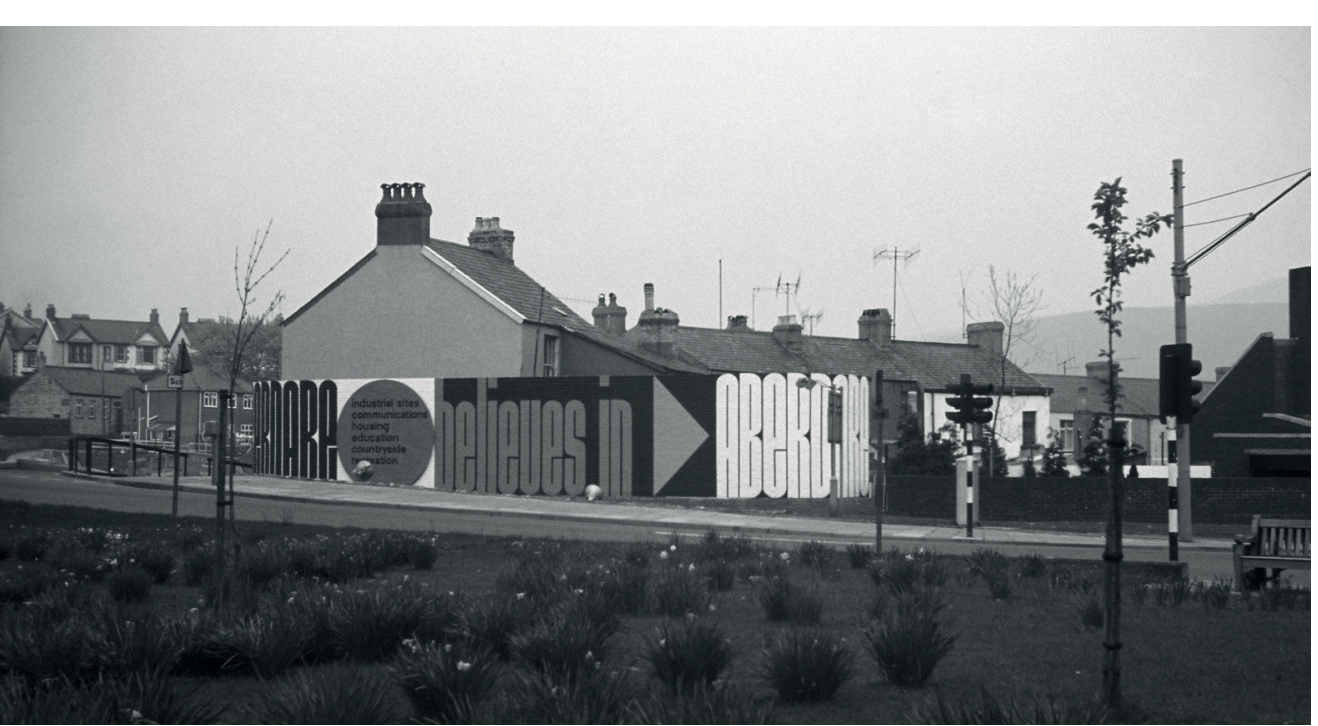

But, in retrospect, while I wouldn't swap the experience, the whole thing was too early in my career for me. I thought I was ready lot of things that I didn't know - and the weren't necessarily to do with architecture per se, but rather with winning work an all that sort of side of practice. Work was terribly short in the early 1990s, in Cardiff particularly, but I managed to obtain som
with Gordon Lewis, who had a pioneering with Gordon Lewis, who had a pioneering urban design practice in Cardiff as part initially through my company and then fulltime for him as an employee. That practice in 1995, when it left the parent company and I became a director of it. We broadened our work into architecture, as well as urban cesign and in 2000, we merged with what by then was Wyn Thom moscit it wh going back to where I first started...
The work at Gordon Lewis Associates was predominantly urban design and regeneration work. We were doing strategic planning for towns and master planning large development sites. The work was mainly for the former Welsh Developmen Agency. But there were architectura projects as well, the most significant of which was the Cancer Research Centre fo Velindre Hospital in North Cardiff, which actually completed a trio of red-brickwork buildings that I designed in that area, including my own house. Just before we merged with Wyn Thomas, Gordon and I won a ver big housing scheme for Westbury Homes.

\section{You mentioned that Owen Hatherley} called them, 'yuppiedromes'?

Yes, that was the Century Wharf project in Cardiff Bay, which went on for about 10 years, completing in 2009-nearly a thousand flats along the River Taff. Not an entirely accurate financial need to go back to five days and I ficial for me in stand the test of time better than most of the terms of my overall working life, my archidevelopments of the same period down there. tectural vocation. So, it was through that Taking an overview, the practices that process really that I had the opportunity to I worked in have been predominantly mul- do a master's-and I'd been hankering after tidisciplinary. When I was there, the $W_{y n}$ doing something in the conservation field Thomas practice had town planning, land- for some years. I met Peter Salter on the scape and architecture disciplines. When landing in the Welsh School of Architecture Gordon and I merged with them, that added one lunchtime, and he'd recently completed an urban design strand and, in turn, when the course at Bath. ${ }^{4}$ I mentioned to him that WynThomasGordonLewis sold out WY WY I'd been considering doing the one at the in 2005, we were joining a huge multidis- AA, but that the teaching day there was a in 2005, we were joining a huge multis- AA, by and I could't imagine getting as a ciplinary practice. I've always worked in Friday and couldn't magine getting back that sort or multidsciplinary environment to Carffrom Londo really and enjoyed ration. And I've had a great variety in my said ho work. Iresist being pigeonholed and try to one. So, I went and found out about it, applied make a specialism out or being a generallst. The master's degree 1 did under Dr Michael Forsyth at the University of Bath from 2012 to 2014 came about again through a downturn in the economy. At WYG several years ago, we were invited to sign a contract variation that would allow the company to put us onto a four-day week, circumstances dictated, rather than making people redundant with those remaining continuing to work full-time. I was leading a group of about 15 people then and was supportive of this approach. However, this variation was put in place with my group without me because I was told that I had plenty of work on. But I resisted because I didn't think that it was a very ethical thing to do. So, I offered to go on to a four-day week as well. Then, over a period of time, when the rest of the team went back to five-day working I decided to remain on four days I was in my mid-50s, I had no particular nd did it, and I enjoyed it very much

What was special about the course, particularly, was the way that it was organised as modules and the teaching days, which in my case, doing it over two years, was a full day each Wednesday. Almost all the lectures were delivered by high-level outside experts, and they all appeared to be introduced as 'the UK's leading expert on conservation law', 'the world's leading expert on historic paint and so on. These were interspersed with visits to such interesting places as Woodchester Mansion, Croome and Stowe - not to mention the amazing resource that the city of Bath itself provided - and the opportunity to spend a week studying at the British School at Rome. I wrote my dissertation on postwar architecture in Wales, and it was an investigation into whether the listing of the architecture of hat period was deficient particulycompared to England. I'd done some research 
in the field back in the late 1990s for a book a batch of commercial office buildings, and hat Malcolm Parry and I were thinking of more recently I think it was about 40 pieces writing but which never came into fruition, of postwar public art. They'll be moving on and this had led to my interest and hypothesis. ${ }^{5}$ In the dissertation, I looked at the legislative and policy context for listing in the countries of the British Isles, then at the statistics relating to listed buildings in England and in Wales, making comparions in various ways, including by building looked at thematic research as a means of proposing buildings for listing - which is not something that Cadw has done. ${ }^{6}$ The all been through its geographical resurvey that it completed in 2005, and through spot that it completed in 2005, and through spot listing on an ad hoc basis since - not really housing as the building type for this, and this described half a dozen themes in postwar housing design and the principal examples of these, very few of which have been picked of these, very few of which have been picked up under Cadw's geographical survey. The second considered the use of an individual architect's oeuvre as a means of proposing buildings for listing, and

work of Bill Davies for that.

came clear to me that the listing of the period by Cadw was "lackadaisical " as Patrick Hannay, the editor, described it in his intro to my essay in Touchstone (2016) - and there was a whole body of architectural works from the 1946-85 period in Wales that were unrecognised. It was also clear that things were quite different in England where the strategic, research-led proch there had seen about 150 postwar domestic projects alone listed and, last year, postmodernism next!

Sir Percy Thomas, whose practice designed many of the buildings here on the Penglais campus, was a remark able character and probably the greatest Welsh architect of the twentieth century. Although he was actually born in the North-East of England, his father was a sea he recognised that he needed to change the architectural approded to chang and his choice to lead this was Dale Octice, Dale was born in Merthyr Tydfil, went to Whitc sur and then tringer ardiff Architecture which was Archict whe war service in the Royal Artillery and he went as a Smith-Mundt and Fulbrigh Scholar to MIT where, as you know, Gropius had been a dominant figure. He spent mor than a year working for Gropius's practic before returning to the UK and working for Sir William Holford. And so he cam back to Wales in 1958 with Bauhaus-derived principles embedded in him, to join what was then Sir Percy Thomas \& Son, and address the need for buildings designed the then fashionable International Style.

There had been a master plan for Aberystwyth University prepared by Percy Thomas in the mid-1930s, and some of the original buildings were done on the lowe part of the site to this formal onte lower layout do in captain from West Wales In the late 1950s, Technical College in those days. He did Tent as a Smith-Mundt a partratern but in

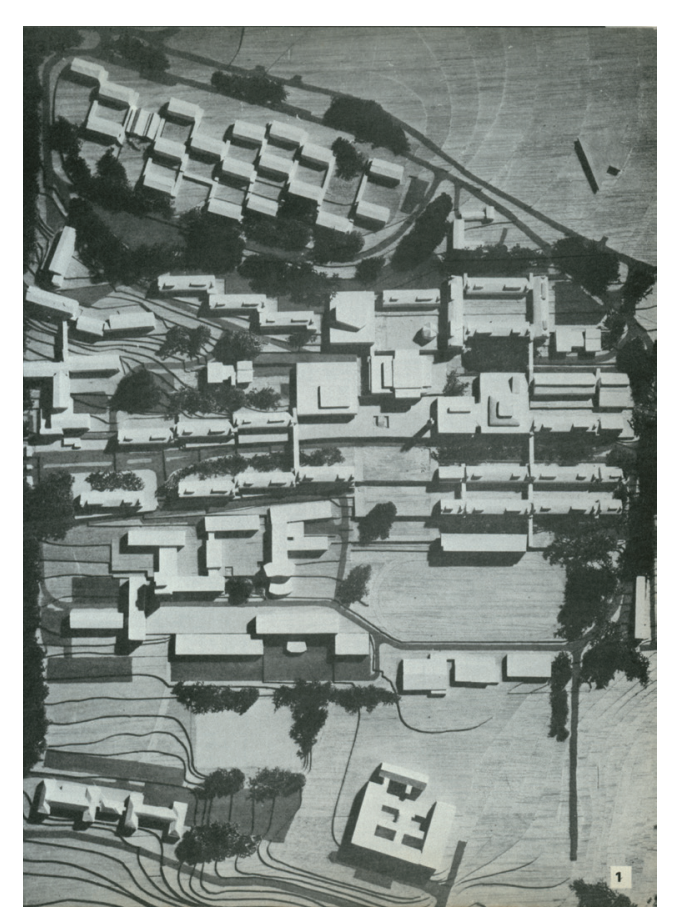

pee today being ces along contours; landscape threaded in between courts; courts at various locations; the idea of an academic and social centre where we are sitting now with a library, Great Hall and Students' Union building. The bell tower, which can be seen from the whole of the campus, signals that this is the focus of the site and, of course, the great piazza has stunning views west out over Aberystwyth and Cardigan Bay. It's a remarkable thing in response to the setting, but obviously windswept when the weather is inclement.

Aberystwyth is very much a university Aberysty suppose the town is pretty town - in fact, 1 by the university now, especially during term tim. The's since the nines a universicy since the nineteenth century, and the Old College building on the seafront, which was started in the1860s, is mainly by J. Seddon and is an extraordinary mixture of Gothic styles. The master plan for the campus here on the hill at Penglais was intended to have flexibility built into it, in a sense, and I think it was pretty much laid out in terms of infrastructure around the 1970s when the Arts Centre was built. The campus has evolved over a period of time, and new buildings have been added. It's a pity that with a lot of master plans you see, it's often just a plan, with seemingly little thought given to the 3D

1.9 Sections and site model,
Aberystywth University Campus
Persy Penglais, Aberystwyth, 1935-6 From the National Monuments
Record of Wales. I Source: $\Theta$ Pe
Thomas formal, and after that the Physics building by Percy Thomas's practice was built. Tha was the one that was the 1970s of new university architecture It's curtain-walled with a sort of late-Corbusia curnork element attached. In the mid1960 s, the master plan by Dal aspects. But if you look at the Percy Thomas archive in the Royal Commission, you will see that the 1960s master plan was not justa plan, it was a physical model It had sections through the site, and it was all seemingly very well integrated ${ }^{8}$ But as we look out of the building we're in now a the recent 
building on the left - all right, it's got too many materials anyway - but in terms of the master plan for the site and any sort of reasonable analysis, it's far too high. It ju blocks the view from where we're sitting now completely, which is pretty nonsenscal really ..

Having participated in the competition,

have come to understand there has been a lack of consideration or even a lack of interest in the original building. Somehow, it's not regarded in the same way as building heritage of an sarlier period, and that may be of an earnier do with materiality and form.

Well, I think that reflects a general feeling Well, think that reflectsageneral feeling Wales, and it was one of the things that I thought about when I was writing my dissertation - the appreciation and recognition of postwar architecture in Wales as a heritge resource and the need not only for that part of our heritage to be properly listed but also for that period to be promoted as having buildings of value just like any other. The building that we're in at the moment, the Great Hall, and the other Dale Owen-led buildings of that time are a monumental set piece, and yes, I do think the 'grandeur' of the form and the materiality has much to do with that perception I suppose it's still the 'shock of the new'

There's something incredibly robust about the building that we're in. There is a lack of fuss, and I think that's something that doesn't appear to have ben followed by the buildings that have been added to the master plan in more recent years. Can you offer a brief commen about the buildings that have been built towards the rear of the site, further up the slope, including the one that was there when the competition was held and the building by the subsequent competition winner, Thomas Heatherwick?

You're talking about Patel Taylor's building and the extension to the rear of the Arts

\section{That's right.}

Well, the first one, the Theatre Film and TV Studies building has a certain resonance with the Great Hallin that it's retalong the with the Great Halin thatis chevientipar vis

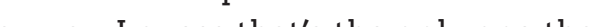
relly makes any atsempt to coord really makes any attempt to coordinate ith Dale's master plan.

The Arts Centre extension is a bit of curate's egg really. On the one hand, the way the new facilities are integrated with th original ones is skilfully done, but externally it goes beyond trying to achieve a level of visual independence - which I assume wa the aim - or contrasting with the existing it just looks very alien to me in that context.

The Heatherwick series of pavilions are a curious addition, I think. There was very interesting programme for those buildings in terms of integration with the creative industries and how businesses relate to the activities of the university itself But the seem to me to be very much just about gimmicky cladding material, which is not detailed exquisitely enough, and not much else really.

Notes

Ceri Richards (1903-71) was one of significant British painters of the twentiest century. The definitive monograph is Ceri Richards by Mel Gooding (2002). Professor Dewi-Prys Thomas (1916-85) was one
of the greatest figures in twentieth-century Welsh architecture. A charismatic and inspir tional teacher and lecturer, he was head of the Welsh School of Architecture from 1960 to 1981 see: http:///www.dewi-prysthomas.org
Professor Wayne Forster (born in Newport in
1952) has been deputy head of the Welsh School of Architecture at Cardiff University since
2002. He is director of the Design and Practice

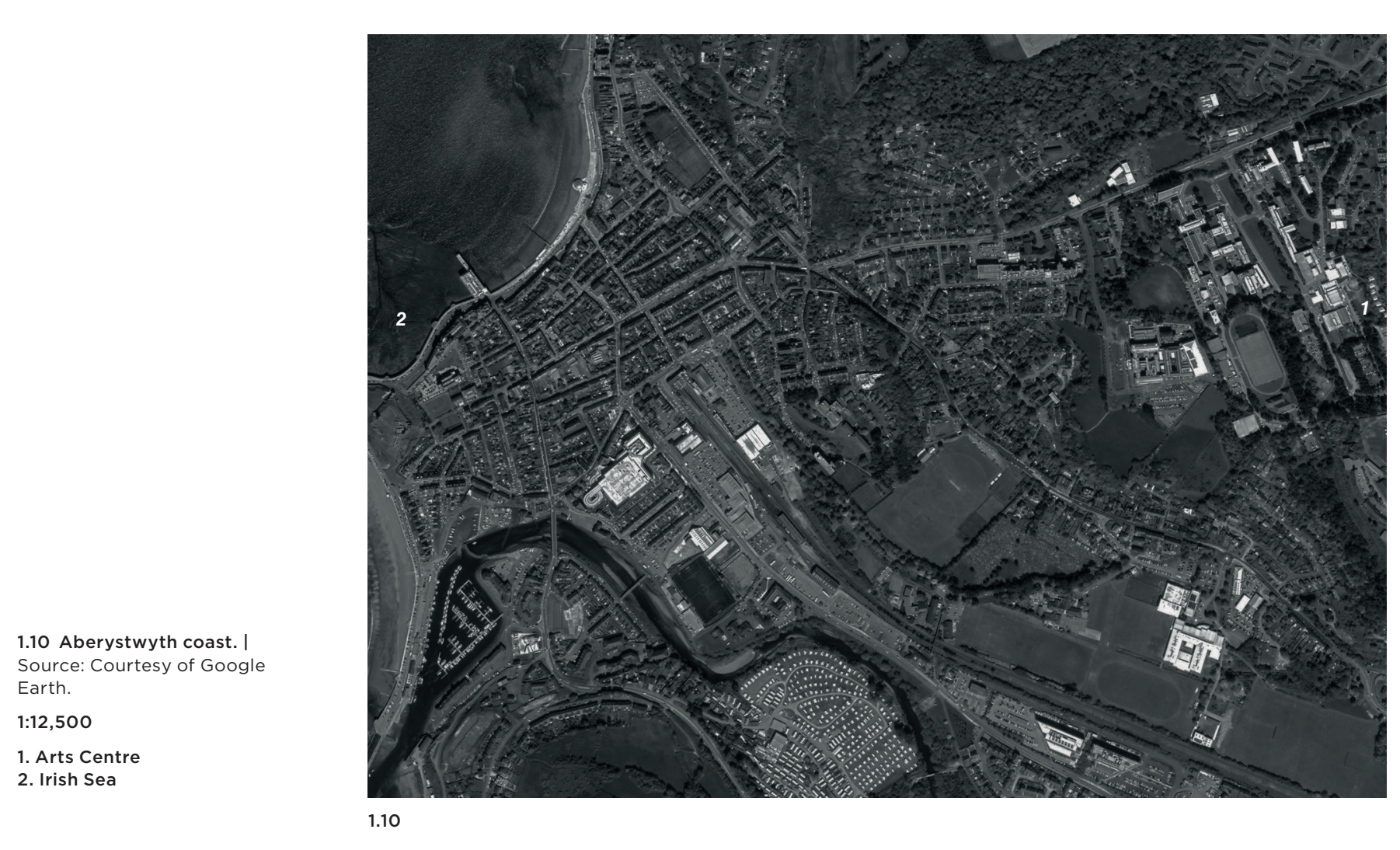
Earth. 1. Arts Centre
2. Irish Sea

Research Group hat aims to encourage designbased research.
Peter Salter is Professor of Architectural Design University. Malcolm Parry (born 1939) taught at the Welsh was head of school from 1997 until his retirement in 2002. ernment's historic advi sory service,
'Touchstone in Wales, published by the Royal Society of The Royal Commission on the Ancient and
Historical Monuments of Wales is based in Aberystwyth and holds a unique collection of documents on the archaeological, built and maritime heritage of Wales. 

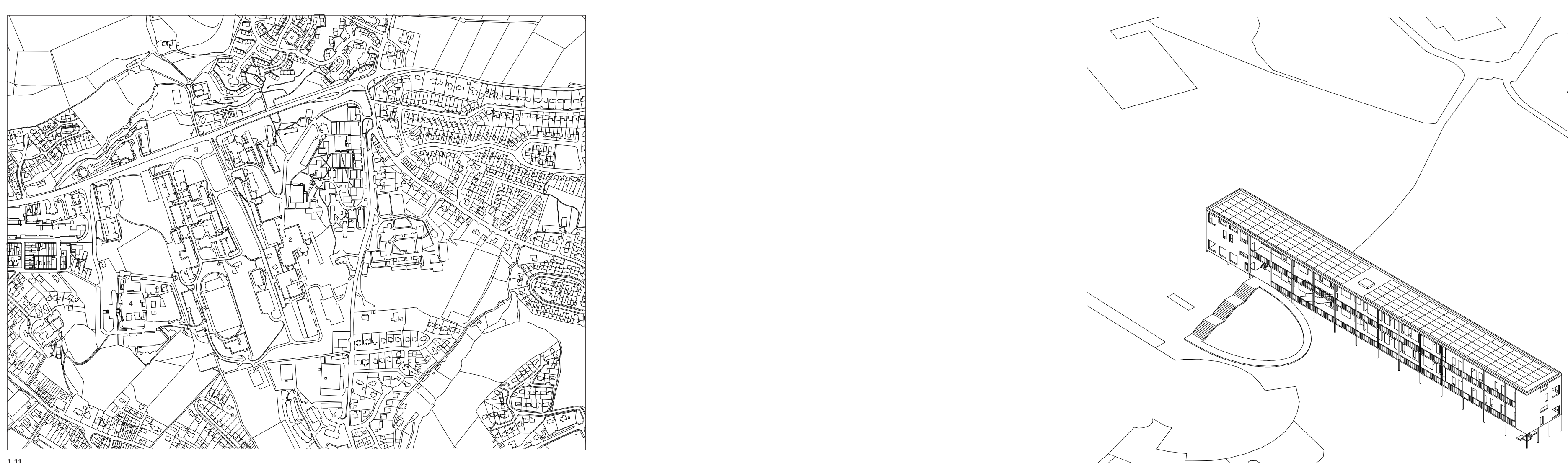

1.11 Location plan

1:30,000

1. Site
2. Aberystwyth Arts Centre
3. Aberystwyth University

2. Aberystwyth Arts Centre
3. Aberystwyth University
Penglais Campus

1.12 Isometric

4. National Library of Wales 


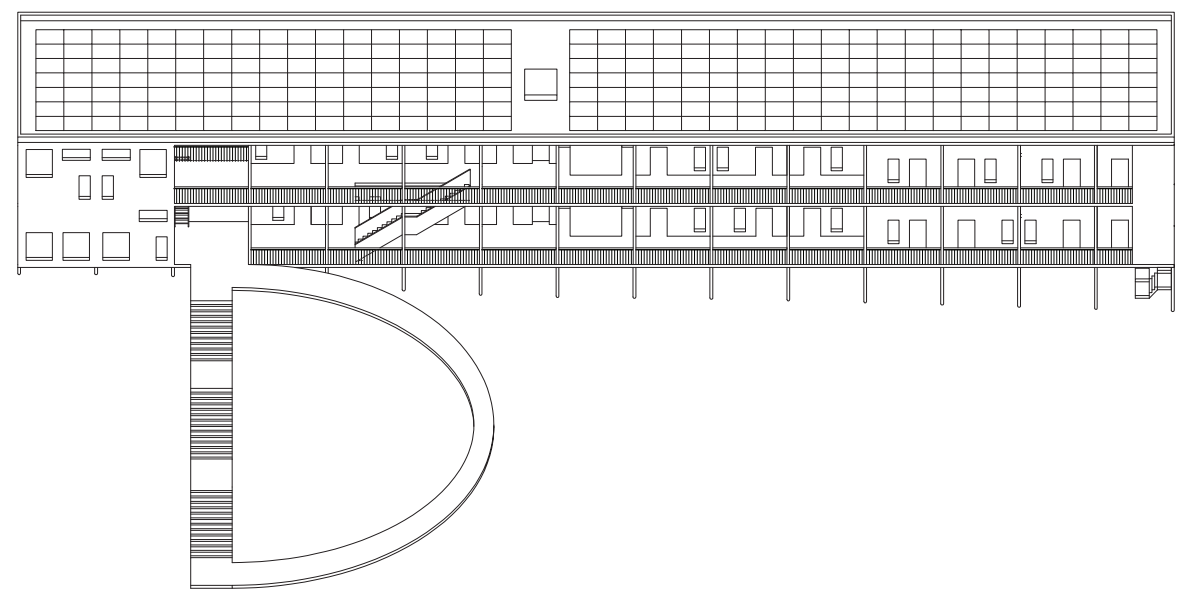

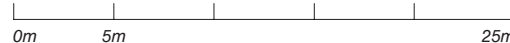

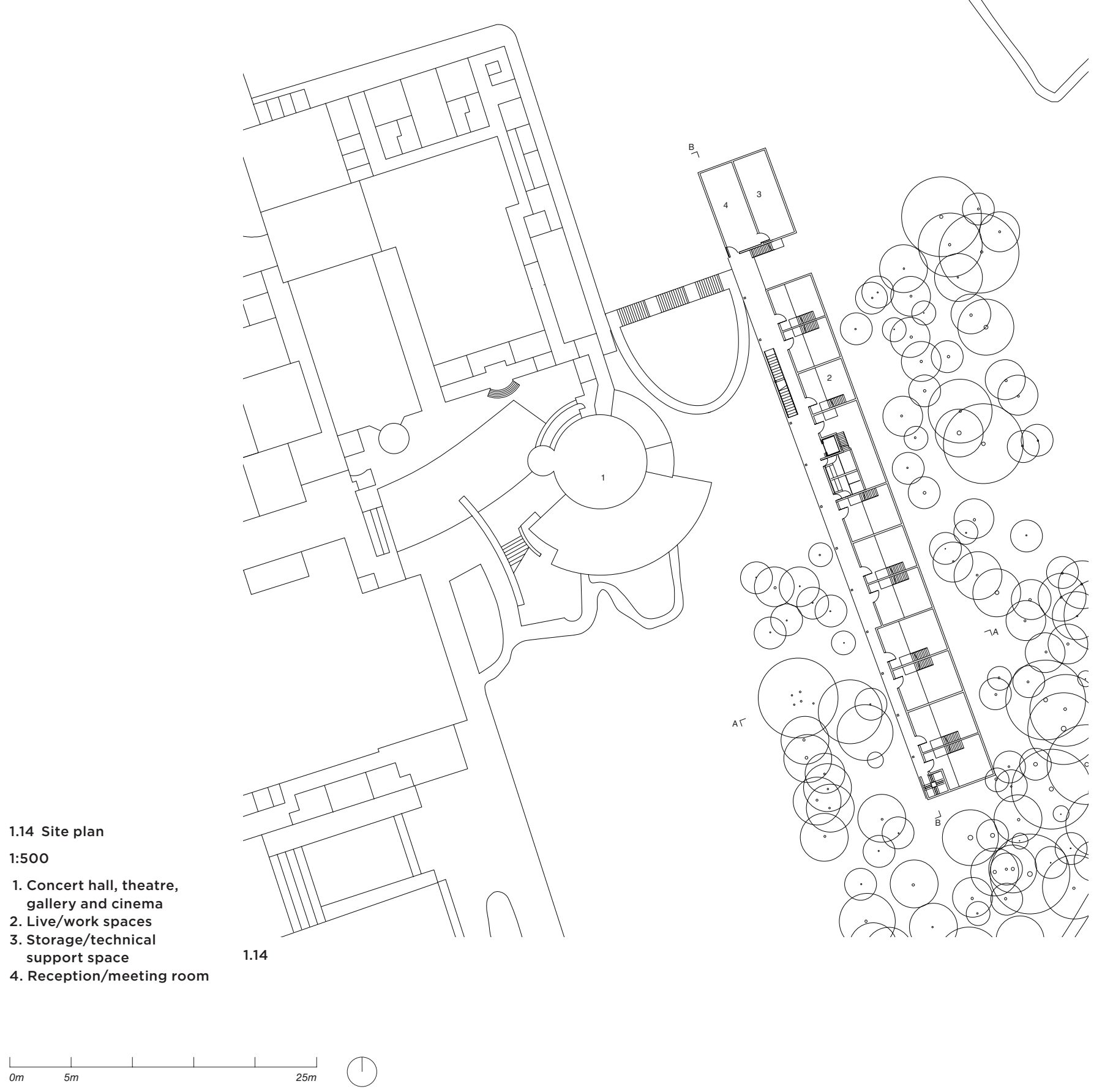




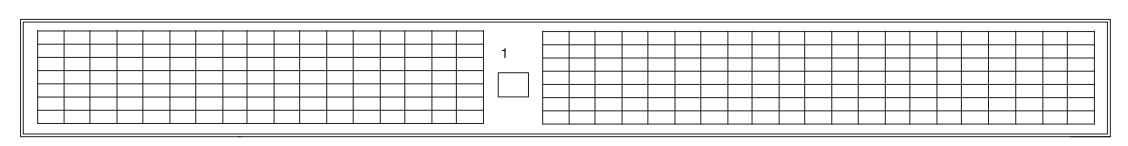

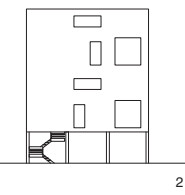

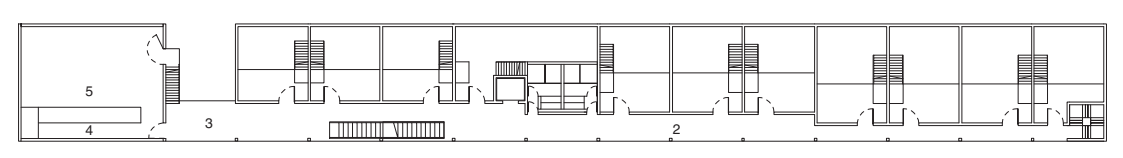

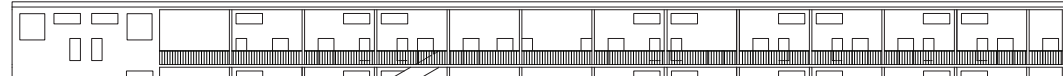

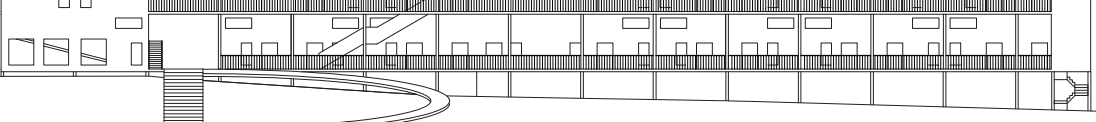

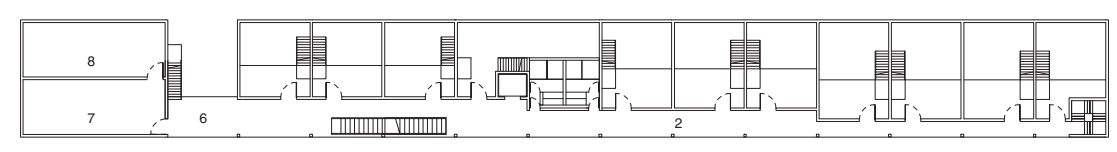

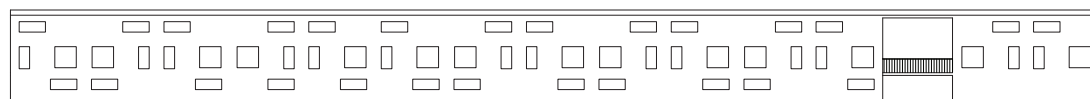

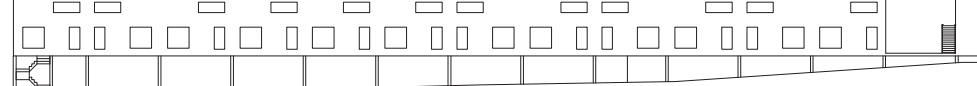

1.16 Plans

1.15 Elevations and perspectiv

1:500

1:500

1. North
2. South
4.

3. West
4. East

5. View from the car park

1. Photovoll
2. Loggia
3. Bridge

3. Bridge
4. Ramp
5 Multi-p

4. Ramp
5. Mutti-iurpose room
6. Entrance

7. Reception/meeting roo
8. Storage/tech support

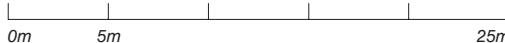

$\begin{array}{lllll} & 1 & 1 & 1 & \\ & 1 & & \end{array}$ 


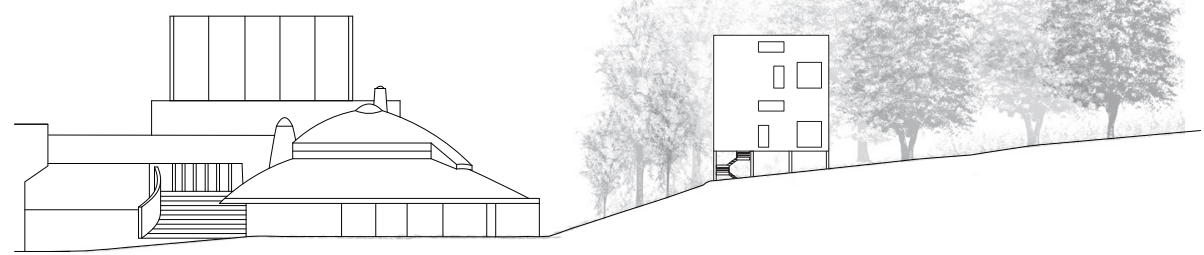
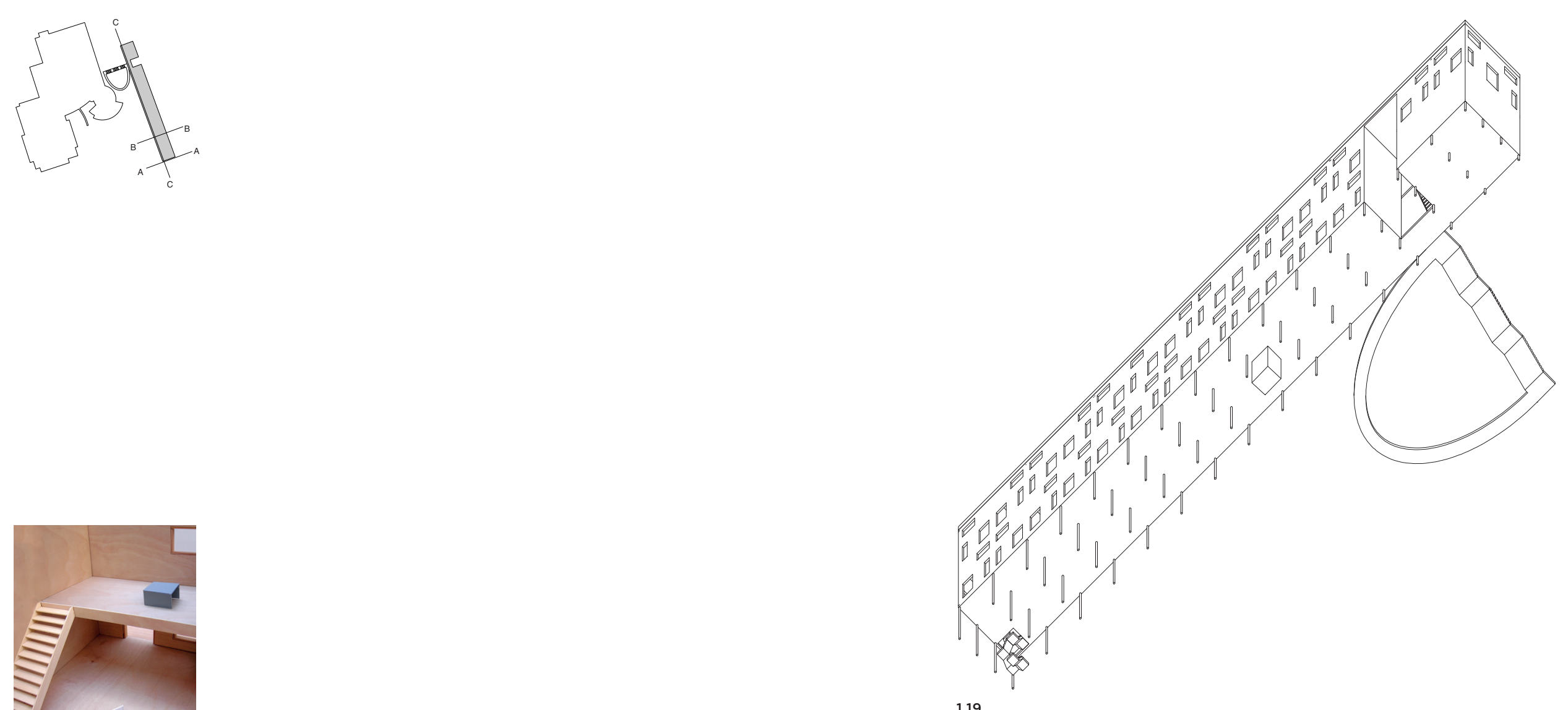

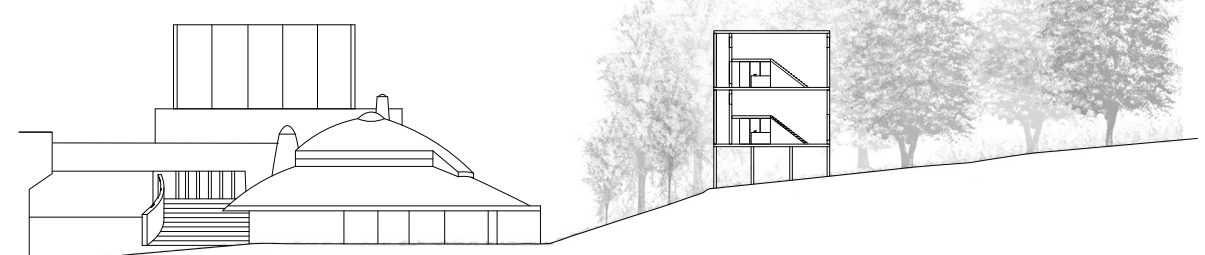

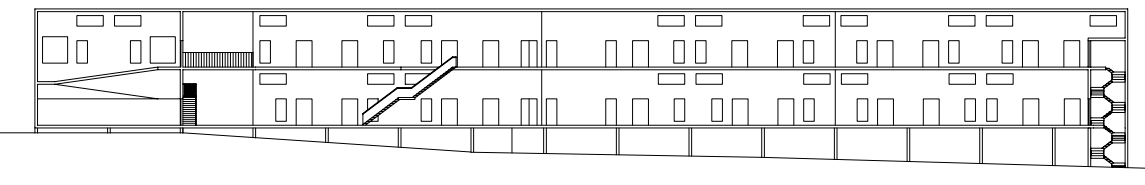

1.17 Elevation and sections

1:500

1. Side elevation $A A$
2. Cross-section $B B$
B.

3. Long section CC

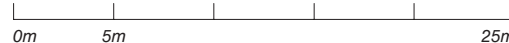

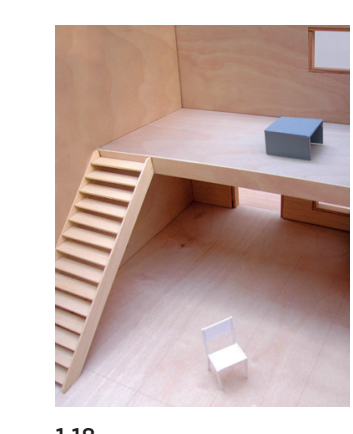

1.18 Model interior with

mezzanine

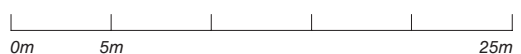



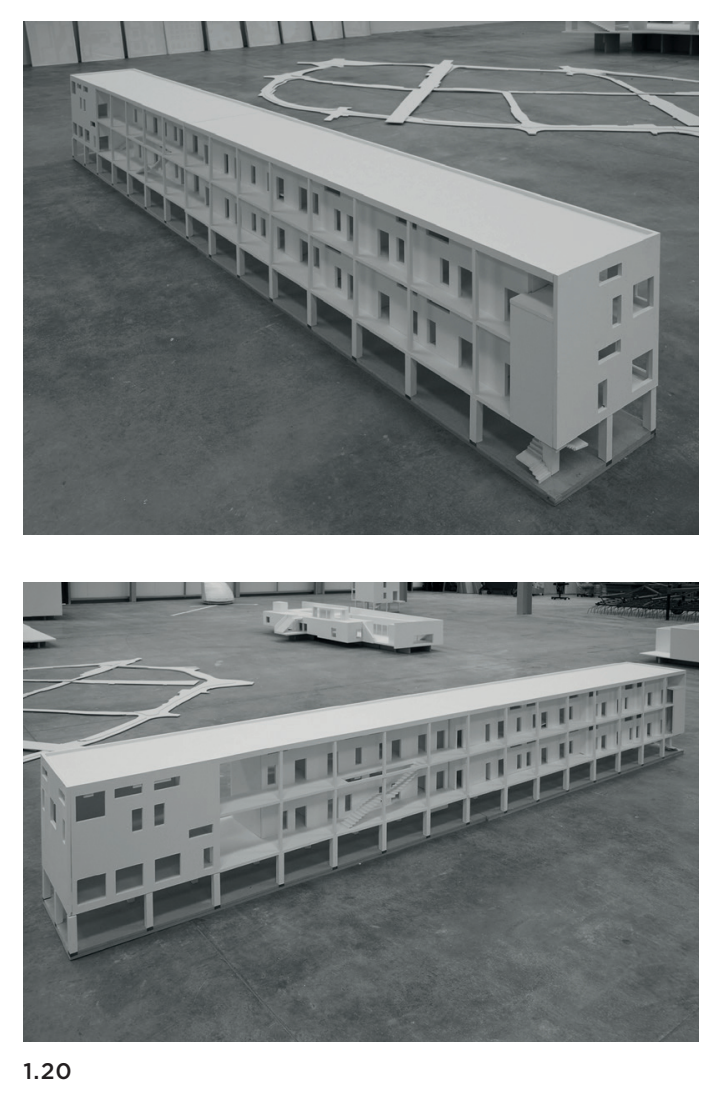

1.21 Atelier One construction
sequence

sequence
1:1000

1. Steel pile sleeves extend to
underside of ground floor

2. Solid timber lift/stair core

solid timber

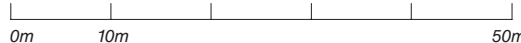

5. Mezzanine floors solid timber

. All external walls solid timber

panels cut in factory prior to
delivery

7. Solid timber roof

Mezzanine floors solid timber
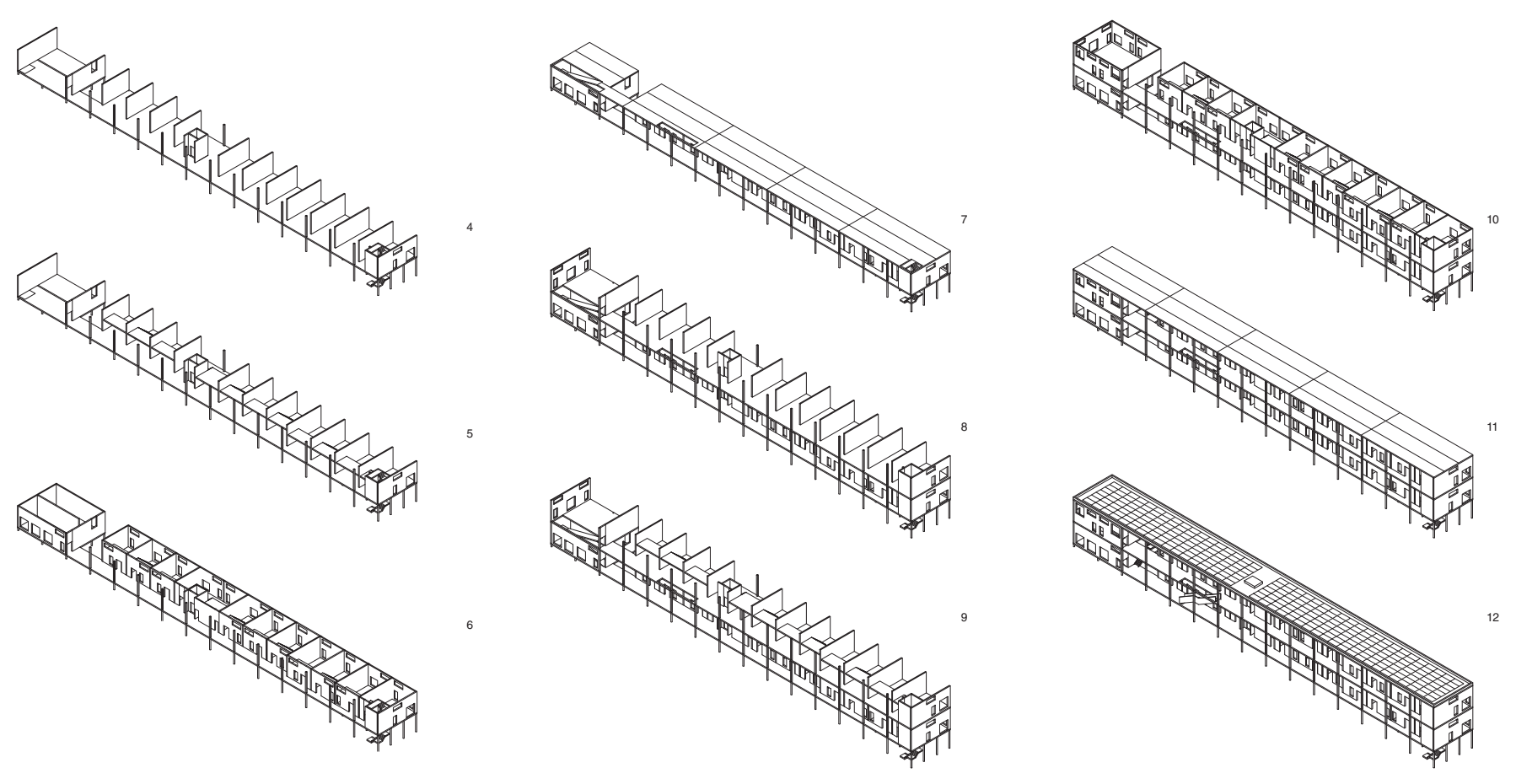

10. All external walls solid timber and
all openings precut timber panels cut in factory prior to delivery
11. Solid timber roof

12. Parapet solid timber and lift
overrun 

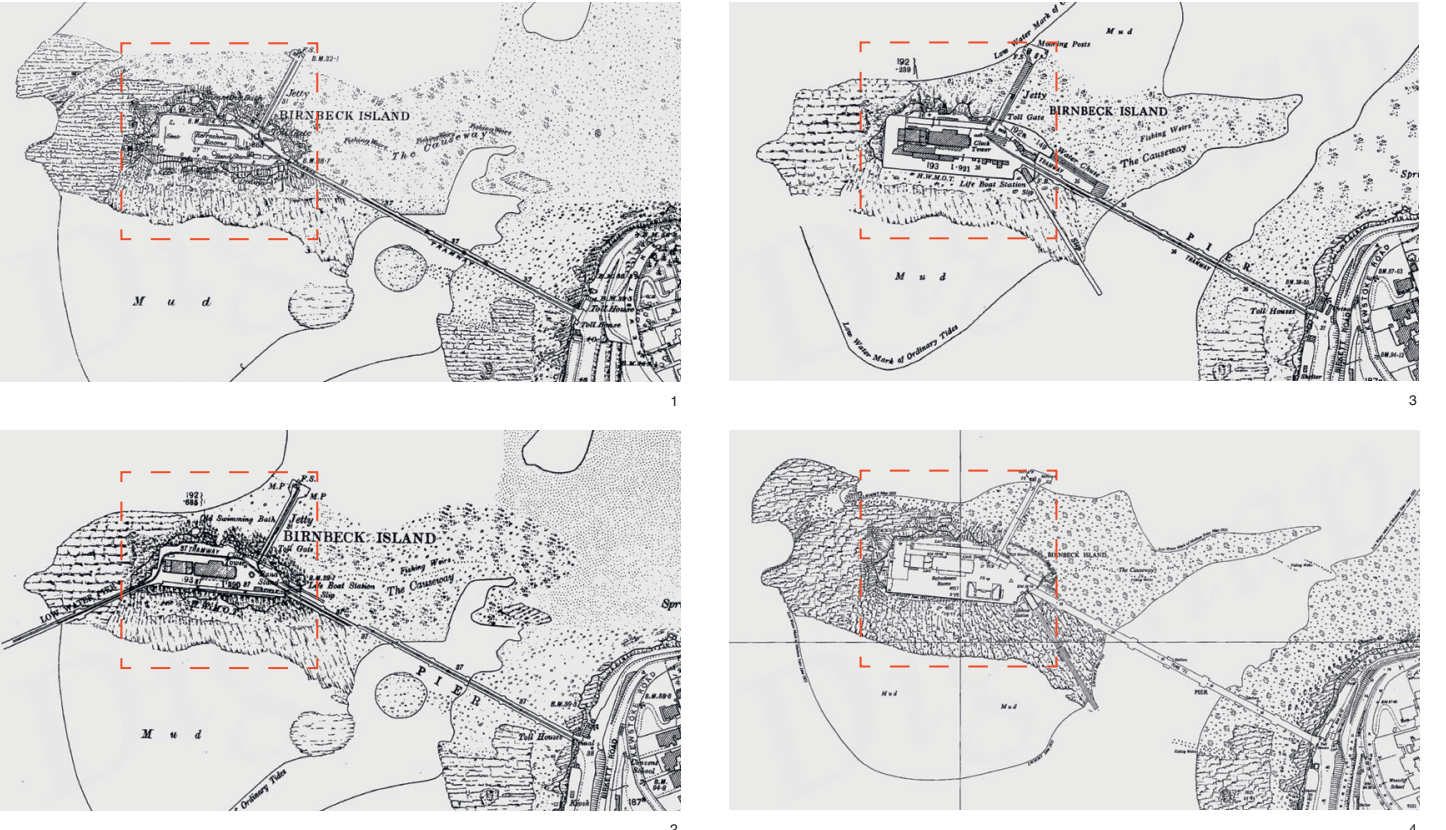

Seaside | Pleasure Holm at Birnbeck Island
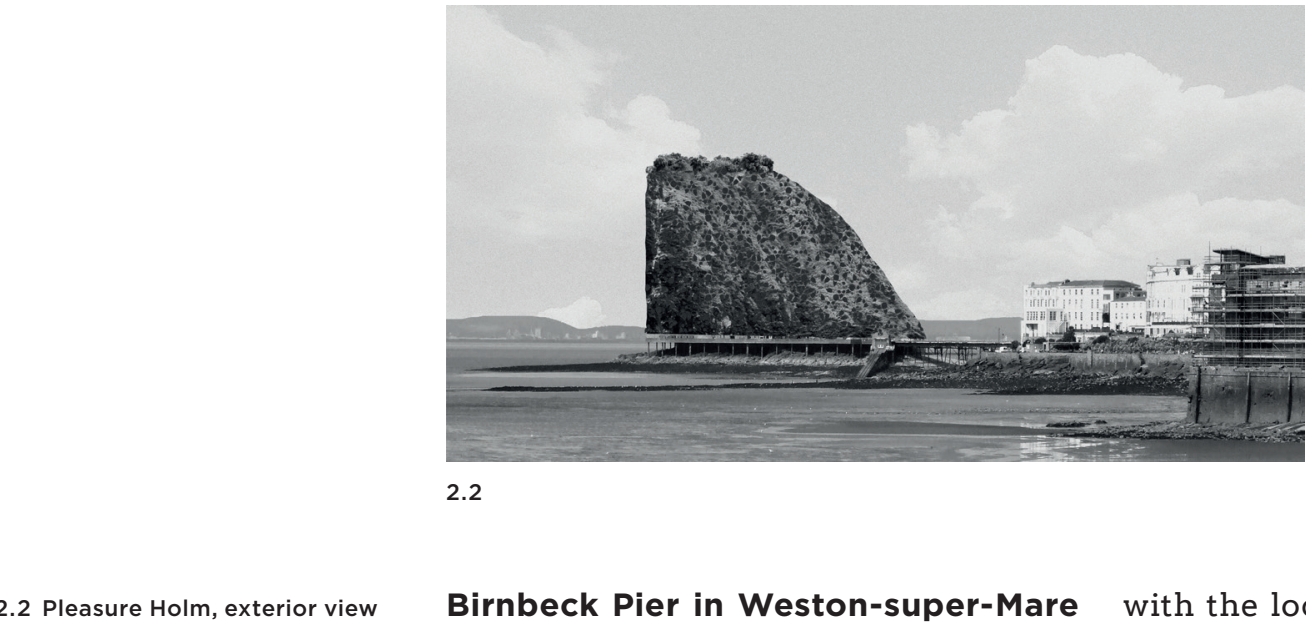

Birnbeck Pier in Weston-super-Mare with the local council, held a competiis the only seaside pier in Britain that tion in 2007 to revitalise Birnbeck Pier, connects the coastal edge to an island. its island destination and its immediate The pier is listed but has been derelict surroundings. The project was designed since the 1930s. It is located at the north in collaboration with Jonathan Vining of side of the town, defined by a wooded WYG, Cardiff

headland, with Town Bay to the south

'Pleasure Holm' is a very big building and Sand Bay to the north.

The town had its heyday in the that is designed to look like a small island -a built in ston era. Large comfortable houses million $\mathrm{ft}^{2}$ ) on Birnbeck Island, Westonland create a pleasant backdrop to the town, building will be a man-made concrete shell, with its seaside promenade, town pier and designed to look like a natural land formabeach where the tide goes out for miles. tion and to function as a natural habitat for Weston may have seen better days: today flora and fauna while containing habitable the drive into the town is a jumble of round- accommodation inside. The south and west the drive into the town is a jumble of roundaccommodation inside. The south and west sides in particular will be punctured with Urban Splash, a residential devel- holes that read from the outside as aperoper based in Manchester in association tures in a cliff face. These will let light and 


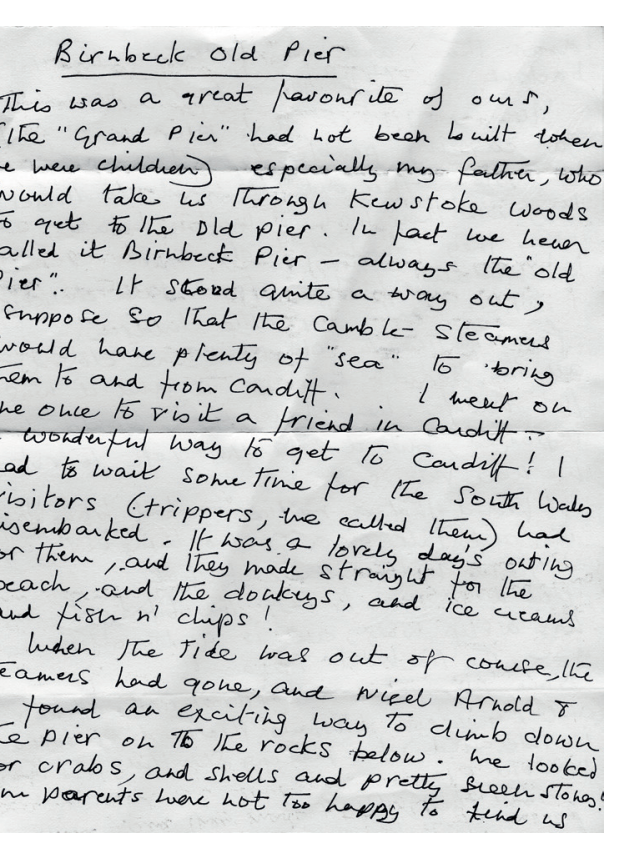

2.3

2.3 Pauline Milligan letter
to Pierre d'Avoine, 2007

views into the spaces behind. Some of the openings will carry through to the other side to relieve some of the wind pressure that will develop.

The interior of the shell may be programmed for use in a variety of ways and could be designed to create any fe desired. It provides a range of accommodation befitting its seaside location and includes a casino, cinema, music hall, hotel and end-of-the-pier activities, as well as two hundred duplex apartments and a data centre-a contemporary social condense

runner-up in the competition. The budget of $£ 16$ million was only disclose at Stage 2. Pleasure Holm, the choice of 11 of the 12-person jury at Stage 1, would cos in excess of $£ 200$ million.

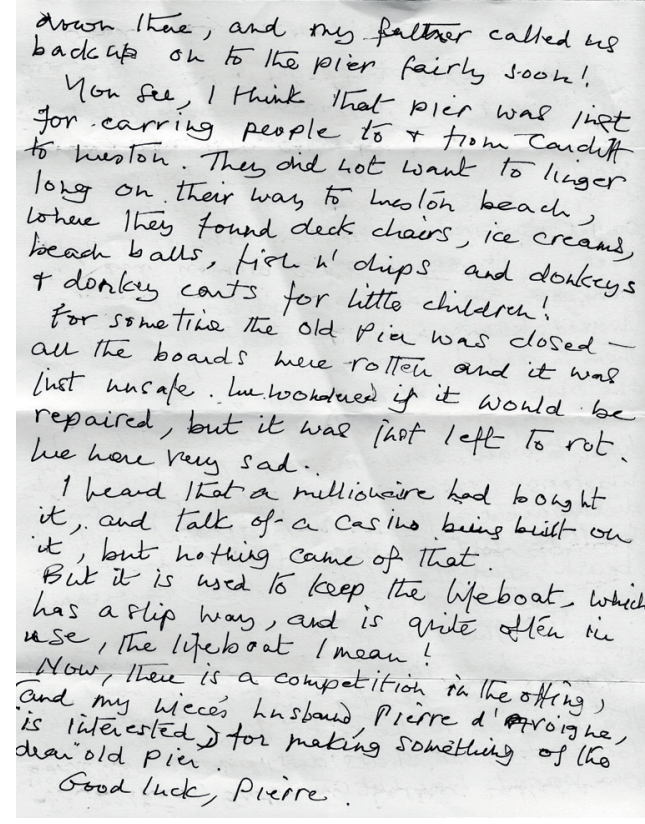

Man-made island data centres-Dat centres do not need views, but they do need a great deal of power and cooling - a majo concern of businesses that are generally ver profitable but with concerns to be green. The proximity to water and wind turbines mean that these energy-intensive elements can b provided in an economical and sustainable manner. Communication with the rest of the data world is by a fibre optic that is easily accommodated. Creating new man-made islands around the UK that are bird sanctuaries on the outside and wind powered dat centres on the inside has huge potential that requires further research andd

\section{Jonathan Vining}

Interview at Aberystwyth Arts Centre, 20 August 2016-Gordon Lewis, who was heading up our part of the practice at the time, wanted to do a major desig competition project to show the rest of the business at WYG what we could do. The Birnbeck Island competition came up, and Gordon was very keen to do it, particularly as it was in Weston-super-Mare where he was about to move. It seemed to me that it was something that we could have done well independently but that we stood a far greater chance of winning it if we had 'proper' architect like you involved.

I don't know about that. For me it was partly to do with the fact that obviousl partly to dow the fiously interests and that the Bir competition seemedlike a reck lsland vehicle on which wecould collatrong

Obviously, there were lots of reasons for doing it from the WYG point of view. We doing it from the WYG point of view. We could bring a whole host of expertise to the table, and we also had some talented young graduates at the time who were prepared to work on it. From your point of view, Pierre, you could bring to the table something that frankly we didn't have.

I was a visiting professor to the Welsh School at the time.So, Idid have a regula reason for coming to Cardiff, and you also came to London quite regularly, and still do. So, the idea of collaboration was interesting from that point of view. I recall you and I spent a long time brainstorming and conceptualising the project.

We seemed to spend a lot of time talking like this and not doing very much drawing.
But scribbling ideas and the design evolved. I think we brought Gordon in tolook at it and just see whether he was comfortable with the initial ideas, and he seemed to be surprisingly positive, which gave us both heart to really move forward.

Well, in all fairness, he'd actually gone (because neither of us could go) on the site visit day that had been organised as part of the competition (I think he was living near Weston-super-Mare by that time), and he went onto the island and took photographs and then reported back to a group meeting hat we had the following day wich was good. But could see thatwew which was in aninterting direction, and something worthwhile was going to and something process. So, wes, he was prety positive We decided quite pretty postive. We Bill Watts ax Invilt Arand remember having a meeting with them in London at the WYG offices. Bill was an ncredible stimulus for the project, and he took it on and added an incredible amount to it, including initiating the idea of including a data centre, which gave the building a wider typological resonance and all of that. Aran in his very direct way had no reservations about the crazy carapace we were proposing. He was just happy to take that n. It was also really helpful to work with range of consultants at WYG, especially the landscape architects and your team of young architects and assistants.

You need people who are committed putting their own time into something like that, as we both did. A lot of that work 


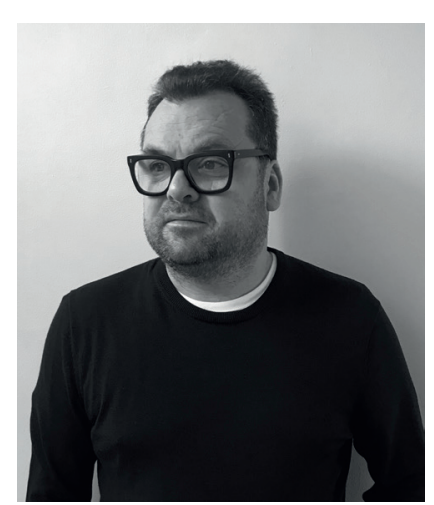

was done out of hours. For a commercia plc organisation, there was a huge financial investment in the competition. I dre to think what it totalled up to. You would never be able to sell that to the business as a proposition really; if you said it was going to cost that much at the start, nobody would've taken it on board. So, it was played on the basis that a lot of it was done in p ple's own time, which largely it was.

that Wayne and I did for Porthmadog Maritime Museum. I would say that, conceptually, was Wayne's design, although we both worked on it together and both drew it together ... There was a little barrister's study that we did in practice together and I mean, that was pretty much all mine with some drawing input from him. The office building I mentioned earlier, conceptually that was Wayne's, although I produced it, ran it on site. There were two little pro-

What about your individual approach jects in the Vale of Glamorgan that I did, What took place in and he contributed to technically It rid was your collaboration with Wayne when was about con thaties-and sense. So, it would be that one person would lead, and one person Well, we know each other terribly well, would act as critic and agitator to make and when we were in practice together, things better, and offer solutions an either one of us would lead on the design of support and criticism, new directions... project. We decided that from the usually bas on who brought the onset, in, I suppose. So, one person would lead, and the other would not exactly assist, but would work in a complementary fashio in order to deliver the project. That's not to say that we wouldn't input into each other's work, but I think there's got to be a definitive lead on a project-someone to make the ultimate decision on the direction. And I think when you and I worked together on Birnbeck Island, I made the decision for myself that you were going to be in the lead and that I was going to act as producer, if you like, in a film-makin ration) to Wayne and me, I've got a CV in front of me here. So, you, Wayne and I were all in the 40 Under Forty exhibition in 1988 I remember we might have shown three projects, one of which was a competition

\section{Aran Chadwic}

elier One, Charlott Mews, London, 9 February 2018-I grew up in South Manchester; I'm a norther boy. I' $m$ from quite a big family. I was one of five kids (I'm the youngest). So, growing up was a bit hectic. My family (bar one) were all from my dad's side. He was a civil enginee and got us all involved at a very young age. So, when I was about 12, I remember we had to underpin the garage because there were cracks in the wall. We were always digging things out and doing building work around the house. I mean, I've got three brothers, It seems a natural thing for me to $g 0$ to that world I went to the local state school, and then after that, I went to the involved in construction or went into con struction, and that sort of comes through and I think my dad saw us as a brothers,
University of Leeds. I did civil engineering, and I have to say that when I was doing it, they were one of the few schools that did architectural engineering, and I wa very tempted to change because I realise quite early on that I was more interested in structures than I was in roads or marine or hydrology or that sort of thing. But I stuck with it because it was for three years, and at the time, I thought that I'd lose a year if I switched courses. So, I decided to stick with it and then do a master's degree in structures. It was very ambitious of in but I the applied to go to the USA to do but I then aster a master's dein (becauseyountrance examination that was like a Mensa quiz at the time, I think it's called the GRE now) but I And I reo a pace a Berkel on in it. And I got a place at Berkeley on their programme that was called 'structural engineering materials and mechanics.lt sounds rather long-winded, but I got a place on that, and I went out to California in 1988 the came back to the UK after three semesters in the USA. In terms of my view on what think was an amazing life experience, have to say that landing alone in a completely different culture is tough, but it's quite good thing to do. I did quite a lot of travelling and met a few people there and did loads of road trips around the USA. I remember you could do this thing at the time where you could deliver a car for someone. So, it was basically free. But you had four or five days, and I did two or three of those where I drove from San Francisco to Phoenix and we wer given four days. So, we went via Vegas. And it was a big old Lincoln-you know, And those with a big leather bench seat.
I don't remember any rules about it other than you paid the petrol, which was incredibly cheap in the USA. And you were given a maximum period of time, which bvviously we extended to the last hour because it was very cool driving around in this big old car. So, I had a really good time. But in terms of the influence on my view professionally, it was a big eye opener because they had some big hitters in Berkeley. It's an amazing school, and it's very well-funded. The research there, you could see they were doing some quite big chingst they were doing earthquake testing on seven-storey scale buildings in the lab and stuff like that. It was very impressive, nd some of the professors there were conthingalloner the world ust teachingus, they were really at the f their gam And that was a big inspiraHef the have a chath you but you knew and act in the field were quite important, the best big impact on me.

hed in California, I came back, and I didn't have any money. So, I moved back home for about two years. 1 had a job in a practice as a graduate engineer in Manchester, and I struggled a little it. I mean, I was fine doing small projects. My first project was an office building. I was doing a school extension in the North of England. So, really, it was okay, but I just felt that I wasn't really engaging in it properly and that I didn't know enough about design, architecture, to really get nvolved. So, I remember I went to the university, the architecture school, with the versty, the archicture school, with the 
evenings or part-time to learn a bit more. And the guy, the admissions guy, he was actually an engineer. He said, 'Well, wh have you done?' And I explained, and he just looked at it and said, 'Really? Well what are you doing here?' And he introduced me to the head of the school. So, ended up going for a beer with him, and this was for having gone in to apply, and of school. He was called Joe Jessop, and he ran the Manchester Metropolitan School. don't you come and teach?' So, I did two things at the time: I was really interested in computers, and it was very early days of 3D modelling; and I also got involved in research, which was really good for me. I'd worked with the diploma students on their final thesis projects as an engineer, and so, they'd be coming in with all these really whacky ideas, and some were really great, but they had no idea what to do with structures. And for me, it was brilliant because I wasn't just seeing what you see in practice, which is where a lot of it is distilled into things that you know are affordable or whatever, it was dealing with ideas and how I could involve structures in that aspiration. I did that for a couple of years, an it was a really, really valuable lesson to me. I think it really helped me to consolidate what I knew about engineering and, actually more importantly, how I could feed contribution.

I taught full-time for about 18 months and then did a competition. It was interest-

ing; you never saw any competitions for engineers. You saw lots of architectural or on a creative level. But the Institute of Structural Engineers did one with the International Association for Bridges and Structural Engineering: it was a design competition. So, I entered that, and I was joint winner. It was an international competition. I think they had quite a lot of entries. I got a prize, and they gave me quite a bit of money, and with it (to my now-wife's dissatisfaction because I'd been with her for about a year at this time), I spent all my prize money on a computer powerful omputer you could the most pow the time, which was brillith it allowed me to do more with the 3D and the 3D and stuff So from that I thought ' $W$ kind of 'uly. I'm nom ally, I'm not an academic. I knew that after being there, $1 \mathrm{~m}$ really not. My pleasure in Istars get ting involved in live projects. So, I started looking around for which companies were doing what, what engineers wer involved in what kind of work. I remember going to a few exhibitions at the time. There were various books that had been published about the art of engineering. There seemed to be an interest in engineering as a slightly more creative discipline rather than just the nuts and bolts at the end of the process. The big stand-out for me was a small exhibition that Atelier On had done. Neil Thomas (who started Atelier One) had done Ron Arad's studio, and there were some nice images of that It just stood out to me as really interesting work, and the other side of it was that there were and the few projects with moving parts that Neil had done with Lorenzo Apicella and also Stufish where there were structures that opened and closed or things that fold that travelled around ... mobile structures. just grabbed my attention. So, I ended up contacting Neil and saying, 'I really like the work. I'm doing this at the moment' I was thinking at the time that maybe I'd do some research for a bit at the university and thought that maybe I could link it into mobile structures. But I met with Neil, and we got on quite well, and I just started working with Atelier One. It was in 1992, and I was doing some part-time teaching, and I was part-time at Atelier One, but soon I go so drawn into the projects.

I was doing some quite interesting stuff on the computer. Everyone takes it for granted now, but it really was. No-on else was really doing any sort of 3D stuff and it was actually quite time-consuming. It was the early releases of AutoCAD and the 3D side of it that hardly anyone ever used. Also, I had various analysis packages that I could model something in and import 3D models and then put layers on and analyse it - that sort of stuff. So, I bascally came to London for a couple of days a week to exchange what I'd been doing and to go through projects, and I'd worke from home or at the university just doing stuff. I think it was in 1996 that I became a director here.

As a Londoner studying in Birmingham, I was acutely aware of the trajecto of people coming to London from the Midlands and the North seeking fortune and fame, because London, even then was an epicentre and vitalising the culture in the capital. And it happened in pop of course. I'm just reading a book called England Is Mine by Michael (1998) about the impact of provincial culture on pop music, but

think it was really important to me because of the people I knew, and in a way, med a slightly more creative view on the world. I mean, Manchester was a great city to grow up in. And you know, think we were 17 when the Hacienda opened Ben Kelly did the design and itwas Tew Order Kelly did the design, there as often as we could and was at universin in Leeds, I'd com hom very pecuse all $\mathrm{my}$ mates wero going Leeds, Manas were going there. You know, musically and for youth culture, it was absolutely brilliant. So, I was in no doubt about it. It was funny when I went to California, it all seemed very sedate. I got involved because I knew quite a few people in and around Manchester who were opening bars, and they'd ask me to design a staircase or do something cool in there, which I would do, but there were no companies in Manchester I could see that were doing the kind of work that I wanted to get involved in. I felt that I had to come to London to get involved in the diversity of work that I wanted to do.

I've never really talked to Neil about it, it's deliberate. I just think it started with Neil. Neil's 


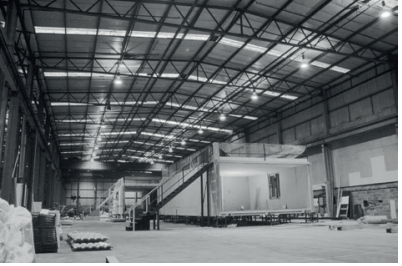

ery enthusiastic people who likes to get nvolved in lots of things. He'll have a co versation and an idea will come up, and he'll pursue it. It keeps it a lot more interesting.

interesting for us because it was all abou the connections. It was all about how you make a building very quickly, and it has to line-up-you don't get a second chance. But I think you took the design further, so that 1 met you in 2001 as the structural con- even the proportions of the space - these sultant to John Thompson of Hanson sorts of boxes suddenly became really TIS as main contractor when we were generous-became architecture not just doing the Piper rooftop houses for a method of building. 2.4 Piper rooftop house under
construction, Hanson TIS factory,
roofispin Kelly of Baylight. We viewred the ing as a brownfield site, and the whole project became about and the whole using modern methods of construction to speed up the building process and minimise the time on site.

We'd done lots of moving things, and through John Thompson, who'd just set up a factory making prefabricated buildings, one could do everything in a factory. (a) touring stuff, but why can't it be used as permanent building? Why, when you'te doing a building that tours around and has to be on trucks, why can't you use the same methods? Because it worked pretty well on that: it's robust, it's good quality, it's not that wildly expensive. Why can't you do that on permanent buildings? An so that's what we were trying to do, and, with you, the best thing was that some of the projects that we'd looked at before process, but architecturally or design wise they were pretty crude. We'd done one for Burger King from foundations to burger. It took 32 hours, which became the world record then for putting up a building. It was

For me, it was a first, and it was exciting to evolve the conversation when we got shortlisted for Swaythling Housing which we collaborated using the volumetric, modular construction system.

They were like 3D puzzles. That's one of the reasons that I've always enjoyed workin with you because in terms of sequencing spaces three-dimensionally, I think you'r brillint atit. And Ithink because my background was always the 3D side, I don't know how, but I can see it quite quickly. I think some people have to build up a pictur through plans or whatever, but I get that quite quickly.

I remember we talked about increasing the width of the modules, and you came up with the idea that you can put two halves together to make bigger spaces, so that the spaces became larger withou the impediment of intervening structure. That was all really interesting, and it did really drive that project for us. I think one of the issues you had about that approach was that itinvolved trasportation, which increased the cost of the

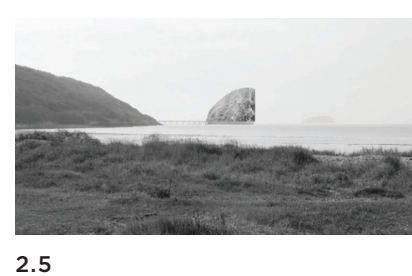

modules and the project. You suggested the potential of setting up a factory on site to manufacture the modules, and could be converted to community or other use. I thought that was a reall wonderful suggestion.

2.5 Pleasure Holm, Birnbeck It just makes perfect sense. And I'm surprised it's not done. I've had many conversations since. We're working on a project with Legal and General at the moment. They've got a site in Crowthorne, moment I and in Yorkhire where some are being bult, but the rire buiding most of them tratibut they re bullding most of them traditionally. It just seems that if you've got projectofthat size, that many houses, that to put up a shed in the corner and - with it designed properly, as we discussed, an community - delivering things in small bits, assembling it in the dry and then you take off all of the transport restrictions on roads because you're on the site, so you can do bigger units and, you know, you can do shift work if you need to.

It could be efficient in terms of speed you can do things faster maybe and more beautifully. We explored that idea with the Piper Building rooftop houses. We travelled to Manchester to the Hanson TIS factory. I think we saw the project you did for White Cube at Hoxton where there was good quality control, as the fit out was done in the factory and, certainl with Piper, if you didn't have a head for heights, it was great to visit the factory at Trafford Park and see the modules under construction at ground level.

We had stalls of about $300 \mathrm{~mm}$ high, but not quite the same view though.

But then what was also interesting, when we subsequently worked together on the Aberystwyth Arts Centre (a shortlisted competition for mixed-use live/ work units there), you had developed an approach for the foundations using mini was excellent for the very wooded sloping site, and then the big hift Ithougt was alsocross lominat timber (CLT).

We're still constantly looking at new products and different ways of building, and I hink what we try to do is not force a par. in a particular way, and you find something that's appropriate, and while we're enjoying the volumetric and we've done the Piper as a successful project with you, the site with ts access and everything else just wasn't appropriate. And I seem to remember the spaces, the geometry of them didn't really work with volumetric restrictions and transport and whatever. So, we'd been looking at timber systems again and were interested in the sustainable aspects of that. And I was really impressed by CLT when I first started to look at it because it seemed to me that in the past, the way that timber's been used in the UK, it's just thrown together, it's not really engineered Traditionalbuilers have been using timber, and they know that if 
they put it at $450 \mathrm{~mm}$ centres in the floor and $600 \mathrm{~mm}$ centres in the walls and use sheet materials and put nails in it, that works. But they all end up looking the sam because that's how the builders do them, whereas with CLT, it seemed that this was a pretty robust piece of structure, and you could do lots more interesting things with it because you could get a panel that was $12 \mathrm{~m} \times 3 \mathrm{~m}$. Well, those are effectively big beams, aren't they? So, Ithink we were quite site as bou the opportunities. But then, the selivering say I you're doing that, you' not extend that thinking into the way it goes into the ground? So, I think we did develop a whole strategy, didn't we, of minimum a whole strategy, didn't we, of minimum
intervention and going in with a simple grid of piles then simple timber panels that sat on those, and the installation would be days.

Well, it's become a very popular technology

It's taken over. When we did that work in 2003 , it was really new at that time.

We did the Birnbeck Island competition in collaboration with WYG, Cardiff, with Jonathan Vining who was the director with Bill Watts of Max Fordham's and yourself. Birnbeck Island is the only seaside pier in Britain that connects to an existing rock outcrop. It's a listed structure, was derelict and hadn't bee occupied since the Second World War. Urban Splash and the local authority got together to hold a competition for which we were shortlisted. Our take on it was to propose a very big building in the form of a small island which appeared as a detached part of the headland at Weston-super-Mare. It had an ambiguity; it looked like a natural form.

It looked like a big rock but with a huge amount of space within it.

The programme was quite varied...

Bill Watts proposed that it should include data centre. I think I remember talking abou such that, if youre only going to do was flats or some thing It was just so complicated getting stuff to the is co complicated getting stuff on to the island that you'd have to put in some It's either that or mayb you con It's either that or maybe you could airlift or helicopter in a couple of houses, but the cost To do anything of any scale, you'd have to pay for the access onto the island, and if you're going to do that, then you're going to wan to maximise the amount that you do on it I think the renders looked amazing; it just looked like an outcrop of rock. It wasn't like a rock with a tall building on it.

The disappointment at Stage 2 was George Ferguson (who was chair of the jury) saying, 'Oh, it's 1 million $\mathrm{ft}^{2}$ of development and that's going to cost upward of two hundred million to build', and we all nodded and said 'Yes', and then Urban Splash said, 'Well, our budget's only 18 million' that would iust about cover the cost of making the tunnel which you proposed for service access'.

Well, it just didn't make sense. Once you've got the development on there, you'd need some pretty robust access onto the island. The budget would be spent on sorting that out before they started building anything. So, I think the interpretation of the brief was to think, 'Yes, you need that infrastructure, so you need as much development on it as possible to make it work' And then from that I think we developed the simplest solution that I think we possibly could in terms of the approach to what could in terms of heach to what materalswe hadand how thas built and everything. I seem to

I think that was your take on it. We had to restore the listed Victorian pier for pedestrian access, and you proposed a tunnel that went parallel to the pier and emerged on to a service deck. But then the superstructure was really ruthlessly simple - it was just a 3D grid.

Well, I quite liked the idea because you had this rock that was geometrically all over the place, but just to impose a simple grid on it was almost like a biscuit cutter landing from above. Then, you just trim the length of the columns to deal with the contours, but everything else is simple.

That was really very efficient. And then the last component of the project was th carapace and how to replicate the flor of the headland on it. You suggested that we have a coffered concrete structure, and the coffers could effectively become a series of giant flower pots - containers for soil. The landscape architects suggested that you could grow quite large trees in very shallow soil. The coffers were only $800 \mathrm{~mm}$ deep. The coffers were designed as inverted or everted to suit a particular situation, and you could occasionally punch through them to bring light in where you needed it.

It was another idea, some kind of system approach but each element could do gs and that it worked on a number of evels $S 0$, the it worked on coffering, you get the stiffness, materially; it's quite efficient but then with soil and structural protection from the wind lods and so on ... I think, again it's an incredible approach to try and syst's an ise something but to try and systemogether, you wouldn't lonce it's all put 'Well, that's just a repetitive tile', you'd kind it's throus the the it's through the planting, and I think that's often the thing. We'd done Federation square, Melbourne, before, which had an incredibly complicated facade. The design was a really complex folding facade of different materials. But the sketches we got originally were just unbuildable, and so we had to introduce, if you like, a repetitive element that you could easily describe to someone who had to build it. And with that one, we worked with mathematicians on a pinwheel triangle that was then repeated so it was a similar thing with the repeated where you get the benefits of repetition. 
Then, when you look at it at the end, you lose sight of that in the overall impression.

we thent ideas and you can refine them. So,

we set things running overnight to creat

during, Isuppose with the conversation 150 iterations or something and so we can during the competition process, includ- do things now that optimise. We set the cria whole series of data centres around the some scripts for, and it was for a grid-shell coast of Britain, was that there was an roof, free form, all glass and steel. We wrote idea that this was a new type of building, loads of things like the size of the glass mixed-use if you like, but underpinned panel had to fit in a container. So, we set by the data-centre element that provides maximum dimensions. I didn't realise, but security and heat. I suppose we never for glass wastage, if you have triangula got the chance to really work through panels, you pay for the rectangle that it's the idea in terms of the cork through pand how that how that would be structured. The are amoun 作 engineered by Arup, and because it was our script that we'll square them off as pre-computer, they had todraw sections much as possible so there's no wastage. mach make sure it really all worked. Could of structural efficiency, and then this was you make a comment about the use of a quadrilateral shape. So, you have to press computation with regard to complex the glass in, and there's a limit in term forms and whether that really does offer of cold bending to get the warranties on new ways of designing?

Well, it makes such a huge difference in rms of refinement. There are two thin one was the modelling of it, and now it's the manufacturing or the fabrication of it. Both sides of it are improving massively and influencing each other. It used to be that mathematically, it was so complex to work through with just hand calculators, you'd intuitively work something down to one solution so you only had to go through the number crunching once. So, a lot of it was from previous experience and guesswork and saying, 'Well, this makes sense, so this math and then I'm glass. So, the form of it would be tweaked based on making sure that you could still get a contractor to warrant it. So, we wrote all of these very pragmatic considerations nothing about beauty or about what it would look like, all very pragmatic criteria. And the programme goes through it, and you'll see that this one is ' 98 per cent of the panels are within the cold bending', or '100 per cent of the panels can be containerised, and so on. So, you set the criteria, and it's incredibly powerful. Also, when I was talking about the manufacturing that on didn't do any drawings; it was ment we less to any drawngs, it was meaning$10 \mathrm{~mm}$ and it's a differen was for a steel roof for example, but we

\section{Urban Splash Competition Brief for Birnbeck Island}

1. What's it all about?

This is the chance of a lifetime, to create an exciting development for a fantastic island.

The only island with a connecting pier in Britain (yes it's technically a bridge, but we like pier!), time to get scribbling

We want to deliver an outstanding seaside development, which realises the potential of the site and reinforces the regeneration of Weston-super-Mare. We need your help to do this. We don't have any set ideas of what should be there, so let your imaginations run wild.

Our objective is to secure the best quality sustainable development, delivered to the highest architectural standards and to put this historic island back on the map.

A lot to ask? Not if you're the best. We want you to engage your creativity and submit your ideas.

Once you've submitted your masterpiece, entries will be assessed anonymously, so don't worry if you're a new practice that no-one's heard of, or if you're a multinational corporation, or if you have crazy hair. We won't know. The judging panel will choose up to six designs for further consideration (we will want to meet you at this point but maybe you could use some gel or something).

It is our intention that the winning design will be built.

2. Where is this heavenly place you speak of?

Weston-super-Mare is in North Somerset, about 20 miles south of Brizzle (that's Bristol to anyone outside the South-West). The town is accessed from Junction 21 of the M5, Weston's railway station offers services to all main routes and it's only a two-and-a-half hour train ride to London village. Perfect.

3. What happened to our seaside towns?

Weston-super-Mare was one of the great seaside destinations. In the olden days, tourists from across the West Country, the Black Country and Wales flocked to the resort to enjoy its beautiful setting and attractions and, more importantly, its alcohol. Wales was dry on a Sunday back then, so packed paddlesteamers used to cross the channel to Weston so that our Welsh friends could quench their thirst.

Like so many British seaside resorts, changes in tourism and the growth of package holidays to 'Costa Cheapaspatatasfritas' have all had an impact. 
Although tourist numbers have fallen, the town still attracts visitors. Weston has retained its classic seaside character what with the donkeys on the beach and fish and chips on the seafront, providing solid bulding blocks for the future.

Birnbeck Island, pier and headland were acquired by Urban Splash in September 2006. We think the development of Birnbeck Island and headland is one of the key elements in the regeneration of not only the Birnbeck area but Weston-super-Mare as a whole. We want to bring Weston into the twenty-first century, so we can visit and have something to do, so our kids can come here and so we can can visit and have something to do, so our kids can come here, how easy the kids of today have it.

So what's the site like?

Birnbeck is to the north of the town within walking distance of the centre. Designed by the great pier builder Eugenius Birch, Birnbeck Pier was completed in 1866 and at first only had a small pavilion and landing jetty. Once they realised they were on to a winner, additions were soon made, including a funfair and landing stage for the steamers from the Welsh coast. Birnbeck was the place to go, to be seen and to have fun.

Today, this poor neglected site is largely derelict, though the RNLI has a fully operational station on the island which has been there for more than 125 years. That's dedication for you

There are still buildings on the island itself and unused buildings on the headland, all of which command great views across the Severn Estuary to Wales and up and down the Bristol Channel. Makes you want to unfold a deck chair, doesn't it?

Urban Splash is looking for inspiration. We want to transform Birnbeck into a beautiful and awe-inspiring destination. We want to deliver a fantastic development with public access, new attractions and facilities to draw more residents, workers and tourists back to Weston. We want Birnbeck to be the place to be again. We want your designs.

5. How you will win

You will win if you can

- Surprise, inspire and enthuse us

Do justice to this fantastic site

- Show us you can deliver world-class architecture

Demonstrate your balance between creativity and pragmatism

- Convey your ideas clearly and simply

- Demonstrate that your vision is deliverable.

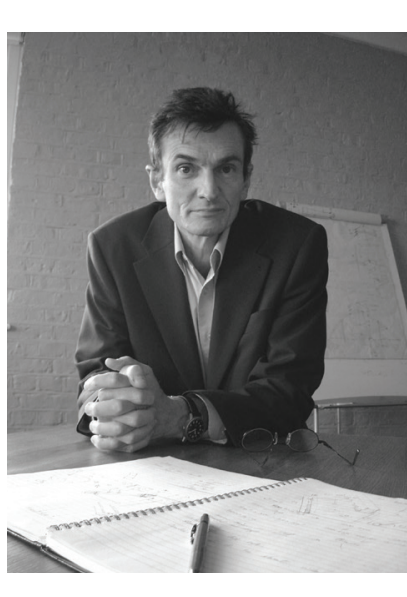

folly was free form. So, with the contractors, it was all done with 3D models dow to the point where all the nodes on it were taken from blocks of steel and milled so each one was milled from solid steel. Every node on it, of which there were about two thousand, was different.

Bill Watts

Interview at Max Fordham LLP,

Camden Town, London, 29

January 2018

Bill Watts, senior partner
Max Fordham 4 P

I wanted to preface the interview by saying that for me, this was a very important project. It was genuinely collaborative and led to an amazing piece of work. I had been involved as a of Architecture in Cardiff, and made a connection with the firm, WYG, where Jonathan Vining, an old friend of mine, was a director. They wanted me to act was a consultant on slightly left-field as a consultant on slightly left-field projects, and the Birnbeck Island competition came up. Jonathan and the WYG team produced the submission through designs, drawings and conversations that I initiated. I invited Aran Chadwick and you to join in, and we had several meetings in London, including with Jon, and the project started emerging from our discussions. My anxiety when I first proposed the potato, which is what I seem to remember you called it, was the idea that our proposal was a very big building masquerading as a very small island, and I was anxious for it not to become just a one-liner. Aran and you helped enrich the idea so that in the you it was the most popular design with the jury and the public. However, it would be good to start by asking you a little about your background.

My background, well my heritage, if you like, is that my father was in the UN as a town planner. I only realised after he died and after I had read his book (Outwards From Home: A Planner's Odyssey by Kenneth Watts, 1997) that he was part of the group of experts that came out of the war thinking that experts could solve every problem. And he spent the rest of his working career And he spent the rest of his working career wasn't 1940s onwards realising that that wexpertise needed to background, which I found interesting. I was born in Indonesia where he was working at my dad cam to liv in for a whil b fore getting a job a (or BRS as itwas get) In a job at the BRE (or BRSas itwasthen). I had an idylic early chers W ther one was a house in he river, which was just mazing. But, anyway, that settled down, normality came back. We moved to Hemel Hempstead, and then when he was settling into being at BRS, he got offered a job back at the UN in New York. So, we went to New York in 1964 when I was seven. I came to school at Bryanston in Dorset when I was 13. I've been in the UK ever since: at school then to university when Jacques Cousteau was the guy I wanted to be. I mean, marine biology was a very strong thing for me I thought it looked adventurous, butalso ha humanitarian aspect to it: feeding the world that I was 
imbued with from having parents working for the UN. I studied zoology at universit but I didn't really know what to do after that So, I did a postgraduate course in fish trackIng in Stirling. I thought that behaviour was very interesting subject. Dawkins was in full flight, and I found studying physiology and behaviour fascinating. Fish tracking was me trying to square the idea of fish being the in seaweed. Academically, I was mid-table shall we say, and certainly not able to go do a PhD So, I was looking for a job when I finished.

Did you have to have mathematics or statistics for that?

Not much. There was a lot of computer programming to be done and analysis, but also some engineering because what I was doing (tagging fish withelectronic tags) had to be screwed to the back of the fish, which was rather unpleasant, but I was involved in designing these things and also in man facturing them because I was employed as a technician making these tags. There was a lot of physics involved in this. I really did enjoy that aspect of things. So, when all Max Fordham had an ad in current vacancies, as it was then, for people who like buildings: 'We're looking for scientists and engineers who like buildings'. I thought, 'I could do that'. So, I applied and got th job. I was interviewed by Hugh Norman who's here now, Richard Shennan and Paul Kirby. It was an eye-opener to me to come to an engineering firm whe the people being fairly casual about things. was a lovely atmosphere, but I had no idea what was going on. When they were inte viewing me, they were showing me things: pictures of buildings that they had done. One was of some fair-faced concrete blocks with a fire alarm call point in the middle of it, and they said, 'What do you think of that?' And I remember thinking that I had nothing to think about it, but the idea that you've got a fair-faced block on both sides with a call point and the torture that'd been gone through to thread the blocks over conduit... well, that was completely missed by me. But I just loved it because for me, by me. But the pysiolo buse, for me, the parallels with biology were all an plain to plain to see. As a biologist, you re studying an animal. how it behaves, how it relatesto of different a d clever ways-and its also of different and clever ways - and it's also physics and it's logic and things like that. And actually a building replicates a lot of the functions that happen within animals and within biology. And it's designed to house animals, so you need to know how an animal works and how it feels as well withi that (animals or people/people or animals) So, I found the transition, intellectually very easy to make into engineering and quite nice, in a way. What I had no background in is any of the formalities of the discipline that engineering people had: the reading, drawing skills and that rigour that you need. Coming from a rather freethinking, pure science background, that was a bit trickier for me. So, I never really picked up the discipline of drawing ver well, but it was okay I of drawing ver well, but it was okay, I got by on that. Then assomedody whow think Iwasi and I was given all sorts of interesting bits and pieces to do. And I had a great time. gained a lot of experience. I joined in 1980 when there were about 20 people and the philosophy at that point was one person one building', which is kind of limitin in many ways and uncompromising. You needed to do everything and do it equally as waterfront, which I might say, I think that's just untenable these days.

How did that work? Was that an absolute - that you ploughed a lone furrow with your particular project?

Well, no. I mean, 'one person, one job', the philosophy of that didn't really work that well I mean of course, I was working with other people all the time, and you got shown the ropes, and you worked through things. There was always a structure that you worked through, and so it wasn't always just one person. Particularly as graduate they were educated and brought throug the system, and we did have bigger build ings that we took on. Norman was running something called Anugraha at the time, which is a big conference centre. And, of course, there was Alexandra Road as well which I missed actually, but that was a ver big building which took a lot of people. Anyway, so I was fortunate to do a smattering of everything: electrics, mechanica and electrical, acoustics, a bit of fire and all that sort of stuff-enough to know your way around all these things and to have a bit of a command ofitall I think that's what makes building servicesso amazing-theres so much of it.
We met when I approached Max about the Birnbeck Island competition. It was obviously great for us to have you join in. Can you explain how projects get allocated in the office? I think mostly, until then, I'd been very lucky, and Max took an interest in what we were doing and would join in.

Maybe he gave it to me as a kindred spirit because he knows what I'm like. I can't remember the exact process.

I think when we first met, at WYG's London office, I may have tabled a section and plan bro and you thought about data centres?'Then it you thoughtabout dact typological aspect to it that we could the in counte dotted all round.

Data centres were just coming along then, and I was learning about hem and also about energy. There was something called the Renewable Energy Systems headquarters in Kings Langley which we did in 2000, I think, and it was an amazing brief to have zero carbon, which at the time was quite innovative. So, you were thinking about this site, what you could do with this site and whether you could make the site zero carbon. And they wanted to do biomass and wind and all that sort of stuff It was a bit far-fetched but I thougt, 'Well, wha bitar-fetched, but for the whole of the UK?' And then you start 


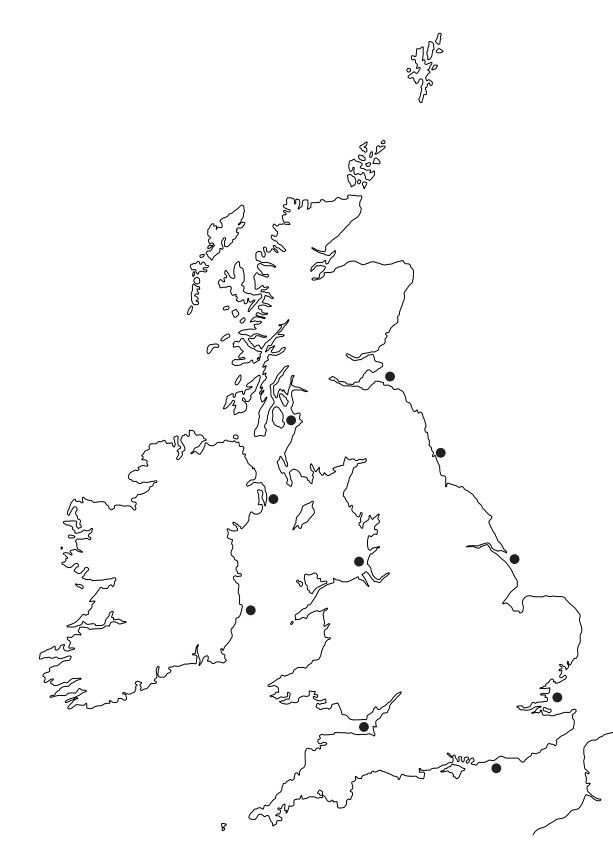

2.6 Coastal is
British Isles

The dots indicate potential
locations of data centres away into the heartland, into the hinterland. And that could be all the way around the UK I mean, people are talking about puttin data centres in Iceland. Oh, the other thing about data centres is that they need a lot of cooling because they generate a lot of heat and so you think, 'Well, is there anything for that? Could you make use of that cooling? Well, maybe if you've got other buildings nearby'. But if you're in the middle of the sea cooling is very easy because you can put it into water So, the remoteness, the access to renewable energy, cooling seemed like good thing for a da colng seemed like it with other things that need hou then link then that semed like a good thing to do.

Yes. For us it was the amazing moment because it was complementary to the looking at where the energy goes and how to use it, and I was going along the same path duplex apartments. There was a hote as David McKay actually in trying to work and the kind of leisure activity associout where these things were going. He did it ated with the seaside, including a music a lot more thoroughly than I did and wrote a hall, a theatre, a cinema, bars, restaubook. But the thought processes, and indeed rants and a casino.

the conclusions, were similar actually. But one of the main users of energy, which was coming up fast, was data centres. And one of the main things they needed to be was Birnbeck Pier is listed and is the only secure and remote, and they used a lot of pier in Britain that is connected to an energy. And if the energy is coming from existing island. It had been derelict since off-shore wind (which certainly is the case), the 1930s. The developer Urban Splash then you want a node somewhere where the formed a partnership with the local energy can come in from off-shore wind. authority to help redevelop it as part of You'd store it locally in batteries (all the an initiative to reinvigorate the town. same sort of technology as you'd want in a data centre) and then maybe that would be a hub for both data and electricity to com

Suffering, like many other UK seaside towns a slow decline. it with the accommodation brief we had given

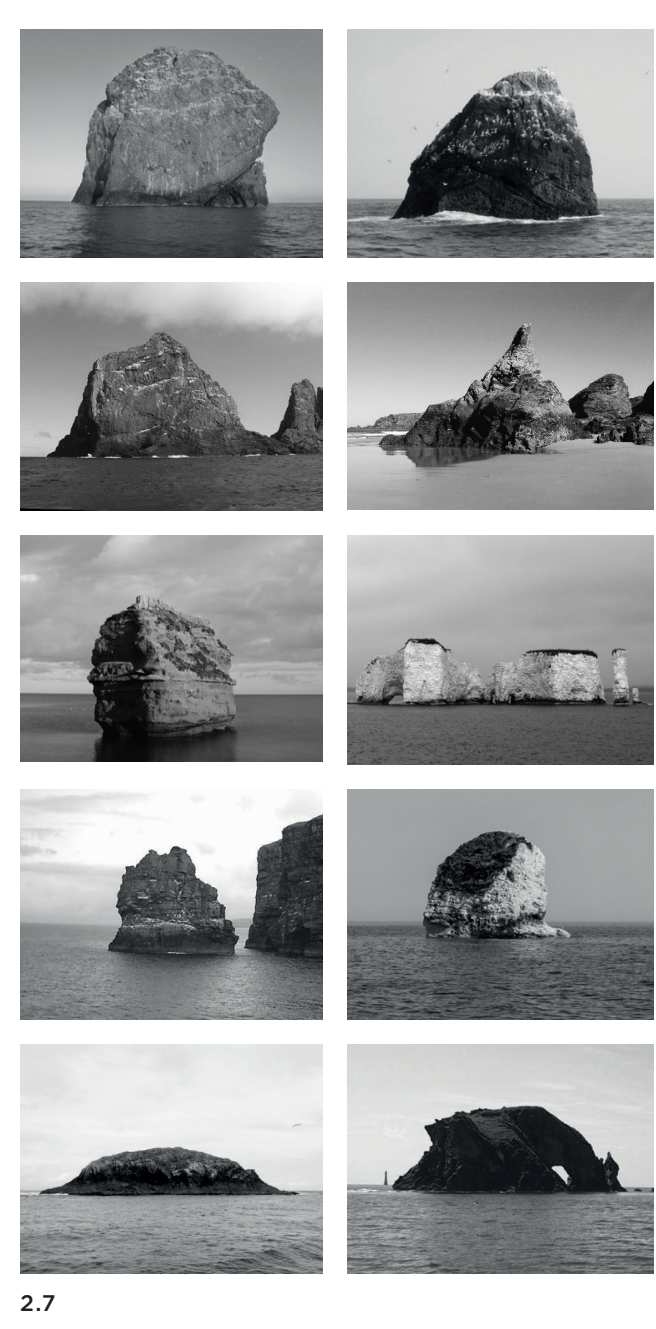
petitors to be playful, even fantastical. But suddenly, with the conversation you introduced about energy and how it is managed and deployed efficiently, it suddenly went from being a singular thing to having...

Lots of dimensions.

Were the ideas you introduced in common use then - data remote locations in the sea and so on?

I'd never done a data centre before. We've l'd never done a data centre before. We've them. We've been shocked at the amount of het and energy they use con anod to the rest of the building and that gets to thinking I was in the zone of think you thinking. I was in the zone of thinking globally about energy and thinking, "Well, it's a lot easier to shift data than it is energy. So, maybe you put the place where you process that data next to the energy and not vice versa'. Hence, you put it away from the centres of where people are.I mean, actually, for these trading systems that the city people use, those nanoseconds matter, so that they want their things in very close proximity. But for things like Netflix...I think they are building them in Iceland now where
2.7 Proposed data centres. I
Source: Images courtesy of Mark Ireland, lain Miller David Hagwood, Pat English,
Classic Cottages and Jon Morley.
When Italked to Pauline, my wife Clare's energy is cheaper. Just like where you put aunt who lived in Weston-super-Mare aluminium plants, you put data centres. So, most of her life, she reminisced about how I guess that was in the ether. I was thinking she and Nigel, Clare's father, would play we should put these things in Iceland. I can in the undercroft of the even-then der- remember thinking that's what we should do elict pier when they were children in the and that's what they are doing now actually, 1930s. This helped to in narrative our pro ing the the cultura 
to a talk once by an American: a bulletheaded guy who was talking about different security levels. He drew the comparison with a car having a flat tyre. Well, the first level is that you've got a flat tyre. So, you stop the car, take the wheel off, wait for someone to bring another one to put the other one on. Then, you go up, and he said, 'Well, you've wheel while you're in motion'. And then the last level is that you've got to be running on all four flat tyres while someone's shooting at you, and you've got to be on these what some of these people do. And some of hat 50 miles outside of Washington, DC, outside the blast zone of a 50 megaton nuclea weapon', and you think, 'This is hardcore stuff', and I guess you wouldn't be too upset if Netflix went down in a nuclear war, but here are some people who are worryin about that sort of thing.

But in the 10 years that have elapsed, is security still an issue for data centres?

Security certainly is. I guess nothing has changed. I mean, there's a push and pull between having it localised and not, but don't know where that's going now. I think there's more processing happening on your phone now than centrally, but there's always going to be huge amounts of data stored on going. Logistics and the infrastructure is an issue for island data centres-landing is a major issue. Off-shore wind is now doing very well, and people don't want on-shore wind turbines, although that's a pretty cheap form of electricity, but off-shor wind, I think, is pretty acceptable. What isn't acceptable is where this gigawatt of power comes on land because that needs a substation, and I think the planning permission for that can be quite difficult -and stops a very large bit of infrastructure happening. I think that happened to the Thames Array: they couldn't get planning because where it hit land was difficult So, as I say, it's non-trivial. You would've thought, 'Well, surely a bloody cable isn't as bug as wind turbine?' thing And if we had these outcrops tha thing. And if we had these outcrops that were dond imply just the ecctricty coming in, you will need a lot of to the rid An the, including connection tothegrid And you might as Anel.

So, it gathers together quite a lot of different kinds of components and the distributes them?

Yes, and then the residential aspect of it doesn't play well with the security of course.

What we called the black-box side of the building was essentially the data centre, with public spaces carved into it, which were only accessible from the public side, with no direct access to the data centre. There would have to be some design and negotiation to clarify that.

But, obviously, people are going to know where cables land from

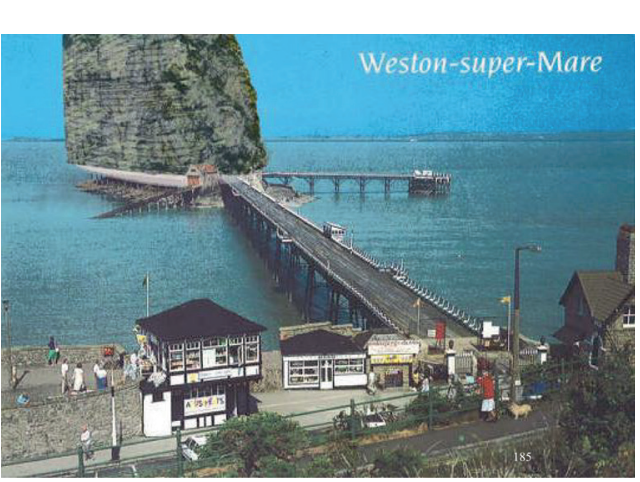

included a subterranean tunnel that provided vehicular access to a lower deck, which at your suggestion became the location for many smaller turbines along the outer edge. We designed it as a horizontal slot, above which the building appeared to hover.

Any gap that you put in it is going to have quite a lot of force driving through it. So, if you put turbines there, you'd get a lot of energy from that. And also the Bristol 2.8 Pleasure Holm at Birnbeck $\quad$ It's just quite interesting that there's
Island, postcard
still a lot of hardware involved in it, It's just quite interesting that there's
still a lot of hardware involved in it, and I suppose the design was partly a comment on that.

'm sure we could've done something with that, although I'm not sure that we

That it was hard hardware. It needs to be hard, and that's got something quite interesting about it.

We didn't because at the time there was the ambition to build a navigable barrage in the Severndownst the site.

I was hoping that Aran would be here to

link up the conversation about structure What's interesting is that I would never as well because he initiated the idea about have thought about doing this. And that's the carapace being concrete. I know that why we need your initiative to do, to think doesn't chime well with notions of sus- about it. It would just never have crossed my tainable construction, but the idea that mind. So, you do need that spark both ways. the coffered concrete shell could repli- And that's why it worked so well and why cate the ecology of the headland was an I love it so much because I can't pretend. important factor in the design. WYG's For me, to do this sort of thing on my own, landscape architects determined the it just wouldn't work.

coffers could be a minimum soil depth of $800 \mathrm{~mm}$ to grow a large tree.

It's quite windy there. So, the weathering of the vegetation would be fantastic.

Collaboration is important. Some of the people I work with are quite young, but they often come up with ideas that really drive the project on.

You proposed a huge wind turbine in They say throwaway things and make you the Bristol Channel. The design also think, 'Well, hang on a minute'. 
I would like to conclude our discussion by asking if you could say something about your Sahara Forest project.

Well, it has a similar ambition to Birnbeck sland, if you like, to do something quite multifaceted that ticks off a number of issues. The motivation behind the Sahara Forest project is the fact that we need more food, we need more energy without $\mathrm{CO}_{2}$ and we need water. And there is dese falling on it which is not used. It might be degraded, but it works very well in terms of growing things. So, pulling all of that gret if we water, which might be in short supply or water, which migh in short supply or there's a lot) and you use solar power to desalinate the seawater, that gives you fresh water that you can grow crops in. Then, the water that you can grow crops in. Then, the
most efficient way of growing crops is in a most efficient way of growing crops is in a
greenhouse, to give you optimal growing greenhouse, to give you optimal growing conditions, you've really got to cool the air
(in the summer anyway) and you can use (in the summer anyway) and you can use the brine from the water that comes out of the plants after you've taken the fresh water out is more salty than the seawater. If you run that The idea of the Sahara First project cam your greenhouse is running nicely at the from three guys sitting in a pub here in right temperature with a load of sun, really Absolutely nothing. And I'm aware that you powering away and producing that stuff, need to come at these things with quite a and there's abundant solar power around to power all of this stuff. So, those are the main elements there of making those technologies: desalination, solar power, horticulture and greenhouses, and pulling that together into some sort of economic unit. We had a pilot in Qatar, which we buil in a hurry. I mean, that was an incredible get on with it'. So, before we'd finished that we we design and construc, and so we were always sort of catchin posal in December 2011, we had to finish But we got it done, and it worked. It was on a petrochemical site, so not ideal for a farm where you're growing cucumbers, but it ran for a year, and then we dismantled it and moved it to Jordan to a more permanent site. It's twice the size of the (and But now we're looking at sizeable things in Tunisia of about four hectares to grow I was very interested in the Sahara I was very interested in the Sahara Forest proj about it in 2011 because of the invention required to make harsh unproductiv atural habitats productive. bit of humility because I've done this often enough to know that hubris is bad. And in Jordan, we were looking at somethin called the Eurava Valley. We something called the Eurava Valley. We talked to the valley very well, and they said, in no stress because we were halfway through the feasibility study when they said, 'Let's up. So, from the time that we put in a proone in Oatar, but it's still only $1500 \mathrm{~m}^{2}$ of untities and pulling trucks

uncertain terms, that this is a unique ecosystem and that the barrenness and the harshness of the climate mean that ther are species that you get nowhere else. And so, the worst thing that you can do is make it green. So, this whole thing about greening the desert, well you've got to be careful. And you've just got to come at things with

bit of humility, but also that if you keep saying no, the issues like climate change are going to swamp you. You will always get people who are defending their patch, and the trick is to try and find out which is the best patch. I mean, any development is going to change things, and it's a question of understanding what's for the best really.

2.9 Birnbeck Island. I Source: 1:40,000 1. Birnbeck Island and Pier
2. Headland 2. Headland
3. Old Town Quarry
4. Weston-super-Mare 4. Westown-super-
5. Grand Pier 6. Seven Estuary

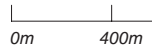

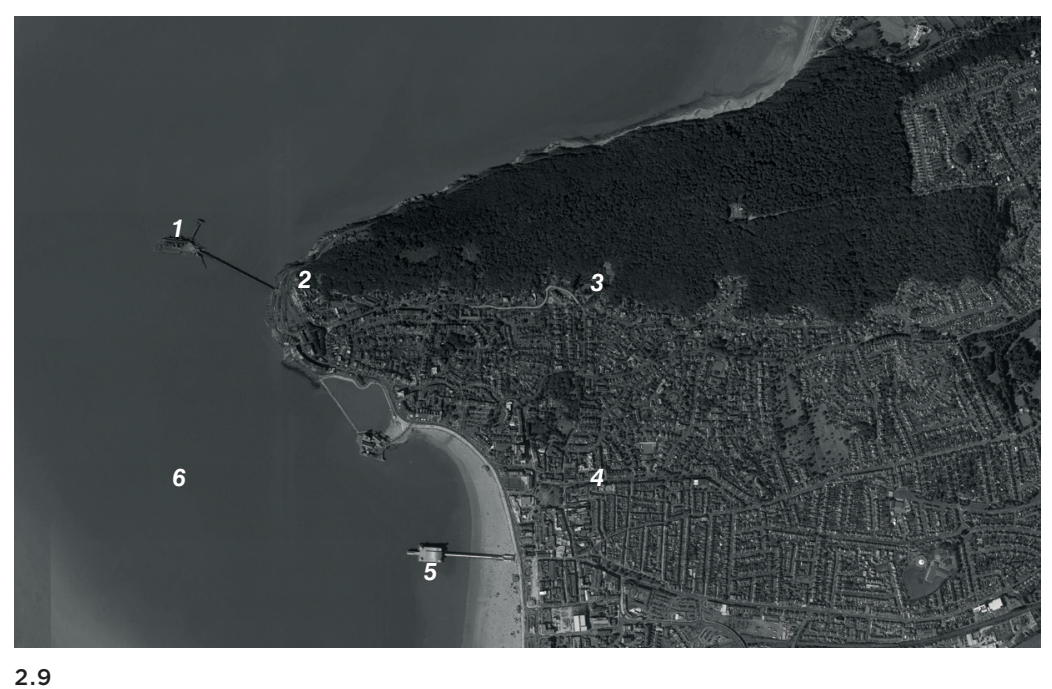

2.9 


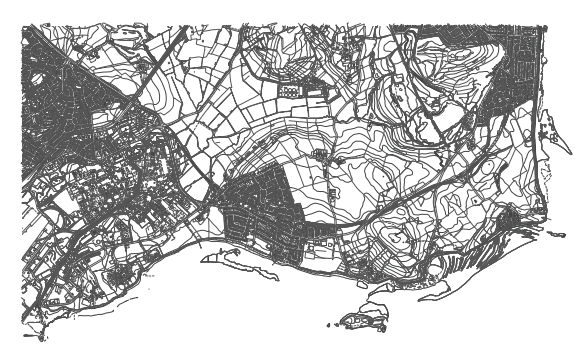

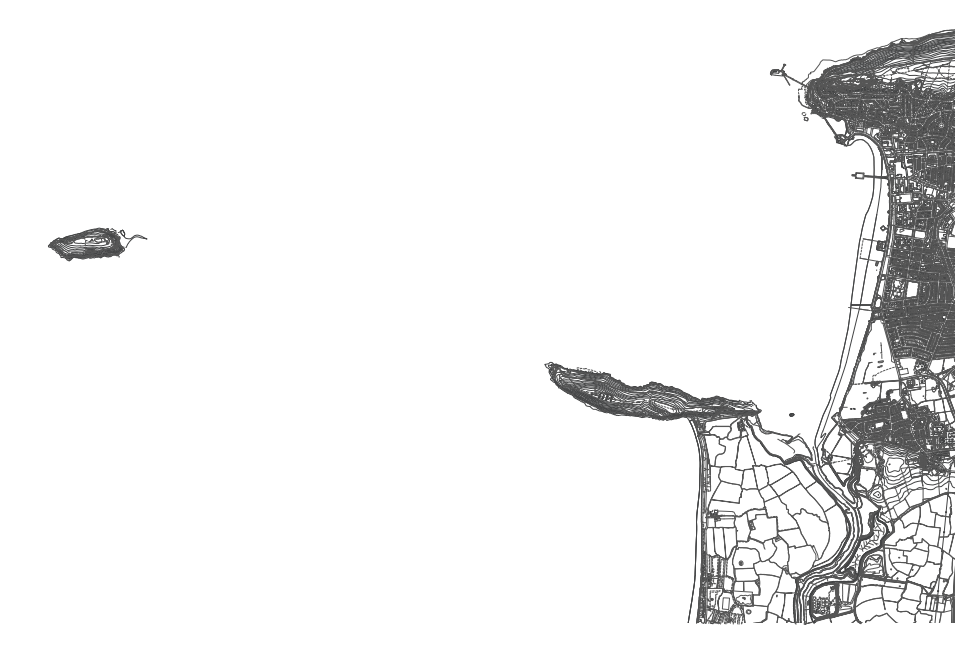

2.10 Location plan

1:100,000

(1) $\iota_{o m} \quad \stackrel{k}{\imath k m}$

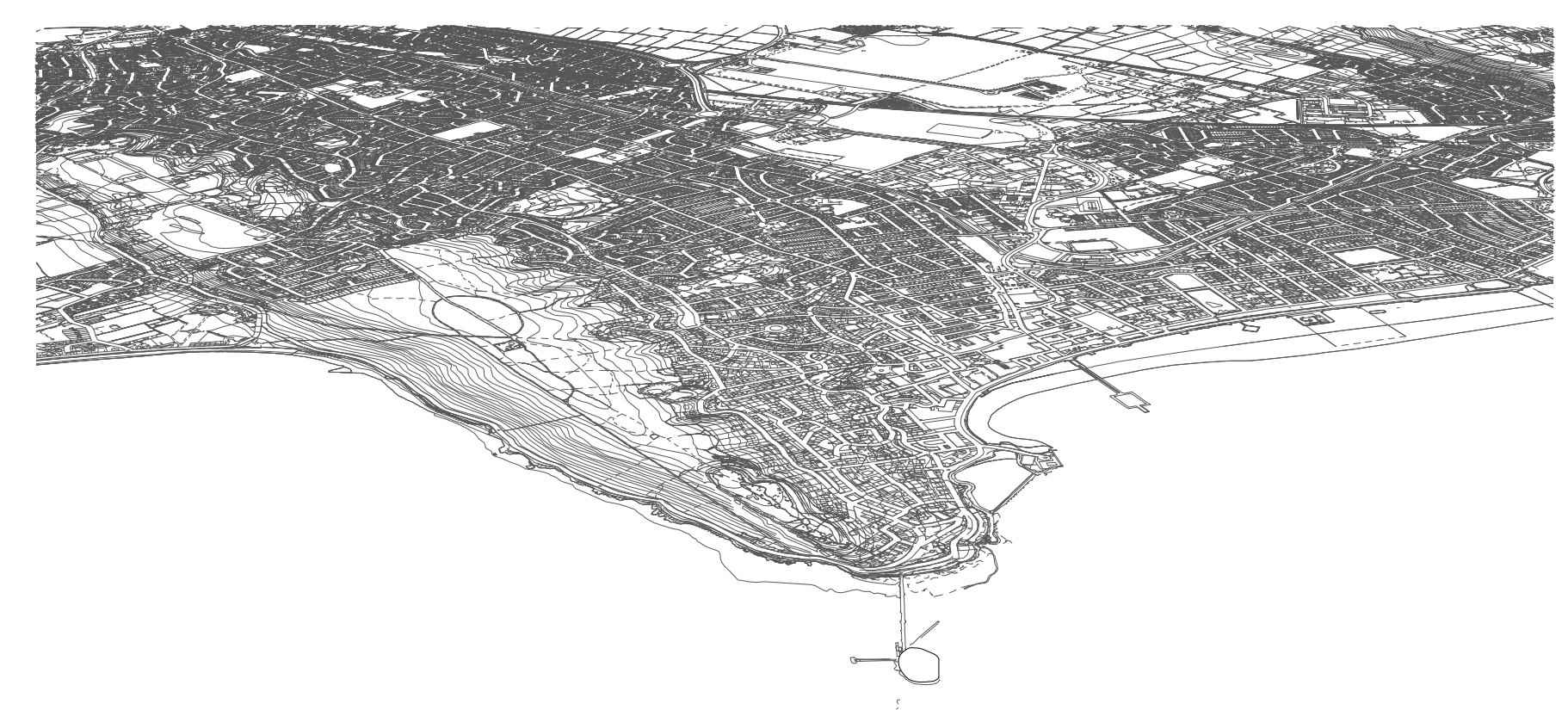

2.11 

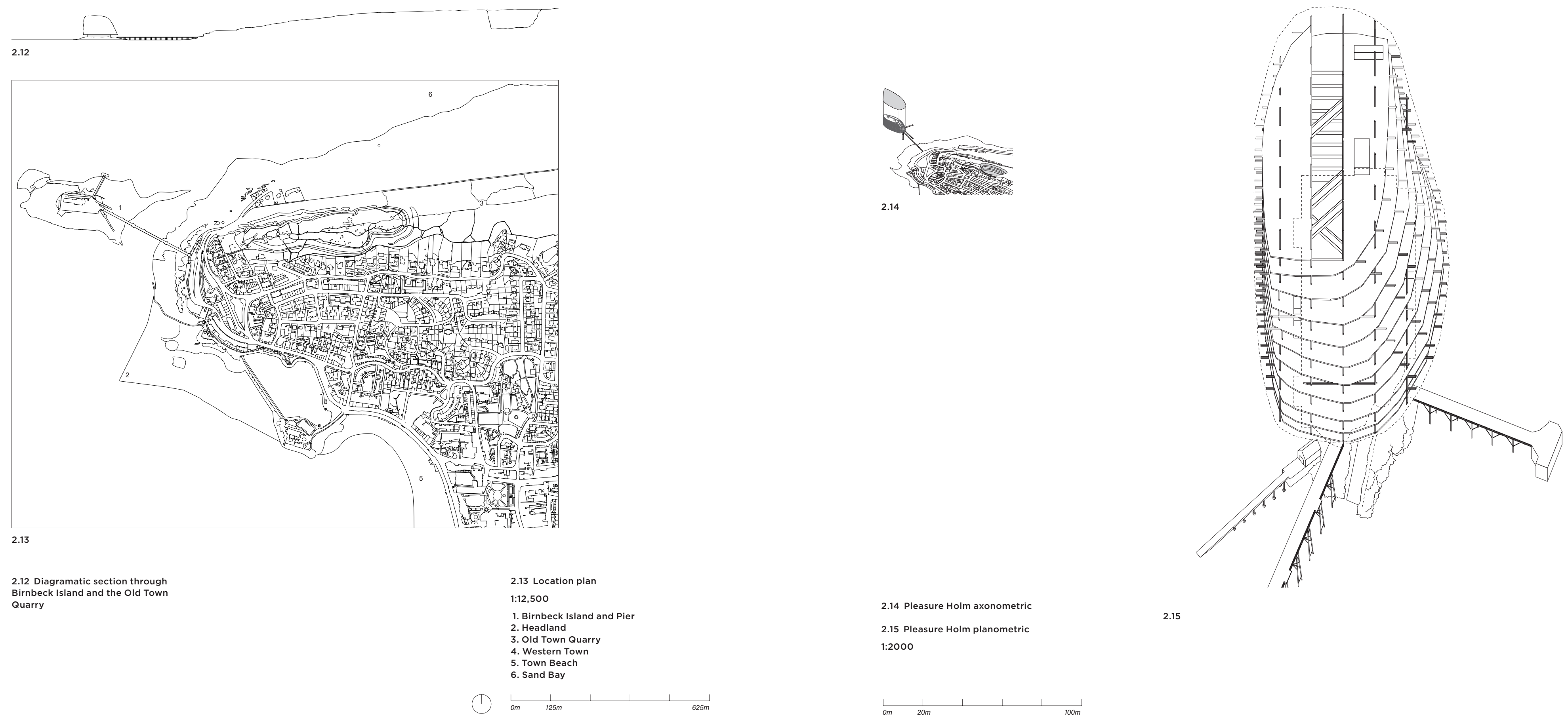

2.14 Pleasure Holm axonometric

2.15 Pleasure Holm planometric

2.15

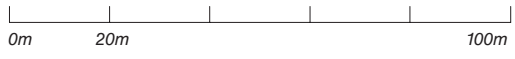




$$
8.8
$$



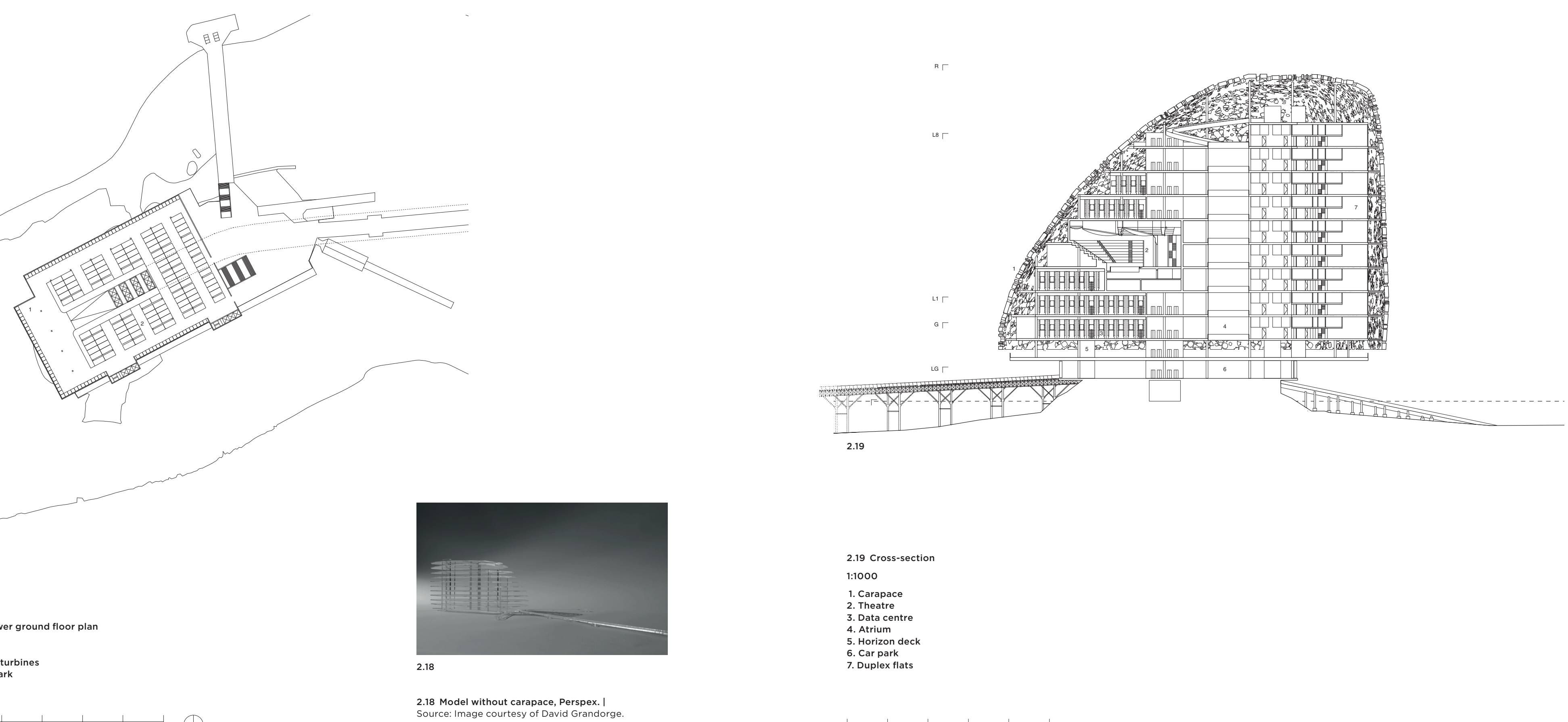

2.19 Cross-section

1:1000

1. Carapace
2. Theatre
3. Data centre

3. Data centre
4. Atrium
5.

6. Car park
7. Duplex flats

1:2000

1. Wind turbin
2. Car park

2.18 Model without carapace, Perspex. 1
Source: Image courtesy of David Grandorge.

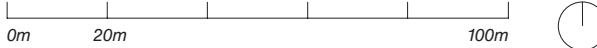



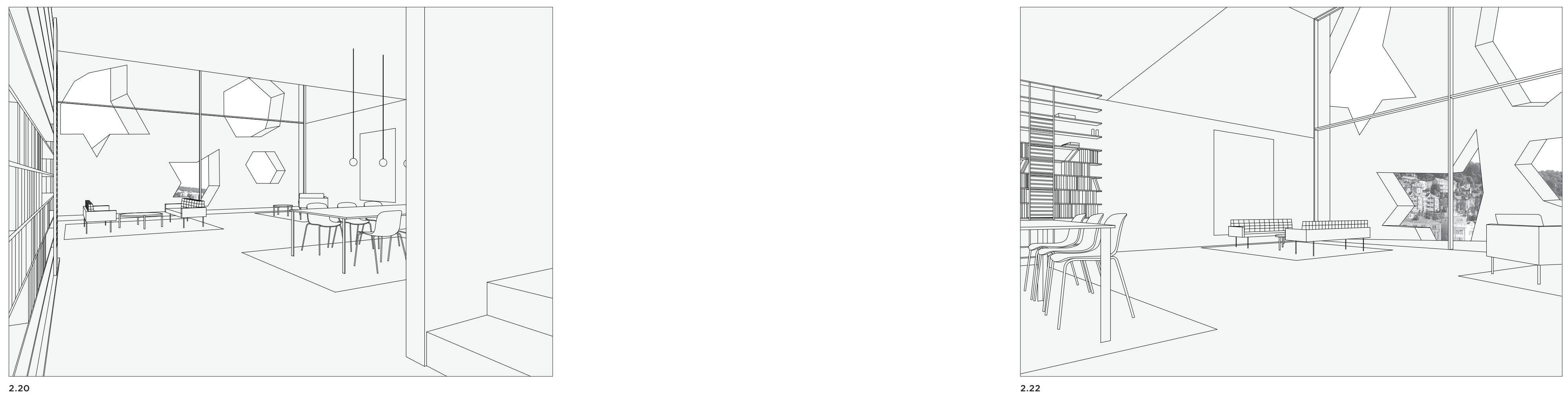

2.20 Duplex flat, interior view

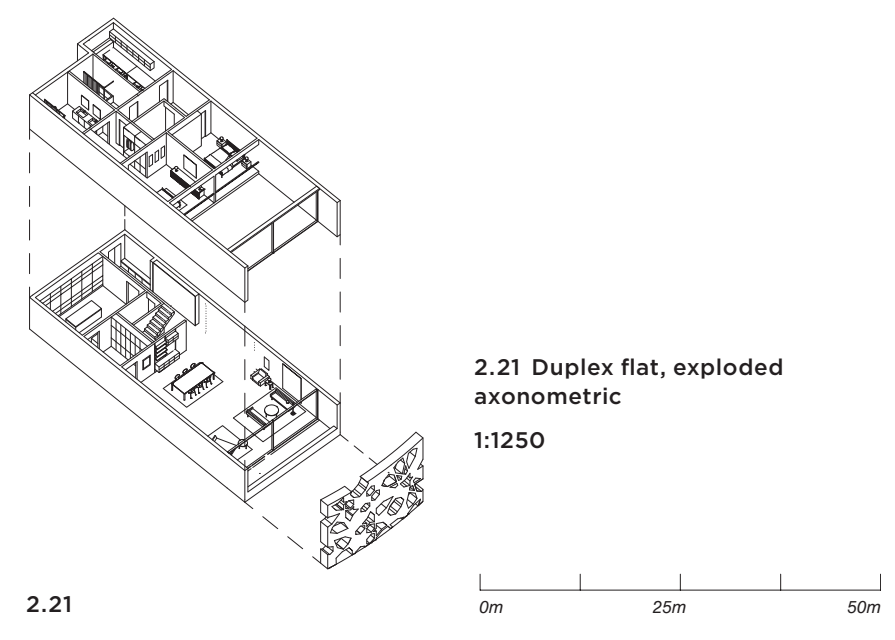



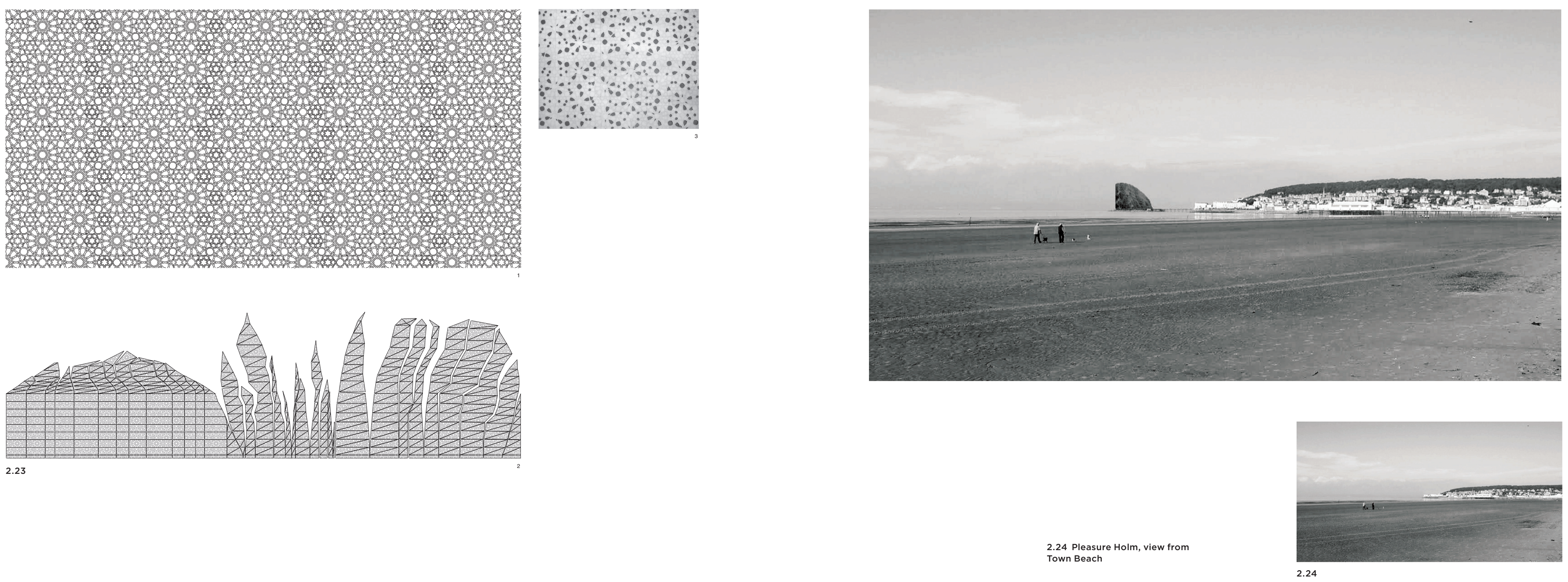


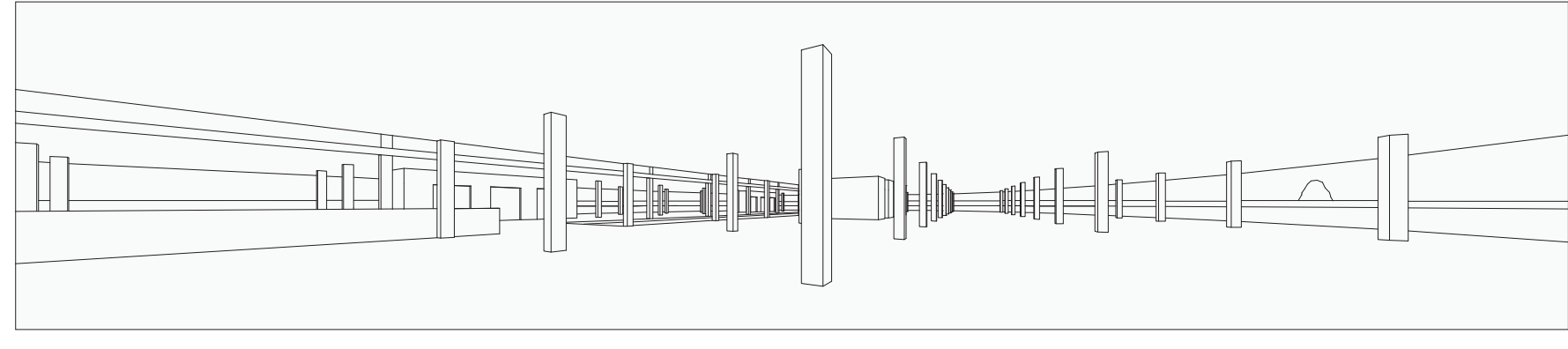

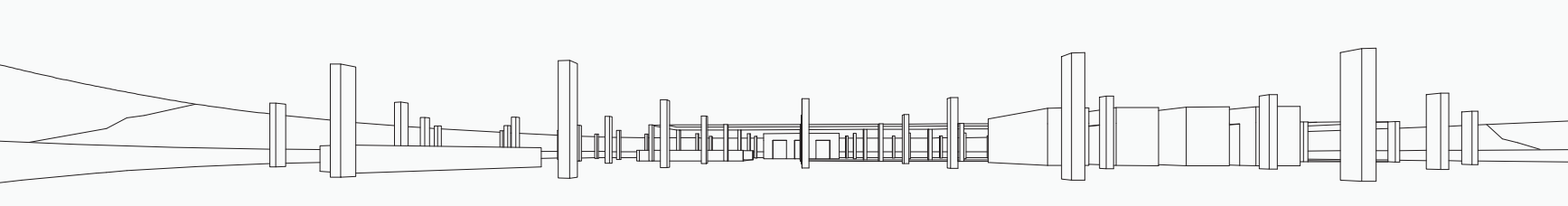

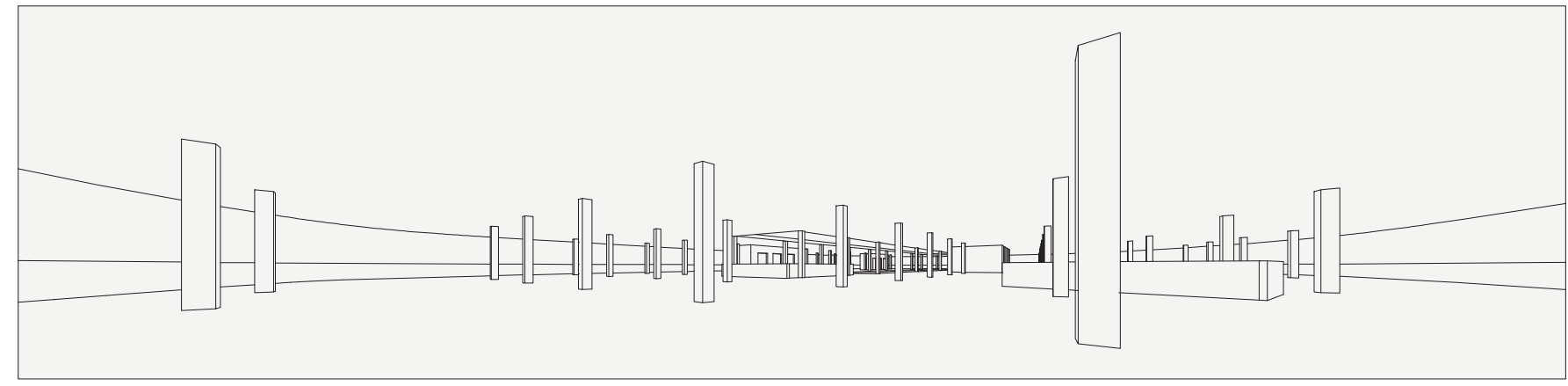

2.25

2.25 Horizon deck, perspective

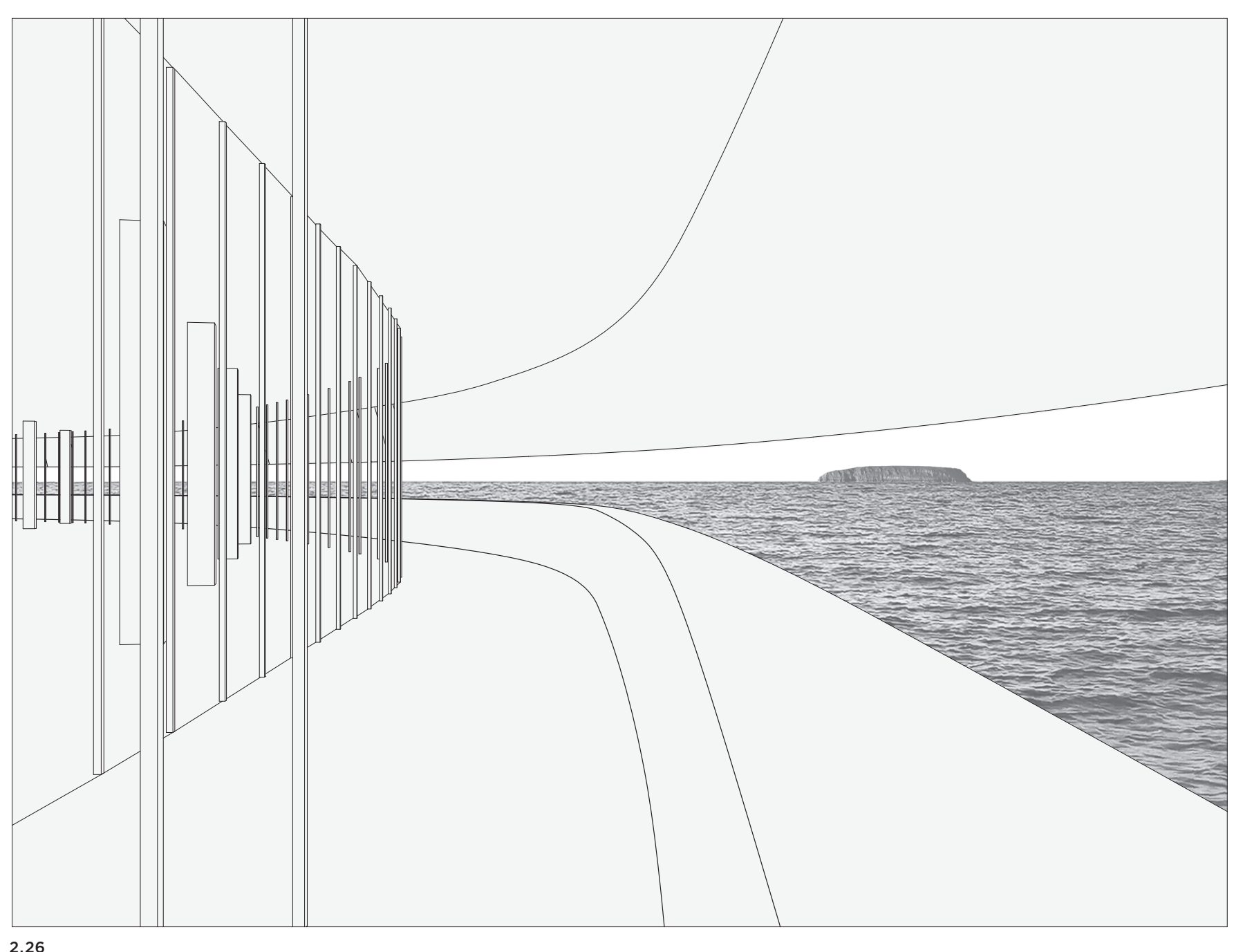

2.26

2.26 Horizon deck perimeter

promenade, views
and Steep Holm 

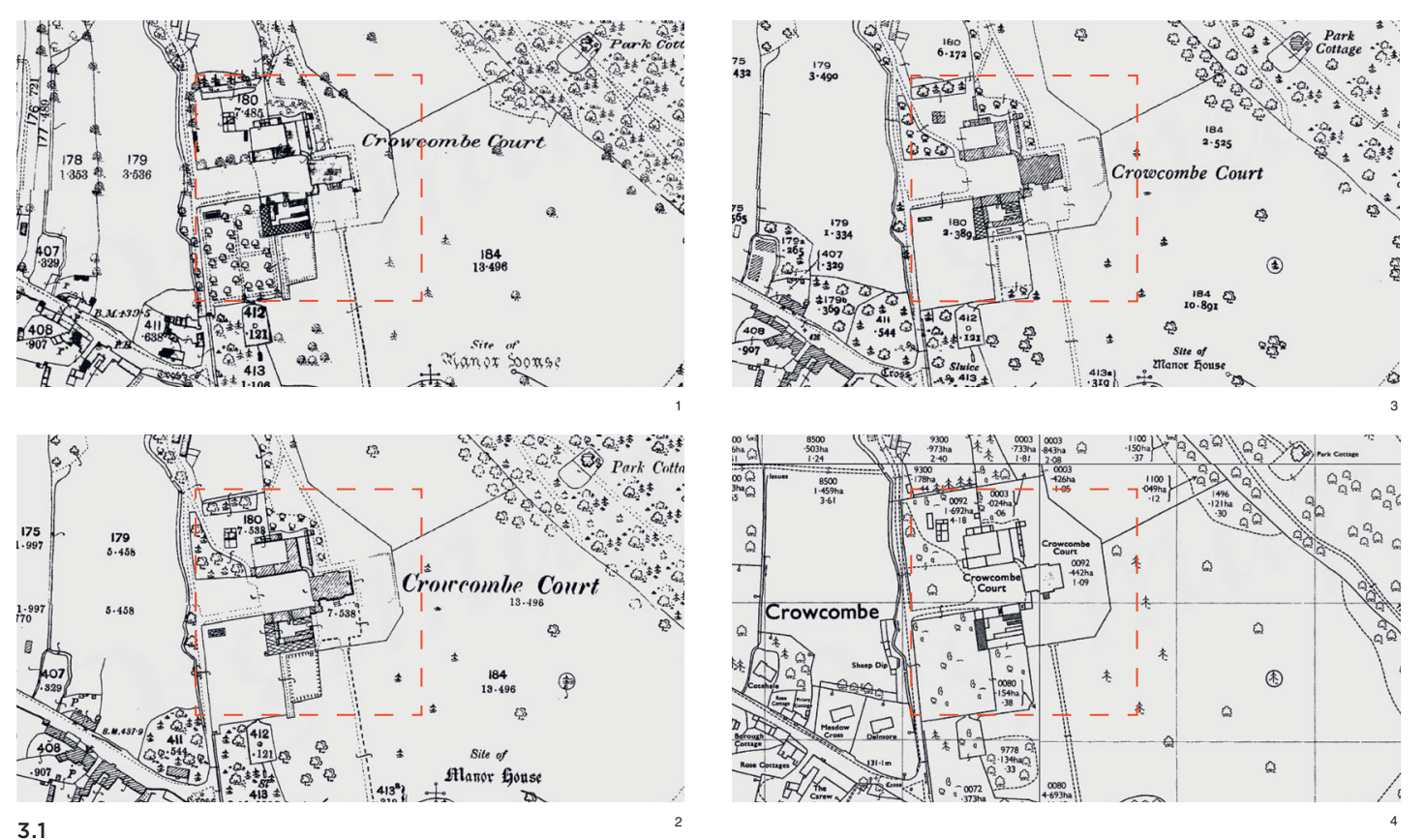

Seaside | Crowcombe Court

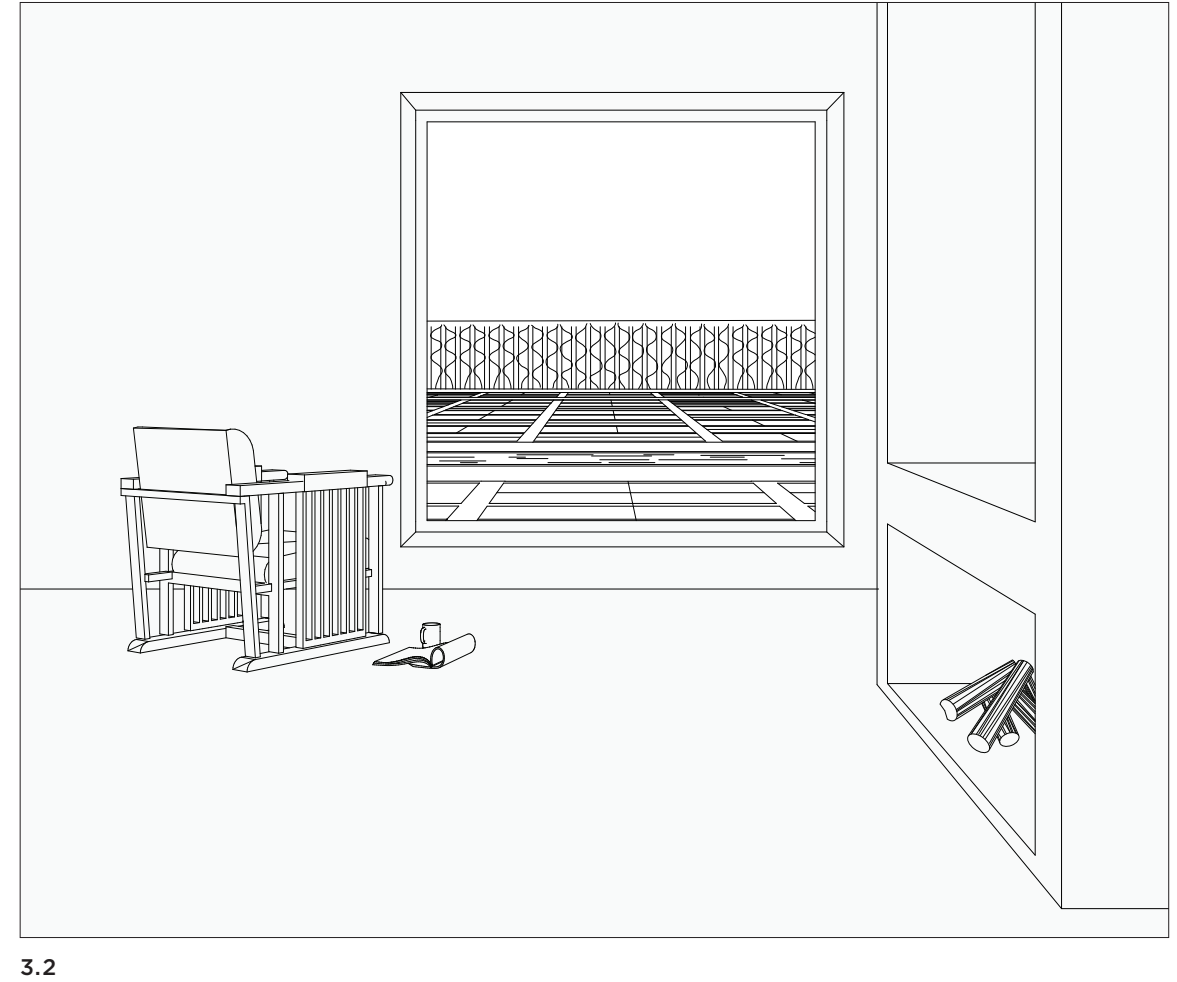

Crowcombe Court is an eighteenth- by Thomas Parker and completed by century English baroque mansion Nathaniel Ireson between 1724 and which stands in its park on the edge of 1739. It was described by Pevsner as Crowcombe Village just inland between 'The finest house of its date in Somerset the sea and the Quantock Hills. The south of the Bath area' (Pevsner, 1958).
house was designed for Thomas Carew The house was owned by the Carew 


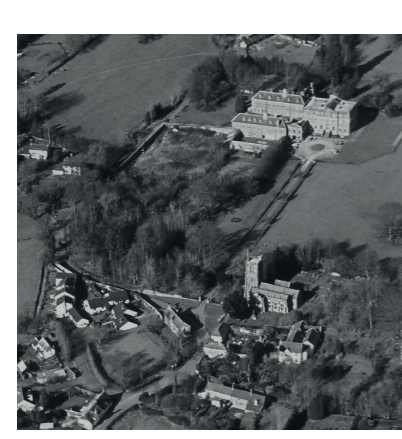

3.3

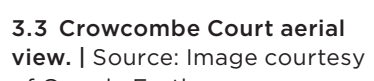

3.3 Crowcombe Court aerial
view. I Source: Image courtesy
of Google Earth.

family until the 1950s when the estate was dismantled and sold off in separate parcels. The Carews built themselves a subdivided into several separate dwellings, and the main house converted into an old people's home. Our clients, an architectural historian and a silversmith, rescued the house in the early 2000 s and lived there during its restoration for weddings. Our brief was to build a new house for the client in the ruined kitchen garden, as well as two more houses, one on the beech lawn and the ther arum House on the dog kent site. The clients intended that the walled garden could be used as allotments by the local community for use as part of the more public-spirited revitalisation of the house and grounds.

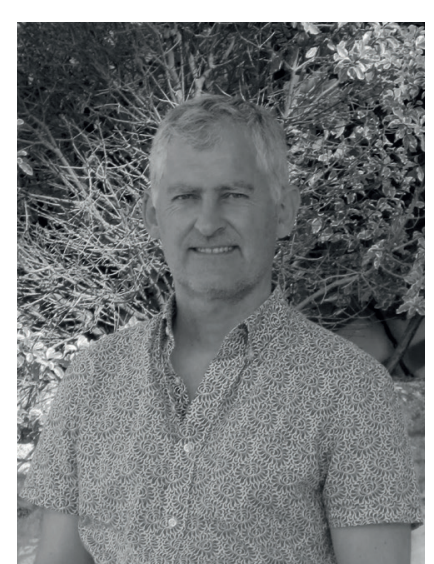

Kim Auston

(terview at Hampton Court, 25 August 2016-I was born in South London in 195 ust on the edge of London. Technically, was a village but one that Londoners call village and that isn't really anymore. went to school at Dulwich College, South London. Then, I went to university where read Geography at the same time and in the same cohort as Theresa May, ou current Prime Minister. When I left unito do. Strangely enough, at school, we had a careers master, whom none of us had a lot of time for, and I was asked to fill in questionnaire, as was everybody landscape gardener, but as somebody who was a relatively high achiever at school, the dea of being a landscape gardener was bit like somebody saying, 'You're going to be a dustman' as far as I was concerned. At the suggestion of a friend, I applied for and ended up getting a job in advertising Not the executive-suited side, I actually was on what was then - I don't know if it's changed now - called the creative side, and I worked as a copywriter. My skill was deemed to be words, and I worked with a chap who was an art director a graduate of an art college, but actually the roles changed constantly: sometimes my partner wrote the words, sometimes it was me who laid out how I thought things should the printed page or storyboard for acommercial or what Anyway I n comfor 10 years and was relatively succesful at it, won a few awards, got well paid, but I began to feel that it wasn't ... There is this cliched comment about advertising that, 'today's ad is tomorrow's fish and chip paper', and I wanted to do something with my life that had more permanence. And so I had accumulated sufficient money to be able to take myself out of paid employmen to university, this time at Manchester to read landscape architecture as a master's, which I did, and then did my Part IVs and qualified, and very quickly, I began to gravito towards historic landscapes.

was 34 or something like that. figured I had to do it pretty damn quickly or it was going to be too late. So, I just took the plunge. So yes, I trained in my 30 s, and I entered the

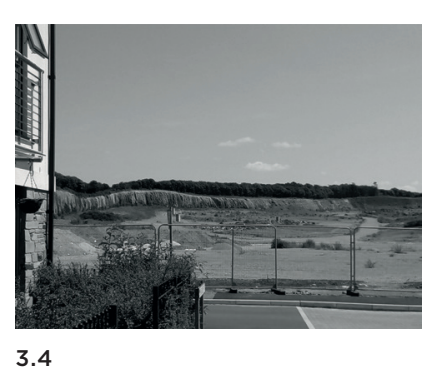

the mega-recession in 2008). Howeve I was lucky enough to get a position as a landscape architect, although not ye specialising in historic landscapes. But as soon as a job came up with recognised practice in that field, I applied at quite a low level and immediately felt that I'd found myself in some way, and I've worked in that field ever since, most recently with Historic England. I always wanted to 3.4 Pressure for development. work for either Historic England or the
The trees on the ridge are in a Devon). I Source: Image courtes Devon). I Source 10
of Kim Auston National Trust at some point in my career up working with Historic England for 17 up working with

I had always felt a connection with designed landscapes. As a child living the edge of London, we would quite of hop onto - I don't know if they eve exist now - a Greenline bus, and wed pitch up at places like Knole fevenoaks and spend the day the So, you'd have a country house in the background while you had a picnic in the deer park. Being the 1960s of course, it was cheese-and-pickle sandwiches not goat's cheese and Mediterranean vegetables. So, I think that connected with me. MY brother, by contrast, was, and still is, much more practical. He was into motorbikes and cars and that sort of thing. So, at the weekend, when we decided that we were going out somewhere, we had to alternate. If it was the weekend that my brother had the right to choose, we ended up at somewhere like Brands Hatch watching moto racing which bored me rigid. If it was my weekend to choose, then we'd pitch up at a big country house with a big park an garden. So, I think it was the whole thing rather than specifically the landscape that appealed. I mean, I appreciated the grounds, but I think would've just been disappointed going to that kind of destination (if I can call it that) if there hadn't been a ruined castle or a mansion forming the backdrop. Also it was more than just a backdrop because one would want to go nto the mansion and experience it.

I don't know whether these things are genetic, but many years later when I was specialising in historic designed landthe Royal Horticultural Society and found a book called the Dictionary of Bitish and Irish Botanists and Horticuturalists by Ray Desmond and Christine Eluod (1977). Because my surname is spelt in a slightly unusual way, I thought "I wonder if there are any way the any bout three or four generation arders arder from 列 , In other words, my which had been working with plants, wich was a bit of a surprise.

My first degree at Oxford was in geography, so that certainly maintained some connection with landscape. Funnily nough, I specialised in historical geography - that was where my focus was. But it wasn't just a random decision to go into landscape architecture. When I was still in advertising and working in London, I remember thinking, 'I want to do something else. But what would that something else be?' I don't know how I became aware of landscape architecture, but I certainly 
wasn't aware of it as a discipline at school; Kent. Basically, we were in a recession, and rchitecture obviously, but I'd never heard I knew that I needed to get a CV togethe of landscape architecture. But somehow, as and as my home was in Northamptonshire, I became older, I had become aware of it, I had to live in a bedsit. But I thought, 'I can't and I contacted various practices in London just sort of wait for work to come to me. I've and spent a couple of days observing what got to get a CV together; I've got to get the people were doing - not doing anything project experience'. So, I worked on a range myself, just sitting next to someone at a of stuff at the Council for a few years, and drawing board (pre-CAD) and thinking, then a job came up in a private practice, 'Actually, I'd quite like to do this' and then specialising in historic landscapes.

reading up about it. I took a subscription to There was no construction work on Landscape Design magazine. Ialso started the Channel Tunnel site at the time tha going to seminars in Central Lo started the Channel Tunnel site at the time that the Architectural Association and the Eurostar since, and I been through on Bartlett I remember attending lectures place because there has been such inten( Bartlet. I recility' Brown and Humphry . Repton and on London parks. And it all person.I recognise that there is a need for began to make me think, 'Well, this looks the bigger picture, but lmuch prefer engagreally interesting'. ing with a particular place and a particula

After studying at Manchester, I worked group of people and making things happen freelance for the devolved landscape I know what I do has a wider context, bu section of the Milton Keynes Development I think I find the wider context actually a Corporation, and I believe the practice was bit daunting, and I know that other people called Landscape Town and Country. It was love it. I mean, I have done some master that classic local authority thing where they planning, but it's not something that I'm had a lot of money unspent and they were particularly drawn to.

being wound up; it must have coincided I have always worked in the South with the time of the Thatcher government. West for Historic England, and also have I was required to visit sites for which a an office in Birmingham. The Birmingham master plan had already been drawn up office covers the rural counties, including showing where the houses were going to be Warwickshire, Herefordshire, Shropshire built, and I had to design the advance plant- and Staffordshire. But there are some striking. Now, whether doing it that way round ing cities as well. But my heart, I guess, meant that when the bulldozers came in is in the South-West where I've lived and to prepare the site, all that planting disap- worked for more than 25 years.

peared, I don't know because I'm afraid to I would say overwhelmingly that say I've never been back to look. But yes, I my work is in rural areas. And that's a started with that firm to look. But $y$, I my work is in rual and that's working for Ashford Borough Council in although I would say the South-West is

although I would say the South-West is significantly more rural than the West me. But overwhelmingly, my work is rural Midlands, it's because there has been a lot in focus.

of money coming into historic parks, not

urban parks but parklands, from Natural We met when I was invited to be the England through stewardship, a lot of it architect for the Westonbirt Equestrian basically European money. And that has Centre. I soon understood that the story kept me very busy because what we've of Westonbirt is extraordinary: the been trying to do is to direct that money to stretch of time from the whole initiation try and get the greatest benefit to designed of the landscape and the estate there. landscapes. And the other funding stream I suppose it's slightly dislocated now which is overwhelmingly urban in focus is and fragmented into several parts. Is the Heritage Lottery Fund (HLF). When I that something that is very much the first joined Historic England (when it was norm-that many of these larguch the still English Herita), the architects, the for various rearso still English Heritace, and surveyors at mentans to suffer fraglandscape archiccts and English Heritagewer monitorsor mentors for schemes.so, HLF

would perhaps grant an open space, let's

ghly Well, it is a huge problem, and before I on certain signifiers of deprivation. They would then ask us to monitor that project. In other words, it wasn't that we had a direct project-management role, but we were a sounding board, if you like. Particularly for design details and initially, we also had some role in cost control, though as the HLF got more sophisticated, it brought in people usually with a quantity-surveying background to handle that side of things. After a period of time, the HLF decided not to use Historic England as mentors/ monitors. So, that work stopped, and that took me away from a lot of my more urban work. These days, the way that I connect to urban work is mainly through the planning system; it's when somebody wants to build a visitor centre in a city park or improve the sports facilities. That's the sort of thing that typically might engage talk about that specific example, you can magine the deep concern the heritage in the system of Inheritance Taxation Exemption, which is where you have, let's say, an established historic estate, and they have an important collection of furniture designed for that house, along with paintings and chattels. Also associated with the house you might have formal gardens of some sort and a landscape park. And sometimes the whole thing has been created over a very short period. In short, It's a coherent historic and cultural entity. terminology of an 'event', which is, in other words, a death, the Estate can be liable for a very large sum of money in death duties or Inheritance Tax To avoid or at least defray that tax, which can usually only be met by Now, under Inheritance Tax and using the 


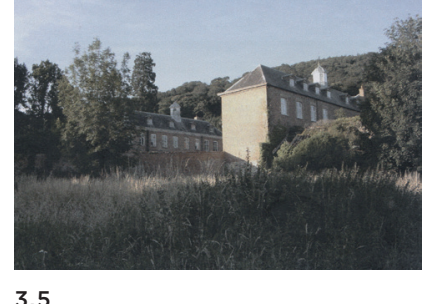

selling off parts of that historic entity ('fragthe Inheritance Tax that it is supposed to pay the government provided it keeps the it to an adequate standard. Inheritance Tax Exemption demonstrates how we fear fragmentation of the very best and the most important historic entities. In short, it's a way of trying to stop that fragmentatio from happening. You see the same thing with our Heritage at Risk Register for parks and gardens, where fragister for parks and gardens, where fragmentation is one of the main indicators of high risk because it makes it almost impossible to achieve holistic management of a designed landscape.

people running businesses and so on and Pat who came from an advertisin background. She had given that up to study at Oxford under Howard Colvin. Her field was early eighteenth-century architecture, which is mainly why the ended up buying Crowcombe Court. They weren't the landed gentry but made a living by renting out the house and grounds for wedding parties and othe events. But they were reaching retirement age, and having spent 20 years their life restoring the propears of

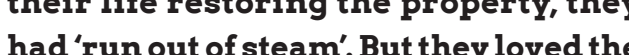
setting they loved the site setting, the loved the site. There was a beautiful walled garden which was overgrown and ruined. The invitation There is a mind-set now that the country- sites on the land they owned, including a side can't be developed. Yet, the number house for Pat and Richard in the walled of people living in the countryside and garden. It would be interesting to talk earning their livelihoods there has con- about the sentiment and attachment to siderably reduced - a process that has where you live and, although circumbeen going on for at least two hundred stances change (maybe to do with age years. Thus, the interesting thing at or budget or whatever), the ambition to Westonbirt, at Rough Grounds, was the still stay there or somewhere near... invitation by you to make the equestrian Could you talk about that in the contex centre bigger and more contemporary of the work you do?

in its design, which was a surprise

to me. The support and the ambition Yes, funnily enough the situation of to do that was really a good moment. one generation passing the estate onto Similarly at Crowcombe, the house another generation or the current genwas also part of a large estate. In the postwar period, it had been dismantled. The great eighteenth-century mansio had been converted into an old people's home, and the two wings had people's divided.I think there were at least nine different leases; people residing there,

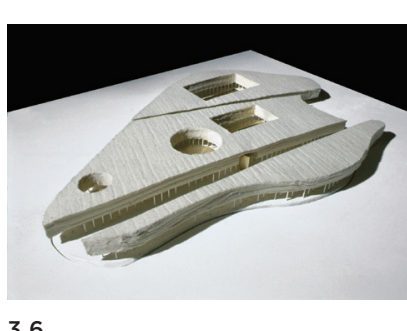

to relocate to, and substantially alter, term 'dower house' was used to describe the proposal. And this term, dower house, is one that gets used again and again, and you wonder if it's being used to dress up development in a historic landscape to make it more acceptable. But the funda-

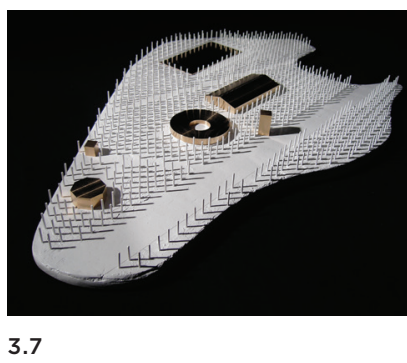
mental thing is (you alluded to this when you were talking about Westonbirt) that you were surprised that a new layer could be added. Contrary to public perception the number of times that I get a letter or an the-mail that says 'Historic England or ants to find a particular period, let's say 1780 to 1 nd a particular period, let's say 1780 and everything has to conform to tha is absolutely rubbish. Our role is about 3.6 Westonbirt Equestrian Centre, we're looking at, always with new develRough Grounds site model with
tree canopy opment, is how it works with everything else that's there already and how it affects the significance of the place. There isn't I think, from our perspective an 'in principle' objection to new dwellings in these
country estates. You're more likely to run country estates. You're more likely to run into issues with the local authority with it being viewed, contrary to policy, as 'unsustainable development in the countryside' Returning to Crowcombe, I was particularly drawn to some of your proposals by their very contemporary nature. As it happens, I think there can be a place for pastiche, but it's a very limited place, principle is appropriate and, after that, if a contemporary expression of that principle is acceptable; using today's materials and technologies but with a clear reference to what has gone before. And that could be in a choice of materials; it could be in the rhythm of the building, picking up on the rhy thm of the bays on the historic building nearby or certain forms - a pedimented form or a cube form, whatever: something that actually shows a reference to what's gone before. I think that's what we're looking at ... although only a few of my colleagues are trained architects. Funnily enough, the architects tend to be conservation-accredited architects who don't generally assess new build. But I think they have a good eye, which may have just come about through architectural training oner with the experience of recognising when a new proposal is quite exciting and innovative and do think that you recognise that practices y and large, when you see the the blocks in the bottom of the draing there times when you think 'Olay what feeling slightly trepidatious, and times when you see who the drawing is by, you actually open it up with some degree oflet's not say excitement but anticipation. And I know we have to treat everything that comes across our desk within the framework provided by policy and guidance. Professional judgement should be there, but it has to be within a context. I think no matter what part of the historic environment we work in, most of my colleagues are pretty interested in contemporary archiecture, and you find some of the greatest apologists for Brutalism - which happens to be a pet hate of mine - among some of my colleagues. They're far more engaged with it than I would say the general public is and certainly than the Prince of Wales! Did I answer your question? 
There seems to be a disaffection for houses close to an existing village but on building in the countryside. I mentioned a greenfield site? Because land-use polic arlier the migration from the country to is determined by the local authority. W the city that took place during the period are, in so much of what we do, adviser of the Industrial Revolution, and now and wouldn't directly get involved except there is a feeling that the countryside is as a consultee (and I'm not sure I'm actusomewhere that shouldn't change. We ally answering your question) in relation have an agricultural policy that ties us to the significance of any historic assets to the European Union about issues of affected by the proposal. I can think of a set-aside land being deliberately kept case in Cornwall. There is a National Trus unproductive. Yet, it is unavailable for property on the edge of Penzance called people to dwell in and there just for our Trengwainton, and within it is a designed visual plosure; rou through it, but is a ceris the this is a certs bintour 'm Imint land use, the availability ofland and the Penzance and wew sore completely conway that land is controlled come o housing this because we've come through the estate in the corner of the view. We wer period where we had an agenda about consulted about a proposal which would've localism which somenow potentially put housing right across tha to devolve central planning responsi- view, and in that particular case, we were bility to the community, and that hasn't doing precisely the job that I think you'd worked particularly well becausethere's potentially find frustrating, which is never been a way of making that work. Saying, 'Hang on, in terms of the designed landscape, this view is one of the key sigas a bit of a political sound bite, wasn't it?

nificances of this place'. It was a conscious decision by a previous owner to build viewing terrace, and what is wonderful

One had to take it seriously for a few about it is that although you're so close years. But it's interesting that you to Penzance, you have a pastoral scene in mention that. I'm just wondering about the foreground, and beyond it, you have the relationship then between the com- the sea, and apart from a very slight intrumunity, the planning authority and sion of housing in one corner, that visual Historic England - just how you think idyll has been retained. So, we said, 'From your role would be in that context? our perspective we don't have a problem our role would be in that context? our perspective we don't have a problem Well, are you thinking in the context of say but what we don't want is for you to build a proposal to build a significant number of within this view corridor'. We felt that for

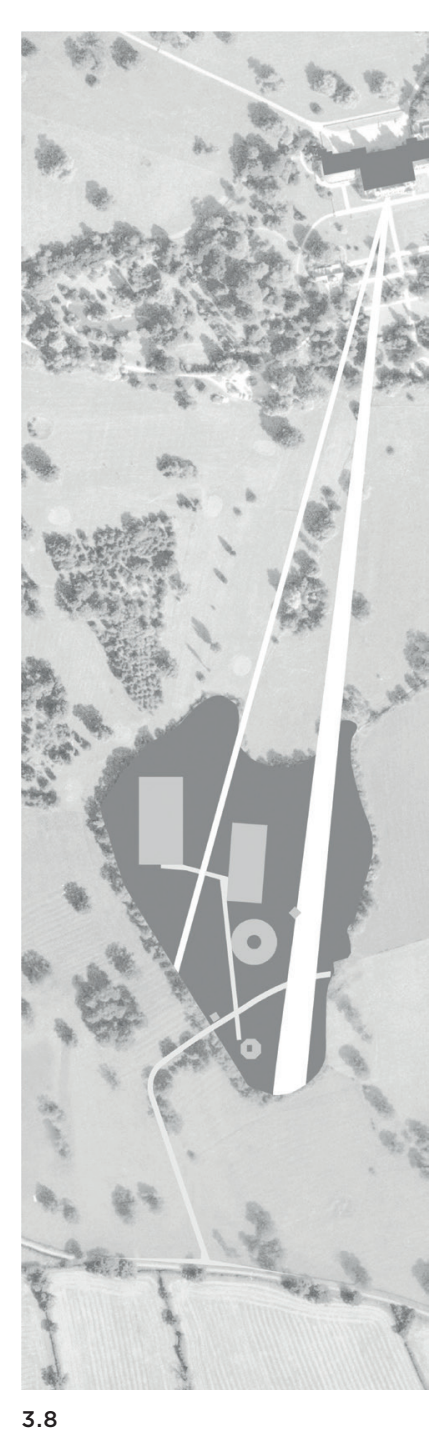

3.8

3.8 Westonbirt Equestrian
Centre, landscape plan the tens of thousands of people who go their money to enjoy the gardens and sit on the benches enjoying the view, this would detrimentally affect their experience and have a detrmental effect on one of the significance of the place - one of the things that makes Trengwainton special. What I find frustrating in a more general context of housing development is the great sameness you find in domestic architecture. There's a similarity of styles and typologies all the way from be dropped into a cluster of new housing and be asked to say where you housing and be askes a where you are, and you a token gesture of cladding, you know, a ablo local stone, but it's sort of window dressing.

There has been a history of that in this country from the Georgian period, suppose, and obviously there's good and bad Georgian -it's not all good, but effectively it's certainly at a higher leve than interwar 1920s to 1930 s suburbia where semi-detached houses became the ubiquitous model and were built throughout the British Isles. As you said you can drive to Newcastle or Liverpool and not know...

I've actually said that to colleagues, and the colleagues surprisingly didn't come back at me using a stylistic argument which, like you, I was proposing which was 'Why is there no local distinctiveness within all those semi-detached?' What they said was 'But you have to remember the context, it was just after the Firs
World War and this model produced a new level of comfort and, in a way, a luxury for the average person and it was seen as aspirational. Everybody wanted a semidetached house because it was so much better than the grim terraces that they'd lived in before'. But you're right; the ubiquity of the 1930s semi diminishes localism more than the contemporary response of having cladding in the local stone which is at least a nod to localism.

Iagree with you. The models put forward sense a moin with the point thatitissomething to or issues of sustainability or national policy. It occurs to me that in terms of the soft landscape someone like 'Capability' Brown [the in ' Kim Auston was visiting an exhibition about 'Capability' Brown's right-hand man, John Spyers] was quite traumatic with his rearranging the landscape for a particular kind of visual effect. He was obviously aware that he was having to plant not for his own generation but for subsequent generations to appreciate the landscape in its maturity. And then there was an issue of management and

Yes, and subsequent generations sometimes failing to understand what he was aiming to achieve, yes.

Does one range between a kind of elitism and trying to work in the cont of 
public realm for the common good? How does one make contributions from your position to a housing estate on the edge of town or in the country? Do you
involved in that kind of project?

Only in a very 'once removed' way. I mean to be honest, our role would be about protecting the views of the countryside from a designed landscape or enhancing them. 1 hate the reactive role that we have in many cases where you're faced effectively with a fait accompli. And you're saying 'Well actually, that's going to have quite a big impact, can you consider some degree of soft landscaping?' So, you'd be looking at some kind of ground modelling, migasome kind of ground modelling, mitigafeels the wrong way round somehow. You're faced with a proposal which you've not been involved in to any great degree, and then you're thinking, 'This has an impact, how do we mitigate it?' So, it's a reactive process rather than a proactive process often. But I mean, the sort of 'tools', if you like, that we would be looking at to mitiga any adverse impacts of development are the same things that I'm sure you're aware of yourself. So, if a proposed residentia development is going to be visible in an important historic view, rather than have the streets facing the view, you flip them around so you've actually just got gable ends so the mass becomes much mor porous. You would obviously consider the the designer to respond to existing features. I mean, we have approved landscape sces. I wes where the clumps in the maph park have been replicated in a housing development on the edge of the park. So rather than a solid ba $\mathrm{er}$ to try and scree the housing, we've actually said, 'Well no, we're accepting the development will happen, but could you continue this form of planting to punctuate the developmen and break down its mass'

May we discuss in a more general sense the role that you would have in the process of making a development and using Westonbirt Equestrian and Crowcombe Court as two examples where there is a fragmentation of the

When you talk about 'influence', I'm saying that for big housing developments, it's very limited, but for specific developments like yours in Westonbirt you canactualy provide a framework within which peoly pro a crative and innova which people fully express ther fully express their creativity. Because that's what you want; you don't want just anothe building. You want something that sings, even if it sings quietly.

At Rough Grounds, Westonbirt and to an extent at Crowcombe Court, ther was a sort of reticence. The equestrian centre at Rough Grounds was buried in woodland plantation.

But it was a lovely shape.

That was a gift to us as designers. But know before I had got involved the clien had several discussions with the lon authority about the siting of the local trian centre, and that was seen as the

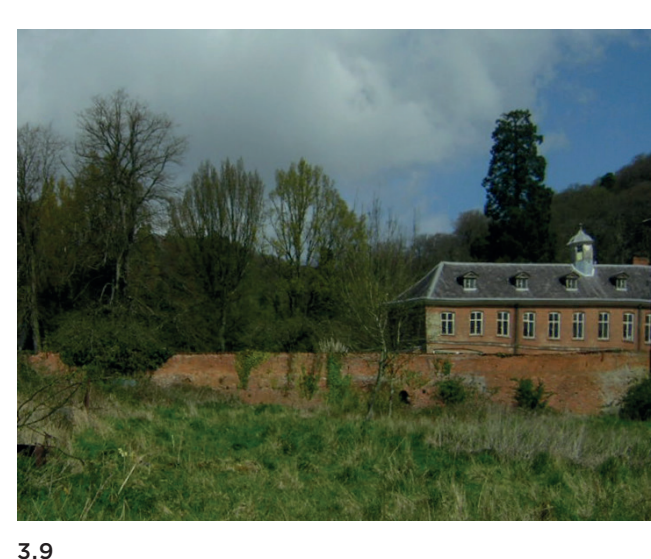

ested in Brutalism which is not your thing. What is your attitude towards personal taste when providing advice?

We do have guidance. Lots and lots and lots of guidance which is quite understandably supposed to give Historic England staff and their customers a consistent approach across the country because you don't want somebody in Yorkshire saying, 'Well, I was talking to this chap in my London club, and he got permission for his house, and I was trying to do exactly the same and was told "no"' So, I mean every case is judged on its merits, but judgem case is judged on ind hopefully its a professionaljudgent,

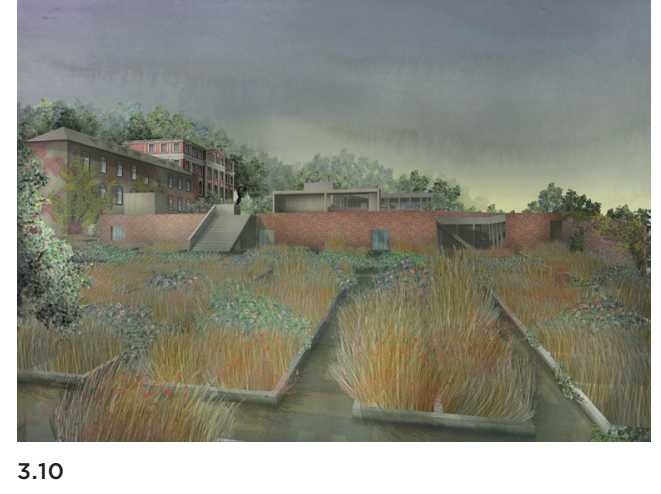

But it's also a question of taste. You can't avoid personal taste.

No, you can't, but you do have to ... I mean, I have worked with colleagues who are complete and absolute Regency buffs and don't like High Victorian. But you have to set aside your own personal taste. You do find

3.9 Existing view of Crowcombe
Court from walled garden 3.10 New walled garden house
with Crowcombe Court in background. I Source:
Drawing by Bodo Neuss. most likely way of getting planning permission. Similarly, at Crowcombe Court we placed the building in a linear form adjacent to and just subordinate to the high wall of the walled garden so that it somehow nestled. It wasn't intended to emulate the old house in any kind of detail. We used a similar red brick.

But it was a very crisp, clean design

Would you say that even at Historic England, it depends on who 'comes to the table'? You've said that some of your yourself dealing with styles of design that you aren't actually all that fond of yourself, but you recognise, nevertheless, that it's important and it has stylistic attributes that make it different from that other thing over there. I do think that if - and this is stating the obvious - somebody has charm, the architect, the planner, the consultant or whoever is charming, then it's a lot easier to work with them, but in the end, you do have to come down to what's on a drawing or a CD or whatever Unfortunately, there are people who are not particularly easy to deal with who are actually good at what hey do. 
Are there dialogues at Historic England I suppose. But of course, our legislation is
that are international? that are international? different, the planning system is different. This was really brought home to me
recently when I was lecturing to a group

There are the cross-border interna- recently when I was lecturing to a group tional and global European networks like of international students about designed ICOMOS. But I would say that at my level, landscapes and listed buildings, and I go we mostly deal face to face with architects to the end, and a Chinese student held up are study tours and that sort of thing, but building?' And you just think, 'Okay, they wouldn't say that we generally bring an can't have got anything out of my talk' international perspective to our work because the idea of protected landscapes, There's a sort of background awareness, protected buildings, is a bit alien actually.

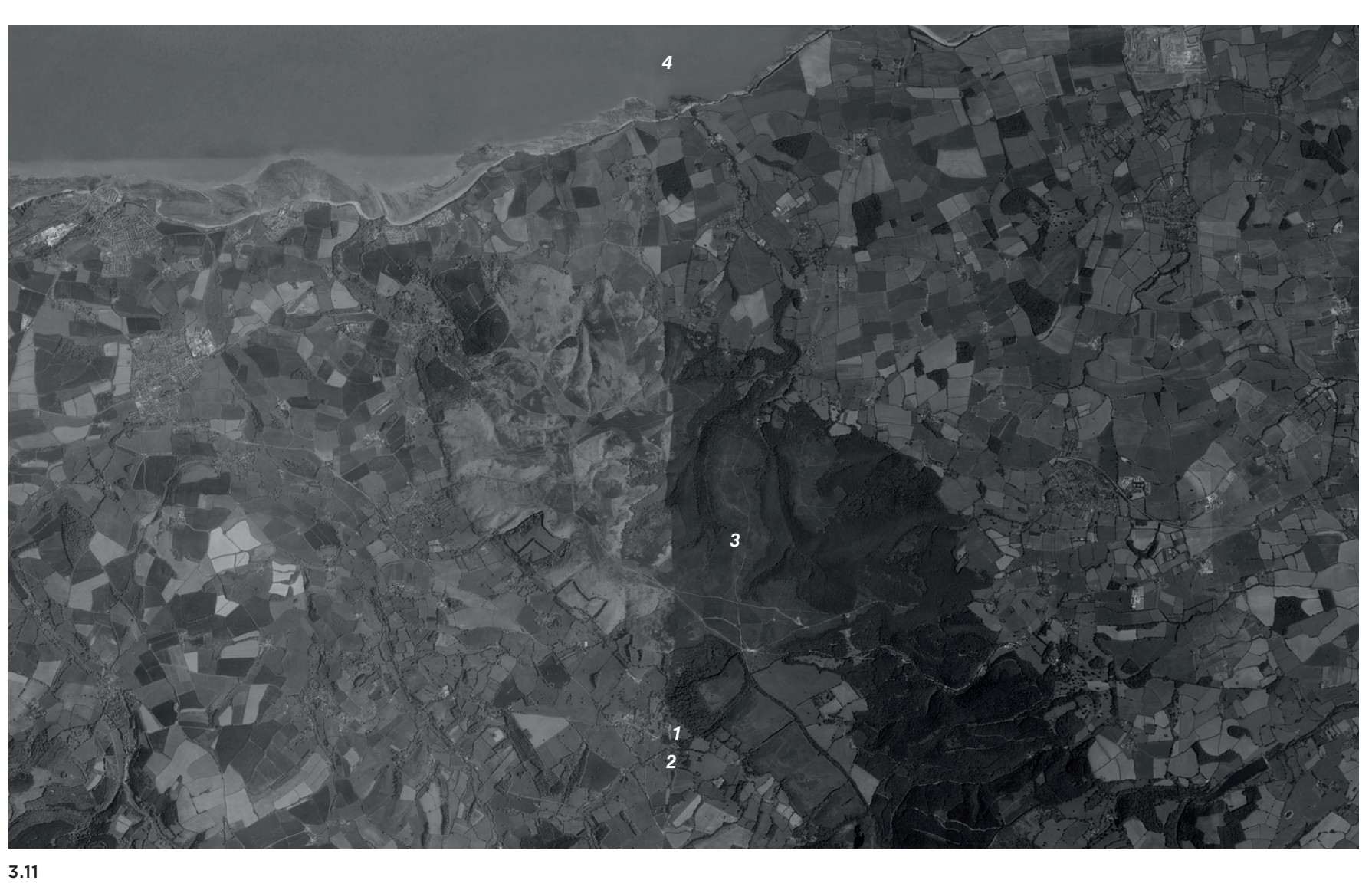

environs. I Source: Image
courtesy of Google Earth

1:80,000

1. Site
2. Crowcombe village

3. Quantomb Hills
4. Bristol Channel

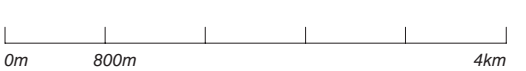




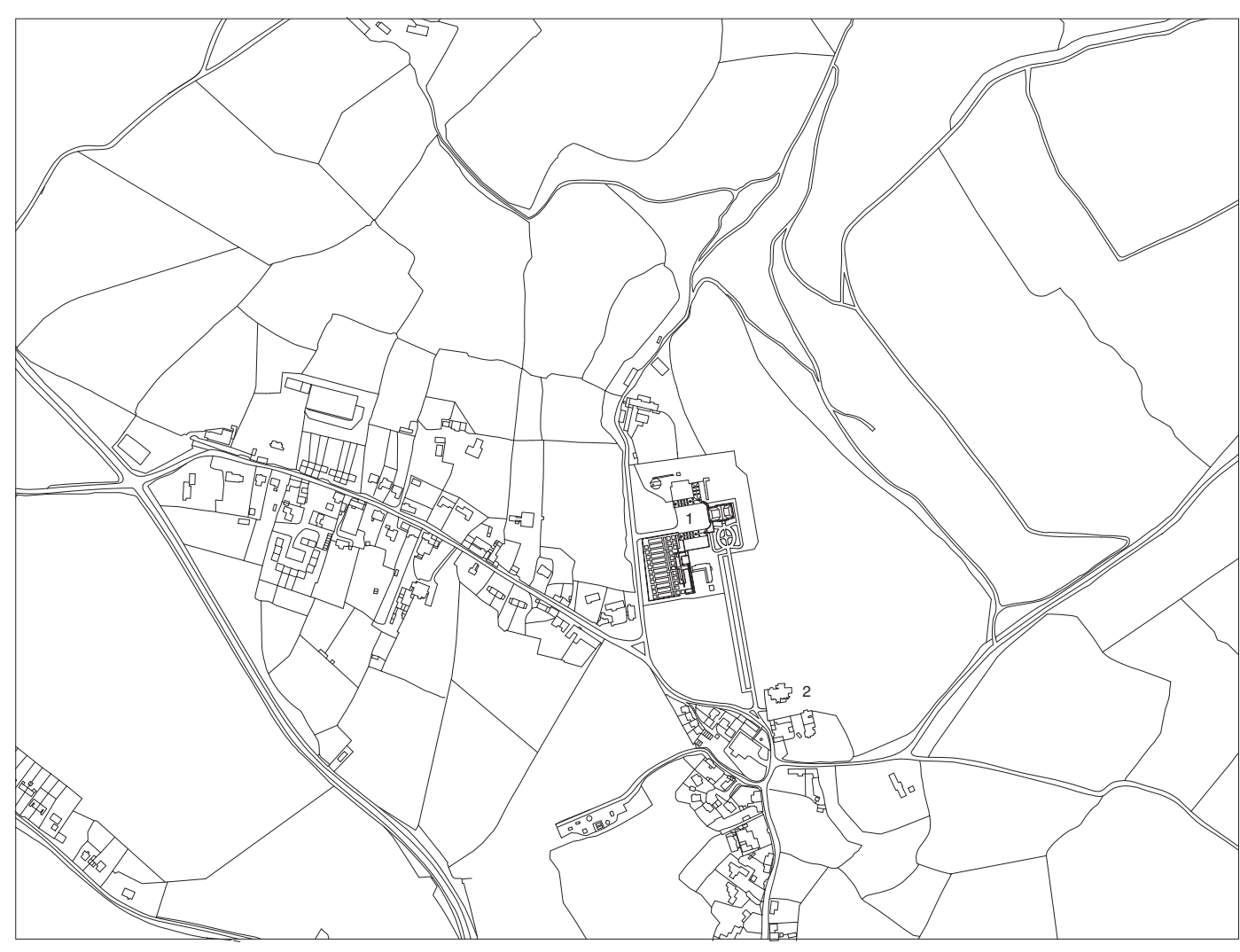

3.12 Location plan

1:10,000

1. Site
2. Church of the Holy Ghost

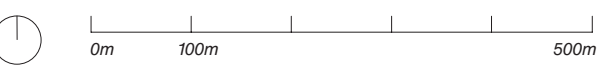

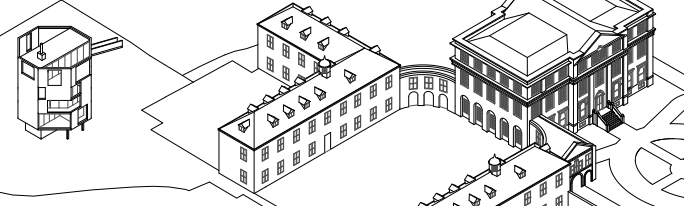
的需思 ती

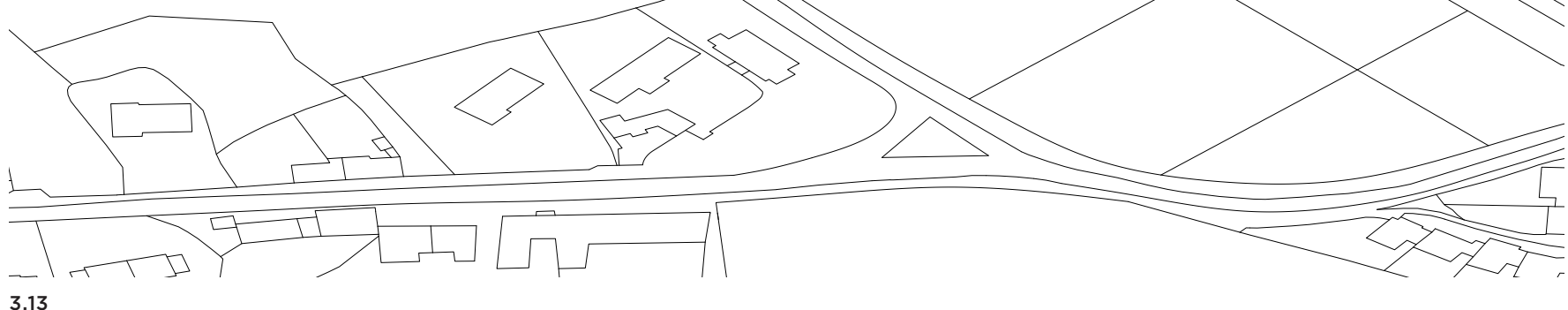

3.131 somem
1:1000

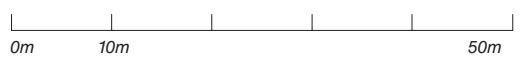




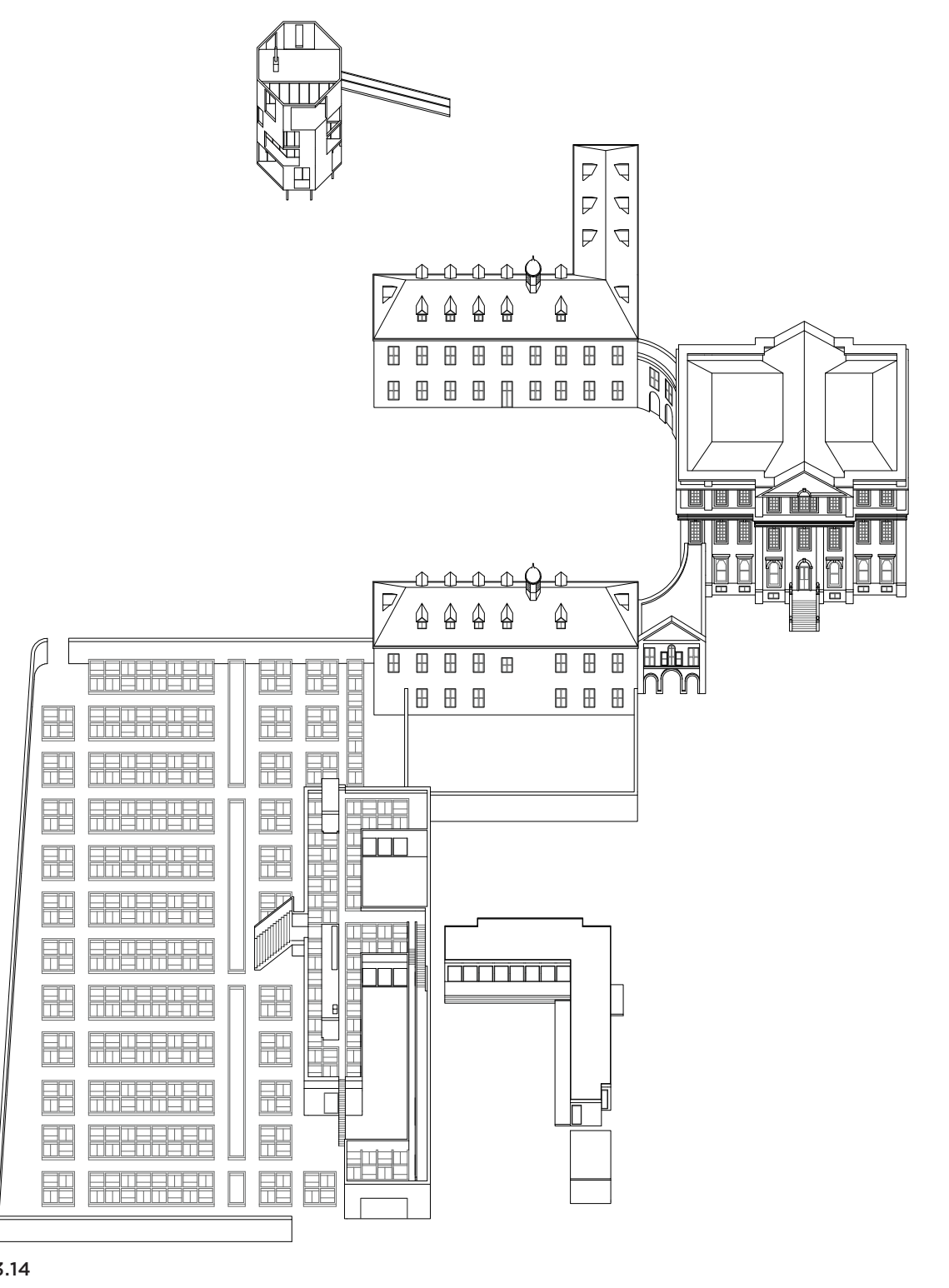

3.14 Planometric

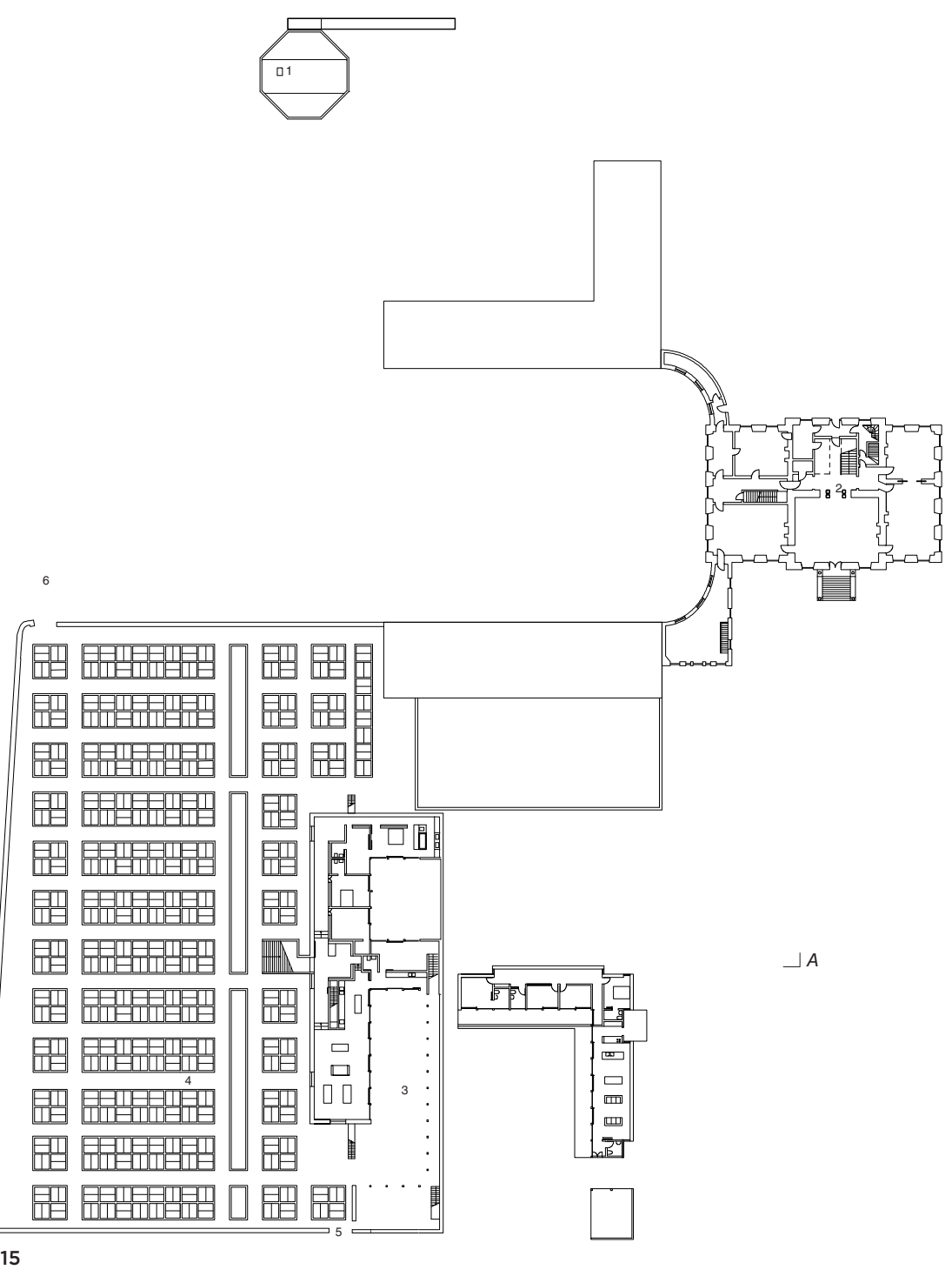



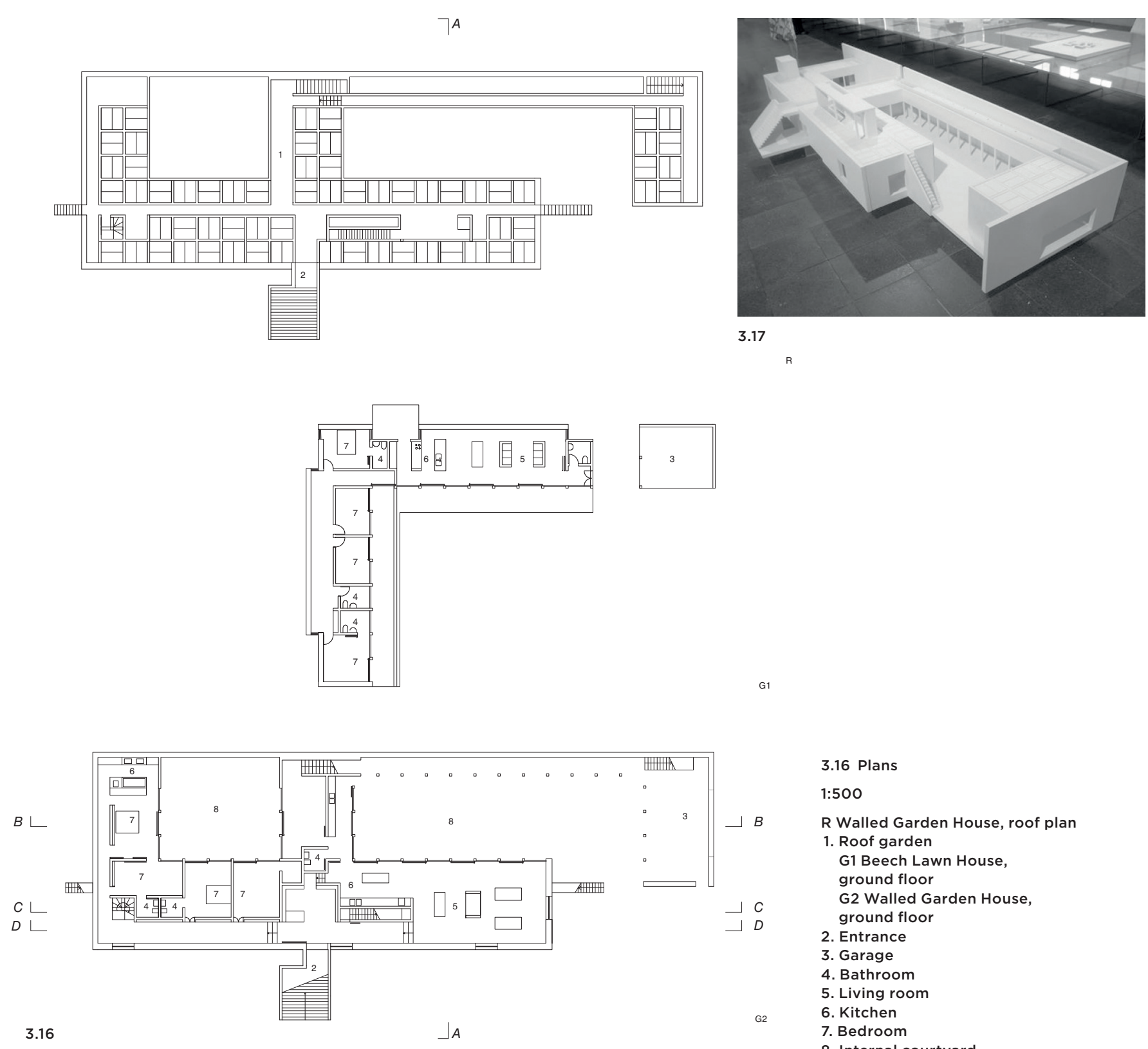

\subsection{Plans}

$R$ Walled Garden House, roof plan

1. Roof garden
G1 Beech Lawn House,

ground floor
G2 Walled Garden House,

ground floor
2. Entrance

2. Entrance
3. Garage

4. Bathroom
5. Living room

5. Living roo
6. Kitchen

7. Bedroom
8. Internal courtyard

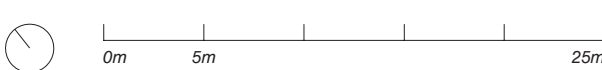

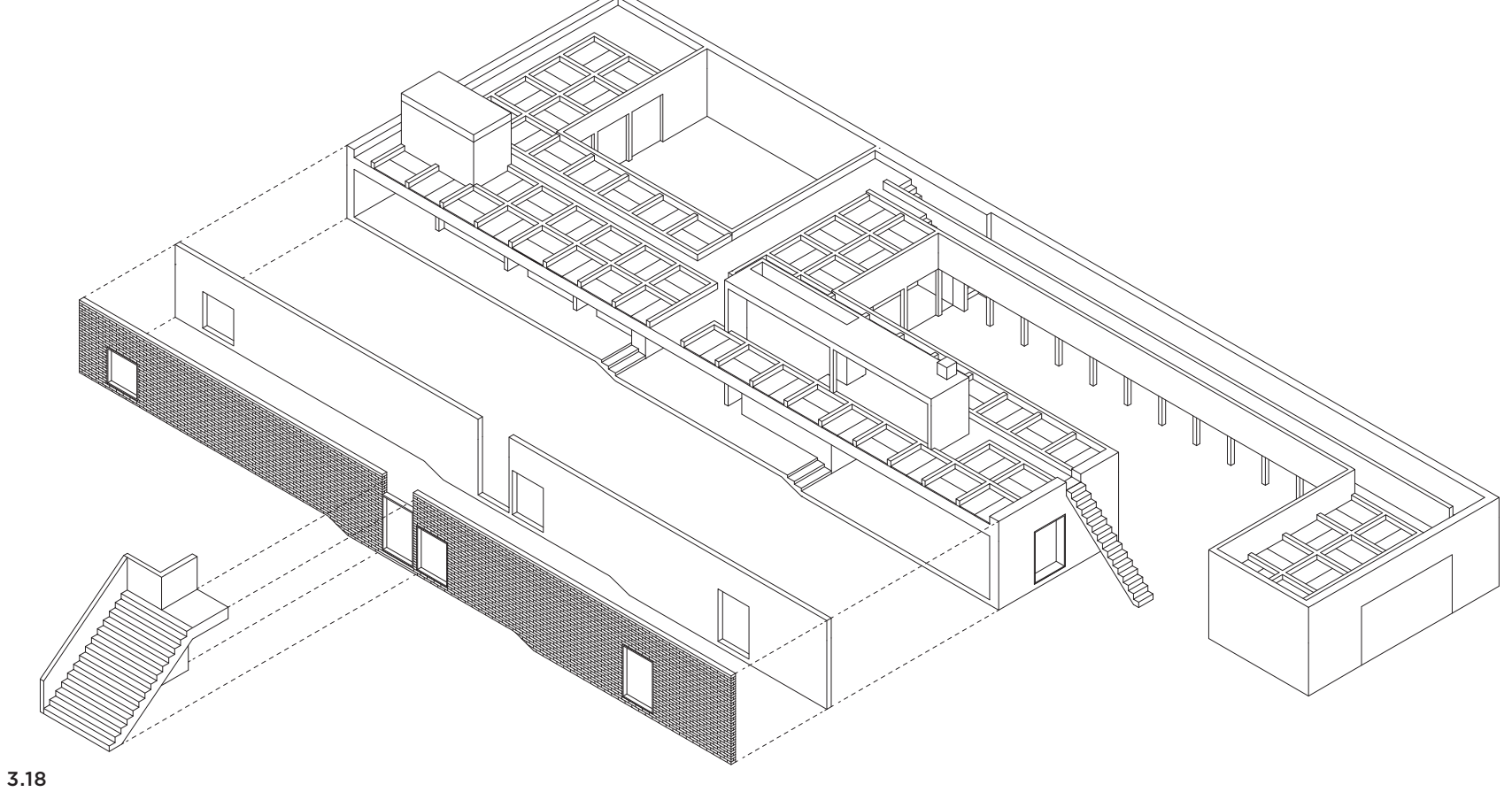

3.17 Land Architecture People
model, painted MDF (opposite)

3.18 Exploded isometric, showing
brick frontispiece applied to

concrete construction

1:500

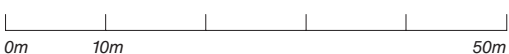



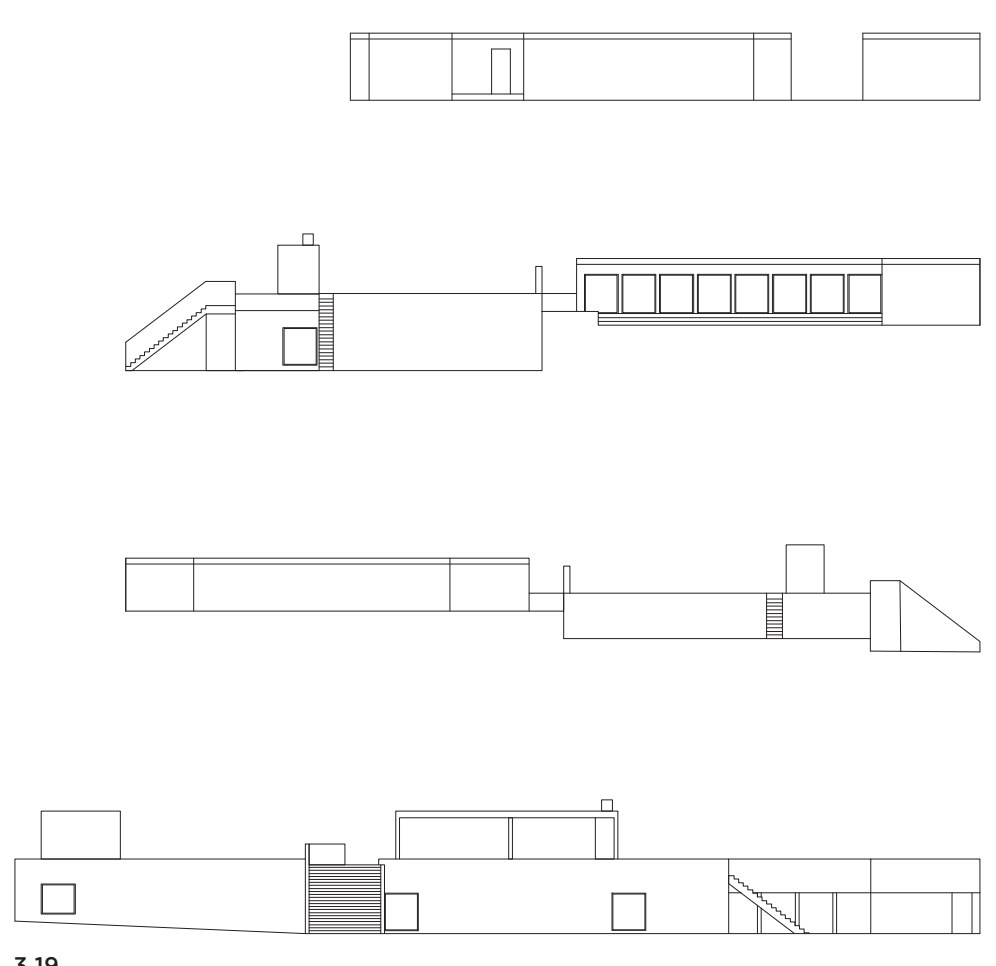

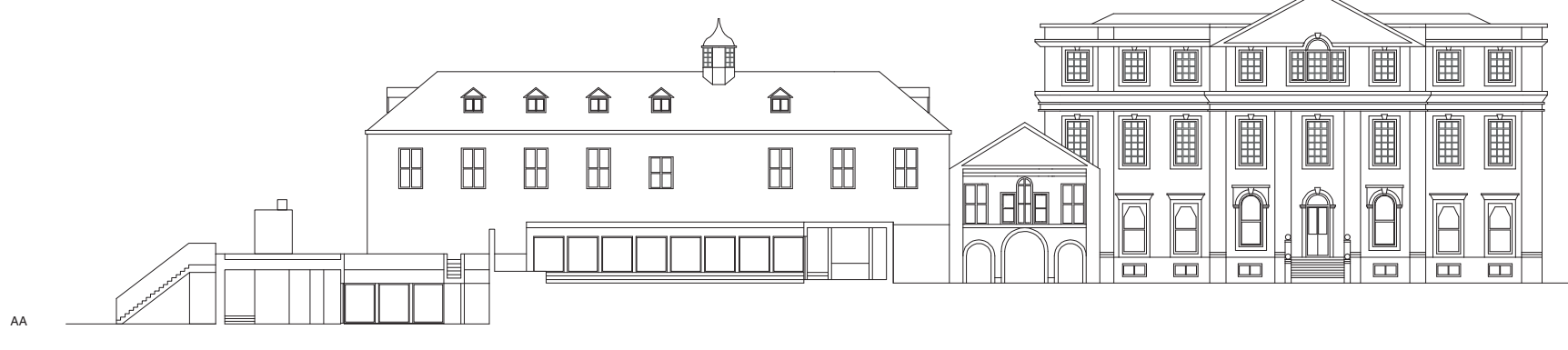

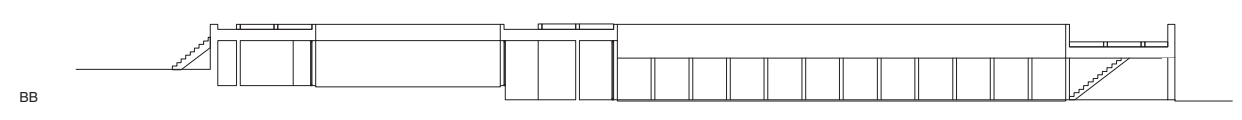

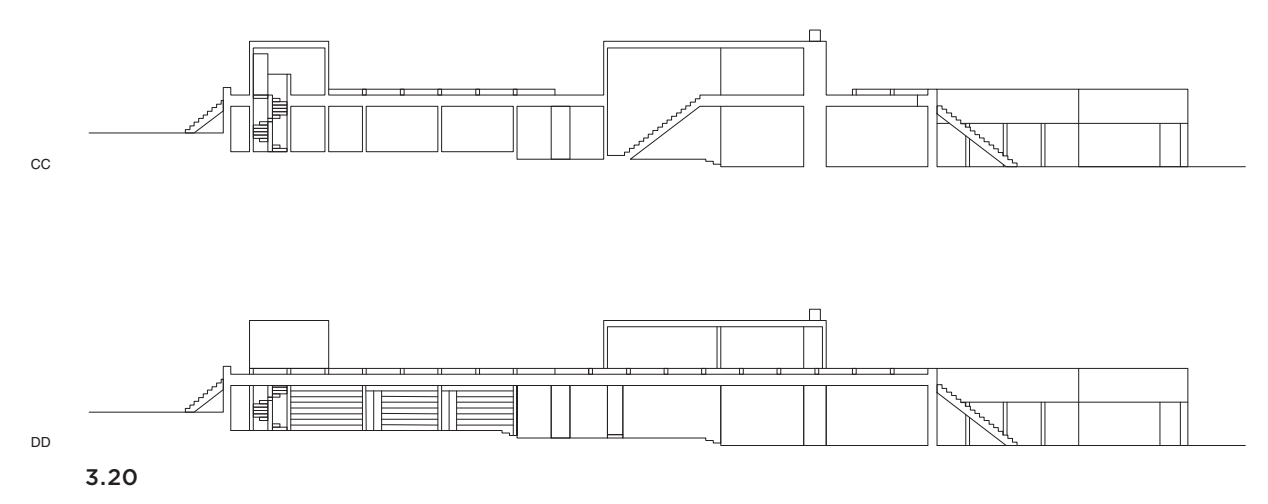

3.20 Sections

1:500

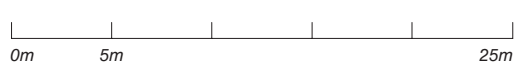



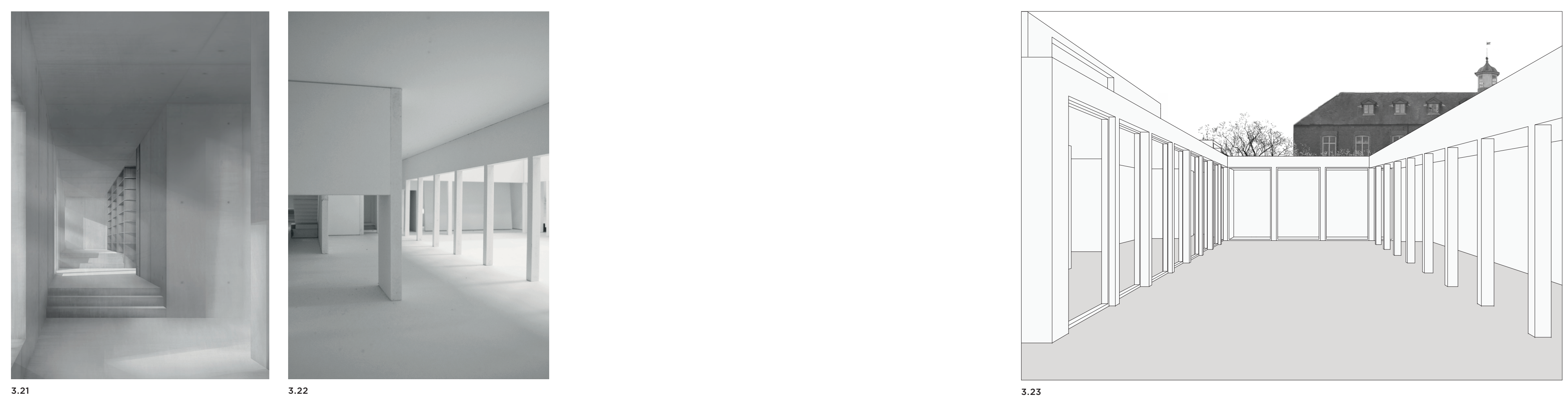

3.23 View of lower courtyard 

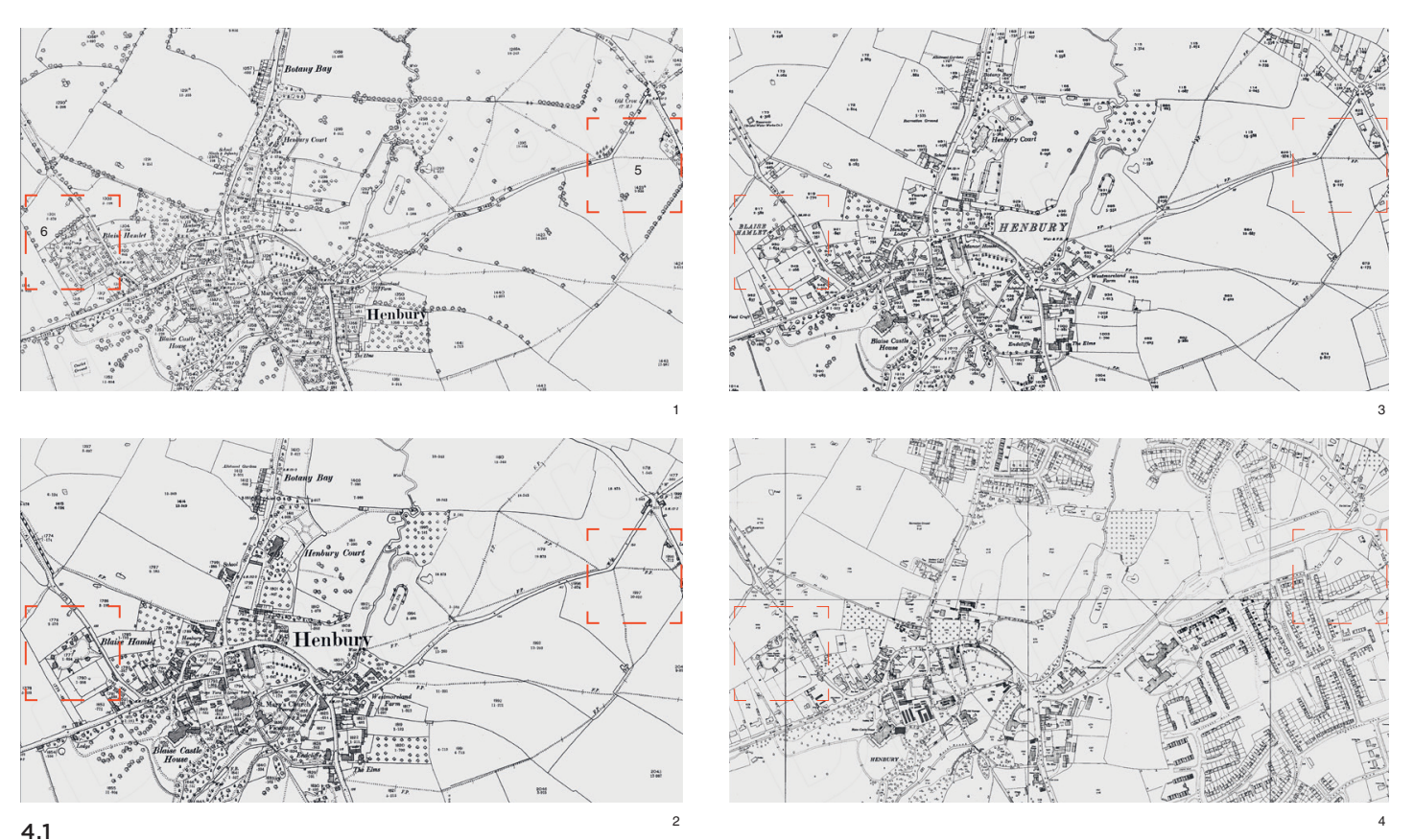

4.1 Historical maps showing site
development. I Source: Images

1:20,000

2. 1900
3. 1930
4. 1950

5. Bengough's House site
6. Blaise Hamlet
Bengough's House is located at the to best practice providing fully wheelcorner of Crow Lane and Passage chair-accessible environments. The Road/Brentry Hill in Henbury, North- development of such a scheme at the West Bristol, on a suburban site with Bengough's House site would also have an approximate area of 0.41 hectares. had the advantage of complementing The existing building was designed as a the adjacent John Foster's Almshouse 40-bedroom dual-registered care home development, which was completed in and was completed in 1996. The care The trustees of Bristol Charities and its option proposed a 15 -store e Chief Execulive, David Jones, consid- indivinalfatswould begrouped around a in the the in the context of the changing nature of as a microcosm of the traditional almsservices and accommodation for older house courtyard. One unit from the basic people. The result was a brief to provide plan form would be omitted at each level to almshouses in accordance with the origi- provide communal balconies, admit light to nal intent of Alderman Henry Bengough the circulation/social space and create an (whose charity can be traced back two abstract pattern of voids in the tower. There hundred years to when he donated would be a complex of colonnaded covered monies to the Corporation of Bristol for walkways and a building housing the comthe erection of an almshouse for poor munal accommodation in the south corner. aged people), albeit almshouses fit for The cloister option proposed that almsthe aspirations of older people in the house flats would be wrapped around a twenty-first century. Bristol Charities central space to form a courtyard on level was committed to providing 'very shel- 3 , with a void on the levels above, affordtered' or 'extra-care' housing as a means ing views overlooking the courtyard. The of providing homes for life and offering orientation of the units would present a the choice of different levels of care wide frontage to both the internal public and support as and when required. The circulation spaces and the external comcharity wished to provide a development where all occupiers had their own front circulation spaces and the external communal courtyard space.

This approach optimised the day- 
a private, enclosed communal space. A older people to live in, but so that they could with a planted green facade encasing the possible - through the design of the flats scheme. This development would provide and through support being provided as far a positive frontage to the two main roads as possible within their own homes. I did a and at the same time satisfactorily enclose concept design for about 60 flats with some a landscaped courtyard as a contemporary private development to help subsidise the interpretation of the traditional almshouse cost of the almshouse development. It was cloister.

This building would be six storeys high, with the communal space housed on the lower two levels, fronting Crow Lane and che localshophas interion create a gradual change in hierarchy from public to private space as one moved from the front to the back of the site.

Jonathan Vining

列 Durham Yard, London, 22 June 2018first met David Jones towards the end of 2006, I think. He was the chief executive Bristol Charities, and we seemed to get o well. A chartered surveyor-friend of min who was acting for David at the time, had recommended me as an architect, and he was aware that we were already working in Bristol on two other projects, so we knew some of the planning officers. He was interested in a site in Monmouth - Willia ones's Almshouses - which I think had been founded about four hundred years ago by the merchant who set up Haberdashers school in Monmouth. The almshouses had been rebuilt a couple of times since then, the latest being in the 1960s. David wanted oredevelop them. He didn't think that they were up to today's standards and wanted redevep them for almshouse flats for in the form of a perimeter block around courtyard, and we took it as far as a preapp, with the planners having done some archaeological and ecological assessments as well, I think. It was received quite well but the project didn't proceed any fur we at that time althoug think the the 列

Then, I should think in the summer of the following year, 2007, I becam involved in Bengough's House, which is in Henbury on the way out or Bristo going north to the M5. It was a nursing cosing designed by Feilden Clegg in brick with lots of timber. It had won a couple of design awards, but Bristol Charities didn't thin that it operated well as a residential car home for various reasons - and, in fact, the closed it the following January, I think. So, Bristol Charities wanted to either conver the existing building or redevelop it completely into 50 or 60 almshouse flats, fully wheelchair accessible, obviously. It was a similar programme to the Monmouth site: there were to be communal spaces, facilities for staff and carers, catering kitchen on. Initially, we were commissioned to do existing building could be whether the isfactorily, laundry, hairdressing, chiropody and so a feasibility study to look at whether the really. David and I went to see the planning officer. I think he wanted to help facilitate what David was trying to do, but was concerned about the scale of adaptation that would have been needed to such a recent building - additional floors and so on. He thought the Feilden Clegg building had some merit, but was not dead against the idea of redeveloping it either, but warned that a high-quality design would be needed for any replacement building, and one that respected its prominent location.

So, we went on to look at options for so, wing the site. This waw the end of 2007, maybe the beginning of the end 2008 , it was at the same time 2008. So, it was at the same time that we were working on the Blnbeck competito invothe in in to involve you in the Bengough's House project as well, not only because of the sensitive nature of the project, but also to continue the collaboration we had started on Birnbeck and to start to build up a critical mass of work together - and at that time, it looked like it was going to turn into a real project, and a pretty significant one at that and one that was actually likely to get built. We gave a lot of thought to the options. I think, in the end, there were four that we presented to the planning officer at the next meeting, which would have been in February 2008, probably. We made a working model of the site and quite a large part of its context, then modelled each of the options and used photographs of the physical models alongside the plans that we had made of the design options. I thought that worked pretty well as a way of communicating the ideas. I think you and were pretty convinced that the two options that offered the greatest potential were the cloister option, with the almshouse flats wrapped around a central green courtyard, and the tower option, which was a 15-storey block with communal balconies at each level. I don't remember getting a formal response from that meeting with the planners, but we were certainly referred to the Bristol Urban Design Forum, and we presented to them sometime in May, I think. They were not fully convinced, really, by any of the options, but they were supportive of our architectural ambitions for the site.

I remember that following the presenation to the Forum, we did some further work together developing the design of the cloister option, which was the one that David preferred, and had a couple of further meetings with him. I also looked at another ite in Henbury where there was the potential for a land swap with Bristol City Council. But the project seemed to peter out over time, and in the end, Bristol Charities just sold Bengough's House. Ironically, it's operating again now as a residential care home...

as pretty entrepreneurial, and the same time as all this was going on, he was also trying to promote his ideas in other parts of the country. There were two or three other sites that I looked at for him in 2008 for conversion/redevelopment opportunities with a similar sort of programme. One was a listed building in Greenwich, part conversion, part new build: the other was in Walworth in London. Both were owned by the Drapers' company but I don't think either of those went any further either. 


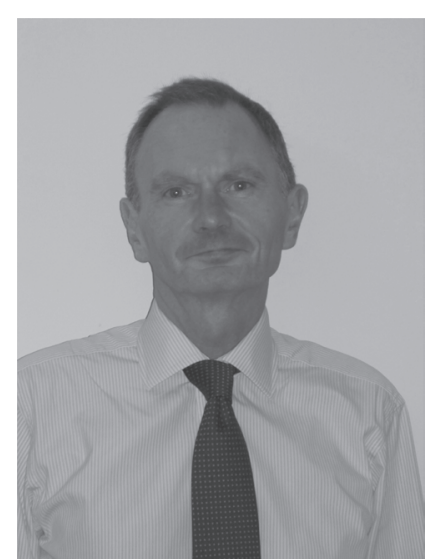

David Jones

older people living in the vicinity. So, as wel Anterview by Clare Melhuish for Land as the 60 flats, we can link electronically Architecture People exhibition-The site to hundreds of older people who will be was acquired 17 years ago. Basically, the socially isolated and link in to the surgery, rustees were advised to build a care home. the library, activities. They can do it via So, they built one to a high specification for television sets, so there's a way of trying a 40-bedroom care home. I firmly believe to ensure there's a lifeline there. There's that older people deserve and expect to very high preponderance of older people have independent living as long as they there; it's a postwar council estate. The area can - their own front door, their own flat. now is particularly troublesome because of The cost of care homes is such that you can provide care in people's homes at a much cheaper rate. Some older people can't live in their own homes for whatever reason. live So, the next best step is to design flats that can actually provide them with the wherewithal to support their needs as the become frailer. They live and die in that flat; there's no need to have the trauma of being shifted off to a care home.

I've been trying to look at a design that

I've been trying to look at a design thats
think is appropriate to meet the needs of older people, borrowing and pinching from ther people's specifications but adding to it myself. That's what the Bengough's scheme is all about - replacing what thought was an outdated, outmoded form behind the continent

Bristol Charities has a range of alm house charities, the oldest dating back to 1395. Here, we are, five hundred years later, building a brand new almshouse that meet trying to do that elsewhere in the countr Difficult because of all the issues we've mentioned - planning issues, land issues, people resisting change. One of the things in my grand plan, when we do build the replacement for Bengough's, is to link in

antisocial and criminal behaviour.

There's a particular shopping street young people congrega the is bea the so it's a place where kids will congregate

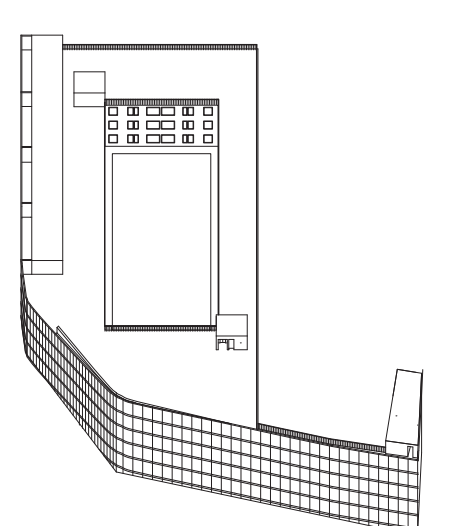

The Bengough's site was originally a old garage and farmland in the middle of a council estate. We closed the care hom in January 2008, and the plan was that we were going to do a site swap with the city council. They would take it on for a dementia home, and I'd get a site and cash. But the city council reneged on the deal. So, I'm about to put it on the open market, and at the same time, I've commissioned a site search. I've instructed surveyors' agents to in Bristol which is notorious for disorder and unpleasantness, and I actually believe that's partly architectural The reson the architecturally the place is a faily baus spot, and the whole feel is on and bing hef out and forg probably lover decades, t's not abenawar probably over decades, it's not been a war Which has seen much support and tension. Basically, here are two 190 s tower blocks, then there's an area of what they would cal parkland, except it's just grass, open space, with a stream running through it which is full of shopping trolleys. It's not overlooked, and do antisocial things, and most people wouldn't go there unless it was really daylight, you might walk your dog and that's it. So, the idea was to shave off some of the space for our development, and then money from that would enhance the remainin parkland to make it like real parkland with some activities. The idea was that the two tower blocks were supposed to be elderly preferred accommodation Council couldn't make a decision-that's th Councilcouldn't make a decision-that's th

4.3

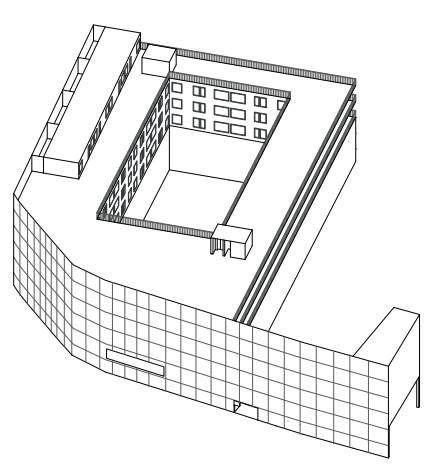

4.3 Courtyard option, planometric 4.4 Courtyard option, isometric the initiatives coming through. find me a site which will provide me with

\section{0 two-bedroom flats.}

Finding land is quite tricky. So, $I^{\prime} m$ in 10 miles beyond the city centre. We're helped at present because of the state We cer cent. So, it's a good time. There are five key things. First, it has to be relatively level because most of my people will have some mobity problems, and people who ve got motorised scooters whom you don't want to be on the side of a hill. Second, it needs to be close to shops. Third, bus routes are quite important. Fourth is the general area - there are some sink [rough] estates that migh be okay in terms of design but not to live there. And so fifth, because I'm building almshouses for older people in need (we don't say poor), one has to be aware that building in a very expensive part of Bristol would look like a strange use of charitable assets.

'm very keen on providing communal space not only for the residents, but also for the community to use, so that other old people come in - that's good for the residents. But I don't want to build an the people's ghetto. I want to make sure that it's accessible and not just by other older people but, if I struct younger people - try and break down some of those generational problems. Particularly in the area I mentioned, in Henbury where Bengough's is, you have a situation where many of the older people are frightened of younger people. The young people feel demonised, and the old people feel marginalised. So, trying to get them together and talk is tricky.

Sixty two-bedroom flats is my ideal development. There's land available, but whether it's in the right place, time will tell The site we've just completed, John Foster's mo I I I ot sure mo f contract, and the client has he respon ibility to ensure that what the get the nd of the day is what they want. Whe end design-and-build, you sign the contract, and 12 months, 18 months later, you get something that might be like what you wanted, or it might not be. The trustees are lucky to have someone like me who's slightly obsessive about the whole thing and gets involved - it's very unpleasant pecause building contracts are made for problems. I'm the client from hell!

The way you achieve what you want is by being clear about what your aspirations are, and relying on the architect knowing all the answers. If you go to an architect who's got a track record in a particular ype of development the danger is they're just going to demonstrate what they did in the past and impose it on you. If you go 
to one who hasn't got a track record, the have my head on a platter tomorrow. That's chances are they're starting from a minus the downside of not being liked - people position, and it can be frustrating. I remem- won't give you a second chance, they'll jus ber saying, 'You do realise this is for older people?' It's tricky; either way, you've got problems.

People have been moving to John Foster's now since May. I got the residents together to meet with them all, see what the problems were, and really - this is part of is a scheme that I know will work. There's a lady there, she's 92 , she looks 20 years younger, full of life, not depressed, off medication. There's a lady, probably in her 60 s, in a wheelchair, and she said, 'I don't know who designed the specification, they should get an award'. That was quite nice. Everyone was full of praise. One said that it's like being in a hotel. So, the user satisfaction is quite high

We might go out to competition [for an architect], or maybe we know somebody, perhaps from a smaller project, so we'd give them a chance. The key thing is having a architect who actually has the vision, the excitement to want to work with you and who will not take professional offence if I say, 'That's rubbish'. People are highly qualified. There's an architect and there's it. So, I suppose mutual respect is the key thing, and that they understand that it's something I believe in passionately, that t's trying to make people understand that old people have rights I'm happy to take the decisions have rights.I'm happy to take the right, marvellous; if I get it wrong, they'll eafter your blood.

If a firm of architects saw design ing for old people as just being another building project, perhaps with some slight nuances, I think it's a big mistake. crete specification - there are also issues about community, about the difference in people. The role of the architect is to do what I tell them really! That's what they hate Materials, colours that's where I am the architect's worse nightmare I suppose listens really and respects what the client wants. What I want them to do is to bring Bengough's been empty sinc april.

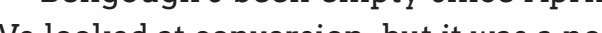
herer it didn't giversion, but it was a nothe shape and layout would have been a compromise. But even though we met with the planners, and they weren't against the idea of demolition, it was quite clear that Because when we closed Bengough's, it was a very successful care home, and I took a lot of flack. So, rather than knock it down it will be sold. I wanted an architect who wasn't based here in Bristol because it's a small city and people know what's going I went to WYG's office in Cardiff - a firm of architects I trust. I can sit down with them and look at the options. It was a question of starting afresh bens. It was a question of relatives of people wholived in Bengough's There is a range of issues, not just conwhat I'm looking for is an architect who me options If som there would have been a public outcry. on. I wanted some distance. So, that's why

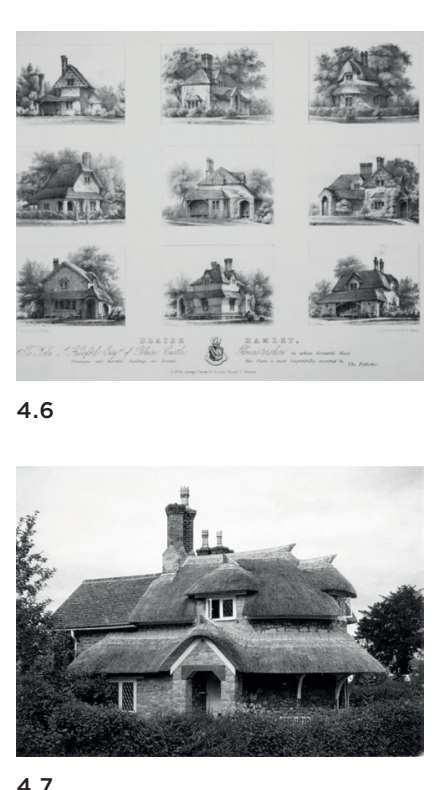

weren't very happy. So, public relation was always an issue. Also, I knew had some knowledge of the area, Henbury

kept an open mind untill met Pierre. Obviously, lonathan had told me about his background, and so far as I was concerned, it was great. It added value to what Jonathan could do. I'm always looking to try and move out of professional ruts, and the way I saw it was that Pierre would bring new ideas and a fresh approach to things. So, was happy to see what came out of the mix really We had some very forthright metings in Cardiff! They were fairly robust ings in Cardifn. They were fairly robust exchanges, and
offence at it.

We talked about multistorey options,

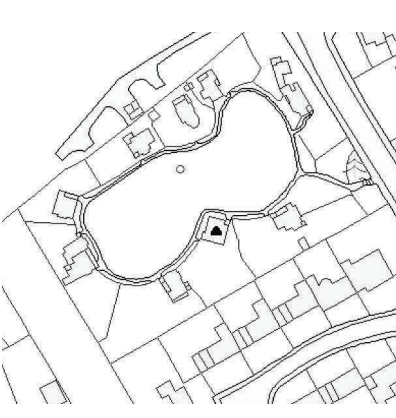
the needs of older people. The site was slightly constrained because of the surrounding two-storey council housing. So, height was an issue, and parking was an issue. But also, it's in a very high-promle location. It's one of the ways into the north of the city, and therefore-Bristol being architecturally challenged as it is - there was a thought of building something spectacular there if possible. Architecturally, Bristol is not brilliant. I'm not sure why. People driving into the north of the city are faced with this postwar council estate, drab, dreary. So, it 4.6 Blaise Hamlet by John Nash,
Almshouses at Blaise Castle, Henbury, c. c.111, cottage Orre 4.7 Circular House, Blaise Ham 4.8 Site plan, Blaise Haml would have been a way forward. I'm a firm believer that the more you play around with ing, it's good not just for everyone around but also for the residents as well. It shows a worth. I think in that location, the only way we would have got away with the sort of building we needed would be if it had been landmarkbeause if less than landmark building, multistorey, I hink we would have got hammered. As long as you've got a standard specification built within a super design, then dents, not just us, not just the architect, put also the local community. And on that particular site, it would have perhaps been good for the rest of the city, the rest of the area. It would have helped, I think, to give some sort of statement about where we're going Certainly almshouses as a form of accommodation need all the help they can get because often the people get associated with the building-some 'olde worlde' building -which is totally inappropiate. In Berksire, I'm daring to say that a sevenenth-century alm 1642 is not appropiate for older people in 2009, and I'm being vilified. You've in 2009 and $\mathrm{m}$. being vilied. You've ging a listed build three times as many units for ould puild three times as many units for older I produce a produmodation. all races. I'm not aiming to design anything for any particular group. In one of my almshouses, I've got Chinese residents, but that's as it is. It's very easy to fall into a trap where you make it almost exclusive. There's a duty when you actually come to recruit people for the almshouses, to eflect the mix if you can. But if people don't apply, then that's the issue. It's certainly a factor which I think about, but to date, I don't think there's much I could have done, hough that might change.

I'm not the most inclusive of people. I don't work in groups I've always mapled 
organisations for the last 30 years. That's do meet with my users on a regular basis, my strength and some would say my weak- and'm happy they tell me, I feed in. I've got a fair feel for on time and to budget.I get things done. I what puts people off. You can sit down an don't make friends doing that. The problem say, 'What would you like?' But I'm just no I've found is that inclusivity is great, but it's sure... There's a theory, isn't there? You're a marvellous way not to do anything. So, I doing it to be seen to be doing it.

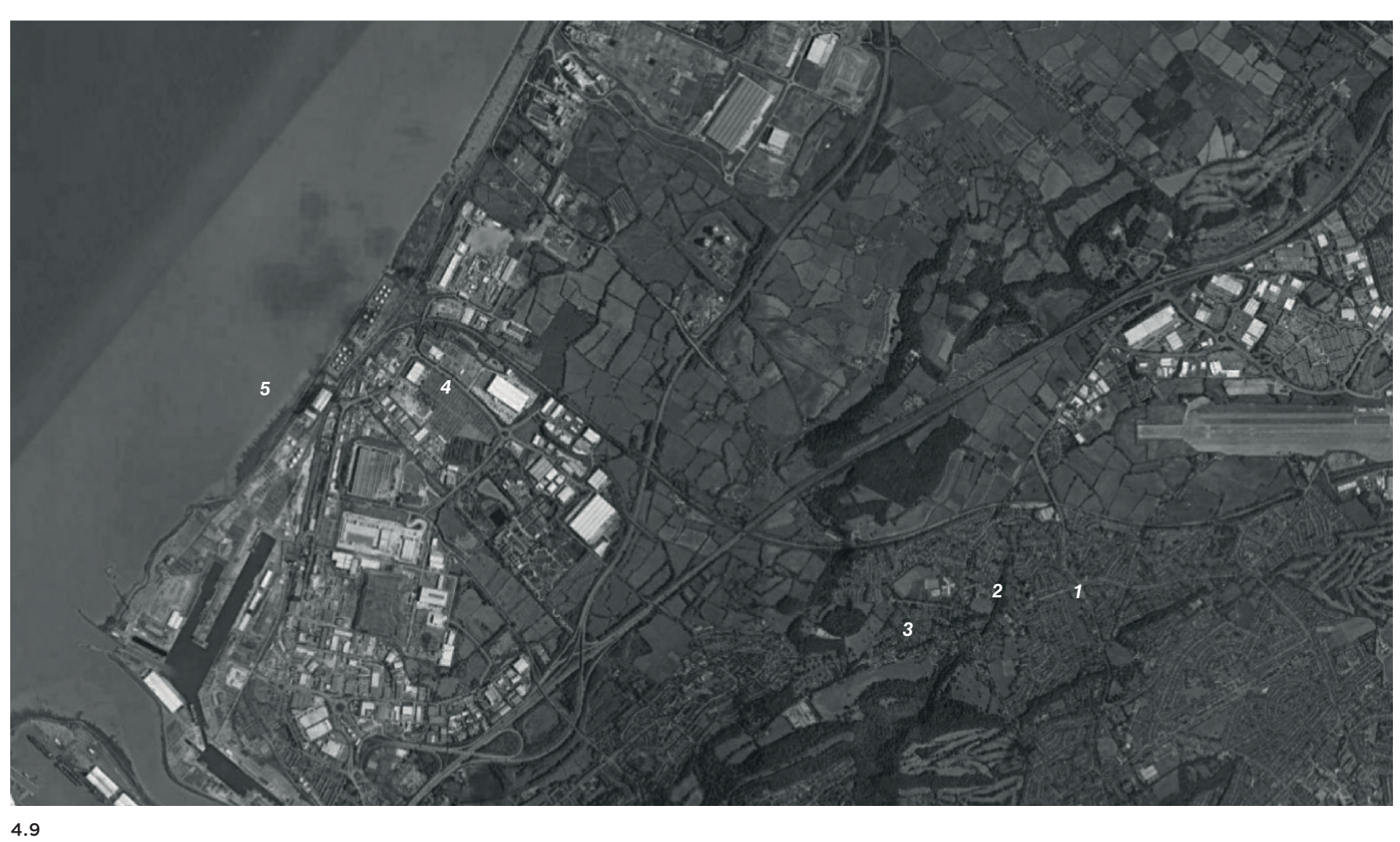

4.9
4.9 Bengough's House and

1:50,000

1. Site, Bengough's Hous

2. Henbury 3 . Blise Hamlet

4. Avonmouth
5. Bristol Channel 


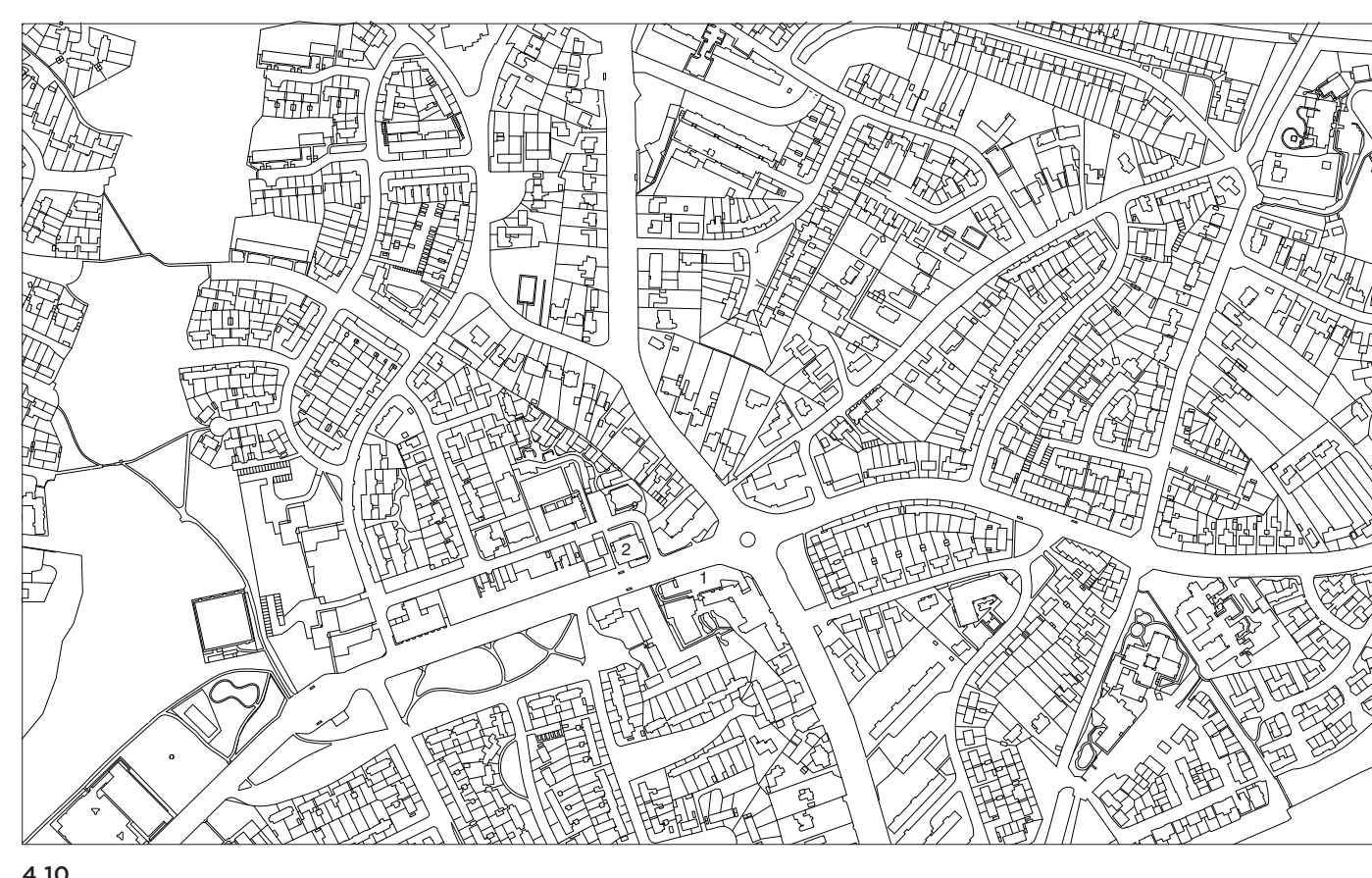

4.10

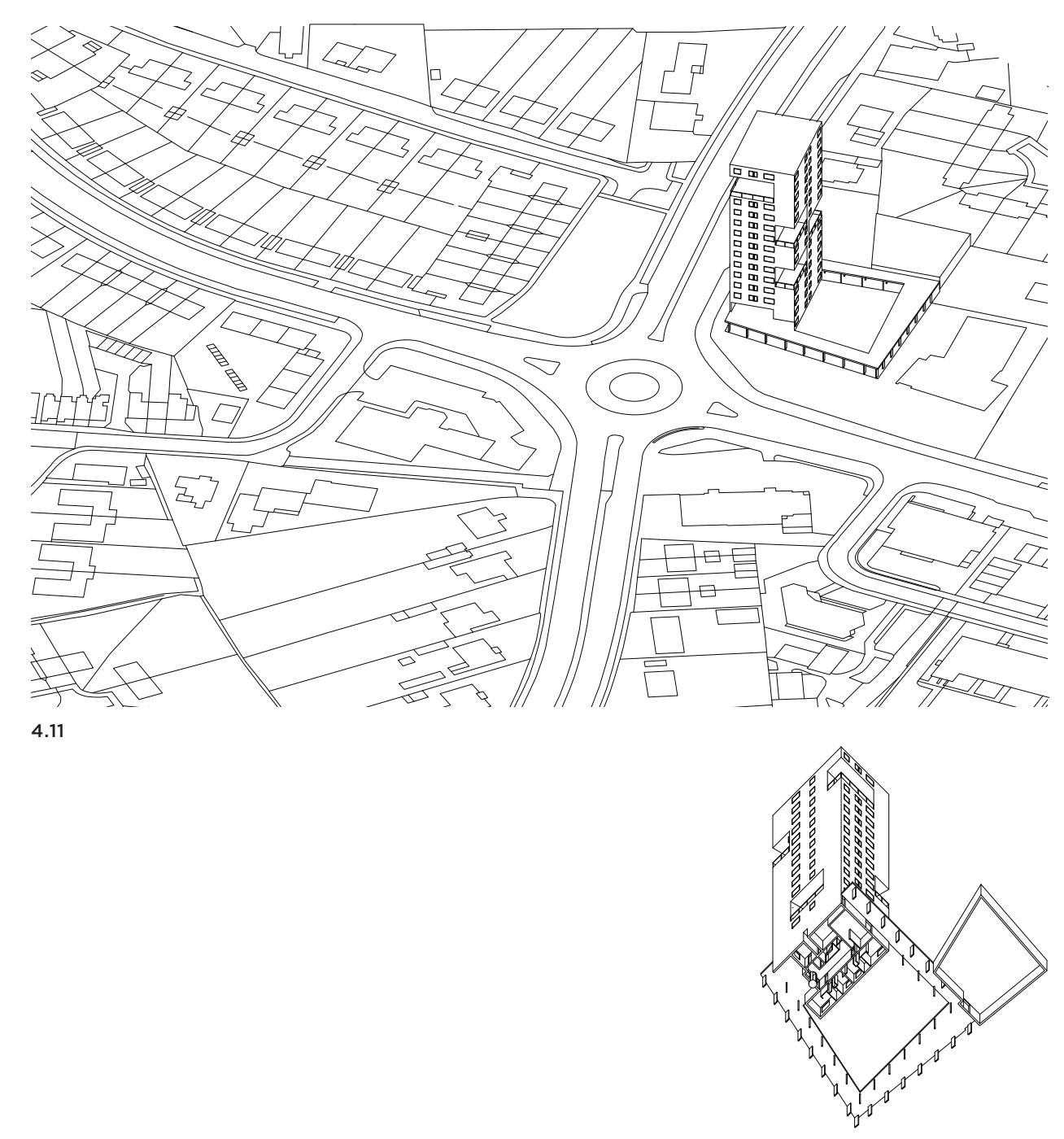

4.12
4.10 Location pla

1:8000

1. Bengough's House site
2. Henbury library

(1)

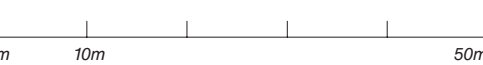

4.11 Isometric 

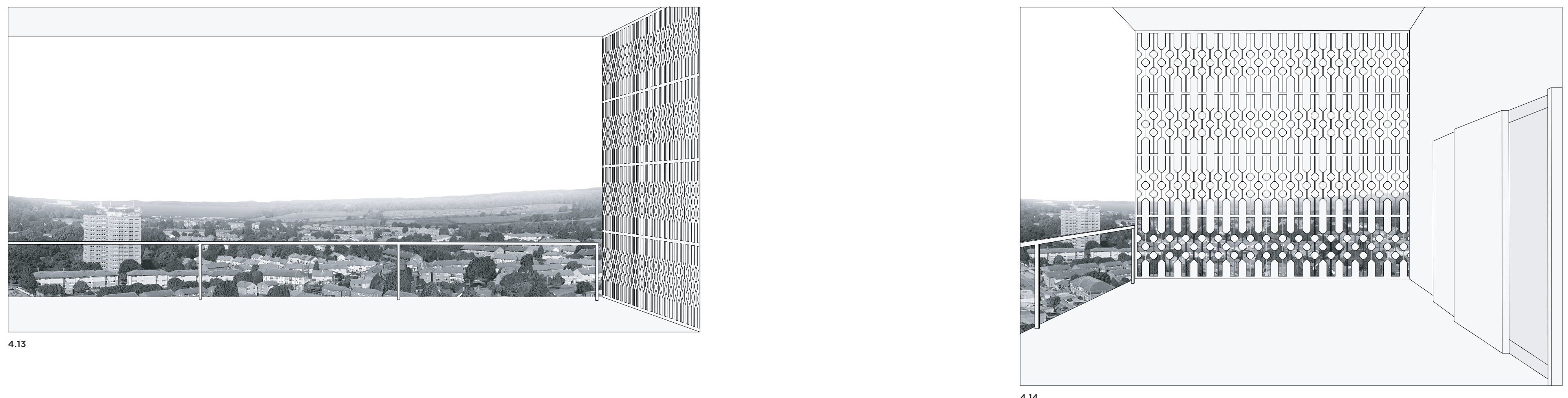

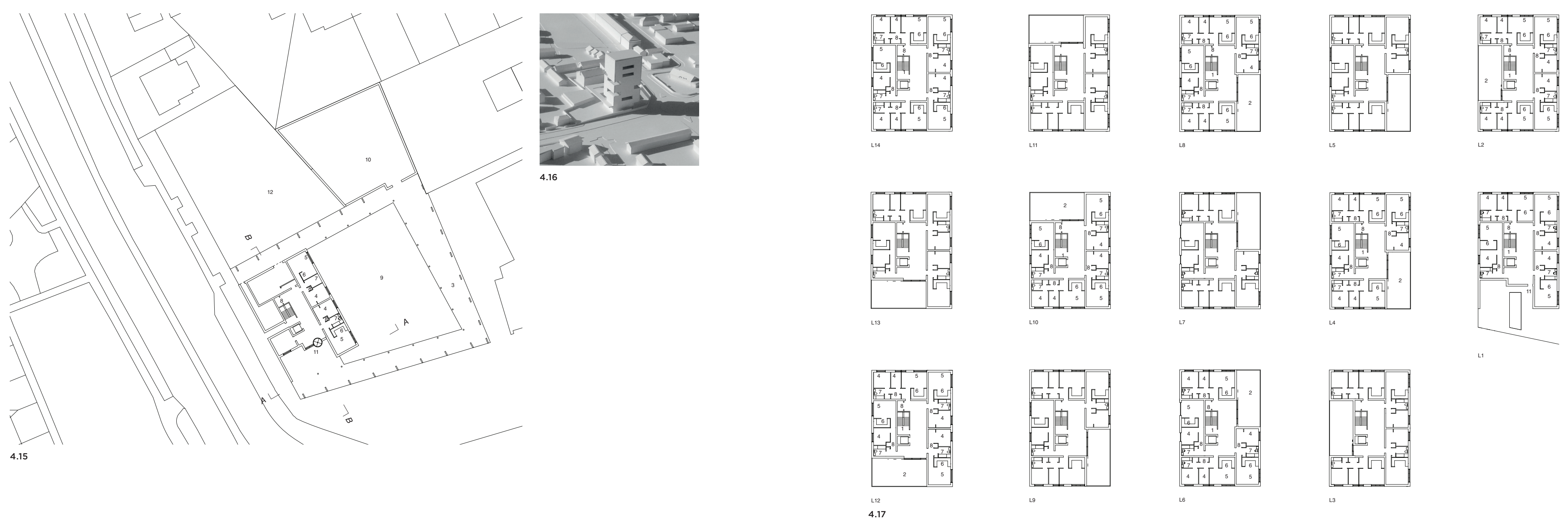


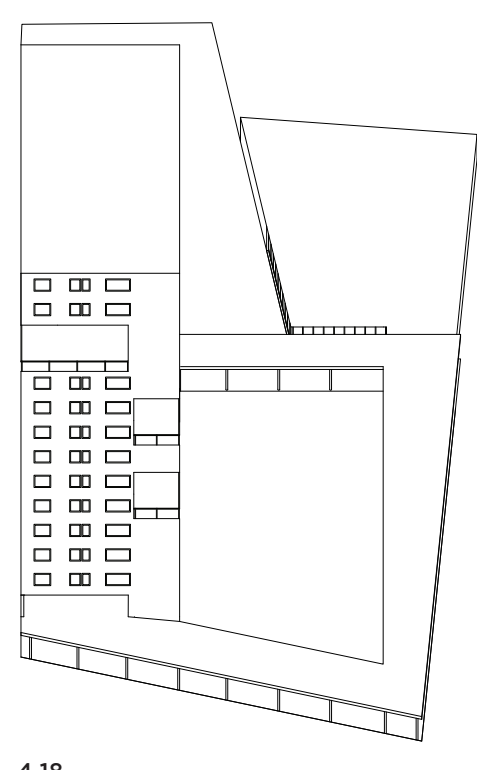

4.18
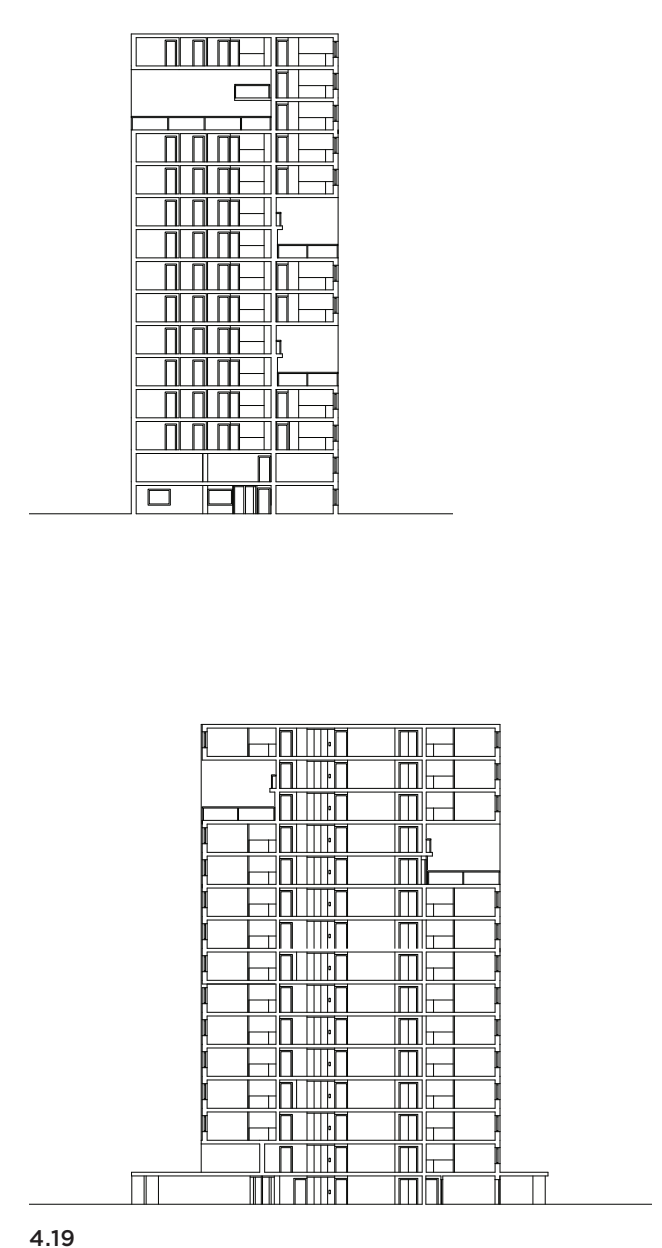

1:1000

1. Section $A A$
2. Section $B B$

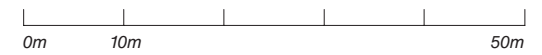

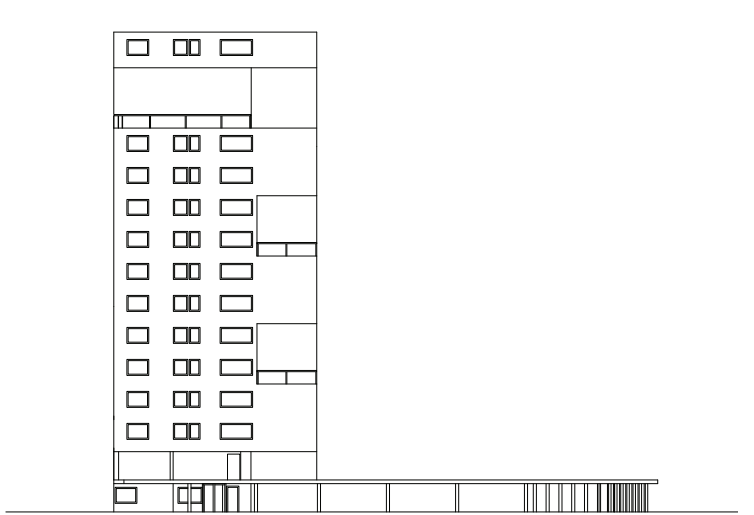

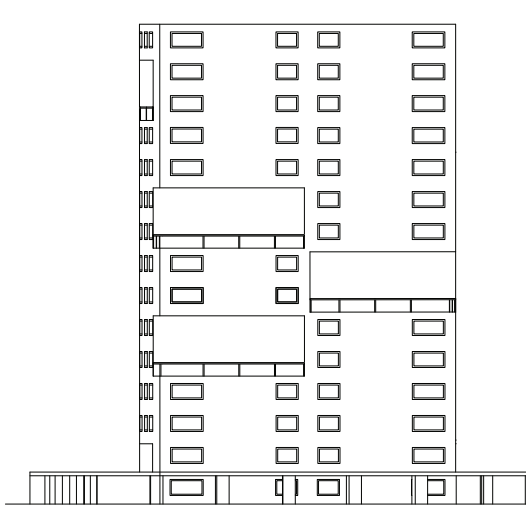
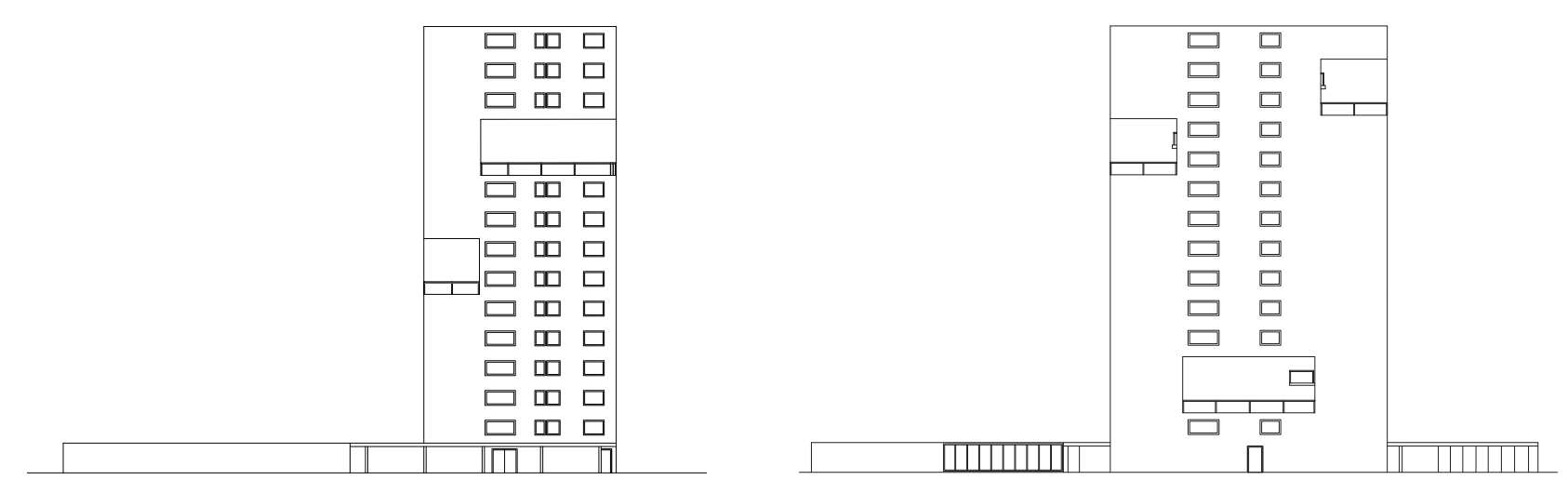

4.20 Elevations

1:1000

1. South
2. North
3. East

2. North
3. East
4. West

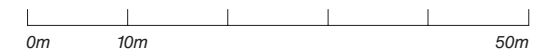



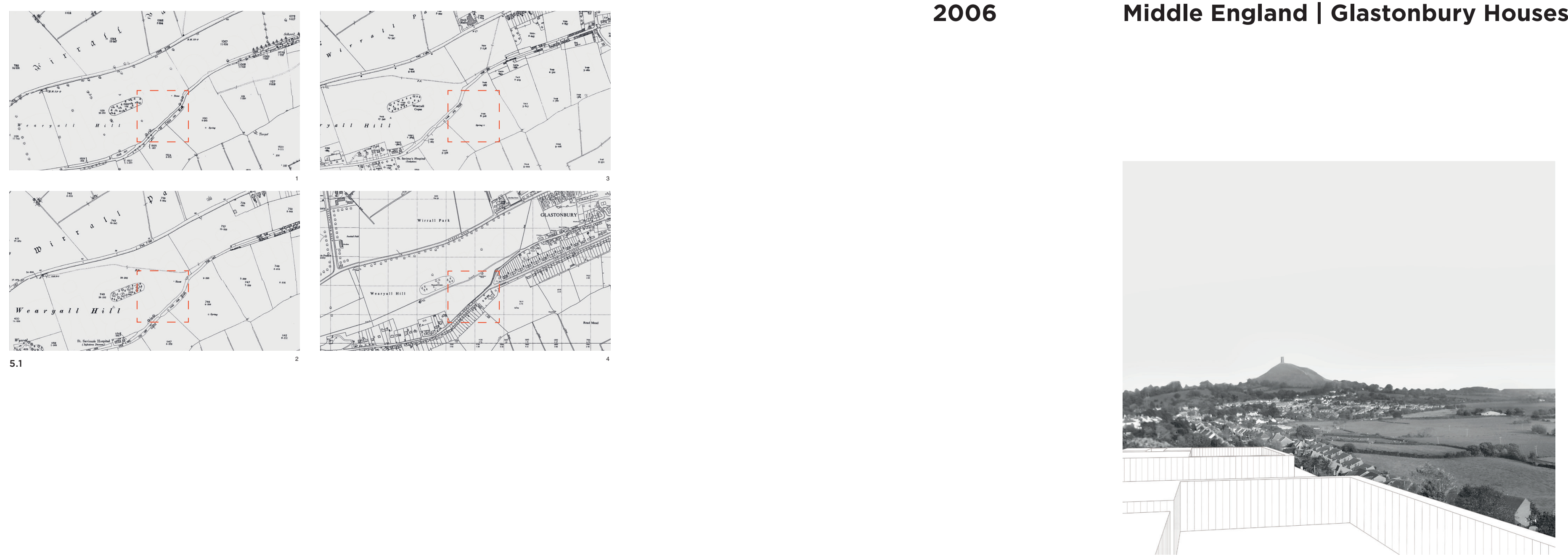

A line of six houses is proposed on making it undesirable to local develWearyall Hill in the grounds of a house opers. Wearyall Hill is one of three built in the 1960s. Access is from The landmarks, together with Glastonbury Roman Way, which forms a suburban Abbey and Glastonbury Tor, which has edge south-west of the town centre over- made the town highly significant across looking the Somerset Levels towards a long stretch of English history. The neighbouring Street. The south-facing area has been badly extended, with a

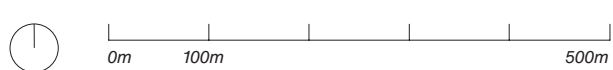




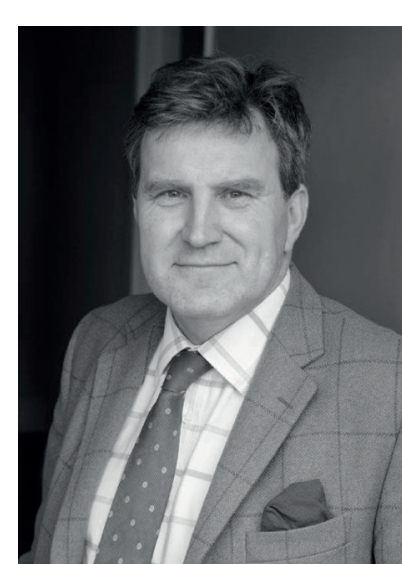

to the north of Wearyall Hill and a maze of surrounding suburban streets. The high street is mostly given over to New Age shops and provides access to the Abbey grounds where the ruins of the great church are still a compelling focal point. The Tor is some distance from the town. The ground rises slowly to the base of the Tor, and a spiral path ascends steeply to St Michaels Tower from which Wearyall Hill may be viewed - a long, low swelling counterpoint to the Tor. The marshy landscape of the Levels is till liable to flooding and is a reminder of its recent prehistoric past when the land was inundated by the sea and its inhabitants lived in villages built on stilts in its watery edges.

Nick Oliver

nterview at Cooper and Tanner, Glastonbury, 3 February 2017-I live in Castle Cary, but I've practised in the Glastonbury office for 30 years. I also worked in Shrewsbury, but 95 per cent of m working life has been based in Glastonbury. work mainly within a 10-mile radius of Glastonbury, including Street, Wells, Shepton Mallet and Midsomer Norton an so forth. Originally, I came here as a land agent principally to advise farmers, but $\mathrm{my}$ work has widened. So, I'm more of a general practice chartered surveyor now, advising farmers and also advising general property owners. I'm heavily involved in sellin sites and also seeking planning permissio via optional promotion agreements with via optional

I was born in Taunton. I am from Somerset, and I have lived pretty much all of my life in Somerset. I went to schoo in Taunton and Bath and then to college at Cirencester for three years and qualified two years after. The course involved learning about advising farmers and landowners. It also included estate management, forestry, evaluations, farming advice in term of husbandry issues and crop rotations and taxation. There wasn't much about commercial development; that has just evolved whilst I've been in practice and through experience and understanding of how that part of the industry works.

$$
\text { I wanted to be an auctioneer originally. }
$$

onary, that's all I wanted to do, And I sold livestock for 25 years at our markets at Glastonbury and at our new market in Frome, a livestock market. I just stepped aside because we had younger people who wanted to sell, and younger people who wanted to sell, and I'd really need to do any more being an auction any more. So, I stopped being an auctioneer about 10 years ago. Bu I still do property auctions, which we hold once a month throughout the year. So, th only auctioneering that I do on a regula basis now is property. No, there was no family tradition of this whatsoever. I was just drawn to be a livestock auctioneer an work in markets. That's all I really wanted to be. But I needed to be a chartered surveyor because I've got to work three other days of the week (not just be an auctioneer). So, that's what I chose, and part of the qualification of becoming a chartered surveyor was to study taxation

Cooper and Tanner have been in Glastopury for more have been in principally as a firm ore than 100 years, tioneers until about the early 1970s, and

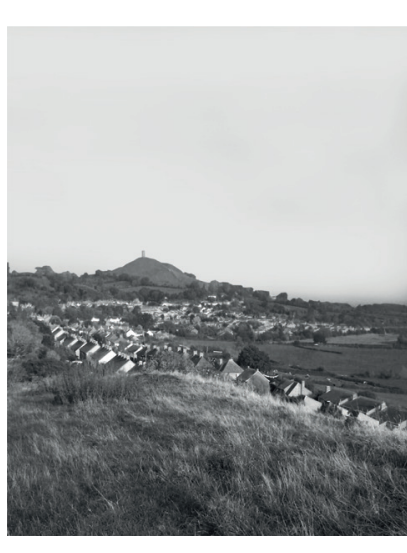

then we started becoming involved in estate agency. The property we sell ranges from a small flat up to maybe a $£ 3$ millio property; that would be our raison d'etre in terms of what we sell. We then also sell land for the benefit of planning permission. We also sell land, agricultural land, farms and commercial property as well. We're slightly unique here because we are a fairly general practice office, whereas $\mathrm{m} Y$ other offices either specialise in sellin houses or specialise in selling farms or in just doing professional work and doin in just doriag professional work and doing practice office ever since I've been here. We've always done a bit of everything And that's probably why we're able to survive in this mabt I think the if here residentily (I'm not sayng we arent here resuly successful) or we were to specialise in one particular field, then I think that we probably wouldn't be able to employ the number staff that we have here at the moment. When I started working with Cooper and Tanner I came to live in the area. moved just into the town in the early 1990

5.3 View from Wearyall Hill to
Glastonbury Glastonbury Tor (top) View from
Glastonbury Tor to Wearyall Hill (bottom) and stayed there until about three years ago Cary

In terms of your experience over the time that you've been in general practice, what are the kinds of opportunities that exist? How have you responded to the vagaries or changing nature of land availability and the way that policy is

Well, land availability in this area is slightly constrained by a couple of factors really.
First, in Glastonbury, it's constrained by the flood plain because we're hampered to the west by a large flood plain so development is limited. That isn't universally the case with towns in the area, but it is a consideration because of just where we are in the middle of Somerset. There is another consideration which has a strong bearing, and that is the historical interest and character of certain settlements. So, in Glastonbury, we have Glastonbury Tor and the Abbey, and that in itself causes constraints as to where land can be built upon secause planners and conservation bodies on't want to see the Tor or the setting of the Tor compromised Similary, You've got the cathedral and all the ancilyourve got the cathedrall constraints in terms of where developments can in terms of where developthems can take place without imposing chen Mallet don' have any real historical significance by virtue of what not quite so great.

If you take Street, for instance, there's a site there which is being developed. It was designed in part by the Clarks family; they were heavily involved in that. It is very much a contemporary development; it's got apartments, and the whole style is not very traditional. It is slightly unique in this area in terms of how it's been designed. In the main, there is still a desire for traditional construction and design of houses. Smaller schemes? Probably. I think planners at the end of the day are more flexible, but when you get to larger schemes and you're wher developers), clearly when you've got that 
individual type, style, that unique contemand in the local planning authority as to how that's fine when you've got someone who new development is going to impact upon isn't driven by maximising the value of existing buildings and the character of their land. But when somebody says, 'You certain settlements and whether they will can build whatever you like, all I want to do compromise that setting. And if they is get the most out of my land', that prob- will compromise it, then it is extremely ably to a point drives the design of a house. unlikely (along with a whole load of other

The Clarks, I think, at the end of the factors) that they will even consider pursuday, but I think they were not driven by ing support for such an application.

money because they don't have to be

miven they wanted something that they

felt was appropriate, beneficial and contem-

porary that would go with Street

they weren't looking to maximise the value

f the site. If it had been with a private

of the private

been built because there would've been

too much compromise on the land value.

I also think they wanted something tha

they thought could work, and largely I
think it has worked. The scheme was done think it has worked. The scheme was done last five years. I don't know if they mployed an architect I wasn't involved personally. What about the 'lie of the land'? You'v talked about the levels and the differen have here in Somerset Does the that we effect on how land is procured or made available?

I think the visual impact, especially in the fact that we've got a number of internationally (I think you could probably use th word) known towns and cities. Glastonbur Tor, for in towne (there's Glastonbury Abbey and Wells Cathedral), does have big influence, and certainly that would be
You said you cover a 10-mile radius from your Glastonbury office. Does that encompass Bath?

No, we have a bit in Bath. My Wells office and my Frome office would pick that up. So we would have influence, but then when you get to Bath, that's going even more ment because Bath is just (more so than Wells -Wells is on a rather parochial scale) so internationally well-known and full of so many listed houses, the whole city is cultural city. Development is just a major major issue there. So, I would've though that in the town of Bath, they would try to push housing outside so that it doesn't compromise too much. And again, it'll be all about visual impact as to where they can put houses that are not going to blight the approach to the city.

In terms of regional development you've got Bridgewater, you've got Taunton you've got Yeovil, and there is massive development taking place in Westonsuper-Mare, there is massive developmen taking lace in Taunton It's literallyment never have thought, primarily extreme in terms of the control of developmore to the east in ares thally edging it's on a junction to the M5. The same with Weston-super Bridgewater's being driven by Hinkle Point. So, the thrust of new development new housing for this county is likely (if not 50 , I would imagine 60 per cent) is going to be within those four particular centres, and you've just got to drive around there, and it's quite astounding just how much development is taking place there and will continue to do so.

That's where you're seeing the thrust of the development. Central Somerset will get housing, but not to the level where we're thousand, twenty thousand new home We're talking at the mom nowes. We're talking at the moment about five hundred, elght hundred, maybe a thou10 years 10 years. Even Frome (which is an up-andcoming town) is not going to have those kinds of numbers because the problem is that when you've got those numbers, you've got to get to where they're all going to go. If you've got to travel through mid-central Somerset all the way to the M5 junction to commute, then that's an awful lot of traffic on the road.

In Castle Cary, we're moving mor towards Yeovil where there's a majo amount of development taking place, and Wincanton where there is also going to be a considerable amount of development. Castle Cary, for whatever reason, has now got planning consent for five hundred new homes, which is a significant amount for relatively small town. That has come about in part because South Somerset has not got its five-year housing supply and therefore developers were able to challenge
They've gone to appeal, and they've just got two appeals for another two hundred houses.

Five hundred houses to a town like Castle Cary is probably too much. It's a huge amount - huge. But unfortunately, Castle Cary has got good road links. It's got good access to the railway station. So, think that when an inspector is considering such appeals, it's all about transport communication. And if towns don't have good facilities and good communications, then it's going to be much much harder and villages to get any real significant amount of housing. It will just be a holding operation. The thrust is that stainability That is where it's all about sustainabity. That is where to travel, we want $n$. We wa to be to the shops and to work rather than getting in acar and having to drive and the milk go drive to get the paper have a shop, don't have a pub, don't have a school will get nove a pub, don't have a school will get nothing. Those villages that have got those criteria will get some element of housing, but it'll be the overriding we do not want to proliferate the need to travel'.

You briefly touched on the significance of Glastonbury: the Tor, the Abbey and coming to the property on 24 The Roman Way. I was directed to that site in 2006 by an agent called Paul Knight. Our brief to him was that we wanted a site on a south-facing slope which a developer would not be interested in because it's on a slope and harder to build on. When we visited the property on Way, we realised it was on Wearyall 
Hill, which for me, as an architect with there will be contributions (whether that is a strong interest in history and the area for open space, whether that is for habita (I've been coming here on and off since protection or what have you) which ultithe late 1960s), is a remarkable historic mately reflects on land values because al landscape. The environs of a town like is a cost involved with that. So, I think that Glastonbury, which is not a big town, land values are probably not at the level consists of an ensemble of highly sig- that they may have been at the peak of the nificant architectural and landscape market. It hasn't picked up again because I elements. How does one resist the pres- think there are so many other constraints, sure to encroach on that? and of course we are with some authorities looking at the Community Infrastructure

I think that the problem with Glastonbury Levy (CIL) which is coming in. It isn't will be that it's going to run out of building here at the moment but it will come in land. If it hasn't already, it's pretty close and that will have a significant effect. If (1) to doing so because of the reasons that you've we touched on before: one is the flood- house and you've got two hundred, then ing risk and one is Glastonbury Tor. And I that's $£ 2$ million, isn't it? And that's all go would think that at some stage, the plan- to come off the land price, off the bottom ners are going to have to accept either line. You can't get away from that fact. So, at that Glastonbury's not going to expand (it the moment, those in Clark are covered by is where it is, and we can't do it) or that a Section 106 agreement, but it's still likely there needs to be some compromise, and that the CIL will probably be at a highe that compromise is likely to be around level, and by any stretch of the imaginaGlastonbury Tor. But I think we're talking tion, that will impact quite significantly maybe about 15 or 20 years away before on land values.

that's ever likely to come up on the agenda.

The existing plan lasts until 2029, and they Can you talk about the difference probably will feel that there is enough between agricultural, rural land (the housing within Glastonbury currently with land outside the settlement) and the way what's being built out and with what has that the settlement is controlled in terms consent and that it's likely that anything else can be provided for by Street or potentially in Wells.

Have you seen significant changes land value for residential land?

I have. I think what has changed is that lanning consents will impose quite a lot of conditions (okay, partly in design), but

\section{of how it might expand?}

I think that where developers look at sites and planners ultimately will be about the visual impact which we've touched upon: how the site fits with the existing development. Does it compromise any significant ment. Does it compromise any significan listed building or heritage sites? Will it munication? And will it have good access
5.4 Glastonbury geological map

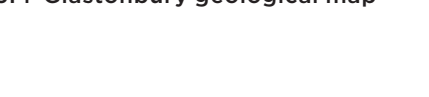
the centre of the town sc walk to the centre of the town land principally. How does it fit within the land principally. How doesit fit win the existing development limis? just going to be like a bolt-on that sticks out like a sore thumb, or is it actually going to merge in and fit quite nicely like a hand-in-glove situation? So, that's how they would look at it. Of course, they then have to conside the needs of the town. Does this town need to be expanded? Can this town take expansion? That's the other criteria. It's no good saying, 'Well, we're going to give a town 100 houses' when it's only got one primary school. That means that they've either go to build a new primary school, and where is everybody going to go when their children have finished primary school? They've all got to get cars, and then they've all got to drive. So, there are these other factors th they need to consider.

There has to be a benefit. The existing town has got to be of a size whereby it can what is being offered. There'll be a lot of people there who say that Castle
Cary cannot really absorb five hundred houses, which is an awful lot. but that's what's been given. It is in five or six parcels, but they're all on Station Road, which is the main road going into Castle Cary. So, they're all going to be pretty much all in one big area. They will probably all go to different developers. My role is more often than not to either identify sites, or a client who has been approached by a developer will come, and they will ask us to take an option promotion agreement out to bring
forward planning, and they will ask me to act for them to negotiate the initial agreements. Once that agreement's been done (if that ance that arseris and and gen ten act It doesn't really impact upon me perIt doesn't really impact upon me perpossibly an to clients. Clesty if there was a development that I felt pretty uncomfortable about (let's just say someone was trying to promote a site for three hundred houses at the base of the Tor), then I think I would have a hard job acting for that client by virtue of the fact that 1 wouldn't agree with what is happening. But if I see that what has been put forward is sensible and that it fits within the needs of the town and that there isn't anything detrimental (whether that's landscaping or otherwise), then I don't have a problem in cting for that person in whatever capacity. I think that any business, whether we are in sleepy old Glastonbury in the middle of Somerset or whether we're in London or wherever personal contacts are important, and you will build up a relationship with 
accountants and with solicitors and with other advisers and with the Council.

clients who have property in Cheshire. I've got clients in Dorset, in Wiltshire. I've It builds up through a reputation, got clients in Bristol. So, my client base is through client contact and then with probably about a 50-to 70-mile radius, and developing a relationship that people that will be about it... I've got one client in want to use you, and you want to use them Gloucester. So, yes, that's about as far as it because you offer a good service. And we would stretch.

have acted for Somerset County Council

(as have other agents in the county), and

we're acting for them on the site of two

properties next month in auction, and

that's an ongoing relationship that we've

probably for the last 25 years, I suspect,

because we're able to offer and provide a

service that they find very efficient an

well organised, and the same with even

the District Council. We've actually don

tion again because obviously they consider that we're appropriate to use.

You said earlier 'sleepy old Somerset', and it seems a relatively local practice, but does your expertise involve you in things across the country or internationally?

No, I haven't done anything internationally. have done work in Cheshire. I have som
Has the EU referendum had an effect?

I think there was an element of uncertainty fter the referendum and right throughou going to bappen and we was edly meant to cave in (as it was predicted to a dealistion that actily the word going to end and things thor worn't rapid (bredicted, there has been a fairy rapid (because it would have to be rapid) return to what we were trading like before the referendum. So, hings have picked up and having talked to quite a lot of people who I know in business in this area, they're hiatus, if you like, but that's gone. Ther was a bit of a shock, but now the shock's gone, everything has moved on. It seem bing to haspen' but then it didn't happen. going to end and things aren't going to be all exceptionally busy. So, there was a slight

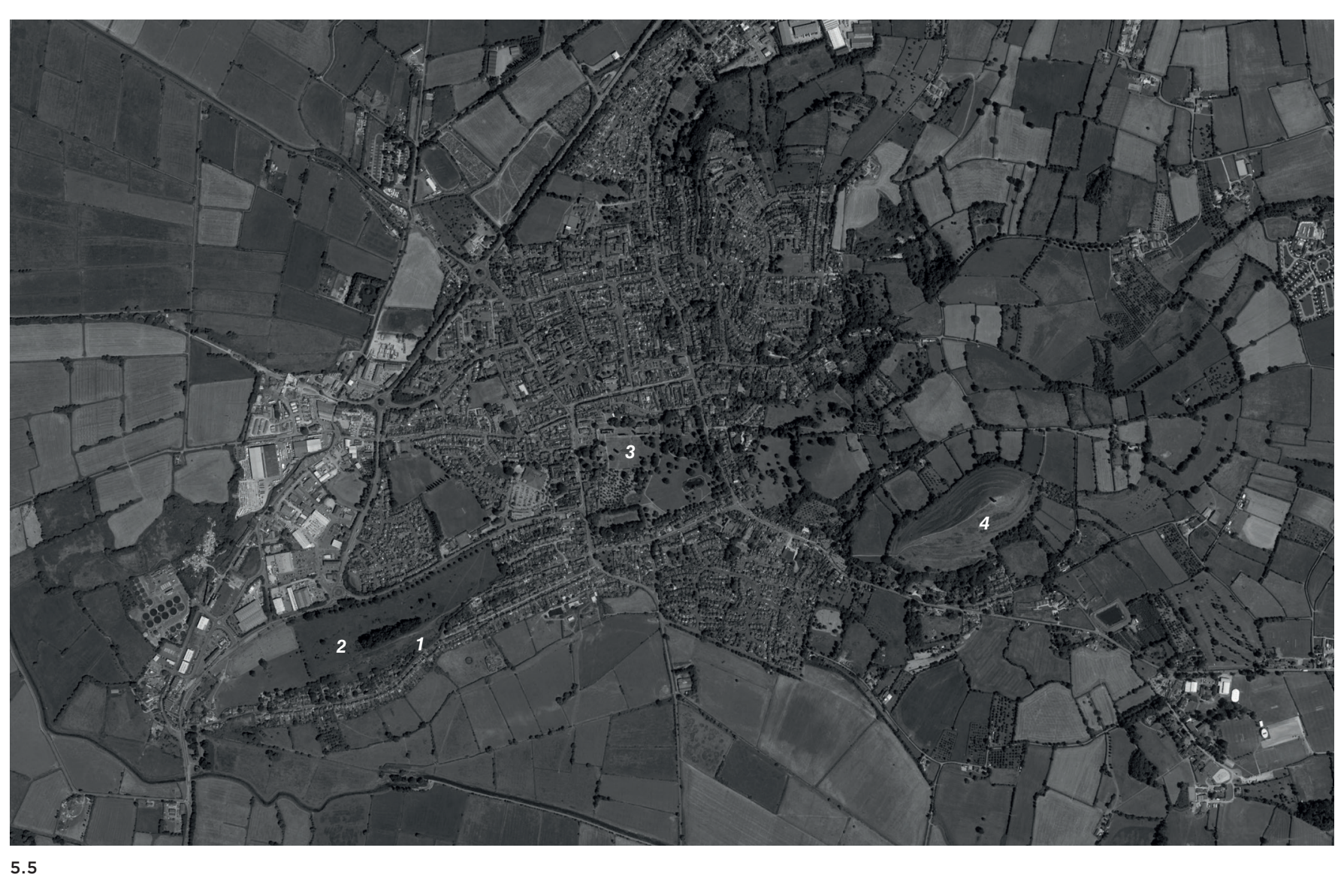

5.5 Site and environs. I
Source: Image courtesy of

Google Earth

1. The Roman Way site
2. Wearyall Hill

3. Glastonbury Abbey
4. Glastonbury Tor 

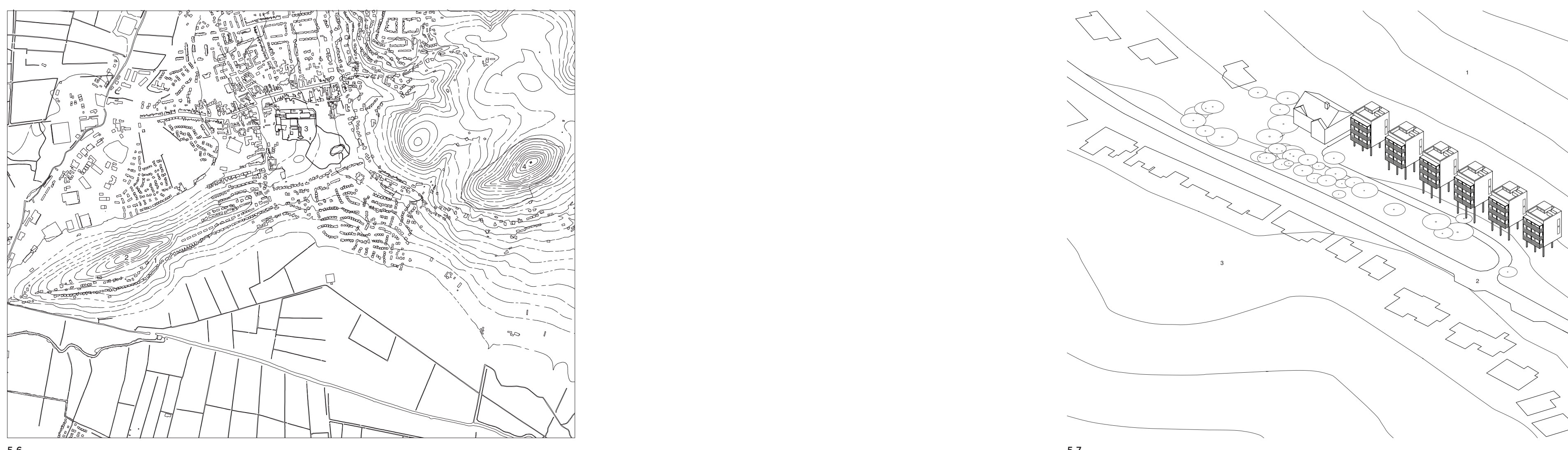

5.6 Location plan

1:20,000

1. The Roman Way site
2. Wearyall Hill

3. Glastonbury Abbey
4. Glastonubury Tor

5.7 Isometric

1:1500

1. Wearyall Hill
2. The Roman Way

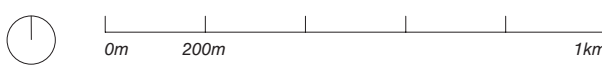

$\begin{array}{lllll}b_{0 m} & 1 & 1 & 1 & \\ & & \end{array}$ 


\begin{tabular}{|c|c|c|c|c|}
\hline 車 & 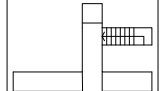 & 再些 & 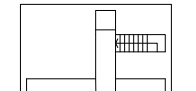 & 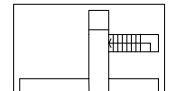 \\
\hline 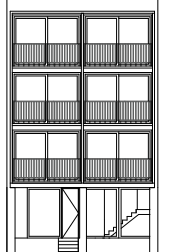 & 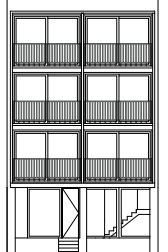 & 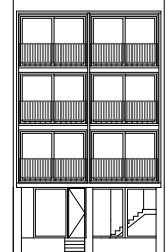 & 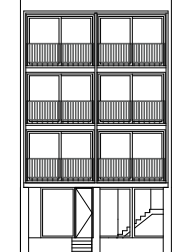 & 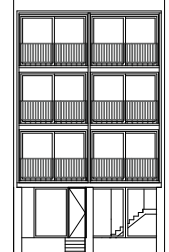 \\
\hline
\end{tabular}

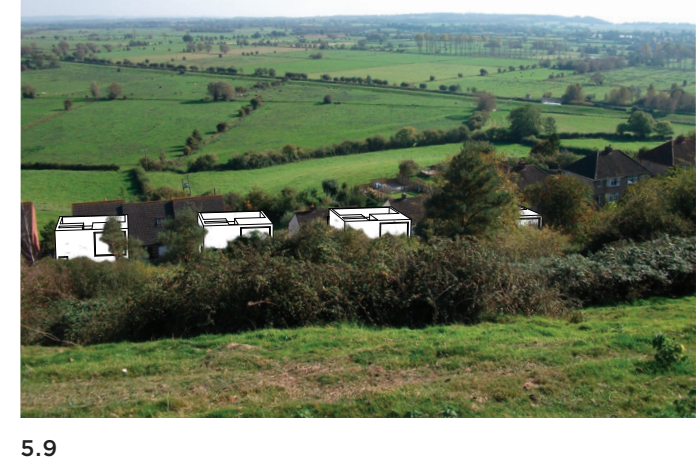



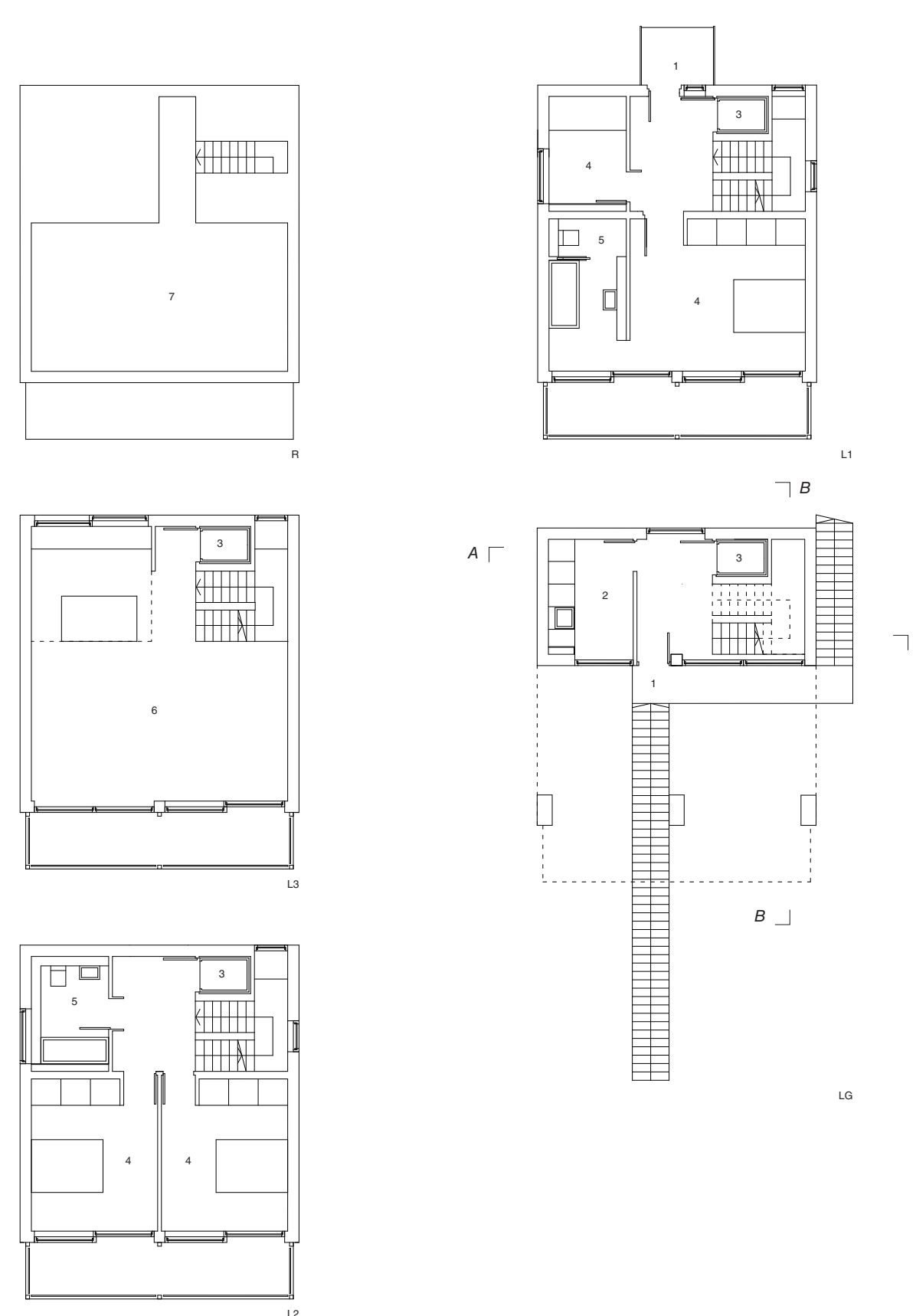

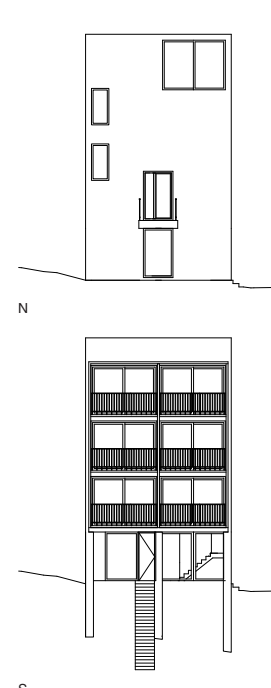

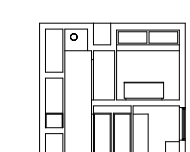

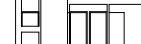

Hint

5.12

5.11 Plans
$1: 200$
1.201 the

1. Entrance
2. Utility

3. Lift

4. Bedroom

6. Kitchen/ddining/living room

5.11 

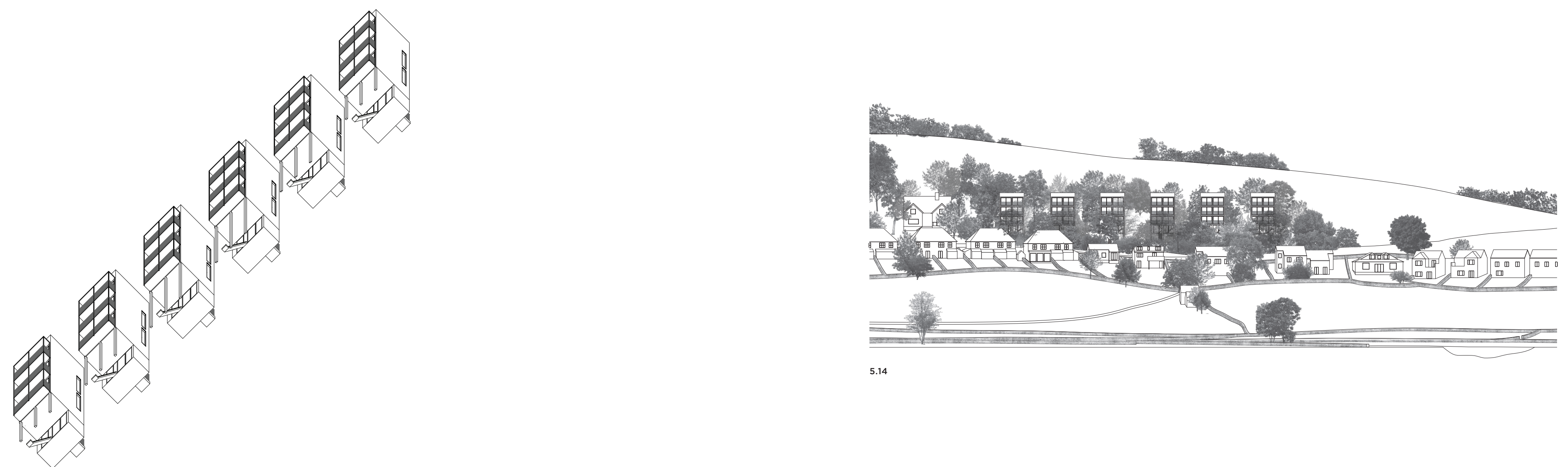


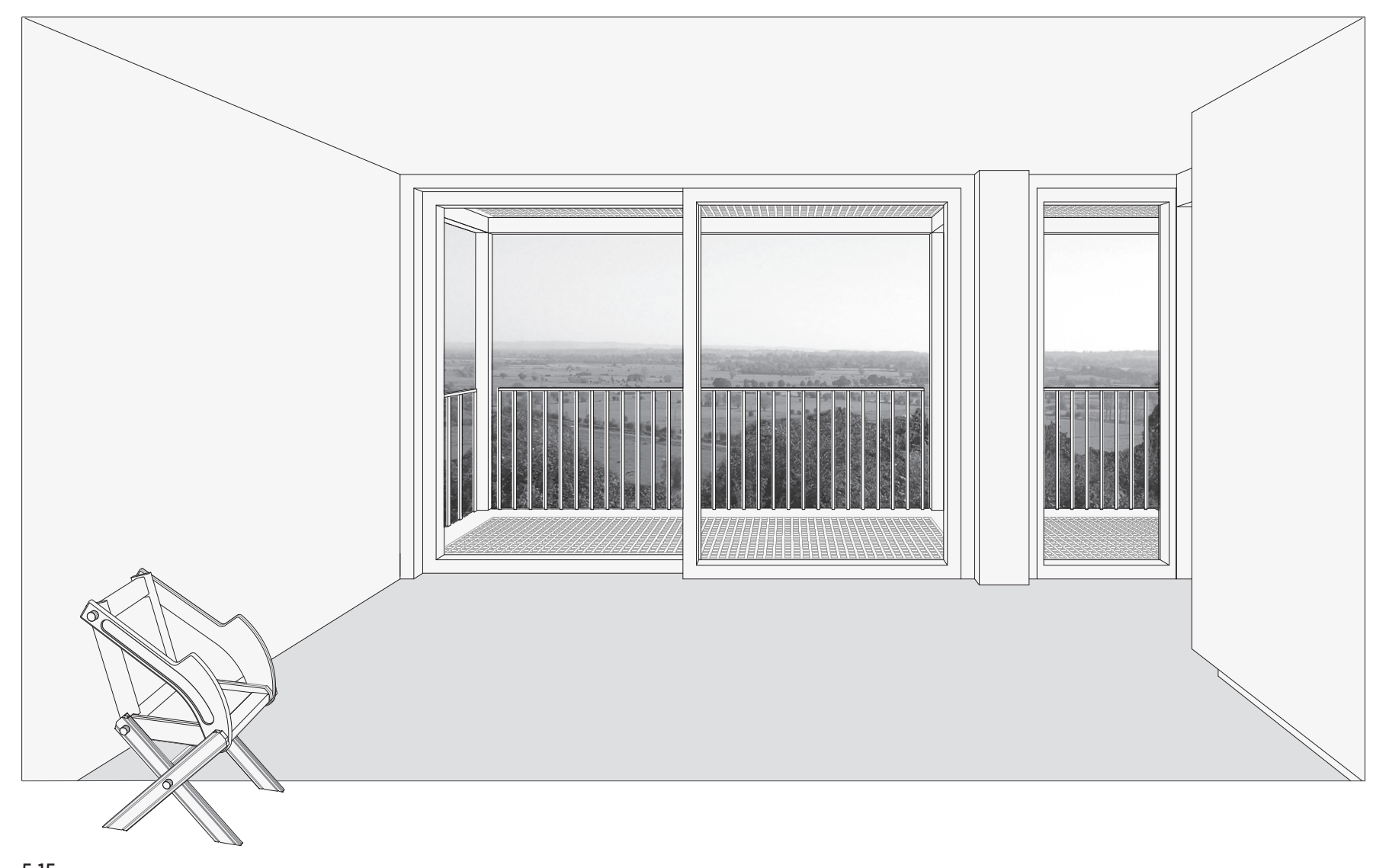

5.16

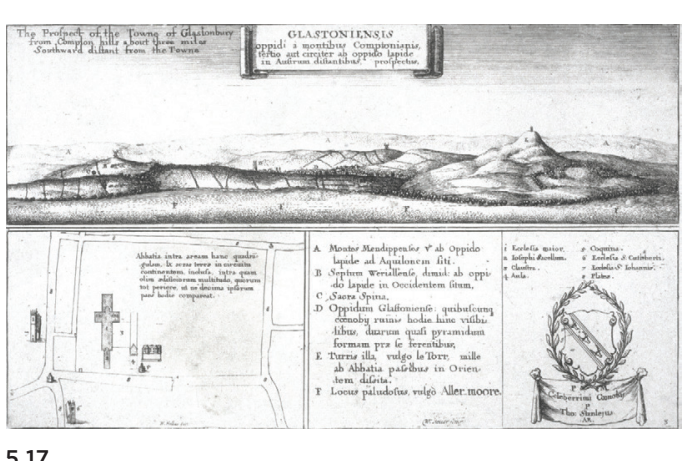




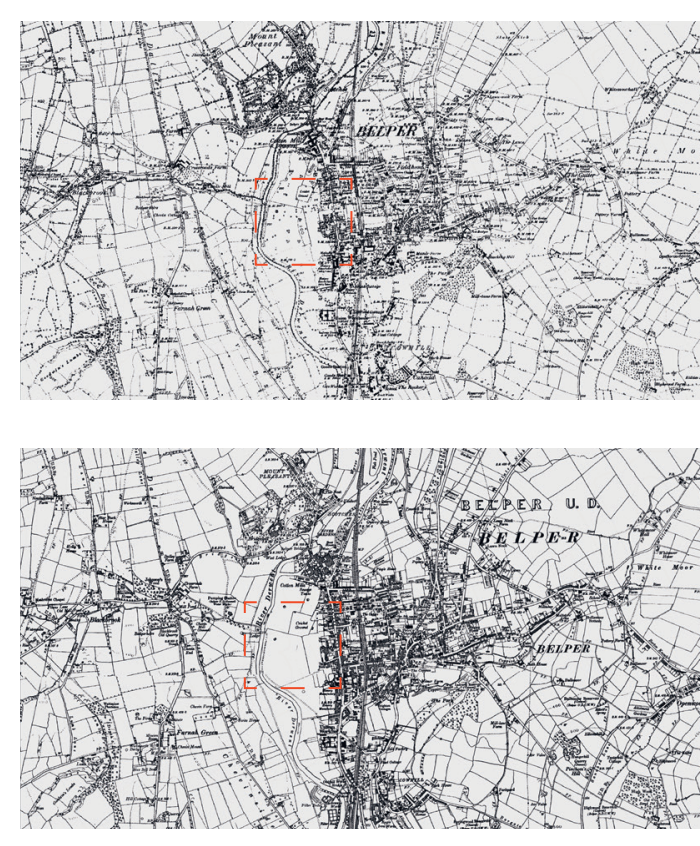

6.1

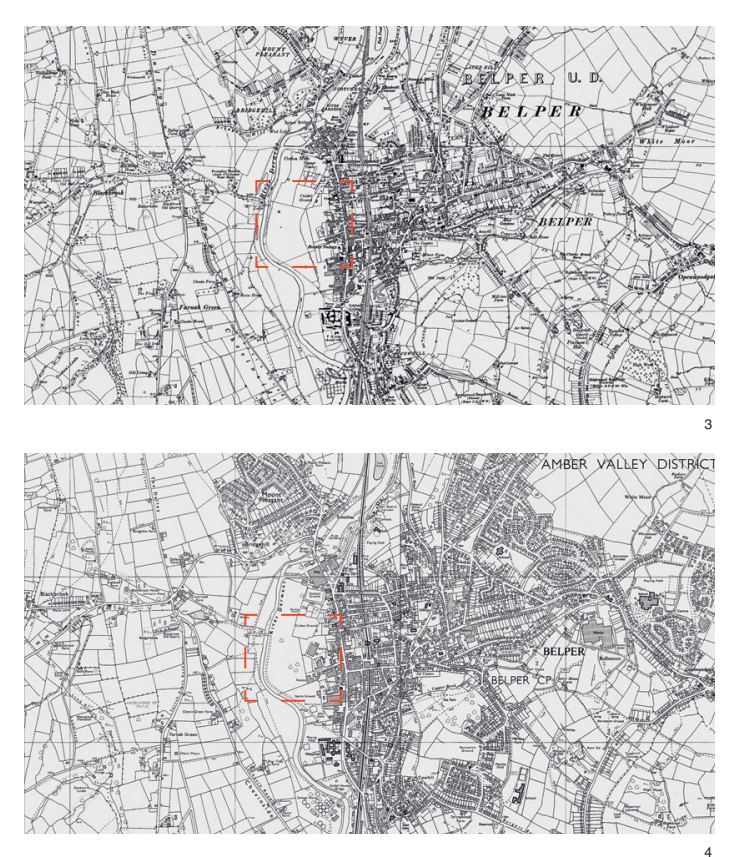

2015

Middle England | A Counterproposal

for Belper

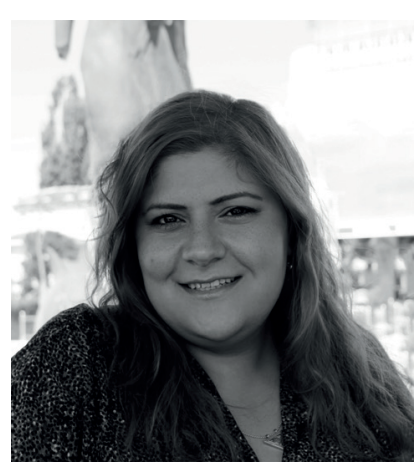
development. I Source: Image
courtesy of Digimap

1:10,000

1. 1860
2. 1900

3. 1930

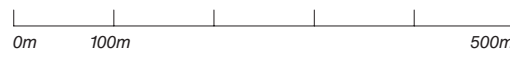

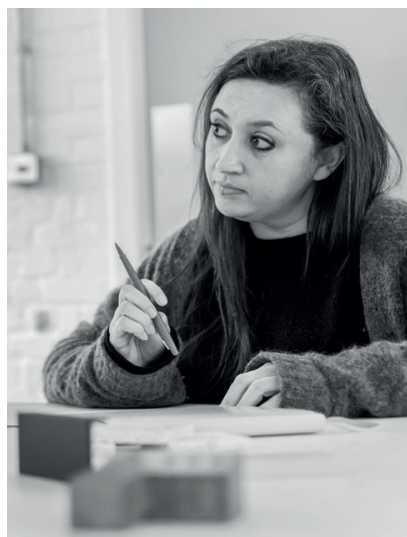

Tesco hoarding land and buildings on an area big enough for 15,000 homes

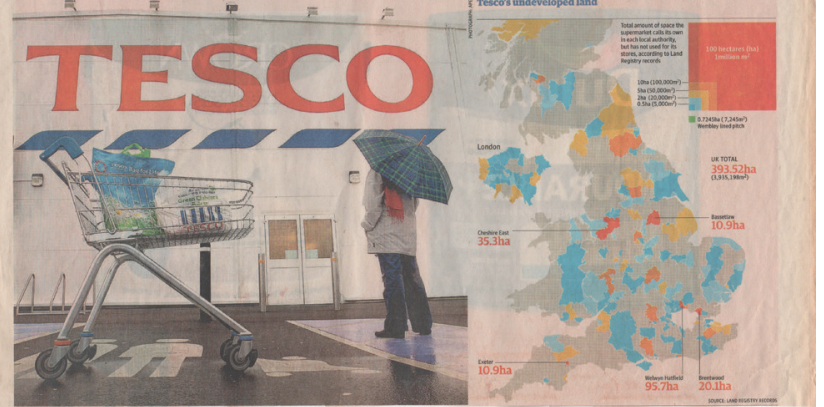

Meadows Edge Studio took place at to try and obtain planning permission Number 28, Belper, over the weekend extended over a decade and had galvaof 18-19 January 2014 on the invitation nised the local community in resistance. of George Jones and Pippa Mansel, Subsequently, there was considerable Mansel Architects, Belper, following an concern the site would be sold off pieceintroduction by Adrian Farmer, local meal without an overarching strategy historian, writer and heritage co-ordi- for its development as an extension of nator at Derbyshire County Council. Belper town centre for the benefit of The Studio included Kingston Unit 4 its inhabitants and the wider Derwent students taught by Pereen d'Avoine Valley World Heritage Site. The site

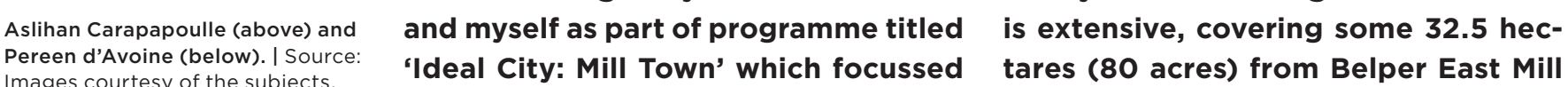
on the Derwent Valley World Heritage in the north to Belper Rugby Club to Site. Meadows Edge Studio occurred at a the south. It is located on the western timely moment. Tesco oc the bef the town centre, bounded by the Belper Meadows Edge. The process Bridge Street to the to the It consists of 


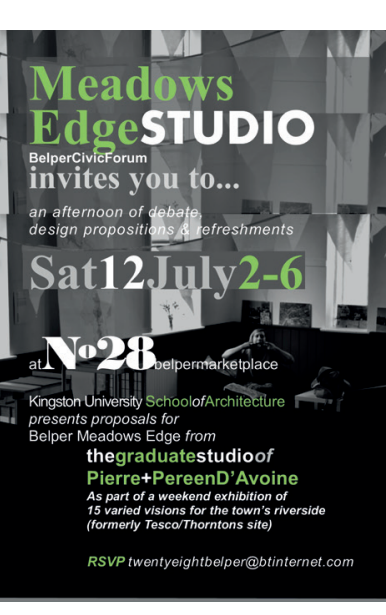

a mixture of shops, offices, the town Derwent River for water power. Pierre area west of Bridge Street has been moribund, student Aslihan Caroupapoulle were partly owing to indecision over Tesco's subsequently invited by Belper Urban plans for the site in their ownership, Forum to expand on student research but also because it contains light indus- and make proposals for the wider site, trial and other businesses which have struggled during the recent economic crisis. Further, Bridge Street forms part of the A6 - a major road artery which runs north from Derby through Belper and to some extent cuts off the site from
the rest of the town. The site including the River Derwent water meadow represents both opportunity and constraint on development. The river itself is a negled resource, andits potents impact on redevelopment is an imporimpact on revelopm is an important issue. Meadows Edge studio was an opportunity for students to consider fabric of the existing town and the surrounding landscape. Proposals were rounding landscape. Proposals were reviewed by a range of protagonists, ncluding Pauline Latham, MP for MId Derbyshire, Stephen Heathcote, local architect and planner, lan Jackson, former chairman of Transition Belper, Adrian Farmer, architects George Jones and Pippa Mansel, members of Belper Urban Forum and Barry Joyce, Vice Chair ICOMOS UK World Heritage Committee and author of The Outstanding Universal Value (OUV) criteria for the UK. The Derwent Valley World Heritage Site was designated in 2001 because it was here that the Industrial Revolution was born in the eighteenth century with the invention of the spinning mill by Richard Arkwright at Cromford using the including Belper town centre.

'Collaborative Practice'

Once upon a time, Zhuang Zhou dreamed he was a butterfly ... flitting about happily enjoying himself. He did not know that he was Zhou. Suddenly he awoke, and was palpably Zhou. He did not know whether he was Zhou, who had dreamed of being butterfly or a butterfly dreaming that was Zhou. (Zhuangzi and Ziporyn, 2009)

I have been teaching an MArch design studio at Kingston School of Architecture and have evolved a collaborative researchhan form bas. The mow foct rather than form based. The main focus for teaching is reflected in the course's curren context within an art and design-base faculty. The curriculum builds on the fundamental creative processes of observation and making, and its ethos could be summarised as thinking through making.

have previously taught in the diploma school at Bath University School of Architecture with Patrick Hodgkinson (1992-5) where the pedagogical approach involved considering the spaces between buildings as well as the design of the buildings themselves, and social engagement using ethnographic methods and spatial apping.

Teaching Diploma 8 at the AA School in he late 1990s, these methods were further developed, particularly in a programme se in the Bombay mill area where, as a result of distress migration, more than 25 per cent of the population occupied the pavements and the interstitial cracks and crevices of the city: the notion of an insurgent citizenship that through sheer numbers in desperate circumstances created a tipping point - an active scenario where the state authorities were overwhelmed into tacit acceptance. Such models from the developing world are viewed with circumspection by Westerneducated students when posited for global application and consumption.

ext particularly The Europe and the USA, which drawsin Europe and tecturalstudents from across the world, has an homogenisinge ing opportunity for debate across cultures and societies where differences as well as similarties may be explored and evolve through the student project. Increasingly, it becomes difficult to offer canonic critiques, as conformity of response cannot be expected, desired or achieved.

There is evidence that students are once more increasingly interested in collaborative forms of practice and design methods that engage with socially motivated outcomes.

At Kingston, where I have taught MArch design Studio 4 with Pereen d'Avoine Colette Sheddick and Alec Scragg, there have been initiatives set by Danie Rosbottom (ex-head of School and currently professor of Architecture of the Interior at TU Delft) which engage the whole school community In the period I have taugh at Kingston, we have focused on World
Heritage Sites over three consecutive academic years: $2012-5$. This provided scope and time to develop research tools and methods to interrogate issues of post-industrial decline across the scale of territory, urban settlement and the domestic in the context of redundant landscape, infrastructure and building fabric in the Derwent Valley World Heritage Site in Derbyshire in the English Midlands. Investigations have focussed on conditions which pertain to local context but aiming to inform a wider, even international application. The longer engagement with site and locale has enabled deper-rooted speculations which draw on relationships established onle across the political and ocias tan with issues, requing time for students with issues, requing ine for students prive vo and find wider in cultiva ton whe embraces landscape, We have refenodes of dwelling. We have refenced David Harvey's ook Spaces of Hope (2008) in which he distinguishes between utopias of spatial form and upias of time. The former have been central to modernist architectural thought and practice, and their political outcomes have tended to homogenising and totalising closure. Cosmopolitan neoliberalism exemplifies the way utopias of time are chimerical constructs in which the 'trickle down' effect is forever one of promise without fulfilment, engendering politics of frustration in an environment of disenfranchisement and dislocation. We have aimed for a ristiocation. utopianism in our programmesin order to 
encourage students to engage with a repoliticised understanding of the potential role of the architect, as well as an appreciation of architecture's limits.

Our programme in 2015-6 addressed the Thames in London between the Palace of Westminster and Putney Bridge where the Putney Debates took place in the seventeenth century and which resulted in ary act led ultimately to the supremacy Parliament and the restricted role of Britis sovereigns as constitutional monarch with limited excutive authority - narchs for democratic states challenged if not wic cuperceded to corporatism. lt opens up a demanding conof a city which in many ways is the epicentre of the neo-liberal project -the riverside tre of the neo-liberal project-the riverside of exclusivity. Students evolved their own critique in which ambiguity is much in evidence. Projects that resulted have been acts of optimism, heroism as well as attempte conciliation, drawing on the work of fem nist artists Roni Horn and Helen Chadwick,
and Gordon Matta-Clark's Fake Estates in which the interstitial provides an inspiratio to find means of occupying and extendin the city and leading to the creation of new common grounds. We engaged in conversation with Professor Pat Brown and students in the Landscape Masters studio to further our mutual understanding of the wider envronmental discourse som the architectural project

Writing about Matta-Clark's practice, We artist Dan Graham emphasises MattClark's process of revisiting illegible spaces in order to renew phenomenal accessibility and to replace social legibility. The impuls of revisitation challenges the modern social ideology of progress that discards the old and moves quickly onto the new. In order to expose what Graham names as 'the containment of the environment according to capitalist interests', Graham understands Matta-Clark's practice as 'an attack on the cycle of production and consumption at the experience of the remembered history of the city' (Graham, 2010).

\section{Barry Joyce}

Interview via Skype, 11 and 17 May 2018My background is in the field of art and design. That was my ambition as a young man, as a schoolboy, but I got encouraged an architectural training. $\mathrm{M}_{\mathrm{Y}}$ father died when I was 10. I had an architect uncle who was very much a fathe figure, and also my school encourage me to think about architectural training and that's what I did. And I was very, very fortunate in getting that training, which I found enormously enjoyable and interesting, and, of course, the first year of $m$ architectural training course was actuall pure Bauhaus. A man called John Starling was my tutor, and he took us through the first-year Bauhaus course, and that was a brilliant education. But as time went on I realised that my passion really was for environmental matters - a little wider than just individual focus on the design of one building. I was very interested in a 'sense of place' in particular and how a 'sense of place' in particular and how places are made, how they are made better much worse. So, it was spaces between

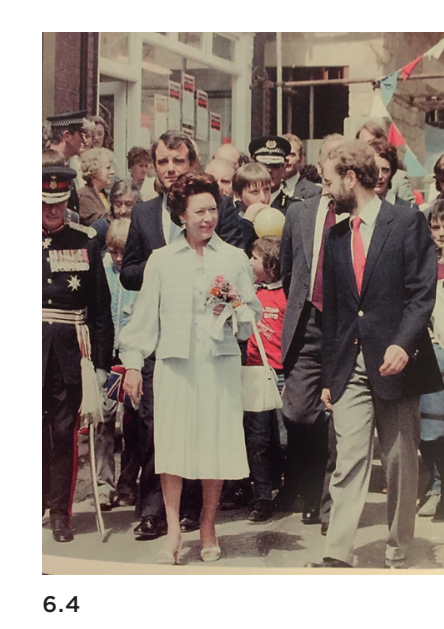

buildings as well as buildings and com1969, I went with four other fellow students (architectural students) to the USA, and we did a six-week tour of the States and saw the results of a laissez-faire approach to non-planning. I went to the USA as a architectural student, and I came back a planning student.

My architect uncle had a very lovely Arts and Crafts house in Gidea Park in Essex The Park was an architectural competition at the time of the First World War (in fact it was interrupted by the First World War). It

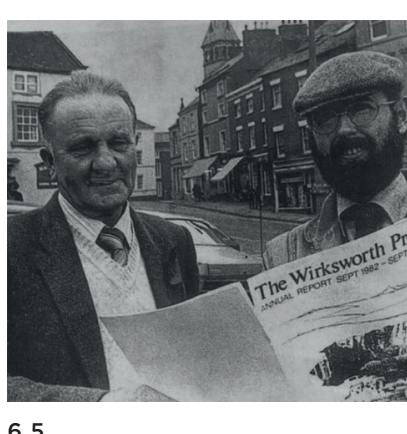

6.5

6.4 Barry Joyce with Princess
Margaret in Wirksworth

6.5 Barry Joyce and town
councillor and chair of town 


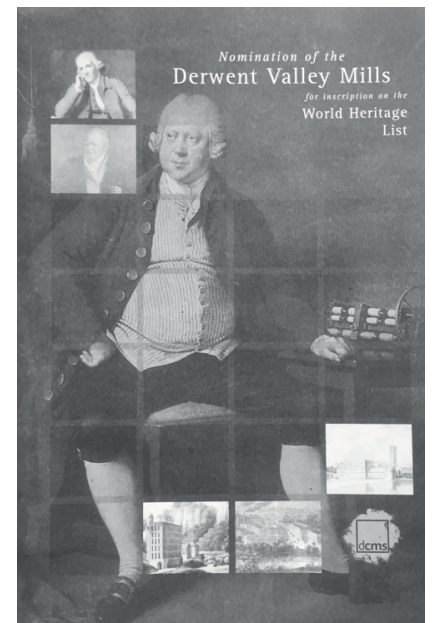

Hampstead Heath when Keith Albarn (Damon Albarn's father), who was teaching for economic and social regeneration. Now, art at Walthamstow Art School at the time, that sounds absolutely commonplace and and I teamed up to put on a gypsy festival on common sense now, but in 1977, that was Hampstead Heath using pneumatic tubes stacked one on another as a blow-up fence.

Well, we'd better not ramble on too much otherwise you'll have to edit it all before we get going... Where did we get to? Oh yes, the World Heritage Site ... Well, to cut out a whole load of my time, after realised that what I wanted to do was in the field of planning, my first job was with the chief architect in the planning department. While there, I came to understand vation, which very much tuned in with $\mathrm{m}$ interest in a sense of place, place making and place shaping, and the protection of great beauty in Britain in terms of wha we've inherited. And so eventually, after working there for about six years, I realise needed to be trained up in the field of conservation, and I did a postgraduate degree at Heriot-Watt University in Edinburgh in conservation - and that was very valuable training as well. So, I came straight from th to a job with Derbyshire County Councilcounty I didn't know and which is a very wonderful county. I came to enjoy my work there hugely. I arrived in Derbyshire in 1977 and it coincided with an initiative taken by Simon Sainsbury, who had his own family charitable trust called the Monument Trust. Simon wanted to use the Monument Trust money more inventively, and approached the Civic Trust to see if they would be inter-

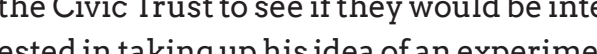
to take a market town, which had histori quite inventive thinking, and I' $m$ very, ver fortunate to take a role in that initiative working with the Civic Trust and consultant architect, Gordon Michell, who was wonderful and clever man who I learnt so much from.

He was awarded the OBE for his work doing that And I, in turn, was awarded the MBE for carrying it on But the work of that project was a huge success and received project was a huge success and received a Europa Nostra Gold Medal for achieveTown Pla planning a hiever for planing achiever. Institu of Directors, wu a speech to the Institute of Directors, quoted it as being brilliantly imaginative, and suddenly the tho wirks our town, Wirksworth, which is just outside the Derwent Valley. It was a complete circu because no-one had ever heard of this little town, and then, suddenly, the entire world wanted to know something about it. So, that was a huge, huge job. I was seconded for half of my time for nearly 10 years to do that. I went back and was then appointed team leader of the conservation team in Derbyshire County. That was my next major project, which was pulling together a team of archaeologists, urban designers, historic building conservationists, conservation officers, ecologists and environmental education teachers And that was a hugely enjoyable task - forming thas a hugely into a multidisciplinary these experts
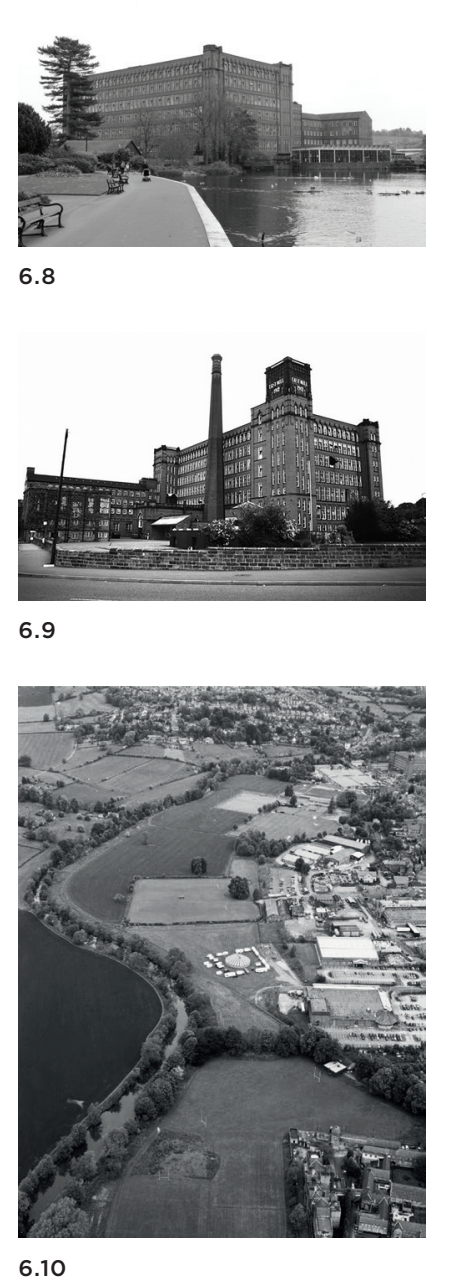

6.10

6.8 North Mill (rear), built in 1804
the world's first iron-framed building. I Source: Image

6.9 East Mill, built 1912, from

the River Garden

6.10 Aerial photograph of site. I
Source: Image courtesy of character assessment of Derbyshire. Thi worked wonderfully well. The landscap character assessment took the national landscape character assessment and broke it down into smaller units - a huge amoun of work but immensely valuable in terms of guiding the protection and enhancemen of the county and also how new development should be accommodated within that wonderful landscape.

And then my final major project was Alementing the ambition that had been held for around 35 years to make the Derwent Valley Mills a World Heritage Site. So, pulling together the document putting together a coherent argument to take to UNESCO of why the Derwent Villey Mills merited addition to the World Heritage cist Many World Heritage Sites are selfist Derwent Valley Millswere notatlobviors Dof most importan mill the 1771 mact, the by $\mathrm{Sir}$ Richar by acknowledgedas he firstsuccessfulfactory in the world-was only listed Grade lil at that ime. And so, it was a pretty substantial job the academic and environ mental arguments for why the Derwent Valley Mills were of world significance. We did it because we needed substantial investment to conserve these mills, which had go Mill had become a paint factory in the 1920 and so there was massive contamination to be dealt with and a very careful archaeological unpicking of what was there. But there are also the mills at La Bath, Belper, Milford and Derby. So, it's 15-mile-long linear site - a string of pearl along the Derwent Valley because the mills were powered by the River Derwent and its tributaries. We move on to Belper, which was really, arguably, the first mill town in the world, developed by Jedediah Strutt and his son, William Strutt, who carried on the work of his father to innovate. He was a brilliant engineer and developed, in collaboration with Charles Bage, a system of fireproof building construction. His North Mill of 1805 is almost exactly contemporary with Bage's Flax Mill in Shrewsbury, which is currently undergoing a multi-millionpound restoration.

Belper is arguably the world's first ilt by a dynasty of philanthropic industrialists Their work was ant innovative and of a high standard. The houses they bult for their workers survive remarkably intact. Strut's provision of houring carried on into the early ine provided chapels and schools, and later provided chapels and schools, and later previde swimming and a complete set of tran facilities and amenities.

\section{Could you comment on the housing} ypes provided and the model farms?

Yes, well, the first housing is the simple linear system of terraced housing. Although in themselves very interesting, particularly interesting are the early nineeenth-century cluster houses, which were blocks of four that could be described as back-to-backs. But they didn't suffer from the problems of classic industrial backto-backs because those back-to-backs, in Manchester and Birmingham and places, 
were linear, and so you got no throughventilation - but in blocks of four, that problem did not occur. And so, if you can imagine a block of four, split into four and then extend the divisions, you also get nice feature, and privies. So, this model of housing was employed by the industrialists in the Derwent Valley, not just at Belper but also at Darley Abbey and, as a model, was exported to continental Europe and the East Coast of the USA. We think (althoug we don't have absolute proof) that it's we don't have absolute proof) that it's a model probably devised by William Strutt, but he had a very good building surveyor
who probably implemented it...

Of equal interest are the model farms that the Strutt Family developed on the fringes of the town. William Strutt employed his fireproof construction techniques. He also used methods of processing materials. So, you get very innovative systems of processing the actual products of the farm through the barns, but also then bringing in the manure from the farmyards to process that back into the fields. And so it's quite an interesting series of very finely designed model farms around the west and north and south fringes of Belper town We're facing a particular challenge now. Although I've retired (I retired in 2012), still have a role in helping to manage the World Heritage Site in an advisory capacity.

\section{Can you talk about your role in setting}

up the Derwent Valley World Heritage

\section{Site and your wider role with UNESCO?}

When we had the task of getting the Derwent Valley Mills added to the World semi-detached pigsties, which is a rather

Heritage List, I discovered the archaic world of UNESCO and its adviser, ICOMO (which stands for International Council on Monuments and Sites) - a parallel universe really where they have their own vocabulary. Initially, I was rather critical of ICOMOS because they seemed to be a selfelected elite. Well, I'm slightly embarrassed to say that I'm now part of that self-elected elite because I'm now vice chairman of the ICOMOS UK World Heritage Committee. But the advantage of being a self-elected elite is that you're pretty fireproof I So I've discovered that ICOMOS an say things discovered hat that no-on els dat because they will be punisher or by a funding ant And seeing as we have only one member of staff and adog, we have alr already lost all of our funding - English Heritage cut the budget they gave us by 100 per cent. I think it was cut soon after the 2008 economic crash, but they did it, I believe, largely to punish us for objecting to the Stonehenge proposals for roads through the Stonehenge World Heritage Site, which was objected to only by ICOMOS UK and the National Trust under the brave chairmanship of CEO Fiona Reynolds, who was rapidly replaced. Her successors have not been so brave, and so they've keeled over. ICOMOS UK remains the only major objector, very clearly damning the idea of putting a dual carriageway through the Stonehenge World Heritage Site. Anyway, UK is able to say to explain how ICOMOS not because say what other bodies dare tough in causing 6.11 Derwent Valley World Heritage site map.
The site in the Lower Derwent valley is 15 miles
long and runs north from Derby to Matlock. don't toe the line.
So, yes, I have the role now as vice chairman on the World Heritage Committee of COMOSUK, which is a very interesting role. We have very limited ability to influence Wings, but we try our very best.I represent ICOMOS UK on the Derwent Valley Mills World Heritage steering group now. Mainly, we have a particular concern at Belper at the moment with the future of the William Strutt 1804 North Mill and the much-later 1912 English Sewing Cotton Company Mill (in Accrington red brickwork) next to it ( off-shore company that is notcarrying out d repairs And so discussions with Amber Valley Borough Council and Historic England with a view to Council and tolice followed up by a compulsory chase for Another hat I wear is that vice chir An the Derbyshire Historic vice Buildings Trust, which has picked up the show bord

could you talk briefly about the idea of 'outstanding universal value' and also, Derwent Valley?

Yes, this is very important. A fundamental atribute of the outstanding universal value of the Derwent Valley Mills is the fact that this was a pioneer of industrialisation in the 1770s and onwards (well, and before that, the 1720 s with the silk mill in Derby but then really picked up Arkwright in the 1770s). this site is that it is a pioneer example of 
industrialisation because the industry went values are and what the attributes are that over from water power to steam power. It represent on

then moved further north to Manchester

primarily resulting in the Derwent Valley Could you talk about Belper in particular Mills industrial sites remaining in the and the initiative along the Meadows agricultural landscape they sat in, in the Edge and the combination of people who eighteenth century. So, it's a wonderful are involved there - people like Adrian example of arrested industrialisation. Farmer, Pippa Mansel and George Jones UNESCO inscription statements emphasise and Ian Thompson of Transition Belper? the importance of this. So, in terms of man- Also, the Belper Urban Forum and how aging it as a World Heritage Site, it's critical that consciousness-raising initiative that we retain its rural agricultural setting has evolved over the Now, this is quite a challenge today we got involved with our Kingston stuNow, his is a chosures - housing dents, it was incredibly uplifting to stubecause of development pressures-housing dents, it was incredibly uplifting to se development pressures in particular. We that taking place and to participate in a are facing two. We have fought a number of planning appeals and have succeeded, but we're facing two more looming up at Yes, that's very important. Well, curiously, we mom in Belat started off as a fantastically damaging want to build in the buffer zone. Now, let threat turned out to be somewhat rather me explain what a buffer zone is... UNESCO beneficial. Nothing pulls people togethe recommends that World Heritage Sites are better than a great threat, and in the case given a defined setting zone. It's not the only of Belper, the great threat came from Tesco consideration in terms of protective setting, who wanted to build an $80,000 \mathrm{ft}^{2}$ superbut it is intended to protect the immediate market on the western side of the town, on setting of a World Heritage Site. In our case, the river, right next to the river meadows. we have defined quite large buffer zones for This would have been enormously damag reasons I've given. At Milford, it's skyline to ing to the town. The town had benefitted skyline. But by the time you get to Belper, the terrifically from a townscape heritage invalley flattens out to some extent, and so the tiative grant scheme run by the Lottery, buffer zone is more extensive. It seems to be English Heritage and the local authorities. a difficult concept for the elected members That grant scheme had particularly put a of the local planning authority to grasp (well, lot of investment into the small businesses that's putting a charitable spin on it). So, that ran retail outlets and small offices in we're getting rather inconsistent decisions the town centre. That investment would've from the Amber Valley Borough Council in been completely undone if the Tesco's terms of planning permissions. So, we do idea had come to pass because $80,000 \mathrm{ft}^{2}$ perhaps need to a little more training in would've been the biggest Tesco ever terms of explaining the idea of first of all developed, and it would've sold every poswhat a site of universal value is, what these sible thing competing with all the tow's hops. So, that was a 10 -year battle to fight Thops. So, that was a 10-year battle to fight in a wonderful community came together massive objection a very valuable role in helping to chalenge Tesco in the expert fields. Tesco wa required to submit its design proposals to the Commission for Architecture and the Built Environment (CABE), whose commen was 'it is insulting to bring this before us, it's such a bad proposal' So, there were a few critical people helping to facilitate this community constructive opposition. Absolutely central to it (as you've already said) were Adrian Farmer the member of the World Herita Site team at the county council I appointed him actually he had council. I appointe him initially appoin officer for the World Heritage Site, but his abilities became very apparent early on, and he was then employed as the World Heritage Site coordinator. He has done a brilliant job, and I'm delighted to say that's recently been recognised by the awarding of the British Empire Medal to him for the wonderful work he's done. Within the town community, there were some wonderful and well-informed and clever people who were experts in the field of design and environmental considerations. So, you've got Mansel Architects, George Jones and Pippa Mansel, who have played a remarkable role in helping to guide laypeople through the in rocess Also, you mentioned Ian, who pros Pre conder has worked together to make the most of

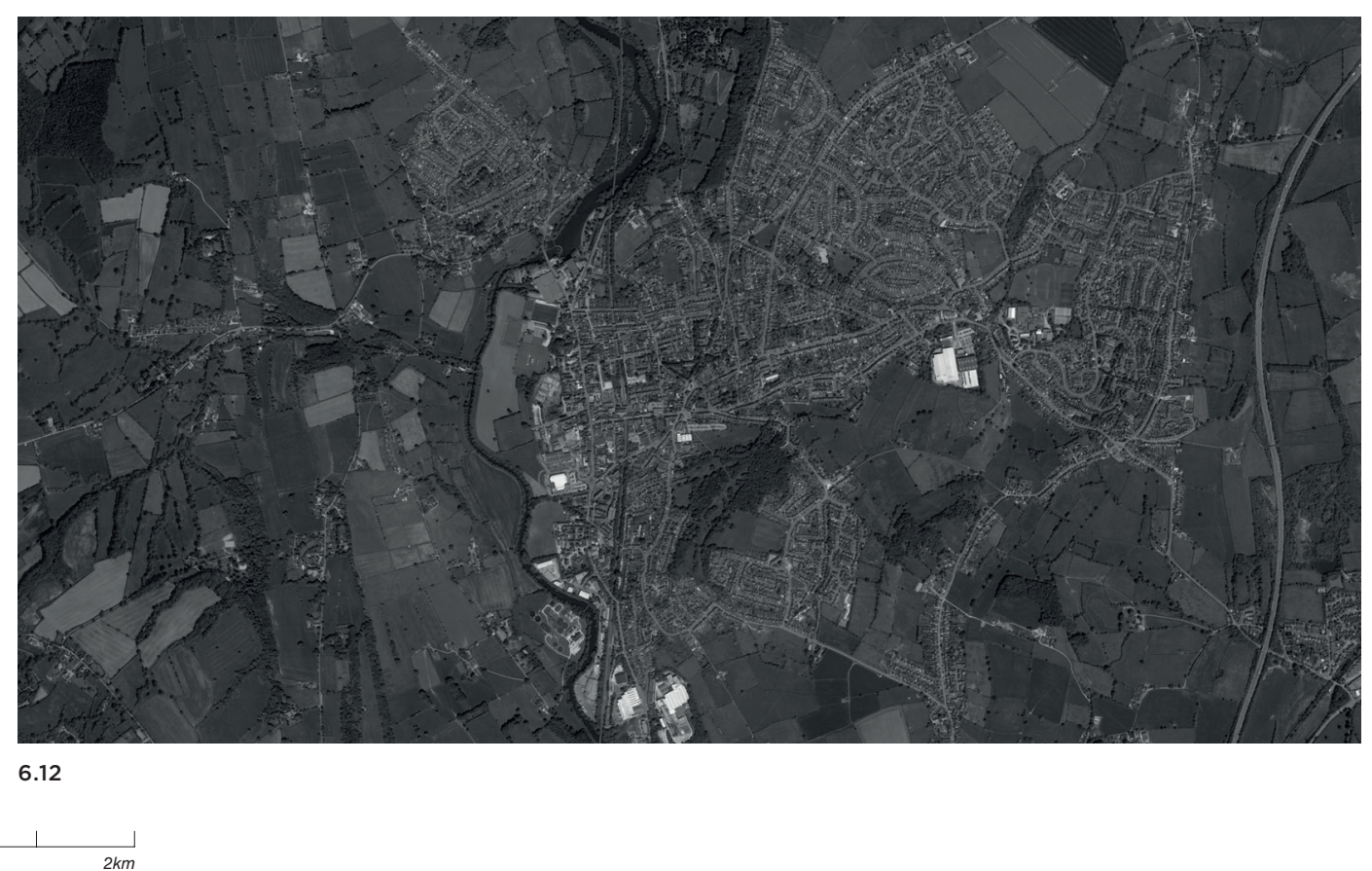

1:40,000

1. Belper town centre
2. Belper Meadow

om $\quad 100 m+1-1=0$ 


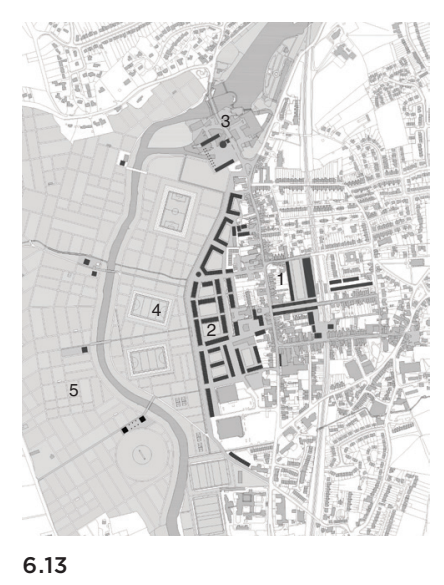

6.13

6.13 Action plan for Belper

\section{Belper Vision}

\section{Menu of Possibilities}

A Counterproposal for Belper evolved out of student research and community consultation. The Menu of Possibilities initiated a series of design proposals for the town and the meadow which could be implemented in phases

The need for a comprehensive strategy for Belper in order to enhance the Derwent Valley World Heritage Site. This can be done by integrating the best of the existing and providing the best of the new.

Linking town centre to Meadows Edge:

A new public realm from Market Place to west of the River Derwent

Privileging the local - calming through traffic on Bridge Street/A6, enabling the existing town centre to connect to the sites to the west of Bridge Street Removing the roundabout

New retail, commercial, residential and leisure development opportunities Removing Poundland to restore the railway bridges vista

Transport interchange and car parking relocated

Petrol station relocated further south on west side of Bridge Street.

2. An alternative to the Tesco proposal:

Terraces of three- and four-storey town houses forming streets and squares Not just residential but terraces of mixed-use development including:

Flats over shops and offices as well as live/work

Light industrial - provide new garage workshops (currently on Derwent Street) Stitching the torn fabric of the site east of Bridge Street with a variety of roads and pathways

The new roads are not a bypass to Bridge Street

Car parking on streets - no new large car parks.

3. East Mill and environs:

A hotel and leisure complex in East Mill

Restoring the mill streams

Cortaulds relocated and the site used as a major public square flanked with residential and other development in two terraces.

4. Landscaping Belper Meadows:

A promenade to Meadows Edge - promenade above/arbours below, the latter linked to shops, restaurants and residential terraces fronting Belper Meadows
Reference: the Royal Crescent, Bath)

(Reference: Matlock Bath, Derbyshire, without the through traffic)

A public park for Belper, extending from the Railway Bridge in the north to Babbington Hospital in the south

Sports pitches integrated into the landscape garden

A site for public events - Belper music festival.

5. Belper West

Extension across the Derwent River:

\section{Phase}

Four new bridges

Flower nurseries/market gardening

Four new focal points:

Sports club building

Swimming baths building and outdoor poo

Youth club building

Civic building.

\section{Phase 2}

A new community - housing, retail, commercial, leisure, agriculture An Urban Code

Using the best locally sourced materials for buildings and hard landscaping A new ground for Belper town centre which links existing and new.

what Belper has to offer. It went through a it's as desirable as that. Tourism can be terrific trauma in the 1990s and 2000s, as damaging as well as beneficial. I think, it were, when the textile industry finally essentially, it's batting itself as a quality collapsed totally in Belper. It was really a place, that's how I'd describe it - a place textile town right up to then, but then the where the quality of life is high and, as a last remaining factories caved in, then the result, it's a good place to locate yourself, mills caved in. So, Belper has had to find a not just to live but also to work.

new role, and as a heritage town, it's really risen to that challenge extraordinarily well.

\section{What would you define as its new role?} Note
1. 'Collaborative Practice' is a short essay first
published in $D$ omus 1003 lune 2016 .

I hesitate to say 'tourism' because I don't think it's as simple as that, nor do I think published in Domus 1003, 'une 2016. The essay
discusses Pierre d'Avoine's pedagogy, in particular discusses Pierre d'Avoine's pedagogy, in particular
the MArch studio he taught with Pereen d'Avoine the MArch studio he taught with Pereen d'Avo
at Kingston School of Architecture 2012-15, during which time the studio focussed on the 


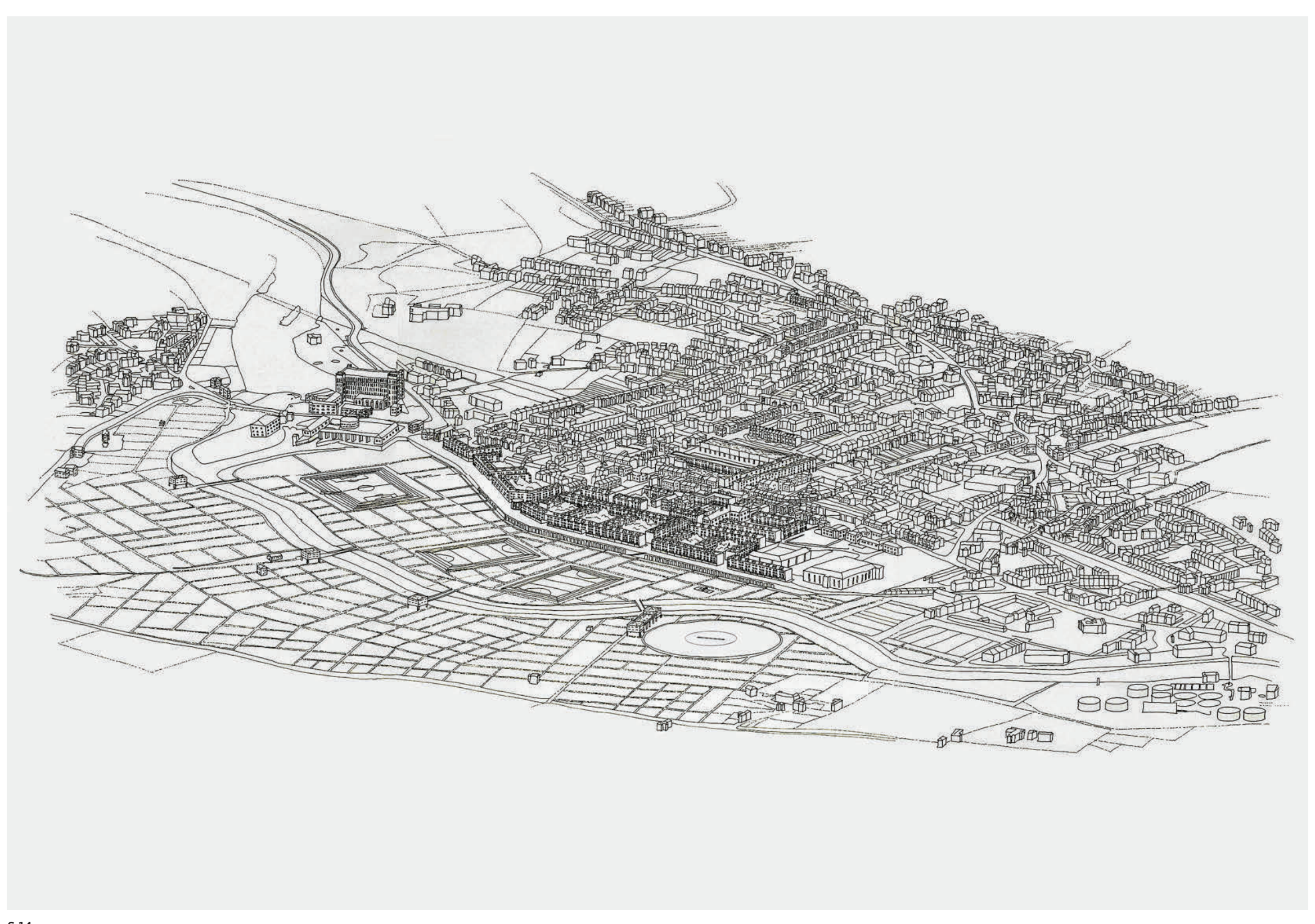



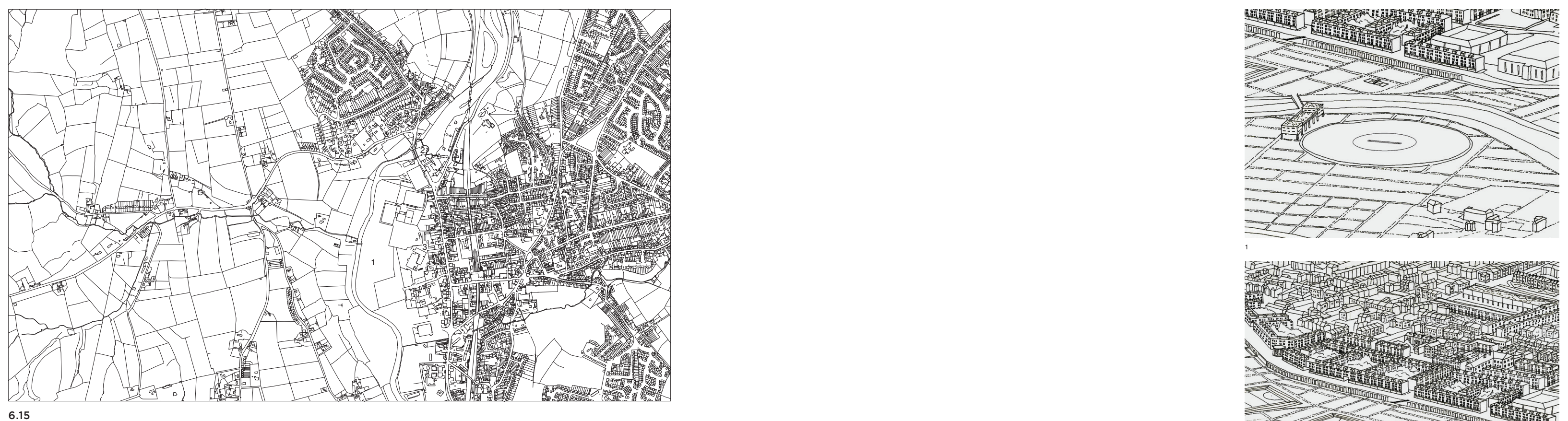

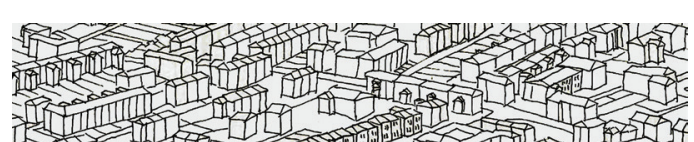

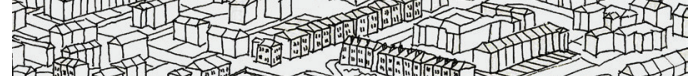
107.

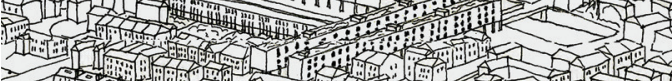
2. 3.

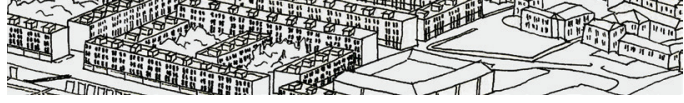
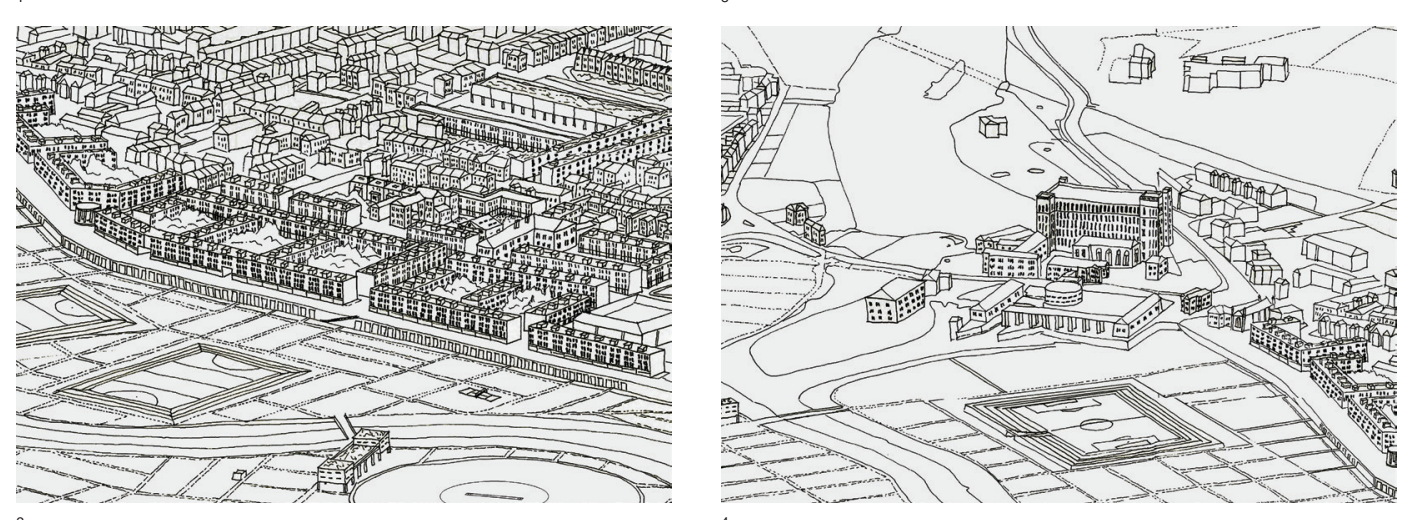


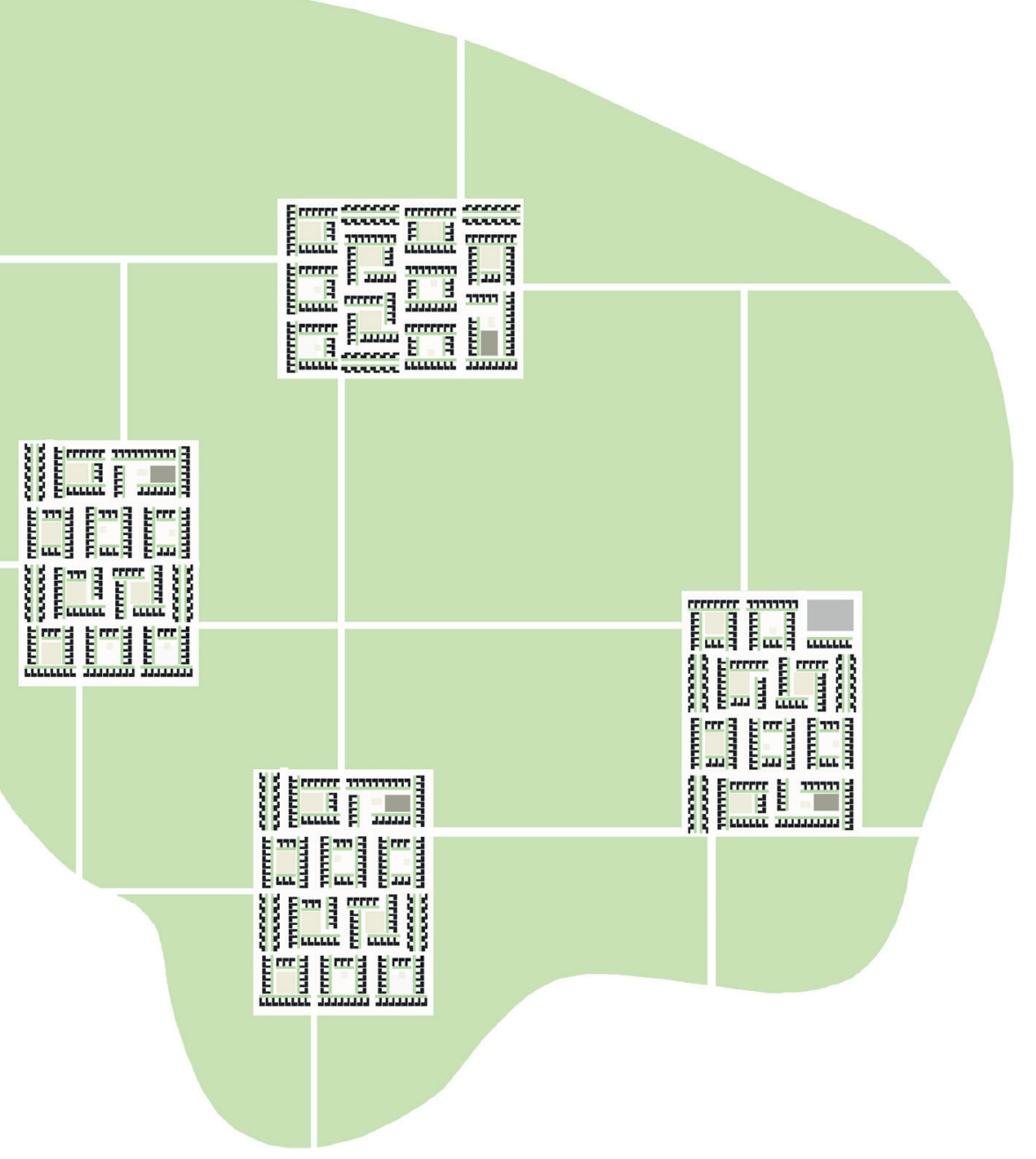

7.1
7.1 Swaythling settlements
integrated into productive

parkland

1:16,000

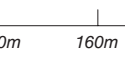

7.2 site plan

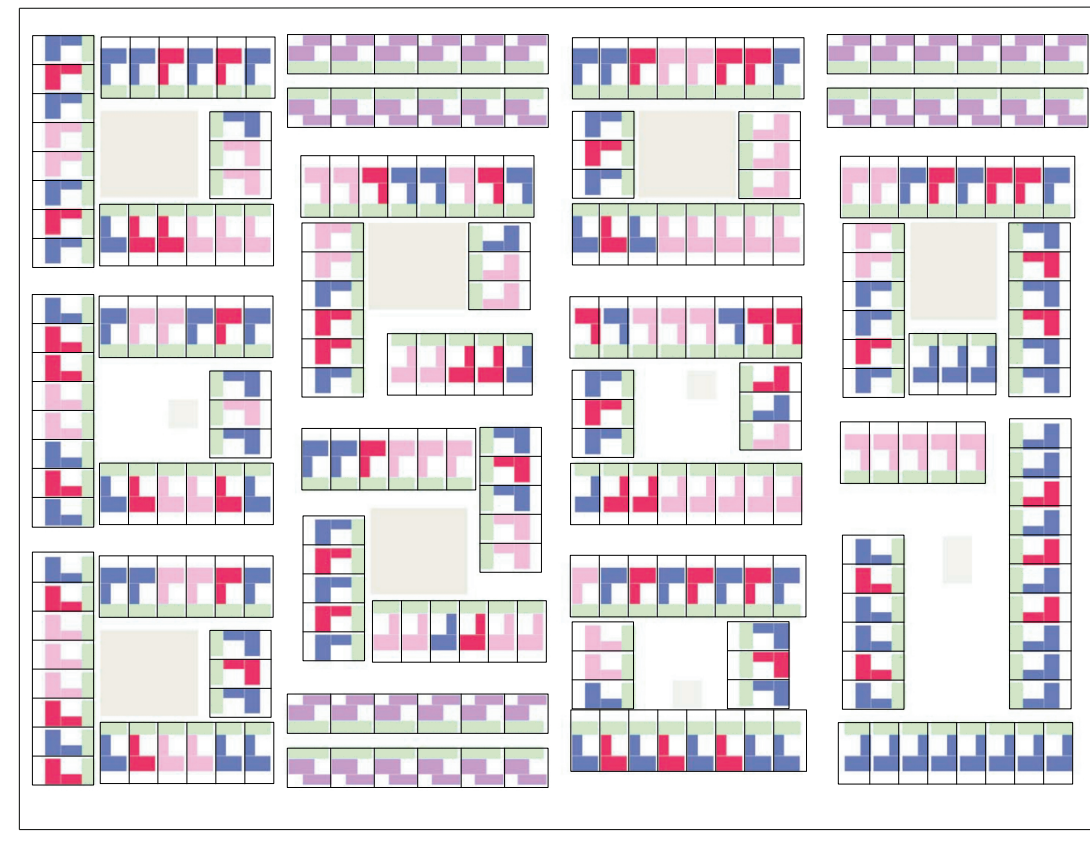

The Swaythling Housing Society, resort towns from Brighton in the east to based in Hampshire near the port of Bournemouth to the west, with the more Southampton, held a competition to densely developed naval and commercial design house types to be developed ports of Portsmouth and Southampton in terraces. A site was not identified. situated in between. Southampton is the However, the general locale was sug- centre of a conurbation of towns and gested as suburban and semi-rural villages bounded by the M27/M3 motordownland north of the city. The south way. The motorway infrastructure built coast forms a loose necklace of seaside in the late 1960s/early 1970 s superceded 


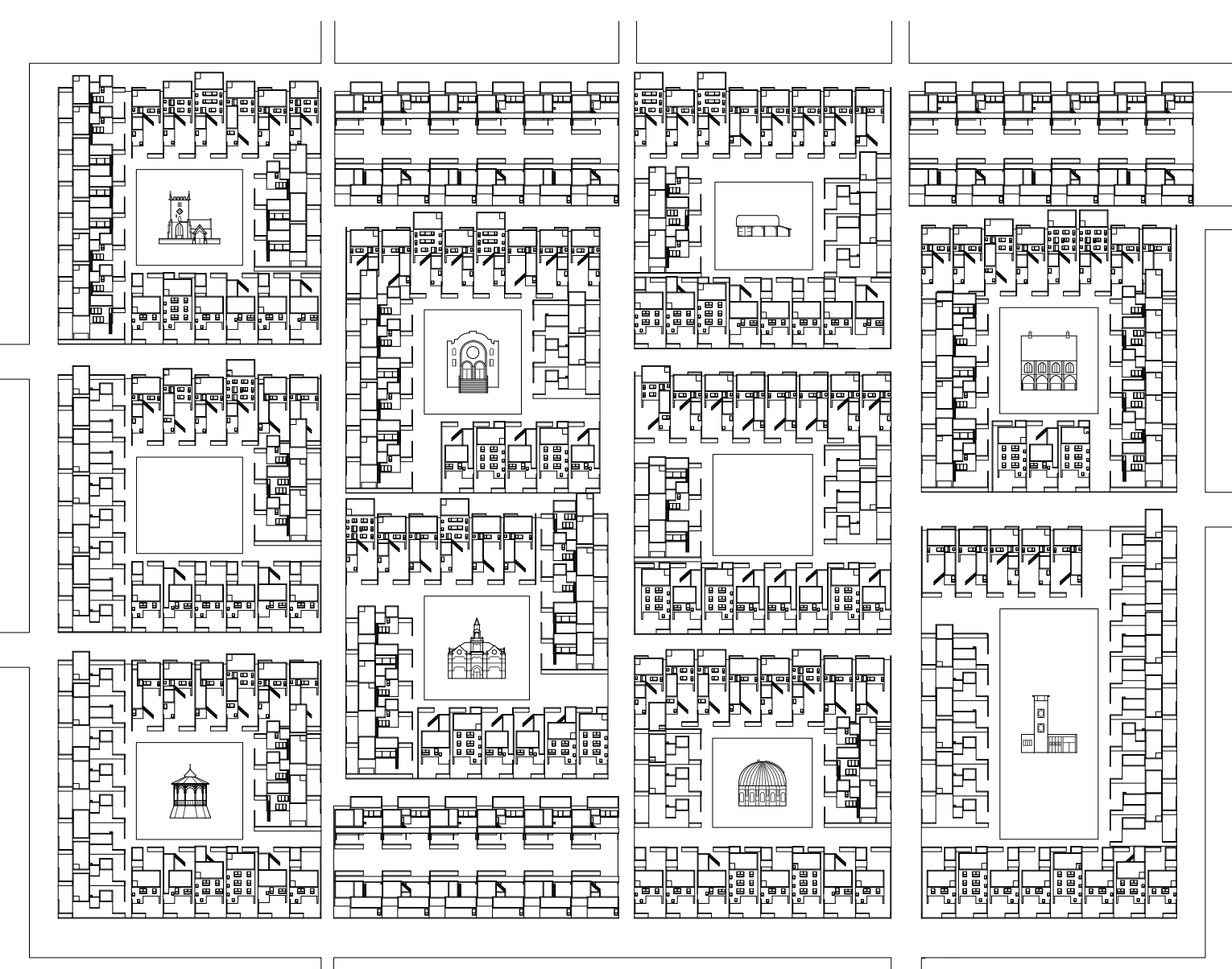

7.3

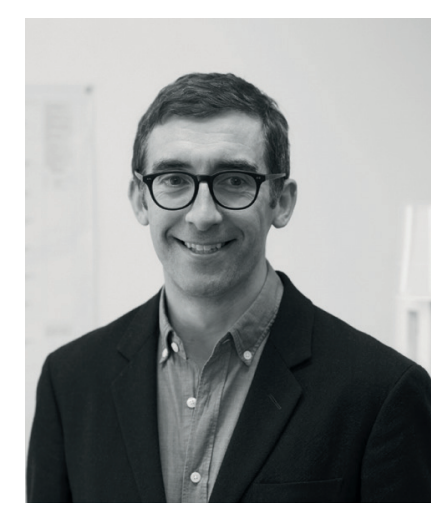

7.3 Planometric showing public
buildings in the squares

1:3000

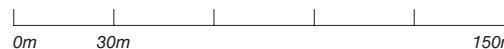
Housing Competition. I Source
Photograph by Katie Hyams. the $\mathrm{A} 3$ to London and provides a major earn a living, he was working in the garden connection to the capital and the rest to grow enough food for a large family. They of England. It leapfrogged the hinter- seemed, in my mind, to produce enough land to Southampton, leaving behind a crops to sustain us. I mean, I'm sure they patchwork of mixed development and went to the shops like everybody else, farmland that lacks visual coherence but it's an Arcadian memory I have. Now, and order. In the period between 1970 looking back professionally, you realise how and 1990, Hampshire County architect unusual that form of existence is because Colin Stansfield-Smith and his team low-density development with a large house designed and built a wonderful series in a big plot isn't really how we can design of progressive schools, including one at professionally today. The cost of land is too Eastleigh, one of the larger towns in the high, we need to build denser to be more conurbation. Our shortlisted proposal sustainable, make better use of land, get conurbation. Our shortlsted proposal sustainable, make better use of land, get includes nhe dwe flats strets and squares. There is potent streets and squ ares. The is pothin to construct public buldingswinthe seemed ment is loc as nithin a Each setlo- garden, trees the ment is located within a park landscape, bulld dens, and t would build up a sense of providing a biomass crop for a district adventure, and we'd take risks and learn heating scheme. The volumetric modular ab

approach consists of steel-framed

modules assembled in a factory located I presume that the food that your father on site within the parkland to provide and family cultivated was seasonal? work opportunities for people living in the local area. All dwellings have the Yes, exactly. Of course, you can still get potential for customisation, within an them today, but we ate gooseberries, mulurban code applied to the buildings and berries and redcurrants, and things that public realm.

Alex Ely aren't necessarily conspicuous in the supermarkets today, as well as the usual staples. It was an interesting mix of things

Interview at Pierre d'Avoine Architects, that they grew.

Durham Yard, London, 1 September 2016-I'm one of five children. I grew up in a village in Hampshire, and moved to
London when I was studying architecture.

And did you store vegetables for winter consumption?

One of my strongest childhood memories is of my parents being self-sufficient in food
production. When my dad wasn't working to

It's funny, isn't it, that today we buy our vegetables from the supermarket or local

market, and they'll last a weet or local 


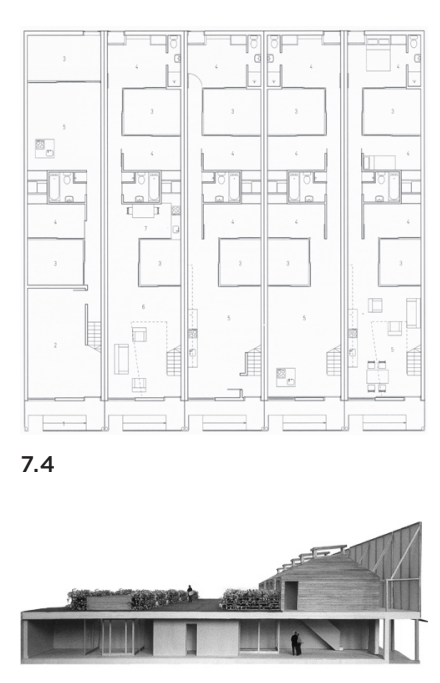
7.5

emember that we used to store apples over winter. We put them in racks, put newspa- was part of my upbringing. But I didn't per down to keep them dry and keep them hone in on architecture as a profession separate so that they wouldn't rot, and then until choosing a university subject. you could make a crumble next season.

What did your parents do for a living? sounds idyllic, but then it also sounds

quite prescient in terms of the way that $\mathrm{My}$ father was a successful lawyer, and we now think about consumption. We my mother started her career as a fashion are critical of the quality of imported designer, had her own business and subfood, as it can be bland and tasteless. I sequently taught fashion at Southampton ' kids, that rather tookover her life I did my think there's something in that.

I think I probably am being as well, but now I'm such a city dweller - and I have been for the last30 yers-that you woover whether you took that lifestyle for granted or whether you could even still have that lifestyle today. I guess I have a different perspective now. At the time, I misse that cultural engagement that we enjoy In cities - that social contact. There was sense of community in the village, but you weren't exposed to broader culture in the way that we enjoy in city living. But at the same time, moving into a city, you have to accept those compromises of imported goods and a remoteness from the means of production. degree at the University of Nottingham. It was a well-rounded course that exposes you effectively to the new language that you're learning with an insight into technical demands, to history and theory, but perhaps lacking critical engagement. enjoyed Nottingham, and it was a solid foundation for architecture. We worked collectively in a studio. So, there was a lo of sharing of ideas and discussion between the students burning the midnight oil an sleeping under the drawing board (precomputers)! This was at the start of 1990. Then I went to work in Hong Kong for Foster and Partners on the Chek Lap Kok Airport, which was a really stimulating experience and incredibly hard work. It was long hours but hugely rewarding. Then What were your interests at school? I decided to come back and study at the Did you have an early interest in Royal College of $\mathrm{Art}(\mathrm{RCA})$ to get a different architecture?

education and to move to London.

I think it was latent. We would visit numer- I taught at the RCA in your first year ous country and stately houses in school although we didn't have much contact ous coys, which I would diligently draw Irecall Dinah Casson was running the in perspective. I was always busy with school, and it was in transition.

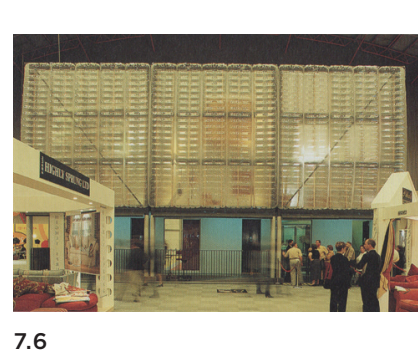

In my first year, there was a strong culture of collaboration with other disciplines. Effectively, we went out, and we found our own projects. We forged our own connections. So, I collaborated with photography students, with product designers, ceramicists and print makers, and that was really appealing. Nigel Coates joined as

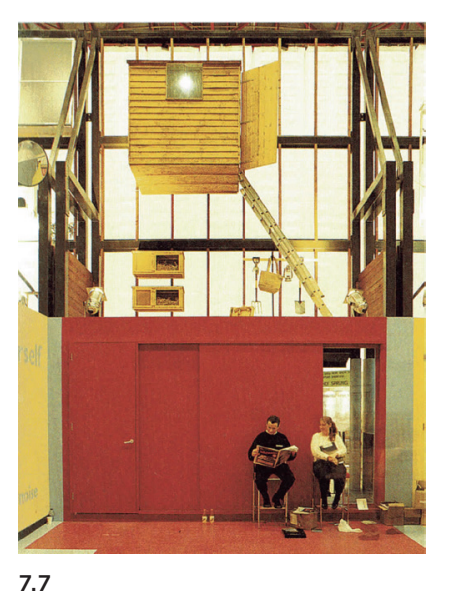

a professor in my second year. He took over running the school and introduced a unit system with more focus on strong briefs and projects; the architecture school turned in on itself a bit. But that's not meant to be critical; it just meant that we focused on our discipline. Nigel was very good at promoting an interest in the relationship between architecture and the city, which perhaps opened up our world view beyond the crafting of buildings.

So, an interest in urbanism and the design of cities. I remember Branson 7.6 Inflatable facade to 'Slim House' prototype, Ideal Hom
Show, 1999. I I ource: Image
courtesy of David Grandorge. 7.7 DIY back to 'Slim House'
prototype. I Source: Image
courtesy of David Grandorge. in 1992. It was quite fantastic

It's something I always remember about Nigel's time as a professor.

Did you travel much in that time to other places as part of the course?

The RCA has affiliations and partnership studios in different parts of the world. I wen to Lisbon where the RCA had a studio, and I used it as an opportunity to explore the work of Álvaro Siza, who I was fascinated by, and spent my time travelling through Portugal, looking, studying, drawing and sketching his work.
Did you go to the Malagueira housing complex in Évora, just south-east of Lisbon?

Yes, but I mainly looked at his public buildings: schools, libraries, museums. I suppose that housing - to come back to the subject f the book - wasn't such a big obsession or interest as a student. It wasn't something that was part of education then in the way that we see now at the Cass and at other schools. Housing seems to be back on the agenda as a subject to study. It wasn't really when I was studying, and in fact, I would probably say that it wasn't until working with you, Pierre, that ideas around housing became much more appealing and stimulated my interest.

\section{What did you do when you left the RCA?}

I drifted between getting some professional experience to get my Part 3, doing private projects and teaching at Greenwich University School of Architecture. And of course, I worked with you on the Slim House.

So, there's the Nigel Coates connection again because the Ideal Home Show had revitalised the House for the Future Competition.

That's right, and the Oyster House was the first Concept House in 1998.

We entered the second competition because Naomi Laviolle, a French architect who was working with us, suggested 
that we do it, and I think we just did it slightly off the cuff.

It was a lot of fun. I can't remember who we were up against .

\section{There were a lot of entries.}

We don't do many open design competitions now as a practice because they are hugely resource intensive, and the odds are very long, but I very much enjoyed doin the Slim House - Concept House - entry.

The main reason we entered is that it had a very good jury. Cedric Price was a juror, as well as Fred Manson, who wa at the time, and Tim Macfarlane. I think that was the stimulus for us.

I think what I enjoyed about that project and working with you was your clear drive to have a very strong idea that underpinne the project, with the form of the building being generated by that idea - by stretching a house over the full plot of a standard Georgian terrace and then extending it verextra space. But then, you also taught m that architects have to accept that there's moment where inhabitation takes over and that the people who live in our buildings will interpret our designs in their own way. So, we had this lovely idea of the Queen Anne front and the Mary-Anne back - a formal contribution to the city and a slightly chaotic DIY back that could have dovectes and hydroponics and garden sheds attached to it.
The following year, the Ideal Home competition again, an through pub conversations with a coupl of friends of mine, Katy Ghahremani an Michael Kohn, we decided to enter and won it. Our thinking then was that rather than just designing a house, we would design a concept for a housing company, and it's something that has stayed with me subsequently in practice - an idea that architects have a duty beyond the life of building. We were interested in an idea that house builders could potentially fulfil a role beyond just building hous and moving on - that they could offer lifetime service, upgrading exterer fetime service, upgrading, extending, downsizing, improving the performance of your home over its lifetime. So, we develcopd a concept called the Hangar House Company, won the competition and built a show home at the Ideal Home Show. It was more like an exhibition stand rathe than a house.

What interested us to enter the competition was the invitation to reinterpre the traditional English terrace house. It interested us as Londoners because that was our bread and butter. We were immersed in that genre. The year before the focus was the suburban villa. Was there a particular theme when you won?

Ours was focused on flexibility and adaptability.

Could it exist in an urban context?

It could, although it wasn't the starting point. We did demonstrate how it could
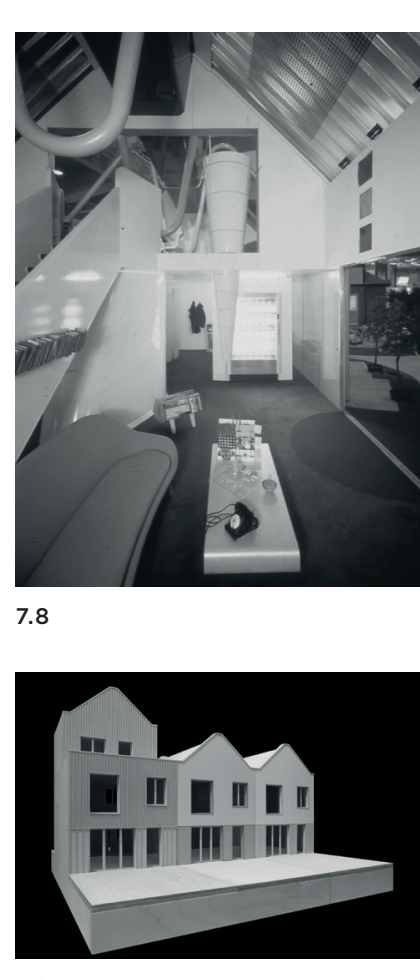

7.9

7.8 'Hangar House' winner
Concepg touse 2000 . Source: Image courtesy of Katy

7.9 'My House', MAE Architects form clusters or larger urban blocks, but essentially it was a detached house.

It's interesting that your approach included procurement and construction, and then also the monitoring of it over a period of time during occupation. It suggests there was a potential for real interaction between the user and the team that designed and built it.

I think that as a profession, generally, we're not very good at post-occupancy evaluation. We're notvery good tatting fee We're notvery good getting feedback an are used, how people enjoy or don't enjoy living in the homes that wo don't enjoy hey like, what they like, whathey dontike. Ithink there's huge scope for us all to improve the quality of our work by having a better feedback loop One of my current projects, informed by both Slim House and Hangar House, is called My House. It's a proposal for custom-build housing. There's a drive, in part from the government, to promote custom-build and self-build. Custom-build is less hands-on, doit-yourself; it's more about catalogue homes built by manufacturers with developers or landowners putting forward sites, adding services and selling plots to customers who the choose a manufacturer offering customisable homes. So, My House is very much in that vein. We're looking to offer houses direct to the customer or via enabling developers.

Can we discuss how you set up in practice and also worked for CABE?

Well, the practice came first. I set up $M æ$ very young-I was 29 - but fee-earning work was slim, and I felt that there was a need to have a different perspective on our profession. CABE was just being set up, and it looked like a really interesting organisation to be part of. So, I applied and was taken on, continuing practice at weekends. CABE was very energetic. It was idealistic, eager to make change and influence the government and convince clients, developers, local authorities, the public sector that design added value. There was a lot of support for CABE; I think its demise is sad. My role wasto devolop CABE's housing anda focusing on policy, res housing agenda, focusing on policy, research and dhe government develop policies to drive up design quality, speak at champion commisvich And by value, I don't just madds value. An but cultural value and social value and around issuessuch as healue value but cultural vale and wein. wer espere insight has proved enormously useful.

You were a juror for the Swaythling Housing competition that my practice was shortlisted for. At that point, you were at CABE and still practising as $\mathrm{M}$. Could you speak about your role as juror?

One of the programmes that $\mathrm{CABE}$ was probably not that well known for was its enabling programme. Enablers were a panel of practising architects and professionals could call on to help advise clie 
role, I would go out and build relationship with the Housing Corporation, or English adaptability could respond to the differen Partnerships and other agencies, and then sites that might come forward.

through them get housing associations

or local authorities to sign up to having We worked with Aran Chadwick and CABE's enabling support. Sometimes, I'd Atelier One, and Guy Nevill of Max provide the enabling support myself. So, Fordham on the competition. Just before when Swaythling Housing Society came this, we had worked with Aran on the forward and said they'd be really interested rooftop houses at the Piper Building in working with CABE on a competition, I using volumetric modular construction helped them develop the brief and sat on which Aran introduced us to as state the jury. The competition brief asked for house yes without providing a site or locaSouthampton called Swaythling. It's in the suburban/semi-rural hinterlan contained by the M27 motorway. When we did the competition, that was the kind of area we situated ourselves in.

Swaythling Housing Society had sites in mind. Effectively, they were looking for prototype to deploy on different sites. Th is both a dilemma and an interest for $\mathrm{m}$ in housing. On the one hand. architects can act as urban designers and as master planners, contributing to place making are embedded as part of the continuity of the urban realm. Yet, at the same time, housing as a mass production process can design prototypes. For instance, Jea Prouvé's Maison Métropole is a classic, prefabricated, industrially produced house. The Swaythling Housing competition was very much focused on developing a of the art at the time. For the competisuburban layout of streets and squ than Some of the squares would accommodate public buildings, one of would be buit at to manufart for the urban pevironment for the urban environment wasn't just housing. It included a public realm and public buildings creating the infrastructure for communal life. Our team visited roaming the town centre and driving around its environs. That was our bit of research, which sounds rather perfunctory. The nature of competitions involves something of a stab in the dark because there is never enough time to conduct serious research. Walters \& Cohen won the competition. Do you know what happened afterwards?

No, to be honest, I lost touch with the project. You've hit on a broader concern about competitions, and perhaps at CABE we could've done more to provide ongoing tion, we proposed an urban rather than could be conver the hous and which munity or Eastleigh in a minibus. We spent the day
Swaythling. I wonder how the competition Swather processes compare with other countries that don't get realised, and given the level of investment that practices make in generating those ideas, it's a pity that so many fall by the wayside. I think that as as a culture, a profession and an industry, we need a competition system that goes beyond the initial design pitch and, if necessary, works with the client to help them deliver. Given that competitions by their very nature are asking clients to take a risk to some extent they probably need a greter degree of help afterwards to keep that vision alive.

I completely agree. The UK Europan competitions in the early 2000s - I was a juror on one- were notorious, as none of the winning schemes was built. This problem occurred in other European countries. However, there were some encourage young practices to build.

I think it's a chequered history. One of the other competitions that I ran at CABE was the Anglo-French initiative wher we invited local authorities and housing associations to identify a site in Londo and two sites in Paris, and invited archtects to partner with a counterpart in the other country. One I ran was Bourbon Lane, White City, West London, for Octavia Housing. We selected the design by Cartwright Pickard with B + C Architectes, and it was realised - and it's a wonderfu athere, at the time of projects, not necessarily competitions, but procurement initiatives that CABE supported through its enabling program that led to very successful outcomes.

Another important topic that I wanted to talk about is housing space standards in which you have established an expertise.

When I was made head of sustainable communities at CABE, my principal focus was policy, which included working with John Prescott's government department on its sustainable communities plan It made me aware of how architects can colmade me he le ad thas something hat the o ractice, we work beyond pur that, as a por icontinued to chase opportures o tender for public policy work on for to write the new London Housing Design Guide. It uride. It was a synthetic exercise: part of f job plethora at were being used at the time - from Lifetime Homes, the Homes and Communities Agency's standards, the BRE standards, Secured by Design, Building for Life, those sorts of things - pull them into one place and edit out all of the duplication because I think architects and planners felt a bit overwhelmed by the sheer volume of standards, and part of the task in London was to bring it into a more concise document. Although there are still lot of requirements in the document, I think that was a notable achievement to simplify and consolidate. The main focus 


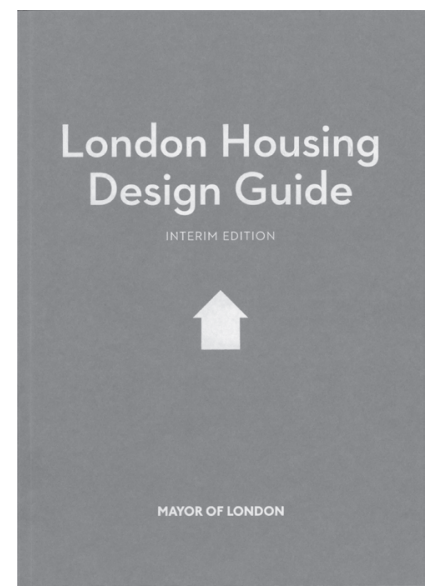

7.10

7.10 London Housing Design
Guide, interim edition.

Source: Image courtes
of Mayor of London. was developing space standards. So, we did needs. So, they might not deal with spempirical research, drawing on the Parker cialist housing, student housing or eve Morris principle of developing space stand- housing for older people, but as a sort of ards around designed occupancy, which benchmark, as a minimum safety net, they allowed us to create a robust methodology seem to work well.

for coming up with the metrics we did. So,

we came up with a matrix that set space

standards based on the number of intended

cccupants. Now, of course, buying a home, It's one of the trickiest conundrum

its intended occupancy, but as a robust because ultimately I think land values have

basis to appraise schemes through plan- a bigger impact on affordability and the

ning, it seemed like the right way to go. price of housing on affordability and the ning, it seemed like the right way to go. price of housing than the cost of producThis was at a time when there was evidence tion, and we talked earlier about moder The the mister sets the were bin the the have, some of the smallest space stand- ity crisis, but actually that's not really the ards in Europe, and the quality of homes problem. You might save a few thousand generally seemed to be very poor - and the but land value in London and the SouthMayor wanted to do somethingabut that. East is such a high proportion of the overal As a policy document, it had to go out to development costs, it's pushing housin consultation. There was a very rigorous beyond the affordability of most.

and formal process of consultation, and I think there are scenarios where the there was quite strong opposition, but like land might be cheap, but with the governny policy, once it's adopted and once the ment prioritising brownfield development legislative body has decided that it's to be the abnormal costs are higher. You've also implemented, we all adjusted and suddenly got to pay for Section 106 contributions house builders and developers factored and infrastructure. So, in some areas, the it into their appraisals, reappraised their cost of actually building the homes will land offers and developed different design exceed any values that can be recovered, approaches that could nonetheless protect and that's why housing production slows their margins. The feedback that I've had down in those areas. I think the thing that is that it's been very well received. To some doesn't get addressed enough in the bigger extent, the design guide, and specifically conversation about housing supply and the space standards, can be seen to be demand is economic growth: stimulat- order to improve access to housing. A lot necessarily about trying to balance out of the reports you read from the govern- our overheated economy in the South-East ment about housing supply and demand versus the shortage of work opportuniare always about trying to increase pro- ties elsewhere. It's a big topic for further duction and lower costs. They're not discussion.
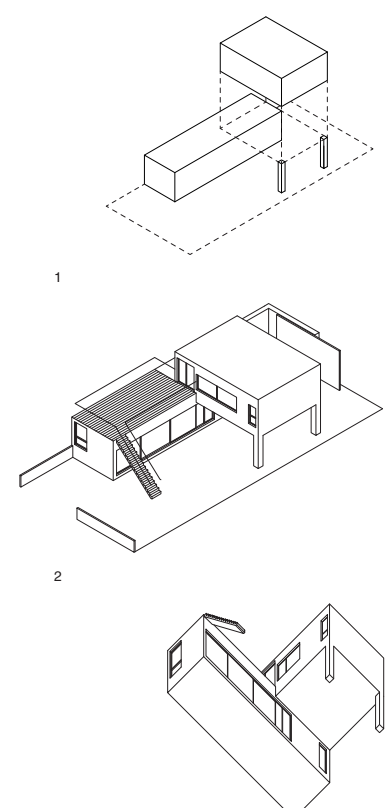

$48 \mathrm{~m}^{2}+45 \mathrm{~m}^{2}$

1. Type A diagram
2. Axonometric

3. Worm's-eye axonometric

4. Front elevation
5. Side elevation

5. Side elevation
6. Rear eleavation
7. Side elevan

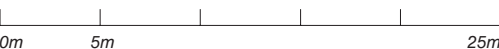
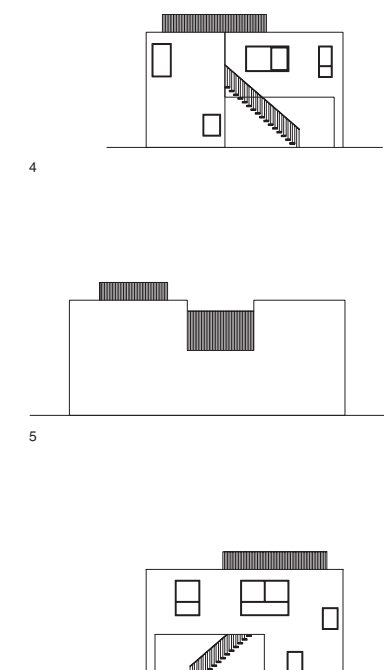
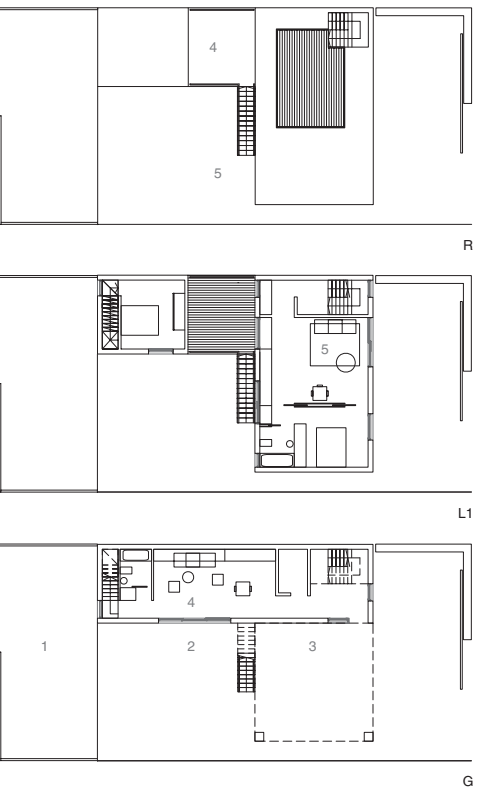

1. Garden
2. Entrance
a

Undercroft/parking
One-bedroom duple 4. One-bedroom duplex
5. One-bedroom flat quite limiting and are based upon general 

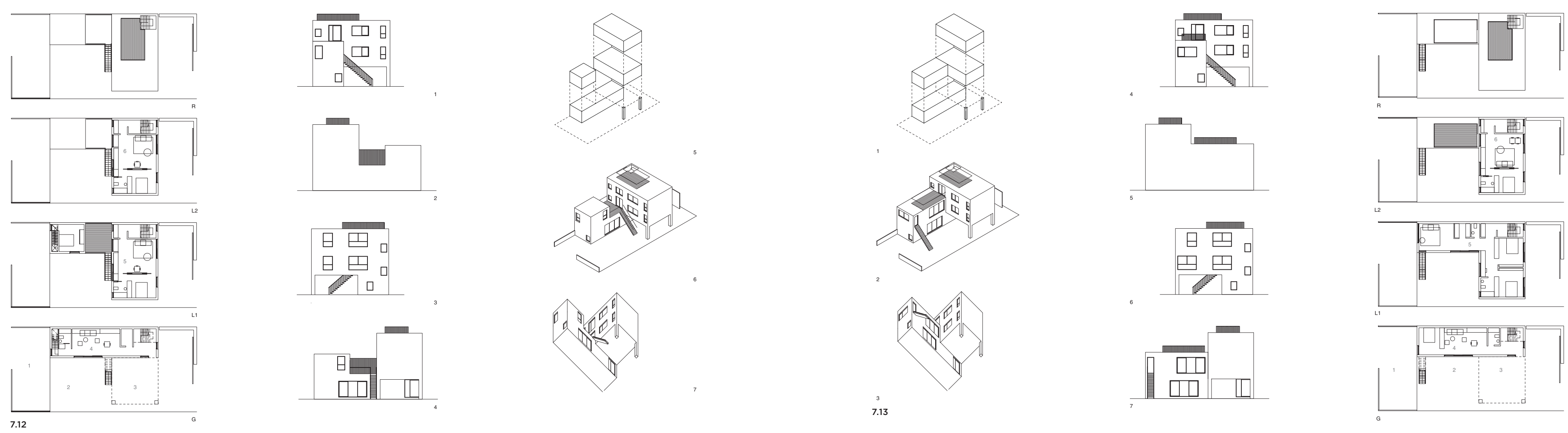

7.12 Type B, 3 storeys, 1 single-bedroom
duplex +2 single-bedroom flats $48 \mathrm{~m}^{2}+45 \mathrm{~m}^{2}+45 \mathrm{~m}^{2}$

1. Garden
2. Entrance
S

2. Entrance courtyard
3. Undercrofott parking 4. One-bedroom duplex
5. One--bedroom flat 5. One-bedroom flat
6. One-bedroom flat

1. Front elevation
2. Side elevation

3. Rear elevation

4. Side elevation
5. Type B Bdiagram
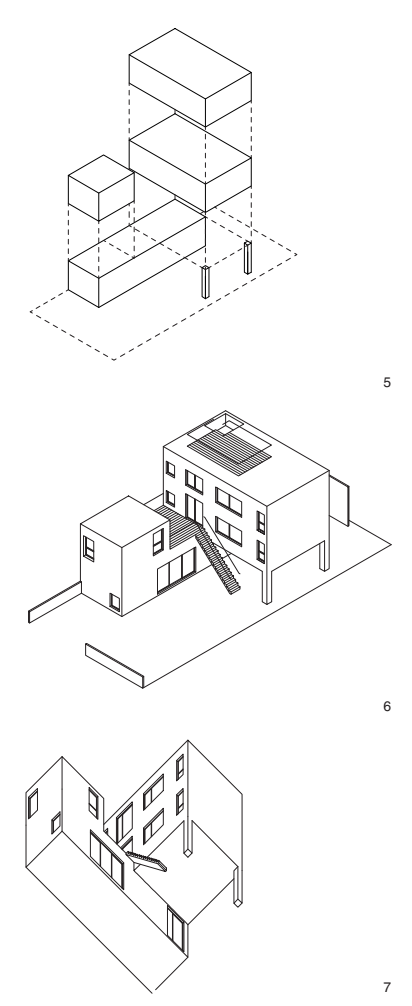

6. Axonometric
7.13 Type $C, 3$ storeys,
2 single-bedroom flats

2 single-bedroom flat
1 two-bedroom flat

two-bearoom fiat

$37 \mathrm{~m}^{2}+45 \mathrm{~m}^{2}+74 \mathrm{~m}^{2}$

1. Type C diagram
2. Axonometric

3. Worm's-eye axonomet

4. Front elevation
5. Side elevation

6. Rear elevation
7. Side elevation

4. Onde-crodt
5. Thoom flat

5. Two-bedrom flat
6. One-bedroom tlat 

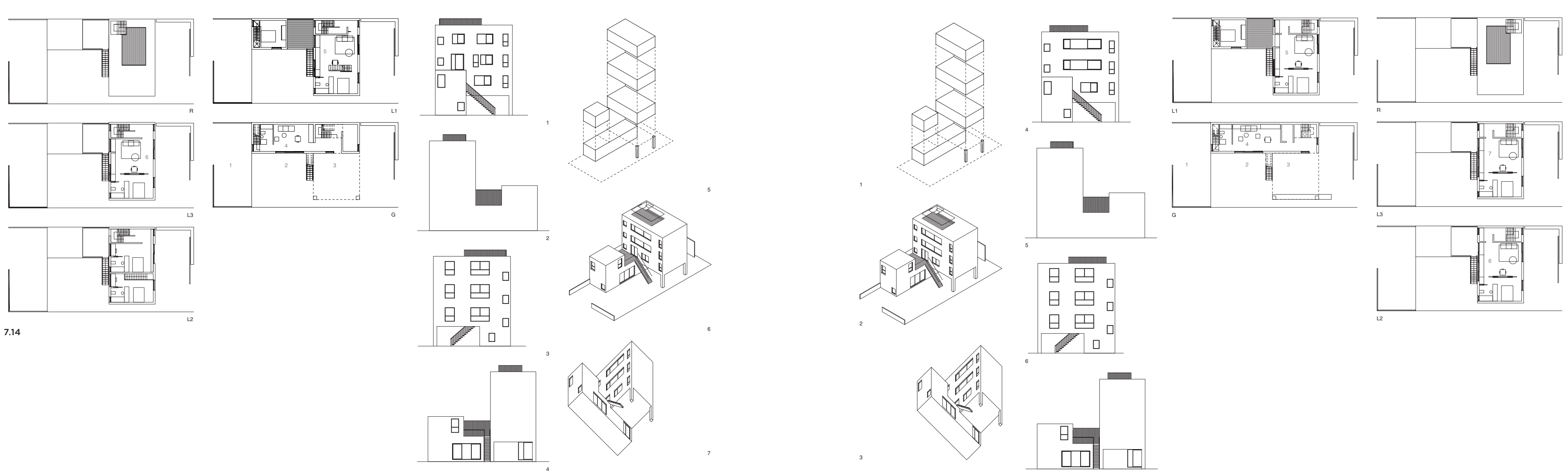

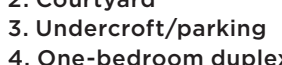

4. One-bedroom duplex
5. Tho-bedroom duplex
6. Two-bedroom duplex

7.14 Type D, 4 storeys, 1 single-bedroom
duplex +2 two-bedrom

$48 m^{2}+69 m^{2}+73 m^{2}$

$48 \mathrm{~m}^{2}+69 \mathrm{~m}^{2}+73 \mathrm{~m}^{2}$

1. Front elevation
2. Side elevation

3. Rear elevation

4. Side elevation
5.Type D diagram

5.Type D diagram
6. Axonometric
7. Worm's-eye axonome

4. One-bedroom duplex
3. One-berking

5. One-bedroom flat
6. One-bedroom flat

duplex, three storeys, 1 single-bedroo

$48 \mathrm{~m}^{2}+45 \mathrm{~m}^{2}+45 \mathrm{~m}^{2}+45 \mathrm{~m}^{2}$

1. Type E diagram
2. Axonometric

5. Side elevation
6. Rear elevation

7. One-bedroom flat

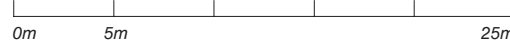




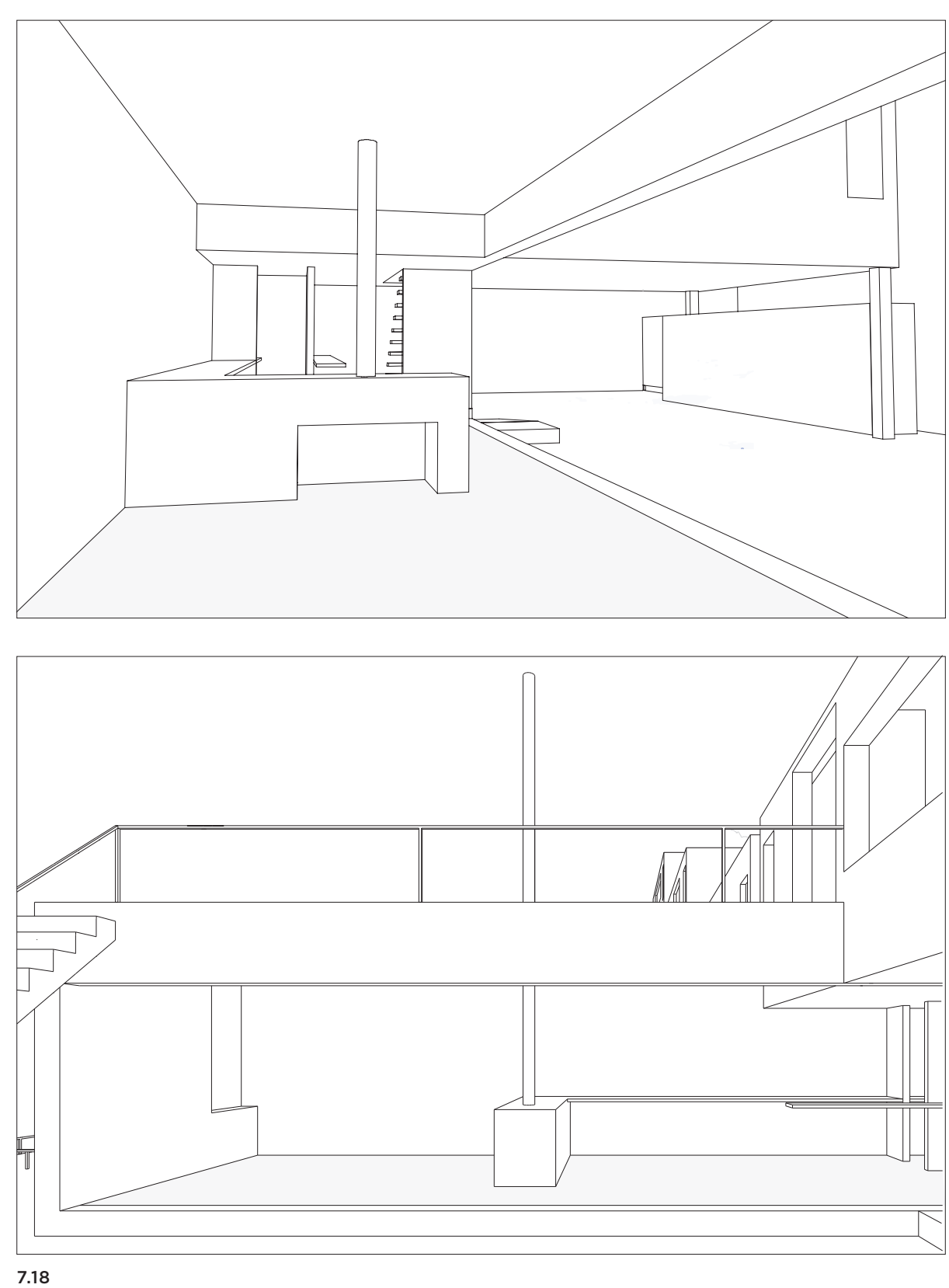

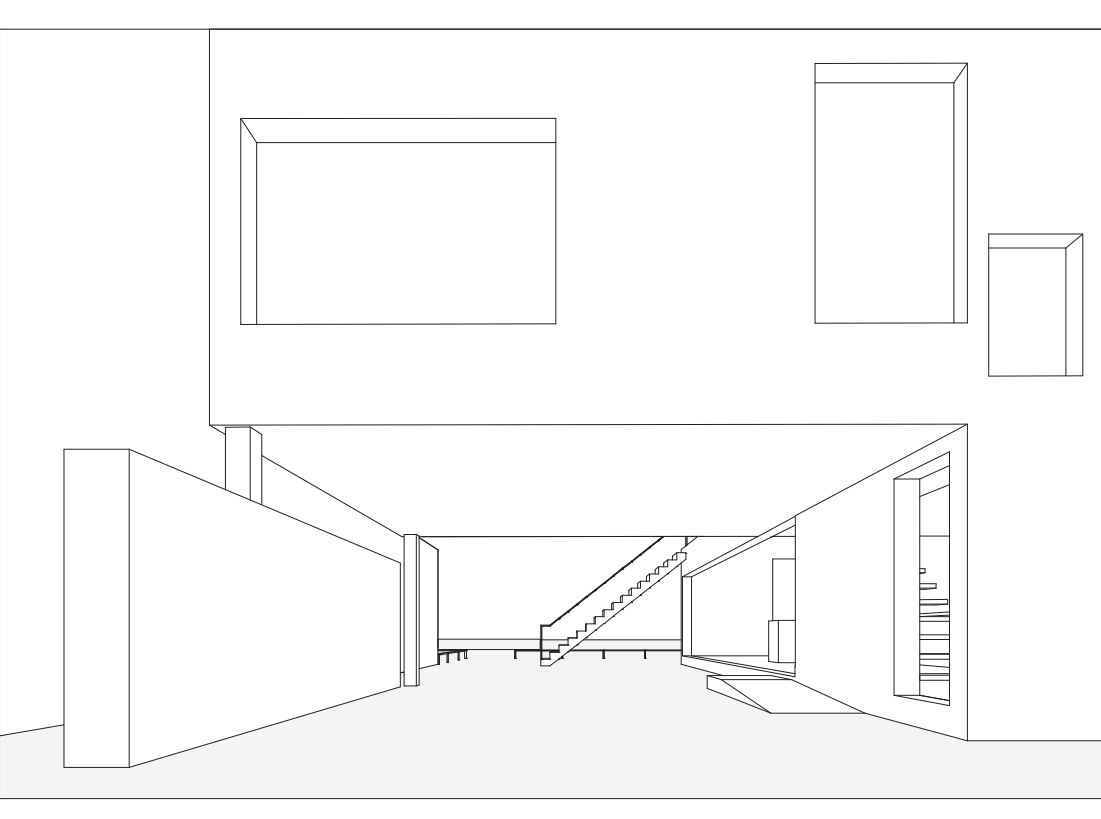

7.19

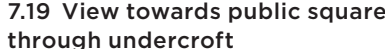

7.20 Customisable features

1. Shed

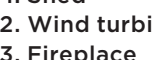

4. Allotment

4. Alloment
5. Photovoltaic panels
6. Hedge

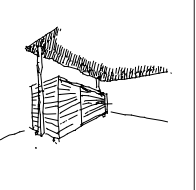
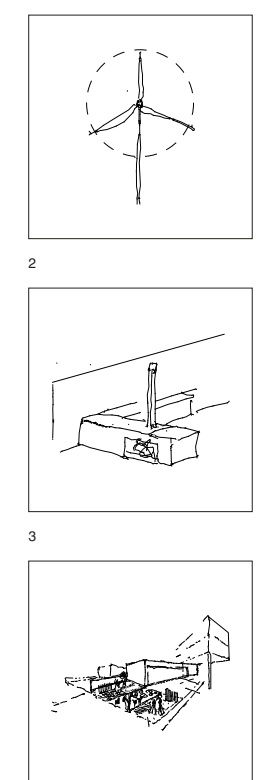

- R 


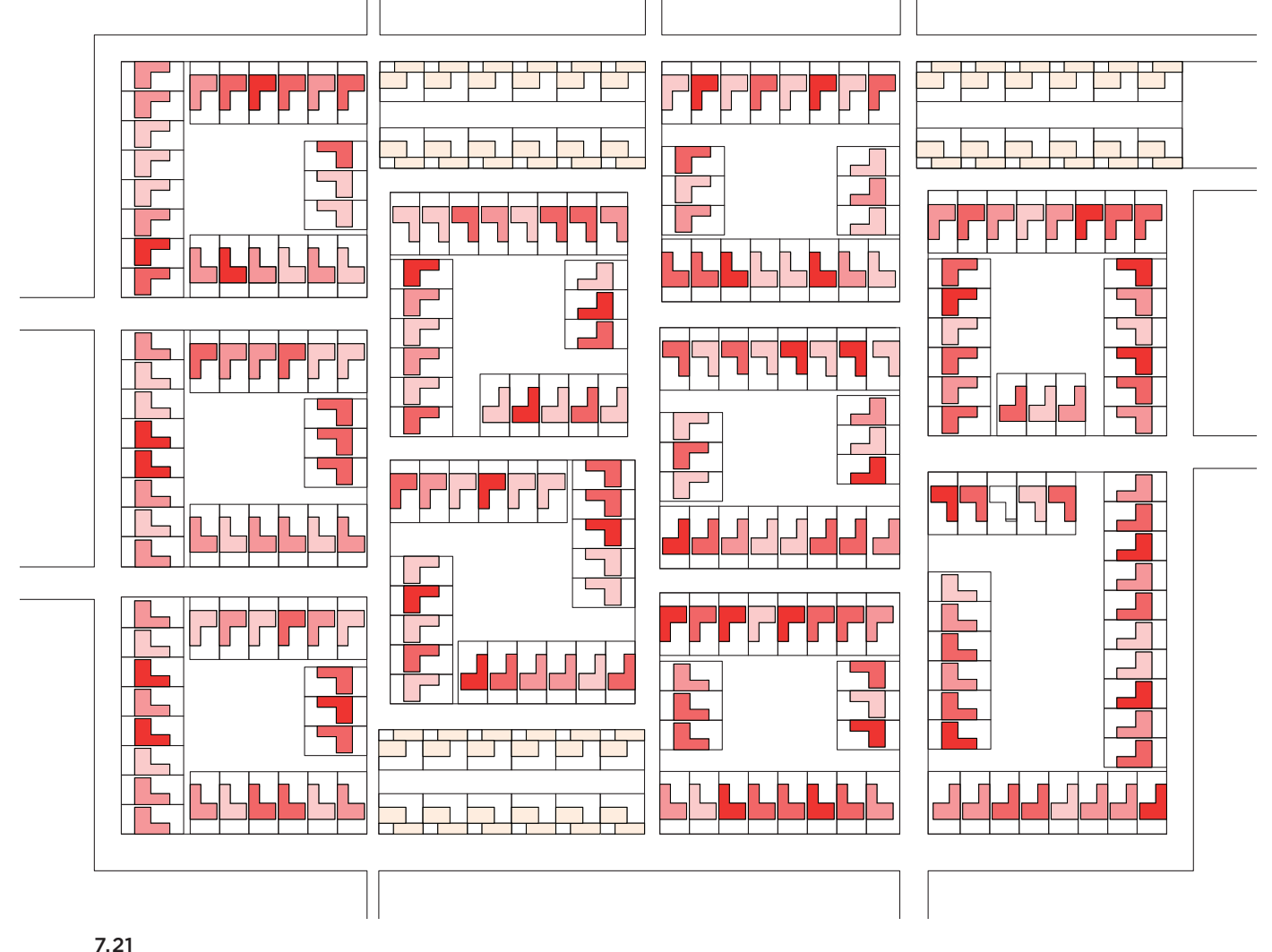

7.21
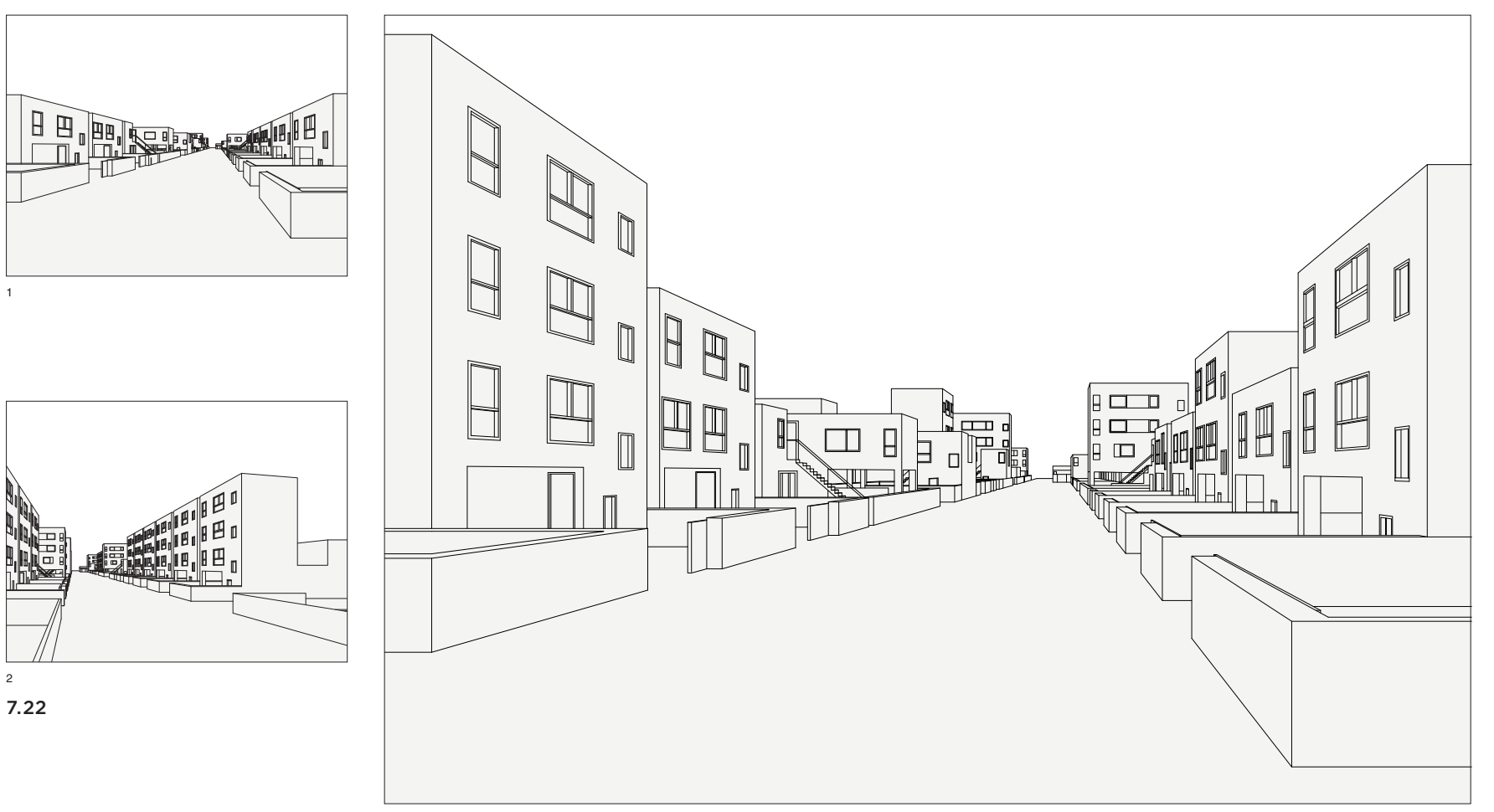

7.23 Model showing mixed scale

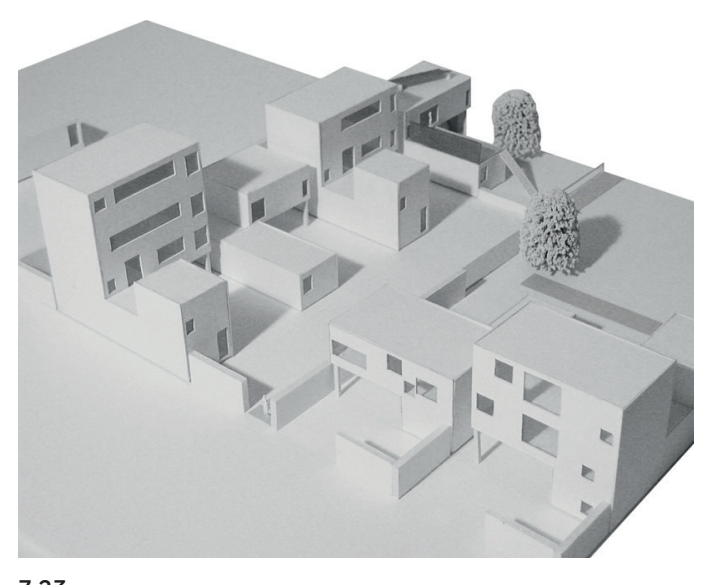



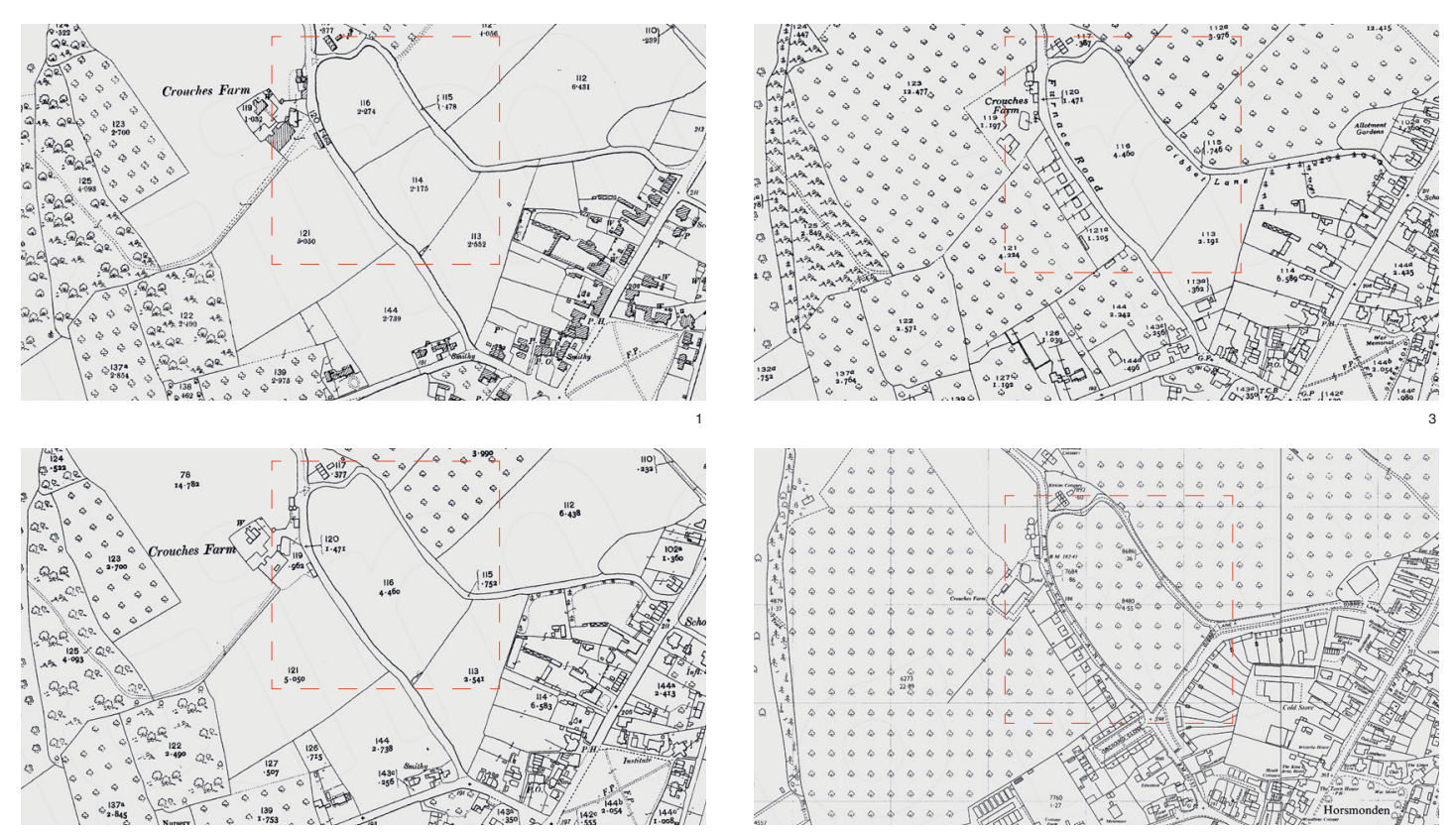

8.1
Middle England | Sixty Houses for

Crouches Field

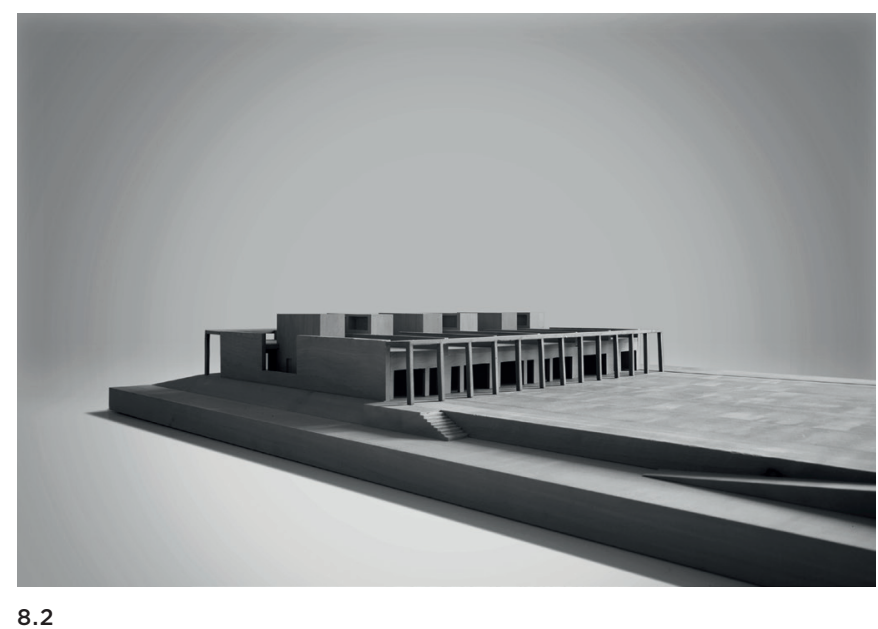

8.2 Pearwood model at 1:100
scale showing Cottage Torra of six houses facing into communal gardens

8.1 Historical maps showing site
development. I Image courtesy
of Digimap.
1:10,000
1 1.1980
2.1990
3.1930
4.1960

Crouches Field is a five-acre 'village landscape is typical of the High Weald exception site' attached to the north and given over to small-scale mixed side of Horsmonden, a village in the farming increasingly interspersed with Kentish Weald about 12 miles east of new and converted residential developTunbridge Wells. Horsmonden was once ment, favoured by commuters owing a small industrial enclave focussed on to its proximity to London - the train iron smelting and the manufacture of from Paddock Wood to Victoria takes guns. The memory of this now-vanished less than an hour. Crouches Field used activity exists in the names given to local to be part of Crouches Farm, and is now routes and landmarks, including Furnace a fallow isolated site which the current Lane, the road which flanks Crouches owner, who was born and grew up in Field and runs down to Furnace Pond, the village, would like to develop with and The Gun public house on the village houses.

green. Horsmonden is now a quiet mainly Crouches Field provides a new neighresidentia community which hosts a bourhood for Horsmondent wit resideol summer fair. The undulating views across thorsmonden, with great 


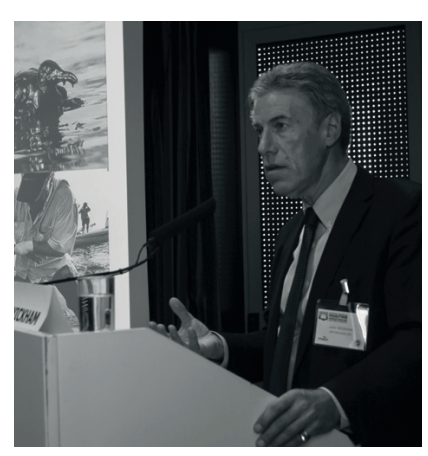

the High Weald Area of Outstanding up a large holding of 17 smaller farms in Natural Beauty and communal garden equivalent in area to the village green. The 2.5-m-high hedge surrounding Crouches Field will be retained. It is an importan feature and has been carefully nurture over the years by the Wickham family. It has been planted more like a hedgerow and is host to a variety of wildlife. The site is landscaped on five levels. Each level steps $1.5 \mathrm{~m}$ down the site and includes two cottage terraces comprising six houses facing each

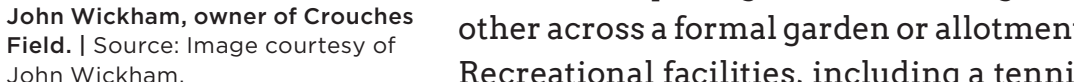
court and pavilion are situated at the lower end the site. The whole development comprising 60 houses was intended to be comprising 60 houses was intended to be a being implemented in five phases with the involvement of the Parish Council and the local community. Design research included a proposal to 'convert' two phases of the development into a community care home. A further initiative included the design of purther initiative included the design of pitched-roof houses, including houses for private ownership and affordable back-toback houses. Circumstances have led to the site being sold to a local housing association with offices next to Tunbridge Wells planning department.

\section{John Wickham}

Interview at The Brasserie, Brompton Cross, London, 24 August 2016was born in 1948 in the neighbourhoo of Crouches Farm in the next village, Brenchley My family have been farmers there for some generations. $M_{Y}$ father was Raymond Wickham who was rather a wellknown farmer in his own right. He buitt the region before the Second World War, during the war and after the war, and he was a major player in promoting Kent fruit growing there of new varieties, control of diseases and so on. He spent a lot of time with the National Farmers Union, for the good of the industry, and he was considered quite a pioneer in many ways and a man to look up to. He was very well respected, and of course, when I went around with him could feel this. So, there's a certain histor there of retaining that tradition and the reputation of the Wicksam fom and the neighbourhood of Kent and Sussex. brother Robin, who's older and years, bascally took years, basically took on the role of running the farms some 25 years ago, and he has thing in mred in us. We ar a family that's thing inbred in us. We are a family that's been around that part of the world; we care about that part of the world - wevery much care about it. We are a link to it for many reasons, many years. My grandfather was actually a brewer and had his own brewery and a lot of hop fields down in Yalding, Kent which is on the River Medway. My father grew up there, got into farming and was bought a farm when he was 21 - that's how wealthy they were in those days. We've maintained this. So, when we carry on to this project that we're talking about, it is important to us to make sure, as a family, that it is in the right vein - it works. We would like it to be something that we can be proud of - some kind of legacy (that's a horrible word), but something that we've left behind that we would be proud of and people would say, 'Well, the proud of and did well out of the land They left som behind. They may've made some money ou of it, but it was a good project, well though through. They weren't out for it just for the big bucks, they were out for it because the cared', and that's the fundamental reason to the way that I've looked at this whole project and from talking to you right from the beginning. That's how I thought about it - that it was a place of interest and of charm, where I would actually be happy to live as well. I mean, that was probably the base of it - somewhere that if I was olde and I wanted to downsize, I could live there, and I wanted to downsize, I could live there, and that was a benchmark. So, we go into mis whe proect with that background in mind. We do name by a fast buck and putting up some but has left a bad taste in por money in the lir and for taste in people's mouth in the air and forever. Because once we've long gone, this will still be there, and I'd like to think that some people would think 'Hmm, they did okay there, they did okay. They did it for the right reasons'

When I was growing up, Tunbridge Wells was my local town, and it was, you know, in theory in those days, it was a little bit where people used to go and have their last days. It's a very pretty town, Regency town, spa town, Royal Tunbridge Wells town by appointment, and a very pleasan place to grow up. Subsequently, because of the burgeoning suburbs and people moving further out from London and finding it impossible to live in Central London Tunbridge Wells itself has become on of the most sought after towns in the region in the country Sevenols, maybe one or two like St Albans - but Tunbridge Wells came out top of a list the other day.
It's understandable why: it's prime architecture, it's Regency architecture (and there's a lot of Nash architecture), it is a spa, it has the Pantiles, which are very famous, with probably the first walking street with no cars at all and it's maintained like that, they've spent money on it and renovated it to a fine level. So, it's really got some of its glory back, and you can see the wealth in the town. The schools re excellent in that area: Tonbridge and Tunbridge Wells schools, you're really in the Judd school system. You've got Tonbridge School you've got Judd, you've ot the two grammar schools at Tunbridge Wells for girs, for boys in Tonbridge and Tunbridge Wells - excellent, some of the Tht in the country. And so if you live in hes fy cou, from the city I mean in box in the book the link to Horsmonden is that it's about eight or nine miles away. There is a bus route that goes in, and the There is a bus route tha gos in, and he gh to Matfield and then hrough to Tunbridge Wells is a well-known route that linksit all, and so there's been very close link between Horsmonden and all those villages in Tunbridge Wells. When we were picking fruit in the old days by hand - raspberries, blackcurrants and gooseberries, all of these sorts of things - we got most of our labour from Tunbridge Wells ladies, and we would send buses out and trucks out to pick them up in the morning and then drop them back at night Tunbridge Wellswas one of our main sources. So, there's a very stronglink, it's 
not all fancy commuters. There's a normal side to Tunbridge Wells - the other side with very good people who came to work for us for years, charming people. So, there's a lot of continuity in the community between Horsmonden and where we're talking about, Brenchley where I come from, the next village and Tunbridge Wells-so there is a link there.

Horsmonden itself is the High Weald. There are two Wealds in Kent. There's the Low Weald, which is the flat lands below, and this is the High Weald, which is much prettier because it's up on the hills. It's got clopes which, of course, are very good for growing frutt particularly. That's why it was called the Garden or England because a lot climate in that part of the world is probchly ably the best in the country, with the most rainfall, and it's the nearest you can get to a continental climate. That's why there are a continental climate. That's why there ar vineyards there now - grapes and a lot of soft fruit and hops. So, Horsmonden was, grew up, a farming village. A few people used to go to town to London, but that was a different era when they would probably catch the 8:30 am train and be home by 6:00 pm, and, I mean, you know, it's no quite the same as today. They used to be very senior lawyers or company senior was a different time. But basically, it was a rural place, and sheep would be herded through Horsmonden and on to the gree and all the way from here to there. I mean, this was way back. It's always been very famous because of the village green. The village green is one of the largest in the year, which is really quite famous. Stow-onthe-Wold in Gloucestershire has one and Horsmonden. I mean, it's a real mixed bag of people who turn up for the horse fairs, you can imagine, but it's a famous event and it's been going back for many, many years. I mean, it's not a new thing. It's been oing back for a long time.

There is a summer fair held every year. It's a big affair, and you can imagine the kind of people turning up to that - every kind of mix. But it gives a life, a spirit to knd of only uses the areen and it's a the place, There is a community spirit the The have a villo hall they have a British have a vilage hall, they have a British Legion, they have one or two shops. Shops they've main they've maintaned one or two here. I don't know if they've still got a butcher, but they used to have all of the basics in the village. What they do have is a really rather wellknown pub called The Gun, where every day they spit-roasted a different haunch of animal: lamb, pork, beef and probably back round again. So, you'd go there, and that's only what you got - but it was excellently cooked on an open fire. I think it started probably in the 1960s, and it was very early for pubs to have very good food. It became really rather famous and a great attraction. So, I used to go there every time I had a first date. I would go to The Gun because it was the best place to go, with a great atmosphere So, it's got a life to it. What's interesting is that Horsmonden church is way out of the village. I believe it's because of the Death. As a result theyuse of the Black Death. As a result, they often moved the left the church behind. But it's an extraordinary area, with a lot of parkland where the church is. Anyway, it's got a history to it. It's an old village, and of course it's changed from when I was a boy and nearly everybody used to live off a farm, or almost.

ust below Crouches Field is what was called the Furnace Pond, and it's an artificial reservoir, it is dammed. I mean, it was dammed way back to provide power for smelting. So, hence the lane is called Furnace Lane. I mean Kent was completely covered in forest and woodland It wast most wooded part of the whole country and they cut a lot of it down for the fury, and they cut a lot in dow A lot of the treswent to navyow where they where they were building ships along the Tha wes in oak were cut down, and basically the landscape changed. As we know, Kent's motto is 'invicta, meaning 'unconquered', and it has a white horse as its emblem. It's a mixed county with north and south. There are some areas that are pretty down, and some areas that are pretty affluent. The only problem with Kent is that it's the gateway to the continent. It is a dead end; there is nowhere else to go. So, you don't pass through it unless you're going on holiday. My mother comes from a very grand family in Sweden and was brought up in a large castle in South Sweden. It's that flat bit in the South, just across from Copenhagen: the farmland, the richest part. There's a big square house, 38 bedrooms, and that was my home from home. I spent every was my home from home. I spent every worked there. I worked on the farms there, and I used to drive the combines. It was wonderful childhood. My father met my mother at Sissinghurst or maybe it was the East Malling Research Station. My mother was over learning some horticulture. My parents got married in January 1939 in Sweden and then came across in January. I mean, can you imagine the North Sea, coming across and landing in England and then the war's declared? She couldn't go home for six years-no contact at all. She was 25. So, her accent was quite strong. I mean, Swedish accent, but then it sounded quite Germanic So, she was well protected by my father, obviously, but still, not easy - the Battle of Britain going on over the top and Hurric pilots coming down on pilots coming down on the farm. I mean, extraordinary sturf, right above your head ide She always spoke with a light accent, a ring ir about her - hat kind of look - gnd was mo was much loved by everybody. And everyody for (quite a big house with seven bedrooms). Everybody would congregate there because my mother was welcoming, and that was where everybody ended up. So, my brother, sisters and grew up in a house full of people - young people - so it was great. I used to go to other houses, and the mother or father didn't low anybody in there, and the place was like a morgue. And they used to love coming to us because my mother would say, 'Ah! Welcomel' and give them a great big hug and a kiss, which none of them even got at home. And she was the favourite aunt in Sweden too, and they still talk about her now There 
were five children. All my Swedish cousins for to have a very fine post house, whic sometimes in twos, for the summer for caught fire, probably back in the late 1960 four or five weeks to learn English - in the or early 1970s. There's a gate as you go in and 1960s when England was really taking off. just to the right, there, almost on the road. So, they arrived, and they couldn't believe it It would've made a wonderful farmhouse. It because there was a whole movement going was really fine with the kilns and the whole on: parties every night, a farm with lots of thing. But that burnt down, and they built a people, my mother welcoming and a house really large pack-house there that was the full of people - they just couldn't believe it. main storage for all of the farms and the And they still today remember that as their packing. They used to grade and pack and best summer holiday ever. And then we used send them off to the supermarkets and so to love having them too. That's how we got to send them off to the supermarkets and so know them so well because we'd take them there and cold storage: chill storage, not knownd and it was rally rally Swedish connection is very strong for us. sitting there across the way, and it was sitting there across the way, and it was

I was introduced to you by Sophie and farm nou always had to woss the wy to Bill, your nephew, and Bill is a woods- it-but they kept it When they sold way to man your nephew, and Bil is a woods- it-butthey keptit. When they sold the farm $\begin{array}{ll}\text { man and a hedge layer and looks after because, like all farming, it goes up and } \\ \text { Crouches Field. } & \text { down with good times and bad times, the }\end{array}$

The history of the field is that it was part of larger farm called Crouches Farm, whic was part of my father's sort of - I wouldn say empire-but one of the quite a few farm that he had. It was my mother's favourite, I think, because she realised it was the be soil. And he invested a lot of money into replanting a lot of fruit, especially apple and hops originally, but we ended up with fruit. As you know, it's a big investment. You've got to plant these apple trees, and you've got to nurture them, and they don't really produce for three or four years and, then, slowly. And it's a long-term invesment but once they're in fruition they keep going So, they spent a lot of time and ke on that and this field was always across the way and separate. Why it was part of it, do toll it (maybe they had a good offer), but they kept that field. My parent kept that field because they saw that it had potential. They didn't realise about village envelopes in those days, but they just knew that it was bolted onto the side of the village with housing round parts of it. It was something that was worth nothing in the scale of it, and so to keep it was easy. Because $m$ brother (this is personal here) got most of the farms, my mother wanted to make sure that I, as the second son, got something. So, she ensured that I was the main benof 60-something per cent), and the rest of the family have the remaining 40 . So, that was her way of looking after $m$, which thas very kin of her So, she me, which was pened, and it's all legally documented. So,

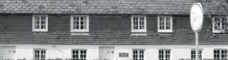
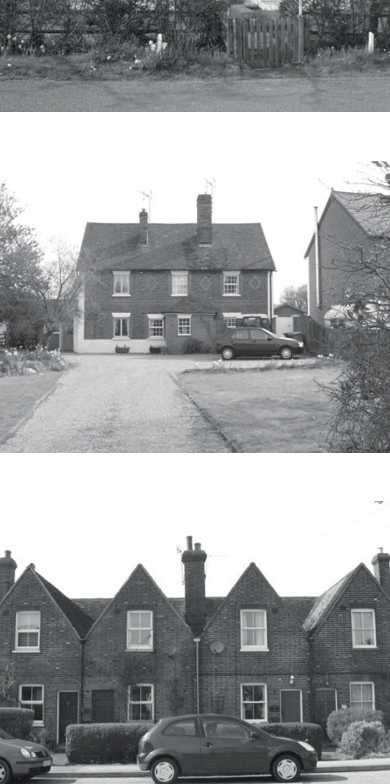
eficiary of this piece of land (to the tune hence my particular interest in it because really looked at the land for years. It's just from it. And the rest of the family are very supportive, but they're letting me run with it because it's my project. I've met you, and I'm running with it, and they're very much supporting me in the background. It's a piece of land that's been empty now for many years; it's been fallow - about 20 years, I can't remember ... I would've thought so. I think there was a time when there were apple trees in there, and they grubbed them all out and then and the grubbed them all out, and then they just my nephew - my eldest sister Mary boy - he is a woodsm hedge laying side laying. He under's side and, basically we've put him in charge go to rack and ruin the sure that it doesn't go to rack and ruin, that the hedges are kep to a certain level and the grass is cut. Of course, we don't really know what's in that field because no-one's ever really walked it particularly. The only people who walk it are the local people with dogs, occasionally, and we don't know what's in there. So, we have to discover that. We have to have an eco-survey, and I think Jim is now talking to William about that for him to get involved, which I think would be very useful because he does understand these things, and he knows the local people. My

8.3 Kent cottage terrace typology brother Robin can help too if he needs any local influence or help because my brother Robin used to be chairman. But he's now back on the parish council in Brenchley, the next village, separate, but it's all part of the same neighourboo Thy all par each other so any way we can help... But it does need looking into because no-one's My brother Robin's farm is in Brenchley. 's two miles, so it's all separate parishes, but they are next-door neighbours. I don't even think there's a particular rivalry. Brenchley will think it's rather smarter than Horsmonden. Horsmonden will say it's more down to earth. But, you know, they'll all fight their corner of course. Horsmonden might be slightly bigger, I syes, maybe in numbers of houses.

My parents sold Crouches Farm in the 1970s. I mean it's a shame. Idon't know why had a lot invested in there. Somebody must've come along and made themagodof businessman andifitwas a good was better to geut, then itwas better than taying ontiment . It'scarrich my brother, heowners ix six years older than me, so he's 74. He's had six yow absolutely clear some hip problems -you know usual things - but he decided some versago, Why should ibe struggling with this? There's a young guy who wants to buy my farm off me, he's got lots of energy and will make a bigger unit and Ill share in the profits'. So, he does all the work, and Robin gets a kind of rental income and keeps the land. He gets an income. So, he's slightly aggregated the role to this younger guy, which suits him fine.

I grew up very much with farming in my blood. So I was, in many ways, considered by my mother to be a more natural, a keener farmer or landsman than my 
brother. I was out there in the fields all day You're absolutely right. The history of Whe long mensing about. Those were the days this field is that it's been for planning come back at 6:00 pould say goodbye and twice. Once in the 1970 s in the boom or nine because I was looked after around went crazy - and you will remember, and and everybody knew me. I mean, we used I remember, the secondary banking and to have five hundred people working on the whole thing-and a local house builder the farmlands, and they all knew who I was bought an option on the land, got planning (there was a lot of picking). So, I mean, it was permission, then went bust (as they all did) a wonderful childhood; you couldn't make it and the whole thing just fell away ... Then up. In the evenings, the lorries would come in the 1980s, a friend of mine called Johnny to pick up the fruit, and it was a hubbub of Woodford was doing assisted housing with activity going on and people and wonderful Meridian Homes, and we got really close women looking after you and giving you to planning In fact the inot really close lunch, which is what I rew up with And it Depan was as wonderful a hildhood as you can seid'I agree', and the minister in chat was, was as wondr. Imagine because the whole summer, I was Mr Woodley, wrote at the top, 'I don't agre just always out. But went to agricultural and no. So, he overrode him for whatever college thinking 'Probably there's room in reasons. I hink was politics because there here, there's quite a big farm'. I went to the was another project down the road that Royal Agricultural College in Cirencester got built, but we never know these things. hinking I was going to carry on with tra- So, it got there twice. So, it always has this dition, but I soon realised, by doing the kind of hope attached. And I left it dorman sums and doing the figures, that a father for a bit-I wasn't pushing it - and I have who was never going to retire and an older friend, Ian Standen who is a local estat brother and then a young son is too much. agent/land agent, who kept his eyes and And I realised that, and I could always be ears open... He's one of these people who the junior partner if I had nothing else to go round keeping their eyes and ears open do, but I realised that I was going to have for pockets of land. So, he was on the case, to look elsewhere.

but nothing really. And you come along an say, 'Well, here's a concept', and put me in

When we first engaged in conversation touch with Crispin Kelly and Jim Green of to make a development at Crouches Baylight, and their thinking was that this Field, the country was in the early throes is a whole new way of doing it. Why don't of the government's 'localism' agenda, you, rather than just taking out the money and we thought we were going to fit in up front, why don't you make it a project quite well with this because we had an and basically give them the land to build idea that you might give the site to the 60 parish the local people.

h 12 house and that is your payment?
I've become quite realistic in life and that can be developed elsewhere. Even if it's not this time, I think the time will come and not being a property man, the days when it could be a very good way to get of packing them in, getting 100 per cent maximum out of a piece of land and walking away with the profits, are long gone. And if you wanted to go down that route, you'd never get anywhere. So, we had this idea and I went along with it - not because I was naive, only because I felt that anything that breaks the mould from the traditional way of just going head on in ('give me the permission and I'll build some houses') anything that could change that dialogue, Iliked. And if it meant that we would take a lesser amount, so be it. Better to have it done and done well and in kepingwith done and done well and in keeping with the philosophy associated wh the beginning largest bucks and make a juss of it largest bucks and make a mess of it. And basically, in our life, in my brother's and sisters' hives, it's a complete bonus in life. If it happens, it is very nice, it's not going to change our lives 100 per cent, but if it will make it more settled. So, we re not in it for the huge money. We'd like it done well. And I thought that the idea of bequeathing the land to the village, well, I felt pretty good about it, to be honest - taking something out of it, but basically saying, 'Here you go' Then, we soon realised that nobody wants to take responsibility for these things. They like the idea, but who's going to run this thing? So, that's always the problem, and you need management companies to run it and the rest of it. So, you're back to almost square 1. If the idea doesn't work out that way, then so be it, but I thought it was an interesting route, and I think it's something things moving.

Could you say a little from a personal hink are needed in the area and maybe Horsmonden and Crouches Field in particular? You've said in the past that there are alternatives now to the big executive house type that maybe they're not necessarily what planners want. What do you know about local needs and how you respond to that?

Well, what I know about local needs is as much as you and Jim have actually old me about them, but I've taken it all on board - that, and it is common sense. Part of the housing problem is the fact that it'seas. Ther's what we call the bed stoppers - people living in four- or fivebedroom houses by themselves, which is ridiculous - which could be upgraded to a decent family to help them move up a slot if they had somewhere to go. They would use that excuse I would happily move out if I had somewhere to go', but what we're trying to do here (and I know we're running out of time) is try to create that space where those people have somewhere that's actually comfortable to go to, somewhere that could go to, that you, Pierre, could go to sary. That's probably the basis; somewhere that we could actually say, 'Yes, we could live there' And it doesn't have to be grand, I mean, with two bedrooms (you probably in 10 years' time or whatever it is, if neces- 

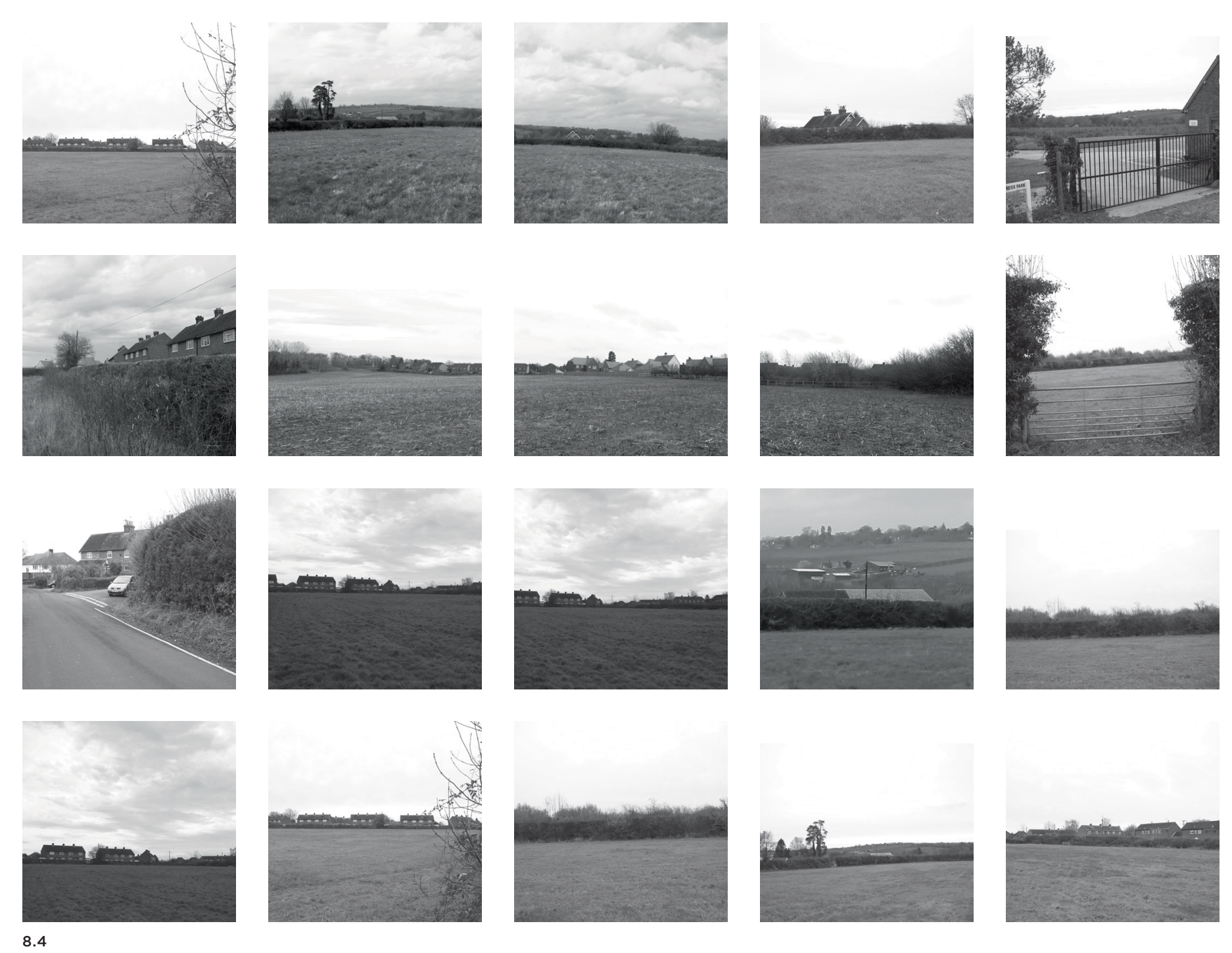

8.5 Axonometric by Ryan McStay

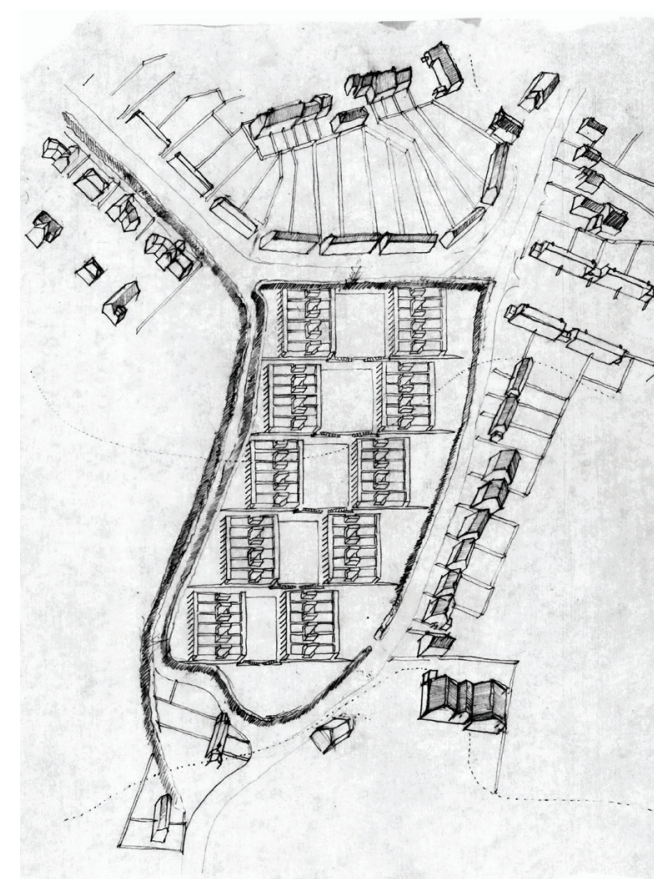

8.5

on the edge of a village', and I think, 'What would you want to do that for?' It might be very nice for a few months in the summer, but most of the time it's dark, wet, cold and muddy, and nobody does anything. You're going to be sitting down there, and you won't see anybody. Much better to be in among your community, whether it's a smaller community like that where there's lights and life, or in a town or a city. Personally, I'm very happy to spend time in London because I like the lights, the air, the magic, the sort of energy. Although I'm a country boy - in theory I should be living in the country. So, this is a microcosm of city life in a small place where life is about rather than sitting in isolation dank, cold because it does get so in the country It gets dark and d ge so in the country. It gets dark and dank, and it's a long winter, and there's nothing going on, and people, their souls, die in the winter. And this is a way to maintain their life.

need two often, only because if you're In relation to the places that you lived in slightly infirm you need somewhere for in Hong Kong and even Athens where, somebody to stay). One bedroom is limit- although you were living in an aparting, there's no extra space for people to ment, there may've been communal stay over to help or to care. So, two bed- facilities - a swimming pool or sports rooms, a simple living room - and I like facilities or a gym attached - do you this idea of walking out of the door to this think something like that could work communal space where it's green, there's at Horsmonden or Crouches Field? no road there, and it's one great big open space. It's something like a village green from a few hundred years ago where you walk out and you know everybody, good or bad. I mean, privacy can be a problem, but better to live in a community with some

don't think a swimming pool, but a leisure facility perhaps. I don't see a full gym there - that would never get used - but a few cycling machines. Something like that to keep them turning over, but a place people around ... A lot of my friends, and where they can have classes. You know, this is diverse, would say, 'I'd rather retire to the country where I have a small house brings people together from outside too, 
it brings the community in; a mixed community. In a perfect world, young families s well as older people downsizing. Not to have an average age of 74 , but an average age of 47. But then, of course, young chldren don't want to be around too many old people either. So, there's a fine balance there. Maybe it has to be segregated a bit ... So, they're all in there, but I don't know. . It has to be thought through. Psychologists will tell you the best format for that, but like the idea. What old people don't want are screaming kids outside their doors night and day either. So, it's a fine doors all but they want to see some children around because it's life. That's for the experts to work out in terms of how that should be but I think it's an excellent idea. Wouldn't you? Wouldn't you like to have some life about you rather than a load of old people? I see these old people's homes, and they're quite well appointed these days, but how can anything be of any inspiration when can anything be of any inspiration when we're all just sitting there? There's deth
in the air as opposed to life in the air.

\section{Jim Green, development manage}

Baylight plc

Interview at Baylight plc, Queensway,

London, 24 August 2016-I was born in 1957 in Bromley, Kent, South-East London. My mother and father both came from that my father came from Sidcup - and they'd already had my elder sister who is eigh years older and my brother who is five years older. Before moving back to Orpington from Exeter, my dad had a job as a registrar there for his career. They were renting, and then he got this job with the Medical Research Council which he then had for the rest of his life and moved back to 'home', as it were, a new house in Orpington, which was very much then a developing suburb, not as you would think of Orpington now. It was out in the country. And I went to nursery school/primary school there and grammar school (St Olave's Gramma School), which had moved out to Orpington the year that I started grammar school from Tooley Street (a brand new school). An interest in the social certainly run An interest in the social certainly run through the family. My brother and sister are exactly the same. I'm sure it's genetic bu worked in When my wife and I first married, we ved at New Ash Green in Kent for fou years from 1982 to 1986. New Ash Green certainly had an influence on me. I can't say that I realised it at the time, and I didn go to New Ash Green with any notions of saving the world or making it better. My sister and brother-in-law Richard were New Ash Green pioneers and moved there in the 1970s when it was first built. For me it was really an exciting place. It felt like home because it was still in Kent. You could commute into London from Long Fields station. You had quite a big house because the housing was very cheap compared with London or anywhere nearer. So, we had a four-bedroom house as newly weds for $£ 32,000$ in 1982. It's only latterly when looked at the development of it (which knew nothing of when I moved there) th knew nothing of when I moved there) that Trealised that it is kind of quite special in the experiment was quite mixed. It was Eric Lyons who conceived it. Whether he really conceived it from a community poin of view, I'm not too sure. Was Eric Lyons an architect? I think he was certainly community minded. Talking about making money out of building houses, I think he wanted to build better, and I think he was moulding New Ash Green. He'd built a previous scheme in Blackheath which my sister worked next to when she was at the DHSS in Blackheath, and she had friends who lived in that scheme So, as ever, ts who always these connections because the $\mathrm{Span}$ house that her friends had in Blackheath was very similo to the Span houses that was very wer'd bin that house, and indeed befor and it was a very and indeed lhad bere, and we live a very interesting house. When we lived in a place called Knights Croft, which was an original Span house and very unusual to look at, it actually looked like a big wedge of cheese - not at all traditional. Inside, it was bare brick. It had a mezzanine floor, which was neve really seen anywhere else before. It had odd things like electric heating in the ceiling which was probably thought to be a great idea at the time but wasn't. It was just a box really, very flexible with movable walls. think that they were actually very cheaply built, but I don't think they were necessarily built that way for extra profit. A lot of money went into landscape. The communities were called neighbourhoods - still are - and each was set up as a company in its own right. Knights Croft had its ow residential association and there were lots f covenants attached to the houses. of the covenants were a bit ridiculous, like about hanging out your washing on certain days, noise and colour. I think residents actually did respect the covenants, by and large. The thing that changed was that Span went bust. And the majority of New Ash Green as you see it today was built by a variety of other national house builders, in particular Bovis, who didn't have the same aspirations, but they did keep to the plan. I suppose if you go to New Ash Green, you can see the difference between the neighbourhoods. The later ones are much more dense, the houses are lessinteresting they're smaller.

I don't think I've ever been very driven by money. It might be easy for me to say that because I come from not a very wealthy but a well-off middle-class background, university degree, always had a job, never had an issue with money. But, at the same time, I've had no real ambition to make loads of money. I'm not driven that way; 'm much more driven by people and the quality of things that you do and particularly helping people really. If I was going to make my mark, I wouldn't see it as a long career in surveying doing rent reviews, buying and selling buildings, development appraisals - all of which has always been interesting, but it hasn't really satisfied that sire to make things better. And it's probably why I've been at Baylight for 20 years because I really enjoy that element of Baylight, which you know is about making hings better.

I met Crispin through a mutual friend, Andy Hogg. I was at Reading University with Andy, and Crispin was at school with Andy. Crispin needed help, and Andy thought the two of us would get on well 
Crouches Field Community Care Centre Owned by the community for the community.

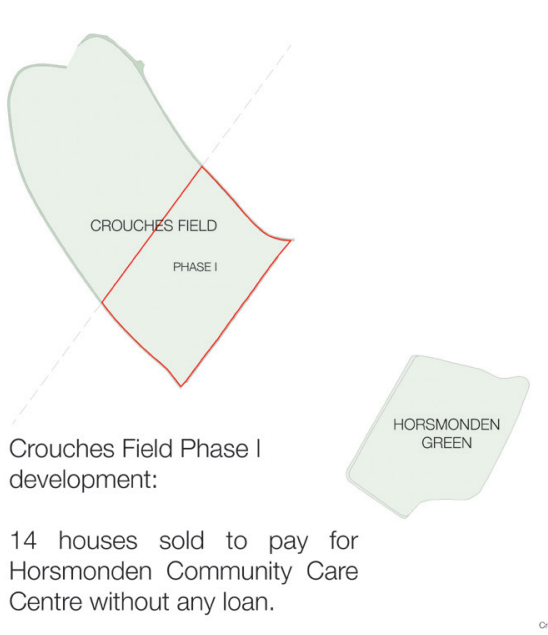

with each other, and so I joined Bayligh n a part-time basis and did the course the other half of the week. So, I ended up doing my master's and working for Crispin at th same time. There've been periods in the early first 10 years, say, when I was probably spending most of my time working for Crispin. In the latter certainly seven or eight years, I've had several other jobs while I've been working here, all really generated one way or another through Baylight often helping Baylight in a sense.

When I finished my master's, or rather finished the examined course, I had to finish my dissertation, and I just happened to go to the RIBA conference on climate change. It must've been in 1999. I'd never heard the word 'sustainability' before. I didn't know anything about climate change or energy efficiency, and I immediately understood there was a link between sustainability and value. I thought I could prove in my dissertation that buildin green would equal better value. However I couldn't prove it, and I was rather disappointed because the evidence suggested that green buildings were costing much much more than they should to build. The commercial sector wouldn't build them because it didn't really see why it should. So, they were all in the public sector, and as usual, the public-sector control of cost on the schemes was awful, and they were just spending twice, three times as much just spending twice, three times as much as they meant to on building a wonderful tion, I was invited by the RICS in 2001 to the board of their new environ 2001 on faculty because I was on en few peopent they knew who'd actually wite they knew who'd actually written a dissertation on the subject. And I guess I'd probably spent the last 15 years trying to prove my dissertation. I've always known the answer to it, which is that the problem is the timeline. If you see things in the short term (and this is all related to value), you're never going to get it, and that's classic developer's perspective. And why shouldn't it be - because most developers are not there to lose money, they're there to make money. They're not going to live in the buildings that they develo or shop or work in them. They'll just put them up, and hopefully they'll take all of the risk out by pre-letting or pre-selling them. They move along from one scheme to another. Their perspective is very short term. The only time it becomes long term is if they're perhaps doing it for a client who has a le perhaps doing it for a client who the moment, despite what people like you could show this - generally the cost of building green and, indeed, the cost of building well, is higher. So, most developer won't do it unless there's a higher retur from higher prices. The market won't do that unless they perceive that these better greener buildings are worth more. I think that's very slowly changed over the years. It has, but the evidence isn't very much there, even now, 15 years later.

I suppose I've known Crispin for pretty much the same length of time that you have, and he approached $m e$, in the have, and he apion in 2005, about wanting to plary suburban developments. And you know, that's why I introduced John Wickham to Crispin with regard to his land at Crouches Field as a potential site for residential development. I understand Crispin and you have set up understand Crispin and you have set up Groundplan to make sustainable developments, culturally
as environmentally.

I'm not sure because we've actually never really talked about it. Crispin's driver was about improved community. I'm sure there's an aspect of that. But after all you know, to actually build that way and prove your point, I think you have to be building larger numbers of houses, and we haven't done that as yet. We've only built 10-15 at a time; large numbers of far, which I think is where crispin mainly sits, is on quality of design, and he's buit flats in London. So, really the aspect so

no doubt about it. Not everybody likes them, I think, particularly to look at, but I think the people who buy them like them. One would assume so. Pusey would be a good example where the people who lived there seem to love them. Even with their faults, perhaps, but I think that the people who live around them are very reluctant to accept that this style and appearance of house is something that belongs in a village like Pusey. But that's something you're going to find everywhere you go, and I think historically you can probably say the same for anything. Perbaps when they started to put on the Queen Anne brick fronts on Elizabethan timber houses, I'm sure there were people at the time hock horor 'What a you What is that uly thing' So, tou doing? for everybody out we would never be able to buidd in Pusey or in an to bur to anybor In terms of come veroved that much. cremse created a little community in Pusey and a little community in Aldershot, although that's very new, and mini-New Ash Greens. And in Aldershot, in particular, has a lot of landscaping and so on, and it probably is the closest that we've done so far to the sort of New Ash Green ethic, if you like. For me, the social side is much stronger. Where Crispin and I inter-join on this is the value mechanics. We both believe this perhaps to different degrees. I think he can afford maybe less to think this because he tends to own the property and therefore it has a direct fin proposal phases 1 and 2 , demonstrating adab
and versatility of the
design approach a lot of very interesting houses. There's crazy to build schemes with a loss made. 
You can be altruistic and have loads of sits very happily with my social side. But do choose to make a loss-making with scheme if you wish. I'm not sure it's a very this equation that I've just been discussin good advertisement to the world at large, (about cost and value) and saying, 'Well even if it's a beautiful scheme. My view is those parameters are fairly well set in every more, and this probably sounds political, appraisal. Everyone is using pretty much but I don't think it is. I've always wondered the same methodology'. If you're trying which side of the political divide I sit on, to find more money in your appraisal in and I can tell you that I pretty much always order to spend more of it on quality in ever voted Conservative or Green in latter years, way - quality of the building, more land, but I think I'm very allied to the Labour way better landscaping - then the whole thing of thinking I just have my doubts about is just a nicer, better place to live So, you're whether that kind of world works finan- spending money on the things that per re cially. So, I guess I'm in the middle but our volume house builders wouldn't nerhap view was always that we wanted to build ily choose to because they wouldn't see the better, and we wanted to spend more money value coming back. They wouldn't want

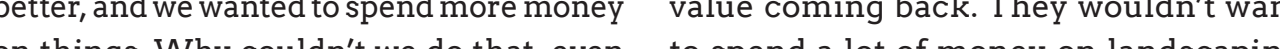
on things. Why couldn't we do that, even to spend a lot of money on landscaping within a proftable appraisal Well, the unless theycould sell therr houses for 10-15 reason more often than not is that if you're per cent more. And that's why hey have competing in a market for sites or bulld- problem with green issues. they don't see ings, you can't really afford to take that the return in the price today. Those houses view because you $1 /$ never buy anything. may be worth more in the future because You'll always be outbid by somebody else. If they've got solar panels and ground source their cost base is lower than yours in their heating, and the volume house builder appraisal, then they can afford to pay the will accept that, but they'll say, 'Yes, great, owner more for the land, and so you can't fantastic, but that's in the future when we really do that. And it's one of the reasons don't own those houses anymore. When it that many of our schemes haven't been on does happen, we'll start building more of the open market; we find schemes through that sort of thing but because the marke connections with people, associations, joint will demand it'

venturing and what have you - we have They're happy to see it tested by others. to - because we can't really compete on Then, they'll come into it when it's become the open market because our cost base is a thing of normality. As with what I said higher. Our aspirations to spend are higher. earlier about green buildings in the late Allied to that is, I think, the more important 1990 s, it's not a particularly good place to point that (particularly at Horsmonden, be a pioneer financially. It's great, it's fun which is only one example of the model [laughs], and there's a lot of self-satisfacthat we were trying to take forward) was tion in it, but it's dangerous because, first originally inspired by localism and com- of all, you're playing with thecause, first to to the
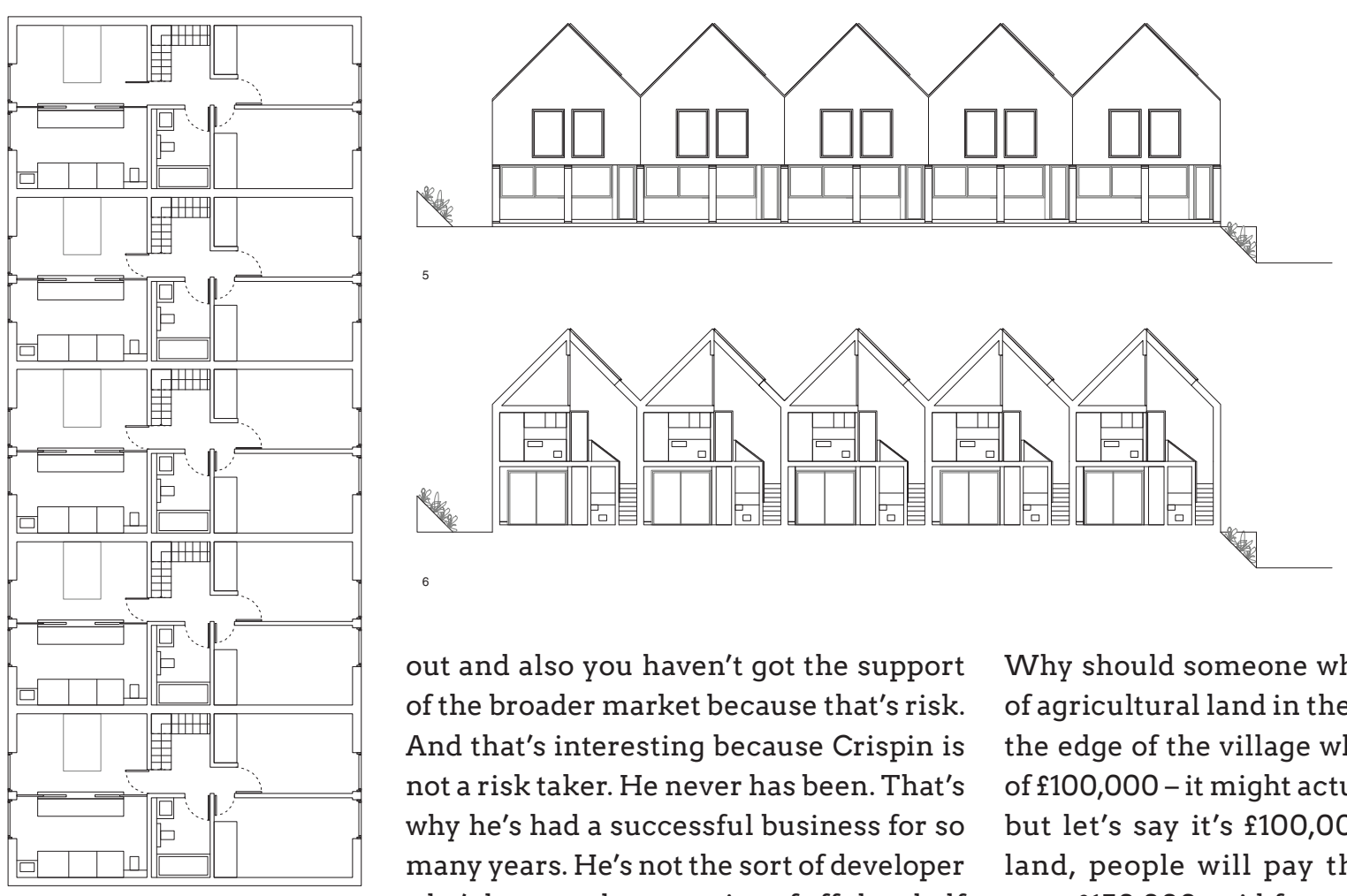

\section{\&}

out and also you haven't got the support Why should someone who owns an acre of the broader market because that's risk. of agricultural land in the countryside on And that's interesting because Crispin is the edge of the village which has a value not a risk taker. He never has been. That's of $f 100,000$-it might actually be $\{10,000$, why he's had a successful business for so but let's say it's $£ 100,000$; for amenity many years. He's not the sort of developer land, people will pay that money. I've who's happy to have a string of off-the-shelf seen $£ 150,000$ paid for an acre of land in companies that can just go bust, and the West Sussex. So, it's possible. But let's say bank takes the loss. That's a reputational you've got an acre or, in John [Wickham]'s issue. Some developers don't care about case in Horsmonden, five acres maximum that, and fair enough. It's up to everybody $\quad\{500,000$ worth of land. The moment that to assess the risk accordingly. We've only you obtain residential planning permisjust started to broach Horsmonden and sion for that, it will go up to the best part how this links together. Let's focus on of $₹ 1$ million an acre So, a 10 times increase Horsmonden and the village...

There are two things there. First of $f 5$ million because you own the land, but

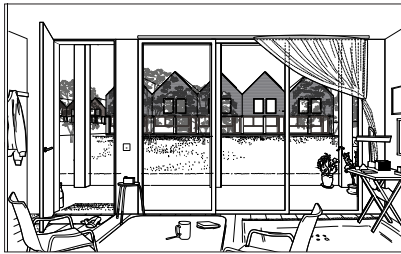
the value element. Horsmonden isn't mainly because of that planning permisthe only place where we've tried this, sion, and that planning permission is given and it is very difficult to achieve. I firmly to you by the community. So, our question believe that the price of land is way too is how much of that enhanced value should high because 30 years ago the portion of remain with the landowner? And we think land value to the overall scheme used to it's perfectly reasonable for the landowner be about 20-25 per cent Now, it's often 40 to enjoy the fact that he's in the lucky posibe about $20-25$ percent. Now, it's 40 to enjoy the fact that he's in the lucky posi- 


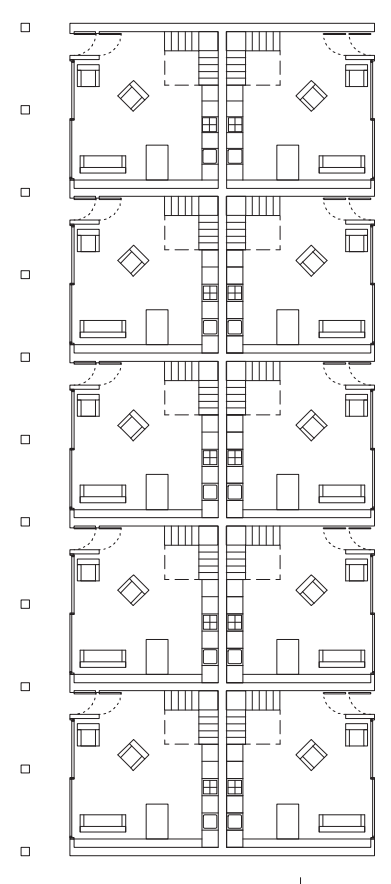

has also had the foresight to think about turning the development appraisal on it what he can do with it, to put it forward, head. As we talked to the planning officer at to promote it and so on, and perhaps win Tunbridge Wells the other day, and instead content in the community because he's of working it upwards and saying 'Here's our come up with the best scheme. He's come costs kept to a minimum, 20 per cent profit, up with quality; he's come up with some- this is what's left for the land out of the thing that the community really wants sales', we're actually pushing the costs up instead of it being a scheme that was forced much higher to integrate the care element on the community through a rejected plan- into it. I'd love to do it in a way where the ning application and an appeal and so on, costs would stay the same, but I don't think which is not to say that scheme's a bad that's realistic. And I don't think, in ver scheme, and so on, but that's not what I basic terms, you're going to get the quality believe in My view is that if the commu- whether it's ordinary housing or housing nity doesn't want it, then we shouldn't be with-care. Now, I have a particular interest doing it Now, I realise there are problems in the housing loth-care elementbecause with Nimbyism. It may be that we would of my own personal experiences over the wim nly never build enough houses in this last few years: losing my parents, losing comply never bulld enough houses in this last few years. losing my parents, losing far in that direction hecause the reality is and out of various different can hat for min that for most people (who have moved into seeing my own mother and father stay in a new house themselves on the edge of a their own home but where my father had village), the last thing they want is to see a live-in carer. And you know that was another new house built next door to them. really deeply personal, intense period fo So, that's the thinking behind it.

The second part of it is much mor ind ecent, and this is the housing-with-care I'm nearly 60 myself in January, I thought, element. On John's part, I suppose my 'There has to be something better in term responsibility is to make John as much of the way care can be delivered'. And it money as possible, but I do believe that seems to me that if you put the ordinary where John has said the family wants to physical elements of care to one side for leave a legacy to the village and although a minute (so bathing people, giving them they don't live in the village any longer, they their medication, perhaps some exercise, were there a long, long time, and they'd like the things that carers do), there's somethin to see a development there that the village much more to it than that which goes all the really does want-that really does add some- way back to the start of our conversation thing to the village and that is something about nuclear families and communities special, that John is engaging with me and And the thing that really struck me most of Crispin in that respect But the result of All about Julie's mother, in particulas, and that will inevitably be that he will receive going into a care home (and this is why so Chat will inging into a care home (and this is why so less money for his land because we're many people say, 'I don't want to go into
roof back-to-back proposal,
two-bedroom affordable hous
1:400
1. Ground floor por
2. First floor plan
S.
4. Front elevation
5. Section $A A$

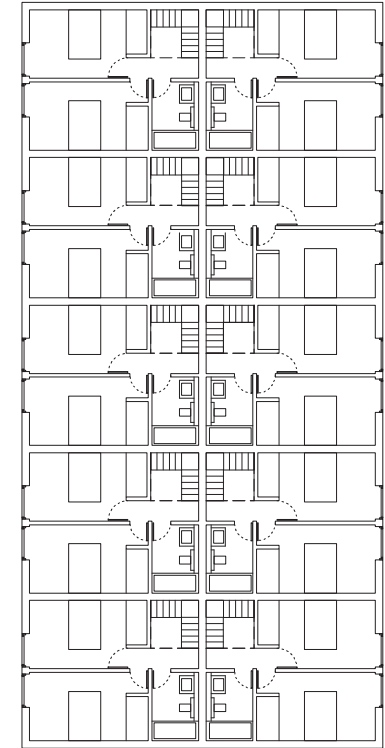

ШШ

\section{$\begin{array}{lll}\square \square & \square \square\end{array} \square \square \square$} e. ${ }^{4}$

\section{2.} 5

care home') is that complete loss of con- can pick something up and take it somenection. Their family and hopefully some where else. I mean the kind of drivers of their friends will visit them in their room that are behind this - the need for elderly in a care home, or in a retirement village villagers to downsize to more suitable come to that, but they're isolated. They're accommodation and stay in touch with not in their community anymore, and that's their village - that's really common evewhat this scheme is all about. rywhere you go. So, I think it certainly should be a model from that perspective.

I was going to ask you about that. The The care element is really tricky, and earlier ambition was to make a mixed we're still struggling with how to deliver development - homes for young people, that, but we're quite determined to see it homes for older people - and I'm just through. I think it may be way less comwondering about the focus of a care plicated than I had originally thought. home aspect which still allows for a I actually think it's really ordinary and mixed development. Does Crouches that it doesn't need a fancy care buildField become a kind of model or is it a ing. I think maybe a day-care centre of one-off? Or are there aspects of it that some sort may well be a big asset there, can be applied elsewhere or is that to but I think it's to do with quality of life $\begin{array}{ll}\text { do with the development, its numbers } & \text { and connections and avoiding isolation } \\ \text { or its location? } & \text { and pleasure in life - it's not really about }\end{array}$ or its location? care in the conventional sense because I think it's a mix of all those things, to be care is already there. There are certainly honest. We like to think in terms of it being aspects of care that I've felt we could make a model. In reality, I wonder whether you a big improvement with, but I'm having to 
listen to other people,which is what the whole consultation process is about. Well, hope so. Too many consultations are about ticking boxes and saying, 'We've done that' as opposed to actually changing your mind when you hear what real people have go to say.

Yes, it has a much greater chance of both ordinary it is and that's why in our convesations with the planning officer, we're still in two minds about all this business abo whether we should have [Use Classes] C2 or C3. The moment we start talking a cre with a panner, they sat talking about canditcold a

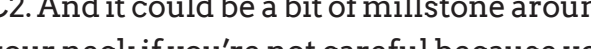
have planning conditions attached that have planning conditions attached that Ine we're looking at. And actually, in our original we're looking at. And actually, in our origina plan, I think I was mistaken; it was only just
about elderly people, it wasn't mixed with younger people originally.

\section{I think it was.}

Are you sure? I'd like to think so...

Well, that was my take on it. When you decided that it should be pepper-potted.

Pepper-potting as in affordable housing.

I also took it that pepper-potting was a way of referring to a mixed demographic were people from young families who wanted to stay in the village but afford to, or children coming to an age

\section{where they were starting families and} getting married.

Our thinking has ... I wouldn't say 'changed so much ... but I think it's matured an developed a bit. Originally, we were ver tied to the village vision and the older persons' questions, and that was a particular thing that we were still hanging our hat on which is 'here are the statistics, here are the numbers, they're not our numbers, they're the village's numbers. They wan somewhere where elderly villagers live and stay in the village in some kind of accommodation' That wasn't about peoment youn the vill a vision it was in tement wasn't in

\section{I think we talked about it when we first} started this conversation in 2011 ..

Maybe we did. It really came home to me when I was talking to people like the ove 60 s club in our local consultations, and th elderly people themselves were saying, " don't want to live in a scheme that is all old people'. It has financial complications because, let's be frank about it, by and large although we can't generalise too much elderly people have more equity in their

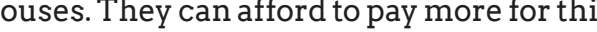
higher-cost scheme that we're delivering to them. If you inject a third of the people as young buyers who have no money then that's a problem because you've then got to be able to build and sell a third of those houses at a lower level.

In an early appraisal, there was an idea that if the parish council took over the management of it with Baylight's advice they would keep some to rent at a particular rate.

This is a slightly different strand of thin ing, but it was the original strand. And the would sell some of the property to afford to be able to do that, as well as giving John two houses per stage.

This was allied to our thoughts about community land trusts, and so on, but I think very quickly we've realised... I wouldn't say we've given up, but the reality of getting anybody locally to take reality or getting any responsibily is really, really differen the only exampleswhereir's actually hapthe only examples where it's actually happened - small, very stron foen quite in interest groups. Maybe we saw it in the village down near Poundbury, that was 10 houses and so on. So, it can be done but that was done by the community themselves. Here, we're always trying to persuade the community, and that's no going to work, not on 60 units certainly. The idea of giving John houses rather than money, some people might've said, 'Well, who cares? What does it matter?' As an owner with an investment perspective, he might actually prefer to receive houses rather than money. Obviously, from an appraisal point of view, it helps the development because you're not having to pay the landowner cash upfront.

It's just the idea that one's almost had an ideal to start with, and then it's affected by the pragmatics of the locality and the

particular.
I think in the back of my mind, there was lso a little bit of me that thought, 'Id quite like John to own some of these houses'. If we're talking about legacy and so on, then isn't that a little bit more proof positive that he really means what he says? Of course, you couldn't restrict him so that he and the family couldn't sell the houses and take their money, but it just shows another level of commitment. That is still a possibility but for a different reason perhaps: he could still be paid his share in houses. That would be great from a development perspective would de-risk the scheme, and we'd borrow less money, but I would n't like we things, it might be very bericial to the lo ure To have bricks and mortar in a place thand . a n . wo gute 作 could be saved somehow.

I think the final thing that is particularly pertinent to Crouches Field (but all such schemes) is to just look at how long we've been doing this now-it's at least four or five years. How much progress have we made? I think we're in a much better place than we were before: we've actually learnt a lot along the way, and because we've been willing to listen, we've changed the way things are being done. I'd like to think that if this was a model, we could accelerate it in the future and elsewhere - because we've learnt lessons-but at the same time, 
you can't. You can't just shove that model this is another take on the sustainability in some other community and say, 'Well, argument - but you have to take a long-term it worked for Horsmonden, it must work view. If you sat here today and said, 'I won't for you too'. But if the village looked at it see the fruits of my labour for 10 years', how and said, 'Well, actually, it does. We've many people would do it unless they're been to Horsmonden', that's what I'd really really committed? But, obviously, they'v like to see. I'd like to see it built, people got other things going on at the same tim living in it and enjoying it, but that's going because you've got to earn a living. But it's to take another five years. So, it can take very important to do these things, I think 10 years, but schemes of this nature often because after all, what is making money? do. You've got to have that - and perhaps It's nothing is it really?

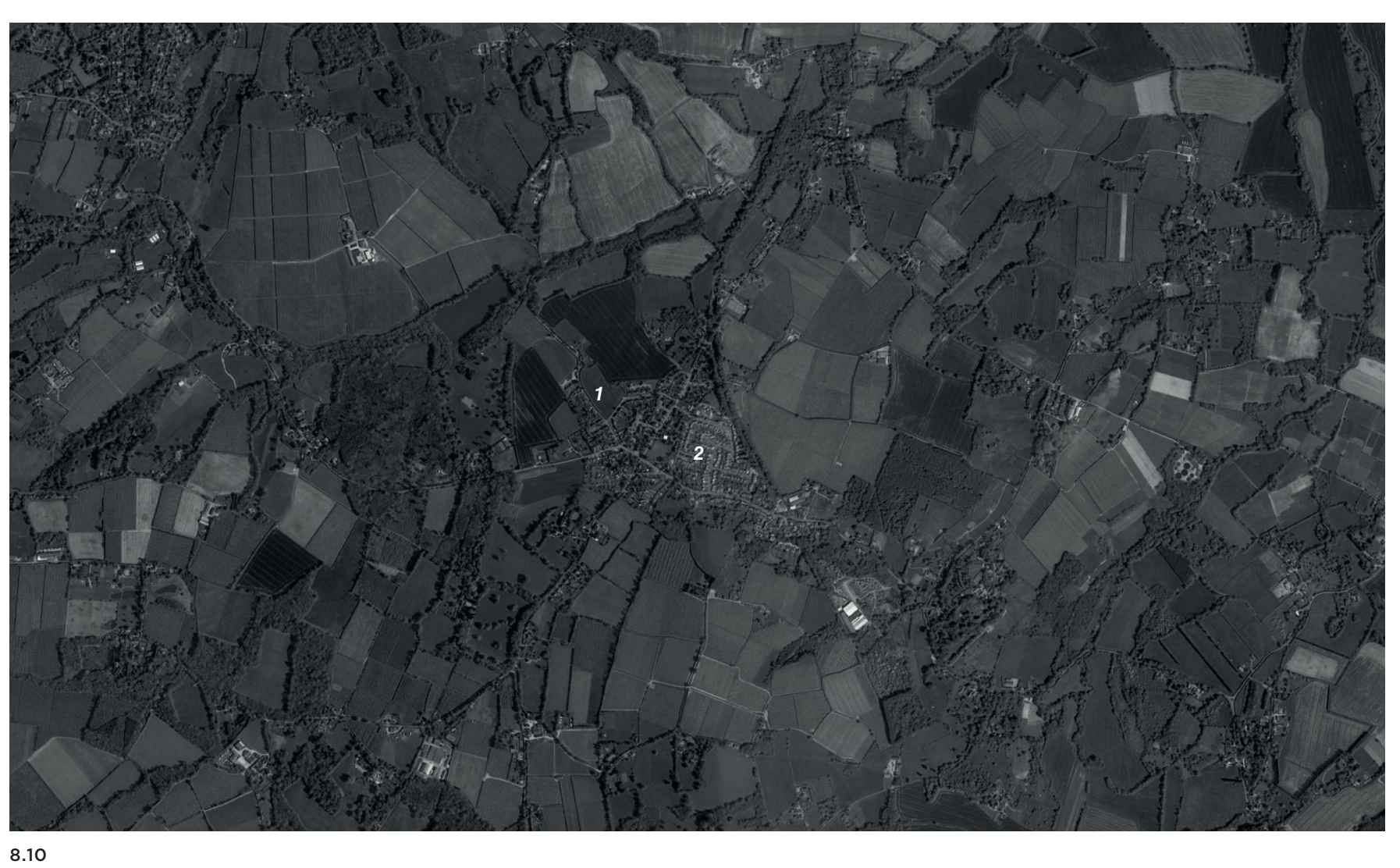

8.10 Horsmonden.I
Source: Image courtesy

Google Earth

1:25,000

1. Site

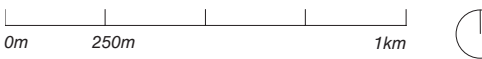



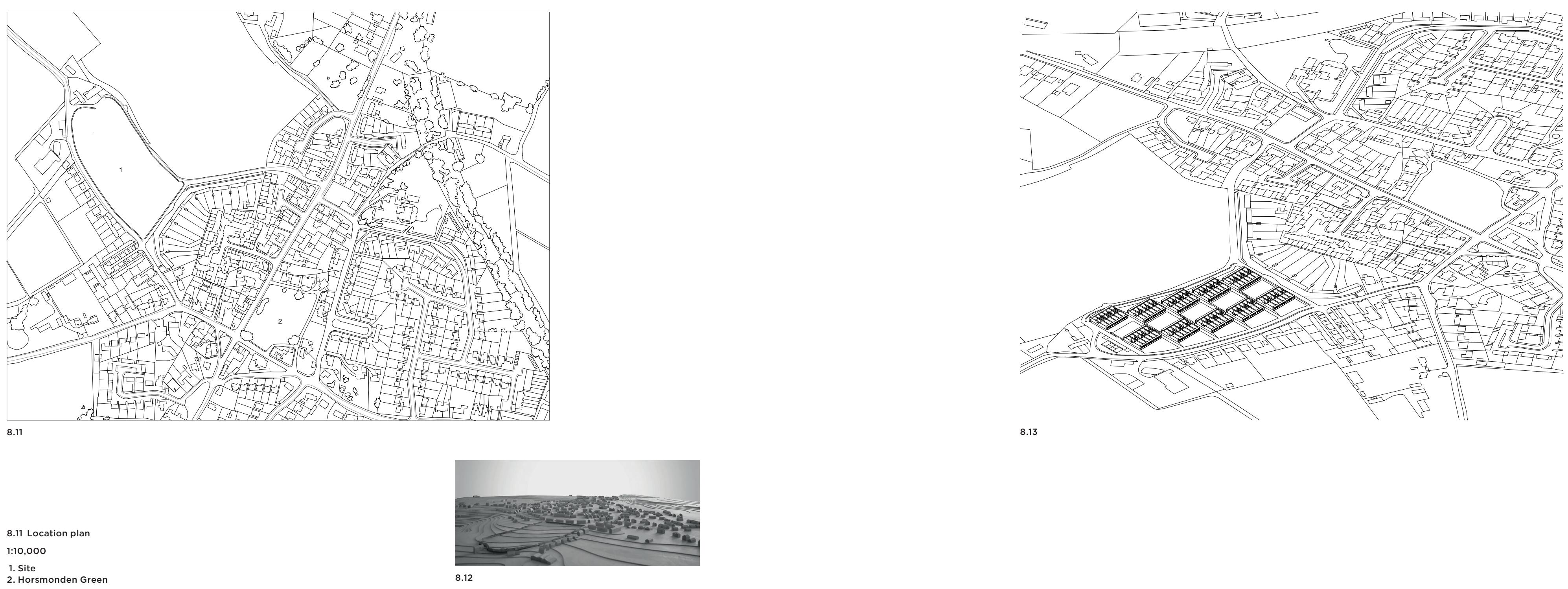

1:110,000

1. Site
2. Horsmonden Green

8.12

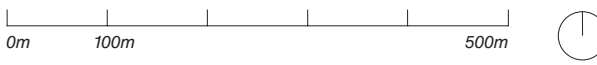

8.13 Isometric

8.12 Village model with Crouches
Field in foreground 

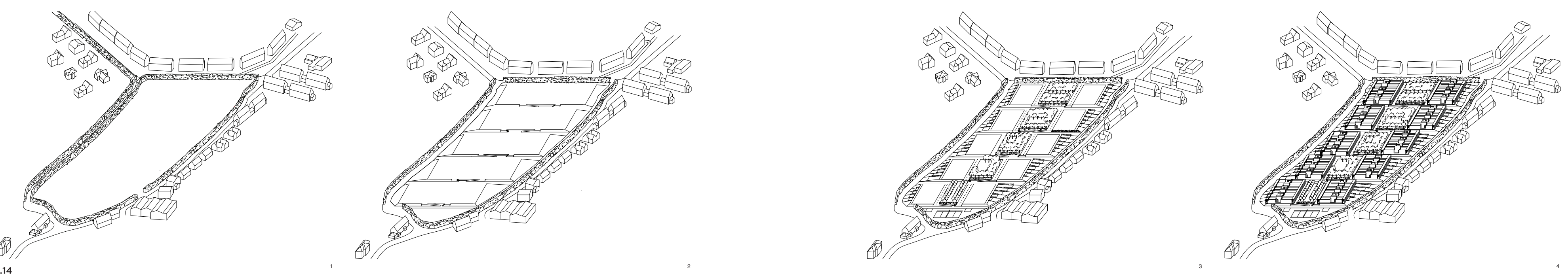

8.14 Site landscaping strategy 1. Existing site surrounded by tall
hedge slopes $7.4 \mathrm{~m}$ from village into valley
2. Site landscaped into five levels 2. Site landscaped into five levels
with perimeter road
3 soft landscaping and parking 3. Soft landscaping and parking
added 4. 60 houses: 2 Cottage
Terraces -12 houses on each
level 


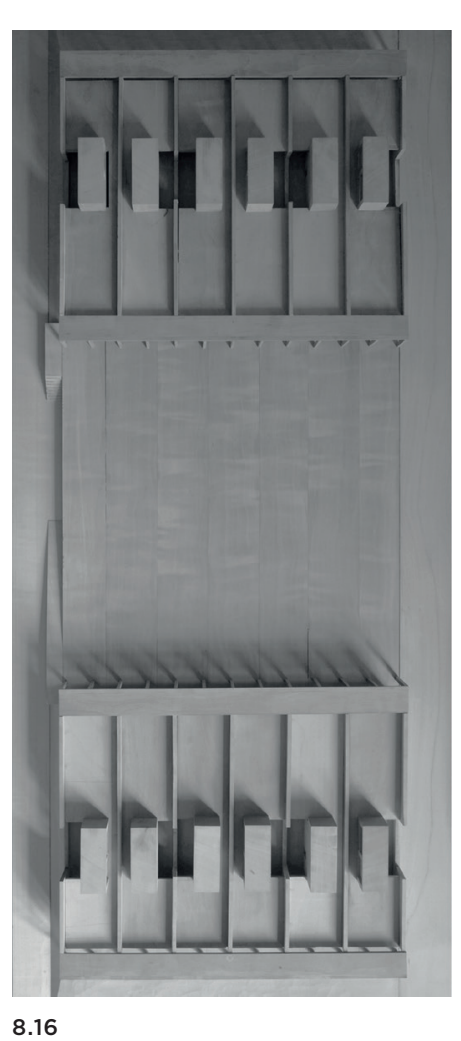

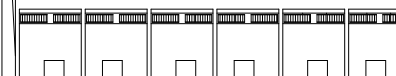

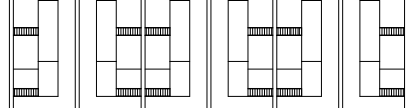

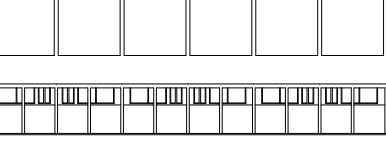

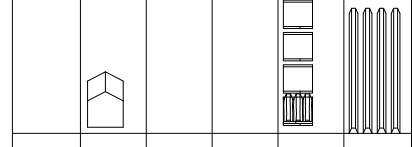

\begin{tabular}{|l|l|l|l|l|l|}
-1 & -1
\end{tabular}

Inim

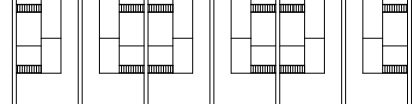

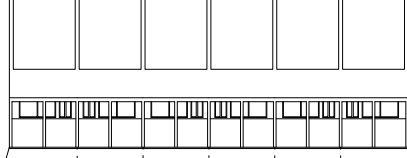

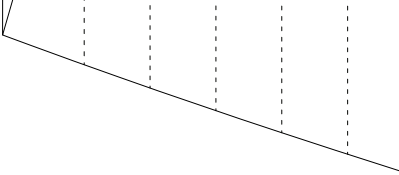

8.15 site plan

1:5000

1. Main entrance
2. Housing units
3. Pedestrian

3. Pedestrian

4. Parking
5. Allotments or garden
6. Existing hedge
7. Tennis court

8.16 Model of 12 houses,

8.17 Planometric

1:750

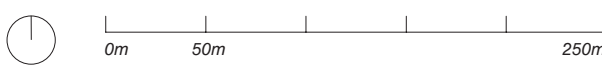

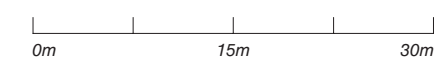



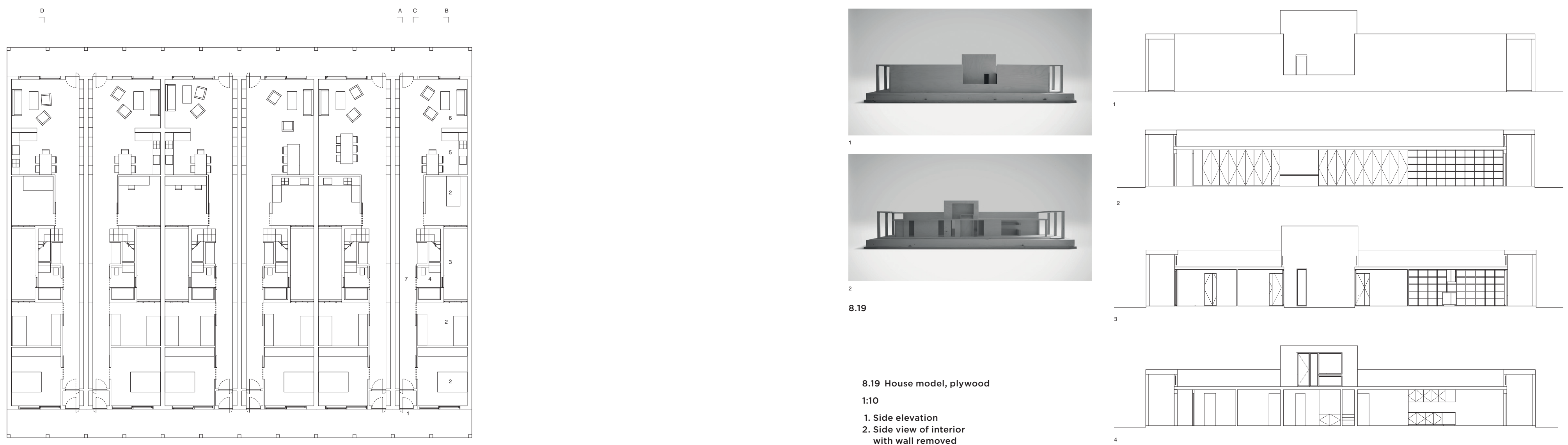

8.19

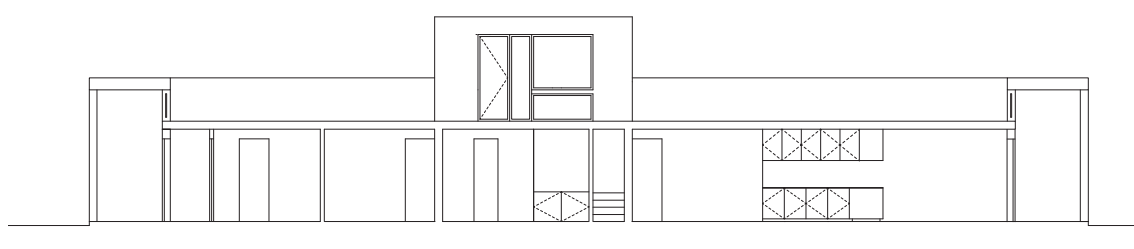

1:10

1. Side elevation
2. Side view of interio
with wall removed

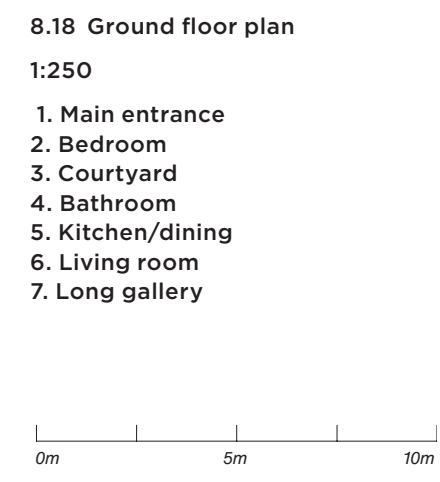

.20 Elevations and sections

1:250
1. Side elevation
2. Section $A A$

2. Section $A A$

4. Section CC
5. Section DD

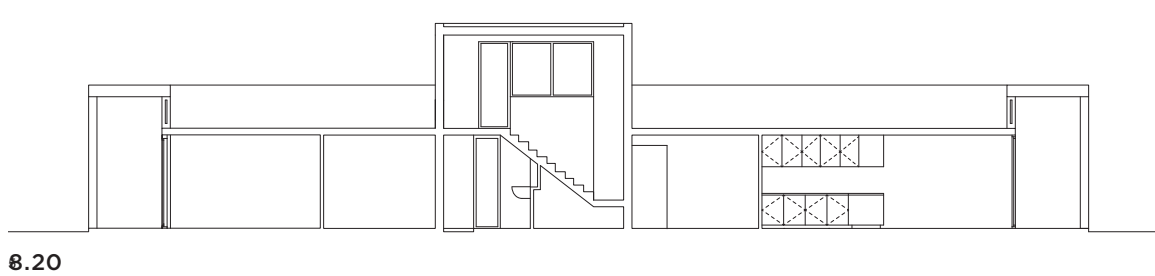



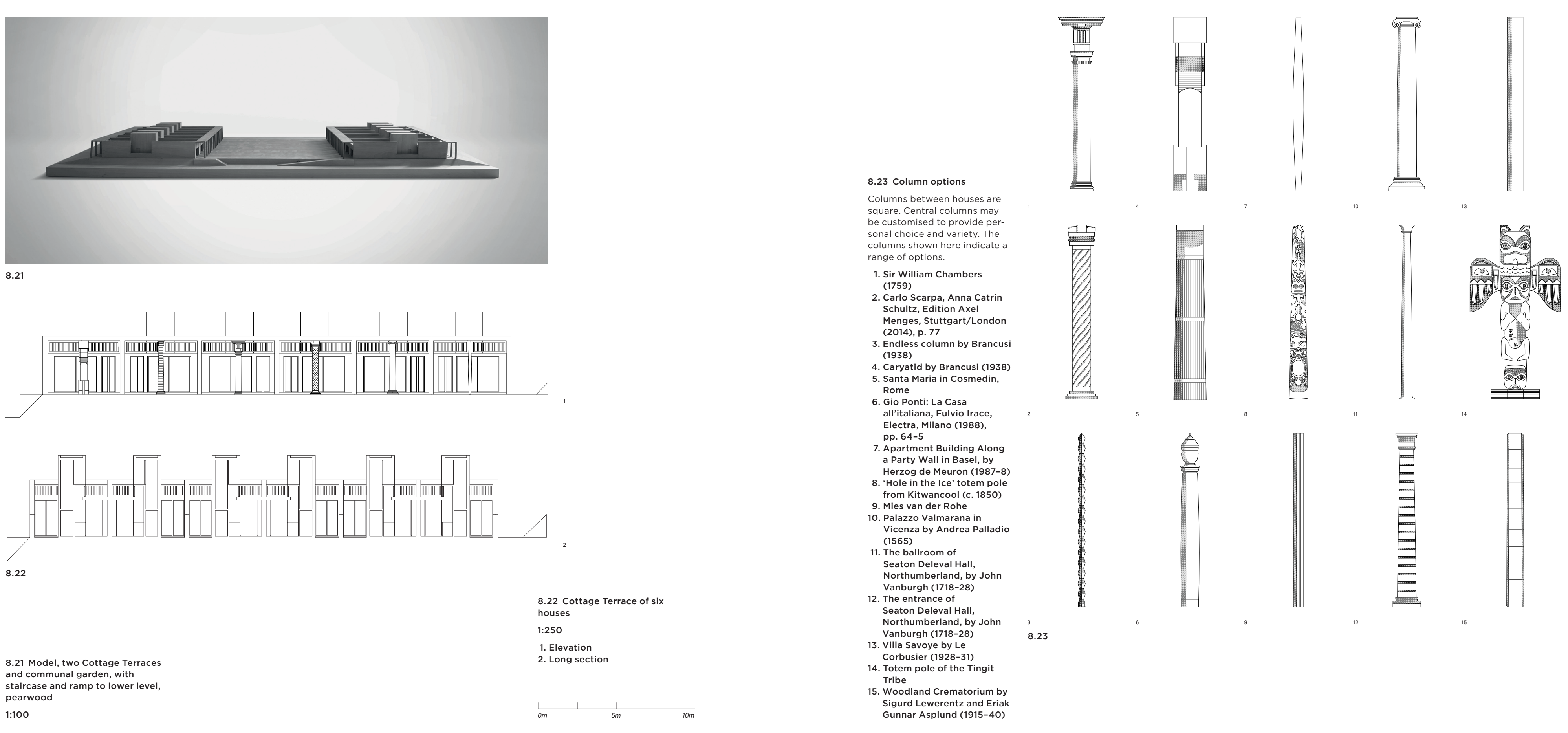

8.22 Cottage Terrace of six
houses

1:250

1. Elevation
2. Long section

8.21 Model, two Cottage Terraces and communal garden, with
staircase and ramp to lower level,
pearwood 1.100

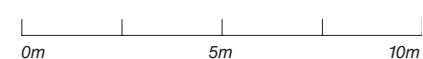




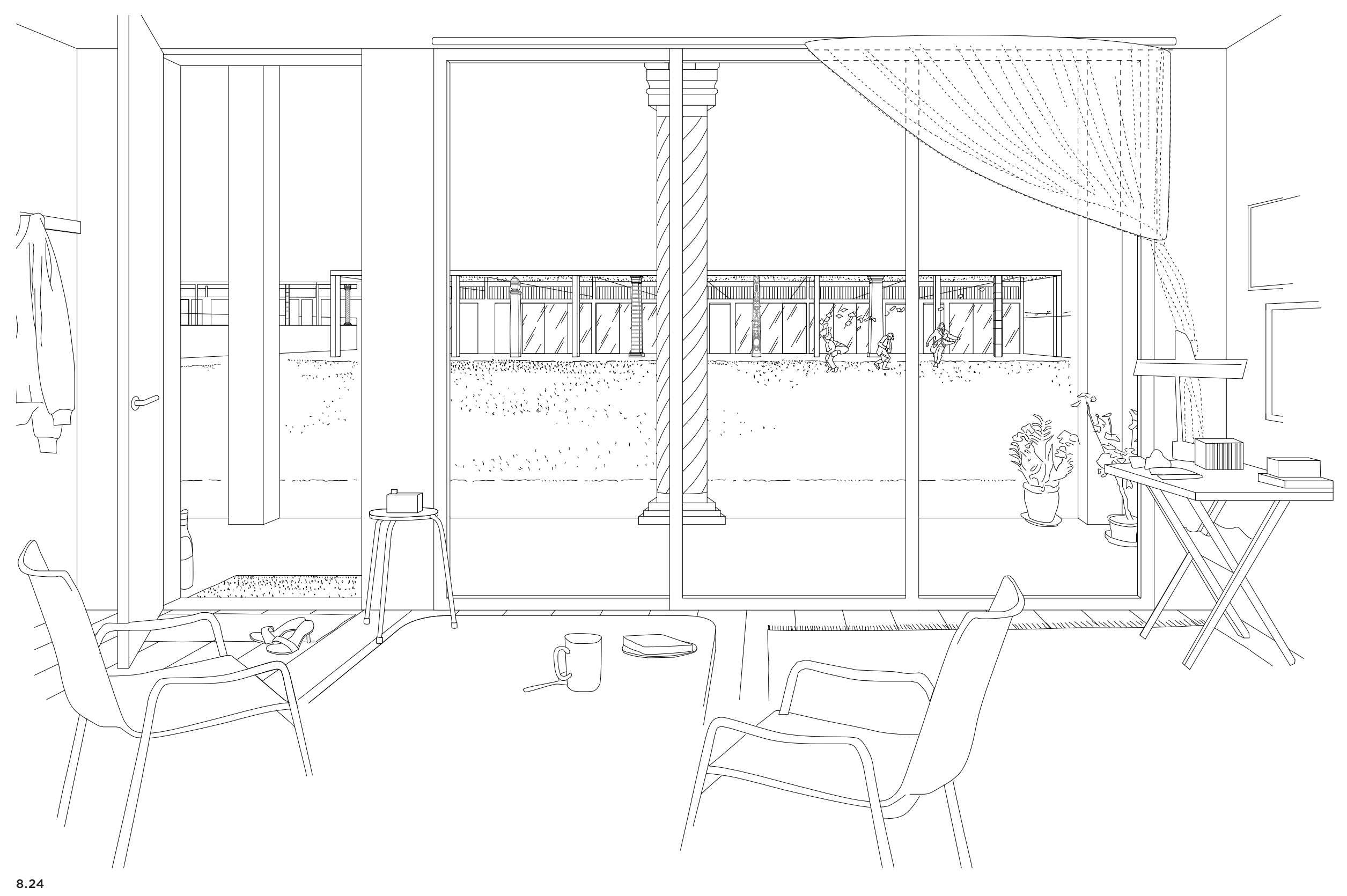



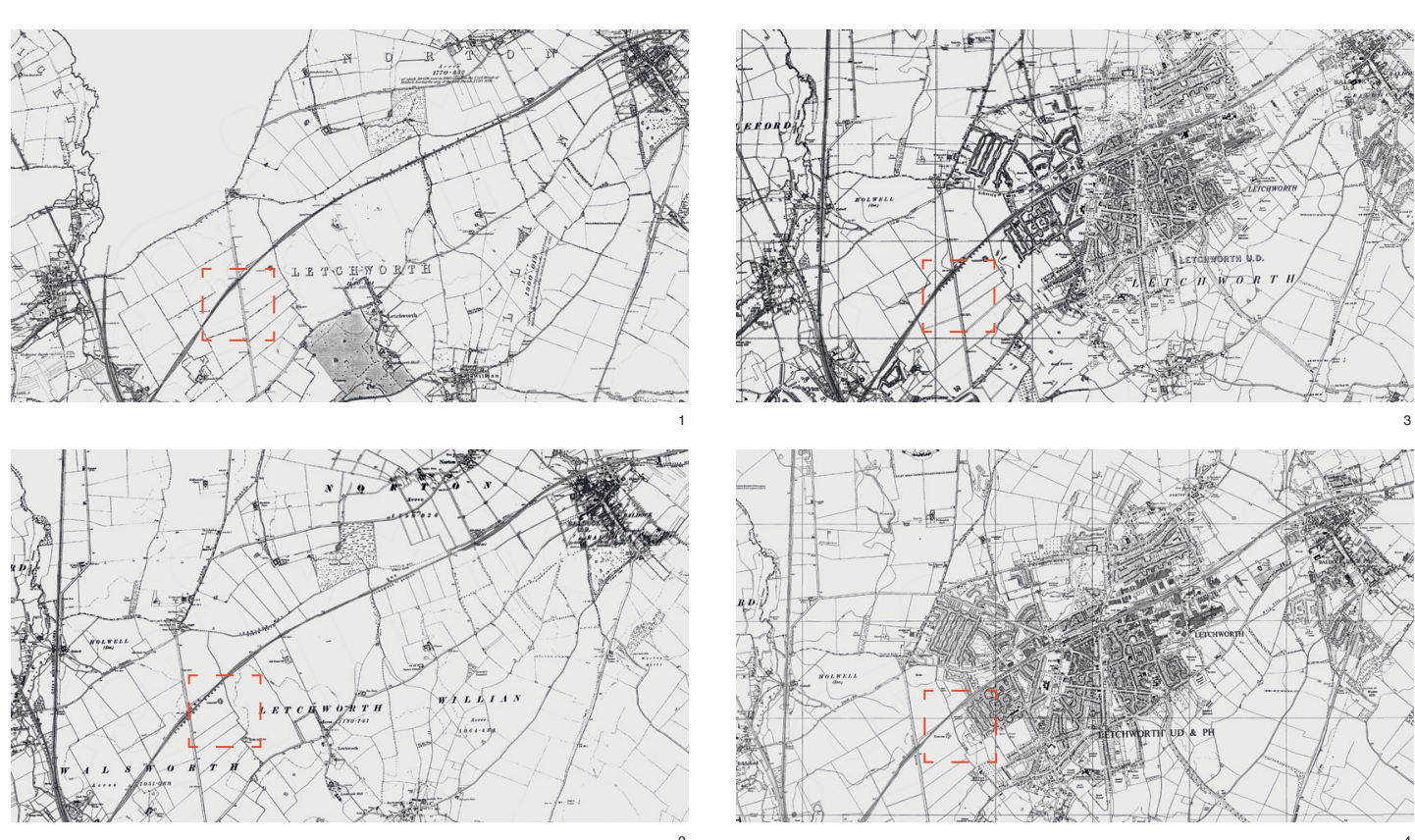

9.1 Historical maps showin$$
\text { Source: Image courtess }
$$

of Digima

1.1880
2.1900
3.1925
4.1940

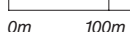

1:75, 000
Middle England | Patterns for Letchworth:

From Garden City to Patchwork City

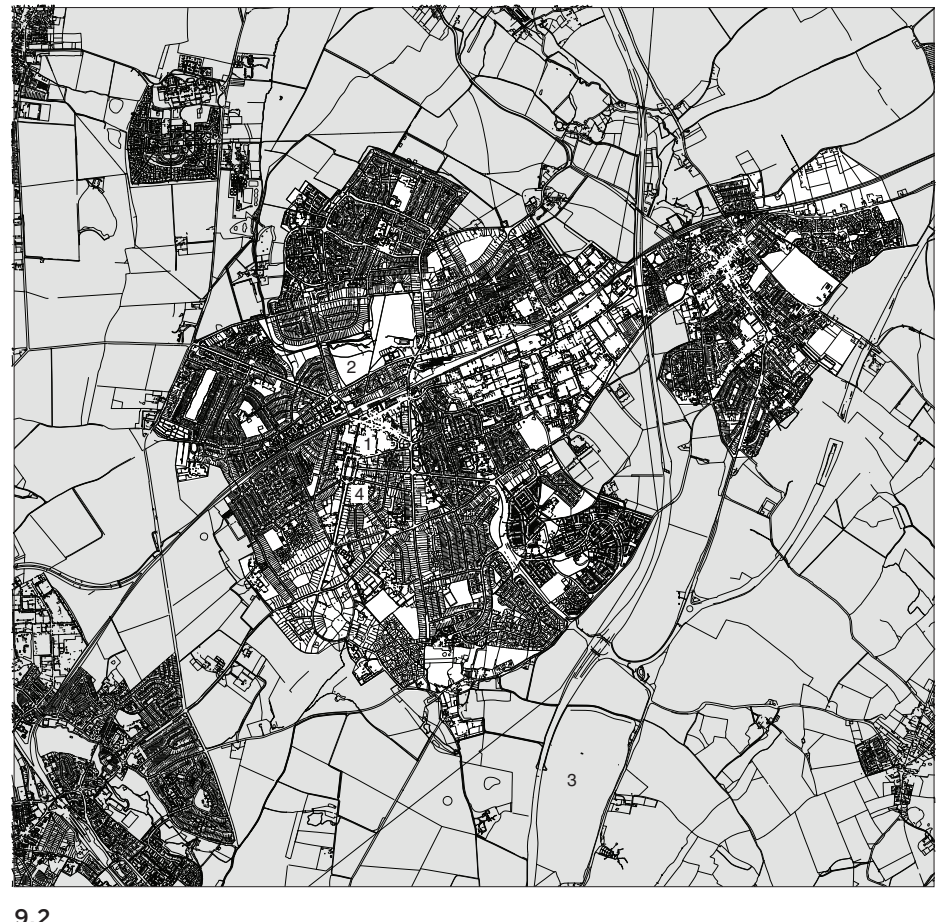

1. Letchworth Garden City
2. North Common

Patterns for Letchworth is a response up by Howard, and was, according to to a competition organised in $\mathbf{2 0 0 7}$ for Sir Frederick Osborn, conceived as the new house types to complement and forerunner of 'progressive experimentaextend Letchworth, the first garden city tion in new forms of social enterprise' initiated by Ebenezer Howard in 1903. (Ward, 1990, 20). Although Letchworth Letchworth was planned by Raymond was an immediate success with its first Unwin on farmland in Hertfordshire just residents, Howard found that his pionorth of London. It was bought by First neering model failed to inspir his pionorrat 


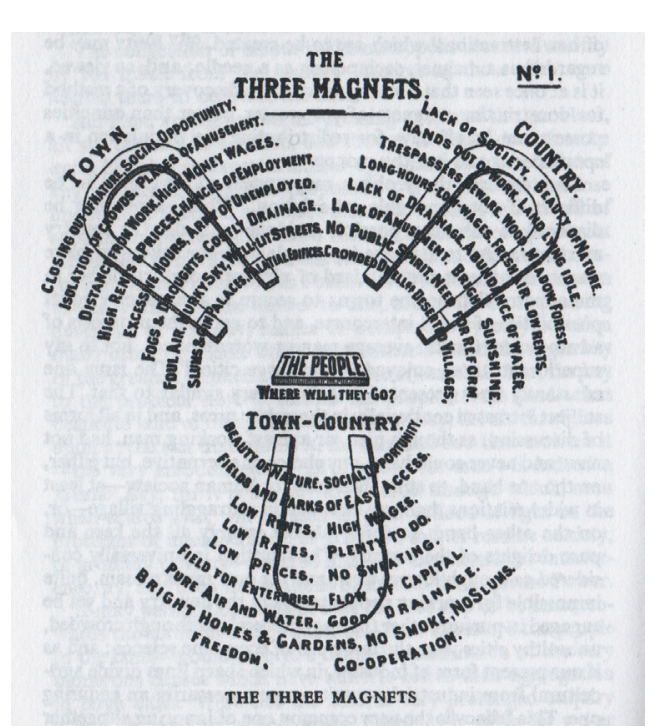

9.3

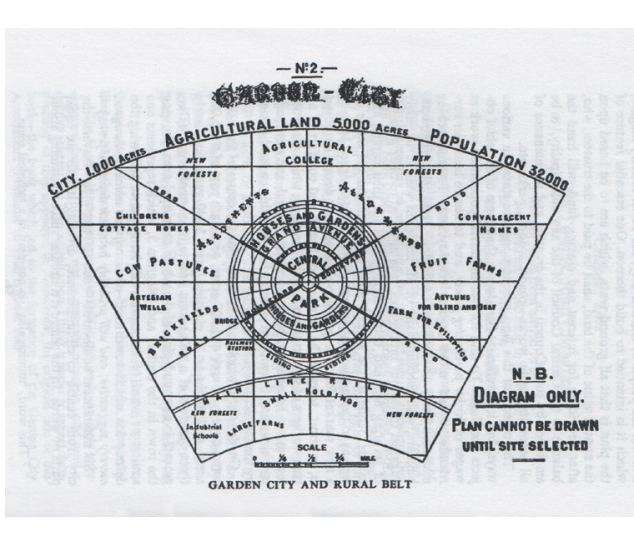

9.4

at nearby Welwyn. Howard's corollary to the garden city was the strategic dispersal of the inner-city population of London to facilitate its redevelopment at lower densities. This ambition was taken over by the state in the 1946 New Towns were designated for development by the government in the face of intense local opposition from local authorities, landowners and residents.

Patterns for Letchworth proposes new residential development on the edge of the city, laid out as garden squares bounded by plots for individual buildings. For guidance, four options for free-standing pitched-roof houses and flats have been designed with potential for customisation by inhabitants. Building plots are defined by linear party structures $2.4 \mathrm{~m}$ high. These are compulsory elements in the layout of each garden square and have been conceived as multivale and have been conceive as multivalent trellis-clad frames acting as host to garden shed, bin store, bicycle sher tered walkway and arbour. In this way, the will be established, even if individual plots are devoped indepently are developed independently. The aim is to offer choice in terms of design as well as procurement method.

The Wolfson Economic Prize 2014 asked the question 'How would you deliver a new Garden City which is vision ary, economically viable and popular? Pierre d'Avoine, Ian Abley and Alec Scragg together with Nabeel Hamdi and Clare Melhuish submitted a proposal for a Patchwork City. The first would be located at Marston Vale, Bedfordshire, near Letchworth, which included the village of Aspley Guise, home of Lord Wolfson initiator of the Wolfson Economic Prize. The proposal critiqued Howard's Garden City which was intended to be a self-sufficien entity, by proposing an opportunistic participatory patchwork development which would be stiched into the fabric of which ing countryside in a responsive the exis- a variety of scales in response to prevailing cultural, economic and political conditions. Thomas Sieverts, in Cities Without Cities: Between Place and World, Space and Time, Town and Country (2003), has explored the increasingly diffused characteristics of the postwar built environment which has replaced the traditional idea of a compact city separated from its rural setting.

The following is the introduction on-technical summary to our Wolfson Economics Prize 2014 submission:

\section{Aspley Guise Patchwork City}

\section{Association}

Vision-Our vision of Aspley Guise Patchwork City is for a permissive, participatory and popular place in which to live, work and play for all its inhabitants and visitors.

Aspley Guise Patchwork City provide $75 \mathrm{~m}^{2}$ houses costing $£ 90,000$ includin the land. It is an active association - an inclusive place to live and not a speculative investment.

spley Guise Patchwork City is a place where Simon Wolfson would love to live, but you don't have to be a lord to afford to live there.

Ebenezer Howard's concept of the garden city was governed by 'four fundamental principles-limitation of numbers and area, growth by colonisation, variety and sufficiency of economic opportunities and social advantages and control of the land in the public interest' (Mumford, 1963).

Aspley Guise Patchwork City respects However, insteado economic entity he envisaged, we propose new settlement with its own identity set within the existing regional economy formed by the employment triangle of Milton Keynes, Bedford and Luton/ Dunstable. It will also be part of the OxfordCambridge Arc thinkbelt that includes Cranfield University and thus within a high demand location where there is a good market for employment.

Aspley Guise Patchwork City will be a large settlement of forty thousand households to support its own civic functions, and unites several existing villages without and unites serat pulsorily purchase their

It will provide a customer base for the currently underused western section of Keynes and Redford and uses Keynes and Bedford and uses the existing infrastructure of the $M 1$ and A-road Aspley Guise Patchwork City is not bounded by a permanent green belt, which was Howard's identifying symbol and which in practice has been almost impossible to maintain, but will be laid out as an opportunist patchwork settlement which works with the natural features of the existing landscape with higher density development on the hilly woodland and lower density in the valley. It will regenerate the industrial brownfield lands of Stewartby, incorporate the pasture and arable land of Marston Vale, use the lake system as public space and in developing existing woodland make the designation of the 'community forest' a reality. It will thus be a landscape of cultivation as well as amenity affording its inhabitan we
9.4 Garden City and Rural Belt

9.4 Garden City and Rural
Ebenezer Howard, 1898 the face of intense 
visitors a vision combining the best aspects of the city and country life.

Governance-The existing $1946 \mathrm{Ne}$ Towns Act provides the legislation necesary to form the Aspley Guise Garden City Creation Company (The Company) as a development corporation. The Company has the express aim of establishing the Aspley Guise Patchwork City Association (The Association) as the legacy Local Authority over a projected 20 -year period. The Company is authorised with pla hing powers, and transfers those planning powers,

'The aim of The Association is to rebuild commitment to wider society and re-engage the householders as citizens' (Hamdi, 2009, 108). The Company is the democratic guarantor, regulating without interference, drawing out lessons through participatory programmes, transferring knowledge and know-how working towards mutualisation - that of commo ownership where public services and community enterprise are governed and run by its members' (Hamdi, 2009, 109). 'Two recurring themes, partnership and mutualisation, are at the heart of governance and underpin much of the thinking on participation' (Hamdi, 2009, 109).

The Association would encourage participation of farmers who want to continue to maintain their farms and landscape. The Association would also encourage participation of existing businesses, like Amazo and new businesses to help develop Association as a community of forty thor sand households.
The Association would aim to suppress lanning gain. However, the householders would collectively have the right to liquidate The Association.

The freedom to liquidate The Associaassociation.

Economic Viability-To ensure economic viability planning gain would be suppressed, first during the developmen and second in the period of leasehold.

Land would be paid for at $4 \times$ agricul-

ral value, thus farmers will not be paid for the 'hope value' of devilopme

Construction cost will be $11100 / \mathrm{m}^{2}$ to current building regulations based upon a attern book approach.

The budget of $£ 90,000$ per household will be raised privately in the open mortgage market. This could either be done

The agility of The Company to buy 1350 hectares in a patchwork is paramount to avoid the inevitable refusal of some farmer forego their 'hope value'.

Aspley Guise Patchwork City will us be an association of households in the wider labour market unlike Stewartby, which was a company model village.

Existing and new businesses will be expected to bring their own capital.

The Legacy Company would raise council tax and access to funds through central government and the EU.

Popularity-The houses in Aspley Guise Patchwork City are not investments but are homes to be lived in and the aim is to

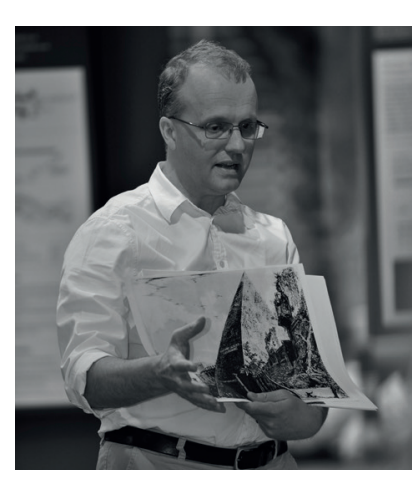

keep them affordable. Thus affordability will be no more than three times household income.

permissive design approach base and d'Avoine, 2005, 13).

Choice and individual expression will be encouraged within a code of permitted development. There will be variety of architectural character and housing typologies within the garden city. The aim is to provide

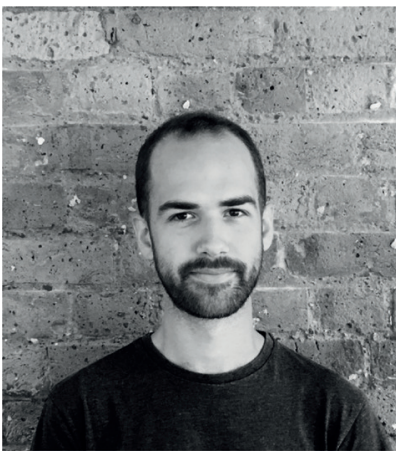

choice in reaction to limited dels offered by volume house builders. There will be a relaxed approach to density. Communal open space will be provided to farmland including the community forest. The M1 motorway will be culverted thus reconnecting the historic landscape arston Vale and Woburn.

lan Abley (above) and Alec
Scragg (below). I Source: courg (bes of Simon Punter
and Alec Scragg, respectively.

\section{Ian Abley and Alec Scragg}

Interview at Durham $Y$ a August 2016-Alec is an urban designe and Ian trained as an architect. We collaborated on the Wolfson Economic Priz 2014 where we proposed the Patchwork City as an alternative for a new garden city.

A: The profession of being an architect has a legally protected title based on current practice. Without annual registration to the Architects Registration Board, I may not call myself an architect, even though I'm professionally qualified as one. I traine in Newcastle upon Tyne in the $1980 \mathrm{~s}$, and obtained my professional practice Part 3 in 1998. The attraction of Newcastle was that was three hundred miles away in South London - not because I hated home, but just because I needed to grow p and leave home. Newcastle was a great place to learn and live in. However, I had mistakenly thought that the practice of architecture was practical. I found it difficult to get through the course as a designer of 'building concepts' with scant information about how you actually constructed them. After qualifying, I quickly ended up as technical support. So, I think I'm probably more accurately a technician than an rchitect, though of course that is quite a a kept me going in Newcastle was a really in (n) 'Housing for Developing Countries', run Chales Cockurn. I spent much in that rather than my own ar course. Most of the people on the course were. archite ts whods arching On Oed had to rely on themselves rather than on

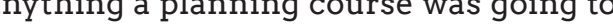
His course got you out of a first-world mind-set. I enjoyed the exposure to third-world realities of shortage and wiculty, while the school of architecture was trying to teach me how to design shiny, expensive buildings but without too much concern for the bothersome problem of construction. Charles introduced me to the ideas of John Turner and Colin Ward, among others.

I wanted to get away somewhere fresh, and Newcastle is a fantastic place in the 
wonderful North-East of England. It wasn' because I didn't like my parents, but you are 18, and you have to grow up. There were grants; we got paid to go to university ... There were crappy houses to live in th cost you little money. I got a full grant; I'm that old. It was never luxurious. But you weren't expected to take out a loan, and it separated going to university from your parents' income.

I'm from the suburbs: 26 Browning Avenue, Sutton. I looked it up on Google Earth the other day. My brother and $I_{4}$ like countless others in suburbia, were brought up with a long garden and fences and neighbours whom you might play with out of school, and a might play wher out of school, and a dad who conwas a City and Guilds-trained cabinet maker, but couldn't make that pay by the maker, but couldn't make that pay by the
1960 s compared to drawing furniture as a draughtsman. He increased his salar by leaving the workbench and joining th civil service. Dad worked for the Proper Services Agency (PSA) and then later for the Crown Suppliers. Where local authorities had their own architectural departments, the PSA looked after the government's stock of properties. By the 1980s, the PSA bureaucracy was criticised by politicians and other government departments, with allegations of corruption involving civil tractors. The PSA was broken up so that various functions could be sold off to begin to create the private property services market we have today. There were lots of arly retirement deals, which my dad had to take. But he missed working with col-

leagues. I was brought up with him building things. Always furniture ... a fishing boat in the garage ... extensions off the back of the house ... or fixing up his mum's two up-two-down terraced house after she had died for my mum's mother to live in for the st years of her life. Both my grandparents ved within walkable distances of Sutton. My mum and dad had met while teenagers. In a few streets, there was a timber yard, joinery and furniture makers - where $\mathrm{m}$ dad was an apprentice - and a French polishing shop, which was my mum's dad's, all of which kept each other variously in business. I think there was an underty in busbut I minht have was an undertaker too, The war had forced them to be evecory The war had forced them to be evacuate London London suburban in the 1950s. My mum became aradographer, learning new X-ray techniques, following an interest in photography she had gained from the family she was evacuated to. They married, struggled to pay a mortgage on a semi-detached house and gave me and my brother a suburban family upbringing.

went to Wallington Grammar School in the 1970s, luckily for me, and it was utter luck, as often things are. I was academic enough, but the sixth form had recognised foundation course that would normally be the first year of art college. A foundation course is not a requirement to get into architecture school, strangely, bu it meant that I could spend the sixth form doing physics and maths while playing with clay, painting and sketching and messing about with metal, timber and plastics. The head of the foundation course was Don Welstead. Initially I thourse was Donald industriad. Initially, I thought being an until I went for an interview and was ridiculed by the interviewer for my ignorance of 'products'. Mr Welstead, as he was to me realised that if I had not taken to industria design, then maybe architecture would be better. He sent me to the Barbican in London, Durham Cathedral. I won a school book prize in 1978, and I was given Great Architecture of the World (Norwich, 1975). It contained pictures of the University of Leicester's Engineering Building drawn isometrically which I thought was amazing The foundation course was the result of the personalities of the teachers in the school per the interested me, aged 17 and 18 .

AS: My natural history is that I was bor in Essex, my dad is from the East End an my mum is Argentinian. So, I don't really know what I am. I grew up in a bungalow in
the English landscape; it was one of those private unmade roads where the fields have been divided up and turned into houses over time. I was born there in 1989 . So, that was still during the Cold War, wasn't it? Before that, I think the family lived in suburbia in Galleywood, Essex. So, actually, if you look at my father's side, there's a really interesting story about social mobility and a consequent movement out of London. He was born in Hackney. He worked in Billingsgate Fish Market - started as a porter and moved up and up, and ended up owning a business there. That was during the financial boom of the 1980s when the city became a big thing Suddenly the city was full of fancy and exotic restaurants, and he made his money by supplying fish to them and as business grew, he moved further and furterinto all tied up with the social phenomenon of the 'Essex Man', which I've spent the last two years researching and exploring in relation to housing. As I'm getting older, I'm becoming a lot more interested in relating family history to a lived understanding of these abstract social phenomena and how we came about. On the one hand, there is my mum's experience of Englishness from the perspective of an immigrant, and on the other, my dad's progression from the city to countryside is tied up with that whole idea of the 'Essex Man', class and social (do ts in the potteries of the Midlands. So, by earning about family history it has made it a lot easier for me to understand how En lishnesscam aboutand those sorts of cio-regional discussions, which is what in very much interested in these days. I've ays been inest in these days. and sociol hink Isturis architectures a profession that a was stabily to it not so $m e$, and there was stability toit - notsomuch status, but was stab yould recause these were the sort I suppose were put into me bility was super important.

My mum, for instance, left Argentina on her own when she was young during a politically tumultuous time and ended up Barcelona. She was there when Franco died. Later, she worked as an au pair in Paris for an interior designer on Boulevard SaintGermain. She came to England to work for a family in Great Yarmouth, and then met my dad through their local butcher, I think. This just goes to show the sher 
complexity that comes from the experience of migration, and her family history is just as complicated, since Argentina itself was an outpost of Europe.

She's from a small town called Sunchales, in Santa Fe. It's known as the milk centre of Argentina, and her fathe was a gaucho and then a farmer, and they owned a small farm. He also drove the village hearse, which was one of those baroque, extravagant artworks you only get in Catholic countries. Her mum comes from a long line of Italian immigrants from Piedmont in Northern Italy, and family got very complicated... I think he was a mix of Swiss-German, Spanish and Guaraní. So, that'sjust a typical Argentinian family mix.

My mum continued to live as a live-i au pair in Great Yarmouth, and then she went back to Paris to au pair. My dad - an this was before the Eurostar - would 90 to Paris every other weekend on the trai ferry, and they used to meet just outside Gare du Nord. They used to meet there every other week, and then they decided to live together. They bought a house in a suburban cul-de-sac in Galleywood, and love hearing stories about this little environment because it sounded full of the sor f Reginald Perrin pastiche of Englishness. One of the neighbours used to hoover the drive every Saturday, which I just think is hilarious, but is probably more common behaviour than we imagine. So, that was a microcosm of the community there, but the house that I grew up in is in the middle f nowhere. There are plots of fields and cound couldn't walk to anywhere useful. We had to drive to school, and then in secondary chool, I learnt to drive myself because was 40 minutes away. So, I wouldn't say that I grew up in a community. I went to grammar school in Essex that pretended to be a private school, which really annoyed me. We had to wear a purple blazer with Latin mottos on it. It would have been perfect setting for a remake of if $\ldots$ with Malcolm McDowell. Growing up, I wanted to be a psychologist. I think it's the firs career move that I could think of because I was interested in understanding people and these sorts of things, and in retrospect, maybe I would've been more open to studying some of the more ambiguen academic subjects like sociol academic subjects like sociology ...I was very good at economics: I won a nationa econos neutral housing policy. So, that was quite od because Id just applied for university at that point, and when I was given the award by Nicholas Stern, he asked, 'So, where are you going to study economic then?' And I told him that I was going to study architecture instead. But I didn't se much difference between them. I simply thought architecture would be more propositional rather than analytical. So, I ended up studying architecture at $\mathrm{UCL}$, and that's where I met you. And then afterwards, started working with architects and decided I didn't like it. So, I went to work at the Olympic Park in public-sector urban design, which I found far more interesting I got far more interested in urban design and the space between buildings - how cities work as an ecosystem. Thgs - how cities work as an ecosystem. Then, I wen was an unusual course in thit you your own research topic. And it was interdisciplinary, and it was a lot broader; it wa about really understanding a context, an rigorously figuring it out. So, 1 used that as an excuse to think long and hard about Essex as a microcosm of the English condition of planning, and these sorts of things, because I was obsessed with the history of how Essex was a test bed for all sorts of development and growth and, also, what the hell Englishness is, or whether it is eve a thing, and how that influences these sorts a thing, and how that influences these sorts the economic aspects of it I've becout the eclly interested in the cultural become property and how people view pects of prow they rate it to landscape, how th how they relate it landscape, how they relatelt re national character and what sort I'm sort of heading at the moment.

Ian, you published your book Why Is lan, you published your book Why Is Woudhuysen in 2004. Could you talk a Woudhuysen in 2004. Could you talk a little about why you and James wrote the book and your interest in house building in this country, and how that led onto ambitions were for that?

IA: Colin Davies wrote The Prefabricated Home (2006), a brilliant book that Martin Pawley rated highly. Colin had pointed me towards your pattern book. Colin's question in his book is 'why is housing so difficult today?' The Georgians and the Victorians had pattern books. You could buy houses from the Sears catalogue, and buy hirban semis needed no architect. In the interwar years, there were all sorts of catalogues of innovative systems and products that people would sell you: kit homes. Dorman Long produced their steelramed asbestos bungalows, which must have been freezing cold, but far better than living in a tenement - they had an inside toilet. Housing has not always required an architect. You could go back to the architecturally generated pattern books that inform places like the Hampstead garden suburb, or the Edwardian attempts by Lever at Port Sunlight, which influenced the speculative house builders of the 1920s and 1930s. The emi-detached houses were logically erated by where you put the stairs, with sidew seve down for a garage in the back. But even befor you could get a cess to so was the basis for all the pota was the basis for all the plot lands in Essex. If you were struggling to earn a living, you could aswa urbia, which his mum had encouraged. For generation, home ownership through a mortgage loan meant the possibility that you couldn't be evicted by a landlord, and that the landlord couldn't keep putting the rent up. Eventually, you'd pay off the loan by working out of your shed at weekends, fixing cars or making timber windows or music boxes just to make ends meet. Maybe too there is a bit of vegetable and fruit growing, which could be enjoyed more as a hobby than as a necessity during wartime. But after the war, suburbia, like everywhere else in Britain, required planning. Paul Barker and Philippa Lewis's The Freedoms of Suburbia (2009) explains that perfectly although he retrot 
criticism of the postwar planning system. 'Non-Plan' in 1969 for New Society magazine by Reyner Banham, Paul Barker, Peter Hall and Cedric Price had marked a brief frustration with the planned environmen The authors were then imagining if things could be any worse with the repeal of the planning law. A few years later, in 1973, Peter Hall wrote a two-volume defence of why the planning system was essential to contain urban England and stop suburba sprawl. The Containment of Urban England established him as Britain's pre-eminen planner. In his early writings, Colin Ward hou want Country Planning Act and set places like Peter Hall in his later years, resigned to th planning system.

On page 287 of Why Is Construction So Backward? (2004), James Woudhuyse and I concluded that planning was holding back the construction industry. Since 1947 no landowner is free to build on their ow land in Britain. The discretionary power of the state to deny development is de gated to local authorities to approve or reject an application to build. This planning permission is then politically handed out through a middle-class committee, ofte to encourage short-term constituency interests. The planning system means that the construction industry can't make the productive leaps that other industries can make. James and I started looking at why construction was stuck in the architectural project-by-project paradigm of site development, rather than able to unleash production. Why wasn't housing massproduced for customers reading pattern books or catalogues, deliberately cheapened and made easier to install on a prepared site? John Turner had wondered that too... Why couldn't the construction industry be advanced beyond the stuttering set of disjointed product innovations made by manufacturers that crashed in recessions? We came to the conclusion on page 287 that a project-by-project-based approach that can hardly get beyond disjointed produc innovation is necessary when you have to respond to the planning system: you can't predict work and as a manufacturer you can't line up an order book. You can't build up stock or become 'lean' and operate a lowstock approach to production because you are unable to guarantee when or pe unable to guarantee when, or even if planning permission is going to be given. Construction is stop-start, and thanks to the need for planning permission, it is The end of the Coss war waction. and I say that as a republican and an old communist of the internationalist sort. But oddly, it is the Cold War warriors of the 1980s who turn to environmentalism. It was a blue/green sensibility that came out of the end of the Cold War as th reds struggled with their past. So, by the time the 1990s had been worked through the idea of sustainability has become an elastic term as politically useful as community was in the 1970s, and particularly among planners and architects. In the 1990s, environmentalism was a reheatin of Malthusian ideas: the lie that there ar too many people, and an anti-human sentiment I'm against sustainability I wanted to develop a criticis of promotion sustainarity
Rogers who used the planning system to find a way of thinking about planning and strengthen the containment that Peter Hall the ideological shifts in policy that affect had identified. In the late 1990s, the Urban construction practice.

Task Force was instructed by New Labour to bolster the planning system. It was John Stewart (who later got a job at the Hom Builders Federation $[\mathrm{HBF}]$ ) who realised that if sustainability meant sterilising the countryside, containing the population in urban areas and opposing suburban sprawl then lower housing production and houseprice inflation would result. The phrase Jrice Stewart was using around 2000 was 'Building a Crisis' The HBF published his argument in about 2002 but I published his ansight in Sustaining Architecture in the Anti-Machine Age in 2001 John Stew in the Anting been proved right The sterilisation of the Britsh countryside through the planning system has meant that we've now got the unaffordable housing market hat managed to survive the financialdifficulties of 2008. If there had not been the planning system predicated on containment as the measure of sustainability, the British housin market would've gone the way of Irelan and Spain. Planning is a virtuous, green underpinning of the financed housin market. The beneficiaries outside of th finance sector are middle-class homeowners, or those who hope to inherit a home and a new section of middle-class landlords who have revived the private rental sector. Institutional landlords now hope to capitalise on joint ventures with local authorities who are both landowners and planning committee, and architectural talk about 'offsite manufacture' has been given a new twist That's the link to the 250 New Town

Club, while it lasted. We were struggling to
Alec, you and I worked on together on a submission for the Wolfson Economic Prize 2014. The theme that year was for a garden city for the twenty-first century and the issues to be considered were vision, governance, economy and popularity.

A: Well, it seems odd, doesn't it? Why would Lord Wolfson, a Tory peer, come up with something that a Tomy peric comas the pposite to the orthodoxy of sustainability and urban containment? It was posed as a conservative challenge to that orthodoxy. conserver sham.

AS: Yes, nothing happened

and and the winner was someone who explicitly believes in urban containment... AS: Well, they were just proposing suburbs. There was nothing different about that. And the other thing that annoyed me was the wording of the competition; it ignored the new towns as any sort of precursor. They were viewing the garden city as something historical, but they didn't seem to realise that the new towns were in many ways an imperfect aspiration to the same sort of ideals because we ended up using the same new towns' legislation as the basis for our competition

IA: Exactly. The New Towns Act 1946 is still on the statute books. The promise of new towns remains. If you really wanted to house the population of Britain at the rate it's growing, you would, over 20 rears, 
need to build around 250 new towns of forty and management for the benefit of evethousand households each. There is plenty rybody, for the benefit of food production of redundant farmland. Legal new town rather than aggressive consumption of development at that pace would blow a resources. You simply cannot decant the hole in the plan set by Richard Rogers to countryside and expect it to become better. refuse planning permission on greenfield IA: Well, you can depopulate the countrysites and force ever-denser development side if you enclose the land for farming on brownfield sites. That inflates house sheep - which is what the aristocracy did. prices on developable urban land, which AS: I also don't agree with the fetish for the suits a lot of people. Urban containment 'wild' and re-wilding, which is so fashionand densification also suits architectural able now. I just think it's not as clear-cut as practice. Architects hate the pattern-book that, I expect. I think what is interesting practice. Architects hate th' pake a living is that we were arguing for is interesting if designs are cheap and readily available. terms of stewardship - that we were actuIf designs are cheap and readily available. terms of stewardship - that we were actuUnsurprisingly, the $250 \mathrm{New}$ Towns Club ally looking after the land in a productive had failed by the time of the Wolfson com- way and promoting ecological diversit petition; we had set ourselves the ludicrous through the introduction of finer-grain task of drawing 50 new towns a year, which divisions of land - as opposed to protectis one a week. We lacked the resources ing it by not doing anything with it and to do that! So, the Wolfson competition trying to confine everybody as much as was a manageable task, which we could possible. You can relate that to Broadacre approach by dropping a new town on Lord City and those sorts of ideas as part of Wolfson's village of Aspley Guise, near this vast, low-density stewardship. While Milton Keynes.

there are obvious issues of sustainability in terms of 'sprawl', so many of these are

Part of our agenda to counteract the issues of behaviour rather than urban form. urban densification proposed by Richard We tried to address the culture of this by Rogers was to reinvent farmland and presenting a different desire for a city of to provide the means for people who stewardship. I think our other innovation weren't farmers to live in it.

IA: That wasn't a new idea. was to think of it in a patchwork way when it comes to land ownership.

IA: Paul Cheshire, as the adviser to Wolfson,

AS: I thought it was about the idea of stew- is often claiming that suburbia is more bioardship and the false assumption that the logically diverse than anywhere else. He countryside is not a 'proper' place for a does that in Urban Economics and Urban development - that it will somehow be Policy: Challenging Conventional Policy better for the countryside to be emptier But Wistom (Cheshire Nathan and Overman, it ignores the extents that urbanisation the a considered process of maintenance were the pride and joy of you you climbed up and made a tree house in. It's a varied, lived-in landscape.

in. and what it's legal status is - who maintains It, who manages it, how it's designed - then on sorts of things. You've got people like particularly in greenfield developments. Richard Mabey doing journeys up the Lea IA: That's British history, isn't it? The denial Valley and recording all of the ecosystems of the commons is the enclosures. Aspley at the margins of spaces, and you've got Guise was a product of the enclosures and Oliver Rackham talking about the plot lands sheep farming. British history from the and their biodiversity versus the sterility Tudor period was one of enclosure - the of large fields. And I've personally become creation of a landless working class. By really interested in the difference between the time you get to the Victorian period, historic open-field systems, and the way enclosure is legalised, systomatised and they are now and whether thatcould work rampant for suburbia: the idea that manament is class is what the British stande is about The tor temporal, it's baid over time. It's not about having an empty the achievements of the enclosures. Peter ing it up and hing ing th up, and how you in troduce rotation planningwant about the containment of and the nuanced ways of ownership and urban England, it was about the containbelonging that occur with that. So, I think ment of the working class. But this is the there's all different ways to look at how twenty-first century. You would still have you divide land up and how you manage it a working class, but people would have that become the basis for understanding ready access to allotments and an acre the architectural implications of a differ- or two, with woodland, all of which could ent economic system, for instance. With be in some kind of private ownership. It the patchwork idea, I think that what we doesn't have to be a common, although didn't think about (that we needed to do) some might make it common land. We was really about the common land as social need to get over ourselves in Britain. The and environmental infrastructure and how idea of containment is just stupid: you can it all connects up together. So, it's not about live in the countryside. Martin Pawley was zoning and allows some flexibility in how a always strong on letting people build vilsettlement emerges. Because I think that lages. Archigram talked about hedgerow if you look at the idea of public realm in housing. The non-planners got it, and then this day and age, it's all based on a very singular idea of ownership. It's more often than not privately owned space between buildings that's managed but if to think more about what common land is retreated from repeal of the 1947 Act.

You are also critical of Howard and the garden city, which was based on a selfsufficient urban unit that also seems to 


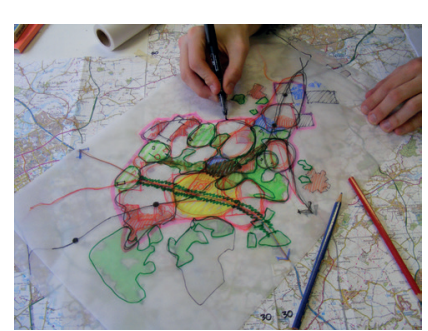

mply the idea of the containment of the towns in places that have got some kind of countryside. We had proposed the idea landscape relationship, whether radiating of a patchwork city to situate it in the around London or on the canal navigation wider economic context of the Oxford- in Norfolk. The critical factor is paid work. Cambridge Arc.

IA: We imagined how Aspley Guise could be extended into the former Stewartby Brickworks in the Marston Vale, between vehicle testing centre. We hoped that farmers would give their land or ther would be some kind of exchange. We worked out a plot price that gave farmers enough to retire on. We were totally strategic in terms of location. We had to build something on top of Lord Wolfson's home...

AS: But we weren't strategic about which parcels of land.

IA: That's right, because it was to sprawl IA: That's right,

all over the place.

AS: Which allowed us to draw our red-line boundary in many ways after we've conpleted land accumulation, though I don know how legal that is

IA: It's completely legal if done using the New Towns Act 1946

AS: It's pretty unorthodox.

A: Britain is so full of redundant land that if we wanted to have one end of a sprawlin patchwork new town in Aspley Guise, you could have bought land in any direction. AS: In many respects, it was like an idea that you could expand out for the entire country, in a way.

IA: That's the problem I found with the 250 New Towns Club: when you lay the map of Britain out and start drawing the map of is so much space. You can start to put new
Where are the jobs? How do you make an income?

AS: It makes you want to question th value of compactness (instead of just an economic thing) to think about the town centre today - what is their relevance now and what could be their importance?

Sprawl has always been a pejorative word. Is sprawl a good thing? Can we discuss it in positive terms?

IA: I think sprawl's a very good thing. I can't imagine Britain without the suburban spraw of the 1920s and 1930s; the semi-detached and detached houses that are now sellin for millions of pounds, and the kind of hom mum and dad, home ownership was a dream because they are the children of workers Their parents were renting. My dad tells the story of Mrs Talbot, who never spok to him after she shook his hand over th fence when he moved in. He was the wrong sort, rough hands and the wrong class. The thing for mum and dad was to pay off the mortgage: you got free of the landlord and lived more cheaply. That was the freedom of suburbia: the promise of home ownership. Then, in the 1980s, there is a growing notion that the house can make you money. The early 1990s are uncertain, but house price inflation is expected by the 2000 s. Th house becomes your pension 2000 s. The house becomes your pension. The elderly r can be assured of health care that I grew up in. I mean, if you look at $m y$
But mum and dad realise their nieces and it's creating a big connection between the nephews are unable to achieve the same. two places. So, that's probably it, in a way. The younger generation can't buy a cheap I mean 'community' is an odd word to be place. Wanting a home to become security is using anymore - particularly when you are one thing, but house-price inflation based in going out with the intention to create new planned containment and under-production places. I mean, I'm interested in polity and has skewed the economy. Finances are in a that idea as something strictly administramess, and the thought of house-price defla- tive. How do people organise themselves tion scares the hell out of people. when it comes to those sorts of city forms, and how easy is it to organise yourself if

It has also skewed society and the you live in the suburb? I don't know, but dynamics of our culture. It's an obvious it's an interesting question.

conversation about the North-South IA: I mean, Peter Hall made a big play divide. I've just been reading Orwell's The Road to Wigan Pier (1937) London being a 'world city. That was 作 particularly the North of England and phrase 'world city' is first attributed to the terrible conditions the working Liverpool in the late 1880s, I think, largely classes lived in. What kind of communi- because Liverpool was a product of the ties would you envisage living at Aspley triangular trade. So, it had the world going Guise?

through it in a way that London and Bristol had too. But nobody talks about a 'world

IA: You don't need to envisage it. If you go suburb'. When you use the academic to Southend on a bank holiday weekend, phrase 'world city', you imagine it as some the entire world is there. The world's in kind of very dense core with a walkable Southend, as it is in Essex. If only those periphery that's got the rich and poor living worlds could organise to take control of a in it-like Charles Booth's map of London. farm and build a new town. But the reality is the world is in Southend AS: I mean, to be honest, I think Southend in Essex or spread out around Sutton in is a really good example of how our pro- Surrey. Now, sometimes, suburbia gets posal would've ended up because it itself very Eastern European, and sometimes is a collage of sprawl, and if you look at it it gets very Caribbean, and often those in a satellite photo, it's just a weird patch- places don't mix easily, but that's a social work of open space, estuary and suburbia, process in itself. I mean, Alec, you're an basically. From what I remember, the town Argentinian and an Essex Man, intermarcentres aren't really that great in it. It's all riage is a great thing. But nobody talks of the really odd bits around it that make about a worldsubur it what it is because it takes advantage quite good airport. It flies to Poland, and which would be really good!
AS: Yes, especially on our site when we

had the Amazon distribution when we 
sort of the centre of the world in many distribute - it's about how you produce, ment of labour. I've just finished reading surely.

a really interesting short catalogue by

Jeremy Deller and Roger Malbert called But we produce more than we need All That Is Solid Melts into Air (2013) of an including in terms of agricultural proexhibition Deller did of the everyday expe- duction. It's there; it's just how we choose rience of the Industrial Revolution and

its relationship to a lot of auxiliary social

phenomena like heavy-metal music. We should talk more about the 'world suburb' as an important cultural place as well as an economic one, and it would be interesting to see what these changing forms of labour could potentially generate in them It's also a criticism on the whole idea of progress: progress towards what and for hom? We always thought that we would in a situation where we liberated by automation with plenty of time to devote the production of a rich cultura life, but it's all been a lie. Flexibility has life, but it's all been a lie. Flexibility has created zero-hour contracts, while places like Amazon and

millions in taxes.

makes me think about a condition of post-scarcity that was talked about in the 1960 s and 1970 s by Murray Bookch and others, and where we are now.

IA: Are we in a condition of post-scarcity?

\section{I think probably we are.}

A: There's long been capital, but that doesn't end scarcity. Isn't it about how you distribute global wealth equably? It's about
IA: Well, production is privatised. The surplus is privatised as capital. Many things have been cheapened through cap duction, but the last thing that the British economy wants is to cheapen busing Yet, it's the obvious thing that you want to cheapen You might be in your 20 a a cher relative Butyor com is costingyou for Irs ths sucking up all of your disposable income when, if you cheapened shelter, people The trate a more disposable income. The trouble is if you cheapen shelter in Britain right now, the City of London would collapse. That was our point in the $250 \mathrm{New}$ Towns Club. If you really want everyone to have affordable housing, you have to imagine that your house is not your pension or your health care in old age. If housing is to be solved as a problem of capitalist production, to drive housing costs down, the planning containment has to cease. Richard Rogers was wrong. His dense urban notion of sustainability has built a crisis. A non-plan approach to land use is due a revival, and the repeal of the Town and Country Planning repeal of the Town and Country Planning tion would'melt into Then house-price inflation would 'melt into air', and housing would
no longer be a scarcity.
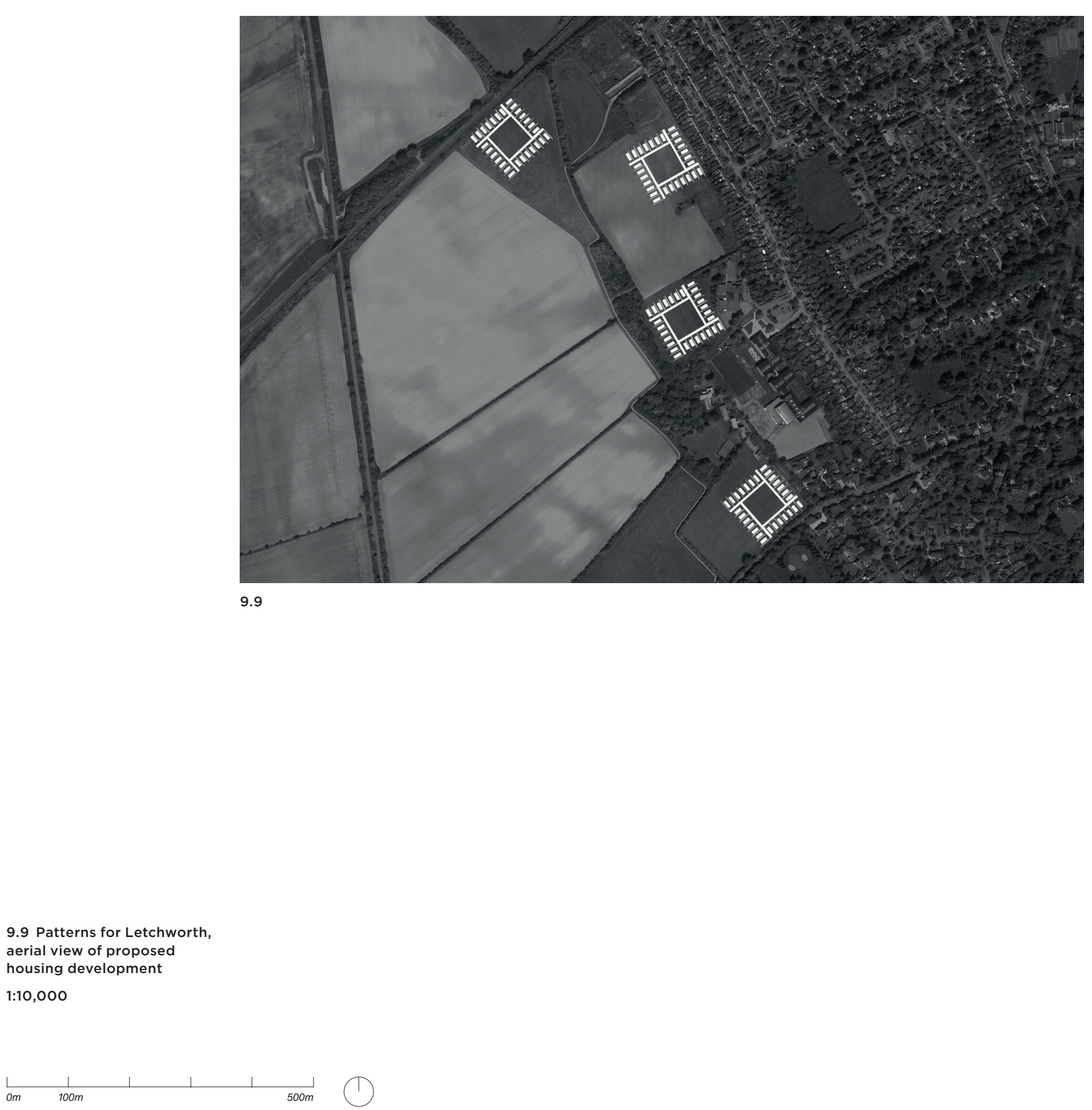


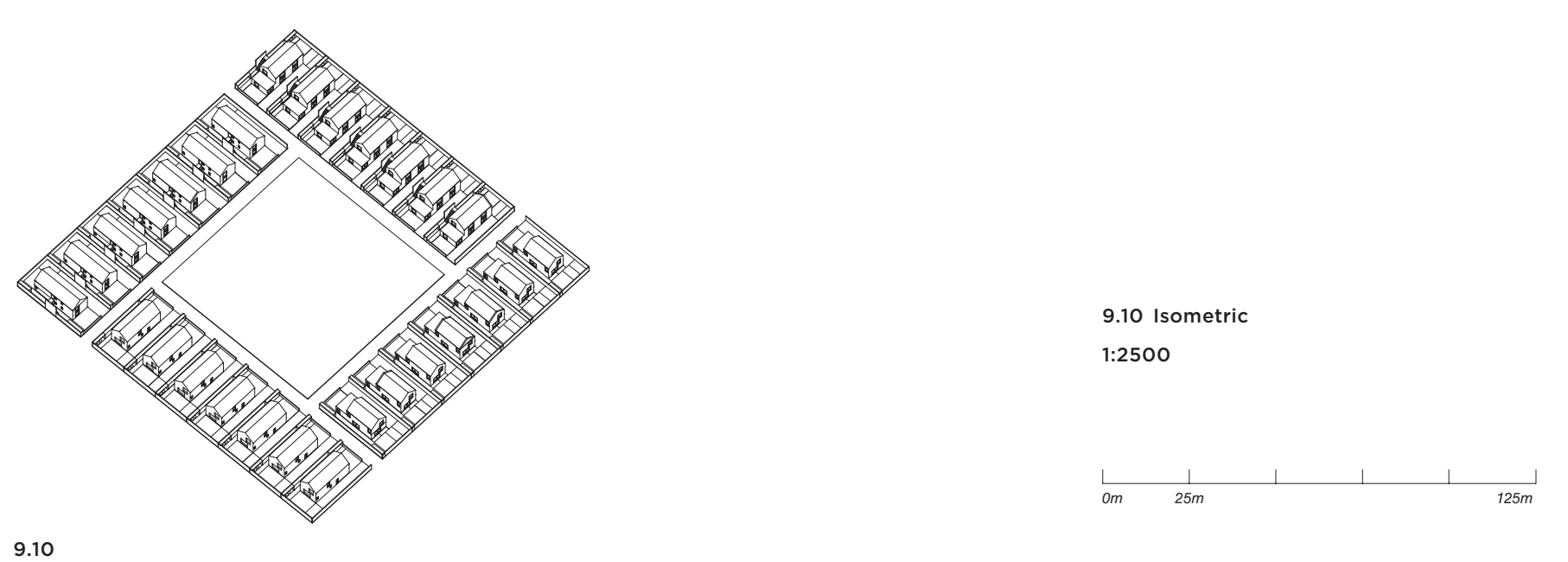

9.10

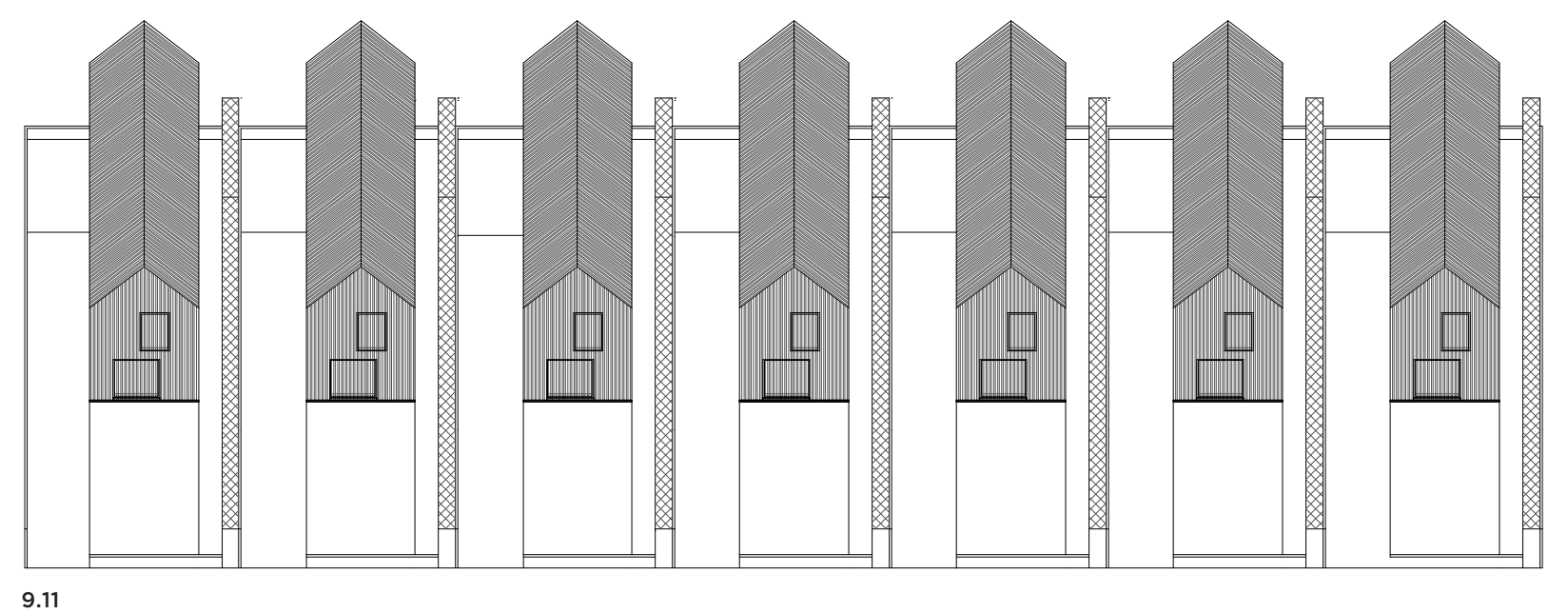

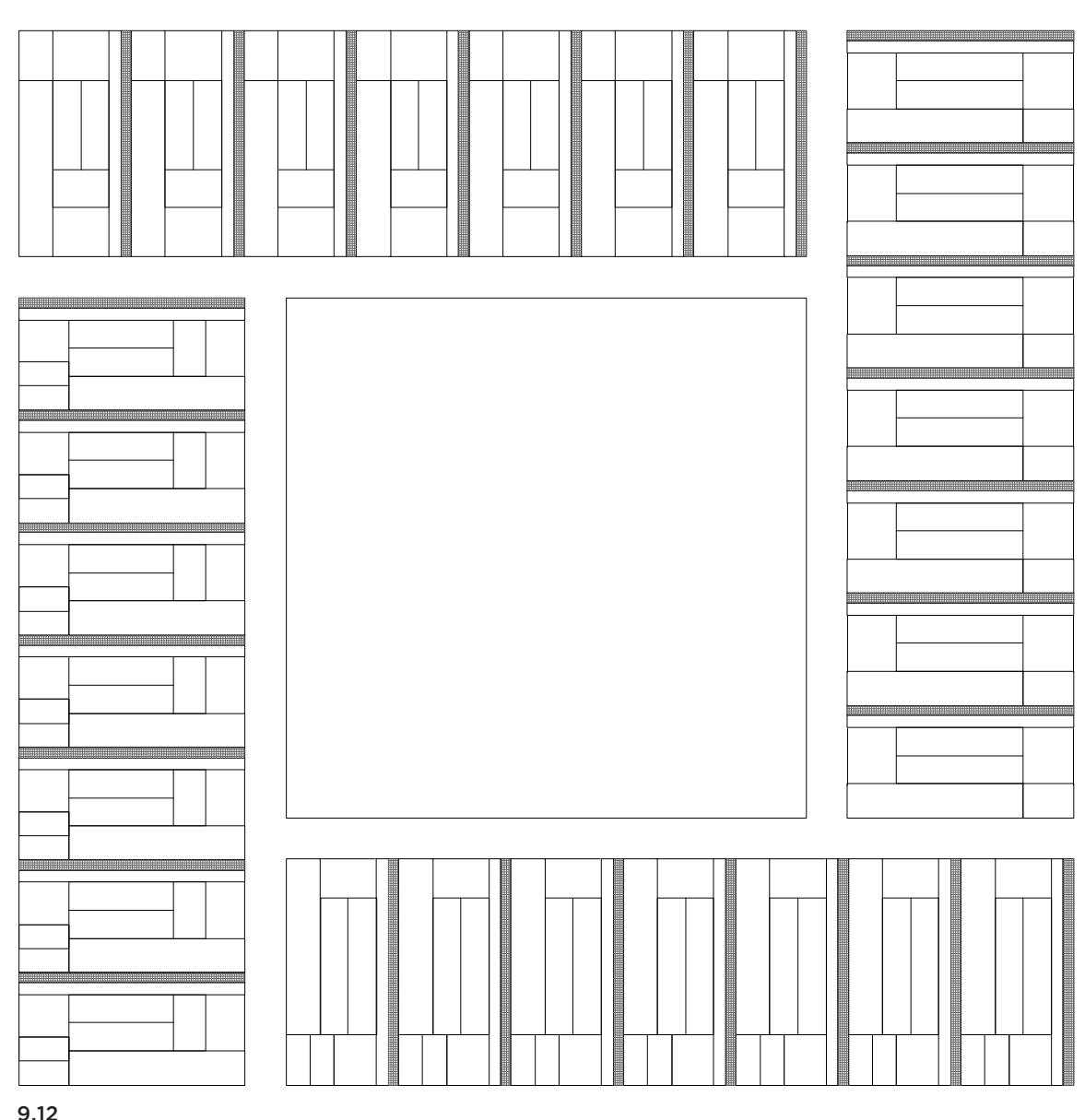

9.12 site plan

1:1000

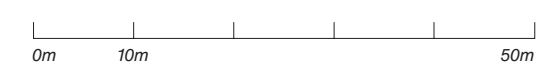




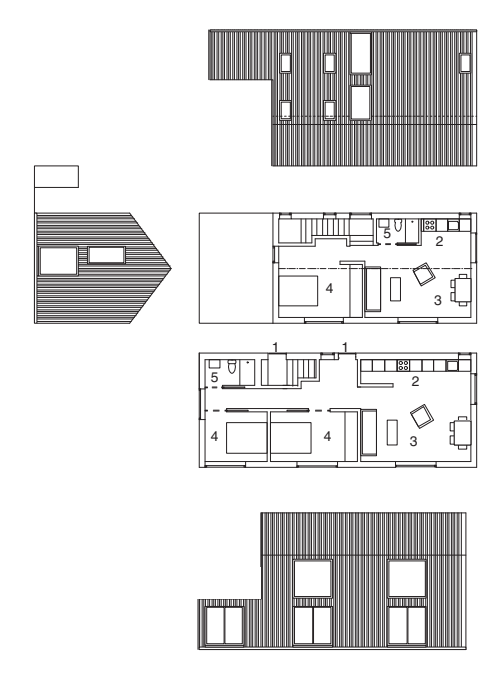

Type 1:
2no. Fats

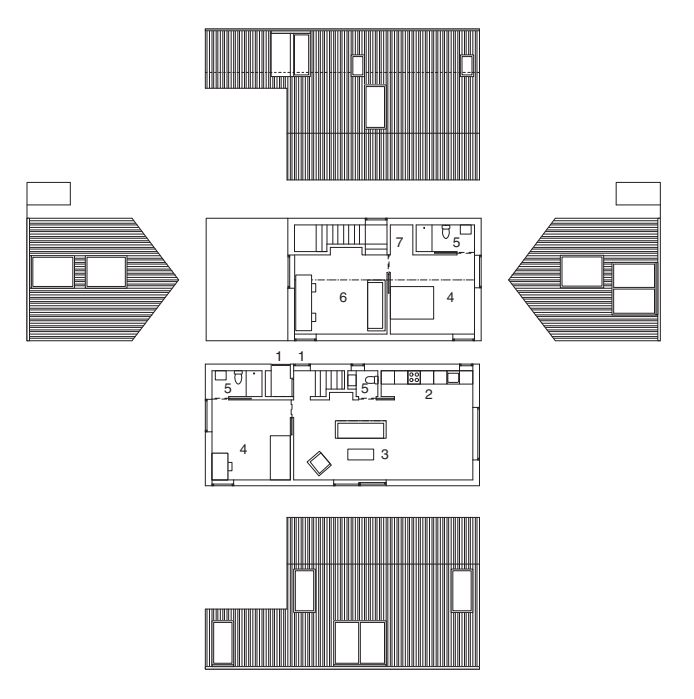

Thpe 2: 2 Bedroom House

9.13

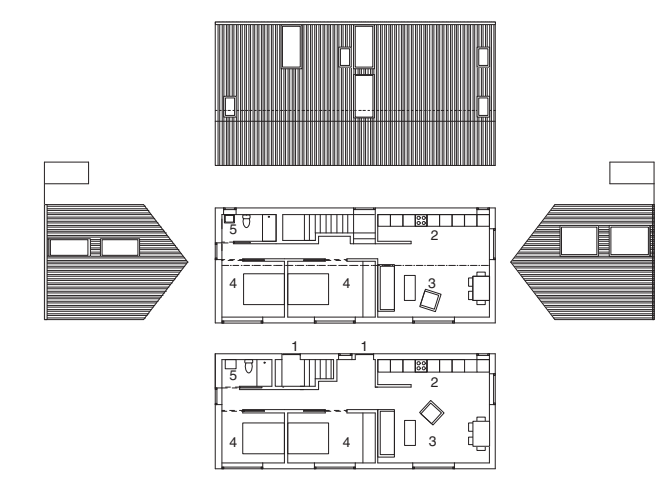

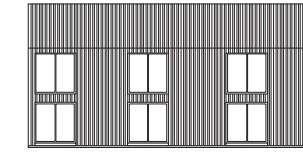

Type 3:
2 no. Two Bedroom Flats

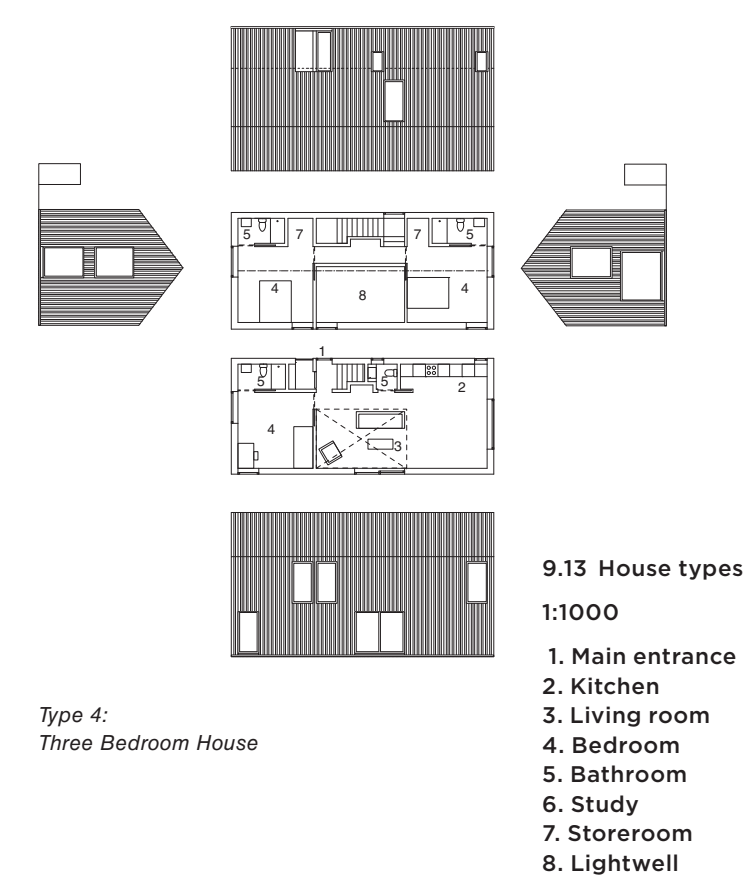

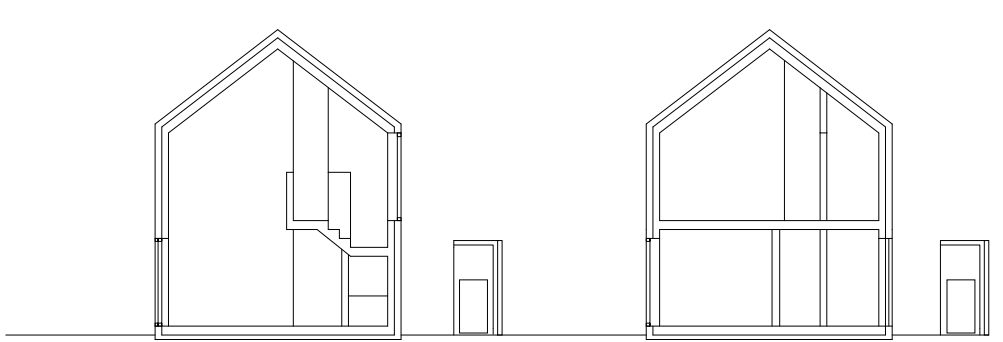

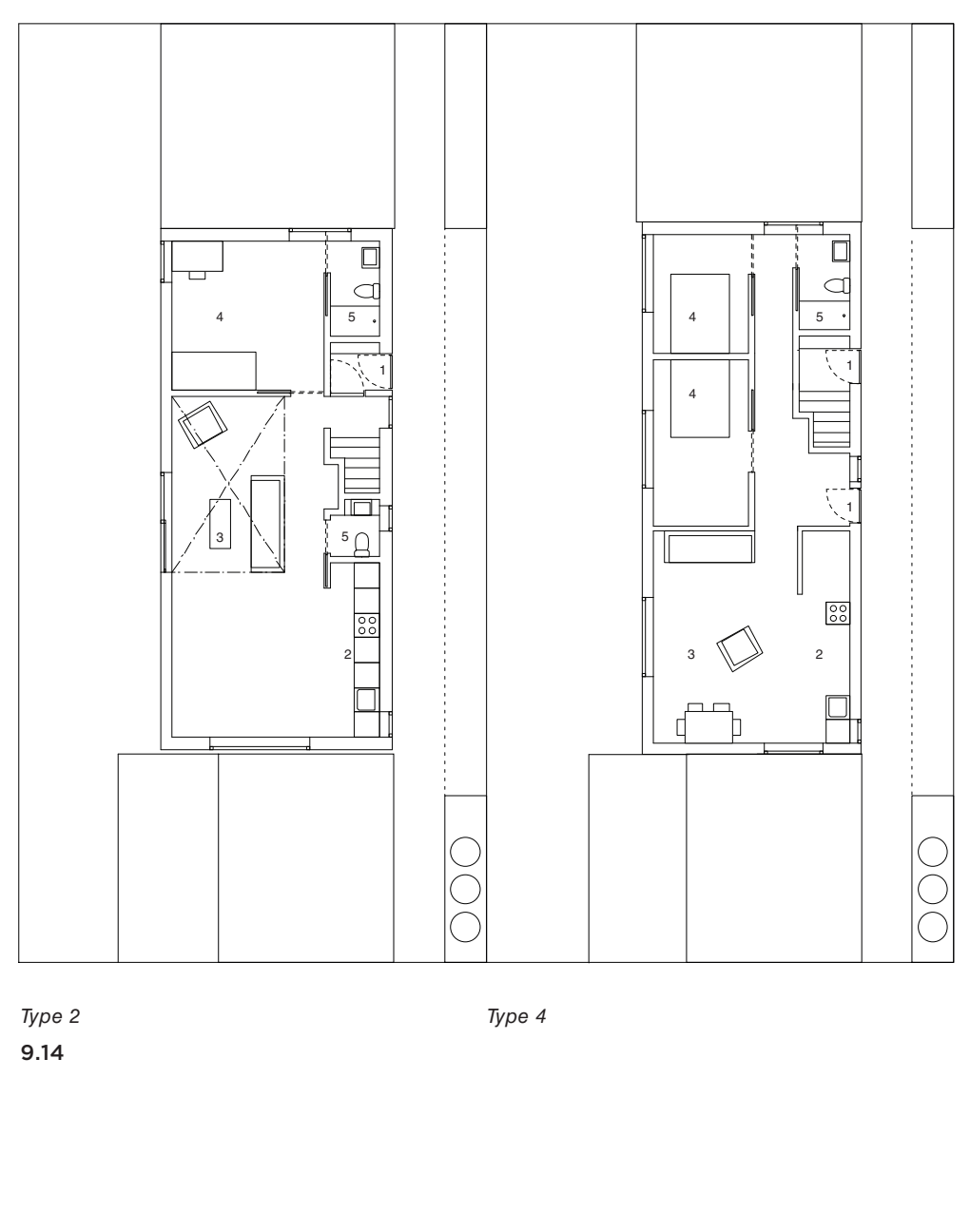

1:250

1.:250 1 . Entrance

2.
2. Eitrtencen
3

3. Living room
4. Bedroom
5. Bathroom
. autrom

House plots are defined
by linear party structures
2

by linear party structures
$2.4 \mathrm{~m}$ high. These have be

designed as multivalent

timber frames acting as
pergolata arbour garden

pergola, arbour, garden
shed, bicycle shed, mete

shed, bicycle shed, meter
cupboard and bin store.

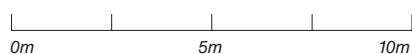




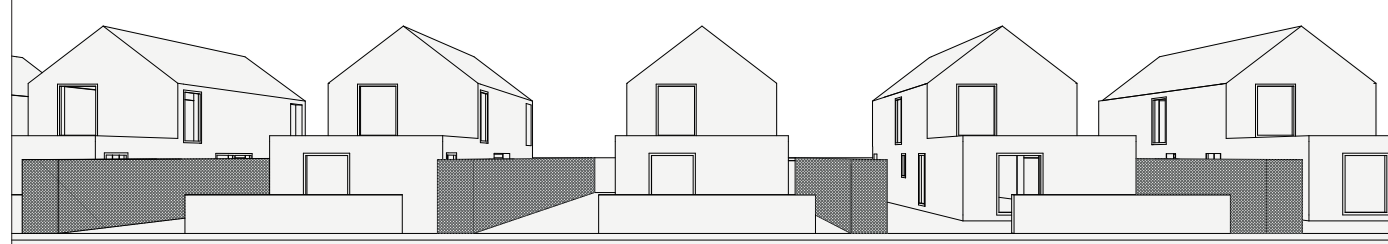

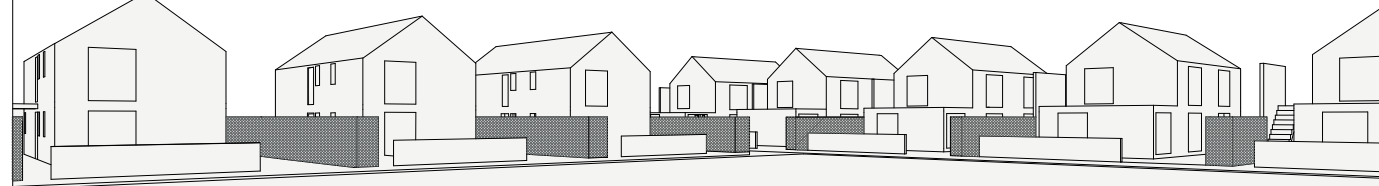

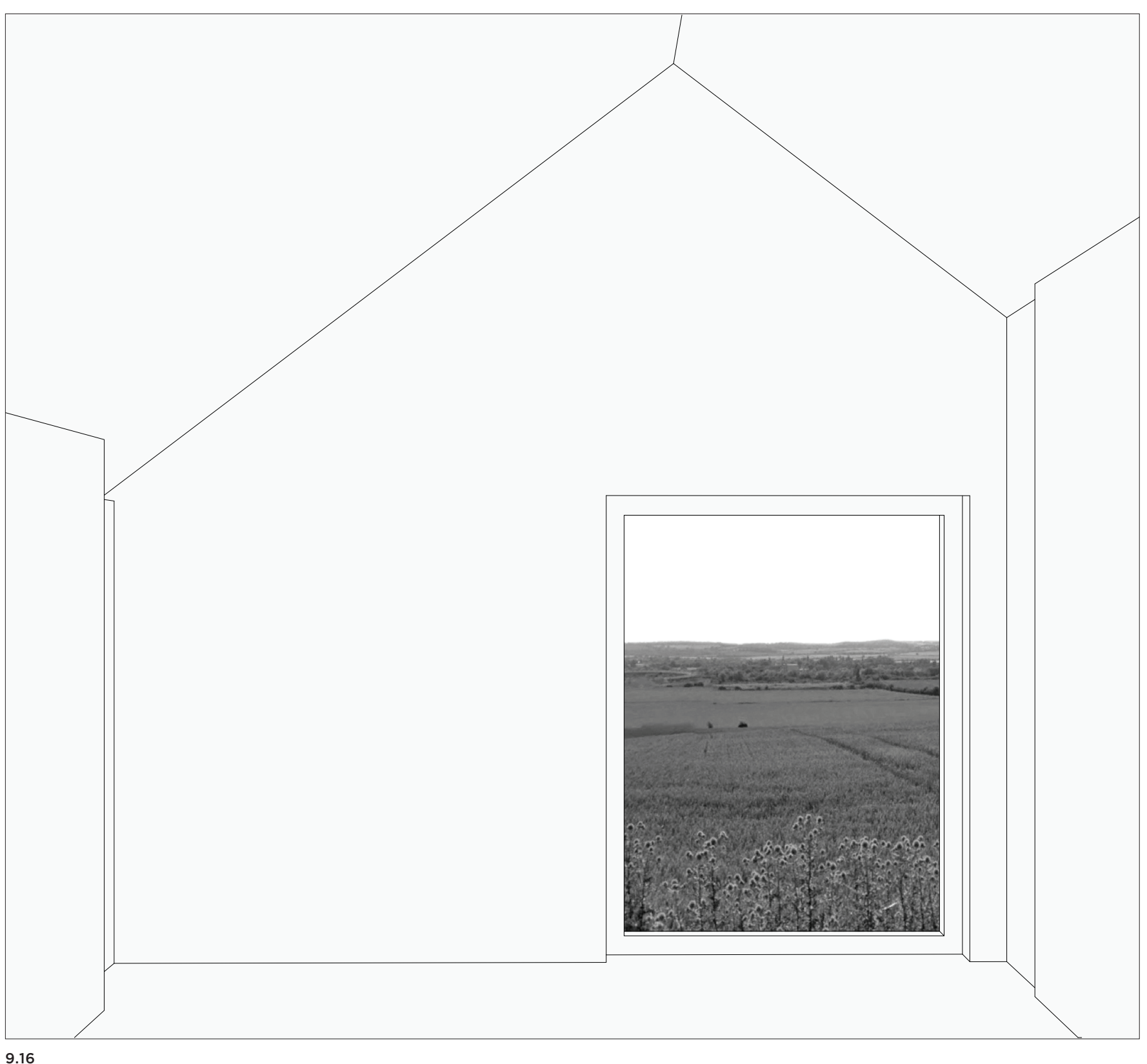

9.15 Exterior views 

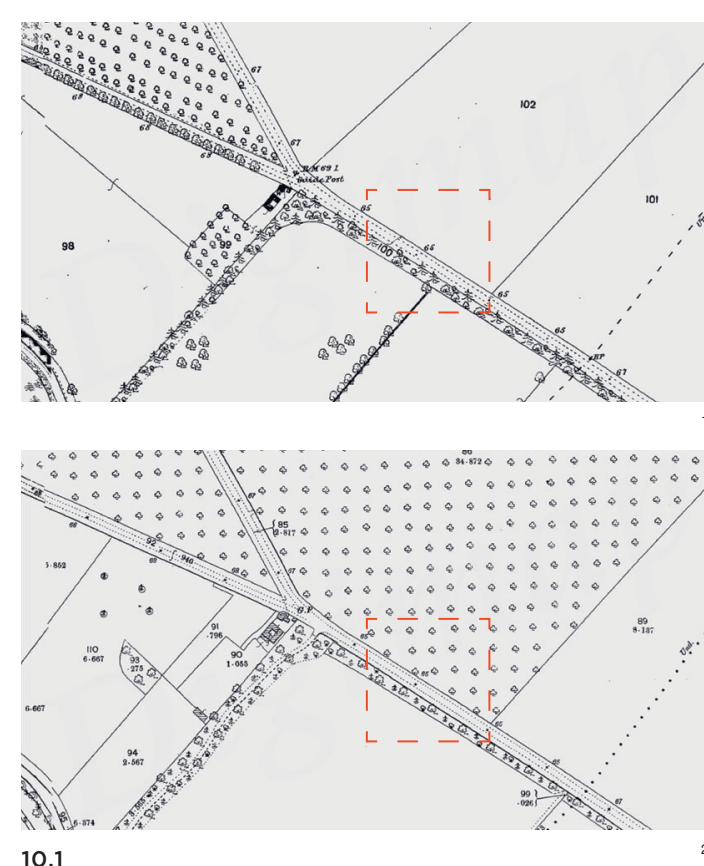

10.1
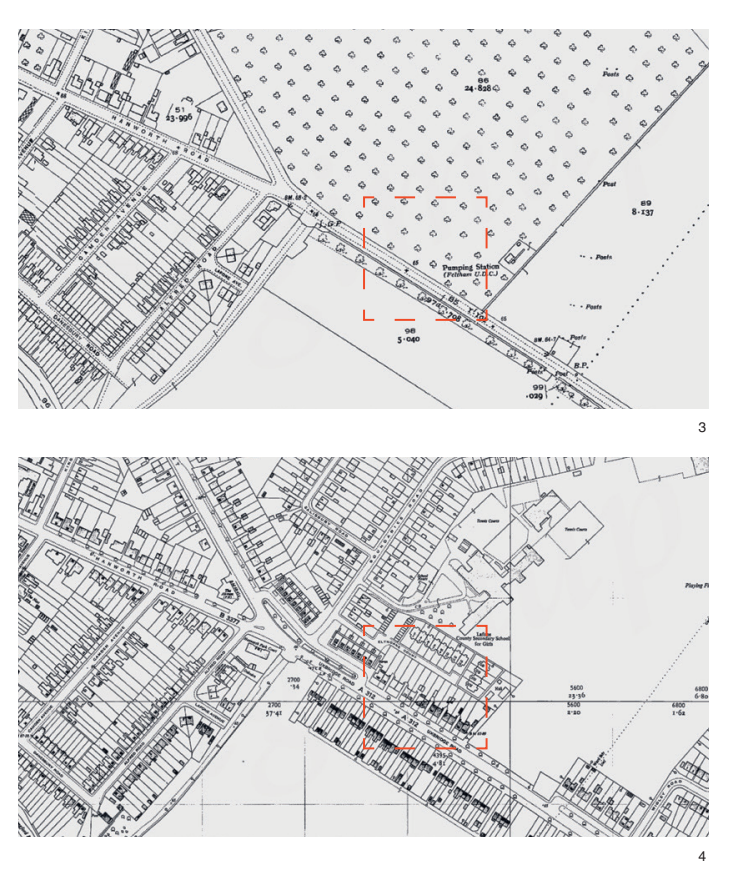

10.1 Historical maps showing site

development. I Source
courtesy of Digimap.

1:10,000

1. 1860
2. 1890

3. 1910

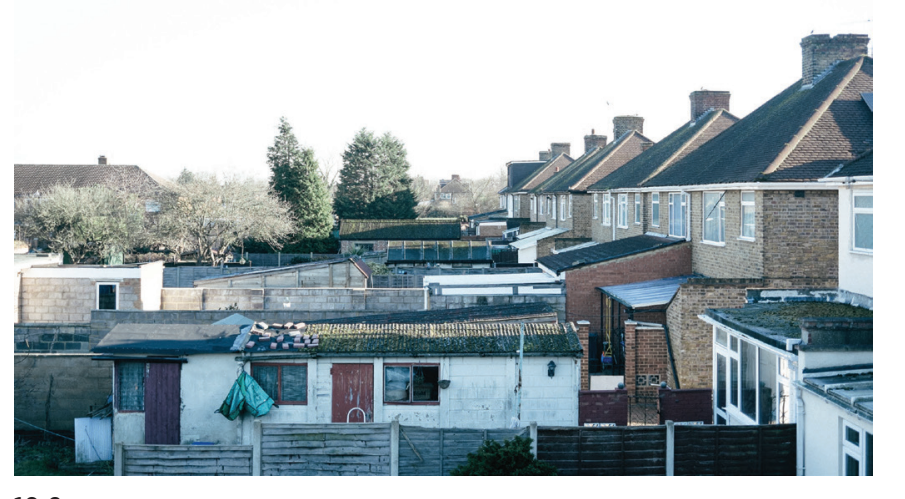

10.2 Back gardens, Uxbridge
Road, Feltham

Feltham, the site for House + Garden $+\quad$ 1947. Residential development is mainly House, is an outer London suburb near modest two-storey buildings in terraces Heathrow Airport and close to the M3 as well as detached and semi-detached motorway. It was originally part of houses. The period since the 1960s has Hounslow Heath - an area of low-quality seen the town centre evolve substanland which provided marginal cultiva- tially, offering a bland mix of shops and tion and subsistence farming to its malls and also an 'out-of-town' shopping inhabitants. Feltham evolved as ribbon centre - a huge car park surrounded by a development during the interwar period variety of restaurants and entertainment as London grew westwards, and pro- buildings including a multiplex cinema. vided a service community to Heathrow Feltham Young Offenders Prison is situAirport which expanded rapidly in the ated nearby and provides the area with 1950s. It became a favourite settle- an unwelcome notoriety.

ment for the Punjabi and Sikh diaspora

from North India and East Afric

A New Suburban Code for Londonperiod after Indian Independence in House+Garden+House: A New Suburban 


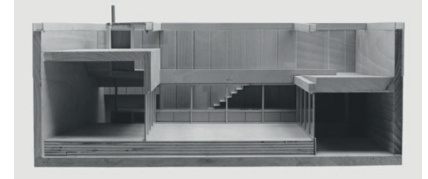

Code for London may be viewed as an antdote to the over-assertiveness of much of the new suburban fabric. It is not intende as a universal strategy but potentially another letter in the alphabet of Londo building types.

Our aim is to help provide Londoners with appropriate places in which to live. For too long, there has been empty talk by politicians and policymakers about housing need without this being translated in action

We contend there is a simple solution an that land is available across the who f London suburbia to build enoug houses to supply the demand This lond is located the back gardens of most subus etached houses.

It is certain the present methods of running up houses in London, not only disgraces us in the eyes of strangers, but threaten continual disasters. Till such a control shall ity, those who have more skill and integrity should distinguish themselves from them by their work. (Ware, 1735)

The green belt surrounding London has ncouraged more intensive development within the city and the suburbs. However, there is a profound mismatch between the old suburban patterns of development tha have evolved since the First World War and the post-industrial culture in which we now find ourselves. New developmen in suburbs is frequently inappropriate and unaffordable. An emphasis on the singlefamily hous has created a monocultural environment which has led to lifestyles out a scenario for back garden
development as a further chal-
lenge to garden policy. that burden working families and isolate the elderly and single.

Pierre d'Avoine Architects designed he Invisible House for the back garden of a semi-detached house in Acton, West London. It met the planning criteria of the time and received planning permission in 1994, but not without objection from local residents and neighbours. The Invisible House is one of a series of interstitial suburban houses the practice has designed tha has its roots in British architectural tradition and also as a response to major cultural changes that have curred major cultura 1945 and are continuing to take place.

There is always concern about new evelopment in residential neighbourhoods. Back-garden development is a sensitive issue but, if carefully designed, need not be invasive and detrimental. Indeed, it could be a positive contribution to the suburban environment - one which acknowledges the rich and evolving mix of communities that now live in London and provides new scenarios for neighbourly living.

Our proposal for House + Garden House focuses on a site in Feltham, SouthWest London, near Heathrow Airpor where there has been a large influx of people of South Asian origin particularly Sikh and Punjabi communities. We propose new small houses, studios and workshops in existing back gardens that could effectively double the density without loss of garden space.

For example, the new house we have designed in the back garden of the semidetached house on Uxbridge Rod detachrises to hod, dining room/kitchen wit gallery and bathroom, with total internal floor area of $76 \mathrm{~m}^{2}$. This house would replace an existing double garage.

The new house uses $60 \mathrm{~m}^{2}$ of garden plus a parking space of the existing garden. The existing three-bedroom semi-detached house $\left(118 \mathrm{~m}^{2}\right)$ has $102 \mathrm{~m}^{2}$ of garden $-42 \mathrm{~m}^{2}$ of front garden and $60 \mathrm{~m}^{2}$ of back garden with a shared driveway. Topsoil dug up during construction is placed on the roof of the new house so that the visual amenity of the garden is retained for enjoyment by neighbouring houses. The roof is partly slope to accentuate its The ro partly sloped to accentuate its emblematic quality when seen from bexist ing hlat in (Rofs mitched We have applied thisidea to the seve

We have applied hisidea to the seven pairs of semide 14 hed houses in Uxbridge Road to provide 14 new houses in individual back gardens. Roof gardens may be used to cultivate vegetables and flowers. Thus, the new houses could maintain the productive potential of suburban back gardens.

In accordance with current supplemen tary planning guidelines, each new house is provided with at least $50 \mathrm{~m}^{2}$ of garden and existing mainly three-bedroom houses have at least $75 \mathrm{~m}^{2}$ of amenity space.

The current Hounslow Borough Local Plan for Garden Land proposed policy options: SC8 states

1. Protect garden land by:

(a) Introducing a general presumption against new development on garden land in view of their specific amenity character and biodiversity value $O R$

(b) Assess proposals for new develor on garden land on case-by-case basis using the general policies in the Local Plan

slow Local Plan, Chapter 5 - Delivering Sustainable Mixed Communities, London Borough of Hounslow, 2010).

We strongly urge that a new policy should be drafted based on our proposal House + Garden + House: A New Suburban Code for London to presume in favour of private development of individual new houses, studios and/or workshops using high-quality design and sustainability criteria, including form, scale, massing, ion to the existing semi-detached house and garden plot To achieve this, we propose simple, straightforwad patternook a contractors appropriate models to build on their sites.

Such an approach would eliminate or at least limit the involvement of large-scale developers that currently have a hegemony coluburban residential development in collusion with local and national politicians. It is vital that a 'bottom-up scenario or small-scale residential, live/work and other kinds of development is established in the UK in the spirit of Kropotkin, Colin Ward and other humane thinkers.

The environment of interwar suburbia, especially the built fabric, has inevitably suffered considerable wear and tear over the years. Houses have undergone a variety of changes and alterations, some good, some bad, but the effect is generally detrimental. Current government relaxation of $p$ anning laws top 


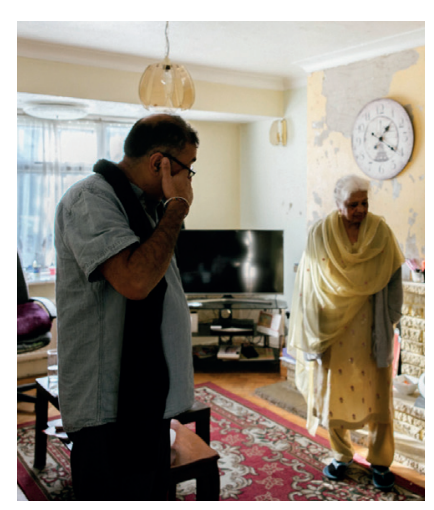

ddition to individual houses exacerbates the situation and misses the point by perpetuating the monoculture of large family homes house builders. Small new houses, studios or workshops in existing back gardens, sensitively eased into the existing environment, can provide older homeowners with the opportunity to downsize in their immediate locale, giving them the opportunity to provide homes for grown-up children who The new houses may also be used to provide much-needed accommodation for newcom ers reflecting the fast-changing cultural changes London is experiencing in a way han in in chat invigorates and ennobles

Interview at Durham Yard, London, 1 September 2016-I'm one of five children
in my family. My parents are both Punjabi by origin; my father was born in North India and my mother was born in Mombasa, Kenya, Africa. I'm the second child of five, and I have two sisters and two brothers. I
have been living in Feltham since 2000. I was born in Nairobi, the capital city of Kenya, in where everybody used to be given accommodation wherever your parents worked, and we belonged to the railway community
My father worked for the British, building a railway line from the coast all the way to Kampala, Uganda. He left India at the age of 21 in the early 1930s. My mother was born there and was 18 years old when she married my father. At the time of Kenyan independence in 1963, my father came to the UK, and my mother and their three children including myself, got sent back to Jalandhar in the Punjab, North India, which is where our families are from originally. This was because the political situation in Kenya was very unstable. Jomo Kenyatta, the first president, was considering sending all the Asian back, a bit like Idi Amin did in Uganda a few years later. We ended up living in India for six years before we came to England in 1969 My father had a house at Hamilton Road, Twickenham, which is where I met spoke Punjabiand English and I was fluen in Swahili.

$I^{\prime} m$ really interested to hear that you also spoke Swahili. Can you remember In those days, you went to school very early because of the heat. It was a Punjab predominant school, but you had to learn Swahili as the first language. And now Swahili and English are the national languages of Kenya. So, everybody speaks English as well as Swahili. There are more than 42 tribes in Kenya, and they all have their dialects, but in Nairobi, the main language is Swahili.

In Kenya, we lived in railway quarters. They were beautiful whitewashed wooden bungalows. So, it was very cool in the summer. It was like New Orleans in the USA; people used to sit out in their rocking chairs. I really loved those houses. The had a brilliant character. The sun used to be really really hot but inside it used to because of the through breeze.
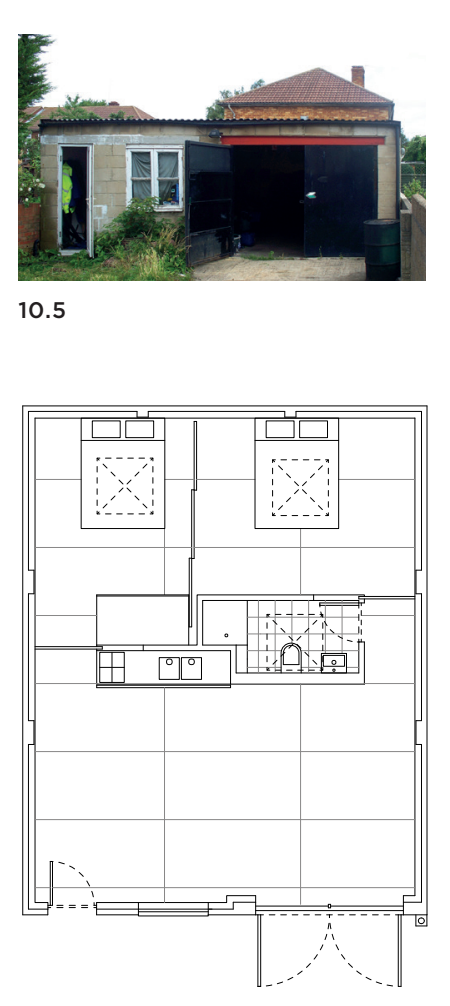

10.6

0.5 Garage in back garden 10.6 Plan for an interior fit-out of the garage to contain kitchen/
living room, bathroom and two 1:200
And what kind of house did you have in Jalandhar?

In Jalandhar, we had a proper building made out of brick. It was a two-store building with a beautiful courtyard and a beautiful solarium at the top. It was a fantastic house. I can't remember much else, but it was very modern. Those houses were designed with insulation because the winters got very cold in northern Punjab. But in the summer, they were very cool. I think it's because of the through breeze again.

It was a very difficult time, Pierre. And do you know why? Because in about 1964 or 1965, there was an Indo-Pakistan war, and wa wa border ... and we used to hear tanks firing and aircraft overhead. It was horrible as a child, and we had no shelter like you did in you had the underground here for shelter or war bunker shelters. But we had nothing. We were exposed; very, very stressful. remember they were recruiting youngsters for the army. It didn't matter what age you were, as long as you were at a certain height then they would take you. Amazing place when you're growing up as a child in India. Very amazing. You had to be a man before you were a boy.

Tell us about your journey to England and then your family house in Twickenham.

I remember we came on a BOACVC10. It's the back, swept wings... I think we flew from Delhi to Istanbul and then London. And I'll always remember this: we came into Heathrow Airport in October, and I'd never seen snow in my life until I got to Heathrow. It was so, so cold, I wanted to go back to India. We moved into my dad's house on Hamilton Road, Twickenham, where it seemed the sun shone on us for ages, including in 1976 when we had the eat wave.

remember that summer because I was living there then.

We had about four Asian families living on our road in terraced houses that still exist today, and will probably still exist in the next century as well. It was very dark in the winter, but in the summer, it was very happy place to be because we had back gardens connected by alleyways, and you could get from one street to the next by going through the back alleyways. And the house that we lived in, to us, it was like a big palace really because we'd never owned our own house until we came to Twickenham - and that's when we got interested in properties, I guess, and how they were laid out. When you look at the house in Twickenham, it was a very simple design, but it worked. It had upstairs, it had downstairs, it had a bathroom at the rear; some people had outside toilets at the time. arrived. The coalman used to come, and he used to deliver the coal on his back. He es at take the coal to the coal store at the back. 


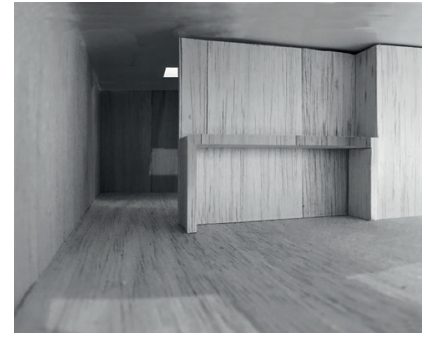
10.7

\subsection{Model, balsa wood and
mountboard, by Ayo Solola and} mountboard, by Ayo Solola an

then. And we had the milkman who used to come and deliver the milk in the morning That was life in the UK back then.

I met you when I was at secondar school in 1973. You bought the house at the end of our terrace with the biggest garden extra bit of land on the side.

I remember you were interested in cars when you were a teenager.

No, I was interested in machinery and how It worked And after leavingschol and how five-year appenticeship on carsol, I dida mechanics at Acton College, and by that time, I'd joind the police force. I w tille, I'd joined the police fore. I worked all over the place. Once I'd finished ny pprenticeship, then Iwas based narnes. lmet my wife Vanita at Richmond College in 1984, and we got married in 1985 at the Southall Gurdwara. We stayed at home for one year at my mum and dad's place. We left in 1986 and bought the botto flat of a house conversion at 16a Summ Road, Northolt. We lived there for two years. We were expecting our first child. So, we bought a house at 158 Uxbridg Road in Feltham in 1989. We bought the house next door in 2000, and we moved into that property and let the other one. Then, unfortunately, my marriage sort of collapsed. I separated from my wife, and currently I'm living next door to my ex, which is brillian

hat came about because I bought numbe din my name, and we got the house next door for our retirement so that we could let one, and if one of us stopped working, we'd still have a way of generating an income. My son lives with my wife. My daughte has just bought a two-bedroom house in Sunbury Cross. So, yes, she's left the nest.

\section{out why you chose to live} in Feltham?

chose Feltham for no other reason than the size of the house. It's what I could afford It was the biggest house I'd seen on th you have $100-\mathrm{ft}$ back you have a 100 ft back garden and 40-ft why I got it is because second reason righ 1 got it is because there's a bus stop right outside, Feltham rallway station is nearby and Heathrow's not that far. The house in Feltham offered a lot of advantages compared to other properties in the area area and very expensive. At the time, the properties there cost upward of $£ 300,000$ which was a lot of money to me, and bought a house in Feltham for $\{89,000$. Flat were available, but flats are no good for young family. The only thing I like about the area is that there are only 14 houses on that street, and they're all different designs, and they've all got individual characters. It is a busy road, and 20 years ago, we didn't there are lots and lots of disadvantages now.

It's interesting that you decided to buy a As you get older, you start to think, 'Well house in Feltham and then buy the house I can't go for a good walk', although we've house in Feltham and then buy the hous next door. market at the time And with this bove Twickenham is predominately an affluen have as much traffic as we have today. So

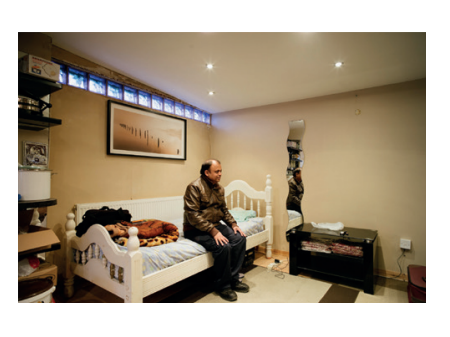

At number 156 where you were living did you buy it with the extension or did you build that?

No, we did all of the extension, and also loft conversion. So, now my ex has a fourbedroom house with a loft conversion and

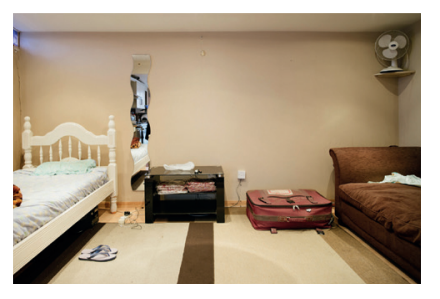
extension. It's a beautiful house.

Please talk about your own business and building the garage in the garden at number 158 .

We built a garage about $25-\mathrm{ft}$ wide and $30-\mathrm{ft}$ deep It was a self-contained workshop. We deep. It was a reff-con usedto was a self-con vehicles for a large fleet company, a loca But, unforturat But, un for u happy about that. So, I had to close it down for legal reasons. I worked out of there for about three years. I don't do it too much nowadays because I'm getting on a bit, but, yes, I thoroughly enjoy working on cars still, but it's more like a hobby now. And help my friends, relatives - anybody - sor out a problem that they've got with a car.

\section{The idea of living next to where you} worked, was that an attraction?

Yes, that was the attraction because you don't need to travel. At the back of your house, you've got a workshop. So, the work work. And also, you can work late into the night, and you're on your own premises. And also, I think the biggest thing is the came to you rather that you going to the $\begin{array}{ll}\text { I can't go for a good walk', although we've } & \text { And also, I think the biggest thing is that designed as a workshop, nothing glamorous, } \\ \text { got a massive field next to us. } & \text { you don't have to pay any rent for premises, no big machinery, but plenty of electricity }\end{array}$

and that's where you save your money. And had two Jamaican guys working with me at the time.

Were they local?

No, at the time they used to live (and they still do) in the Peckham area, and they used to commute. I gave them a van so that they had a vehicle to come to and from work, and I paid their fuel as part of their employment.

\section{How did you get to meet them?}

met them through Yellow Pages. Their names are Richard and Kayden Barratt. They're brothers; same father, different mothers (they said it was a Jamacan hing). I got accuain in in cen in with them many. with them many tim I I know Jamaica because of them from Kingston to Saint Ann's down to Negril - the whole lot. I've sland more times than Bob Marley.

We can come back to the Jamaican connection, but can you talk about the

The garage was built by a Punjabi builder. If you look at the garage, there's nothing to it: it's just a rectangular plan with an eight-degree pitched roof. It's a very simple building. There are no windows; it was designed as a workshop nothing gamorous, 
and lighting. It's very spacious. And I guess on a good day, I could get about four vehicles in there and still have room to work but I could actually park about 10 cars.

be quite a dangerous area at night-time because there were a lot of skinheadtype characters who used to hang aroun because of the National Front. And even if you said today that you live in Feltham Did other neighbours do the same sort a lot of people think, ' $\mathrm{Oh}^{\prime}$, because the of things in their back gardens?

No, only one other person did, and that's the house on the end. He's got a massive yard and he had a skip business where he had skips coming in and out, and lorries used to it. So, actually, there were only two people our road.

But was this something that people did in the area? Yes, they did. On the opposite side to us, there's a carpenter. There are lot of people who do small businesses from their garages. A lot of people back in the early 2000s were looking for premises with big gardens so that they could operate from their premises to save on the rent because lots of small businesses - people like carpenters, tree surgeons, plumbers, electricians - couldn't survive otherwise.

Did people socialise in your neighbour hood in Feltham?

There's not much socialising apart from the neighbours, just the pub routine. It was more about family. But in the 1980 s, there was a National Front head office in Feltham. I don't know much about it because it closed down by the time I came to live here. There was racism in the Feltham area, and a lot Asiacion because of the National Front I think they moved to Northolt. I remember it used to associate it with young offenders. We have a prison for young offenders in Feltham and everybody assumes that it's all connected to that. But other than that, I don't know what Feltham is famous for apart from Hanworth Air Park

\section{You work at Heathrow Airport now.}

I used to work for the Met Police for over 25 years. Then, I went self-employed for about three years in Feltham. Then, I didn't do anything for two years - I literally just had a busman's holiday driving here, ther and everywhere, not working but sightseeing. And then I got a job with Britis Airways as a mechanic for their vehicle maintenance section. It was only for Friday Saturday and Sunday, but in the space of about six months, they closed it down. didn't know at the time that, by law, th with the company. So, I went in for check-in at British Airways for one day. I didn't like it. And they offered me a role in the baggage department, and that sort of worked for me. So, I became what they call a ramp agent - but everybody knows us as baggage handlers. So, I started there in 2001, and I've been there ever since, and now I am a team leader. I have eight guys - eight personnel working with me - and I'm also an OSD on-site train tich employer had to find you an alternative job

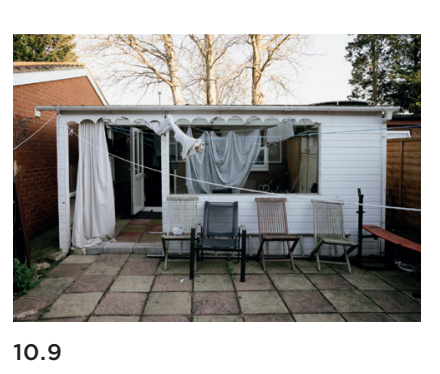

years ago. So, we have students who join for 18 months with the airline, and we teac them from the ground to wing level. The do six months with each department. So, I have students with me for six months. So, the current job that I have right now involves me travelling a lot with the students, which is a standard thing becaus we're in the airline businesses. I travel to

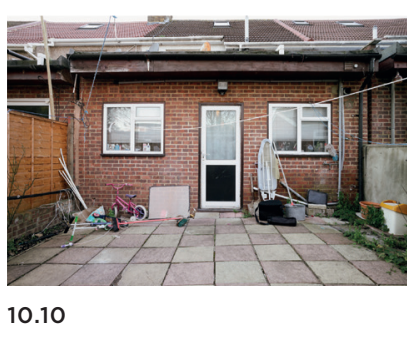
es like Los Angeles, Hong Kong and Lagos. I enjoy the job very much because you're learning from youngsters. It's always nice to give somebody an opportunity to learn about the airline business I'm hing to leave the airline, unfortuss 'm hoping nately, this year because I'm 57 now, and I've done 15 years with British Airways - and I've enjoyed it - but I think it's time to look

$10.9 \mathrm{Ni}$
garage at my health. Health is the main issue.

10.10 Shared courtyard

Can we go back to the late 2000s whe you asked me to investigate the potentia of converting the garage into residential accommodation because you knew I had got planning permission for th Invisible House in Acton some years ago. I thought that was a really interesting opportunity, but in fact, Hounslow planners turned us down. But it did lead to us having much more extensive conversations about back-garden development and, as a result of that, you introduced me to one of your friends who works with you at the airport and lives in a garage in Southall.

Well, when I finished my business, I approached you to have a look at the garage at 158 Uxbridge Road to see whether Icould because clearly there's enough room there for two bedrooms, a living-come-dining area, a kitchen and a bathroom. You came up with a simple idea for a courtyard house. ve got a friend who lives in a garage in Southall. I took you and one of your students to meet him and to have a look at his home. We only saw one person, but I know many people who live in situations like that where gardens are not gardens, they're actually like courtyards. And they have accommodation where the family's so huge that they can't afford to buy a house or whatever, but they keep everything within the house; they know that at the back of the garden, there's perfectly the lso, Ithought that idea couldwork property, and you and your team thougt that it could work anecause I've gon though pace to do that It's not often got nough per with. I think my garage had more than my friend's garage because of the way you designed it. There would have been lots of natural light, and you could have a little courtyard. I thought it'd be like a place in Italy I've seen. But unfortunately, we got turned down by the planners. The reason why this all came about was because my daughter could not afford to buy her own house at the time. So, it would've been a ery good idea for her to live close by but independent from her mum and dad where she could have her own space. My daughter was quite happy with that idea. Nowadays, London is so expensive, you need to have a bank with you all the time to get it off the ground Indians are more family minded. It is a cultural thing where th 
and the parents live very close by to each hunter, and he would provide the meat for ther. The reasol when occasions happen within the family quite gruesome - but once a month, he'd (birthdays, weddings - even death, for hunt an elephant. An elephant doesn't die that matter), it's not far to travel. Also, the very quickly, as you can imagine. It was mother will always want to live quite close poisoned, but it's not as bad as you think it to her children simply because she could is because they don't kill just any elephant, spend a couple of days with the older son it has to be staked out to make sure it's an then with the daughter. The only way the old bull that's had his day that's lived a Asian family changes is when the daughter good life. And sooner or later, that animal's gets married, and she goes to the north of going to die either naturally or somethin the country and we're still in the south, or will kill it. So, they were very methodical even to a differ we restin hus to a differe con will always stay close to the mother very four days to hunt an elephant. And I know ill alc to the stay closed to will always stay clould daughters who move forthe me, it was just that their husbands wher Hounslow andwewer in Thich it just worked out that way. We didn't plan I know that. An elephant always falls to it or anything like that, but the interesting the side, either this way or that, but it will thing about my sisters is that they married never fall back, it just can't, gravity pulls two brothers, and they live next door to it to one side. It makes it very convenien each other. But it was never planned. And to cut the animal up. The hunter would $\mathrm{my}$ younger brother is married to $\mathrm{my}$ cut the stomach open, and my job was to ex-wife's sister. So, we're married to two get the liver out with a knife because I wa sisters and two brothers, and it's amazing the right height to walk in. That was $\mathrm{m}$ how that all happened. I didn't really know job. I was a butcher's assistant basically that Mano was courting Susan at the time, for the liver.

but it happened, and here we are. When I

was born, I lived in Nairobi for two years, So, you used to get inside the elephant's and at the age of two, we moved down to body?

the coast to Mombasa because my father

got posted there. I actually lived with the Maasai tribe in a village called Mtwapa for about three years, and that was an experence. They taught me everything about ife from the age of about three untilabout five. I was actually assigned to the village s, and you have to be very quick because a dead animal, especially when the woun is open, other animals smell it, and the vultures will be at it. You'd be outnumbered by wild animals, and so you had to movevery quickly. It used to take a good half a day to walk from the place I lived with the Maasai. I also learned to light fires and even open beer bottles without an opener.

It seems it has very much affected you own life.

Well, yes it has. I thought that I had a black father, right, because I never saw any Asian people in Kenya and especially because we were out in the sticks, and honestly, once you get attached to a hunter, you think, well, that's your father, you know? And you treat him like your father because he's teaching you so many things about life: how to repair things, build, how to get water when there's no water - amazing skills hese people have being nomadic.
10.11 Feltham. Image
courtesy of Google Earth.

1:50,000

1. House + Gard
House site

House site
2. The River Crane
3eathrow Airpor

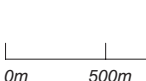

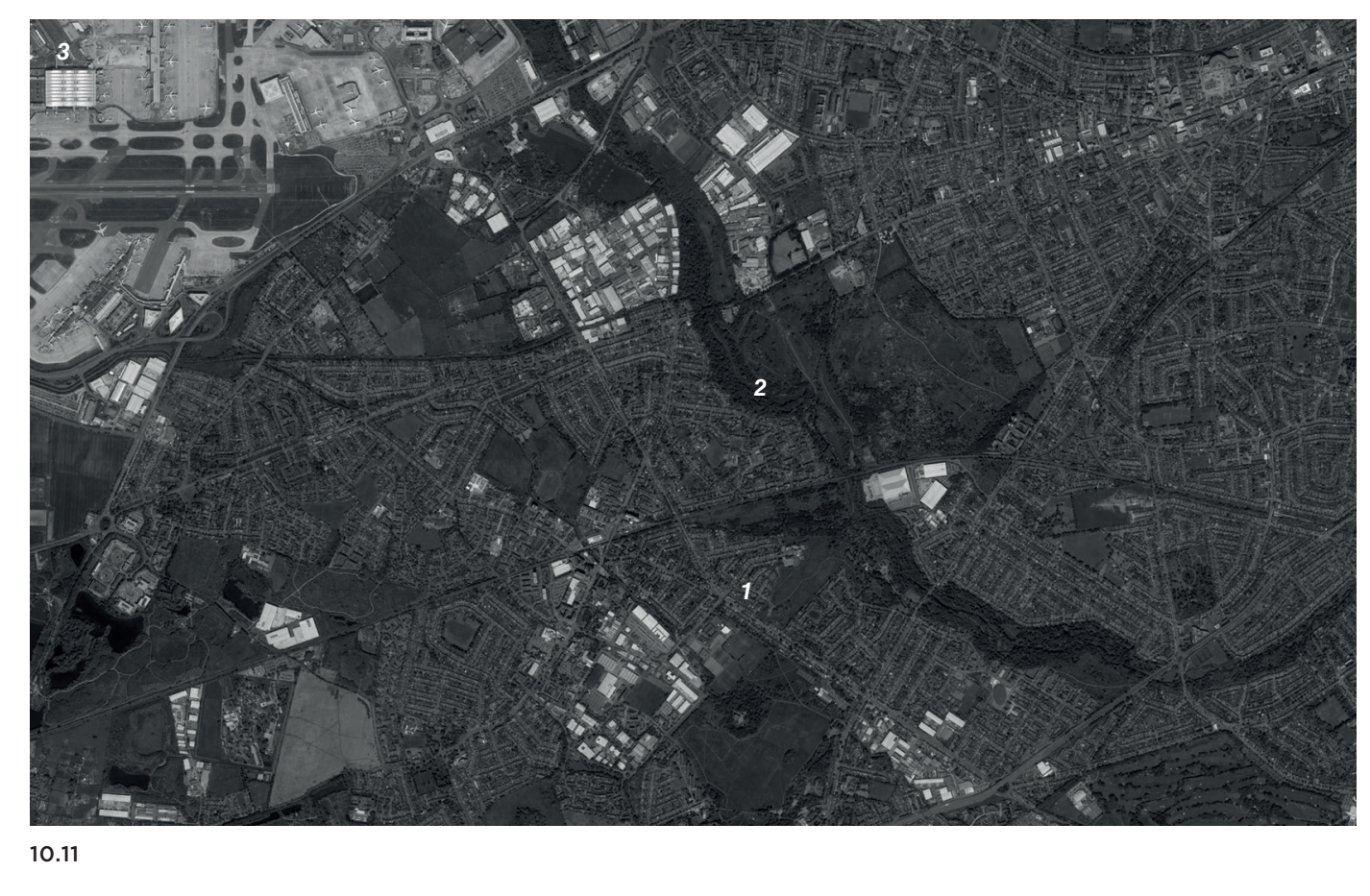



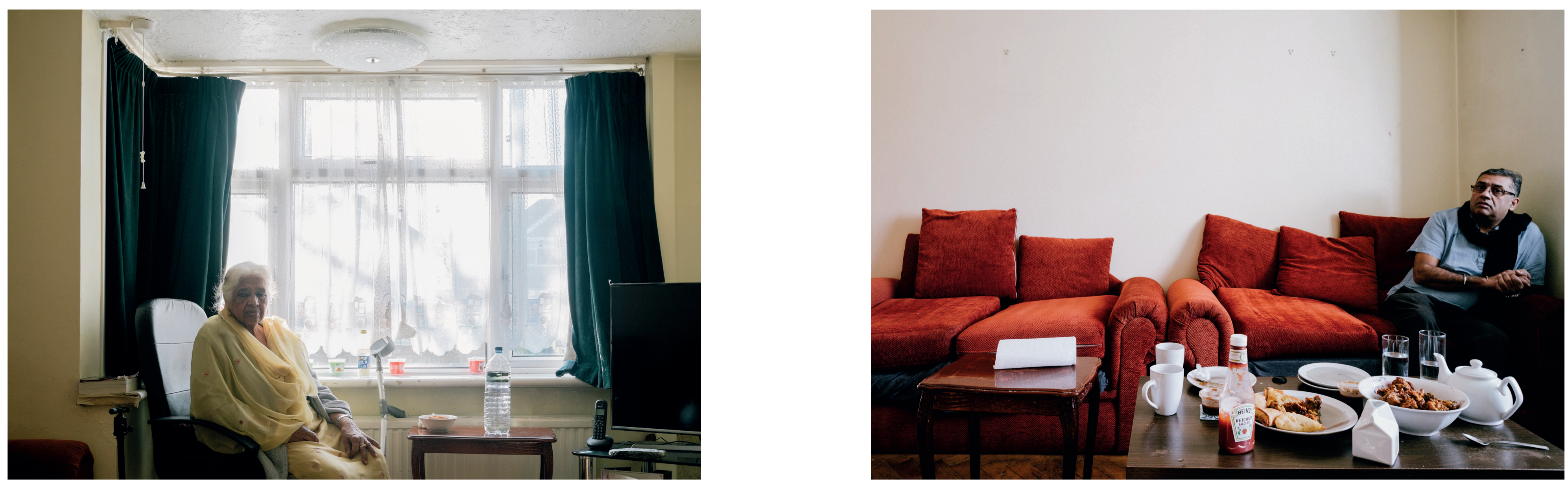

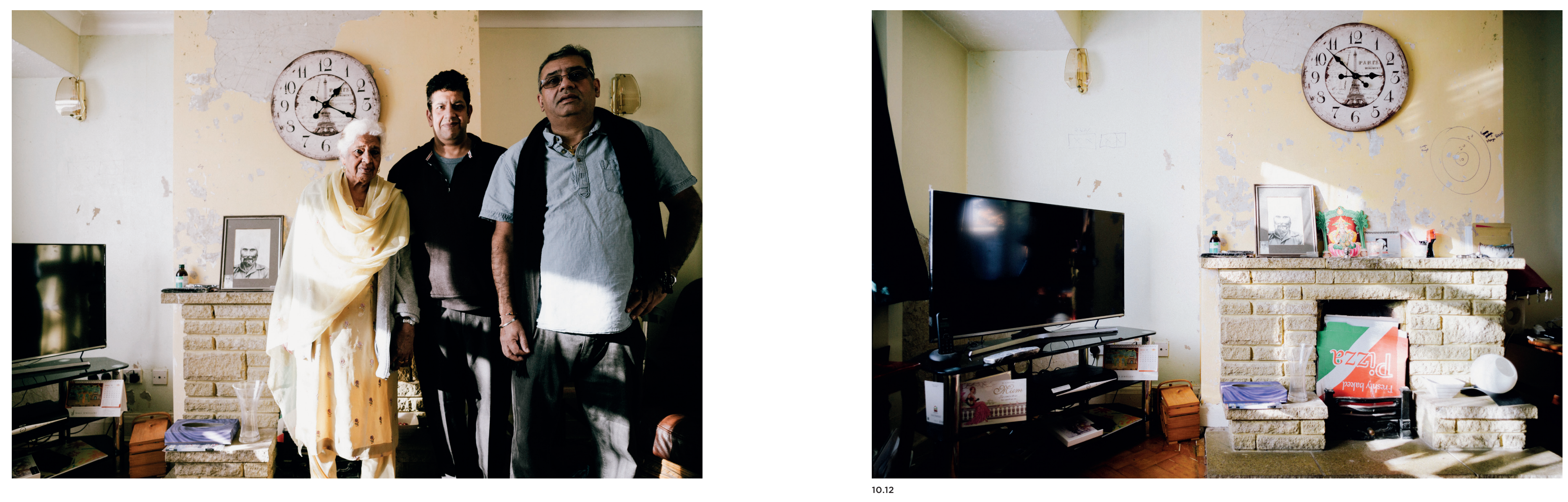

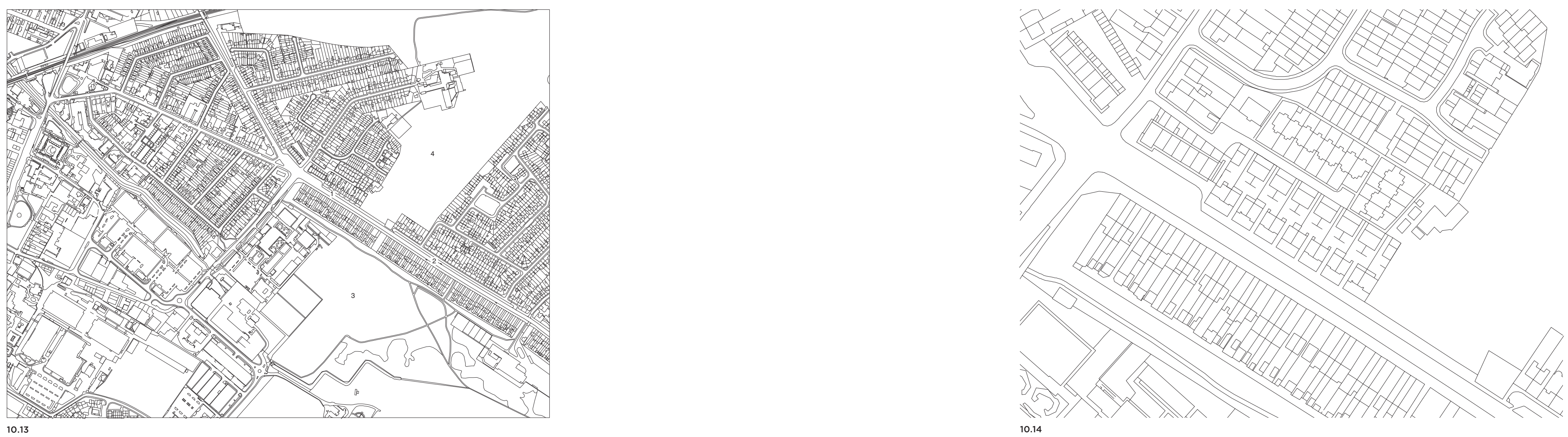

10.13 Location plan

1:10,000

1. House + Garden + House site
2. Uxbridge Road

3. Hanworth Park
4. Leitrim Park

10.14 site plan

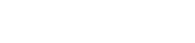

1:2000

(1) $\frac{1}{0 m \quad} \quad \frac{1}{100 m}$

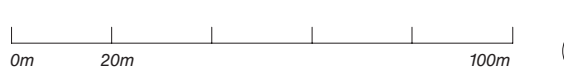



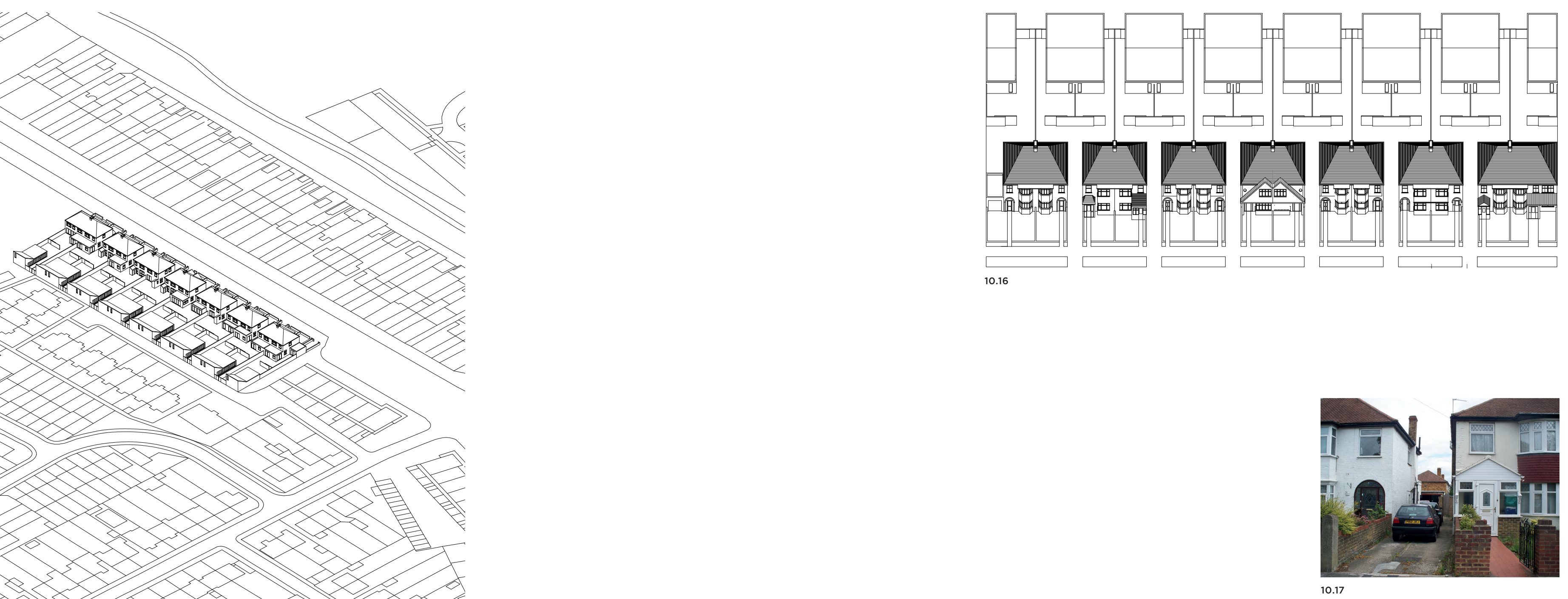

10.17 View from street showing
garage to rear 


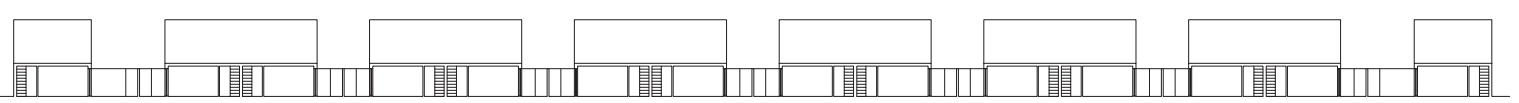

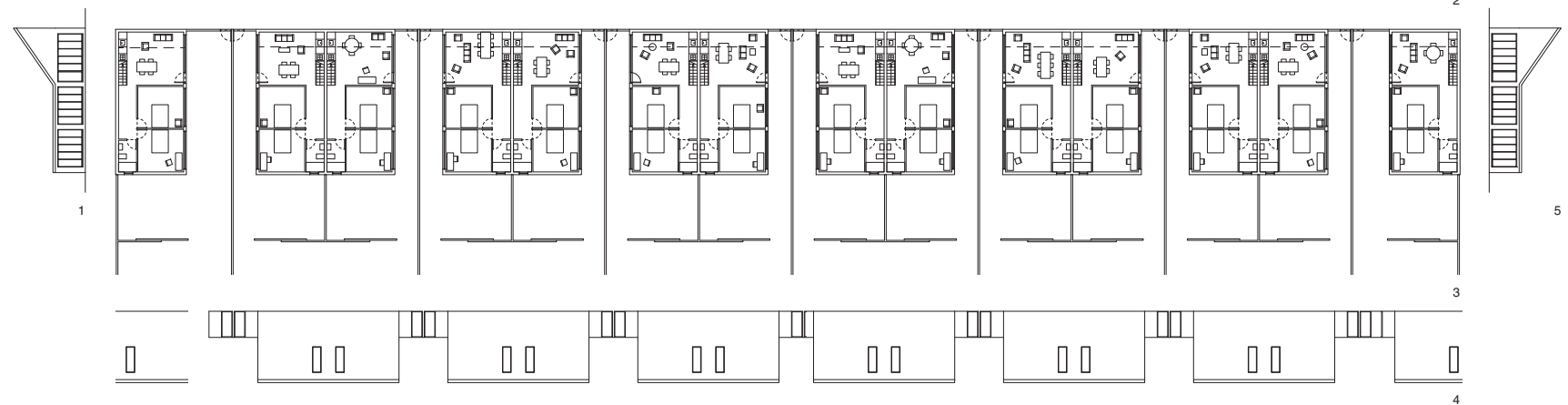

10.18
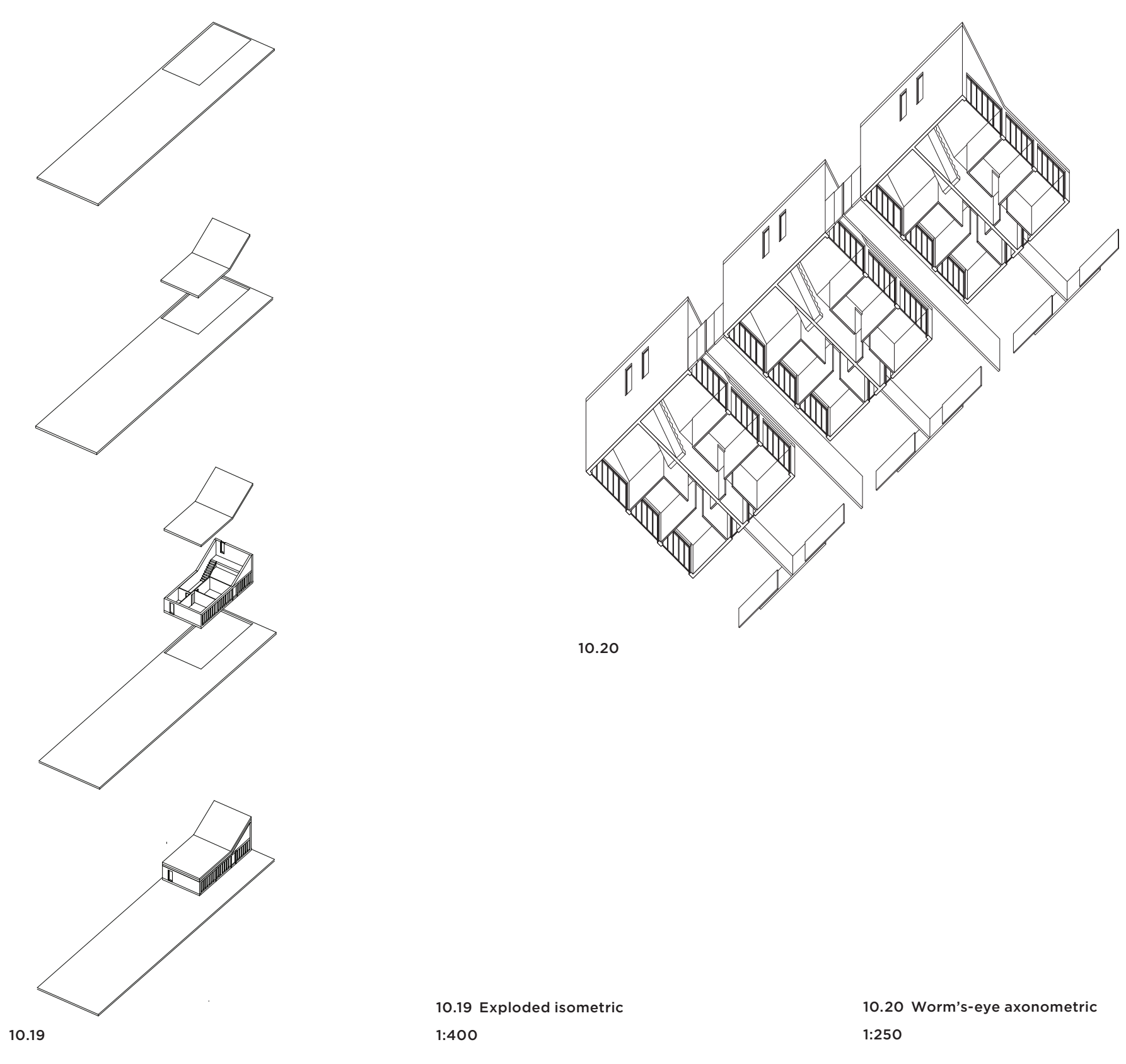

10.18 Plan and elevations

1:750

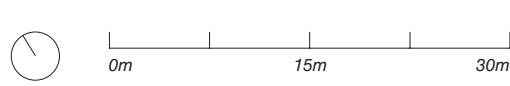

10.19 Exploded isometric

1:400

10.20 Worm's-eye axonometric

1:250
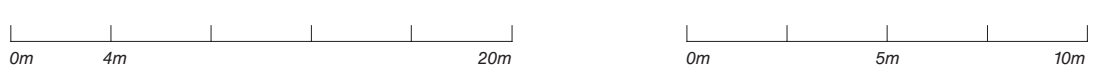


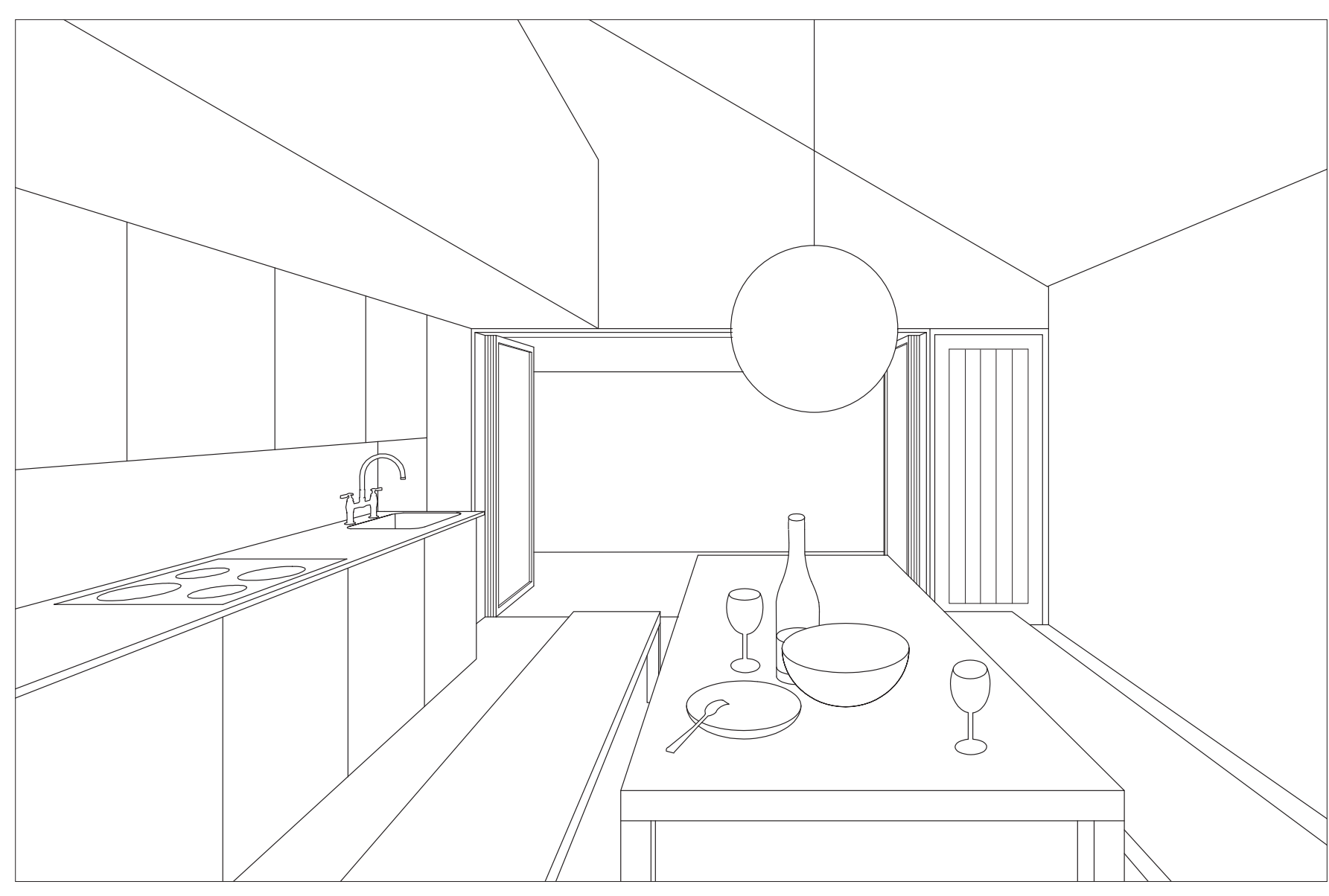

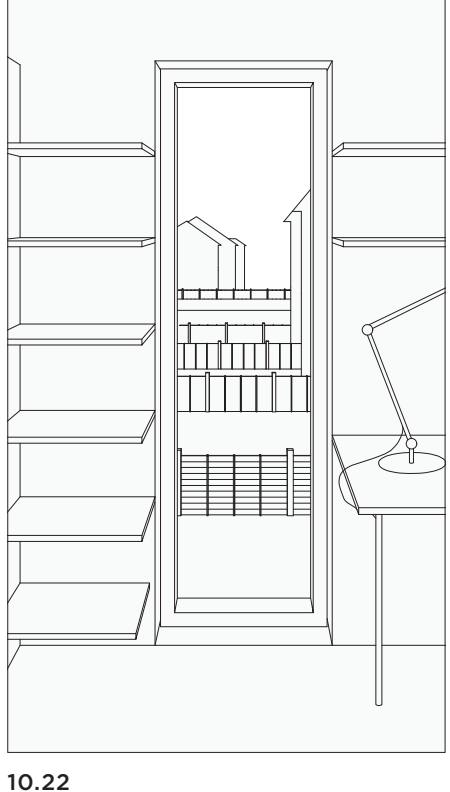

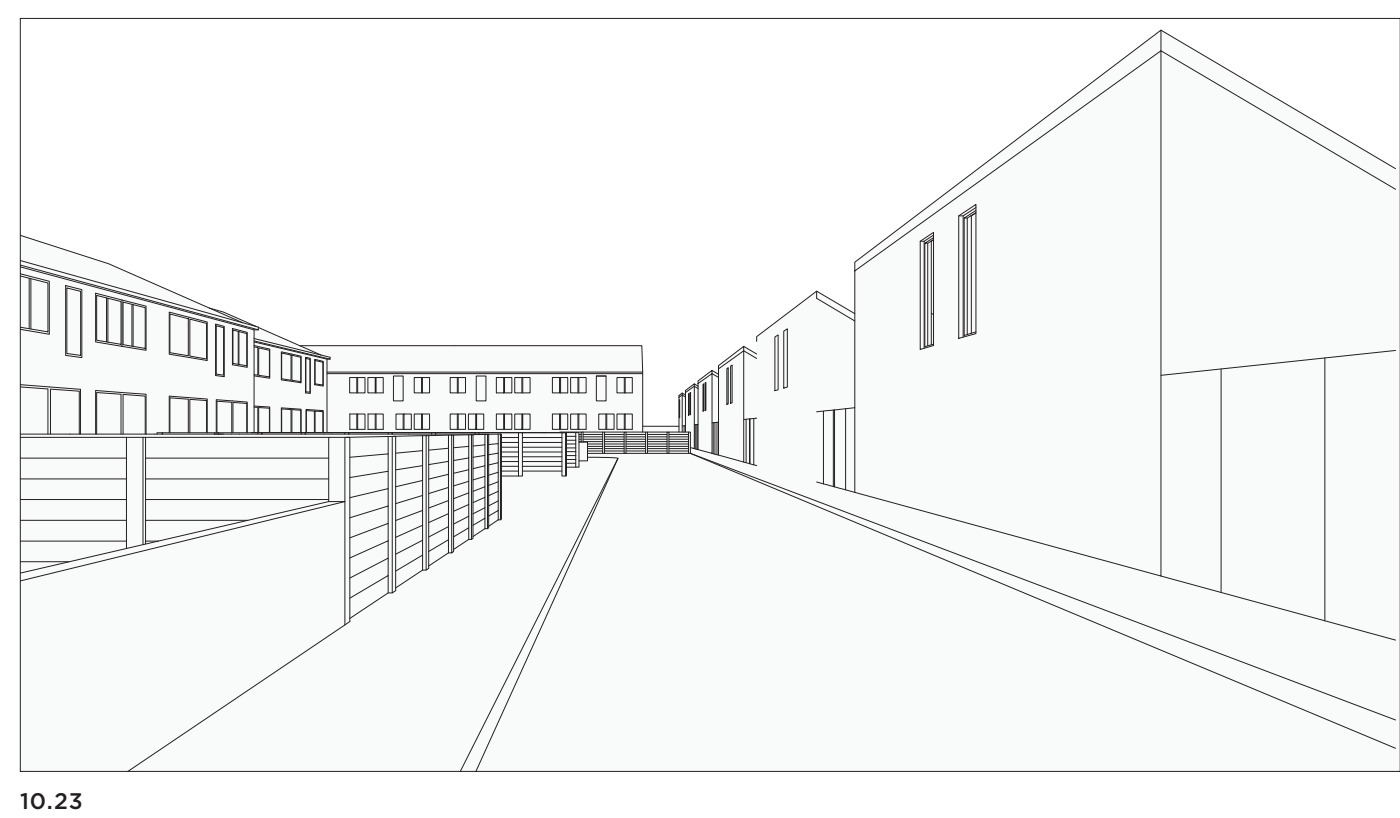



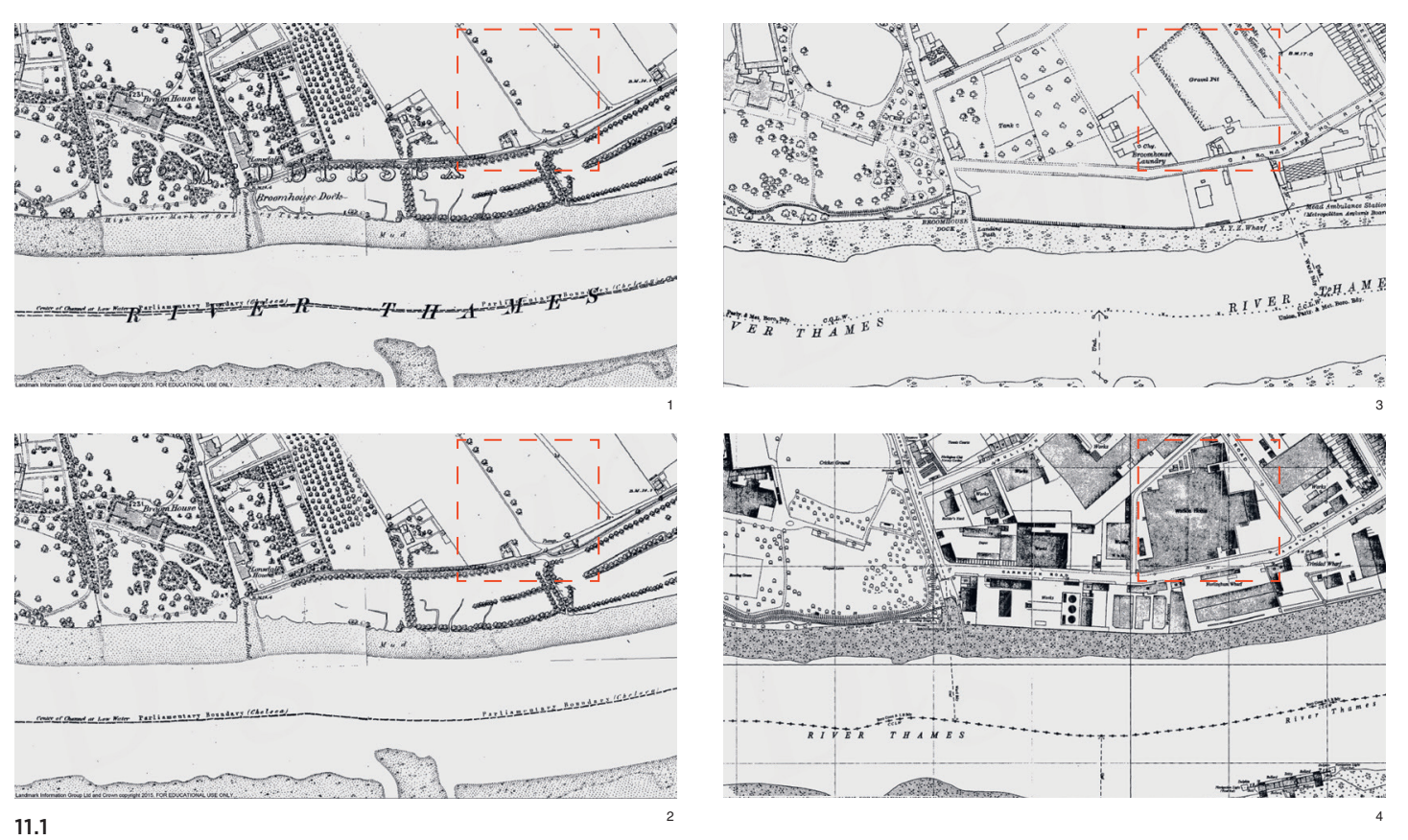
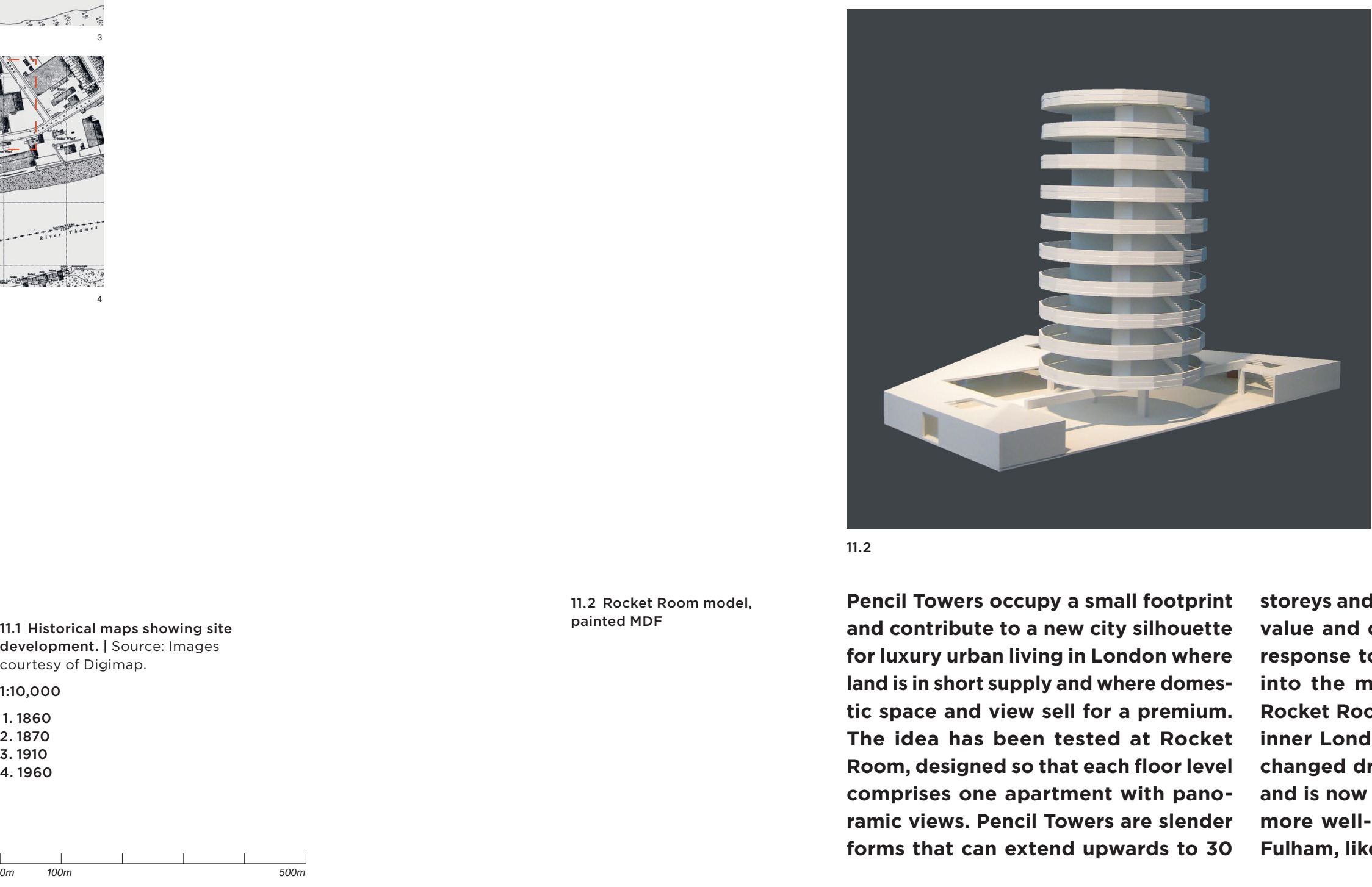

Pencil Towers occupy a small footprint storeys and beyond in response to land and contribute to a new city silhouette value and demand - an opportunistic for luxury urban living in London where response to the flow of global capital land is in short supply and where domes- into the metropolis. The site of the tic space and view sell for a premium. Rocket Room, Fulham, may be termed The idea has been tested at Rocket inner London suburban. The area has Room, designed so that each floor level changed dramatically since the 1960s, comprises one apartment with pano- and is now considered an extension to ramic views. Pencil Towers are slender more well-to-do Chelsea to the east.

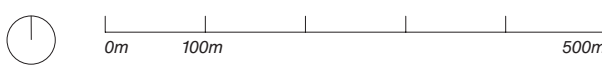




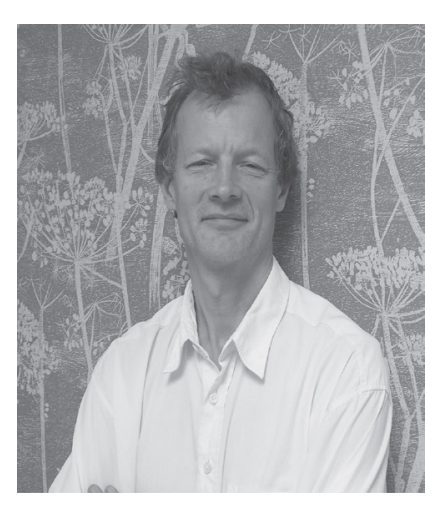

was given over to intensive industrial an Irish passport. My mother was British development, including Fulham Power but she married my father who was halfStation. Redevelopment of these sites Irish and half-French. His parents lived in as upmarket private residential enclaves Ireland as retired diplomats, and they wen started in the 1980s at Lots Road, includ- on holiday there regularly, and that's why Chelsea Harbour. The area, although pri- all my life.

marily working and lower middle class,

I studied history at Oxford. I suppose I contained pockets of high affluence,

including The Hurlingham Club just to the west of the Piper Building site, itself a conversion of a research and development complex built in the 1960s. The site was bought by developer Crispin Kelly in1996, when it was known as Watson House, and was the headquarters of North Thames Gas.

The upper floors of the building were used for offices, the ground floor for research and testing of gas appliances and gases. The Rocket Room got its name from
the testing of specialist fuels there. Between 1998 and 2000 , the building was converte into apartments and B1 and warehousing space. The scheme included demolitio of about 20,000 $\mathrm{ft}^{2}$ of ground floor space to enable circulation and parking. Pierre d'Avoine Architects converted the existing tank rooms on the roof of the main 12-store Piper Building into two rooftop house in 2004 built using volumetric modula construction. The proposal for the Rocket Room includes a faceted tower comprising nine flats one on each floor above a B1 plint and porte cocher

\section{Crispin Kelly}

Interview at Baylight plc, Queensway, London, 24 August 2016-I was born by

accident in County Wexford, and I have liked reading books about things that happened as a reality that had passed, and the Medieval Period was one where you could read relatively little, and that attracted me. As my special subject, I did St Augustin of Hippo and the beginnings of the collapse of the Roman Empire. I was the onl person to do that So, they had to setme paper. Being with very bright tochers who were very methodical and quick aulling ideas together was interesting As much fun was the peple I as learning sure how I ould make the what I'm doing now. Istill

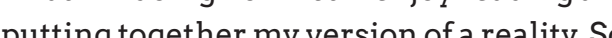
pun toger my version of a reality. So, Isuppose that's about the closest one could get to how Medieval History is influencing me now. There is also an excitement of being with the source. So, if one's workin in a team now, one is with the source, and ou're putting things together in real life. When I left university, I didn't really know what I wanted to do, and as a result I wrote fiction for three years, which really didn't suit me at all. It was a lonely business, and when I was doing up my first flat which was in Fulham in 1980, I realised that I really enjoyed the whole business of doin building work with sawdust, plaster and so on. I increasingly lookd plaster and so . I increasingly looked round to doing introduction to property very was my residential development using the intricacies of the leasenord's format and the ability to buy the frer's format and the process of enfranchisement

formally set up Baylight in 1982 and spent five years doing increasingly larger projects and some mixed-use projects like converting an old taxi garage into studios. Then, I was concerned that my soul was being overtaken by the desire for money. So, on the advice of my ex-wife, I enrolled at the AA in 1986. I took a year out in 1989 and was doing the 60 Sloane Avenue project with Stanton Williams. The recession was pretty full on at the time, and I wanted to finish diplo ot aA as duckly as possible - perhaps no sible -perhaps not the best approach to $\mathrm{m}_{\mathrm{Y}}$ architectural education. The fact that I was ver of it as I wo de done if I had't out of it as I would've done if Thadn't had three children and a full-time job. That's a question really - whether life would've been different if I'd have been in a different position. When I left the AA, I felt that I didn't have a clear kind of aesthetic or mission as an architect, but that I did have the skills as a developer who now understood more about architecture. I pretty much continued as I was before, working with architects who I had met and who were part of the AA network, which was a pretty big group of people. I continued to do mixed-use projects, and after Sloane Avenue, I was very anxious that I would do another big project. I felt that the Sloane Avenue project had been a rather magnificent undertaking which we more or less won through with, and then suddenly I didn't have a project anymore. That was when the opportunity of the Piper Building arose.
Before we talk about the Piper Building, can you talk about studying with Peter Salter in Diploma at the AA?

I suppose there was the idea of a touchtone - the idea that an object could be made that would in some way summarise place or an approach. It was a potent ambition which had material at its heart. That was something that one couldn't escape in Peter's project: the idea of materials and that materials were loaded. Peter didn't really like talking about theory or culture its widest terms So Peter Beardsell was lways brought in to deal with that side of anins I Berrill and I used to discuss to 1 hink Peter [Salter] was looking on to see what was going on in discussions about Proust whang there were two other very strong things with Peter Salter. One was locang Wil Peter Sater One was locating your The sort of very absessive about. To me, it seems itcould be here or it could be there, and you DexperiPer Peter [Salter]. The other was the idea of detail. You know that he would constantly embellish and refine and make anything your project amazing. Anything could be turned into gold really with his thick pen n trace. So, it was quite a challenge to see that going on - that he had the generosity of taking on your gutter detail for instance and making it into something rather amazing.

Did you feel that you were influenced in terms of how you designed and drew and conceptualised things like Peter? 
I think not in terms of making shapes. I must be able to do something better than think Peter's imagination was his own, but knock it down. It was completely covere think in terms of what materials could do, with stuff from the occupier so that what definitely. You know the sort of importance we call the Rocket Room was filled with of materials and what impact they could turbines and machinery and huge bits of have. I think that was very, very obvious kit. They were no longer using it; there was for everybody. I think for me it was about just a skeleton staff knocking about, and materials and detail and the idea of the the top floor was the staff canteen. I think touchstone-so, everything to do with the most of them moved to somewhere else. power of materials really and materials So, I thought surely we can pay as much

\section{How did the project for the Pipe} Building happen?

as the housing association which was a tiny amount of money like £2.5 million. you're going to have to act very quickly you're going to have to act very quickly if you want to do this. You've got a week From my office in Sullivan Road, I could in whi see what was called Watson House in those was a hectic week, and what we uncovere days, which was a great hulking 1960 s was a series of quite serious problems with glass block. I think it was 1991 , and the the property, which I suppose explain economy was stilkind of recovering from why the housing association thought it the 1989-92 recession, and there wasn't was better to knock it down. The probmuch confidence in the market about any- lems were that it had asbestos which was thing in particular. There was certainly not embedded in the structure. It wasn't really a lot of interest in sustainability, and one of a question of being able to remove it; it the main buyers of property were housing was going to be there. It had been used associations. So, you couldn't really have in the formwork which was left in the had a more different approach to property building. It then became clear that the than we have now. I'd heard that a housing building had been built on a tip, and ther association had agreed to buy Watson was methane coming out of the tip and House and were going to knock it down that some of the stuff in the tip was quite and build a terrace of houses, and I thought nasty: heavy metals and things. So, there this was an interesting opportunity to look was contamination, there was gas, there at the existing building and see if one could was asbestos and also the last joy that we keep it because it was enormous (about discovered was that high alumina cemen $250,000 \mathrm{ft}^{2}$ on, I think, three and a half had been used for the structure, which acres). I went round (this was all directed was cutting edge in 1959. So, really, we through the Property Director at British had to address all those things to sul wow Gas), had a look and got very excited. There we were going to get round them. There Gas), had a lok and double or triple height, and I thought one who held our hand through that process.
So, we basically thought that we would probably be okay - that we would probably be able to address these things if we kep the building. So, we bought it, and then it became quite a big worry really because suddenly we owned this big building which had all these problems and was empty. So you know, I was worried about vandalism and the planning and so on. Basically, we bought ourselves a big worry ..

\section{When you refer to 'we', is that Baylight?}

Yes, Baylight had got going. It wasn't large we were four people. So, that was kneadin we worry really. The team includa manager, an accounts person, a projects person and then there was me. So, Watson House was my project

In terms of a model for being a developer, what were your influences?

There wasn't a small developer model that I had seen. Much more prominent was the big developers like Land Securities and British Land who had big operations with lots of capital, and I definitely felt that didn't want to be doing that. I wanted to be my own agent really.

I first met Peter Salter in the early 1980 s when I had an office in Fulham with David Conner and Julian Powell-Tuck, where Peter was working with Ingrid Morris. We rented space from Nigel Crump whom I think you know because he also whiding you know because him the ' was doing posh apartments in South
Kensington and Knightsbridge, but he was different from you in that he was also doing the contracting. He would buy the property and do the whole package. That was the 1980s model: developers like Nigel who'd seen opportunity in smart West London residential development. In contrast, you dived in with Sloane Avenue: a different type of project where you were in competition with larger mainstream developers.

I think our projects were always slightly off-pitch Sloane Avenue, although it was a htly off-pitch for a big com com dilding was definitely not a development a large The idso of converting offiny would do. The idea of converting office/tndustrial buildings wasn't around at that time. I think Manhattan Loft had been doing their project in Clerkenwell at the time, but it was very early days for that idea. I went to visit the one in Clerkenwell and thought it was great. I suppose my training as an architect had shown that these big existing spaces could be something else.

It was visionary in a way.

It definitely was at the beginning of the B1 to residential. Planning was the big thing because planners were fairly opposed to the whole idea. Planning has always been aig battleground for me. It was at Sloane Avenue, which went to a public inquiry. remember the first meeting with the planners at Hammersmith and Fulham Council. They said "The Piper murals are being listed, the whole building is gong to 


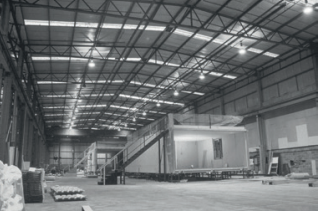

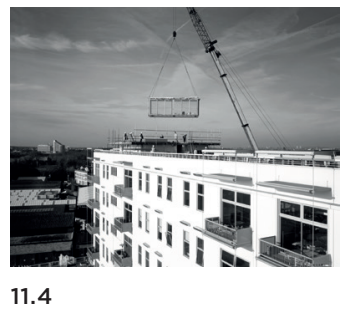
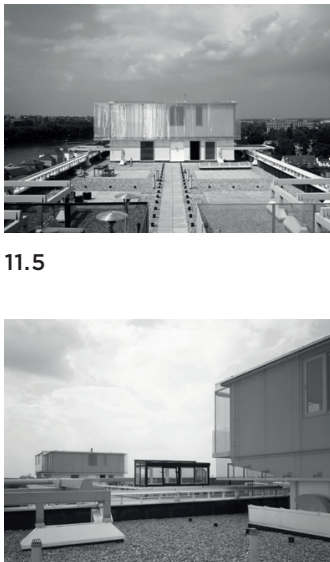

11.3 Assembly in factory
Manchester- IS urce P Pho Manchester. I
by Greg Ross.

11.4 Craning onto rooftop. 1
Source: Photograph by David Grandorge.

11.5 View of rooftop west from
rooftop east. I Source: Photogra rooftop east.
by David Grandorge. 11.6 View of both rooftop houses.
Source: Photograph by David Source: Photo be listed so what are you going to do? You're not going to be able to change anything. So, there was constant opposition to evefor us, English Heritage decided not to list it in the end.

And how did that project evolve? Was it straightforward in terms of the way you organised the space for residential?

From the outset, the ground floor was going to be commercial. We thought that we would edit some of the outbuildings and that the upstairs was going to break into flats off corridors, and that the flats

How did you set up the Piper project?

The first thing was choosing Alex Lifschutz to be our sort of partner. Alex was unusual in that he has a lot of interest in the process of development. I'd met him through his wife who was on the same course as wife wife at the National Film and Te as my School. Monique was a writer like School. ex-wife. Alex has got an acute interest ately clicked. He was pretty important in handling the negotiations with the plan ners, and the key thing there was giving them money. They wanted money for th Section 106 agreement.

What did that involve? Was there an thing in particular like buildings o other sites?

No, no, they just wanted money. So, I was extremely nervous because this was not a field I'd ever got involved in, but Alex had the whole thing in perspective, realised they were quite happy to get the money and that this whole thing of $B 1$, kind of blue-collar workers having Labour votes, because it was an Employment Zone, and they were willing to let itgo if they were and enough. So, Alex was very good about that. were going to be double height with small mezzanines. We took the decision that we would have to put a new skin on the building, and I suppose my greatest worry was how we were going to fund such arry was and bonks werent Ilooked round for a partner and found troked around for a partner and found tor David Calverley at the Try Group. did a joint venure on the residroup. We Try Group whic po for the Try Group which paid for the Bl to be modernised. So, there was a very sweet deal. never could believe that residential was going to sell. I thought this is so weird and ing and so on, but David held my hand and said, 'No, this is all going to be fine' an was pretty much breaking new ground for the Try Group who were doing suburban housing. He wanted to learn about this, but even while he was learning about it, he was pretty good at sorting it all out. His insight was that if you have a good firm of solicitors when you're selling the flats and you've prepared reports for all of the probthis big firm says. And there's no reason why they should't so, that was my reaso which quickly went awa They sold vorry ment We were coming to fund such a developthere are so many problems with the buildlems, other solicitors will just accept what the Piper Building. I think it's reasonably

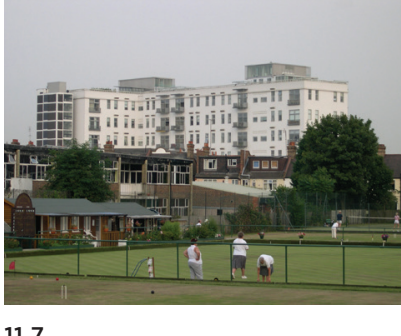

well. They sold very quickly, and it was very exciting. We had our first ad in the Sunda Times. I was on holiday in the Lake Distric when I got the paper and saw the ad which included one of the Piper murals, and it just seemed really fantastic.

Did the Piper murals have an influence on your decision to buy the building?

the postwar period and also the idea of craft. Subsequently, I bought one of the panels from his widow that was made as a trial panel, which I've got upstairs.

You also acquired Piper's sketches and drawings?

Yes, I've got quite a lot of material.

11.7. Piper Building with rooftop $\quad$ Yes, very much so. Piper was a post-First houses from north-west. I source: World War artist who got mixed up with
photograph by Greg all the great twentieth-century artists in Paris at the time. But back in the UK, he was really having to earn his livin, ho, was really haing to earn his living. So, the also took on comer. After the Second World War, he had a successful career, including public commissions the Piper Bulding I think it's reason for unusual as a Piper mural, which represents the 'spirt of energy' for North Thames Gas, in that he was confident to do something abstract. I think his church series or landscape series were more typical commissions. And it was typical of Piper that he used fibreglass, which was a completely new material in art practice. He actually got two graduates from the Royal College to make the pieces that went on the Piper Building. He did his drawings, and they made the artefacts. Apparently, a part of Piper's understanding of craft was that he would let go and let the craftsmen evolve the work from his small drawings. It was definitely a collaboration. He wanted to
see how the craftsmen would extend and intensify what he had drawn I've remain interested in the spirit of optimism from
How did the design of the building

We thought we couldn't spend too much money, as it was a new initiative, and we didn't really know the market. Our approach was to use economic materils generally, such as Sto-render for the evations, and add quality in the details, including the balconies, the blinds and the double doors. I think it has been pretty successful. I think having a white building in London is a bit of a challenge, but we've crisp. The yellow blinds haven't worked so well, they're more problematic about how they operate; they still look good, but they don't all work. I think those decisions were pretty sound. The roofscape was something we didn't really understand, and it's been moch more ad hoc in its development, first ff all with your rooftop houses and then with people doing little access pods and

We refer to the rooftop as Dungeness.

I think that people really enjoy the rooftop spaces. They're very unusual for Fulham. redone it regularly, and it still looks pretty 
The residential units weren't all sold as tube. So, it's hard to re-let in a recession shells. About half were shells. We did My feeling was that to have more flat three standard types. We actually ended there would be a good solution to that up building most of them and selling them problem.

as that, and then the ones that were shells, people would do their own fit-out. I thin it's probably fair to say that of the ones that were sold as shells, about 70 per cent, were quite ordinary in the way the fit-outs were done. But I think 20-30 per cent were pretty interesting and had interesting architects doing them. It's unusual to have tall ceilings in a building with to have tall ceilbeams and large windows. So, it was the warehouse dream really, and with amazin warehouse

Did you set up a residents' association?

We didn't set up a residents' association The building is owned by the company th originally bought it. There's an interme-
diary company; we continued to own the commercial space. In fact, we're taking the next evolution now, which is converting Carnwarth Road into flats.

What drove you to change your view about change of use of the Carnwath Road buildings which are not residential or haven't been residential historically?

I think, as a property owner, each recesgo bust, and the landlord then pays empty rates and service charge for that space which, as it's a recession, is pretty painfu whecause by definition things are had Also the Piper Building is a long walk from the

\section{When did you take that decision?}

Only about two years ago. It was when the B1 to residential as permitted developmen policy came through, but we'd been thinking about it for a while.

I know it's very much a personal project for you because you've had your office floor

I think the reason they went there was to help me really. You know, it was sort of the first sale. They used to live in a very conventional large Chelsea townhouse in Carlyle Square, and for them, this was a pretty big jump in terms of both living on one floo and living in Fulham. But I think they both really enjoyed it. My mother died about six person to live in a flat like that, but I thin she actually did enjoy it, and my fathe definitely enjoys it. They've got a massive flat, and he loves entertaining and havin lots of people round and so on. So, it's really the perfect party flat. He has the security of reception and people around to help him out. He has lots of his grandchildren visiting. So, he's very well supported.

\section{Can you talk about the Rocket Room?}

The building was used by British Gas fo testing fuels. It has one extraordinary years ago, and she was not the most obvious triple-height room. Originally, it was all like that, and it just seemed like an extrao dinary space to use for commercial. W didn't really have much of an idea of how it was going to be used, and the first tenant Shiltons, were not really a very suitable tenant, as they wanted a conventional office building. It is currently occupied by Phase Eight, who are a fashion company, on a short-term basis.

How receptive are the planners regarding more development on the site? Rocket Room took us nearly a yearin pre-application planning At the time there were schemes to develop the Fulham riverside by others.

The whole world changed about 10 years ago when people started thinking towers were a good idea. I suppose there's always the thought that towers along the river wer a good idea, but the towers that were proposed seemed to be really bad. When we were doing the Piper Building, six storey was a tower, and we were the big building in the local area. About five years ago, the idea was that everywhere could be a tower, and I think that when we were developing the ideas for a tower on the site of the Rocket Room, there still wasn't really the appetite for towers that there is now, but it was logical that you could have a building that was the same height as the othe buildings on the plot. We're looking at projects on other sites and thinking of a tower where the existing building is two storeys, but you know, towers are fine So, Piper's slightly odd in that having a tower there would have been controversial when we first talked to the planners, but now it's completely normal. In fact, you would ask, Should it be taller?

You could double or triple the height?

I think young developers do think like that.

It just seems like you can try it on, in a way. There was a shift of opinion about what development in London could be...

Needed to be.

Needed to be or could be taller. Deyan Sudjic, in the sudjic, in the Eveningstandardrecenty sugered that if London is a world Git or even anything remotely European, but that it should look something like Shanghai (Sudjic, 2016).

That's not my perspective. I think from my perspective, what happened was Canary Wharfgot buil, and those were really the first towers that I would see in London. And you expected the centre of the city to be tall buildings. So, there was Canary Wharf, where a new place had tall buildings, and you thought, 'Well, that's okay. That's in the middle of nowhere. No-one cares about tall buildings there'. But then I think what happened was that the pressure on land became more and more intense, and people felt, 'Where are we going to find the space for all the trade and desire for homes in fondon?' So, I think this idea that it was going to be like a world city followed the 
reality of becoming a world city, so that people thought, 'We need to have tall buildings because there was a need to meet' don't think it was like saying, 'Wouldn't it be nice to have lots of tall buildings'. think people thought, 'If we don't do a tall building, we're not making proper use of this site'. There's probably a slight overlap.

I think the other point Deyan mentioned was that in London for 50 years after the war, the population remained steady at around seven million people but since arestart the millennium the populaion has increased to more than million and is predicted to increase much further. As a reaction, there has much further. As a reaction, there has in towers.

mean that you live in a flat. If you live in Islington or you live in Fulham or you live in Wandsworth, you're probably living in a house. So, I think there's a great attraction about living in a house: you know, no having a neighbour on top or below you an having your own garden and the idea of the street as your common ground. I think building towers of flats is much more problematic. I think it's great for some people and at the moment, there's enough demand for it to be met.

A completely uneducated opinion ould be that young people are much more willing to live in a tower block. You see that in Trellick Tower, for examp But think Imean, it's a waslo with kids do like living in to young people with kids dolike living in towers, and there I have a difference of opinion about that. I that and enjoy it, but a lot of people don't think some people love to live in a flat in and I thinkschooling is a big thing. Schools the city. The Barbican is a good example, in London have got a lot better in the las and, you know, the taller the better. But I decade or so. That's been a big change. So, think that is a minority sport, and I think you can get a good education if your kids that most people who have families and are in London, but I don't think that autowho want a good school for their kids are matically means that you'd want to live in less certain about that as a way of life. a flat. You can live in a house and get your So, I think it's divided, and it's also about kids a good education, and that's a pretty phases of life. A lot of people want to start good deal.

in the city, maybe move to the suburb and maybe come back to the city, but I think Did you anticipate the incredible it's much more that the city offers some property bubble that occurred in the things at some times, some things that noughties and which still continues? Not some people think are really attractive, but that long ago, we were astonished that I think, equally, a house with a garden is flat in Regents Park sold for 817 million. lso very attrative, and London has a lot Now, flats are being sold for 9150 million. of houses with gardens So, you can live in tho have in the is a bubble in the sense that it's all going been since British Gas developed the to collapse and that you'll be able to buy a $£ 100$ million flat for $£ 10$ million. I thin that we have lived through a big change in London, and London has got a new statu that it didn't have even 10 years ago. I don't think Brexit will change that. It might even be good for London. We've got the advantage of language and a time zone that's very good for financiers and trading. We're now a place where everybody wants to be, and I don't really see that changing in my lifetime. I'm sure it will change one day. There may be a city in India where everybody wants to be, but we've got a lot.

Do you have a comment about the quality being delivered now?

I think what's ironic is that there are the best intentions for public space now. If you talk to any developer, they come up with the most tremendous lines like, 'What's impo tant is the space between buildings and so schools not on any development but on the ones of what But there's no real understanding that are by the river. If you go a bit further - What that is, and most of the public space east, there's a big new Sainsbury's and some is that bivered is poor.I think the problem massive developments that are taking place it's very, very hard to create something new to mean bad. It's the loss of grain that you that is good. So, if you look at King's Cross, get from these big developments. You go which you couldn't have put more effort into along the river, and it's terrible. But I think making look good than Argent did, yet you London's got enough of its protected villages that it will remain very attractive as a city. If you look at Bedford Square, Ican't Well, just coming back to Piper, it's a see that ever changing, and that's why gated community, and I suppose it has people will come. 

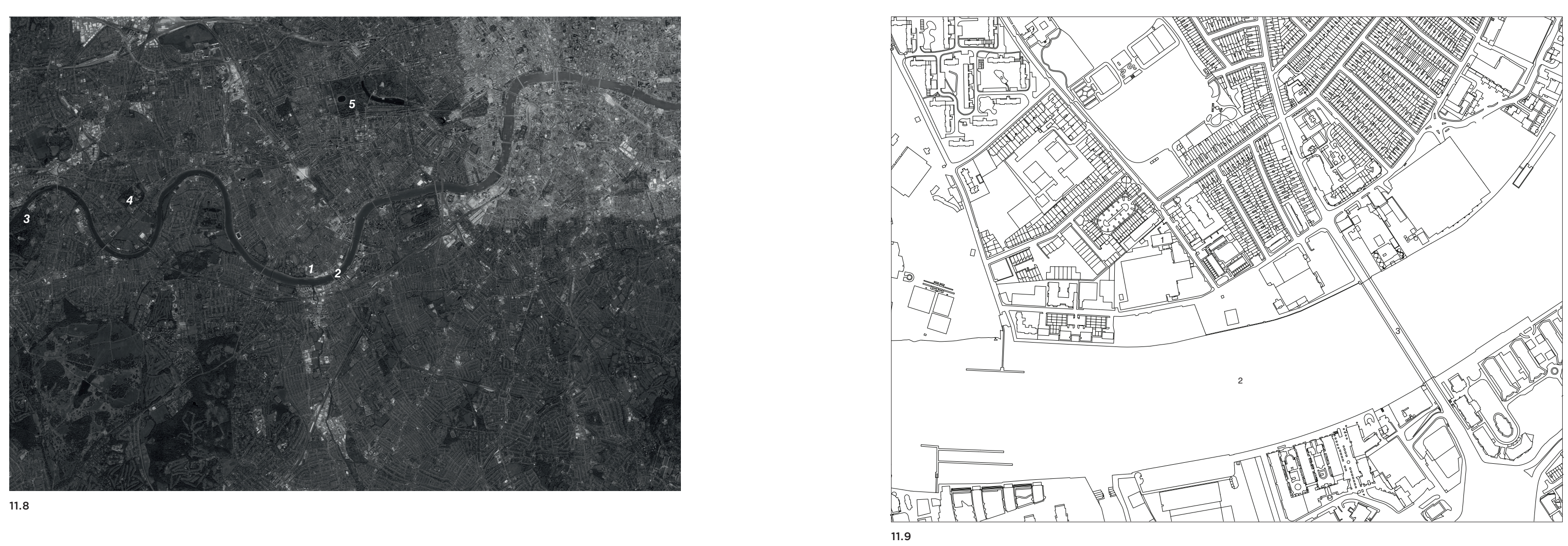

11.8 South-West London. I
Source: Image courtesy of

1:100,000

1. Piper Building
2. Wandsworth Bridge

2. Wandsworth Bridge
3. Kew Gardens

4. Chiswick House
5. Kensington Gardens
Hyde Park

1.9 Location plan

11.9 Loca
1:8000
1. Site
2. Piver

1. Site
2. River Thames
3. Wandsworth Bridge

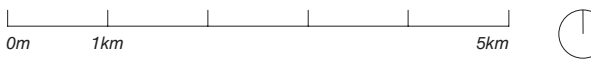




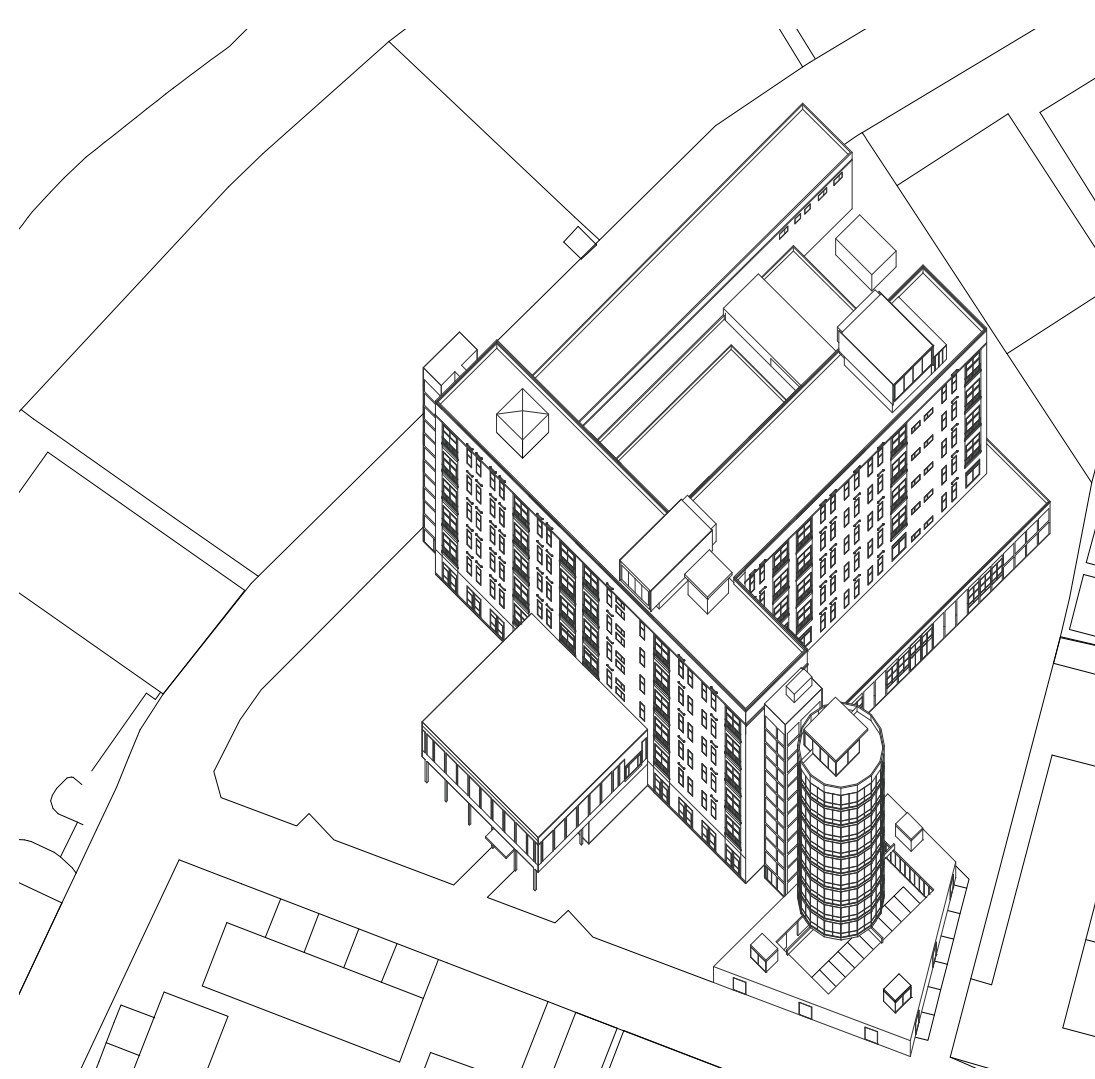

11.10

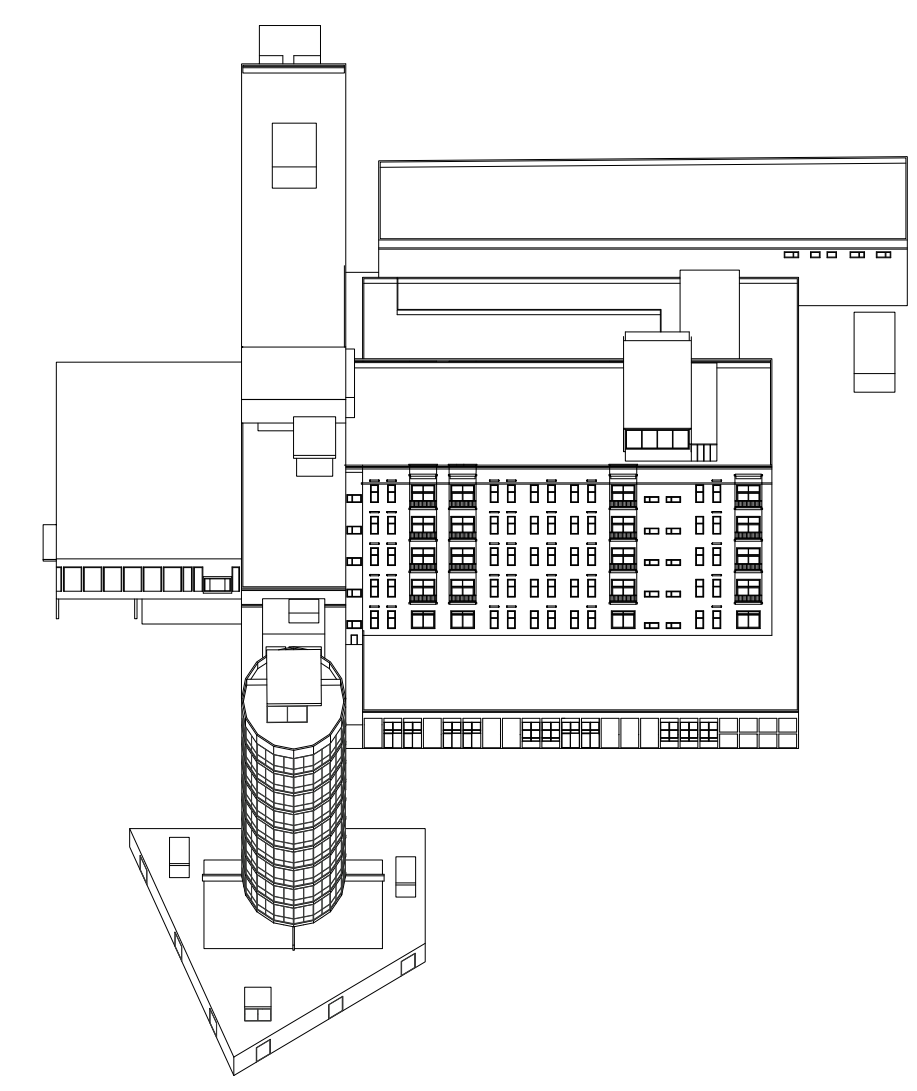

11.11

11.11 Planometric

1:3000

11.12 Gas holder

11.13 Elevations

1:3000

1. Ten storey
2. Twenty store

3. Thirty storey
11.10 Isometric

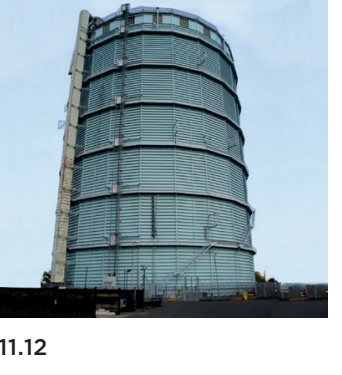

minn
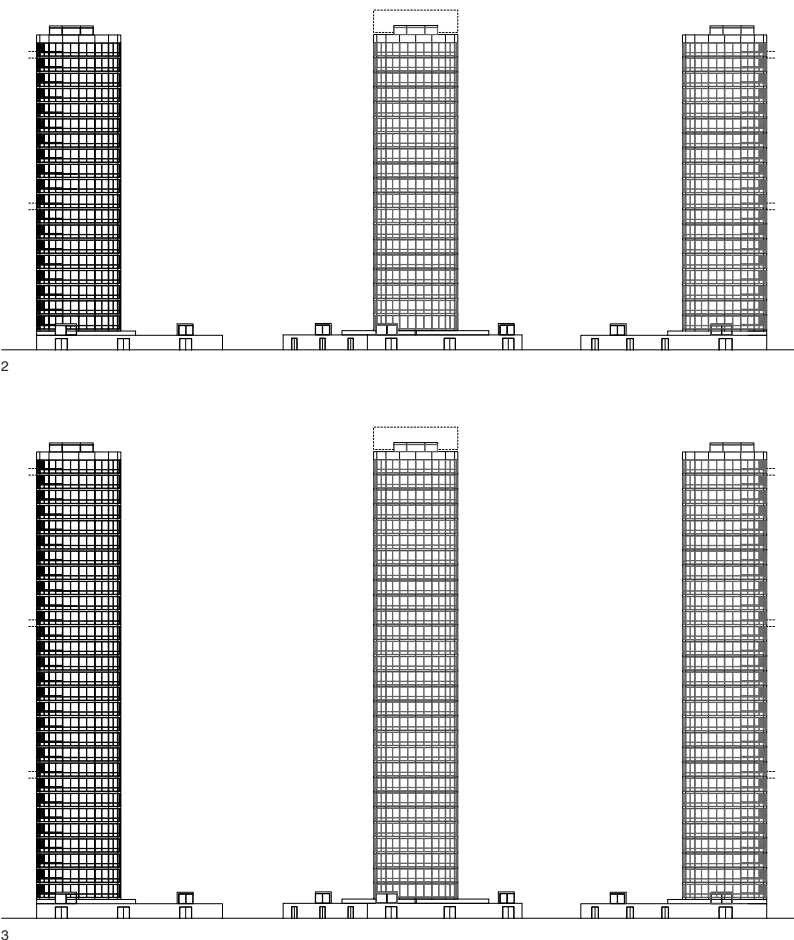

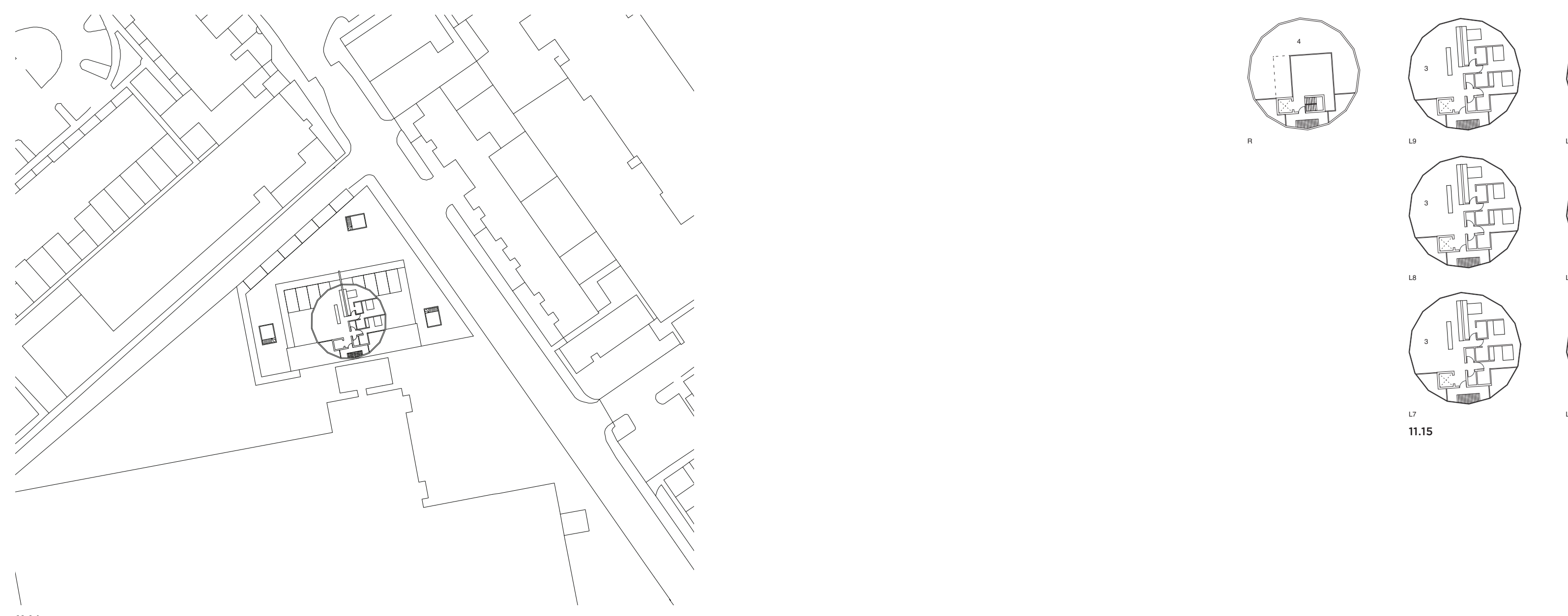

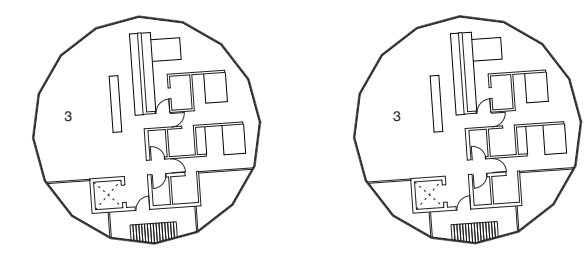

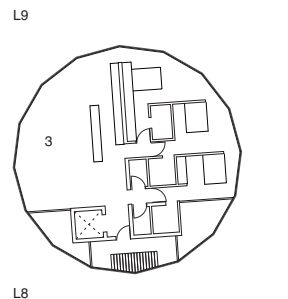

3

(1)
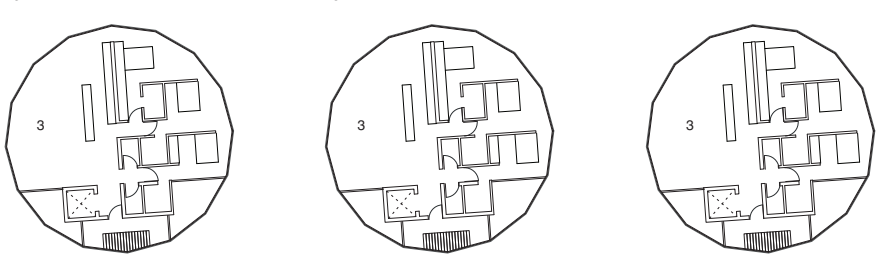

11.15

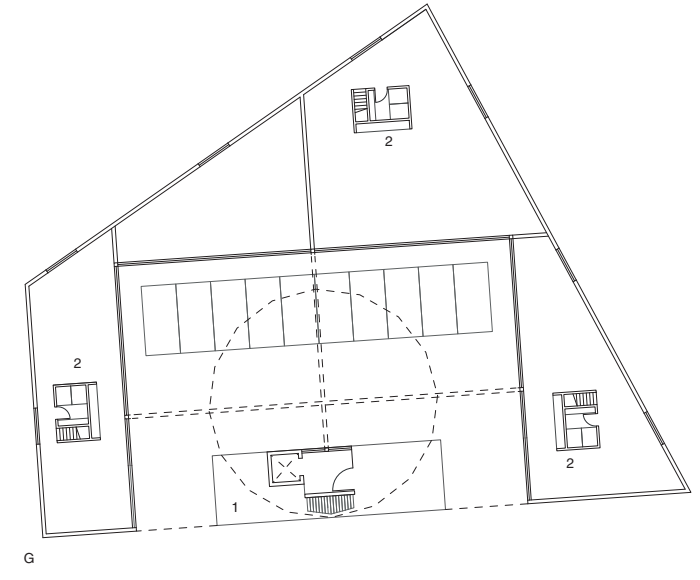

11.15 Plans

11.14 Site plan

1:2000

1:2000

1. Porte cochere
2. Office

2. . Ffice
3. Flat
4. Roof gard

(1) ${ }_{0 m} L_{20 m} \quad 1 \quad 1 \quad 1 \quad$

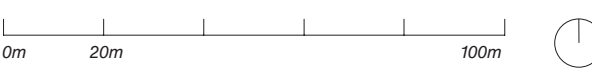




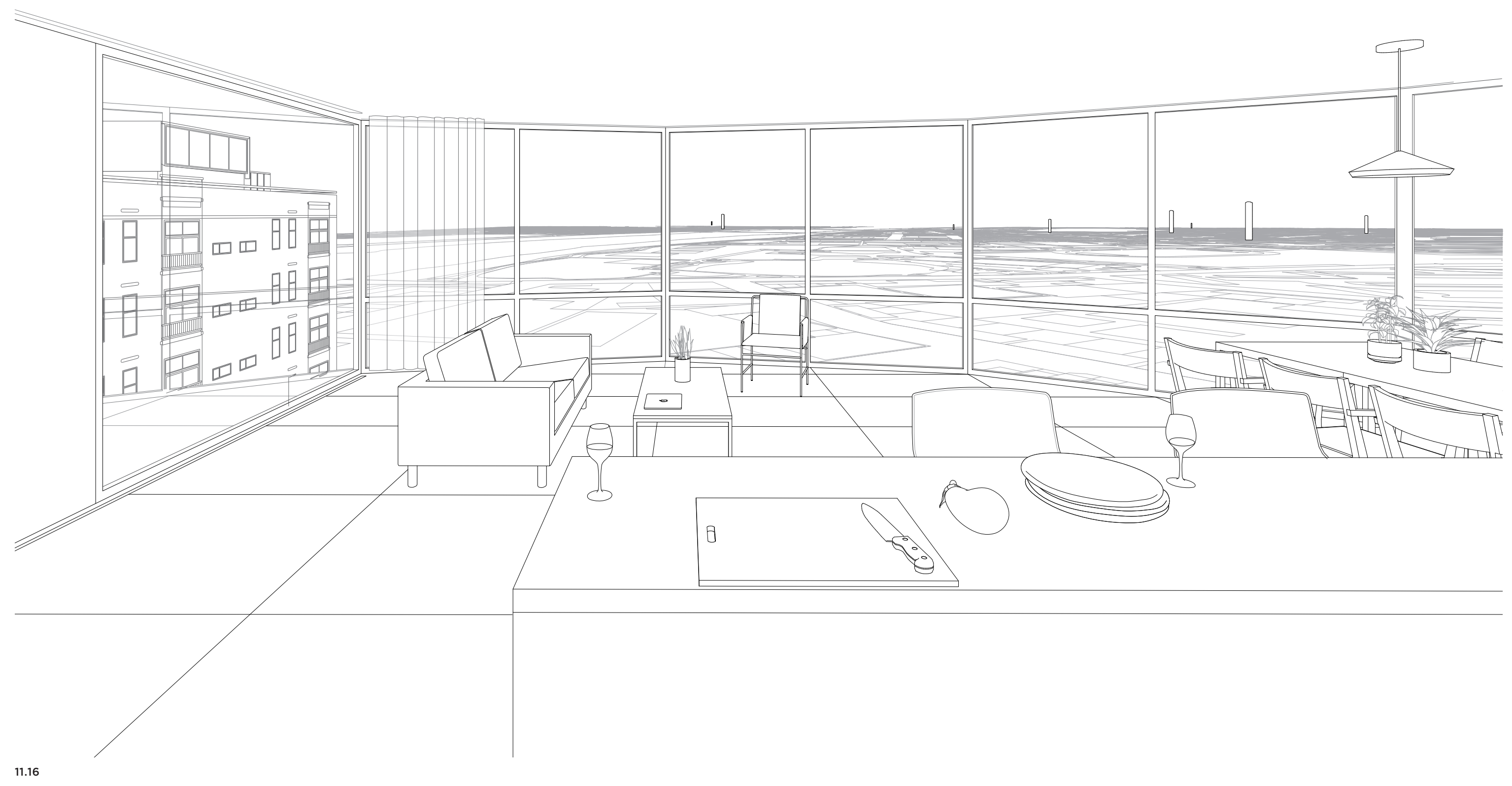



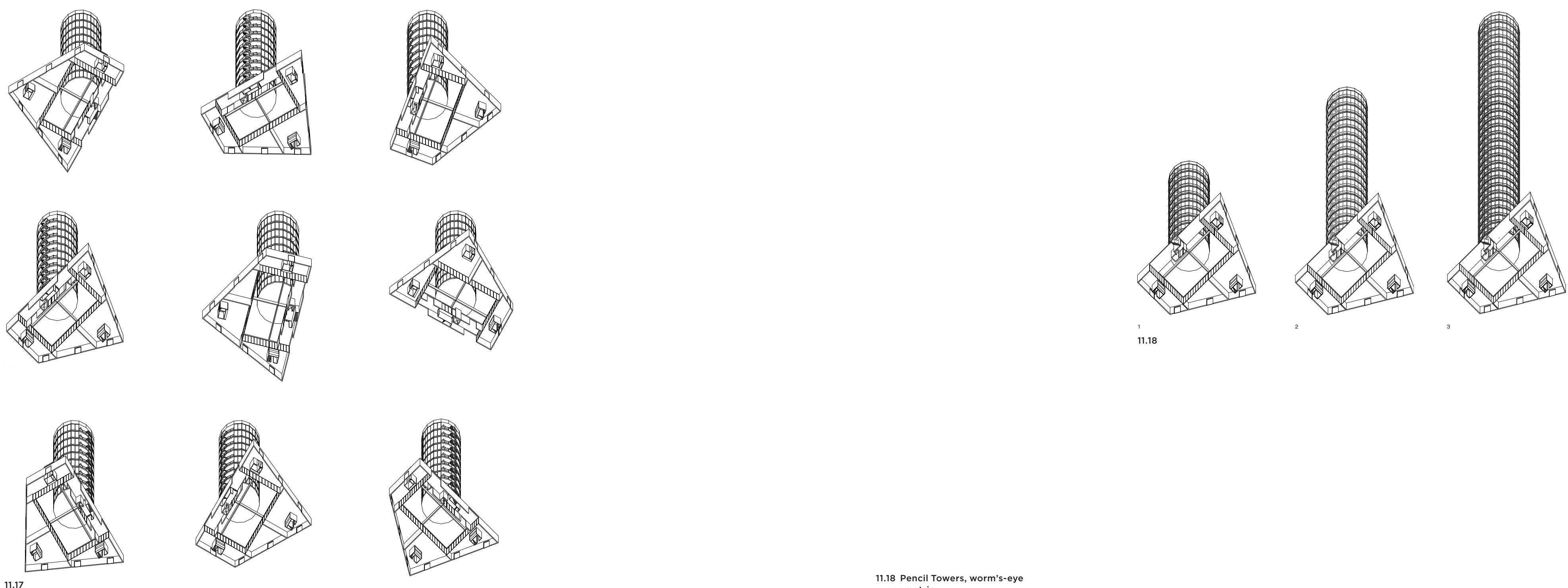

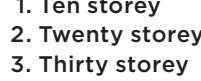
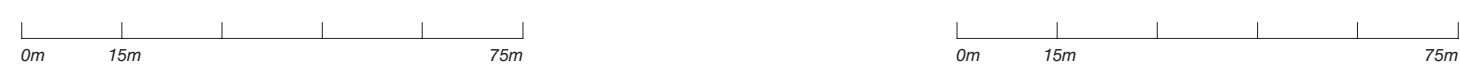

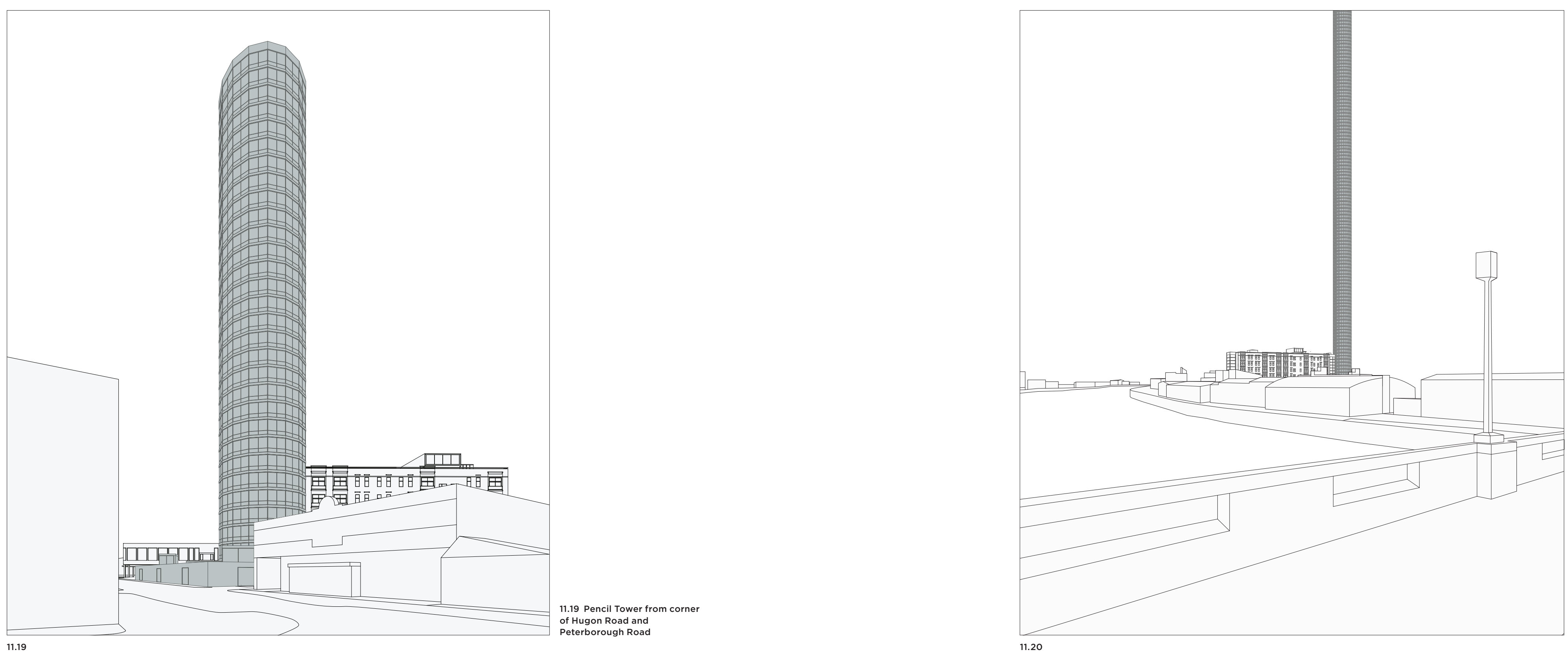

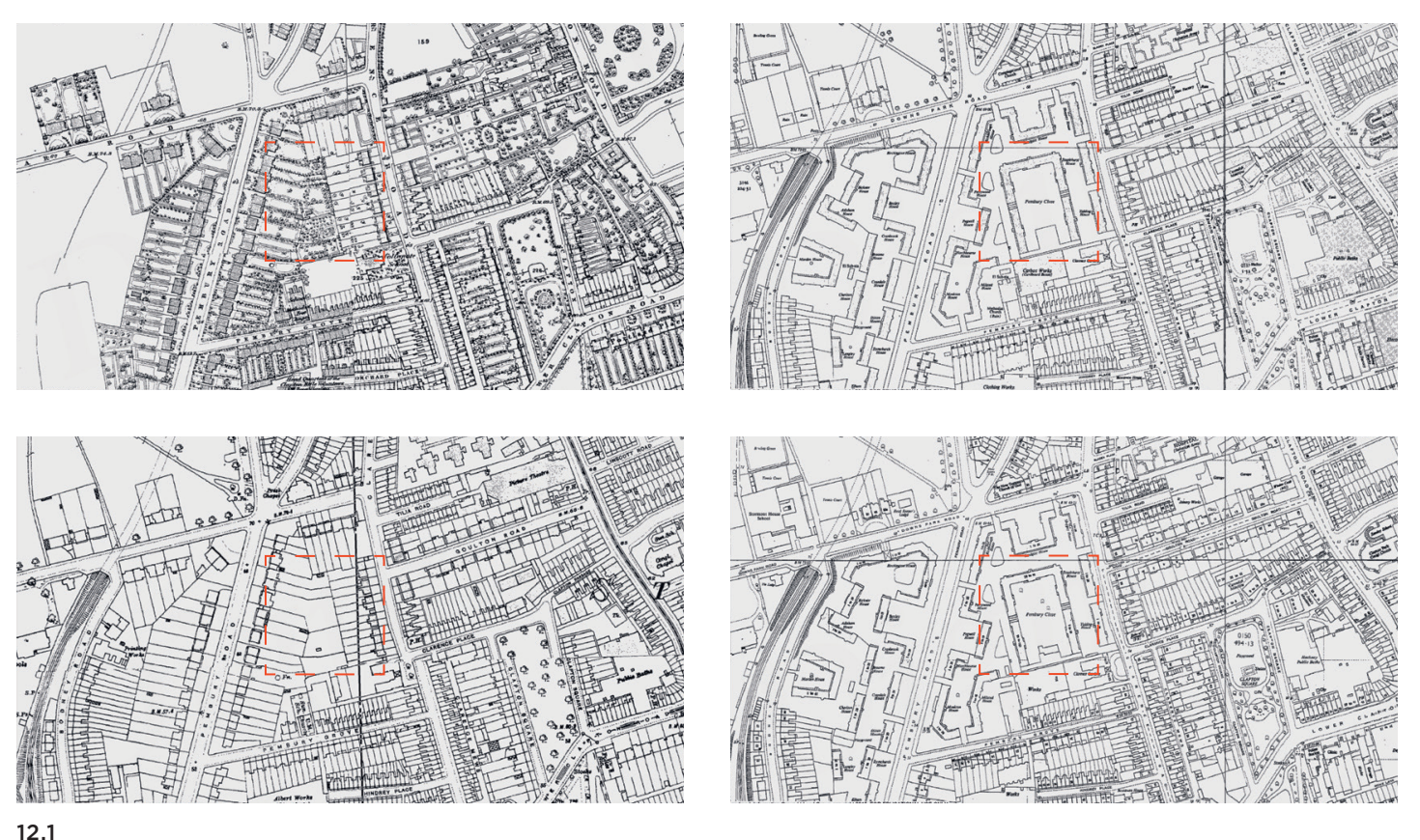

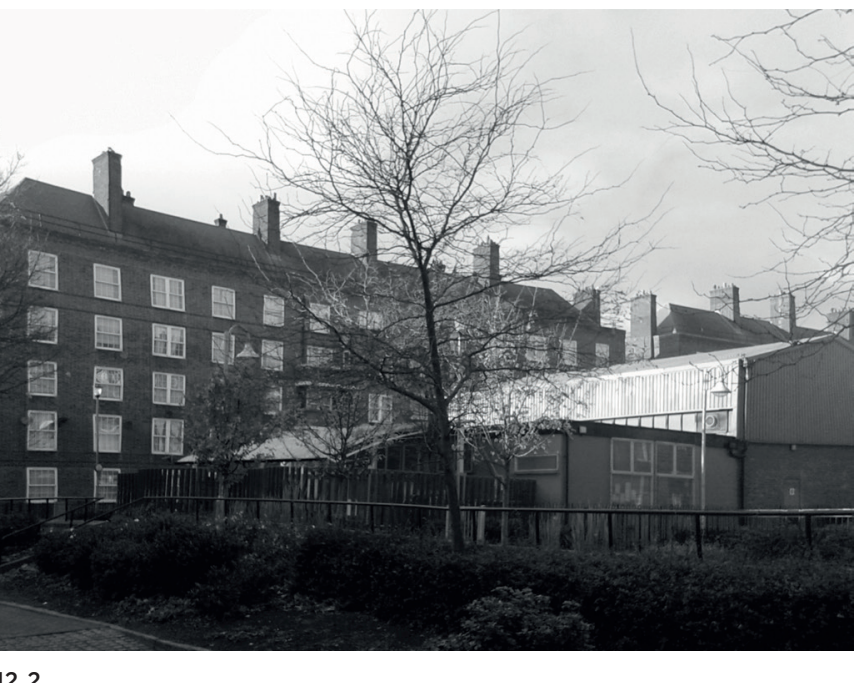

Hackney in East London, the location of run-down inner-city areas where propPembury Octagon, used to be a predomi- erty is cheap and available. Today, it nantly white working-class area. Like accommodates a wider demographic, other similar inner London suburbs, its including immigrant communities from population experienced unemployment Turkey and West Africa, as well as young and a diminishment in living standards as professionals who are attracted by its local industry declined owing to a lack close proximity to the City of London. of long-term planning and investment The revitalised London Overground as central government focus on ser- railway infrastructure has helped to open vices increased throughout the postwar up the area to new initiatives. It curperiod. It was famous in the 1980 s for rently contains a lively mixed community. having the greatest concentration of However, the pressures created by genhaving the greatest concentration of However, the pressures created by genartists anywhere in Europe. This may be trification are causing further change to understood as the first wave of change take place. Not all of this is desirable to 


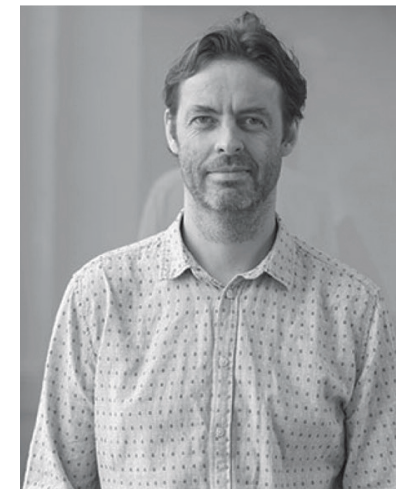

the indigenous population and more recent ethnically diverse inhabitants. The Peabody Trust owns and manages the Pembury Estate which consists of two parts: Old Pembury built in the 1930s as mansion blocks and New Pembury which was laid out in the 1960s with smaller maisonettes and bungalows. It is a large estate with near two thoufounded in 1862 by George Peabody, an American banker/philanthropist based in London. The Trust was later constituted by Act of Parliament with the objective f reling poverty in London by the of relieving poventy in London by the provision of model in Longs. it is now the attendant strictures necessary to operate within an economic agenda framed by austerity. Pembury Octagon is a proposal for affordable housing on land currently occupied by a community building situated at the front of the main building situated at the front of the main courtyard of Old Pembury. The aim of the proposal is the provision of generous residential accommodation supported by communal rooms on the ground and top floors, including a roof-garden crèche, and an architectural response the grand formal setting.

Liam Dewar

Interview at Eurban, London, 24 August, 2016-I guess one starts with $\mathrm{m}$ parents: one's German and one's Scottish. I was born in Edinburgh and lived ther until Primary One, then moved to the Borders and lived in the country until was 10 years old and then moved back to Edinburgh. My mother spoke to us in
German, and we responded in English (or Scottish). She'd studied at Edinburg College of Art where she met my father. She's an artist. My father's a compute scientist. With no architects in the family, architecture wasn't something that was really on the agenda. I didn't want to study in Edinburgh, and Bath was quite far away and quite congenial in a sense because it's quite similar to Edinburgh. We had very good tutors at the University of Bath. One doesn't always know it at the time. So. I'm happy that I went to Bath It's small enoug to actually have a Bommunity feling it is campus university but the to feeling. It is far away, and there's a lot of architecture there So you're always subjected to it. It's a sois you re always subjected to it. t's a poisoned chalice at times, but at the part of your study. Th course itself was part of your study. The course itself was he first two years, and and architects in leading the leading the school at the time. He had valuable insights to give us as architects, bu it also set us on a track to consider archtecture as being a collaborative proces involving others like the engineers. But it didn't really matter to what extent they were involved, it was more that one already perceived it to be that... And yourself an Richard Padovan, Patrick Hodgkinson and Keith Bradley - we had some very good architects, each with their own focus to comment on our work and guide us in the right direction.

I remember you making a bench which led to an interesting conversation about economy and robustness in terms of making.
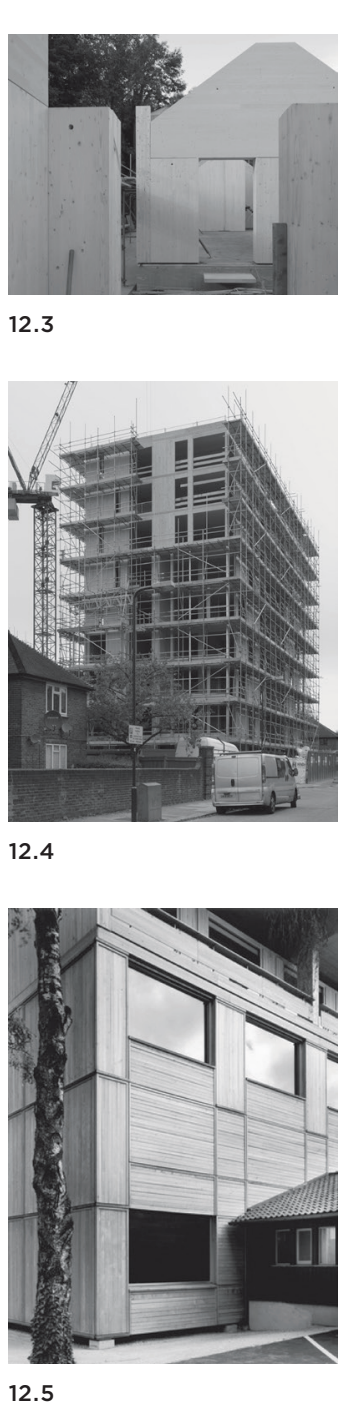

12.3 Shatwell, Hugh Strange
Architects/Eurban, 2014. I Source:
Photograph by David Grandorge.

2.4 Press House, Geraghty

Taylor/Eurban, 2017. I Source:
Photograph by David Grandorge.

12.5 School of timber engineering
Meili Peter Architekten/Eurban

1999. I Source: : Photograph by

1999. I Source.
Georg Aerni.
That bench still exists. It's at my father's. I saw him speak in Basel, and I was just Yes, there was craft involved in our very interested in what he had to say. He tus ally mention were my fellow students. architecture (although he is an engineer). We had a relatively small year, and it was So, I felt that as I was doing my learning, a very interesting year. There were a lot this was a person who could teach and who of different people, including Erasmus I could learn something from. So, I applied, students which made for an interesting and he accepted, and the next thing, I was dialogue. I particularly remember some up in a ski resort. Herzog \& de Meuron of Steve Tompkins's briefs... I remember was only 15 people when I joined and 50 one had a wine stain on the front cover. when Ileft So, there was quite a big iump in You know, they were creative briefs. We the year that I was there. That was 1995-6. were interested in trying out newideas, and And then 1996-7, I was at Conzett's. There experimentation was allowed. Computers were a number of bridge projets in the did exist in our fourth year. We were in that office. So, I was helping draw those. I was dransition based, and we were working in an Alison

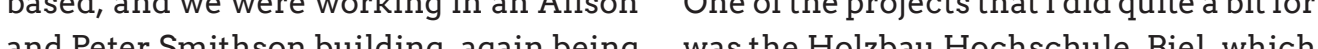
and Peter Snithson building, again being was the Hof ba Hochschle, Bill, which subjected archicts as architectural practice, and I think it all Switzerland at the time. It was for timber Wo the mix

Working for Jurg Conzett and Herzog \& de Meuron after Part 2 came about because Patrick Hodgkinson wrote letters introduc-
ing me to them to get an interview, and the ing me to them to get an inter that I could speak German helped. M fact that I could speak $\mathrm{G}$ in the end becaus I could speak German and because I was prepared to put my hand to anything. When they had visitors from other countries, was showing them around the Herzog \& de Meuron buildings, and I was able to parbeing held that excluded English speakers. Herzog \& de Meuron are quite hierarchical in the office, and I didn't quite fit in any box particularly well. So, I was allowed to upset the hierarchy.

Conzett started working for Peter Zumthor in his office; he is an engineer. engineers in Biel, and their new build-

ing was an with with acoustic perforations. It was an interoject because it was all based on looking at the cost benefits of different tone for wat in in Chur, which was a primitive hut where the floor plate was given. It was a square, which I wasn't particularly happy about, with a pyramid roof, but as Jürg said, that was one of the most primitive ways of doing it. And most of the timber came from the site itself. So, we ended up putting logs on their ends and cutting them down, tongueand-grooving them and insulating with 
some Lewerentz-type glass details, but it it was hemp insulation or even grass insuended up looking quite Japanese, I think, lation. There's a whole bunch of projects because of the formality that was forced that were the first in the UK using certain upon it. materials that had been developed on the

I was thrown out of Switzerland, not continent and were cutting edge at their because I'd done anything wrong but time, but that no-one had heard of in this because the market picked up, and I was country. One certainly got an introduction an outsider. So, my work permit wasn't to building biology - the idea that there is renewed. I went to the UK, and I looked actually some sort of relationship between for a practice to do Part 3. There were a the building and the people who migh number of us who were project architects inhabit it on another level than purely all roughly the same age, with the same aesthetic. One also saw how contractors experience, doing mainly residential were largely uninterested in what clients work for Part 3 . work for Part 3. had a chance encounter wanted to do or indeed what the architects hen found ways ecause I had ordered various sustainable not to do it.

timber products from them. They were

Is that something which you think is more particular here than, say, on the because they were German products. So, it was of interest. I wasn't really building

much. I was doing interior fit-outs. So, I I think it's easier here due to the way that thought at least this is a way of getting buildings are procured. I think it's to do with more involved in construction. And I quite the business model as well and, again, it's enjoyed the materials and felt that I was very much about what people's interests learning about the materials that they use, are. Unfortunately, a lot of builders in this and having direct access (being the dis- country are not that interested in building. tributor in the UK for some of these large Eurban got started almost out of frustracompanies on the continent), I/we would tion at the apathy towards architecture and have direct access to good technical infor- construction from the contracting side. mation and discussions straight from the For anyone who's interested in design, it's people who know best. It meant travelling almost the end of a process. If one doesn't to the source companies, doing training get to that end, it's very unsatisfying. If it courses and preparing English literature remains on the drawing board, one doesn't for them because it didn't exist. It was all deliver what one had hoped. So, it was a way in German. So, that meant that I did need of short-circuiting that in a sense, but also to understand it, as I needed to translate remaining in the delivery side I I ay it often it for an English market In terms of what now: life's too short. I wasn't saying it then we an English innovative materials at the time whether frustrated at how slow things were. I could

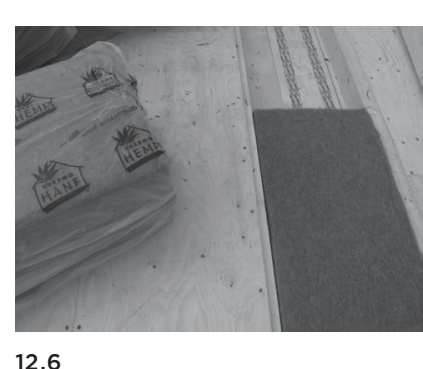

12.6

12.6 Hemp insulation.
Source: Image courtes

of Eurban. think quicker than things would happen and therefore, there was always a delay in things. That's just a personal thing that happened but there was certainly a feeling at that time that This is obvious, and why don't people see it?' and 'Well, if they don't see it, then we'll do it anyway'. Our first projects were a little bit in that vein in the sense that we were offering to do other complicated things because no-one else wanted to do them, but it gave us an entry into doing what we think is actually very simple. We just had some tough projects at the beginning. Our first contractor went une beginning. Our firtcon that was unfort to be fair but it could have gone so ber to be far, but could have gone so badly wrong if we hadn' done that because that project But again, it shows you project. But again, it shows you the whole risk involved in the process, which isn necessarily your own competence, but it's just to do with the fact that you're so subservient to others in terms of whether it's going to be a success and whether you're going to be able to do what you want to do. And think the same is true for architects. A lot of their frustration is the fact that it's not the architects' competence, it's just their ability to actually deliver to what they can delive It's frustrated by various others who actively turn things so that things don't happen. So, the whole idea of collaboration, I think, is a question. As much as one could aspire to it, there is a question as to whether people are capable of it.

We've evolved remaining largely curious. We've been slow to pin ourselves particularly to be one thing or anothe because we didn't really fit that well into the typical traditional procurement route. We were a consultant on the one side, we were a contractor on the other side, and what tended to happen was that consultants thought of us as contractors, and contractors thought of us as consultants, neither of which was good. So, it didn't really matter what we did. It was all to do with how the people viewed us. Being an architect, I was very surprised at how we were being treated by other architects because, again, it wasn't anything to do with the fact that they didn't know, it was just the fact that they thought, 'Well, we look down at you because you're 'ower down in the food chain', and contractors cert asubcons of the law So, it's very easy for them to do

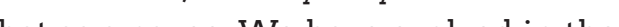
the hor for people to dismiss us in hat the could in the ens had people who have supported us.

Eurban was set up in 2003, but there were certain key projects in the beginning where it was of course collaboration. I was very much working with the architect and, you could say at times, with a naive client, but that's kind of what was required. They weren't stupid, they just weren't affected by the way that things typically happen. So, they were just naive to how much a contractor could change something and were therefore more willing to trial what we were proposing and to their success as much as to ours. So, we did have those sorts of successes, and it did enable us to start building higher: five storeys in 2005 , which was sort-of un soard of in the world at the time. Then, once we got traction, 
there were others who came to compete mainly because architects were unhapp as to there only being one. Suddenly, you come up against all of these things you didn't quite expect when you set out, which is that people are actually very unhappy if they don't have the choice, even though you're offering alternatives to some of the There's a sort of fear in society of bein ripped off or whatever else and a lack trust, and a lot of what we do does depend on trust. If we don't have the trust, depen send a lot of time doing stuff that's ren we spenda lot of ine don the trust, her weally do that, but we notice it, and the larger the clients are, the more annd he larger the chents they don't trust us. Actually, it's because they don't trust themselves -it's more of a they don't trust themselves -it's mor

We no longer use consultants or contractors. We decided that they're not helpful in that context. So, we do refer to ourselves as being specialists in the field
of solid timber, and that then allows one to provide a stronger synthesis between the designer team and the contracting side. And the collaboration is more of delivery; it's more of process rather than about trying to bring people together. And the material is the medium. I mean, I've heard it described in lots of different ways,
and one always looks for one way to bes describe what it is and how one can work it. I mean, it is a medium as an artist has mediums to use So, it is one of a number of things that they could be painting with, let's say. And one chooses to use it or not. The issue is more that if one does choose to use it, one makes that decision and doesn't think one can wait until halfway throug the painting before one decides what one medium they're working with. Artist certainly wouldn't do that, but for some reason, architects feel that they're able to do that because of planning or because they don't get the confidence. It's very strange, this lack of feeling towards their tools or the materials that they're actually going to use. Because it's such a base material an is relatively primitive (it's one of those fundamental materials), it has technological advances that means it tas technological issues, particularly moisture, which is no is issu but it requires a , which is not to deal with moisture - with timberience to deal with moisture - with timber on doesn't have. So, it's a primitive material ners in the sense that som of the ners in the sense that some of the more risky aspects of it have been removed. But that then almost makes people fearful of in the sense that it's too good to be true and then there's no grid, so there's very little to hang on to as well. So, one sort of ends up with this material that's actually ideal; it's this ideal architectural material that you can do whatever you want with it, but like the tabula rasa, it doesn't necessarily give people confidence. It worries a lot of people, and they start looking for questions and looking for reasons not to use it rather than just accepting that it is an ideal material. And the final aspect, which is actually the wheel driver, is that as a crop, as a material that you're harvesting to use for something its utility value is best placed with the architect because it's worst placed by burning tect because it's worst placed by burning it. In 1968, Reyner Banham introduces
Environment with a parable about the tribe who want to create shelter for the night and they have a choice: they either use the timber to make a hut or a shelter, or they burn it. And he states that architect tend towards the structuralist approach which is to use it as structure and as the building envelope rather than as an energy source. But, of course, as time goes on, the energy side, the idea that architecture's all about energy, the technical approach seems to be quite prevailing. A lot of what's happening now is very much driven by that; architecture's very subservient to energy, which I completely disagree with I do hop that a some point we overcome this and actually realise that there is an abundance actually realise that there is an abundance of energy; we just don't really know how to harness it. But energy's not a problem, whereas there's not an abundance or good architecture. That's actually the thing that we should be focusing our energies on Those are the two sides of what you can do with it, but what's interesting about that, which Banham doesn't talk about, is the fact that in burning, it releases carbo immediately, whereas building with stores it for 60-100 years.

We have a huge issue just now. On the one side, we're trying to build more housing, and on the other side, we're trying to reduce our environmental impact. Now, construction's one of the greatest increase on the impact. So, how on earth can we increase construction while at the sam time reducing the impact? Well there's only one way and that is to build in timber. There is just no other option. You've got to do something at source you can't just make it an externality. So, th driver. It's not simply a question of architects' choice. It's kind of an obligation that's imparted upon the architect as the person who's deciding to use timber unless they've got a good reason not to. And there is good reason why one doesn't use it, whether it's because of the ground conditions or whatever else (it wouldn't necessarily perform for that 60 years). But in most instances, timber does perform as long as it's proected, and as a rule, it should be protected, and it should be robust. And again part of the architect's responsibility is to detail and design it so that it is protected. With regard to the technology, I talk the use of less timber rather than more is all about an economic material and of course economic means financial. Now, some would argue that less material is ood bouse ral but that defeats the story on the ide We actully have a lo of timber, and we we no to use it. And this is sustainable we'retal it's premised on the fact that wood forest a crop here, not a hardwood forest in the Amazon. So, the idea that you're using more timber is because the timber is a multi-performing matehal, it's not just structure. We have to get beyond 'structure.'So, a lot of people do look at it as a structural solution. It's not; it's a construction solution -it's a method of construction. At that point, one is dealing with, again, what an architect deals with, which is all of the performances of strength achieved, as well as the arrangement and the context and the other aspects. And once you start looking at it in terms of thermal, moisture, ir tightness-all of these 
things - then you suddenly realise that this it doesn't have the moisture movement that more complex. This isn't just a single, you'd otherwise get across the board, whic one-trick pony. And it's exactly for that is quite significant in a piece of timber. reason that more is better because the Along the length, it's not significant at all more material that you have, the better that but radially and tangentially it is. So, that's it can do those things. It's more durable. really the development.

And this high-tech approach is the opposite The technology is actually the same as for me and was very much the British way in the glulam, and the reason for glulam to use it as structure and then to try and get is because you don't have such large trees it down to the minimum. But in the timber anymore. So, you have to use smaller bits industry, that's meant that everything's of timber. You get better utilisation out of been reduced to the absolute minimum, smaller bits. You can use younger trees, so that any failure becomes a catastro- and you can use more of the tree. The smal so that any failure becomes a catastro- and you cans phe because there is nothing there left to component of glue (which is less than 1 per protect against human error or against cent) is the main environmental issue of unexpected circumstances. And that's a a glulam component, but it would be a lo very high-risk way of building. It's not a less environmental if you tried to dowel it very durable way of building, and we need together with glue or screw it together. So to start looking beyond it. It certainly is it's the most environmental way of intronoticeable. People do now talk about life ducing bits of timber together.

cycles. They do start understanding that In the UK, we're importing from It's not simply about today, it's about tomor- Switzerland, Austria and Germany, but row, and that's another example why we factories exist in Norway, Sweden, Finland, have to build more robustly. Our biggest Eastern Europe, Canada, Australia and New issue in Britain is that we have such old Zealand. Legal and General are setting up stock, and there's a reason that it's still a company to import boards and manuthere: it's because buildings are meant to facture here and in Scotland. There is a last. But equally, it means that we've got an argument to say that Scotland shouldn't obligation to this stock in the future, not be planting low-quality timber or the sor simply today.

So, the cross-laminated material is different from, let's say, a wood cabin, which is lots of timbers dowelled together or butted together in a big board, because it has the cross-lamination. So, it uses small sections of timber, and rather than creating a glulam beam, it creates a panel. So, it's panelised rather than linear which of course is ideal for a building enclosure rather than frame. And because of cross-lamination, of timber that you'd make boards out of With spruce, you get much better yields in a place like Sweden than you would in a place like Scotland because of the landscape. One has to think of this as a crop and choose which crop to grow based on the context. A higher-value timber as such is hardwood. Cherry, for example, would be and then it wouldn't be used for tima panels, and the issue of transporting the a better solution for a place like would be

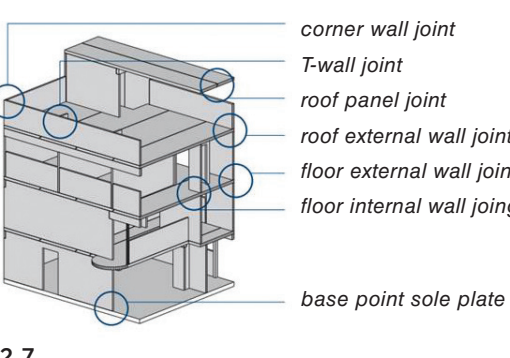

12.7

12.7 Luigi Snozzi, Guidotti House 1984. Eurban axonometric drawing illustrating how the
original concrete house could built using cross lamininated timb
as a sustainable alternative form of construction. I I source: Image
courtesy of Eurban.

(20)

materials is always a question as to how local is it. When it comes to moving timber you can move it five times as far as concrete because of its weight $\mathrm{So}$, you can get five tonnes more on a lorry for the same environmental impact. But then, equally, people start shipping things once you start talking about larger quantities. Timber is often shipped around the world. So, then you have very low impact, actually.

Currently, our work is housing, spe cifically for mid-rise which is anything between 4 and 10 storeys. There are cheaper ways to do low rise like timber frame. It's not as if house builders aren't interested in this, it's just that their driver is cost, and the value is in the land. The industry here is about speculation. Fritz Schumacher was aware of this back in the 1970 s and proposed ways of changing this, but unfortunately, we are still dominated by the whole speculative market, and all that happens is that people try to manipulate the speculation by subsidising rather than addressing it. In this context, once you get to medium rise, the competition is no longer the lightweight SIP panel timber frame or cheaper methods. You're talking about more serious construction methods such as concrete, and then it's in that sort of context that some of the inventors are really coming through because there's a lot less disruption than when you build in solid timber. There are a lot more deliveries for concrete frame construction. There are more people on site. There is more noise on site, more dust. It's much slower. So, actually, what happens is that the costs are not necessarily different, but the disruption is a lot less, and the programme is a lot less and therefore the cost should be less or certainly the return should be quicker. It's for that reason that we have now delivered number oflarge, mid-rise residentialproects with $100+$ units in London because of the market.

The way that houses are sold in this cuntry, people tend not to have much panies are beginning to prefer occupying entative However, people are very uninformed when it comes to purchasing a house and have very few rights in that purchase. For example, a structural warranty that only lasts as long as the collateral warranty of the design team is not worth anything, particularly when there are $£ 2$ billion worth of claims a year against these companies. Clearly, it's not a system designed to really protect the consumer. So, I'd like to see an opening up of that market because it's necessary. And I'm waiting on that revolution in a way. There's now communication media that allow people to find other ways of learning rather than simply believing what they're told. I think that's a good thing people are also now being overwhelmed 
with information. It means they're incapale of making decisions these days because here are just too many conflicting bits information out there.

but it introduces an idea of dialogue and o position. It also is very much to do with an approach to the world that (not from a sustainable side but from a cultural side) he's very much addressing these very importan

You wrote your dissertation at Bath on aspects about when we do something as Luigi Snozzi. I thought it was a brilliant architects, we actually have quite a signifipiece of work. How did your interest in cant impact whether we like it or not, and Snozzi begin?

we should take that seriously. It's a privilege to build. And one often feels that other

I wrote my dissertation on Liugi Snozzi people who are building just simply don't at Bath, and I've started to think that I've understand what responsibility they've been influenced by him. One doesn't been given and are almost irresponsible always know what attracts one to certain in the way that they perform their duties. architects. I mean, all of his work is in con- I live in a 1960s tower block, and I'm crete. You could argue how curious it is constantly fighting against the devaluthat someone who does so much in timber ation of the asset - the putting in of started off writing about someone who does plastic windows to replace the meta so much in concrete. There a a similarity windows - and I feel why are we so happy there, and part of what I was picking up to discard the good work that was don on was the fact that the material medium then? And where is the continuity? You wasn't as important as what was being said. really have to look for it, and fortunately, He came up with the idea of the Alternative I can afford to buy architecture books so Project, which was a critique of the brief in that I can look at them to understand wha the form of a project. To a degree, we also people were doing, but where is this in eduhave an element of that where one wants cation? I think about what we're doing now to proactively do something to introduce and it'simages, it'sinformation-there's no change and one doesn't necessarily see depth to it. We don't know where it's going. what one's doing to the end result, but one I mean, there is interesting stuff happenfeels that it's important in order to deliver ing in housing. It's happening in places a change over a period of time. And in that like Japan where they're just conceptually same sort of way, it's a critical approach. very active and perhaps because they don't Now, whether you then take to mean it's a have planning to disrupt them as much as political approach, I'm not so sure. we would here. In Switzerland, because

What I like about Snozzi is the fact that they respect it more and they're prepared he's not scared of having this opinion; he's to write proper briefs, it's funded by the not scared of taking a position. He's not in councils, so from the government. There that English way of avoiding the potential was a silent beauty in Brutalism, and it is conflict. He's quite allows you to either react or agre to it the buldings thatwe're producing It's all (a) ( step in and say, 'No, our cultural heritage and our cultural future is not all about money'. We can't simply say that 'banks pay for art' and link them that way. That's not healthy. We need to set standards. Snozzi in Monte Carasso was trusted to deliver a good quality of work there, as was Giancarlo De Carlo in Urbino. They were hard-nosed modernists in their way and did a bad job, people wouldn't like it, and
so it was a brave move. But it also enabled something to change and to happen in development and there's a scen hion in one can one cansa to make allowa one ne to to fail, but by doing so, you also have the it's this sort of idea that you can control everything. The totalitarian approach is wrong, and that whole social side of things seems to have gone out of the window: how, then, at Atelier 5 it wasn't about consulting with the community, it was about architecture and its social responsibility. And Neave Brown was quite critical about Halen, but I'm not sure how, 50 years later, ne can say it's a failure. Neither would I necessarily say that Neave Brown's work's failure. I think Neave Brown's very good, but it's interesting that even at that time, you've got two people who we now look you've got two people who we now similar in terms of what they were delivering but who were not actually agreeing on want to be? We want to have people who re batting for the right side, pen if they very different players. 

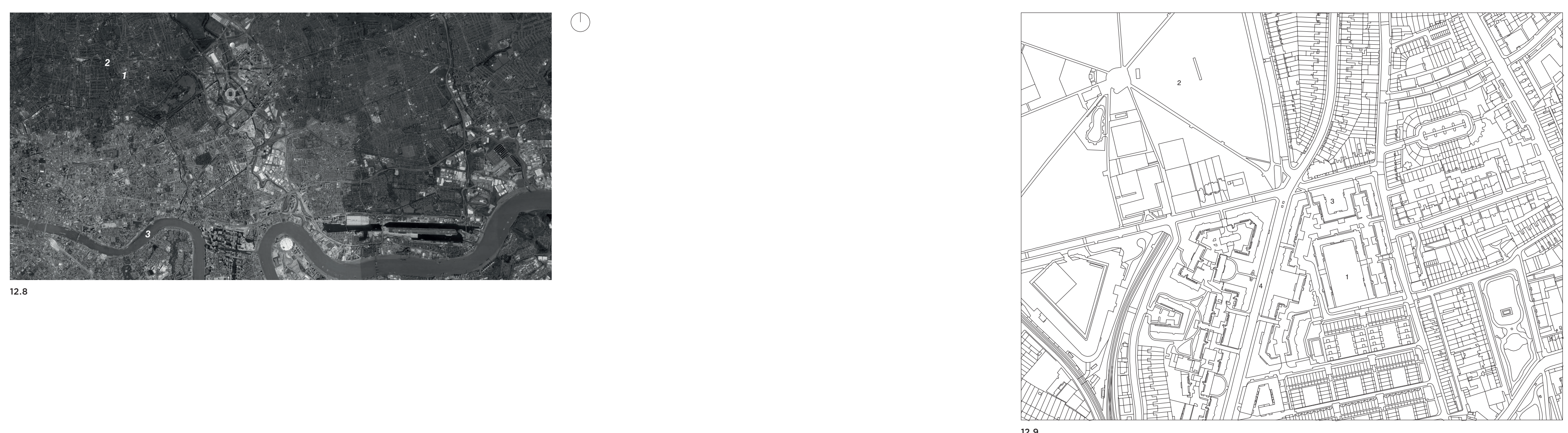

12.8 Central and North-Eas

courtesy of Google Earth.

1:100,000

1. Site
2. Hackney Downs
3. The River Thames

1.5ite

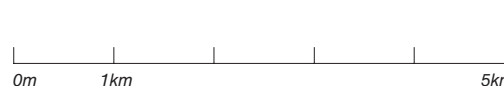

2. Hackney Downs

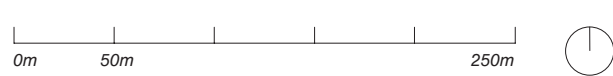




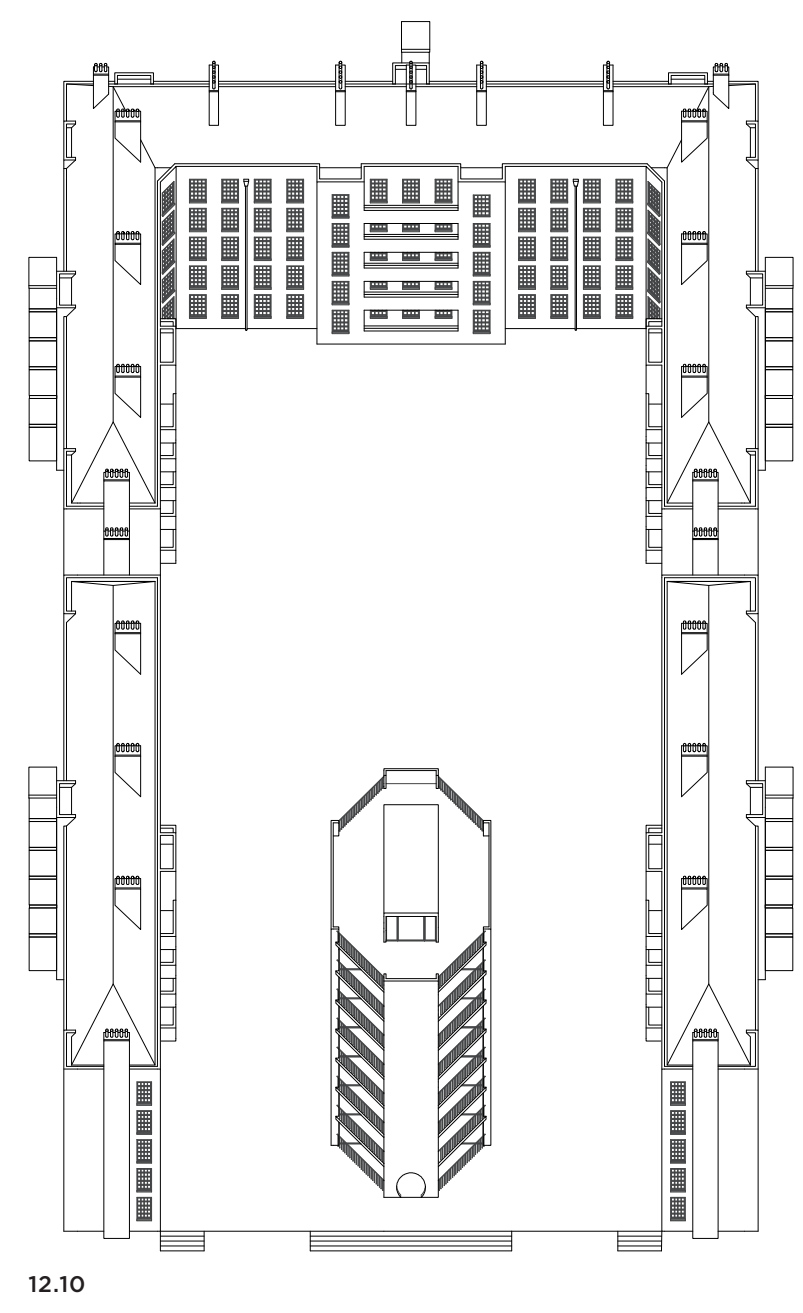

$$
\text { ion }
$$



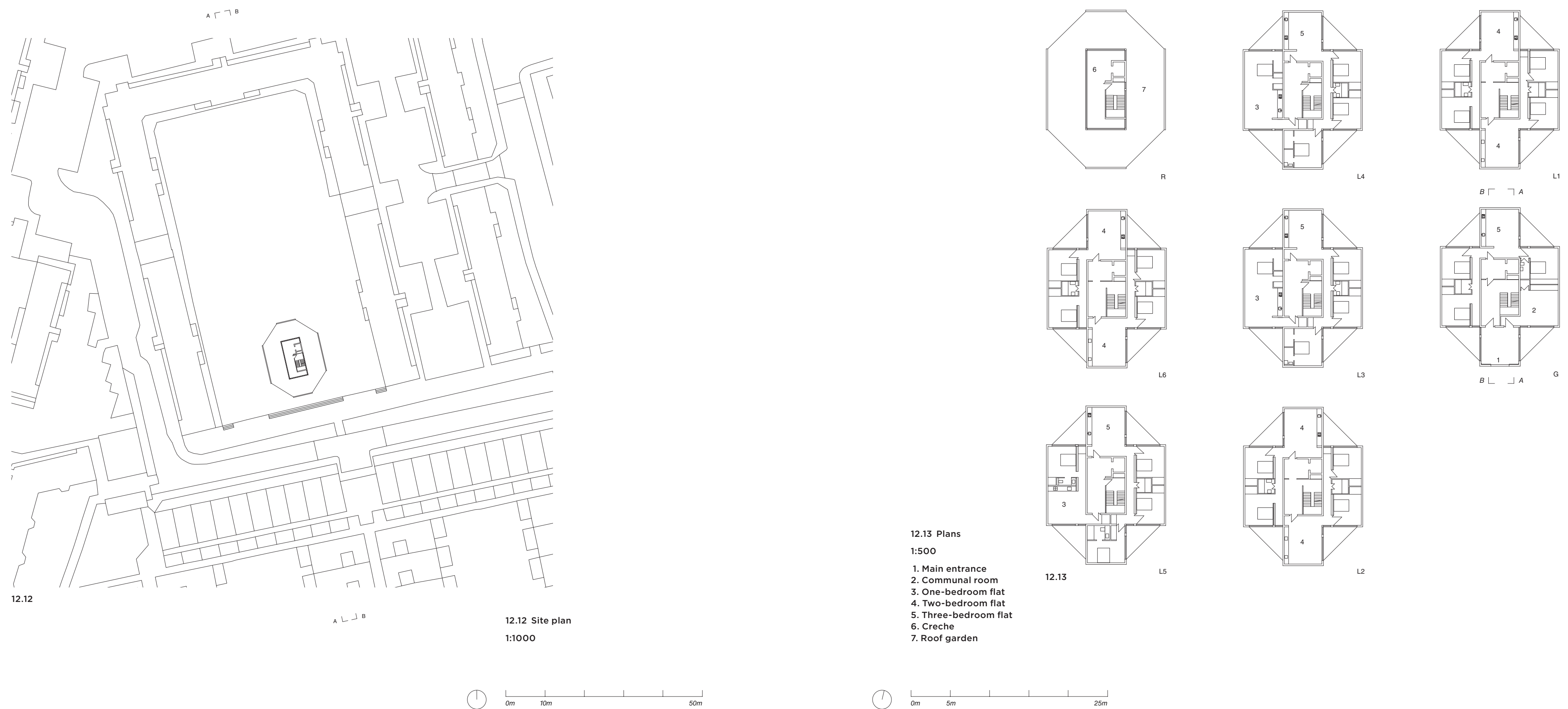

(1)

1:500

1. Main entrance
2. communal roo

2. Communal room
3. One--eedroom flat
4. T. Tho-bedroom flat

4. Two-bedroom flat
5. Three-bedroom fla

6. Creche
7. Roof garden 

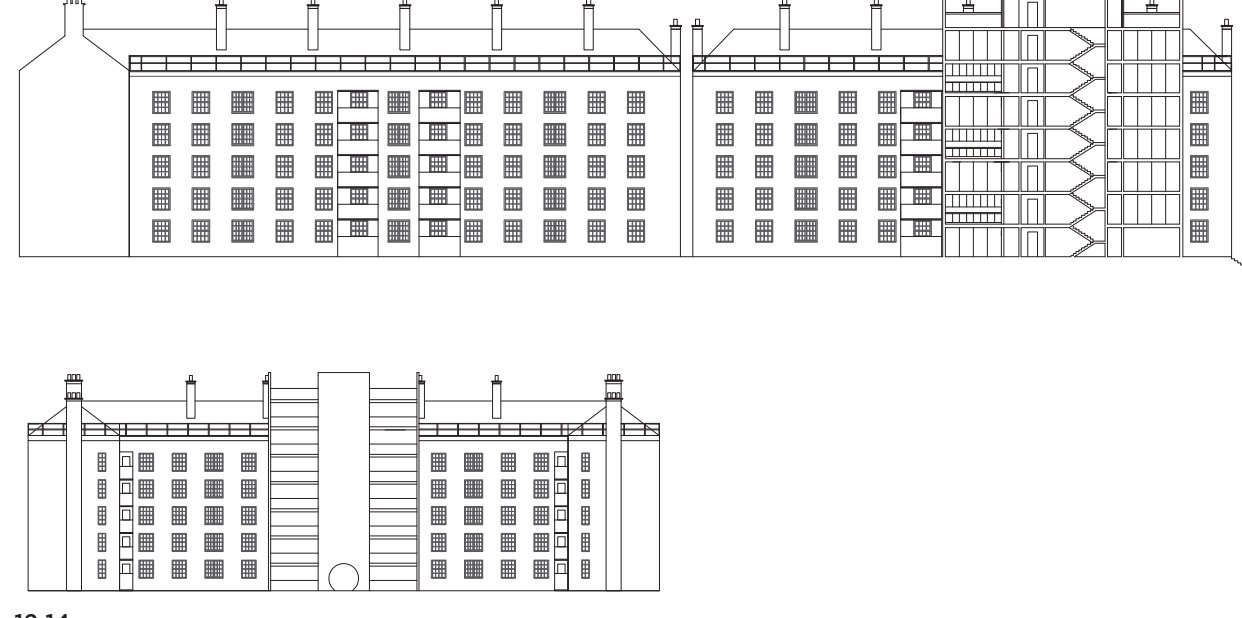
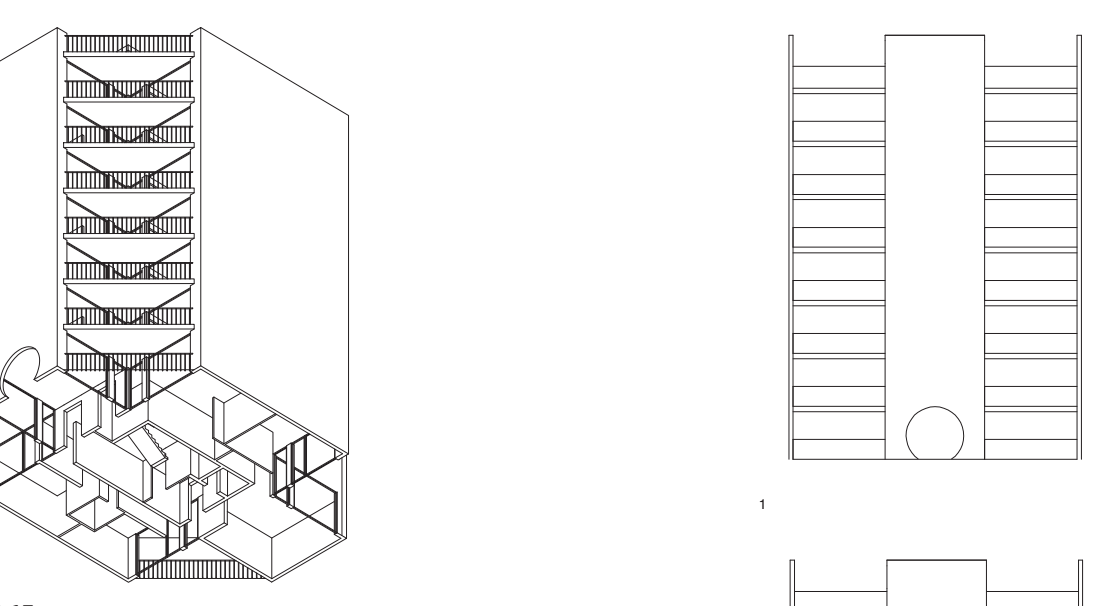

12.15

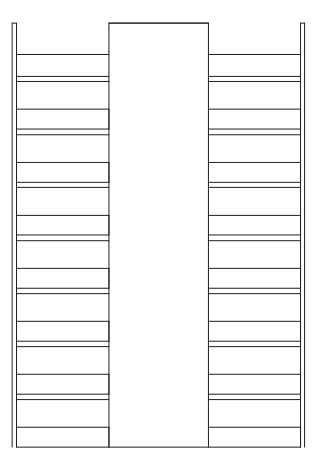

1:500

12.16 Elevations and sections

1:500

1. Front elevation
2. Rear elevation

3. Section $A A$
4. Section $B B$

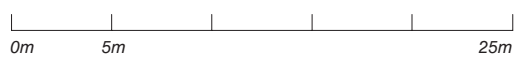

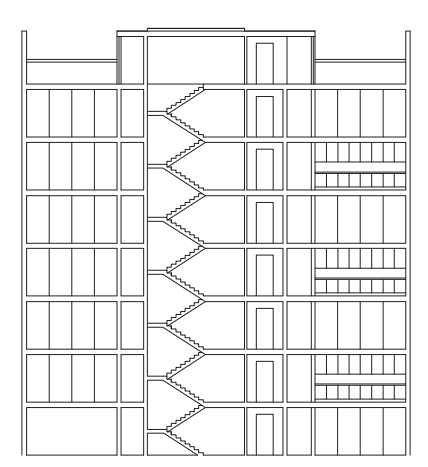

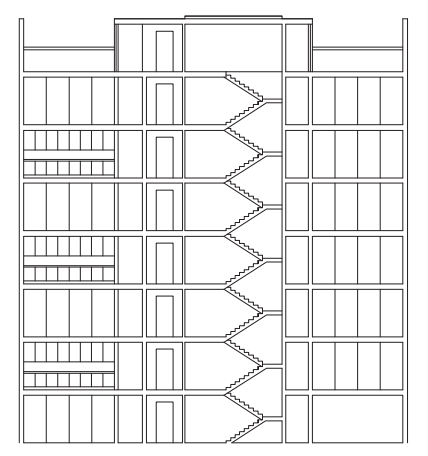




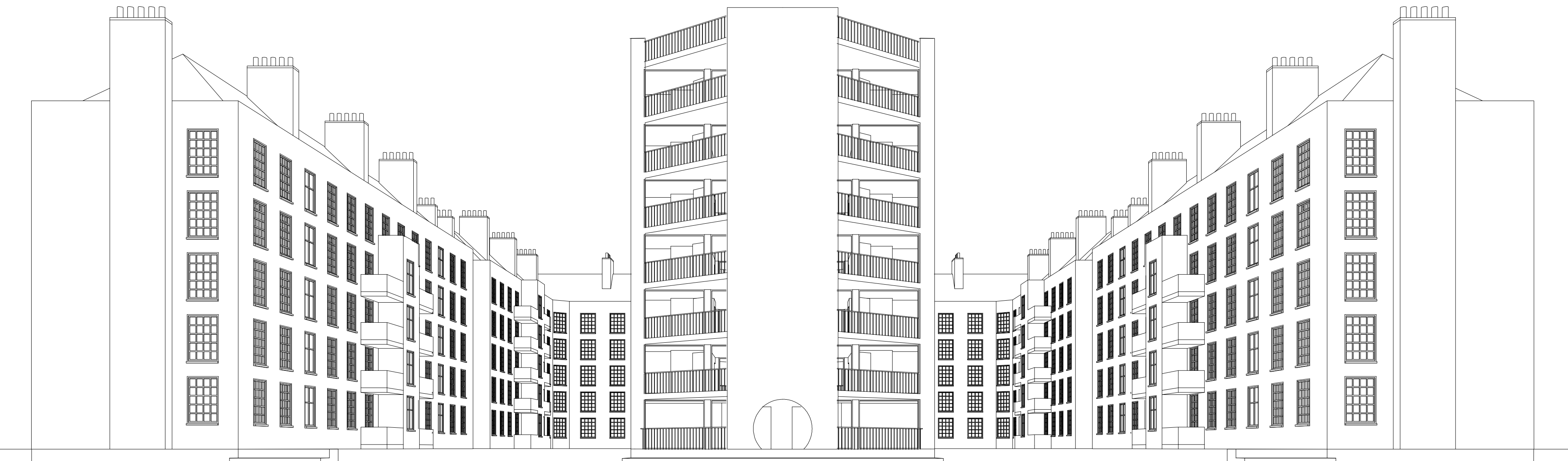




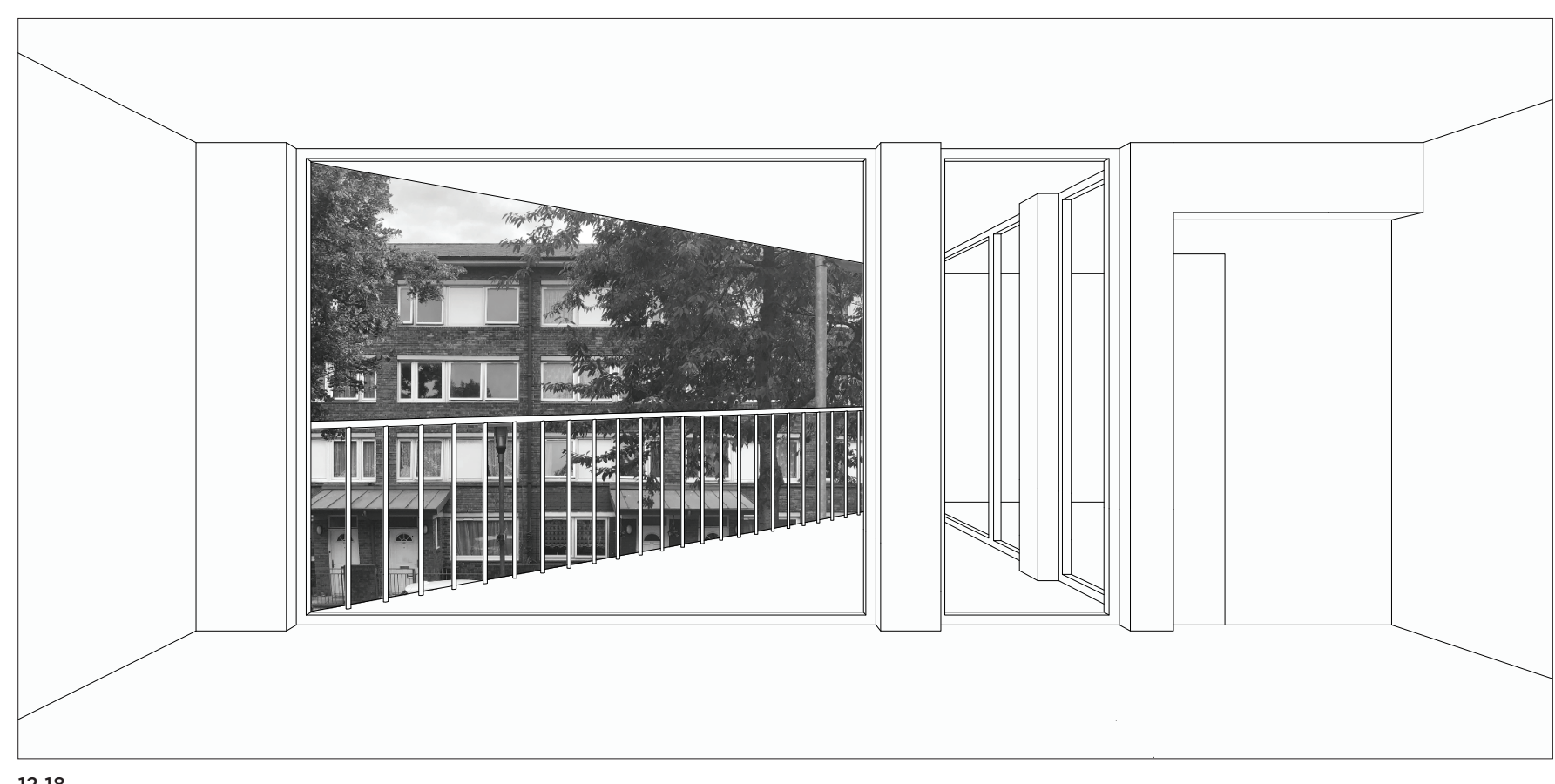

12.18 Third-floor bedroom

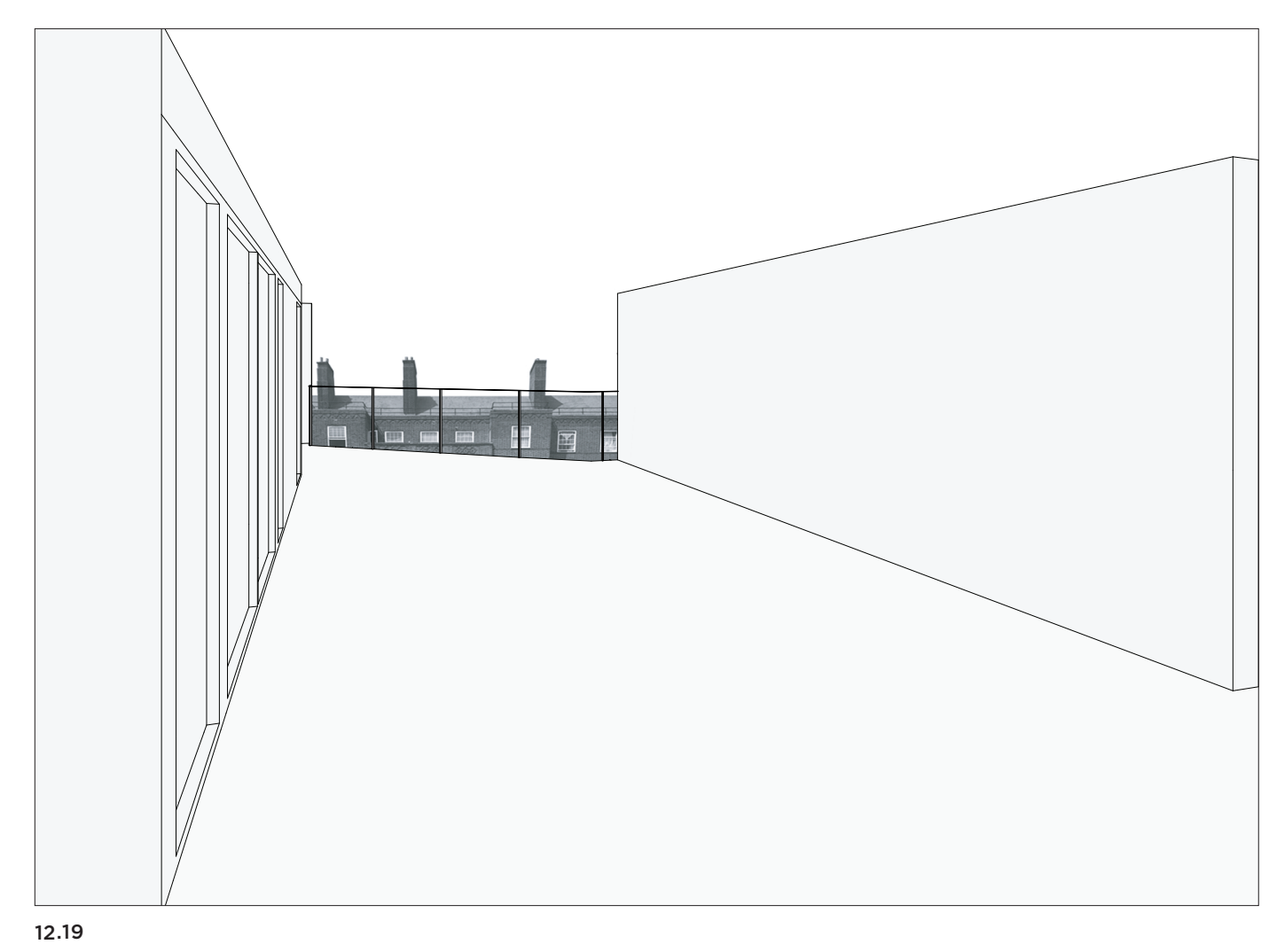

12.19

12.19 Roof garden 
Dwelling on the Future

It is easy to feed the pessimism of the intel-

lect, but it is important to find sources of

hope to keep fuelling the optimism of

the will. And the best basis for optimism

might ultimately be the strangeness of the

situation we find ourselves in... There are

junctures in history when the elements

come unstuck and rearrange themselves

of events becomes impossible to predict.

Time moves raggedly, in leaps and rup-

Time moves raggedly, in leaps and ruptures. Another
(Tarnoff, 2018)

English Journey by J. B. Priestley was

published in 1934. He referred to it a

'Being a rambling but truthful accoun

of what one man saw and heard and felt

and thought during a journey throug

England during the autumn of the year

1933'. Priestley's journey begins at the

seaside in Southampton and Bristol. He

travels through the Midlands to Yorkshire,

Lancashire and the North-East before

lived, via Lincoln and Norfolk. Dwelling on

the Future echoes this trajectory Englis

Journey was written to commission and

probably 'conceived as a travel bon and

the popular sort' (Bainbridge, 1987, vii).

At the time it was written, Priestley was hugely popular with the public, with Middle

England, and this probably accounted for

sunpopularity with the literary establish-

ent, including Waugh on the right and

Orwell on the left Priestley writes that he

had seen a lot of Englands. How many?

... once, three disengaged themselves from

shifting mass ' 'He identifies, first, England th century and third, England (bers far more to the age itself than to this paricular ticular island. America, I supposed, was its real birthplace' Meillen Isup be in Priestley's terms the fourth England or even the fifth or sixth, given the accelrating pace of change that is taking place in a globalised world where even the USA's prepotent influence has waned and dissipted, as a myriad of competing cultural narratives declare themselves in the age of the Internet. The impact has dissipated the influence and authority of the centre which Middle England and the provens always deferred. However, an nti-authoritarian mistrust with the centre, the metropolis, which has to some extent always been there, as ways of life in rural England and the post-industrial Midlands and North have been undermined by economic forces beyond national borders, has led to anger and resentment of disaffected 
J.P.PRIESILEY

English Sourney

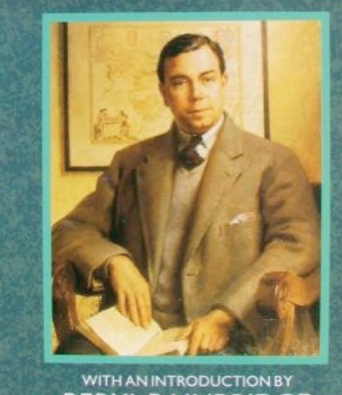

communities unable to provide for and the valley of the Slaughters that he 'thought $\begin{array}{ll}\text { maintain themselves in an age of auster- } & \text { these two villages, Lower Slaughter and } \\ \text { ity and global migration. We appear to } & \text { Upper Slaughter, beautiful before, and }\end{array}$ ity and global migration. We appear to Upper Slaughter, beautiful before, and
have a political system that is incapable think them so still. They should be preof engaging with a society in which family served for ever as they are now. A man and personal life has become increas- bringing a single red tile or yard of coringly individualised and employment rugated iron into these two symphonie less secure and more fragmented. The of grey stone should be scourged out of complexity of the situation is discussed by Ulrich Beck in Individualization: '. we cannot think about societies as we did before, as existing within the container of the nation-state with clear boundaries and relationships with others. We have to think globally. People are no longer living en simply local cultures any more' (Beck viewees in this book are evidence, even with such a small sample, of the range of mixed backgrounds and identities including Anglo-Welsh, Scots-German, Anglo-Irish, Franco-Indian-Irish, AngloArgentine, Kenyan-Indian, Anglo-Swedish as well as English, that contribute to th body politic and create a national idenity. The interviews themselves, althoug deliberately informal and discursive, have elicited a wide range of responses to the current housing situation. The aim has been to record narratives of personal an professional life focussing on the projects documented in this book in order to provide a commentary and wider understanding of the conditions for the production of contemporary architecture.

Priestley in English Journey describe the changes to landscape and the built fabric of the villages, towns and cities and reflects on his visit to the Cotswolds and the district' (Priestley, 1934). The dilemm for architects, for Middle England and for most of us is the innate understanding we have of Priestley's symphonic, conservative vision of continuity exemplified by the Coswold village in exe 1930s and its corollary in vilage in the 1930s and it choices we have available to us now. Thi manifests itself in the new marials and construction posal in the design and production of the puilt environment, offering built environment, ofering perhaps too much choice. There is also the confidence the wider public-individuals-now have in their own taste and judgement to take an active role in the determination of their own domestic environments. An Englishman's home has always been his castle, but increasingly with his own choice of 'knobs on'. For architects, it has certainly becom problematic to design houses and homes in such a pluralistic scenario in order to accommodate conflicting requirements of individuals and community, and within the institutional context of the welfare state, the nation state and a work-oriented society. The quality of architecture and especially housing provision is a reflection of the current situation, and has led to a povert of expectations amongst the general public and the construction industry including the architectural mainstream, so much so that most people 'expect to live in a crap brick box and so they do' except the well-todo who used to include a shrinking middle class. As Simon lenkins has pointed out, in England, it is all about class (Jenkins, 2016). In the aftermath of the Second World War working-class communities were broken up, and many rehoused in local authority tower blocks. Many of these are substantial works of architecture and provide decent accommodation. However, a lack of management and maintenance, as well of management and maintenance, as well as supporting communal facilities, has le to the towers, as well as other forms of social housing, being demonised and discredited. There is nothing inherently wrong in building high. It is possible to build better towers a amenities for more than just the rich, just as it is possible to build new settlements with houses supported by appropriate and necessary community, commercial an industrial infrastructure instead of

Mean little boxes dotted around dead end streets with no shops or amenities. It's not just the layout either, it's the quality. Outside you'll have crap bricks, crap concrete tiles, crap plastic windows and crap detailing. Enter through the pvc door with its twee Edwardian glass, noting the plastic carriage lamp. The hallways will have cottage height ceilings, with a faux Victorian staircase and stunted Georgian skirtings made of mdf. The living room will boast a fire surround that apes some period between 1720 and 1920 and looks like it was made on a 3d printer... (Proud, 2014)
The lack of joined-up thinking on the environment, including provision of decent physical and social infrastructure which embraces new models for homes and housing, is a problem that is actively addressed in schools of architecture and increasingly by recently qualified young architects. This generation is developing strategies to engage with the status quo in an attempt to bring about muchneeded change from inside the system, but increasingly the situation calls for a radical reconsideration of the availability of land on which to build sustainably. It laso requires a parallel inition (a) crought into full use for the people who broug in ned it most and in ways in which their duty of ar a d respons to the qure and responsibility. One returns to the question posed by Le Corbusier in question of building which lies at the root of the social unrest of today'. Le Corbusier saw architecture as a means of avoiding revolution. It seems, however, that a revolution has taken place over the last 40 years in the sense that the civic has been increasingly diminished, and that architecture, including house building, has increasingly een avoided, and so have architects. The housing crisis is systemic and not just limited to house builders. We urgently need to redress the increasing inequality in our society being instigated by the Establishment in Britain -a demonstration of its evident disdain for the wider populaion. We must urgently reconsider to the way we make provision for housing and the 
built environment which now most impor- has increased drastically over the las tantly includes the land outside our cities. 10 years of aust

Franco Berardi suggests that human pletely extinguished the space and time for emotions and embodied communication considered cultural production. Further become increasingly central to the pro- to this, massive increases in the cost of duction and consumption patterns that land on which to build homes to buy or sustain flows of capital in post-industrial rent has contributed to endemic cultural society, and that 'the solution to the eco- conservatism and subservience to the nomic difficulty of the situation cannot be market model for delivery of housing and solved with economic means: the solution is not economic' (Berardi, Genosko and Thoburn, 2011). Mark Fisher discusses a diminishment of expectations in the 'sheer persistence of recognisable forms', despite the massive changes of the last 30 years brought about by the transnational restructuring of the capitalist economy during which:

the environment generally.

$$
\text { Dwelling on the Future proposes a }
$$

wide range of models for housing that offer informed choices and invite meaningful collaboration atevery point in the process, so that we may materialise liveablocess, ronments at every scale, avilable for all. An inclusive vision of housing for everyone should be a fundamental roquirement should be a funda requirement in the shift into so-called Post-Fordism-with the twenty-first century. It is worth stating, globalisation, ubiquitous computerisation political and it is most evident in the way and the casualization of labour - resulted that land has been systematically been priin a complete transformation in the way vatised in the UK over the last few decades. that work and leisure were organised. In It is a criminal scandal that since Margare the last ten to fifteen years, meanwhile, the Thatcher became prime minister in 1979, internet and mobile telecommunications some two million hectares of public land echnology have altered the texture of eve- about 10 per cent of the entire British lan ryday experience beyond all recognition. mass, has been sold off to the detrimen Yet, perhaps because of all this, there's an of the majority of the British population increasing sense that culture has lost the (Christophers, 2018).

ability to grasp and articulate the present. The answer as to how to reverse the Or it could be that in one very important situation can only come from below. It will sense, there is no present to grasp and not be a top-down initiative, given that the articulate any more. (Fisher, 2014)

politicalclasses almost everywhere are now completely compromised and ultimately discredited by their corrupt relationship with global capital almost to the point of with global capital, almost to the point of derangement and self-destruction. We need a new groundswell of public expec-

He goes on to suggest that the current neo-liberal system has systemat deprived artists (and architec resources necessary to produce

The ideological attack on public new socio-democratic settlement similar to society focussing on properly funded and the one that politicians responded to in the rewarded production in order to create postwar period and then went on to create and maintain a more equable society. This the welfare state. The situation calls for includes the creation of inspiring well huspolitical initiatives to activate 'green' indus- banded environments, including housing, trial policies to help establish a post-carbon in which we may all dwell equably. 


\section{Aberystwyth Arts Centre}

Architecture: Pierre d'Avoine Architects

(Pierre d'Avoine, Clare Melhuish, Alex

Bank, Chris Thorn. Alex Tsangarides)

Structural consultant: Atelier Ongarides)

Chadwick, Dave Morison)

Quantity surveyor: Dobson White

Boulcott (Phil Boulcott)

Environmental consultant: Max

Fordhant consultant: $M$ ax

Fordham LLP (Guy Nevill)

\section{Pleasure Holm at Birnbeck Island}

Architecture and landscape: Pierre

d'Avoine Architects and WYG (Pierre

d'Avoine and Jonathan Vining). Pier

d'Avoine Architects: Ana Nicolaescu

Sebastian Tiew, Mo Wong. WYG:

Kirsten Anderson, Phillip Bryan,

Gordon Lewis, Carlos Nicolini, Siân

Rookwood, Matt Williams

Structural consultant: Atelier One (Aran Chadwick)

nvironmental consultant: Max

Fordham LLP (Bill Watts)

Client: Urban Splash

\section{Crowcombe Court}

Architecture and landscape: studioDA

(Pierre d'Avoine, Anne-Marie Cifsza

Marie Jorgenson, Bodo Neuss, stian Tiew, Mo Wong, Diana

Zaharia)

Client: Pat Smith and Richard Anderson

Historic England: Kim Auston

Bengough's House

Architecture: WYG (Jonathan Vining

Kirsten Anderson, Gareth Lewis,

Carlos Nicolini, Siân Rookwood, Dean

Summers and Paul Thomas with

Pierre d'Avoine)

Client: Bristol Charities (David Jones)

\section{Glastonbury Houses}

Architecture: Pierre d'Avoine Architects (Pierre d'Avoine, Ryan McStay, Sebastien Tiew)

Landowner: Edward and Jane James Property adviser: Nick Oliver, Cooper and Tanner

A Counterproposal for Belper

Architecture and landscape: studioDA (Aslihan Carapapoulle, Pereen

d'Avoine, Pierre d'Avoine)

World Heritage consultant:

$$
\text { Barry Joyce }
$$

Local history consultant: Adrian Farmer

Belper Urban Forum: George Jones,

$$
\text { Pippa Mansel }
$$

Transiton Belper: Ian Jackson 
Swaythling Housing

Architecture and landscape: Pierre 'Avoine Architects (Pierre d'Avoine, Carlos Cottet, Greg Ross)

Structural consultant: Atelier One (Aran Chadwick)

\section{Crouches Field}

Architecture and landscape: studioDA (Pierre d'Avoine, Ryan McStay, Jame O'Brien, Andrew Power, Hawar Sagalo, Sebastian Tiew, Joseph Van der Steen Amelia Baldie, Rachel Buckley) Construction advice: Eurban (Liam Dewar)

Dever: Baylight Properties plc (Crispin Kelly, Jim Green)

Client and landowner: John Wickham

\section{Patterns for Letchworth from Garden} City to Patchwork City Architecture. studioDA (Pierre d'Avoin Pereen d'Avoine, Siobhan O'Keefe)

\section{House + Garden + House}

Architecture: studioDA (Pierre d'Avoine, Jo Greiveine, Ana Nicolaescu,

Sebastian Tiew)

Client: Jess Rayat (Pierre d'Avoine, Kuo Jze Yi, Colette Sheddick, Mo Wong)

Structural consultant: Atelier One (Aran Chadwick)

Environmental consultant: Max

Fordham LLP (Max Fordham)

Rights of light consultant: Scahtunowski Brooks

Client: Baylight Properties plc (Crispin

$$
\text { Kelly) }
$$

\section{Pembury Octagon}

Architecture: studioDA (Pierre d'Avoine, Pereen d'Avoine, Kate Tomlinson

Urim Islami)

Client: The Peabody Trust

\section{Book Drawings Team}

Glover, Jo Greviene Georgia Hazblutzel, Eleanor Lygo, Ryan MCStay, Bodo Neuss, Ana Nicolaescu, Geeta Pandit, Elena Pardo, Erika Pietrovito, Andrew Skulin Sebastian Tiew

\section{References}

Abley, I., and Heartfield, I. 2001. Sustaining Chichester, UK: John Wiley.

Amsler, Sarah. 25 February 2010. The

Times Higher Education Supplem last modified 31 May 2020, https//www timeshighereducation.com/books

/ Bainbridge, B. 1987. Introduction to English Journey, by J. B. Priestley. London: Penguin

Danham, R 1968. The Architecure of (n) IL: University of Chicago Press.

Banham, R., P. Hall, C. Price, and P. Barker. 1969. 'Non-Plan: An

Experiment in Freedom'. New Societ

[online] (338). Available at: https://

architecturesofspatialjustice. .wordpress.com/2013/09/w08_barke thinking_the_unthinkable.pd (accessed 7 February 2019).

Barker, P., and P. Lewis. 2009. The Freedoms of Suburbia. London: Frances Lincoln.

Beck, U., and E. Beck-Gernsheim. 2003. Individualization. London: Sage. Bellos, D. 1999. Jacques Tati. London: Harvill.

rardi, F G Genosko, and N Thobu 2011. After the Future. Oakland, CA. AK Press.
Bloomer, K., and C. Moore. 1979. Body, Memory, and Architecture. New Haven, CT: Yale University Press. Blundell Jones, Peter, 1978. Hans Scharoun: A Monograph, p. 128 London: Gordon Fraser

Boyer M. Christine, 1996 . Cyber Cities. New York: Princeton Architectural Press.

enell, Michael. 1998. England Is Mine: Pop Life in Albion from Wilde to Goldie. Flamingo.

Cahill, K. 2002. Who Owns Britain Edinburgh, UK: Canongate. . 2014. Urban Economics and Urban Policy: Challenging Conventional Policy Wisdom. Cheltenham, UK: Edward Elgar.

Christophers, B. 2018. The New Enclosure. New York: Verso.

Clifford, J. 2002. The Predicament of Culture. Cambridge, MA: Harvard University Press.

Davies, C. 2006. The Prefabricated Home. London: Reaktion Books. Deller, I., and R. Malbert. 2013. All That Is Solid Melts into Air. London: Hayward Publishing.

Desmond, R., and C. Ellwood. 1977. Dictionary of British and Irish Botanists and Horticulturalists 
Including Plant Collectors, Flower Painters and Garden Designers. London: CRC Press.

Douthwaite, R. 1992. The Growth Illusion Dublin: A Resurgence Book in association with The Lilliput Press Ltd.

El Lissitzky, L. 1930. Russia: An Architecture for World Revolution. Cambridge, MA: MIT Press.

Elyot, T. 1531. The Boke Named the Governour. London: T. Berthelet. Fisher, M. 2010. Capitalist Realism. Winchester, UK: Zero Books. Fisher, M. 2014. Ghosts of my Life. Winchester, UK: Zero Books. Glass, R. 1964. London: Aspects of Change. London: MacGibbon \& Kee Quoted in Melhuish, C. 2015. Case Quoted in Melhuish, C. 2015. Case Studies in University-Led Urban Regeneration. London: Laboratory.

Goodchild, R., and R. Munton. 1985 Development and the Landowner. London: Allen \& Unwin

Gooding, M., and C. Richards. 2002. Cer Richards. Moffat, UK: Cameron \& Hollis.

Graham, D. 2012. 'Matta-Clark's Inspiration and Sources in Architecture', In Gordon Matta-Clark Moment to Moment: Space, edited by P. H. von Amelunxen, A. Lammert, and G. Matta-Clark. Vienna: Verlag fur moderne Kunst Nurnberg.

Hall, P. 1973. The Containment of Urban England. London: Allen and Unwin [for] Political and Economic Planning.

Hamdi, N. 2009 Small Change. London: Earthscan.
Harries, K. 1998. The Ethical Function of Architecture. Cambridge, MA: MI Press.

Harvey, D. 2008. Spaces of Hope

Berkeley: University of California Press. Healey, P., and R. Nabarro. 1990. Land and Property Development in a Changing Context. Aldershot, UK: Gower.

Jenkins, Simon. 26 January 2016. 'Simon Jenkins: Panic over a Property Crash

Will Just Jeave London Poor and

Ugly' Evening Standard, London.

https://www.standard.co.uk/comment

/comment/simon-jenkins-panment -property-crash-will-just-leave-over-a propraly-3165241 tavi london 31 May 2020).

akov, I., and E. Kabakov. 2001. Not Everyone Can Be Taken into the Future [Installation]. Vienna. MAK Wein.

velly, Crispin. 2009. Unpublished interview with Clare Melhuish for Lan Architecture People exhibition at Royal Danish Academy of Fine Arts, Copenhagen

Klingmann, A. 2007. Brandscapes.

Cambridge, MA: MIT Press

Lafargue, P. (1883) 2011. The Right to $B e$ Lazy. Chico, CA: AK Press.

Leach, N. 1999. The Anaesthetics of Architecture. Cambridge, MA: MIT Press.

Le Corbusier, and J. Cohen. 2009. Toward an Architecture. Los Angeles, CA: Getty Research Institute.

Linklater, A. 2002. Measuring America. London: HarperCollins.

London Borough of Hounslow. 2010

Hounslow Local Plan. London
Borough of Hounslow. https://

democraticservices.hounslow.gov.u

/documents/s119024/Appendix\%20

1\%20Hounslow\%2OLocal\%2OPlan\%20

Version\%20for\%20Adoption\%20

September\%202015.pd

(accessed 31 May 2020).

Lonsway, B. 2009. Making Leisure Work:

Architecture and the Experience

Economy. London: Routledge.

Martin, Geoffrey. 2003. Introduction

to Domesday Book: A Complete

Translation. London: Penguin Books.

Melhuish, C., and P. d'Avoine. 2005.

Housey Housey: A Pattern Book of

Housey Housey. A Pattern Book of

Ideal Homes. London: Black Dog.

Mitchell, J. 1984. Women: The Longest
Revolution. London: Virago.

itchell, W. 2007. 'There Are No Visual Media, In Media Art Histories, edited by 0 . Grau. Cambridge, MA. MIT Press Monbiot, G. 11 October 2017. 'How Labour Could Lead the Global Economy out of the 20th Century'. The Guardian. https://www.theguardian.com /commentisfree/2017/oct/11/labour -global-economy-planet.

Mumford, L. 1963. Introduction to

The New Towns: The Answer to

Megalopolis. Edited by F. Osborn and A. Whittick. New York: McGraw-Hill. New Towns Act. 1946. London: HMSO. Norwich, J. 1975. Great Architecture of the World. New York: Random House. Orwell, G. 1937. The Road to Wigan Pier. London: Gollancz.

Pevsner, N. 1958. South and West

Somerset. London: Yale University

Press.
Priestley, J. 1934. English Journey. London: Gollancz.

Proud, A. 2014. Why Is Britain So Terrible at Domestic Architecture? The Telegraph [online]. https://www telegraph.co.uk/men/thinking-man /11092924/Why-is-Britain-so-terrible-at -domestic-architecture.html (accessed 7 February 2019).

Raworth, K. 2018. Doughnut Economics. New York: Random House Business. Said, E 1978 Orientalism. New York: Pantheon Books.

Sieverts, T. 2003. Cities without Cities: Between Place and World, Space and Time, Town and Country. London: Routledge.

Sudjic, D. 2016. 'Whatever Happens to Bra, London Whill Remain a City State.' Evening Standard [online]. https://www.standard.co.uk/comment /comment/deyan-sudjic-whatever -happens-to-britain-london-will -remain-a-city-state-a3326606.htm (accessed 20 March 2019)

Tarnoff, B. 2018. 'The Next Left'. Guardia Review, https://www.theguardian com/books/2018/dec/17/the-next-left -socialism-in-the-uk-and-the-us.

Tati, J. (director). 1949. Jour de Fête [film] France: André Paulvé Fred Orain. Town and Country Planning Act. 1947. London: HMSO.

Tschumi, B. 1996. Architecture and Disjunction. Cambridge, MA: MIT Press. Venturi, R. 1977. Complexity and Contradiction in Architecture. New York: Architectural Press/Museum of Modern Art. 
Ward, C. 1990. Talking Houses. London Freedom Press.

Ware, 1.1735. A Complete Body of Architecture. London: T. Osborne \& J. Shipton.

Watts, K. 1997. Outwards from Home. Brighton, UK: Book Guild.

Williams, A. 1993. 'Bath School

of Architecture' (unpublished

dissertation).

Williams, R. 1993. The Country and the

City. London: Hogarth Press.

Williams, W. C. 1966 'A Sort of a Song',

The William Carlos Williams Reader, edited by M. Rosenthal. London: MacGibbon \& Kee.

Wilson, A., and R. Hamilton. 2011

Swingeing London 67 (f). Cambridge,

MA: MIT Press.

Woudhuysen, I., and I. Abley. 2004.

Why Is Construction So Backward?

Chichester, UK: Wiley-Academy.

Zhuangzi. 2009. Zhuangzi. Translated by

B. Ziporyn. Indianapolis, IN: Hackett

Publishing Company.
Image Credits

While every effort has been made to trace 0.11 Goyal, A., Brabourne Stadium,

and acknowledge all copyright holders, we online, accessed on 12 October 2019,

would like to apologise should there have https://commons.wikimedia.org/w/index

been any errors and omissions. If your work .php?search=brabourne+stadium\&title

is uncredited please contact the publisher $=$ Special\% $3 \mathrm{ASearch \& g}=\mathrm{GO} \& \mathrm{n} \mathrm{NO}=18 \mathrm{~ns}$

so it can be credited. $\quad=1 \& n s 12=1 \& n s 14=18 n s 100=18 n s 106=1$ t $=12 \mathrm{~ns} 12=12 \mathrm{~ns} 14=12 \mathrm{~ns} 100=18 \mathrm{~ns} 106=1 \mathrm{~A}$ media/File:Cricket_Club_Of_Ind

0.6 Duchamp, M. 1913, Parade From Pier Herne Bay, postcard, Lecnbachhaus, Bergmann.

0.7 Hackney Downs overground station

online, accessed on 18 March 2019,

https://anonw.com/2011/08/19/hackney

-downs-station/dscn5592/

0.8 Swingeing London, book cover,

Wilson, A. (2011), London: Afterall Books.

0.9 Surveyor's chain, online, accessed on

13 September 2019, https://www.qld.gov

.au/recreation/arts/heritage/museum-of

(c) The State of Queensland 2019

0.10 Portrait of postman François painted

on a shop window in Saint-Sévère-sur-

Indre, Allymcpatate, online, accessed

on 12 October 2019, https://commons

wikimedia.org/wiki/File:Le_village_de

Saint-S\%C3\%A9v\%C3\%A8re_Indre)

Lieux du tournage de \%22jour de

f\%C3\%_Ate\%22_de_J_o22jour_de

JPG, Crative Commons Attribution-

Share Alike 40 International
Attribution 2.0, the image has been adapted for reuse.

0.12 Director General of the Ordnance

(183), Twick of the Ord d

Survey (1863), Twickenham, map, Director General of the Ordnance Survey, Southampton.

.12 Director General of the Ordnance Survey (1915), Twickenham, map, Director General of the Ordnance Survey, Southampton.

0.12 Director General of the Ordnance Survey (1934), Twickenham, map, Director General of the Ordnance Survey, Southampton.

1.1 Director General of the Ordnance Survey (1880), Aberystwyth, map, scale 1:1800, Director General of the Ordnance Survey, Southampton.

1.1 Director General of the Ordnance Survey (1900), Aberystwyth, map, scale 1:1800, Director General of the Ordnance Survey, Southampton.

Survey (1930) Abat of the Ordnance
1.1 Director Genpton. 
1:1800, Director General of the Ordnance Survey, Southampton.

1.1 Director General of the Ordnance Survey (1960), Aberystwyth, map, scale 1:1800, Director General of the Ordnance Survey, Southampton.

1.3 Frank Vining's pots, photographs, Courtesy of Gwyneth Vining

1.4 1963, Aberystwyth Arts Festival

poster, collection of Jonathan Vining

1.5 Vining, J., 2001, Courtyard house,

photograph, $\odot$ Jonathan Vining

1.6 Vining, J., 1999, Courtyard house up

view, drawing $Q$, Courtyard hou

17 Vining 1974 , Gateway mega-graph-

(

Iins in Aberdare, photograph, $\odot$ Jonathan
Vining

1.8 Stewart Bale Ltd., 1970, Exterior view of Aberystwyth Arts Centre, photograph RIBA Collections.

1.9 Percy Thomas Partnership, 1935-66, Sections and site model, Aberystywth University Campus Penglais,

Aberystwyth, drawing and photograph, National Monuments Record of Wales. 1.10 Google Earth, 2017. Aberystwyth coast, 1:10,000. Google Earth [online]. Image $\odot$ DigitalGlobe.

2.1 Director General of the Ordnance Survey (1880), Birnbeck Island, map, scale 1:2500, Director General of the Ordnance Survey, Southampton. 2.1 Director General of the Ordnance Survey (1900), Birnbeck Island, map, scale 1:2500, Director General of the Ordnance Survey, Southampton. 2.1 Director General of the Ordnance Survey (1930), Birnbeck Island Survey (1930), Birnbeck Island, map, Ordnance Survey, Southampton.
2.1 Director General of the Ordnance Survey (1950), Birnbeck Island, map, scale 1:2500, Director General of the Ordnance Survey, Southampton.

2.4 Piper rooftop house under construction, online, accessed 20 March 2019, http://thepiperbuilding.co.uk/gallery .html

2.7 Scottish Island Explorer, 2017, Stack Lee Boreray, photograph, accessed on 12 February 2019, http://john-humphries .blogspot.com/2017/07/hamlet -mountaineering htm

27 Webb, R. West side of Stac an Armin, photograph, accessed on 17 Septer po19, https//Www. orguk/photo/1441490, O Richard Webb, Creative imative Commons Attribution 2.0, 27 Ireland, M. Triassic fan reuse 2.7 Ireland, M. Triassic sandstone Clifs at Ladram Bay England, photograph, accessed on 17 September 2019, https://commons.wikimedia.org/wil /File:Triassic_Sandstone_Cliffs_at _Ladram_Bay_England.jpg, @ Mark Ireland, Creative Commons Attribution 2.0, image has been adapted for reuse. 2.7 Standard Rock, photograph, accessed on 18 March 2019, http://www.orkney -seastacks.co.uk/standard.htm, @ Iain Miller.

2.7 Pennington, M. Out Stack from March 2019, https://www geograph or .uk/photo/5522166 @ Copyright Mike Pennington (cc-by-sa/2.0), the image has been adapted for reuse.

2.7 Strangeway. A. Rockall, photograph

accessed on 18 .

wikiwand $\mathrm{com} / \mathrm{n} / \mathrm{Rock} / \mathrm{O}$ (
Commons Attribution-Share Alike 2.0, the image has been adapted for reuse 2.7 Hawgood, D., Queen Bess Rock, Bedruthan Steps, photograph, accessed
on 19 September 2019, https://commons .wikimedia.org/wiki/File:Queen_Bess _Rock,_Bedruthan_Steps_-_geograph .org.uk_-_54649.jpg, @ Copyright David Hawgood, Creative Commons Attribution-Share Alike 2.0, the image has been adapted for reuse.

2.7 English, P. Old Harry Rocks, photograph, accessed on 14 September 2019 https://squirrelbasketwordpress 2019 , -picture-galleries/my-favourite-places -in-dorst/old -157298 o OC Copyight Pat Bnglish, the inase - Copyright Pat English, been adapted for reuse.

2.7 Freshwater Bay, photograph, $\odot$

Classic Cottages, 2018

2.7 Drinking dragon calf of man, pho-

tograph, accessed on 18 March 2019,

https://twitter.com/BespokelOM/stat

1885534948085694465, @ Bespoke

Recruitment Limited.

2.9 Google Earth, 2017. Birnbeck Island,

1:20,000. Google Earth [online], Image Landsat/Copernicus.

2.18 Grandorge, D. Model without carapace, photograph, @ David Grandorge. 3.1 Director General of the Ordnance Survey (1880), Crowcombe, map, scale 1:1800, Director General of the Ordnance Survey, Southampton

3.1 Director General of the Ordnance

Survey (1900), Crowcombe mance

1.1800, Director General of the Ordale

Survey, Southampton.
3.1 Director General of the Ordnance Survey (1930), Crowcombe, map, scale 1:1800, Director General of the Ordnance Survey, Southampton.

3.1 Director General of the Ordnance Survey (1970), Crowcombe, map, scale 1:1800, Director General of the Ordnance Survey, Southampton.

3.3 Google Earth, 2019. Crowcombe Court aerial view, Google Earth [online], Image Landsat/Copernicus.

3.4 Auston, K. Saltram Devon, photograph, (C) Kim Auston.

3.11 Google Earth, 2016. Crowcombe Court and environs, 1:80,000. Google Earth [online], Image @ 2019

Getmapping plc.

4.1 Director General of the Ordnance Survey (1880), Henbury, map, scale 1:5000, Director General of the Ordnance Survey, Southampton. 4.1 Director General of the Ordnance Survey (1900), Henbury, map, scale 1:5000, Director General of the Ordnance Survey, Southampton. 4.1 Director General of the Ordnance Survey (1930), Henbury, map, scale 1:5000, Director General of the Ordnance Survey, Southampton. 4.1 Director General of the Ordnance Survey (1950), Henbury, map, scale 1:5000, Director General of the Ordnance Survey, Southampton. 4.9 Google Earth, 2017. Bengough's House and environs, 1:50,000. Google Earth [online], Image Landsat/Copernicus. 5.1 Director General of the Ordnance Survey (1880), Wearyall Hill map scale 1:1800, Director General of the Ordnale Survey, Southampton. 
5.1 Director General of the Ordnance Survey (1900), Wearyall Hill, map, scale 1:1800, Director General of the Ordnanc Survey, Southampton.

5.1 Director General of the Ordnance Survey (1930), Wearyall Hill, map, scale 1:1800, Director General of the Ordnance Survey, Southampton.

5.1 Director General of the Ordnance Survey (1960), Wearyall Hill, map, scale 1:1800, Director General of the Ordnance Survey, Southampton.

5.4 Director General of the Ordnance

Survey, Geological Map of Glostonbury Survey, Gelogical map, scale 1.50,000, Director General the Ordnance Sum 5.5 Google Earth, 2017. Glastonbury s and environs, 1.20,000. Google Earth [online], Image 2019 DigitalGlobe. 6.1 Director General of the Ordnance Survey (1860), Belper, map, scale 1:7500 Director General of the Ordna Survey, Southampton.

6.1 Director General of the Ordnance Survey (1900), Belper, map, scale 1:7500, Director General of the Ordnance Survey, Southampton.

6.1 Director General of the Ordnance Survey (1930), Belper, map, scale 1:7500, Director General of the Ordnance Survey, Southampton.

6.1 Director General of the Ordnance Survey (1950), Belper, map, scale 1:7500, Director General of the Ordnance Survey, Southampton.

6.2 APEX, 2014, Tesco hoarding land and buildings on area big enough for 15,000 homes, photograph. The Guardian. 63 Meadows Edge Studio, 2014, King studio exhibition invite, poster.
6.4 Barry Joyce with Princess Margaret in

Wirksworth, photograph, Barry Joyce.

6.5 Barry Joyce and town councillor an chair of town regeneration project,

photograph, Barry Joyce.

6.6 World Heritage List Nomination

2000, document cover, Barry Joyce.

6.7 Strutt Mills, Map of Belper, map.

6.8 Carapapoulle, A., Belper North Mill

photograph.

6.9 Allen, C., East Mill, Belper Taken

before the fine chimney was demol-

ished after a lightening strike in

1990, online, accessed on 12 Oct

https://come, accessed on 12 October,

/index comp?

index.php?search=belper+mill\&title

-Special\%3ASearch\&go=Go\&ns $0=1 \&$

$=1 \& n s 12=1 \& n s 14=1 \& n s 100=1 \& n s 106$

=1\#/media/File:East_Mill,_Belper_Commons Attribution.

6.10 Google Earth, 2017. Belper, 1:30,000. Google Earth [online], Image Landsat/ Copernicus.

6.12 Google Earth, 2017. Belper, 1:40,000 Google Earth [online], Image Landsat/ Copernicus.

7.6 Grandorge, D., Ideal Home Show,

photograph, $\odot$ David Grandorge.

7.7 Grandorge, D., DIY back to 'Slim

House' prototype, photograph, @ David Grandorge.

7.8 Ghahremani, K., Kohn, M., Ely, A.,

'Hangar House' winner Concept House 2000, photograph, @ Katy Ghahremani

Michael Kohn and Alex Ely.

7.10 Mayor of London, 2010, London

housing design guide, interim edition,

document Agency.
8.1 Director General of the Ordnance Survey (1890), Crouches Field, map, scale 1:2500, Director General of the Ordnance Survey, Southampton 8.1 Director General of the Ordnance Survey (1900), Crouches Field, map, scale 1:2500, Director General of the Ordnance Survey, Southampton.

8.1 Director General of the Ordnance Survey (1930), Crouches Field, map, scale 1:2500, Director General of the Ordnance Survey, Southampton. 8.1 Director General of the Ordna Survey (1960), Crouches Field, Surve (1250), Crouches Field, map, scale 1.2500, Director General of Ordnance Survey, Southampton. 8.10 Google Earth, 2017. Horsmonden, 1:25,000. Google Earth [online], Image Landsat/Copernicus.

9.1 Director General of the Ordnance Survey (1880), Letchworth, map, scale 1.20,000, Director General of 9.1 Director General of the Ordnance Survey (1900), Letchworth, map, scale 1:20,000, Direc General of the Ordnance Survey,

Southampton

9.1 Director General of the Ordnance Survey (1930), Letchworth, map, scale 1:20,000, Director General of the Ordnance Survey, Southampton. 9.1 Director General of the Ordnance Survey (1960), Letchworth, map, scale 1:20,000, Director General of the Ordnance Survey, Southampton. 9.3 Ebenezer Howard, 1898, The three magnets, diagram. In: Howard, E. (1965) Garden Cities of Tomorrow, edited by F. Osborn. Cambridge, MA: MIT Press. 9.4 Ebenear Howard 1898, GaT Pros 9.4 Ebener Howad, 1898, Garden city
(1965). Garden Cities of Tomorrow edited by F. Osborn. Cambridge, MA MIT Press.

9.5 Frith, F., 1965, Aspley Guise square, online, $\odot$ Francis Frith, accessed on 21 March 2019, https://www.francisfrith .com/aspley-guise/aspley-guise-the -square-c1965_a161041, the image has been adapted.

10.1 Director General of the Ordnance Survey (1860), Feltham, map, scale

1:2500, Director General of the

Ordnance Survey, Southampto

10.1 Director General of tore

Survey (1890), Feltham map scale

1.2500, (1890), Feltham, map, sca

Ordo, Director General of the

101 Director Gey, Southampton.

.1. Director General of the Ordnance

Survey (1930), Feltham, map, scale

1.2500, Director General of the

Ordnance Survey, Southampton.

.1 Director General of the Ordnance

Survey (1960), Feltham, map, scale

1:2500, Director General of the

Ordnance Survey, Southampton.

10.11 Google Earth, 2018. Feltham

1:40,000. Google Earth [online]

Image $\odot 2019$ DigitalGlobe.

11.1 Director General of the Ordnance Survey (1860), Wandsworth, map, scale 1:2500, Director General of the Ordnance Survey, Southampton. 11.1 Director General of the Ordnance Survey (1870), Wandsworth, map, scale 1:2500, Director General of the Ordnance Survey, Southampton. 11.1 Director General of the Ordnance Survey (1900), Wandsworth, map scale 1:2500), Wandsworth, map, Ordnance Survey, Southampton. 
11.1 Director General of the Ordnance Survey (1910), Wandsworth, map, scale 1:2500, Director General of the Ordnance Survey, Southampton 11.3 Ross, G., Rooftop house assembly in factory, photograph, $\odot$ Greg Ross. 11.4 Grandorge, D., Piper building cra onto rooftop, photograph, (ङ David Grandorge.

11.5 Grandorge, D., Piper building view of rooftop west, photograph, $\odot$ David Grandorge.

11.6 Grandorge, D., Piper building view

(1.6 Grandorg

of both rooftop houses, photograph,

David Grandorge.

Ross G., Piper building with roofto Ouses from northwest, photograph (c) Greg Ross.

1.8 Google Earth, 2018. South-West London, 1:100,000. Google Earth [onlin Image $\odot 2019$ DigitalGlobe.

2.1 Director General of the Ordnance

Survey (1870), Hackney, map, scal

1:2500, Director General of the

Ordnance Survey, Southampton.

12.1 Director General of the Ordnance

Survey (1910), Hackney, map, scale

1:2500, Director General of the

Ordnance Survey, Southampton.
12.1 Director General of the Ordnance Survey (1950), Hackney, map, scale 1:2500, Director General of the

Ordnance Survey, Southampton.

12.1 Director General of the Ordnance

Survey (1970), Hackney, map, scale

1:2500, Director General of the

12.3 Grandorge, D. Shatwell, photograph

(c) David Grandorge, the image has been

adapted for reuse.

12.4 Grandorge, D. Press house, photo-

graph, $\odot$ David Grandorge, the image has

been adapted for reuse.

12.5 Aerni, G. School of timber engineering, $\odot$ Georg Aerni, the image has been adapted for reuse.

.

127 Snozzi hou diag for

128 Goozle

12.8 Google Earth, 2018. Central

Google Earth [online], Image Landsat/

Copernicus.

13.1 English Journey by J. B. Priestley,

book cover, Penguin, with permission

from Penguin Books Ltd., Copyright

๔ Penguin Books, 1977. 
Index

Aberdare, 25- 6

Beck, Ulrich, 318

Aberystwyth and the Arts Centre, 2-3, 6 ,

Abley, Ian, 7, 222, 225-36

access to housing $172-3$

Addis Ababa, 17

affordability of housing, 19-20, 236, 29

Albarn, Keith, 150

almshouses, 113

Amber Valley Borough Council, 153-4

American influence, 317

Apicella, Lorenzo, 50-1

Apicella, Lorenzo, 50-1
architects, responsibilities of, 112, 299, 3

Arkwright, Sir Richard, 146, 151, 153

Arkwright, Sir Richard, 146, 151,

Aspley Guise pro

assimilation, 17
auctioneering, 126

auctioneering, 126

austerity measures, 320

Auston, Kim, 6-7, 84-94

back-garden development, 246-7

'back-to-back' housing, 151-2

Bainbridge, Beryl, 317

Banham, Reyner, 230, 298-9

Barber, Vernon, 26

Barbican, The, 278

Barratt, Richard and Kayden, 25

Bath, 128

Batley, Claude, 16

Baudelaire, Charles, 5
Beardsell, Peter, 271

Bedford Square, 27

Belper, 4, 6, 151-7

Belper, $4,6,151$

Bengough, Henry, 107

Bengough's House, 3-7, 106-23

Bengough's House, $3-2$

Berardi, Franco, 319

Berardi, Fanco, 319

big gardens, 252

Birnbeck competition, 109

Birnbeck Island. See Weston-super-Mare

Blackheath, 197

Blaise Hamlet, 14

Bloomsbury Estate, 17

Blundell Jones, Peter, 21

Bombay, 16-17

Bookchin, Murray, 236

Booth, Charles, 235

'bottom-up' approach to small-scale

development, 247

Brabourne Stadium, Mumbai, 16-17

Bracewell, Michael, 51

Bridgewater, 129

Bristol 113; City Council, 109-10; Urban

Design Forum, 109

Brown, 'Capability',

Brown, Neave, 303

Brown, Neave,

Brutalism, 89, 93, 302

'bubble' phenomenon, 278-9, 
Cahill, Kevin, 12

Canary Wharf, 27

capitalism, 12

Carapapoulle, Aslihan, 4, 145-6

Cardew, Michael, 24

Carew, Thomas, 83

Casson, Dinah, 166

Castle Cary, 129, 131

Chadwick, Aran, 6, 47-59, 65, 170

Chadwick, Helen, 148

Charles, Prince, 150

Cheshire, Paul, 232

Clarks family, 127-8

class divisions, 319

Clifford, James, 9,16

Cockburn, Charles, 225

Cold War, 230

collective action, 8

collective identity, 16

columns between houses, 217

Commission for Architecture and the

Built Environment (CABE), 155, 169-7

communal space, 111, 294

Community Infrastructure Levy (CIL), 130

competitions, architectural, 3, 109, 112

167-71, 221

and contractors, non-use

of, 298

Cousteau, Jacques, 5

Cromford Mill, 15

Crouches Field, 4, 6-7, 13, 184-219

Crowcombe Court, 3-6, 82-105

cultural heritage, 302-3

custom-build housing, 16

Dakar, 17

data centres, 61-

data centres, 61

Davies,
d'Avoine, Pereen, 4, 145-7

d'Avoine, Pierre (author), 1, 4, 7, 24, 113,

$146,222,246$

d'Avoine, Pierre Avicenna, 15-17

De Carlo, Giancarlo, 303

decimal measurement, 1

Derbyshire Historic Buildings Trust, 153

Derwent Valley World Heritage Site,

145-7, 151-4

design-and-build contracts, 111

Dewar, Liam, 7, 294-303

Disneyfication, 14

Domesday Book,

'doughnut' analogy, 13

Douthwaite, Richy, 13

Douthwaite, Rich

Duchamp, Marcel, 7

economic crash (2008), 12-13, 153

economic growth, 12

and Christine, 85

Ely, Alex, 7, 165-73

Elyot, Sir Thomas, 11

English Heritage, 153-4

Enlightenment thinking, 5

environmental degradation, 5, 10, 12

environmental impact, 299

environmental quality, 279

European Union (EU) referendum, 132

Farmer, Adrian, 145-6, 154-5

Feltham, 4, 245-6, 250-2

Ferguson, George, 54

Fisher, Mark, 8, 31

flood risk, 126-7

Fordham, Max, 47, 54, 60

Forster, Wayne, 27

Forsyth, Michael, 29

Forsyth, Michael,

Friedman, Milton,
Frome, 129

Fulham, 4-6, 269-79

garden cities, 221-4, 231-3

gardens, protection of, 247

gated communities, 279

gentrification, 5, 19, 293

Ghahremani, Katy, 168

Ghent, 13

Glass, Ruth, 19

Glastonbury Houses, 124-43

Glastonbury town, 125-7, 130-4

Graham, Dan, 148

Green, Jim 7, $192,196-206$

Green, Iim, 7, 192,1

'green' policies, 32

'green' policies, 321

(GBK) architec-

tural practice, 16

Gropius, W.A., 30

growth limitation, 13

Guardian, The, 145

Gun, The (pub), 188

Hackney, 5-6, 293

Hall, Peter, 230-5

Hamdi, Nabeel, 22

Hamilton, Richard, 7

'hangar house' design, 168-9

Hannay, Patrick, 30

Harvey, David, 147

Havana, 17

Hayek, Friedrich von, 8

Heathcote, Stephen, 146

Heatherwick, Thomas, 32

hemp insulation, 297

Henbury, 107-9

Henbury, 107-9

Heritage Lottery Fund (HLF), 87

Herne Bay, 3
Heron, Kate, 1

Herron, Ron, 149

Historic England, 85-9, 93-4, 153

historical interest in particular

locations, 127

Hodgkinson, Patrick, 295

Hogg, Andy, 197

Holford, Sir William, 30

Horn, Roni, 148

Horsmonden, 185-91, 200-1, 207-8

Houlton, Andrew, 1

Hounslow Local Plan, 247

House + Garden + House project, 4-7, 244-67

Housey Housey: A Pattern Book of Ideal

Homes (book), 1, 199

Homes (book), 1,

Howard, Ebenezer, 221-2, 233

human rights, 12

Ideal Home Show, 168

(ith, 114

for older people, 110

India, 16-17

inequality, 2, 13, 319

nheritance Taxation Exemption, 87-8

International Council on Monuments

and Sites (ICOMOS), 153

international perspective, 94

interviews for purposes of the presen

book, 1, 6-7, 318

'invisible hand' metaphor, 12

'Invisible House, The', 4, 240

Ireson, Nathaniel, 83

Jackson, Ian, 146

Jain epistemology, 20

Jenkins, Simon, 19-20, 319

Jones, David, 7, 107-14

Jones, George, 145-6, 154-5

Jones, J. Christopher, 26 
Jour de Fête (film), 14

Joyce, Barry, 7, 146-50

Kelly, Ben, 51

Kelly, Crispin, 7, 192, 197-201, 270-9 King's Cross, 279

Kirby, Paul, 60

Kohn, Michael, 168

Kropotkin, P., 247

Lafargue, Paul, 14

land: availability of, 111, 127-8, 319; cost

of, 1, 130, 320; ownership of, 11-12, 18

systematic privatisation of, 320

Land Architecture People (exhibition,

Copenhagen, 2009), 1, 7

land banking, 12

Latham, Pauline, 146

aviolle, Naomi, 167-8

Leach, N., 5

Le Corbusier, 9-10, 319

Letchworth, 4, 6, 220-43

Lewis, Gordon, 28, 46-7

Lewis, Philippa, 229

Lifschutz, Alex, 27

Linklater, A., 11

Lissitzky, El, 8
Liverpool, 235

localism, 90-1

London, 2-4, 16-20, 277-80, 293-4, 30

London Housing Design Guide, 171-2

Lyons, Eric, 196-7

Mabey, Richard, 232

Macfarlane, Tim, 168

Malagueira housing complex, 167

Malbert, Roger, 236

Mansel, Pippa, 145-6, 154-5

Manson, Fred, 168

Margaret, Prin market model applied to housing and the

environment, 320

Matta-Clark, Gordon, 148

McKay, David, 62

Melhuish, Clare, 1, 7, 23, 222

'metropolis' concept, 5

Michell, Gordon, 150

Middle England, 4, 15

Mies van der Rohe, Ludwig, 2

Mitchell, Juliet, 9

mixed developments for young and old$$
\text { 203-4 }
$$

Monbiot, George, 13-14

moral-cultural system, 12

mortgage costs, 19-20

\section{Nairobi, 248-50}

Nash, John, 14

ational identity, 318

neo-liberalism, 8,320

Nevill, Guy, 170

New Ash Green, 196-9

Newman, Paul, 27

New Towns Act (1946), 222, 231-4

New York City,

Nimbyism, 202

Norman, Hugh, 60-1

North Mill, Belper, 151, 153

Notting Hill Gate, 17

oil crisis (1973), 18

older residents, 110

Oliver, Nick, 126-32

Orwell, George, 235, 317

Osborn, Sir Frederick, 221

'outstanding universal value', 153

Owen, Dale, 23, 29-32

Parker, Thomas, 83

Parry, Malcolm, 29-30 'patchwork' development, 222-5, 233-6

pattern-book approach to design, 247

Pawley, Martin, 229

Peabody, George, 294

Peabody Trust, 294

Pembury Octagon, 5-6, 292-315

Pencil Tower, 288-91. See also Rocket Room

'pepper-potting', 204

personal contacts, importance of, 131-2

Pevsner, Nikolaus, 83

Piper Building, 4, 53, 170, 270-7

Pitfield, Jacqueline, 18

planning procedures, 192, 201, 230-3,

246-8, 273, 277

plot seen as active and anticipatory, 9

polemical projects, 5

political classes, 320

Powell, Philip, 26

prefabrication, 172

Price, Cedric, 168, 230

Priestley, I.B., $117-18$

gency (PSA), 226

Proud, A., 319

Prouvé, Jean, 170

public relations, 112-

public space, 27

Pusey, 199

Putney Debates, 148

Raworth, Kate, 13

Rayat, Jess, 7, 248-58

Reagan, Ronald, 8

Regent's Park, 278

registration of architects, 225

Repton, Humphrey, 15, 56

Reynolds, Fiona, 153

Right to Buy legislation, 19

Rio de Janeiro, 17

Rocket Room: Pencil Tower, 4, 6-7, 269

Rogers, Richard, 230-2, 236 roof gardens, 247, 294

Rosbottom, Daniel, 147

Royal College of Art (RCA), 166-7

Sahara Forest project, 66-7

Said, Edward, 16

Sainsbury, Simon, 150

Sainsbury's (company), 279

Salter, Peter, 29, 271, 273

schools provision, 131, 187, 278

Scotland, 300

Scragg, Alec, 6-7, 147, 222, 225-36

seaside towns, 3

semi-detached houses, 17, 91, 229

Sheddick, Colette, 147

Shennan, Richard, 60

Shepton Mallet, 127

Sieverts, Thomas, 223

Simmel, Georg, 5

'slim house' design, 166-9

Snozzi, Luigi, 302-3

social housing, 17,

socialising, 252

Somerset County Council, 132

Southend, 235

sprawl seen as a good thing, 234

Spyers, John, 91

standards, diversity of, 17

standards of living, 13

Standen, Ian, 192

Stansfield-Smith, Colin, 165

Starling, John, 149

Stevin, Simon, 11

Stewart, John, 231

Stonehenge, 153

Street (town), 127-8

Strutt, Jedediah, 151

Strutt, William, 151-3

subjectivity, 21 


$\begin{array}{ll}\text { Sudjic, Deyan, 277-8 } & \text { Vanbrugh, Sir John, 14 } \\ \text { Sunchales, 228 } & \text { Venturi, Robert, 7 } \\ \text { Surrealists, the, 5 } & \text { Vining, Gwyneth, 25 } \\ \text { Swaythling, 4, 6-7, 52, 169-83 } & \text { Vining, Jonathan, 6, 24-33, 45-8, } \\ & \text { 108-9 } \\ \text { Tarnoff, B., 317 } & \text { volume house builders, 1, 91, } \\ \text { Tati, Jacques, 14 } & \text { Ward, Colin, 225, 230, 247 } \\ \text { Taunton, 128 } & \text { warranties, 301 } \\ \text { teaching architecture, 146-9 } & \text { Watts, Bill, 6, 47, 54-6, 59-67 } \\ \text { terraced housing, 151, 168 } & \text { Watts, Kenneth, 59 } \\ \text { Tesco (company), 145-6, 154-5 } & \text { Waugh, Evelyn, 317 } \\ \text { Thames sewer project, 279 } & \text { Wearyall Hill, 125-30, 133-6, 143 } \\ \text { Thatcher, Margaret, 8, 19, 56, 320 } & \text { welfare state provision, 321 } \\ \text { Thomas, Dewi-Prys, 26-7 } & \text { Welstead, Donald, 226 } \\ \text { Thomas, Neil, 50-2 } & \text { Welwyn, 221-2 } \\ \text { Thomas, Sir Percy, 30-1 } & \text { Westonbirt, 87-92 } \\ \text { Thomas, Wyn, 24-9 } & \text { Weston-super-Mare, 2-3, 6, 44-81, } \\ \text { Thompson, In, 154-5 } & \text { 128-9 } \\ \text { Thompson, John, 52 } & \text { Wickham, John, 7, 186-96 } \\ \text { timber, use of, 299-301 } & \text { Wickham, Raymond, 186 } \\ \text { Tompkins, Steve, 295 } & \text { Wickham, Robin, 186, 190-1 } \\ \text { tourism, 157 } & \text { Williams, Raymond, 15 } \\ \text { towers, living in, 278 } & \text { Williams, William Carlos, 9 } \\ \text { Town and Country Planning Act (1947), 236 } & \text { Wincanton, 129 } \\ \text { Tozer, Bruges, 27 } & \text { Wirksworth, 149-50 } \\ \text { track records of architectural practices, } & \text { Wolfson Economics Prize (2014), } \\ \text { 111-12 } & \text { 222-5, 231 } \\ \text { transport links, 129, 164-5, 185 } & \text { Woodford, Johnny, 192 } \\ \text { Trellick Tower, 278 } & \text { 'world cities', 235 } \\ \text { Trengwainton, 90-1 } & \text { Woudhuysen, James, 229-30 } \\ \text { Tschumi, Bernard, 7 } & \text { Yeovil, 129 } \\ \text { Tunbridge Wells, 187-8 } & \text { young architects, 319 } \\ \text { Turner, John, 225 } & \text { young people, housing for, 203-4, 278 } \\ \text { Twickenham, 18-19, 249 } & \\ \text { 'unhomely' housing, 20 } & \text { Zhou, Zhuang, 146 } \\ \text { United Nations Educational, Scientific and } \\ \text { Cultural Organisation (UNESCO), 153-4 } & \text { Zumthor, Peter, 295 } \\ \text { Unwin, Raymond, 221 } & \end{array}$




\section{Series Editors:}

Murray Fraser,

The Bartlett School of Architecture, UCL

Jonathan Hill,

The Bartlett School of Architecture, UCL

Lesley Lokko,

Bernard and Anne Spitzer School of Architecture

at City College of New York, CUNY
Dwelling on the Future focuses on the design of dwellings and their varied environments, and questions how an architect responds to the challenge of providing humane places in which to live for a growing, multifarious population in an increasingly divided world. The issue is never just housing. People — individuals, groups and societies - can and do have different goals and aspirations. Is it possible to imagine and implement a world in which a level of comfort and stability is available for even the poorest members of societies?

Pierre d'Avoine covers a wide range of examples, including proposals for luxury housing and designs for low-cost dwellings, which all address the needs and desires of their potential inhabitants. He explores an inclusive approach to the design of settlements - and not just in cities - that recognises difference, an approach that demands a fresh political vision to resolve humanity's increasing inequality, for the benefit of all. D'Avoine asks if we can respond with optimism to the Kabakovs' mordantly titled installation 'Not Everyone Will Be Taken Into the Future (2001)'. While this was perhaps a statement of fact in Russia and elsewhere in the Soviet Union during the Cold War, it is implicit, and ever more so, in the West today.

Pierre d'Avoine is an architect and teacher based in London. He set up Pierre d'Avoine Architects in 1979 and studioDA with Pereen d'Avoine and Nilesh Shah in 2017. Pierre practices, teaches and exhibits internationally. He published Housey Housey: A Pattern Book of Ideal Homes with Clare Melhuish in 2005.
Free open access
version available from
www.uglpress.co.uk

\section{^UCLPRESS}

Cover image: (c) Pierre d'Avoine

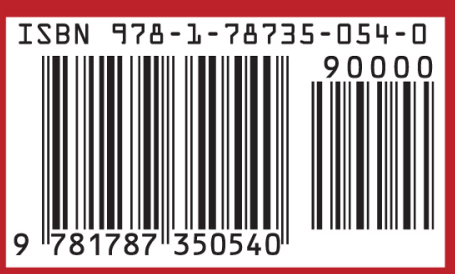

